
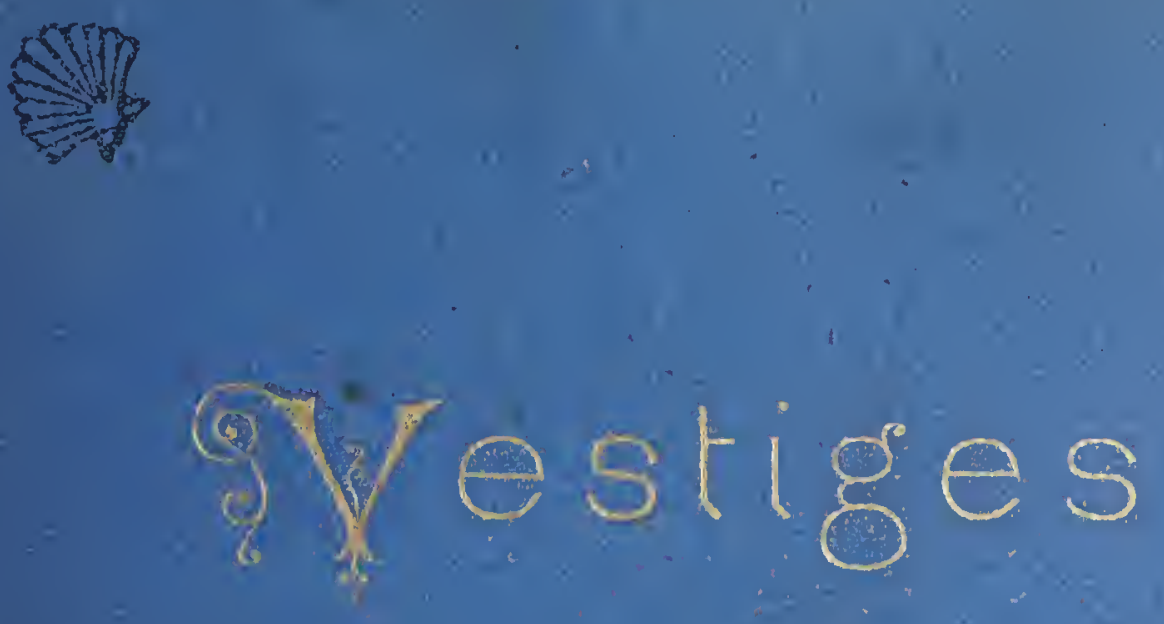

$$
\text { Sereation }
$$
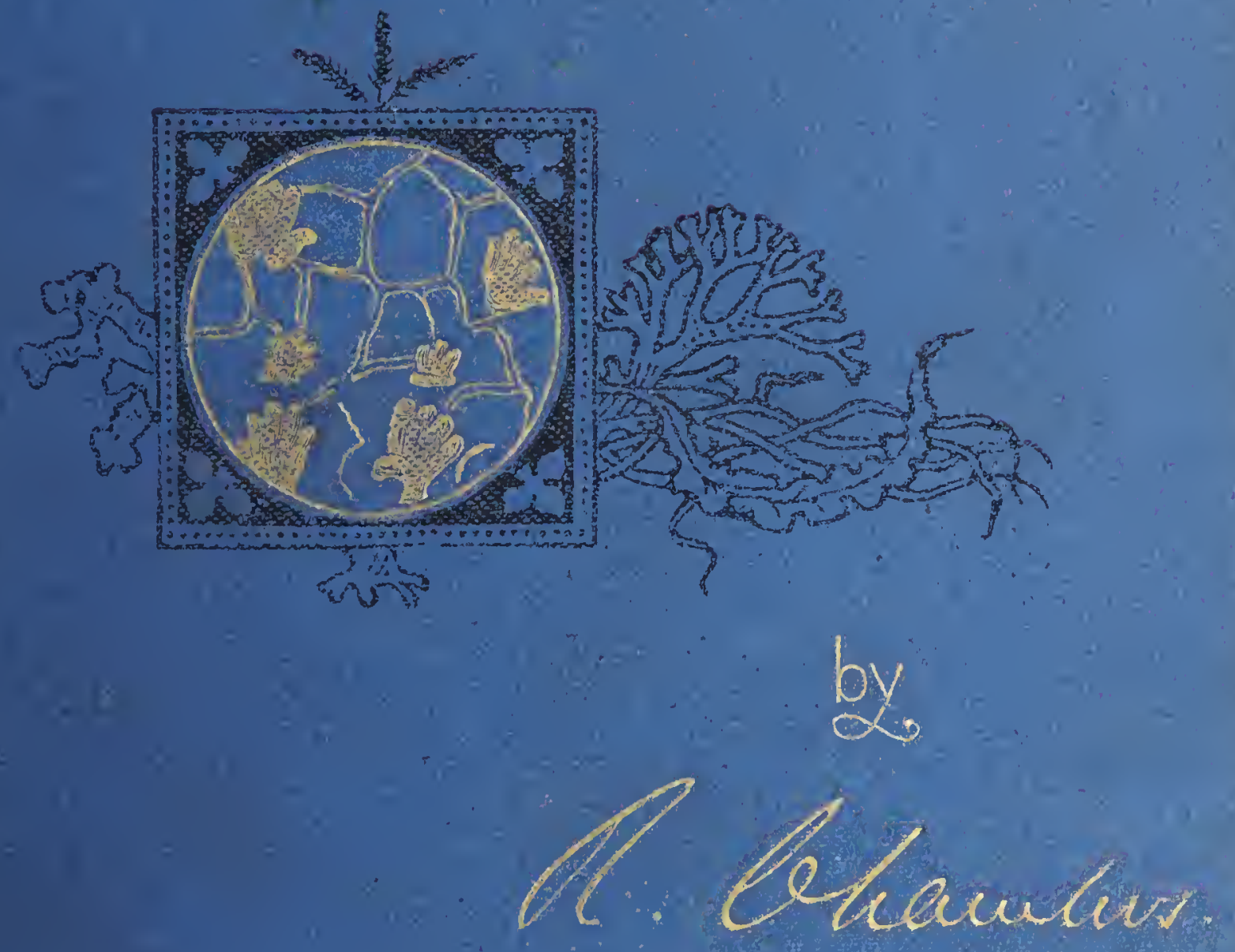

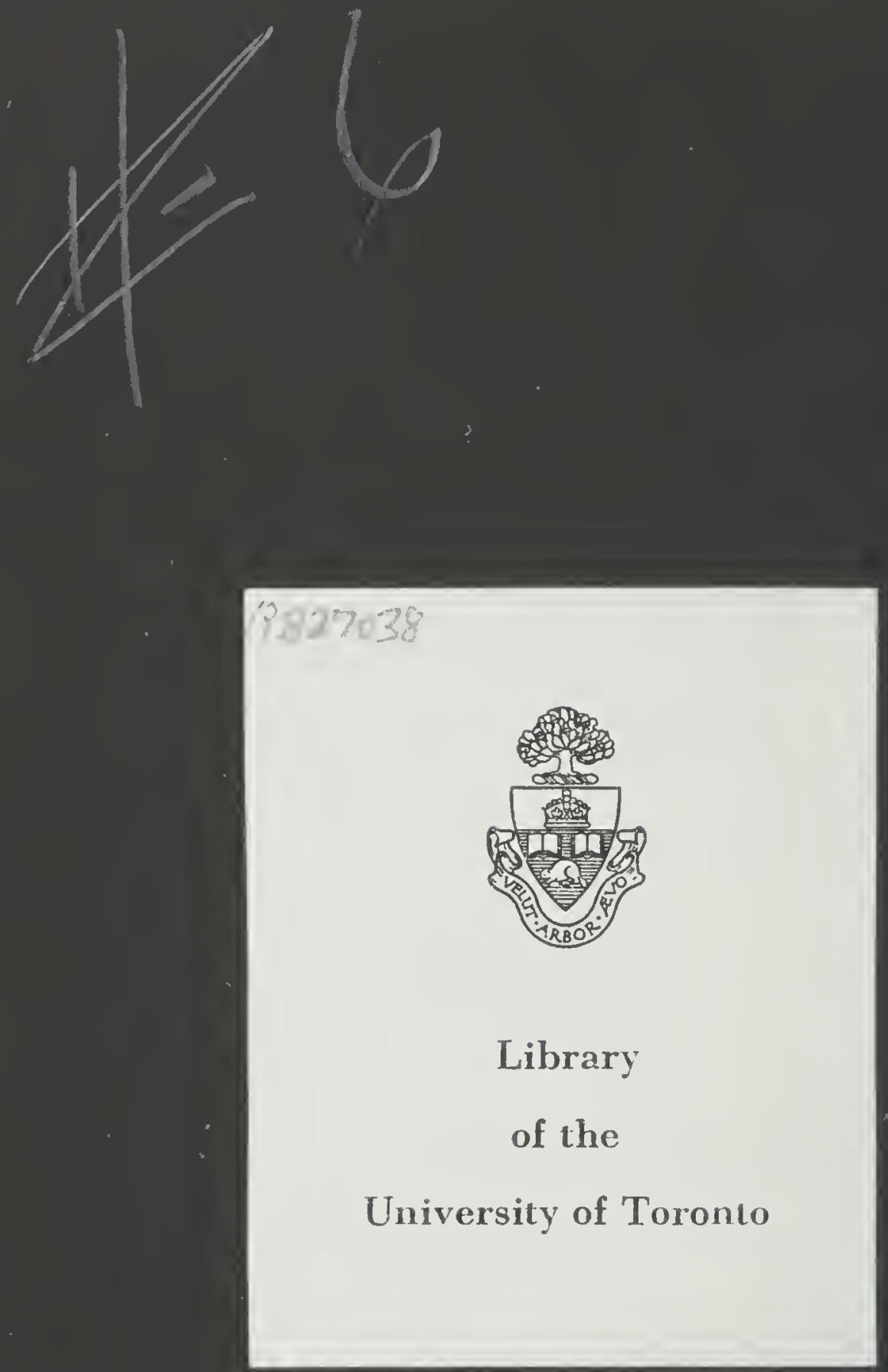

buses

servinaculo

$1 / 4,84$

1-

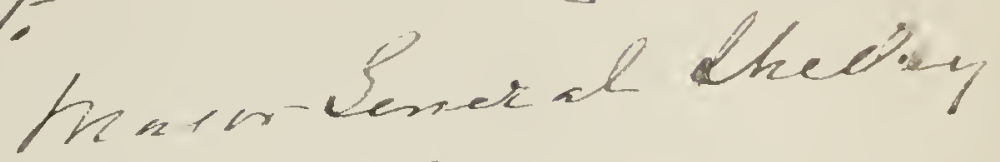

11903

VESTIGES

OF THE

NATURAL HISTORY OF CREATION. 

Digitized by the Internet Archive in 2020 with funding from University of Toronto 

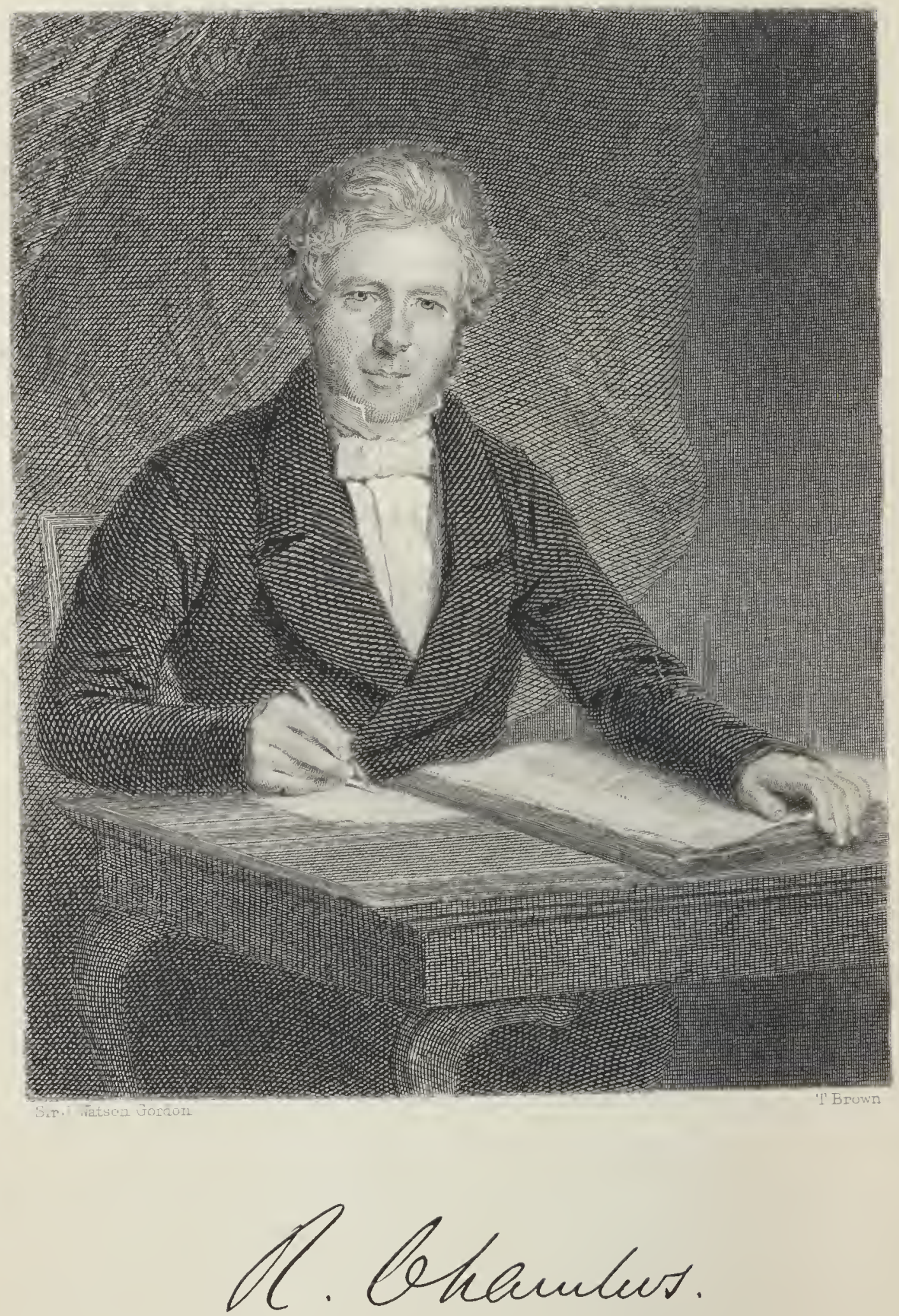


\title{
VESTIGES
}

\author{
or true
}

\section{ATURAL, HISTORY OF CREATION}

BY

ROBERT CHAMBERS, LL.D.

AUTHOR OF ANCIENT SEA MARGINS; TRADITIONS OF EDINBURGH; ETC.

Twelttb Esition

WITH

AN INTRODUCTION

Relating to the Authorship of the Work

BY

ALEXANDER IRELAND

AUTHOR OF MEMOIRS AND RECOLLECTIONS OF R. W. EMERSON, ETC.

\section{W. \& R. CHAMBERS \\ LONDON AND EDINBURGH \\ I 884}





\section{CONTENTS.}

PAGE

INTRODUCTION TO TWELFTH EDITION $\ldots$...

The Bodies of Space, their Arrangements and Formation ... I

Constituent Materials of the Earth, and of the other Bodies $\begin{array}{lllllllllllll}\text { of Space } & \ldots & \ldots & \ldots & \ldots & \ldots & \ldots & \ldots & \ldots & \ldots & \ldots & 23\end{array}$

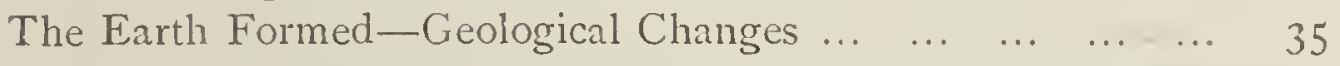

Lower and Upper Silurian Formations-First Forms of

$\begin{array}{llllllllllllll}\text { Life } & \ldots & \ldots & \ldots & \ldots & \ldots & \ldots & \ldots & \ldots & \ldots & \ldots & \ldots & 39\end{array}$

$\begin{array}{llllllllllll}\text { Upper Silurian } & \ldots & \ldots & \ldots & \ldots & \ldots & \ldots & \ldots & \ldots & \ldots & 54\end{array}$

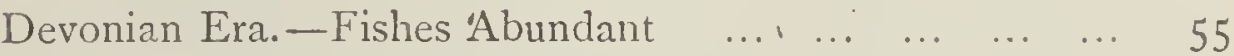

Carbonigenous Era. - Land Plants and Animals ... ... 66

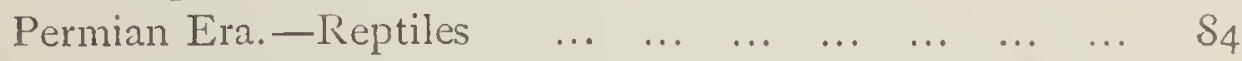

Era of the Trias and Oolite. - Reptiles Abundant.-First

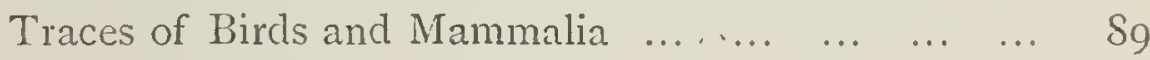

$\begin{array}{lllllllllllll}\text { Trias } & \ldots & \ldots & \ldots & \ldots & \ldots & \ldots & \ldots & \ldots & \ldots & \ldots & \ldots & 89\end{array}$

$\begin{array}{lllllllllllll}\text { Oolite } & \ldots & \ldots & \ldots & \ldots & \ldots & \ldots & \ldots & \ldots & \ldots & \ldots & \ldots & \text { I } 00\end{array}$

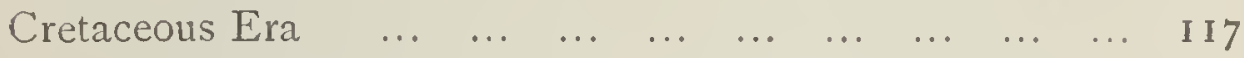

Era of the Tertiary Formation.-Mammalia Abundant ... I24

Era of the Superficial Formations. - Existing Specific

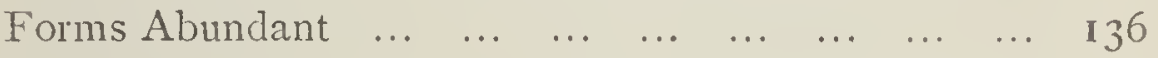

General Considerations respecting the Origin of the Animated

$\begin{array}{lllllllllllll}\text { Tribes } & \ldots & \ldots & \ldots & \ldots & \ldots & \ldots & \ldots & \ldots & \ldots & \ldots & \ldots & \text { I } 44\end{array}$

Particular Considerations respecting the Origin of the Ani-

$\begin{array}{llllllllllll}\text { mated Tribes } & \ldots & \ldots & \ldots & \ldots & \ldots & \ldots & \ldots & \ldots & \ldots & \ldots & \text { I } 59\end{array}$

Hypothesis of the Development of the Vegetable and Animal

$\begin{array}{llllllllllll}\text { Kingdoms } & \ldots & \ldots & \ldots & \ldots & \ldots & \ldots & \ldots & \ldots & \ldots & \ldots & \text { I } 79\end{array}$

Affinities and Geographical Distribution of Organisms ... ... 238

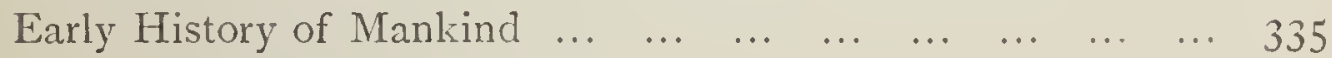

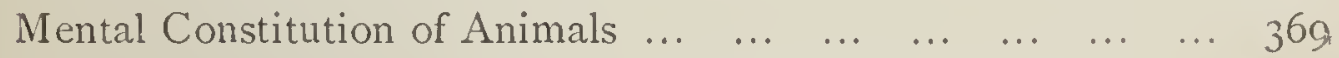

Purpose and General Condition of the Animated Creation ... 394 
PROOFS, ILLUSTRATIONS, AUTHORITIES, ETC

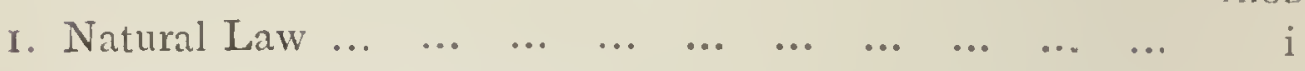

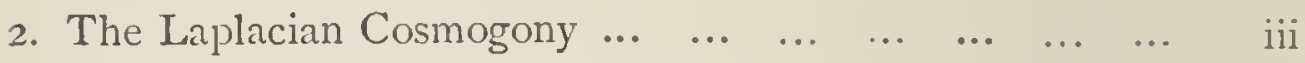

3. There was Dry Land long before the occurrence of the

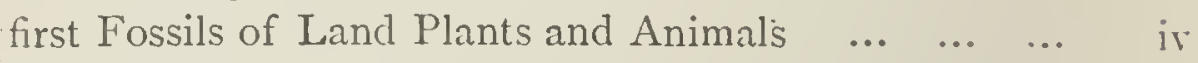

4. There are Species common to different Formations, and an unbroken Succession of Animal Life from the

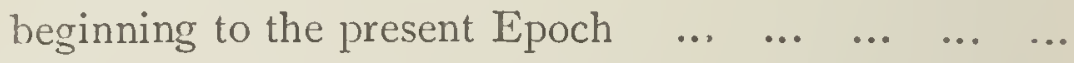

5. The Lower Silurian Formation is the Record of an Era $\begin{array}{lllllllll}\text { of Invertebrate Animals } & \ldots & \ldots & \ldots & \ldots & \ldots & \ldots & \ldots & \text { viii }\end{array}$

6. The Genera of the Lower Silurian Formation are humble

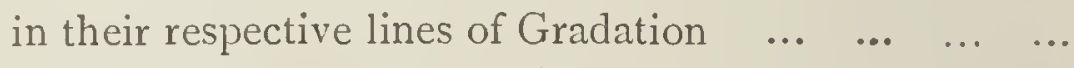

7. The early Fishes were low, both with respect to their class as Fishes, and the Order to which they belong (Cartilagines)

8. In all the Orders of Ancient Animals, there is an ascending gradation of character from first to last ... $\quad \ldots \quad \ldots$

9. There is a succession from Low to High Types in Fossil Plants, from the earliest Strata in which they are found, $\begin{array}{llllllllll}\text { to the highest } & \ldots & \ldots & \ldots & \ldots & \ldots & \ldots & \ldots & \ldots & \ldots\end{array}$

ro. The comparatively large bulk of some of the early Fossils is to be regarded as a mark of their inferiority in the

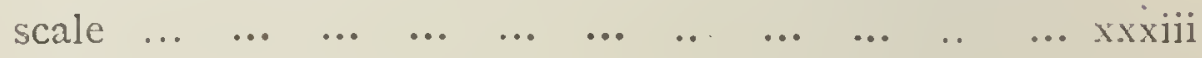

II. Variability of Species $\ldots \begin{array}{lllllllll} & \ldots & \ldots & \ldots & \ldots & \ldots & \ldots & \ldots & \text { xxxiv }\end{array}$

I2. Answers to Objections :

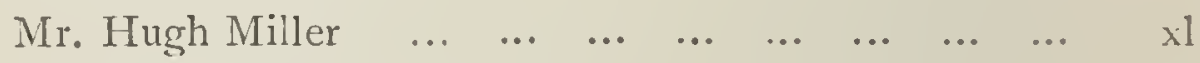

$\begin{array}{llllll}\text { Professor Sedgwick's Preface, etc. ... } & \ldots & \ldots & \ldots & \ldots & \text { Ivii }\end{array}$

$\begin{array}{lllllllllll}\text { Dr. Hitchcock } & \ldots & \ldots & \ldots & \ldots & \ldots & \ldots & \ldots & \ldots & \ldots & \text { Ixxii }\end{array}$ 


\section{INTRODUCTION}

\section{TO THE TWELFTH EDITION.}

STORY OF THE AUTHORSHIP OF THE "VESTIGES" TOLD FOR THE FIRST TIME.

The recent death of Dr. William Chambers leaves me the sole surviving depositary of a secret which, about forty years ago, was entrusted to four persons. only. That secret was the authorship of the work entitled "Vestiges of the Natural History of Creation."

It is due to the author's memory and to his reputation as a philosophic thinker that I should now record the fact that the late RoberT CHAMBers was the sole author of that work. By many of his friends and relations he was suspected, if not believed, to be its author, or in some way intimately connected with the authorship; but the fact of his being so was never actually known by them. The secret was loyally kept by those to whom it was confided. The four persons to whom he disclosed 
it were, his accomplished wife, his brother William, Mr. Robert Cox (nephew of the late George Combe and Dr. Andrew Combe), ${ }^{*}$ and myself. Mr. Cox and I enjoyed the privilege of his intimate friendship from about the year 1834 , a friendship which, in the case of Mr. Cox, continued unbroken until the death of the latter in 1869 , and in my case, until the author's death in I87I. I may add that in I846, two years after the publication of the book, the late Dr. Neill Arnott, author of "The Elements of Physics," was made acquainted with the authorship.

The late Dr. William Chambers, up to the end of his life, was unwilling that his brother's connection with the work should be divulged. A few years ago, when William Chambers and I were the sole surviving possessors of the secret, he expressed a wish that after our death the matter should be allowed to lapse into oblivion. I promised to keep the secret during his lifetime, but urged many reasons against my further compliance with his wishes, the chief one being, that a time might come when it would be an injustice to his brother Robert's memory to conceal the fact any longer. And so the matter rested up to the time of William Chambers's death, which occurred on the 2oth of May, I883. Now that he has

* Mr. Cox was editor of "The Phrenological Journal," and author of "Sabbath Laws and Sabbath Duties," "The Literature of the Sabbath Question," \&c. 
passed away, and I am left the last authentic holder of the secret, I am unwilling that it should die with me, and that thus another should be added to the list of undisclosed authorships, to be fought over perhaps by future disputants, as the authorship of the "Letters of Junius" has been fought over in the past. Moreover, as will be found from what follows, Robert Chambers did not prohibit me from disclosing his connection with the work, should I survive him.

Although the chief motive with me is to do justice to the memory of the author, I also consider it desirable to put an end to the numerous conjectures regarding others to whom the authorship has been attributed. There will also be a gain in saving the time of curious and diligent inquirers who might fruitlessly investigate the matter in future times. I am assured that there is in existence an elaborate MS. Essay, demonstrating that Robert Chambers could not have been the author, a production which must have cost the ingenious writer much valuable time and labour.

Not long before Robert Chambers's death I was on a short visit to him at St. Andrews. On that occasion he was sufficiently well to preside at dinner, and to enjoy the society of a few friends during the evening. On the morning on which I left he was unable to make his appearance at breakfast, having passed a bad night; and 
he sent for me to sit by his bedside and talk with him. We had a long and affecting conversation, in the course of which he spoke pathetically of bygone days, and of dear relatives and friends who had passed away. Some of the events of the earlier and brighter years of his married life he recalled and dwelt upon with much tenderness. He spoke of the circle that used to gather so often about his hearth,-noctes cancque he called these occasions, - the merry family junketings, the Sunday rambles with one or two companions on the breezy Pentland Hills, and many other pleasant social incidents of those days, to which his memory seemed to cling with loving tenacity. It was touching to witness the perfect serenity, I may almost say cheerfulness, with which he regarded his failing strength and the approach of the inevitable end. He spoke of the cloud of life in which we all seemed now to move, and of the hope of an ultimate emergence from shadows and obscurities into full light.

rThe final subject of our conversation was his authorship of the "Vestiges." He thought it probable that I should outlive his brother, and in that event he wished me to act according to my own discretion, not only with regard to the disclosure of his connection with it, but also as to any future republication of the work should I think it desirable. He also said that, as science progressed, he was convinced that his endeavours, along with those of 
other thinkers, to extend the conception of the province of Law in the Universe, and to establish the Theory of Development, would become more generally appreciated - that every discovery of a new scientific truth was but a stepping-stone to something beyond, leading to a more accurate knowledge of the august laws by which the Divine Mind acts in the material and moral world. He expressed his belief that this earth would never be without a succession of earnest Truth-seekers devoted to the following of truth and of the God of Truth wherever He shall lead them; and that a continued and increasing human progress was an assured certainty.

Hence, as probably the oldest survivor of his intimate associates, and cherishing, as I fondly do, the recollection of his valued and irreplaceable friendship, it seems to me to be a duty to the memory of Robert Chambers that I should place on record, while it is still in my power to do so, the honourable fact that to his genius the world was indebted for that remarkable work which in this country was the immediate forerunner of Darwin's Theory of Evolution. The "Vestiges" is a work conceived and executed in a reverent and truly religious spirit-the author attempting to set forth, in befitting language, the system of law ordained by the Almighty, whereby all things from the beginning of time and throughout illimitable space have been and are con- 
nected and bound together as the orderly manifestations of his Divine Power. Darwin himself does justice to the work. He speaks of "its brilliant and powerful style," and considers that in its later editions "it did excellent service in this country in calling attention to the subject, in removing prejudice, and in thus preparing the ground for the reception of analogous views." $*$

It is almost needless to say that the "Vestiges" was the outcome of many years of thought and earnest study. In $\mathrm{r} 84 \mathrm{I}$, its author left Edinburgh with his family, and retired to the quiet university town of St. Andrews, where during the two following years, in a pleasant mansion called Abbey Park, he devoted himself mainly to the preparation of his work for the press; but, nevertheless, during that period, furnishing many papers to "Chambers's Journal," which he and his brother had founded, and to which he still continued to be a frequent contributor. He could not have done this amid the claims and distractions of society in Edinburgh, where he, of all its citizens, was perhaps the most in request, not only on account of his bonhomie and unfailing courtesy and kindliness, his irrepressible sense of humour, and the attractions of his domestic circle, but also for his vast stores of historical and antiquarian lore, which

\footnotetext{
* Darwin's "Origin of Species," Historical Introduction.
} 
made him the prince of ciceroni whenever any distinguished stranger paid a visit to the Scottish capital.

In the comparative isolation, therefore, which attended his residence at St. Andrews, he diligently prepared the materials for the work which he had now resolved to give to the world. He had already published, as the fruit of his own literary exertions, some thirty volumes; but these were chiefly historical and biographical. Science, except by way of popular exposition in "Chambers's Journal," or in occasional papers read before scientific societies, had not as yet entered largely into his compositions; the work therefore upon which he was now engaged formed for him a new departure. From the nature of the speculations also into which it led himspeculations which, though "caviare to the general" then, are but as familiar words in the mouths of scientific workers and thinkers now-he was quite alive to the fact that the book, if it escaped falling still-born from the press, would in all probability be made the subject of no little opposition and abuse. Hence, with such a prospect before him, it was only natural that he should seriously take into consideration the propriety of giving the book to the world without his name.

An author, in debating with himself the question whether he shall issue a work anonymously or otherwise, is swayed by a variety of motives and considera- 
tions, which do not always admit of very definite expression. Sir Walter Scott, in publishing "Waverley" anonymously, tells us that his original motive for so doing was the consciousness that it was an experiment on the public taste which might very probably fail, while at the same time there was no occasion that he should take on himself the personal risk of discomfiture. "Of literary fame," he adds, "whether merited or undeserved, I had already as much as might have contented a mind more ambitious than mine; and on entering into this new contest for reputation, I might be said rather to endanger what I had, than to have any considerable chance of acquiring more."* And as regards Scott's continued desire for secrecy throughout subsequent editions of this and other of his novels, even after success had been preeminently assured, the author of "Waverley" admits that he could render little satisfaction to queries on the subject, except by saying with Shylock, that such was his humour.

In Robert Chambers's case, a somewhat parallel line of thought was observed. As the author of many works, and as editor of "Chambers's Journal," he had already achieved no small degree of success and no little popularity, and he might well, like Scott, hesitate before he put all this to the hazard of a new and as yet uncomputable

\footnotetext{
* General Preface to the Waverley Novels.
} 
risk - more especially that up to that time he was unknown in the fields of purely scientific research. Another consideration was that to which I have already referrednamely, that in the uninformed condition of the public mind at that period upon questions which enter largely into the higher scientific conceptions of cosmic economy, his work would in all probability be assailed with a hurricane of unreasoning hostility and clamour, which would be certain, if the author's name were known, to involve him in many bitter and probably painful personal disputes, such as a prudent author desires in general to avoid. $\mathrm{He}$ also thought that the theory was more likely to meet with fair treatment if left to stand or fall by its own merits than if bearing a name which then at least bore no scientific authority. There was also a pressing consideration which appealed to other than his own self-interest, and that was the fact that he was his brother's partner in a publishing business, in which the rule had been laid down from the beginning of their co-partnery to avoid as far as possible, in their publications, mixing themselves up with debateable questions in politics and theology.

These considerations were amply sufficient to dissuade even a rash man, which Robert Chambers was not, from entering upon a course of procedure which might have involved others besides himself in a certain amount 
of trouble, and perhaps, in the public temper of the period, not a little obloquy. But it was not a mere regard for personal results that weighed with him in coming to the decision at which he finally arrived, to publish the work without his name. He had, as I well know, and as we have it under his own hand, much higher motives for his remaining anonymous than were due either to the fear of attack or the dislike of notoriety. In a letter, a copy of which I possess, addressed to his friend George Combe, author of the "Essay on the Constitution of Man," who was ignorant of the authorship of the "Vestiges," but who had, through the publishers, shortly after its appearance, expressed his high opinion of the work, Robert Chambers wrote: "I exceedingly regret that I must deny myself the pleasure of disclosing my name to you and other well-wishers. This matters little to the world, provided that truth is spoken. To me, wishful only to do good in the way pointed out by my faculties, anonymity matters not at all. To escape strife at the expense of losing any honour that may arise from my work, is to me a most advantageous exchange, since I really do feel, with respect to a theme so august, that to entertain a thought of self-glorification would be inexpressibly contemptible."*

* The copy of this necessarily unsigned letter is in the beautiful hand. writing of Mrs. Chambers, who at that time frequently acted as her husband's amanuensis. 
xvii

The question of anonymity being thus settled, the next problem to be faced was the channel of publication. In considering the various methods by which he could launch the work without admitting the publisher to a knowledge of the authorship, it occurred to him that a sure and safe way of effecting his object would be to take advantage of my residence in Manchester (whither I had removed from Edinburgh in 1843 ), and constitute me the intermediary between himself and the printer and publisher. It was therefore arranged that the original manuscript of the work, which had, as an additional precaution, been transcribed by another hand, should be forwarded by me to the late Mr. John Churchill, the eminent medical publisher of London (to whose most honourable conduct throughout I have the pleasure of bearing sincere testimony); that the proofs should be posted to me in Manchester by Mr. Savill the printer, and then sent on by me to the author under fresh covers; and that these proofs, after correction, should be transmitted to me, and then retransmitted from Manchester to London. By this circuitous process all suspicion on the part of the printer and the publisher that the book emanated from Scotland was averted, and curiosity and inquiry regarding the author were effectually baffled. The same course of procedure was followed with regard to the successive nine editions which appeared between r 844 and r 853 . 
The book was published in October, I844, and immediately attracted attention by the boldness of its speculations, and by its brilliant and classic style. The curiosity to ascertain its authorship was wide-spread. A scientific correspondent of the author's, totally unaware of his connection with the work, wrote to him from London, that nothing like it had occurred since the publication of "Waverley." Little else was talked about in scientific circles. The wildest and most ridiculous surmises were afloat, and the authorship was attributed to several distinguished persons,--amongst others, to Thackeray, Lady Lovelace (Lord Byron's daughter), Sir Richard Vyvyan, and Sir Charles Lyell. In the British Museum catalogue the work has from time to time stood in various names, and so late as 1877 it was accredited in that catalogue to George Combe. Suspicion at the time of publication even fell upon Prince Albert, who, although then only in his twenty-fifth year, was regarded by those acquainted with his inner life as a man of varied parts, much given to philosophic thought, and taking a deep interest in scientific inquiry, as well as in those great questions which touch on one side the domain of science, and on the other that of theology. Between curiosity as to the authorship of the work and something like consternation in many quarters as to the boldness of certain of its speculations, a great portion of 
the learned public kept themselves in a state of perpetual excitement, as was evinced by the "Answers" which at once began to pour forth from the press.

The authorship of the "Vestiges" was indeed a subject both widely and keenly discussed in those days. It was an unfailing topic of conversation at dinner parties, and at every conversazione, where literary and scientific persons congregated. On some of these occasions very amusing incidents occurred. One of them is worth relating. In June, I 845, Sir John Herschel, at a scientific meeting in London, assailed the work in hostile but temperate language, for its advocacy of so great a scientific heresy as the Theory of Development. From the weakness of his voice he was little heard, but in the small circle which did hear him, there were marks of approbation and concurrence in his views. The author himself was one of the audience-being then on a visit to London. As the assembly was dispersing, a scientific professor, a lecturer on Physiology, who knew Robert Chambers,-whom he moreover suspected to be the author of the much-abused work,-came up to him and said, "The poor author of the "Vestiges' has got it in all directions to-night." The reply was, "Yes, it would be curious if he had been present and heard it all. I wonder how he would have felt." To which, with a nudge in the elbow and a laugh, the Professor responded, "Some people think he is not very far 
off at the present moment." The author laughingly replied, "What you say may have two meanings." The rejoinder was, "Ah, but I have denied it out and out;" and then they were separated in the crowd.

I remember a ludicrous incident which occurred at the author's own table, on the occasion of a dinner party at his Edinburgh house in Doune Terrace, after his return from the St. Andrews seclusion. One of the guests, a noisy, obtrusive gobe-mouches, with a strident voice, and zealous in the pursuit of truth in season and out of season, started the subject of the authorship of the "Vestiges." Various guesses were hazarded from all parts of the table, and a brisk fire of conversation ensued. It so happened that three of the confederates were of the company, besides the arch-conspirator himself, viz., the hostess, Mr. Cox, and myself. The situation was delicious. As the talk went on, the consciously guilty ones exchanged furtive glances, and were scarcely able to maintain the gravity required for the emergency. At length the persistent truth-seeker addressed himself across the table to a middle-aged lady novelist, then resident in Edinburgh, but long since dead,-a very clever, eccentric person, having besides the reputation of dabbling a little in science. "I have a strong suspicion," said the questioner, "that my vis-à-vis, Mrs. —, is the author of that naughty book. Is it not so? Come now, confess. You cannot deny it." To 
our surprise and infinite amusement, the lady did not deny "the soft impeachment." She hesitated and looked embarrassed, but said nothing, only shaking her head and laughing in a sly significant way,- -as much as to say, "I can keep my own secret when I choose, and I will not have it forced from me by this rude fellow." The incident was a source of much amusement when recalled in after days, and afforded many a hearty laugh to the chief-conspirator and his confederates.

The book was reviewed in every newspaper and magazine of the day, and within a short period after its publication it had provoked a multitude of tracts, pamphlets, essays, sermons, addresses, disquisitions, and lectures,-all of them mainly hostile and deprecatory,-some attacking it on scientific and others on religious grounds. All of these I collected and sent to the author. Some of his critics he respected, but the majority of them he considered ignorant, frivolous, or dishonest. What surprised him most was the hostility to his views shewn by many men of science. On this subject he said-and his words are memorable"I feel embarrassed in presenting myself in direct opposition to so many men possessing talent and information, but I think there are reasons independent of judgment for the scientific class coming so generally to an adverse conclusion concerning my views. As the case really stands, the 
ability of the purely scientific class to give at the present time a true response upon such a subject, appears extremely challengeable. It is no discredit to them that they are, almost without exception, engaged each in his own little department of science, and able to give little or no attention to other parts of that vast field. From year to year, and from age to age, we see them at work, adding no doubt much to the known, and advancing many important interests, but, at the same time, doing little for the establishment of comprehensive views of nature. Experiments in however narrow a walk, facts of whatever minuteness, make reputations in scientific societies; all beyond is regarded with suspicion and distrust. The consequence is that philosophy, as it exists amongst us at present, does nothing to raise its votaries above the common ideas of their time."

In some quarters the work aroused an amount of virulence and hostility which to the present generation would seem almost incredible. Strange to say, the idea of law and order pervading creation was at that time looked upon with disfavour by many of the most distinguished of our men of science-a singular contrast to the present state of scientific opinion on the same subject. In some publications the author was held up to detestation in a style of invective now happily unknown. There were other critics, however, who viewed the work 
in the spirit of comprehensive philosophic thought and with calm judgment, as the following will show: "If any one will approach this volume in the right spirit, he will confess that the Author is a man of devout and contemplative mind, infinitely far from endeavouring to see nothing marvellous in a world in which every extension of knowledge shews us more reason to admire and adore. . . The Author writes in a tone equally modest and self-balanced, and looks on his arguments as hereafter to be confirmed, when investigation shall have been directed to them. . . . He has done much to excite inquiry, and help on the advance of unbiassed philosophical thought. . . . Philosophy will be freer in research, and more fertile, for his having written." *

No such misconception of the author as that which certain critics fell into could have been formed by any one who had ever known him. One who knew him well, and who had the best opportunities of judging of the deep sincerity of his character, said of him, speaking immediately after his death: "He was a man of high endowments, great and varied knowledge, deep philosophy, sound judgment, and refined taste. He was also - what is far better than all this-a man of up-

* Francis W. Newman-Review of "Vestiges" in "The Prospective Review," ז845-6. 
right and unostentatiously religious life, noble and kind in his nature, gentle and modest in his manner, genial and warm in his sympathies, faithful in his friendships, and generous in his dealings. . . . He was a great lover of nature, and a patient, nor by any means an unsuccessful, student of her works; and he was ever ready to encourage the investigations of every man whose heart was loyal to the truth, even though the investigator might seem, in his better judgment, to be proceeding upon a wrong principle. But certainly, in his conversations with myself, he ever evinced the clearest recognition of a Personal God moving amidst His own creation, and ruling it constantly by His word. . . . He seemed to have had so great a reverence for the deep things of God, and so humbling a sense of his own inability to grapple with them, that he was ever most unwilling to converse about them. . . He seemed to be a man of vigorous, manly intellect, sparing no labour, no self-devotion, in the acquirement of whatever knowledge he thought it good for himself and for his fellow-creatures to possess; and, at the same time, a man of pure, gentle, kind, and unselfish character, whom it was impossible to know and not to love." * I do not quote these words .by way of defending Robert Chambers's religious character; it has

* Funeral Sermon by Rev. Mr. Tuttiett, St. Andrews, quoted in "Memoirs of William and Robert Chambers" (twelfth edition), pp. 333-4. 
long been seen in its true and loyal aspect; but as indicating how little the judgment of the public is to be trusted in its opinions of those whom it does not know, yet whom it does not hesitate, in the heat and confusion of polemical discussion, to bring to its bar and condemn; and this, too, on the strength of dubious or isolated phrases which it may have misconceived or misunderstood.

But to return to the history of the "Vestiges." Between October I844 (the date of publication of the first edition) and April 1845 , a period of seven months, four editions were called for. In I 846 appeared a fifth, and in $\mathrm{x} 847 \mathrm{a}$ sixth and a seventh - - the latter being in a cheaper form for more general circulation. In $\mathrm{I} 85^{\circ}$ and $185 \mathrm{I}$ two more cheap editions were published. In I 853 the author brought out a very handsome illustrated edition with fine wood engravings and an appendix. The physiological sections in that edition were revised by Dr. W. B. Carpenter, the eminent physiologist, at the request of the author, conveyed through $\mathrm{Mr}$. Churchill. In I860 the same edition was reprinted in smaller type, but with the preliminary chapter omitted. This was the eleventh and last edition. It may also be stated that after the appearance of the fourth edition in I 845 the author issued a supplemental volume, entitled "Explanations: A Sequel to "Vestiges of the Natural 
History of Creation,' by the author of that Work"- the object of which was to reply to the flood of criticism evoked by the original publication. In the illustrated edition of 1853 , the substance of this supplemental volume is embodied in an appendix, extending to 67 pages. Of the eleven editions, 23,750 copies were printed and sold. The book has been out of print for twenty years.

In his earnest desire to render the work more complete, and the argument more conclusive and convincing, the author sedulously endeavoured to introduce corrections and amendments into each successive edition. The curious reader who compares the first edition (1844) with the sixth (I847) will be surprised by the number and extent of the alterations and improvements made between these dates. For example, the sixth edition contains I 22 more pages than the fifth. The later editions will be found more precise and accurate in scientific details and particulars than the earlier ones-more comprehensive and philosophical with regard to the exposition of general aims and views, while the main argument has been immeasurably strengthened. Darwin, in his "Origin of Species," notices this in his remarks on the "Vestiges."

In looking over between three and four hundred letters addressed to me by Robert Chambers between r 844 and I 853 , I find many interesting passages relating to the criticisms of his book, shewing his incessant desire to improve 
it by rigid revision, by the elimination of errors of scientific detail, and by the use of additional illustrations calculated to strengthen the main current of his argument. In these letters there is also much entertaining gossip regarding the curiosity of the scientific world to ascertain the authorship. I venture to append only a few passages illustrative of the spirit which animated him throughout. Many pages could be filled with extracts from these letters, but from considerations of space I feel that I must now bring this statement to a conclusion. The writing of it has taken a burden off my mind. Liberavi animam meam.

\section{ALEXANDER IRELAND.}

INGLEWOOD, BOWdon, CheshiRe,

March, 1884 . 


\section{APPENDIX TO INTRODUCTION.}

EXTRACTS FROM LETTERS, ETC.

"When the whole of the copies of the first edition are sold, Churchill may announce that a second is in the press, and will speedily appear. I wish a dignified modesty to be observed in the style of this and all other advertisements-none of the common puffing of the London literary world. The book is an emanation of the higher feelings, if I can judge of my own nature, and nothing connected with it should be inconsistent with that character."

"6 'Explanations' will form a kind of supplement to the original work. This mode of publication will, I think, be most dignified, and the character of this new attempt demands such consideration, for it is far more powerful in argument than the 'Vestiges' itself, although not so popular in its nature. I must make a decided effort to render the fifth edition as near perfection as possible."

"I quite concur with you as to the propriety of addressing the work to the people at large through a cheap edition, and this I shall do as soon as the press of criticism is past, as I should like to take advantage of every suggestion that is offered for correction and amendment before putting the book into that popular form."

"I am at present engaged in making a rigid revision 
of the scientific facts advanced in the work. I expect to be able to put the hypothesis upon a much better basis than it ever has been yet-facts more conclusive, and more guarded against challenge, and arguments less assailable. I can now deal much more effectively with objections, and think I can blow both Sedgwick and Miller out of the water."

"The April number of the Edinburgh Review (I860) makes all but a direct amende for the abuse it poured upon my work a number of years ago. It now hesitates about disputing that the lowest animals and plants arise by heterogeny, or what used to be called spontaneous generation; and, without affirming the development hypothesis, boldly countenances the idea of an orderly succession and progression of organic beings by 'a continuously operating creative force.' It pointedly rebukes Professor Sedgwick, who wrote the article in the same review reviling the 'Vestiges.' This change is the index to one which appears to be going on at present in the scientific mind of England, in consequence of the recent writings of Darwin, Wallace, IVollaston, and Hooker, regarding the origin of species, favouring the idea of a common descent; particularly the volume published last year by Darwin, intended to show how, by 'a principle of selection,' all existing animals may have taken their rise in four or five primordial species. Professor Huxley, of the School of Mines, has become an ardent apostle of this doctrine, and it has been embraced by Sir Charles Lyell and others. It will be very curious if the much-reviled 'Vestiges' turns out to be approvable after all in its general principles, and has to be assigned a place in some future edition of Sir David Brewster's 'Martyrs of Science.'" 
From a (necessarily unsigned) letter to GEORGE COMBE, dated December, 1844.

"I can assure you, sir, that of the many more or less gratifying letters which my book has brought me, I received none with more pleasure than yours. Your ingenious 'Essay on the Constitution of Man,' and your fearless advocacy of the only approach to a true science of mind against philosophical and theological odium, sufficient to chill the hearts of most men, have endeared your name to me in common with many lovers of truth. To hear you declare that my little volume has to you all the sublimity of a grand poem, at the same time that it exhibits the earnestness and perspicacity of a rigidly philosophical induction, is indeed a reward for many hours of severe application and toil." [Here follows the passage already quoted at page xvi.]

Letter from the Rev. BADEN Powell, Savile Professor of Geometry, Oxford, to the author of "Vestiges of the Natural History of Creation."

"Oxford, April I6, I848.

"Sir,-Though at some distance of time since the publication of the last edition of the 'Vestiges,' and the 'Explanations,' \&c., I have only lately had leisure to read them attentively, and cannot refrain from expressing to the author, however unknown, the high satisfaction I have derived from the work, which, great as it was on reading the First Edition, has been materially increased by the improved form in which the argument has been brought out. I am the more impelled thus to state my 
impressions from most cordially participating in the view you take of the general lamentably low state of real philosophic spirit among men of science (Expl., p. I I 7, \&c.), and from an anxiety to assure you that there is at least one cultivator of science, however humble, who takes a more worthy view of the subject, as I think you will admit, if you allow me to refer you to a small work of mine (which I am induced to infer you have not met with), published so long ago as 1838 , "The Connexion of Natural with Divine Truth' (Parker, West Strand), where (at page $\mathrm{r}$ I) you will, I think, perceive that even at that time I had a strong leaning towards the very views you have since so much more ably expounded, while the whole tenor of my argument I think will be found to stand in striking accordance with yours.

"Trusting you will pardon this intrusion, I remain, etc., "BADEN POWELl." 



\section{THE BODIES OF SPACE,}

THEIR ARRANGEMENTS AND FORMATION.

IT is familiar knowledge that the earth which we inhabit is a globe of somewhat less than 8000 miles in diameter, being one of a series which revolve at different distances around the sun, and some of which have satellites in like manner revolving around them. The sun, planets, and satellites, with the less intelligible orbs termed comets, are comprehensively called the solar system; and if we take as the uttermost bounds of this system the orbit of Uranus (though the comets actually have a wider range), we shall find that it occupies a portion of space not less than three thousand six hundred millions of miles in diameter. The mind fails to form an exact notion of a portion of space so immense; but some faint idea of it may be obtained from the fact, that, if the swiftest racehorse ever known had begun to traverse it, at full speed, at the time of the birth of Moses, he would as yet have accomplished only half his journey.

It has long been concluded amongst astronomers, that the stars, though they appear to our eyes only as brilliant points, are all to be considered as suns, representing so many solar systems, each bearing a general resemblance 
to our own. The stars have a brilliancy and apparent magnitude which we may safely presume to be in proportion to their actual size and the distance at which they are placed from us. Attempts have been made to ascertain the distance in some instances by calculations founded on parallax; that is, the change of relative situation produced on a heavenly object by our planet passing from one part of its orbit to another exactly opposite; it being previously understood that if, upon this base of nearly two hundred millions of miles, an angle of so much as one second, or the 3600 th part of a degree, could be raised, the distance might be assumed in that instance as not less than I 9,200,000 millions of miles! In the case of the most brilliant star, Sirius, even this minute parallax could not be found; from which, of course, it was to be inferred that that star is farther removed than even this vast distance. In some others, on which the experiment has been tried, it was equally impossible to detect a parallax. We seemed thus to be left in a hopeless state of ignorance regarding the measurements of the sidereal universe, as if it were such a question as man was not destined ever to answer; but at length, in our own time, responses came from several points almost at once. By Professor Henderson it was ascertained that the star $a$ of the constellation of the Centaur, the third in brightness in our heavens, but in reality a double star, and believed for various reasons to be among those nearest to us, had a parallax of a full second, establishing its distance in miles at about nineteen millions of millions. Afterwards, Bessel assigned a parallax of thirty-one hundredths of a second to the double star 6 I Cygni, placing it at a distance nearly 670,000 
times that of the earth from the sun. ${ }^{1}$ Such are but the first steps we take in imagination amongst the hosts of orbs by which we are surrounded. If we suppose that similar intervals exist between all the stars, we shall readily see that the space occupied by even the comparatively small number visible to the naked eye must be vast beyond all powers of human conception.

The number visible to the eye is about three thousand; but when a telescope of small power is directed to the heavens, a great number more come into view, and the number is ever increased in proportion to the increased power of the instrument. In one place, where they are more thickly sown than elsewhere, Sir William Herschel reckoned that fifty thousand passed over a field of view two degrees in breadth in a single hour. It was first surmised by the ancient philosopher, Democritus, that the faintly white zone which spans the sky under the name of the Milky Way, might be only a dense collection of stars too remote to be distinguished. This conjecture has been verified by the instruments of modern astronomers, and some speculations of a most remarkable kind have been formed in connexion with it. By the joint labours of the two Herschels, the sky has been "gauged" in all directions by the telescope, so as to ascertain the conditions of different parts with respect to the frequency of stars. The result has been a conviction that, as the planets are parts of solar systems, so are solar systems parts of what may be called Astral Systems-that is, systems composed of a multitude of stars, bearing a certain relation to each other.

1 Herschel's Address to Astron. Soc. of London, I84 I, and Transactions of that body, vol. xii. 
The astral system to which we belong, is conceived to be of an oblong, flattish form, with a space wholly or comparatively vacant in the centre, while the extremity in one direction parts into two. The stars are most thickly sown in the outer parts of this vast ring, and these constitute the Milky Way. Our sun is believed to be placed in the southern portion of the ring, near its inner edge, so that we are presented with many more stars, and see the Milky Way much more clearly, in that direction, than towards the north, in which line our eye has to traverse the vacant central space. Nor is this all. A motion of our solar system with respect to the stars, first suggested by Sir William Herschel in $\mathrm{I}_{7} 8_{3}$, has since been verified by the exact calculations of M. Argelander. The sun is proceeding towards a point in the constellation Hercules. It is, therefore, receding from the inner edge of the ring. Motions of this kind, through such vast regions of space, must be long in producing any change sensible to the inhabitants of our planet, and it is not easy to grasp their general character; but grounds have nevertheless been found for supposing that not only our sun, but the other suns of the system, pursue a wavy course round the ring, from west to east, crossing and recrossing the middle of the annular circle. "Some stars will depart more, others less, from either side of the circumference of equilibrium, according to the places in which they are situated, and according to the direction and the velocity with which they are put in motion. Our sun is probably one of those which depart furthest from it, and descend furthest into the empty space within the ring." 1 According to this view,

1 Professor Mossotti, London, Edinburgh, and Dublin Philosophical Magazine, 1843. 
a time may come when we shall be much more in the thick of the stars of our astral system than we are now, and have of course much more brilliant nocturnal skies; but it may be countless ages before the eyes which are to see this added resplendence shall exist.

The evidence of the existence of other astral systems is much more decided than might be expected, when we consider that the nearest of them must needs be placed at a mighty interval beyond our own. The elder Herschel, directing his wonderful tube towards the sides of our system, where stars are planted most rarely, and raising the powers of the instrument to the required pitch, was enabled with awe-struck mind to see suspended in the vast empyrean astral systems, or, as he called them, firmaments, resembling our own. Like light cloudlets to a certain power of the telescope, they resolved themselves, under a greater power, into stars, though these generally seemed no larger than the finest particles of diamond dust. The general forms of these systems are various. So also are the distances, as proved by the different degrees of telescopic power necessary to bring them into view. The furthest observed by the astronomer were estimated by him as thirty-five thousand times more remote than Sirius, supposing its distance to be about twenty millions of millions of miles.

More recently, the Earl of Rosse has brought a superb instrument to bear upon these distant objects, and thus revealed them in more wondrous forms than before. Many which Herschel saw only as filmy matter, spread in patches over the sky, are now found to be vast aggregations of stars. Many which to the elder philosopher 
seemed round and well defined, are seen by his successor to have branches starting out in different directionsfilaments, as he calls them-the language applicable to the smallest of objects examined in our hands, being thus found applicable to the promontories of those great continents, each atom of which may be said to be millions of miles removed from another.

Such is the universe, as developed to the perceptions of the modern philosopher-different indeed from that of our forefathers, who did not know the bounds even of this little world, and beheld in the sun, moon, and stars, only a set of menial lights, ordained, usefully or not, to attend it. And to such contemplations are we raised by modern science, if we choose to leave for them the strifes and selfseekings of our social scene. Thinking of such acquisitions of knowledge, one cannot but go warmly along with the living Herschel when he speaks of the discoveries of Struve, Bessel, and Henderson, as among the fairest flowers of civilization. They surely justify, as he says, "the vast expenditure of time and talent which have led up to them," and show that "there are yet behind not only secrets of nature which shall increase the wealth and power of man, but TRUTHS which shall ennoble the age and the country in which they are divulged, and, by dilating the intellect, re-act on the moral character of mankind." 1

Where our perceptive faculties are baffled, we dream; where they compass their object, we inquire after cause. Such is a law of our minds, which cannot have been bestowed upon us without being designed for a good end.

'Herschel's Address, ut supra. 
And, indeed, it is by experience placed beyond all doubt, that to yield to this impulse is to use a direct means of improving our condition on earth, and to advance in the scale of moral as well as intellectual being. Nor are we left to doubt that extensions of knowledge, either in simple fact or in cause and relation, are not to be estimated by their immediate and apparent effects; for both are there often good results of the most tangible kind where no such thing was expected-as from Napier's discovery of the logarithms, or, to take an opposite instance, from Smith's ascertainment of the order of rocks-and it is utterly impossible in any way to reckon the benefits which light confers upon mind wherever it is allowed to enter. Assuming the legitimacy of such inquiries, and yet holding fast by the reverence which Created owes to Creating, we may without fear yield to the instinct which sends us to ask after cause with regard to this vast and beauteous scene. How has it been that these orby myriads have taken the places in which we find them? To what authorship are we to ascribe the whole?

It has often been found, in philosophizing, that the prime difficulty lay in bringing down the mind to sufficiently simple conceptions. The many soar and mystify, and come to nothing; to few is it given to find truth where it usually lies, amongst the things most familiar. The ideas which the ancients formed of the movements of the heavenly bodies were lofty, but entirely erroneous. It was reserved for the geometers of the last two centuries, by pursuing truth on more solid grounds, to establish the simplicity which is now known to extend through the physical constitution of the universe. It has been fully 
ascertained that the planets have obtained their forms, keep their places with regard to the sun and to each other, and pursue all their various motions, in obedience to certain laws which are to be every day seen acting on the humblest scale in our very presence. Thus, the earth is a globe for the same reason that a dew-drop is so. It is slightly flattened at the poles, as a consequence of rotation on an axis when in a soft state, for the same reason that a mass of clay whirled rapidly round will become of a similar shape. The sun and earth are mutually attracted in proportion to their respective masses, and inversely as the square of the distance, which is a law prevailing with not less certainty upon two rose leaves floating on the summer lake into which they have fallen. The revolution of the planet or satellite in an orbit round a central mass is, again, the result of a composition of two opposite forces-one of them this attraction of gravity in its proper proportions, the other a primitive motion of the one mass away from the other in a straight line; and this phenomenon is exemplified when we see a stone which has been thrown from a boy's hand, brought in a curve to the ground. All these marvels rest on mathematical calculations of the nicest exactness, insomuch that, taking one as an example, astronomers have computed ten years beforehand, the time at which the planet Jupiter would pass our meridian, and the predicted time was correct within half a second.

Since Newton stated the laws of gravity and of the planetary motions, there have been some important additions to his philosophy. It has been shown, that certain perturbations in the planetary movements, which 
appeared to him as denoting a necessary end to the system, observe periods, and are only further proofs of the stability of the whole arrangement. It has also been discovered that the laws of motion extend beyond the solar system. Amongst the orbs, which seem so still and serene to our ordinary perceptions, we now know that there is no such thing as rest. Stars are ascertained to have proper motions, of the same nature with that found in our own sun. Many are seen to be, in reality, double or triple-- that is, composed of a plurality of suns, which perform regular revolutionary motions round each other in cllipses. The periods of some of these movements and revolutions are of such brevity, that their elements are already in the book of the astronomer; others are seen to be of such vastness, that the times which have determinated the youth and death of our oldest empires, would be, in comparison, but as a little spoke in some enormous wheel. Yet of all of them no doubt can be entertained that they depend upon those simple physical laws which preside over every particle of tangible matter in our own sphere.

Here it is right to advert to some general features of the solar system, most of which have also been discovered since the days of Newton. It is, in the first place, remarkable that all the planets move nearly in one plane, corresponding with the centre of the sun's body. Next, it is not less worthy of attention, that the motion of the sun on its axis, those of the planets around the sun, and the satellites around their primaries, ${ }^{1}$ and the motions of

1 There is an exception, but doubtless apparent only, in the motion of the satellites of Uranus, which, compared with the rest, is retrograde. The ares of 
all on their axes, are in one direction-namely, from west to east. Had all these matters been left to accident, the chances against the uniformity would have been, though calculable, inconceivably great. Of the motions of the twenty-three bodies known in the early part of this century, it was found by Laplace, that the adverse chances were as upwards of four millions of millions to one. It is thus powerfully impressed on us that the uniformity of the motions, as well as their general adjustment to one plane, must have been a consequence of a single cause acting throughout the whole system.

Some of the other relations of the bodies are not less remarkable. It is, perhaps, of little consequence that the larger planets are towards the outside of the system, since there is an absence of regularity in the gradation in this respect. In the series of comparative densities we find an approach to a regular gradation: they stand thus in decimals, the Earth being considered as I-Mercury, 2.95; Venus, '99; Earth, I ; Mars, '79; Jupiter, 23; Saturn, 'I I Uranus, $\cdot 26$; the last being the only very decided violation of the rule. Then the distances are curiously relative. It has been found that, if we place the following line of numbers,-

$$
\begin{array}{llllllll}
\circ & 3 & 6 & \text { I } 2 & 24 & 48 & 9^{6} & \text { 192, }
\end{array}
$$

and add 4 to each, we shall have a series denoting the

the planets are, as is well known, at various degrees of inclination to their orbits; for which there must have been a cause in the circumstances under which the planets were produced. The axis of Uranus is removed but eleven degrees from the plane of his orbit: I suggest, as the explanation of the apparent exception, that what we call the north pole of this planet is in reality the south, the axis having passed across the plane of the orbit, so that the planet may be said to be in that small measure upside down. It will be observed, that between the admitted and the suggested arrangement, there is only a difference of 22 degrees. 
respective distances of the planets from the sun. It will stand thus-

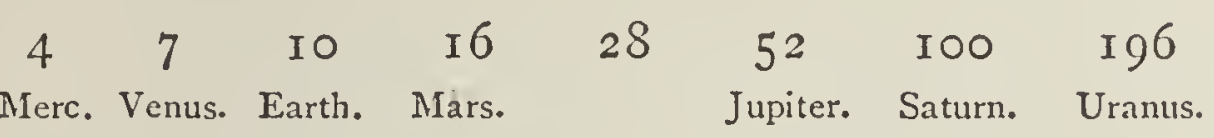

It will be observed that the first row of figures goes on from the second on the left hand in a succession of duplications, or multiplications by 2 . There is here a surprising signification of unity in the solar system. It was remarked, when this relation was first detected, that there was wanting a planet corresponding to 28 ; the difficulty was afterwards considered as overcome, by the discovery of four small planets revolving at nearly one mean distance from the sun, between Mars and Jupiter. ${ }^{1}$ The distances bear an equally interesting mathematical relation to the times of the revolutions round the sun. With respect to any two planets, the squares of the times of revolutions are to each other in the same proportion as the cubes of their mean distances, - a most surprising result, for the discovery of which the world was indebted to the illustrious Kepler. Sir John Herschel truly observes- "When we contemplate the constituents of the planetary system from the point of view which this relation affords us, it is no longer mere analogy which strikes us, no longer a general resemblance among them, as individuals independent of each other, and circulating about the sun, each according to its own peculiar nature, and connected with it by its own peculiar tie. The resemblance is now perceived to be a true family

I Since that time several other members of this community have been discovered. In 1846 , a new planet of greater magnitude was discovered beyond Uranus, and named Neptune. Till our knowledge of this stranger is somewhat extended, the text may be left undisturbed. But it is meanwhile worthy of remark, that the linear extent of the solar system is now nearly double what it was supposed to be. 
likeness; they are bound up in one chain-interwoven in one web of mutual relation and harmonious agreement, subjected to one pervading influence, which extends from the centre to the furthest limits of that great system, of which all of them, the Earth included, must henceforth be regarded as members."

The tendency of all the later discoveries has been to dcepen the conviction arising from the first, that the physical affairs of the universe are all under the regulation of laws; the forms, the distances, the movements, the interdependencies, are determined in this, as distinguished from any arbitrary manner. What, in the science of nature, is a law? It is merely the term applicable where any series of phenomena is seen invariably to occur in certain given circumstances, or in certain given conditions. Such phenomena are said to obey a law, because they appear to be under a rule or ordinance of constant operation. In the case of these physical laws, we can bring the idea to mathematical elements, and see that numbers, in the expression of space or of time, form, as it were, its basis. We thus trace in law, Intelligence-often we can see that it has a beneficial object, still more strongly speaking of mind as concerned in it. There cannot, however, be an inherent intelligence in these laws. The intelligence appears external to the lazes; something of which the laws are but as the expressions of the Will and Power. If this be admitted, the laws cannot be regarded as primary or independent causes of the phenomena of the physical world. We come, in short, to a Being beyond nature-its author, its God;-infinite,-inconceivable, it may be, and yet one whom these very laws present to 
us with attributes showing that our nature is in some way a faint and far-cast shadow of His, while all the gentlest and beautifullest of our emotions lead us to believe that we are as children in his care, and as vessels in his hand. Let it then be understood-and this is for the reader's special attention-that when natural law is spoken of here, reference is only made to the mode in which the Divine Power is exercised. It is but another phrase for the action of the ever-present and sustaining God. ${ }^{1}$

Viewing Nature in this light, the pursuit of science is but the seeking of a deeper acquaintance with the Infinite. The endeavour to explain any events in her history, however grand or mysterious these may be, is only to sit like a child at a mother's knee, and fondly ask of the things which passed before we were born. In modesty and reverence we may even inquire if there be any trace of the origin of that arrangement of the universe which is presented to our notice.

In this inquiry, we start with the clear fact of the orbs being determined in their forms by law. The fact here pointed to necessarily infers a previous form of matter, one in which the molecules were separately moveablefluid or gasiform-just as the law by which the dew-drop is spherified, implies that the constituent particles were in such a condition before it took effect. We thus see the Will which constitutes law acting in a non-material manner in that portion of what we are accustomed to call Creation. In the places and relations of the orbs, there is equal proof, though of a less popularly tangible kind,-

'See Prools, Illustrations, \&c., No. I. 
that law was concerned. The work may be said to have been done by the will of God, expressed in the form of the law of gravitation. When we come to consider the motions, and regard them as necessarily results of an impulse, we are apt to suppose some immediate and more direct or arbitrary application of Divine Power necessary: but this cannot bear a second consideration. The motions, as well as the arrangements, are inextricably wrought up in relation with the magnitudes; a totally different mode of their origin is therefore inconceivable. Having, moreover, in gravitation, a general source of motion, and knowing in what various ways and to what various results a motive power may be applied,-see, for a familiar example, the wheels of a clock revolving under the influence of a weight,-all difficulty in supposing an actual origin of a natural kind for the motions of the heavenly bodies vanishes, however obscure our notions may remain as to the process concerned in the case. Thus, everything leads us to the belief that there was a previous form of matter, out of which were educed the present forms and motions of the bodies of space, in the manner of, though certainly not by any self-dependent efficacy in, Natural Law.

At this point we might rest, for in the general conclusion that the orbs were formed and arranged in such a manner, enough has been gained for the present object. It is worth while, however, to touch slightly on the ideas which have passed through certain eminent minds, with respect to the births of these bodies.

The first idea of what has been called the Nebular Cosmogony arose with Sir William Herschel, in conse- 
quence of the observations which he made regarding a class of heavenly bodies, to which the appellation of netulce had been applied, in reference to their cloud-like appearance. Some of these bodies were ascertained, by a high telescopic power, to be only astral systems, like our own, placed at such a vast distance, that the individuality of the stars composing them was lost to ordinary perception. Others resisted the highest telescopic power which the astronomer applied, and, from various considerations, he came to regard them (it has since appeared, erroneously) as masses of diffused luminous matter. In these he further discovered a variety of appearances, marking what seemed a gradation of characters, as if they had been in various degrees of condensation; and hence he was led to surmise that they were solar systems in the process of being formed out of a previous condition of matter. Without any knowledge of these speculations, M. Laplace started one of his own, founded on the known features of the constitution of the solar system, as the uniformity of plane and of motions. When he afterwards became acquainted with Herschel's idea, he regarded it as in harmony with his own. He showed that, if a luminous matter such as had been described by Herschel, existed, and if nuclei were established in it, these might become centres of aggregation for the neighbouring diffused matter; on such centres a rotatory motion would be established, wherever, as was the most likely case, there was any obliquity in the lines of direction in which the opposing currents met each other: this motion would increase as the agglomeration proceeded: at certain intervals, the centrifugal force acting in the exterior of the 
rotating mass would overcome the agglomerating force, and a series of rings would thus be left apart, each possessing the motion proper to itself at the crisis of separation. These, again, could only continue in their annular form, if uniform in constitution. There being many chances against this, they would probably break up, and be agglomerated into either one or several masses, which would then become representatives of the primary mass, and perhaps give rise to a similar progeny of inferior masses. The result would be-Planets and Satellites; each having an orbitual speed corresponding with that of the zone constituting it; each obtaining a rotatory motion from the excess of speed observed by the outer, over the inner portion of the zone. All this Laplace showed to be possible under the physical laws of the universe. In the case of our solar system, the results tally in the nicest way with the hypothesis; for example, the rapidity of the revolutionary motions of the planets is in proportion to their nearness to the sun; so also, do the primaries rotate more rapidly than the satellites revolve in their orbits. There are even singularities tending to support the hypothesis; the small planets between Mars and Jupiter may be regarded as an example of a zone which agglomerated in distinct parts, while the rings of Saturn, now believed to be three in number, are instances of zones still in their original state.

A law presiding over the solar system, which may be said to constitute a fourth of the series of which the three first are associated with the name of Kepler, has lately been discovered (I $85^{\circ}$ ) by Mr. Kirkwood of Penn- 
sylvania, and it is important to observe how entirely it accords with the Laplacian hypothesis. The discoverer points to an imaginary space extending in each direction from the orbit of each planet, at the outer limits of which its attractive power ceases and that of its neighbour commences. This expanded orbitual space he calls the planet's Sphere of Attraction. He has found in the spheres of attraction the periods of the rotations of the several planets:- "the SQUARE of the number of times that each planet rotates during one Revolution in its orbit, is proportional to the CUBE of the breadth or diameter of its Sphere of Attraction." This law, flowing out of a combination of the most important elements of the system, namely, the relative distances and attractive weights of the several orbs, "virtually tells us," says Professor Nichol, "that the rotation of each planet is not a scparate or isolated attribute, but a consequence of the relations of that planet, in all its habitudes, with the general mechanism of the system; and thus it impresses a view of that system, analogous in every important respect to that which characterizes the philosophic speculation of Laplace. I hail it therefore as a virtual confirmation of that order of speculations, as well as an eminent positive discovery."

The Laplacian hypothesis, it will be observed, only comes to the point at which we must needs arrive under a consideration of the "web of relation" traceable in the constituents of the solar system--namely, that they have had a common origin in a soft and diffused form of matter. Such a form of matter may now, as is alleged, be no longer actually seen in the heavens; and yet there may remain good reasons for believing that it once existed. 
One of these will afterwards be presented in the facts connected with the density of the planets and the internal heat of the earth. Another rests in the curious phenomenon called the Zodiacal Light, an oblate luminosity surrounding the sun, and very conspicuous in the twilights of tropical climes; a remnant, as has been supposed, of the diffused solar atmosphere of the nebular cosmogony. There is even a support to the theory in what would seem at first to be an anomaly and an objection-the existence of the many binary and ternary solar systems. It may be supposed that, at a certain point in the confluence of the matter of these regions of space, the solar nuclei would become involved in a common revolutionary motion, linked inextricably with each other, though it might be at sufficient distances to allow of each body having afterwards its attendant planets. Such a phenomenon is occasionally realized to us on the surface of a river flowing between irregular banks. There we not only see single dimples rotating and passing onward, results of that obliquity in the meeting of currents which is thought to have set solar systems in motion; but uiten two or more of these dynamic microcosms will come within range of a mutual influence, and go on wheeling around each other. These fantastic eddies, which the musing poet will sometimes watch abstractedly for an hour, little thinking of the laws which produce and connect them, form an illustration of the mechanism of binary and ternary stars, and bring an unexpected aid to a theory of the history of the heavenly spaces.

A remarkable approximation has also been made to what may be called an experimental verification of this 
cosmogony, by a living professor, M. Plateau, of Ghent. Divested of technical terms, the experiment was nearly as follows:-Placing a mixture of water and alcohol in a glass box, and therein a small quantity of olive oil of density precisely equal to the mixture, we have in the latter a liquid mass relieved from the operation of gravity, and free to take the exterior form given by the forces which may act upon it. In point of fact, the oil, by virtue of the law of molecular attraction, instantly takes a globular form. A vertical axis being introduced through the box, with a small disc upon it, so arranged that its centre is coincident with the centre of the globe of oil, we turn the axis at a slow rate, and thus set the oil-sphere in rotation. "We then presently see the sphere flatten at its poles and swell out at its equator, and thus realize on a small scale an effect which is admitted to have taken place in the planets." The spherifying forces are of different natures, that of molecular attraction in the case of the oil, and of universal attraction in that of the planet; but the results are analogous, if not identical. Quickening the rotation makes the figure more oblately spheroidal. When it comes to be so quick as two or three turns in a second, "the liquid sphere first takes rapidly its maximum of flattening, then becomes hollow above and below around the axis of rotation, stretching out continually in a horizontal direction, and finally, abandoning the disc, is transformed into a perfectly regular ring." At first, this remains connected with the disc by a thin pellicle of oil ; which, however, on the disc being stopped, breaks and disappears, and the ring then becomes completely disengaged. The only observable difference between this 
ring and that of Saturn, is that it is rounded, instead of being flattened; but this is accounted for by the learned professor in a satisfactory way.

A little after the stoppage of the rotatory motion of the disc, the ring of oil, losing its own motion, gathers once more into a sphere. If, however, a smaller disc be used, and its rotation continued after the separation of the ring, rotatory motion and centrifugal force will be generated in the alcoholic fluid, and the oil-ring, thus prevented from returning into the globular form divides itself into several isolated masses, each of zuhich immediately takes the globular form. These "are almost always seen to assume, at the instant of their formation, a movement of rotation upon themselves, - a movement which constantly takes place in the same direction as that of the ring. Moreover, as the ring, at the instant of its rupture, had still a remainder of velocity, the spheres to which it has given birth tend to fly off at a tangent; but, as on the other hand, the disc, turning in the alcoholic fluid, has impressed on this a movement of rotation, the spheres are especially carried along by this last movement, and revolve for some time around the disc. Those which revolve at the same time upon themselves, consequently then present the curious spectacle of planets revoluing at the same time upon themselves and in their orbits. Finally-besides three or four large spheres into which the ring resolves itself, there are almost always produced one or two very small ones, which may thus be compared to satellites. The experiment presents, as we see, an image in miniature of the formation of the planets, according to the hypothesis of Japlace, by the rupture of the cosmical rings attribu- 
table to the condensation of the solar atmosphere." I It must of course be admitted that the process of the experiment was of a reverse kind, and attended, as far as M. Plateau's description informs us, by slightly various effects; but the general reflection which it gives of Laplace's cosmogony is certainly such as to confer upon that theory a strong probability.

To conclude this section of the great history. What we see is-a boundiess multitude of bodies with vast empty spaces between. We know of certain motions amongst these bodies; of other and grander translations we are beginning to get some knowledge. Besides this iclea of locality and movement, we have the equally certain one of a former soft and more diffused state of the materials of these bodies; also a tolerably clear one as to gravitation having been the determining cause of both locality and movement. From these ideas the general one naturally suggested to us is-a former stage in the frame of material things-perhaps only a point in progress from some other, or a return from one like the present-universal space occupied with gasiform matter; this, however, of irregular constitution, so that gravitation caused it to break up and gather into patches, producing at once the relative localities of astral and solar systems, and the movements which they have since observed, in themselves and with regard to each other, from the daily spinning of single bodies on ideal axles, to the mazy dances of vast families of orbs, which come to periods only in millions of years. How grand, yet how

${ }^{2}$ See Professor Plateau on the phenomena presented by a free liquid mass withdrawn from the action of gravity, - Taylor's Scientific Memoirs, Nov. 1844. 
simple the whole of this process - for a God only to conceive and do, and yet for man, after all, to trace out and ponder upon. Truly must we be in some way immediate to the august Father, who can think all this, and so come into his presence and council, albeit only to fall prostrate and mutely adore! 
CONSTITUENT MATERIALS OF THE EARTH, AND OF THE OTHER BODIES OF SPACE.

THe orbs being all inextricably connected in the manner which has been described, are we also to presume that the constitution of the whole is uniform? - that is to say, do the whole consist of the same chemical elements?

What are elements? This is a term applied by the chemist to a limited number of substances (fifty-five is, or was lately, the number ascertained), which, in their combinations, form all the matters present in and about our globe. They are called elements, or simple substances, because it has hitherto been found impossible to reduce them into others, wherefore they are presumed to be the primary bases of all matters. It has, indeed, been surmised that these so-called elements are only modifications of a primordial form of matter, brought about under certain conditions; but if this should prove to be the case, it would little affect the present speculations. Analogy would lead us to conclude that the modifications of the primordial matter, forming our so-called elements, are as universal, or as liable to take place everywhere, as are the laws of gravitation and centrifugal force. It therefore appears likely that the gases, the metals, the 
earths, and other simple substances (besides whatever more of which we have no acquaintance), exist under proper conditions, as well as in the astral system, which is thirty-five thousand times more distant than Sirius, as within the bounds of our own solar system or our own globe.

Matter, whether it consists of about fifty-five ingredients, or only one, is liable to infinite varieties of conditions under different influences. As a familiar illustration, water, when subjected to a temperature under $32^{\circ}$ Fahrenheit, becomes ice; raise the temperature to $212^{\circ}$, and it becomes steam, occupying a vast deal more space than it formerly did. Some of the gases, by being subjected to pressure, have become liquids, or been solidified. Heat is a power greatly concerned in regulating the volume and other conditions of matter. The chemist will probably yet tell us what additional amount of heat would be required to vaporize all the water of our globe; how much more to disengage the oxygen which is diffused in nearly a proportion of one-half throughout its solids; and, finally, how much more would be required to cause the whole to become vaporiform, which we may consider as equivalent to its being restored to its supposed original nebulous state. He may calculate with equal certainty, what would be the effect of a considerable diminution of the earth's temperature-what changes would take place in each of its component substances, and how much the whole would shrink in bulk.

The earth and all its various substances have at present a certain volume in consequence of the temperature which actually exists. On the supposition that its matter and 
that of the associate planets was at one time diffused throughout the whole space now circumscribed by the orbit of the outermost planet, it follows, after what we know of the power of heat, that the nebulous form of matter was attended by the condition of a very high temperature. The nebulous matter of space, previously to the formation of stellar and planetary bodies, must have been a universal Fire Mist, an idea which we can scarcely comprehend. The formation of systems out of this matter implies a change of some kind with regard to the condition of the heat. Had this power continued to act with its full original repulsive energy, the process of agglomeration by attraction could not have gone on. We do not know enough of the laws of heat to enable us to surmise how the necessary change in this respect was brought about; but we can trace some of the steps and consequences of the process. Neptune would be formed at the time when the heat of our system's matter was at the greatest, Uranus at the next, and so on. Now this tallies with the exceeding diffuseness of the matter of the outer planets, Saturn being not more dense or heavy than the substance cork. It may be that a sufficiency of heat still remains in those planets to make up for their distance from the sun, and the consequent smallness of the heat which they derive from his rays. And it may equally be, since Mercury is nearly thrice the density of the earth, that its matter exists under a degree of cold for which that planet's large enjoyment of the sun's rays is no more than a compensation. Thus there may be upon the whole a nearly equal experience of heat amongst all these children of the sun. Where, meanwhile, is the heat once 
diffused through the system, over and above what remains in the planets? May it not have gone to constitute that luminous envelope of the sun, in which his warmth-giving power is now supposed to reside? It may have simply been reserved to constitute, at the last, a means of sustaining the many operations of which the planets were destined to be the theatre.

The tendency of the preceding considerations is to the conclusion that our globe is a specimen of all the similarly-placed bodies of space, as respects its constituent matter and the physical and chemical laws governing it, with only this qualification, that there are possibly shades of variation with respect to the component materials, and undoubtedly with respect to the conditions under which the laws operate, and consequently the effects which they produce. Thus, there may be substances here which are not in some of the other bodies, and substances here solid may be elsewhere liquid or vaporiform. We are the more entitled to form such presumptions, since there is nothing at all singular or special in the astronomical situation of the earth. It takes the third place in a series of planets, which series is only one of numberless other systems forming one group. It is strikinglyif such an expression may be used-a member of a democracy. Hence, we cannot suppose that there is any peculiarity about it which does not attach to multitudes of other bodies; in fact, to all that are analogous to it in respect of cosmical arrangements.

It therefore becomes a point of great interest-What are the materials of this specimen? What is the constitutional character of this object, which may be said to be 
a sample, presented to our immediate observation, of those crowds of worlds which seem to us as the particles of the desert sand-cloud in number, and to whose diffusion there are no conceivable local limits?

The solids, liquids, and aeriform fluids of our globe are all, as has been stated, reducible into fifty-five substances hitherto called elementary. Of these, forty are well-characterized metals, twelve non-metallic bodies, and the remaining three solid substances of intermediate character, which form a connecting link between the two great groups. Among the non-metallic elements, fourviz., oxygen, hydrogen, nitrogen, and chlorine, are permanently gaseous; bromine is fluid at common temperatures; and the remainder (with the exception of fluorine, which has never been isolated, and whose physical characters are consequently unknown) are solid.

The body oxygen is considered as by far the most abundant substance in our globe. It constitutes a fifth part of our atmosphere, eight-ninths of the weight of water, and a large proportion of every kind of rock in the crust of the earth. Hydrogen, which forms the remaining part of water, and enters into some minerals, is perhaps next. Nitrogen, of which the atmosphere is four-fifths composed, must be considered as an abundant substance. The metal silicium, which unites with oxygen in nearly equal parts to form silica, the basis of about a half of the rocks in the earth's crust, is, of course, an important ingredient. Aluminium, the metallic basis of alumina, a material which enters largely into many rocks, is another abundant elementary substance. So, also, is carbon, a small ingredient in the atmosphere, but the 
chief constituent of animal and vegetable substances, and of all fossils which ever were in the latter condition, amongst which coal takes a conspicuous place. The familiarly-known metals, as iron, tin, lead, silver, gold, are elements of comparatively small magnitude in that exterior part of the earth's body which we are able to investigate.

It is remarkable of the elementary substances that they generally exist in combination. Thus, oxygen and nitrogen, though in mixture they form the aerial envelope of the globe, are never found separate in nature. Carbon is pure only in the diamond. And the metallic bases of the earths, though the chemist can disengage them, may well be supposed unlikely to remain long uncombined, seeing that contact with moisture makes them burn. Combination and re-combination are principles largely pervading nature. There are few rocks, for example, that are not composed of at least two varieties of matter, each of which is again a compound of elementary substances. What is still more wonderful with respect to this principle of combination, all the elementary substances observe certain mathematical proportions in their unions. When in the gaseous state, one volume of them unites with one, two, three, or more volumes of another, any extra quantity being sure to be left over, if such there should be. Combinations by weight are also governed by fixed and unchanging laws, of the greatest beauty and simplicity. It has hence been surmised that matter is composed of infinitely minute particles or atoms, each of which belonging to any one substance can only associate with a certain number of the atoms of any 
other. There are also strange predilections amongst substances for each other's company. One will remain combined in solution with another, till a third is added, when it will abandon the former and attach itself to the latter. A fourth being added, the third will perhaps leave the first, and join the new comer.

Such is an outline of the information which chemistry gives us regarding the constituent materials of our globe, and their combinations. How infinitely is the knowledge increased in interest, when we consider the probability of such being the materials of the whole of the bodies of space, and the laws under which these everywhere combine, subject only to local and accidental variations!

In considering the cosmogenic arrangements of our globe, our attention is called in a special degree to the moon.

In Laplace's Hypothesis, satellites are considered as masses thrown off from their primaries, exactly as the primaries had previously been from the sun. The orbit of any satellite is also to be regarded as marking the bounds of the mass of the primary at the time when that satellite was thrown off; its speed likewise denotes the rapidity of the rotatory motion of the primary at that particular juncture. For example, the outermost of the four satellites of Jupiter revolves round his body at the distance of $\mathrm{I}, \mathrm{I} 80,582$ miles; hence, according to the hypothesis, the planet was about $3,675,50 \mathrm{I}$ miles in circumference, instead of being, as now, only 89, 770 miles in diameter. This large mass would take rather more than sixteen days six hours and a half (the present revolutionary period of the outermost satellite) to rotate 
on its axis. The innermost satellite would be formed when the planet was reduced to a circumference of 309,075 miles, and rotated in about forty-two hours and a half.

From similar inferences, it would result that the mass of the earth, at a certain point of time after it was thrown off from the sun, was no less than 482,000 miles in diameter, being sixty times what it has since shrunk to, At that time, the mass must have taken rather more than twenty-nine and a half days to rotate, (being the revolutionary period of the moon,) instead of, as now, rather less than twenty-four hours.

The time intervening between the formation of the moon, and the earth's diminution to its present size, was probably like one of those vast sums in which astronomy deals so largely, but which the mind altogether fails to grasp.

The observation made upon the surface of the moon by telescopes tends strongly to support the hypothesis as to all the bodies of space being composed of similar matters, subject to certain variations. It does not appear that our satellite is provided with an atmosphere of the kind found upon earth; neither is there any appearance of water upon the surface. Yet that surface is, like the face of our globe, marked by inequalities and the appearance of volcanic operations. These inequalities and volcanic operations are upon a scale far greater than any which now exist upon the earth's surface. The mountains are, in many instances, equal in height to nearly the highest of our Andes. They are generally of extreme steepness, and sharp of outline, peculiarities 
which might be looked for in a planet deficient in meteoric agencies, such as those which operate so powerfully in wearing down ruggedness on the surface of our earth. The volcanic operations are on a stupendous scale. They are the cause of the bright spots of the moon, while the want of them is what distinguishes the duller portions, usually but erroneously called seas. In some parts, bright volcanic matter, besides covering one large patch, radiates out in large streams, which appear studded with subordinate foci of the same kind of energy. A large portion of the surface is covered with circular emiFIG. I.

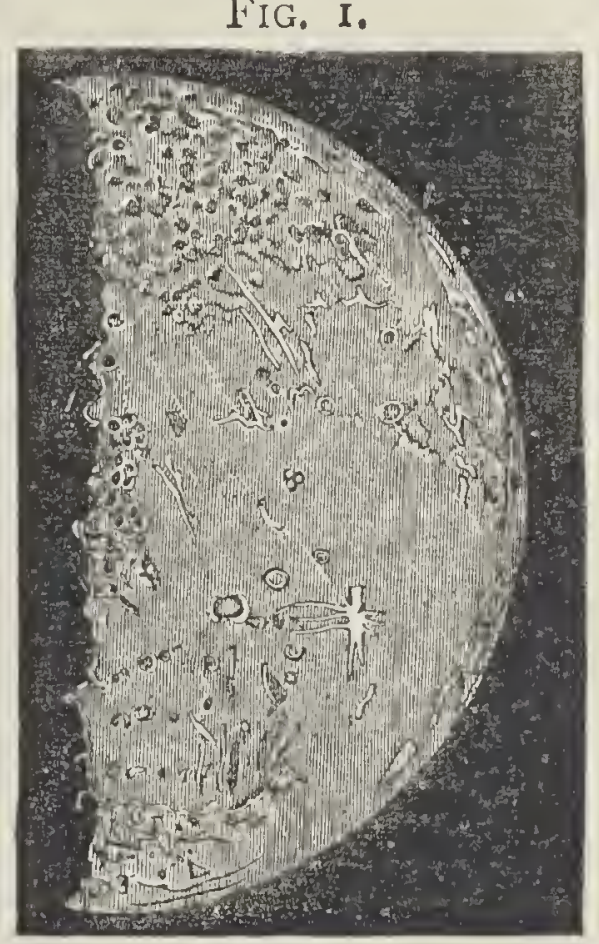

Surface of the Moon, at her first Quarter. nences, called Ring Mountains, of various diameters, from a quarter of a mile to several hundred miles, and in some places as close together as the circles on the surface of a boiling pot, which they in no small degree resemble. Some even intrude upon and obliterate portions of the neighbouring circles, thus leading to the idea of date, or a succession of events on the moon's surface. Generally, in the centre, there is a mount, which appears to be connected in the way of cause, with the annular eminence, beyond which again vast boulder-like masses are in some instances seen scattered. What, however, most strikes the senses of an observer, is the vast pro- 
fundity of some of the pits between the ring and the inner mount; in one case, this is reckoned to be not less than 2,000 feet, or twice the height of Etna.

These characteristics of the moon forbid the idea that it can be at present a theatre of life like the earth, and almost seem to declare that it never can become so. But it is far from unlikely that the elements which seem wanting may be only in combinations different from those which exist here, and may yet be developed as we here find them. Seas may yet fill the profound hollows of the surface; an atmosphere may spread over the whole. Should these events take place, meteorological phenomena and all the phenomena of organic life, will commence, and the moon, like the earth, will become a green and inhabited world. ${ }^{1}$

1 Among the most extraordinary phenomena of natural science must be placed those relating to the fall of meteoric stones. The fact itself, so long doubted, has now been established by an accumulation of the most positive and unexceptionable evidence. The stones have been seen to fall, and taken up in a still heated state; - there can be no manner of doubt about the fact, although the explanation is extremely difficult. All these stones are found on examination to resemble each other in their general characters ; they usually consist of an earthy material, having disseminated through its substance globules and small masses of metallic iron containing nickel in the state of alloy. The stones are often covered by a thin vitreous crust, as if partial fusion had commenced. It is well known, also, that large masses of soft malleable iron, also containing nickel, are found in several places far removed from each other, lying loose upon the earth, as in South America and in Siberia, and no doubt can exist of the meteoric origin of these masses. It has been conjectured that these meteoric stones proceed from the moon, having been shot out from volcanoes with such violence as to be brought within the reach of the earth's attraction. A view now more generally received supposes the existence in space of very numerous small bodies, moving in more or less regular orbits around the sun and larger planets, which at certain periods undergo such perturbation, that their motion becomes completely deranged, and they at length fall upon the surface of the earth or other planet, whose attraction has been the exciting cause of the derangement of their orbits. Whatever may be their real origin, they are by common consent looked upon as foreign to the carth: their physical constitution is completely different from any known minerals. But what is exceedingly remarkable, and particularly worthy of notice as strengthening the argument that all the members of the solar system, and perhaps of other systems, have a similar constitution, no new elcments are found in these bodies; they contain the ordinary materials of the earth, but associated in a manner altogether new, and unlike any thing known in terrestrial mineralogy. - Note by a Correspondent. 
It is unavoidably held as a strong proof in favour of any theory, when all the relative phenomena are in harmony with it. This is eminently the case with the Laplacian cosmogony, for here the associated facts cannot be explained on any other supposition. ${ }^{1}$ It remains that a few words should be said of the well-known hypothesis of a central heat. The immediate surface of the earth exhibits only the temperature which might be expected to be imparted to such materials by the heat of the sun. There is a point a very short way down, but varying in different climes, where all effect from the sun's rays ceases. Then commences a temperature from an entirely different cause, one which evidently has its source in the interior of the earth, and which regularly increases as we descend to greater and greater depths, the rate of increment being, in general, about one degree Fahrenheit for every fifty feet; and of this high temperature there are other evidences, in the phenomena of volcanoes and thermal springs, as well as in what is ascertained with regard to the density of the entire mass of the earth. This approximates five and a half times the weight of water; but the actual weight of the principal solid substances composing the outer crust is as two and a half times the weight of water; and this, we know, if the globe were solid and cold, should increase greatly towards the centre, water acquiring the density of quicksilver at 362 miles below the surface, and other things in proportion, and these densities becoming much greater at greater depths; so that the entire mass of a cool globe should be of a gravity infinitely exceeding five and a half times the

See Proofs, Illustrations, \&c., No. 2. 
weight of water. From these considerations arose the hypothesis of a central heat, causing an expansion of the materials. This is now, however, losing favour, in consequence of experiments which show that substances cannot be maintained at a high, while in contact with similar substances at a lower temperature. ${ }^{1}$ It is now thought that electric currents will yet account for the high temperature of the interior. While the matter remains undetermined, it may be pointed to as one tending to support the Laplacian cosmogony; the statical fact alone, which is not questioned, appears in remarkable harmony therewith, in as far as it proves a rarity of materials in the interior.

I The researches on this subject were chiefly conducted by the late Baron Fourier, Perpetıal Secretary of the Academy of Sciences of Paris. See his Theorie Analytique de la Chaleur, 1822. 


\section{THE EARTH FORMED-GEOLOGICAL}

\section{CHANGES.}

In our version of the romance of nature, we now descend from the consideration of orb-filled space and the character of the universal elements, to trace the history of our own globe. We shall see that it falls into connexion in an interesting manner with the primary order of things indicated by Laplace's Theory.

The nature of the materials of the externe or crust of our globe, is known to a greater depth than might be supposed, in consequence of the relation of position of its various masses. Confused as these at first appear, an order of arrangement, connected with time, has been detected in them by the labours of modern geologists. It is found that a certain kind of rock, below which there is never, in ordinary circumstances, any other kind, is of crystalline character. Sometimes elevated in naked mountain masses, sometimes found only at great depths below other rocks of a different kind, Granite (for such is its name) appears as the basis rock of the earth's crust; the form into which the once fluid matter of our planet was primarily resolved, although, in many instances, subjected, under heat, to new movements at times long subsequent. The crystals of granite are of distinct sub- 
stances-quartz, felspar, mica, and hornblende (each of which is, again, a combination of a certain number of the simple or elementary substances); two of these, sometimes three, associated in various proportions, compose the rock, which thus appears in many varieties, passing under different names.

Where granite does not appear upon the surface, or else some other igneous rock, such as will presently be adverted to, we find that great flooring overlaid with rocks of a different character and history-namely, what are called Aqueous or Sedimentary Rocks. These are in the form of strata or beds, and have evidently been for the most part produced as a sediment of sand, clay, or other materials, at the bottom of seas, the matter being hardened by heat and pressure after its deposition. Whence the materials of these rocks? With some peculiar exceptions, each group of them has been derived from the substance of such rocks as were previously in existence, the earliest from the original granite, and so on in succession; and this, by means of processes which continue in operation at the present day. That is to say, the atmosphere, by the chemical action of its materials, and the vapours with which it is charged, wears down whatever rocks are exposed to it; rivers carry the particles into the sea; the sea also erodes the rocks against which it impinges, and strews the matter along its bottom; thus are sediments laid down, to be in time formed into rocks. Many of the earliest or lowest strata are obviously composed of material but slightly changed from the original granite; such are all the rocks bearing the name of Gneiss. Others present the component materials in 
different combinations; as, for instance, where, with clay derived from the felspar and the addition of mica, Micaceous Schist has been formed. Sometimes the quartz forms a sedimentary rock by itself. For such elections of materials, as they may be called, we see natural means of accounting, when we reflect that the lightest particles of any substance suspended in moving water are liable to be carried most rapidly, and to the greatest distance. ${ }^{1}$ It is also to be remarked of all these early rocks, that they have evidently been subjected to an extraordinary degree of heat, insomuch that they generally have acquired a new crystalline texture, are strangely waved and contorted, and often cannot be distinguished from the underlying granite, the adjacent parts of which may sometimes be detected as having been placed there after the deposition of the aqueous rocks. Now the lowest stratified rocks are sometimes found lying in a nearly horizontal position, as they would be originally formed; but more generally they are tilted up in high inclinations, with the broken edges directed towards granitic mountains; indicating that the rise of these mountains from below was the cause of the change of position in the stratified rocks. Thus the earliest strata were in their turn exposed to the wearing influences of sea and atmosphere, and the materials appropriated to form new rocks. And, precisely as might be expected, these new rocks are laid down unconformably to the old; that is, their verges rest at an angle against the sides of the senior formation. These new rocks are again, in their turn, broken up and placed in high inclinations by new and similar upbursts

I De la Beche's Geological Researches, I834. 
of igneous rock; so as to become liable, of course, to similar disintegration. Such a repetition of wearings down and raisings up, implying frequent changes of land and sea, has been in reality the history of our globe since it took its present shape. A granitic crust, containing vast and profound oceans, as is proved by the extent and thickness of the earliest strata, was the infant condition of the earth. Points of unconformableness in the overlying aqueous rocks, connected with protrusions of granites, and other similar presentments of the internal igneous mass, such as trap and basalt, mark the conclusions of subsequent sections in this grand tale. Dates, such as chronologists never dreamed of-compared with which those of Egypt's dynasties are as the latter to a child's reckoning of its birthdays-have thus been presented to the now living generation, in connexion with the history of our planet.

The aqueous rocks, taken in their details, are a vast number. Geologists, however, group them in formations or sj'stems, partly with reference to their lithological characters and the breaks in stratific arrangement above described, and partly with regard to an entirely different class of particulars. It is now time to say that, from an early portion of the sedimentary rock series to its close, the mineral masses are found to enclose remains of the organic beings (plants and animals) which flourished upon earth during the time when the various strata were forming; and these organisms, or such parts of them as were of sufficient solidity, have, in many instances, been preserved with the utmost fidelity, although for the most part converted into the substance of the enclosing mineral. 
Now, as we pass along through the series of strata, we find a cessation of certain specific forms of plants and animals, while others come to view; at some points, the change is almost complete-at others, it is very considerable. Such demarcations are taken into account by geologists in the grouping of the rock series. They speak of a Palceozoic Period (IIadaiòs, ancient, '̧wov, an animal), comprehending a large early section, terminating at a point where the specific forms are for the first time almost wholly changed; a Secondary Period, and a Tertiary Period, - these also giving groups of species all but distinct. Under each period are reckoned certain systems, more or less organically distinct, and these we shall now proceed to treat separately.

\section{LOWER AND UPPER SILURIAN FORMATIONS-} FIRST FORMS OF LIFE.

IT follows that the strata in their order might be described as a record of the state of life upon our planet from an early to a comparatively recent period. It is truly such a record, but not one perfectly complete. For neither are we to suppose that every kind of organism has been entombed in the matter afterwards hardened into rocks, nor are we to presume that examples of all which have been so entombed are now liable to detection. Those composed of soft substance only, even if so entombed, would have little chance of leaving any trace of their form and character behind them. Some rocks have been subjected to so great a change by means of heat, that any 
organisms involved in them would be almost sure to disappear. There is, moreover, but a limited portion of the earth-namely, that uncovered by sea-open to inspection, and of this but a few scattered parts have been inspected : we cannot tell what blanks there may be in the Stone Book, yet to be filled up by more extensive and happier inquiry. It is therefore necessary, in looking over this singular chronicle, to make certain allowances for falterings and shortcomings, even while we pause breathless in admiration at the wondrous historical detail which it has so unexpectedly disclosed to the perusal of modern men.

The earliest system, that of the Gneiss and Mica Slate, appears to be Azoic, or entirely devoid of the remains of living things. This would seem to indicate that, at the same time when these rocks were forming, no living things existed on the face of the globe. It is remarked, however, that many of these rocks have been subjected to a degree of heat calculated to metamorphose their physical character, and therefore presumably sufficient to have obliterated all trace of any organic remains originally embedded in them. It is also observed that, if, as has been thought, living creatures have been concerned in the production of limestone, then living creatures must have existed in the time of this formation, as it includes several beds of that kind of rock. ${ }^{1}$ To the same purpose is the fact of ammoniacal products appearing in certain chemical experiments with the primary rocks. And still more decisive were the detection of minute objects supposed to be the cases of infusoria (shelled animalcules), if this

1 De la Beche's Geological Researches, 1834 . 
fact, which has been announced, could be satisfactorily verified. At the same time, it is admitted that there are strata of immense thickness in this portion of the rock series in some parts of the earth, which exhibit no tokens of that metamorphose from heat which has been spoken of, and yet are truly Azoic, or destitute of fossils. For this various reasons might be surmised, apart from the assumption of this being a time when no life existed on earth. Some geologists who have a theory to support explain it away very ingeniously, calling on us to observe that the evidence of azoism is merely negative. But others, of the highest reputation, seem disposed to admit that there is an azoic formation. Professor Sedgwick, for instance, considers the Skiddaw slates as nearly marking "the descending limit of organic life." "Below them are other beds of great thickness, not metamorphic, and fit for receiving impressions of organic remains, yet without any traces of animal or vegetable life." Sir Roderick Murchison, in like manner, believes he has found an azoic series in Scandinavia, and M. Barrande's examination of the lowest fossiliferous deposits of Bohemia presents it as resting on an azoic basis. The probability for the present seems to be, that any animals entombed in these non-fossiliferous rocks, must, for the most part, have been animals possessing soft parts only, totally unfit for preservation.

Traces of life first appeared in considerable force in the Silurian formation, a series of beds (sandstones, limestones, slates, \&c.) on which this name has been conferred, because of its large development in a region of western England, occupied in the time of the Romans by a people 
called by them Silures. In England this formation is of immense thickness-perhaps not less than 30,000 feetimplying its deposition in deep seas, and the lapse of a vast space of time between its beginning and its close. In the State of New York, in Bohemia, in Scandinavia, in India, and Australia, it has been examined with more or less care, and everywhere found to exhibit certain general characters, and particularly as to its fossil contents. And what were the vessels of the mystery of life in the Silurian era, or more particularly its earlier portion, as far as these rocks inform us?

One would imagine that, if our present amount of geological knowledge had come to us by some sudden revelation, it would have been with a kind of awe that its first recipients would have waited for this portion of it. But, had they done so, they would quickly have had to admit that nature is simpler than man's wit would make her; for, behold, a broad answer to the interrogation brings before us little besides the humblest and most unpretending forms of vegetable and animal life!

The list includes no land-plants or land-animals. It includes no marine creatures so high as fish. Even of the classes below fish (Invertebrates), it presents generally only examples of humble families. As we grope downward among these early and obscure fields of creation, we find from time to time a few fossils lower than they had before been found in the same situation, but always the tendency is to a limitation of these primitive creatures to very humble forms. In the Skiddaw slates, for example, which are perhaps older than any part of the Silurian formation, we have only fucoids, or impressions 
of fuci, a tribe of lowly sea-plants, and graptolites, a humble polypian family, allied to the sea-pens of our modern seas. At the base of the Silurians in western England, and in what appears the corresponding situation in America, the fossil that perseveres farthest downwards is the lingula, a simple bivalve shell. ${ }^{1}$ In the same formation,

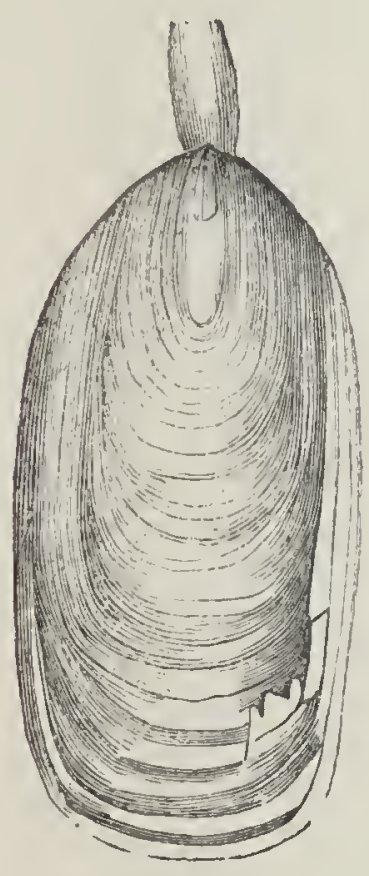

FIG. 2.

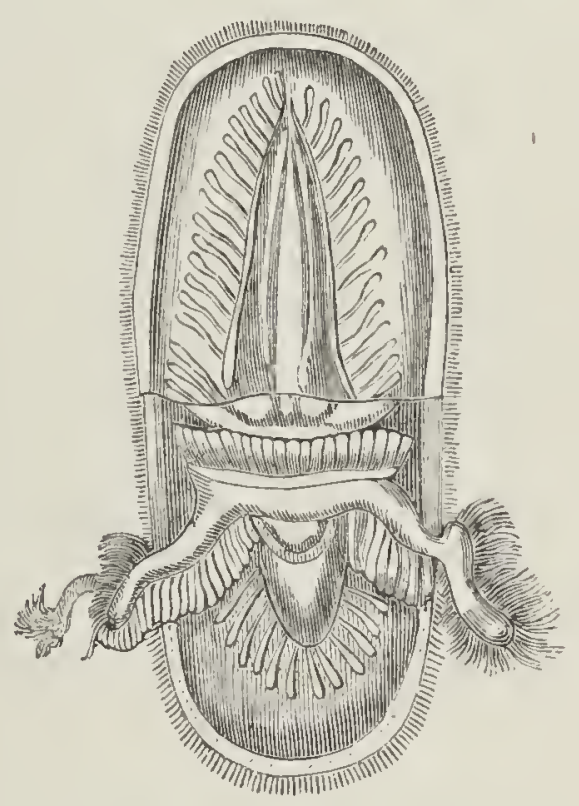

Lingula anatina.

as developed in the chain of mountains crossing the southern part of Scotland, graptolites are the lowest fossils as yet found, and next above them appear impressions

1 Professor Sedgwick places below the lowest of the Silurian rocks certain thick beds in Wales, of which one series are called the Lingula F!ags, from their containing that fossil. When the reader has acquainted himself with the order of these sub-Silurian strata, and their approximate thickness, he will be able to appreciate the interim importance to the theory of the present work of the fact of this humble animal being found unattended by higher grades of existence in such a situation. The learned professor places them in the following descending order:-rst, Arenig Slates and porphyry, 7000 feet ; 2nd, Tremadoc Slates, rooo feet; 3 rd, Lingula Flags, 500 feet, \&c.-Quarterly Fommal, Geological Society, May, 1852 .

"In Lingula the shell is of horny texture, and neither of the valves is per- 
of annelidans, or sea-worms. In a building stone at Lampeter, in IVales, far down in the Lower Silurians, we

FIG. 3 .

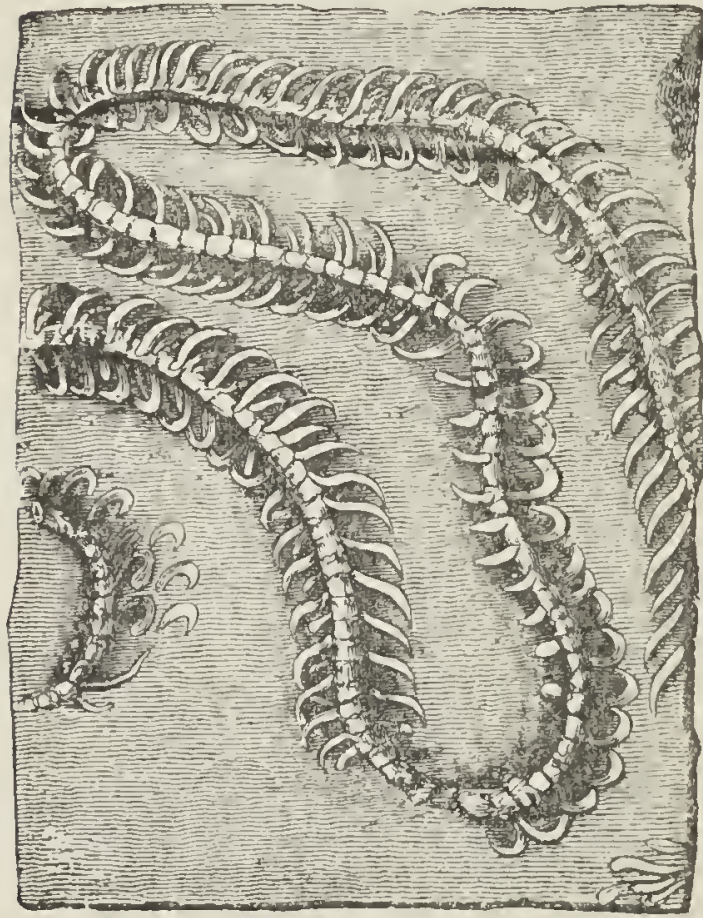

Nereites Cambriensis. find a creature of this kind, supposed to be allied to the nereis of our seas, laid in a long coil, as it might be supposed to have arranged itself when it lay down on the bottom of the sea to die. Another of the characteristic fossils of the very early rocks is orthis, a brachiopod mollusk.

Taking the Lower Silurian formation as a whole, and including any fossiliferous rocks that may be ascertained to be lower, the fauna or assemblage of animals which it contains must be pronounced humble, though it is not deficient in a class which stands high in the sub-kingdom to which it belongs. What constitutes high and low in animal organization? An animal is said by naturalists to be low, when its organiza-

forated; but the peduncle, which is longer, is attached to both alike, and serves to hold them together. There is no frame-work for the arms, which are unattached, except at their bases, and may be extended beyond the shell ; and the animal further departs from the ordinary type, in having the mantle raised into fringes, which may be considered as rudiments of the special branchia of the Lamellibranchiata. It is probable from the circumstances under which the Lingulæ are found, that they possess more locomotive power than the Terebratulæ; the former live near the surface, whilst the latter are inhabitants of very deep water."-Carpenter's General Physiology, 1851, p. 312. 
tion is of a simple kind, subservient to a comparatively narrow range of functions, and suited to a comparatively narrow field of existence-if, for instance, like the polypes, it be fixed in situation, and consist mainly of an alimentary receptacle, with means of filling that with food. Elevation is marked in the scale by an animal ceasing to be compound (which is the case of the coralline polypes), assuming a power of locomotion, having sex assigned to separate individuals, exchanging a multiplicity of parts serving one end (as the many pairs of feet in the centipede), for a smaller number; attaining, in short, at once a more complex and more concentrated organization. ${ }^{1}$ On such ground the animal kingdom is primarily divided into Vertebrate and Invertebrate; animals with a backbone, and the superior nervous system which that structure implies; and animals devoid of that structure, and possessing a humbler nervous system. In the latter are placed first the rayed animals (Radiata); then, on a higher platform, as in some degree co-ordinate, the Articulata, or jointed animals, as crustacea, insects, spiders, and the Mollusca, or pulpy animals, of which oysters, cowries, and cuttle-fish are examples. To all these, the Vertebrata are as a beautiful superstructure upon a rustic basement, in the four great classes of ascending rankFishes, Reptiles, Birds, Mammalia.

In a general enumeration of the organisms of the Lower Silurians, we may first notice the examples of an order which is placed in the lowest subdivision of the animal kingdom-Polypiaria - the creatures to which we

${ }^{1}$ In the highly organized animal " the number of dissimilar parts is larger, and the consequent adaptation of the whole to a variety of purposes is mcre complete."-Cirpenter. 
owe those vast coral reefs by which the course of the mariner is so often obstructed in tropical FIG. 5 .

FIG. 4 .

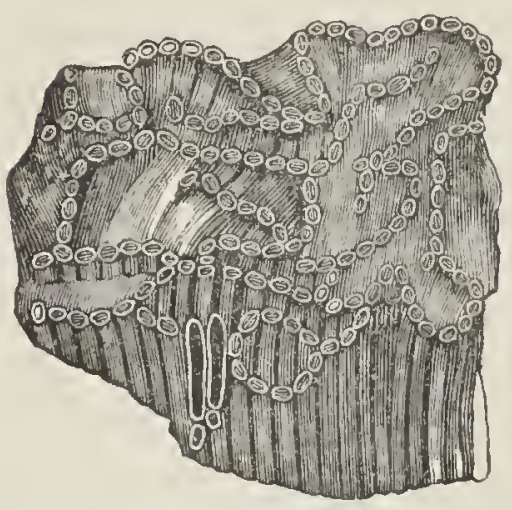

Catenipora escharoides, a Silzurian Coral.

seas. It was, perhaps, by some peculiarly early development of this family that the materials were formed, out of which, in a reduced and modified state, were formed the few limestone strata which occur among the first sedimentary rocks. In the early rocks of Snowdon, in the Bala limestone, in the Llandeilo rocks, and others classed in this department, detached corals occur (cyathophylla, favosites, \&c.), but not nearly in such large quantities as in higher strata. In this order are also to be placed those Graptolites which form so characteristic a fossil in the lowest zones of the system.

We come to creatures comparatively well organized, and yet still within the lowest division of the Animal Kingdom, when we speak of Crinoidea, which might be described as a lowly kind of star-fish, fixed on the top of a flexible stalk arising from the sea-bottom. Numberless calcareous plates enter into the composition of the stalk, body, and multitudinous tentacula or arms of the crinoid, forming Actinocrunte, altogether a wonderful example of the elabo- Encrinitc. 
rateness of pattern on which nature sometimes works; and yet it is a very humble animal,- - only, indeed, a stomach with arms wherewith to supply itself with food. The echinodermata, however, to which order it belongs, are the destructives of their grade. The true crinoidea do not make a prominent appearance in the Lower Silurians, and certainly not in such a style in England as to allow of species being determined. But there appears in these rocks what is considered by some as a lower crinoidal form, in the Cystidea, a family in which the tentacula are

FIG. 6.

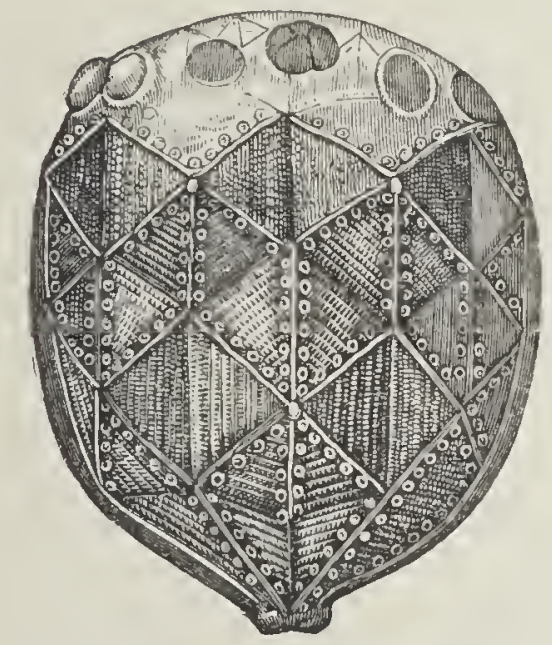

Caryocrinites ornatus, one of the Cystidea.

usually wanting. In the words of the eminent geologist, M. de Verneuil, this family is the more interesting, since " it seems to have preceded the other crinoidea in order of time, and presents, as it were, the primitive form of animals of this class." What is further remarkable, it makes little appearance above the Lower Silurians.

By far the most conspicuous fossils of the Lower Silurian formation, are Brachiopods, the bivalve order to 
which lingula belongs. This is a family of mollusks now slenderly represented on earth ; in those early ages it was both abundant and extensively diffused. The animal is

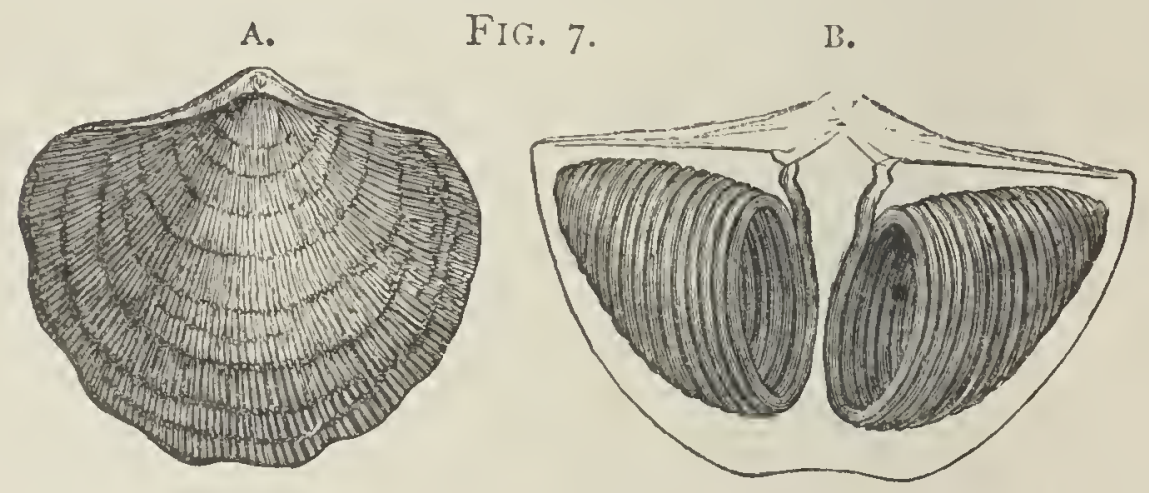

A, Terebratula reticularis; B, Interior of Spirifer hystcricus.

a humble one in its class, having its two valves not connected by a hinge, as is usual in superior bivalves, but kept together by a bundle of fibres. Its destiny is to remain fixed at the bottom of deep seas, and live upon nutritive particles which it collects by means of an

FIG. 8.

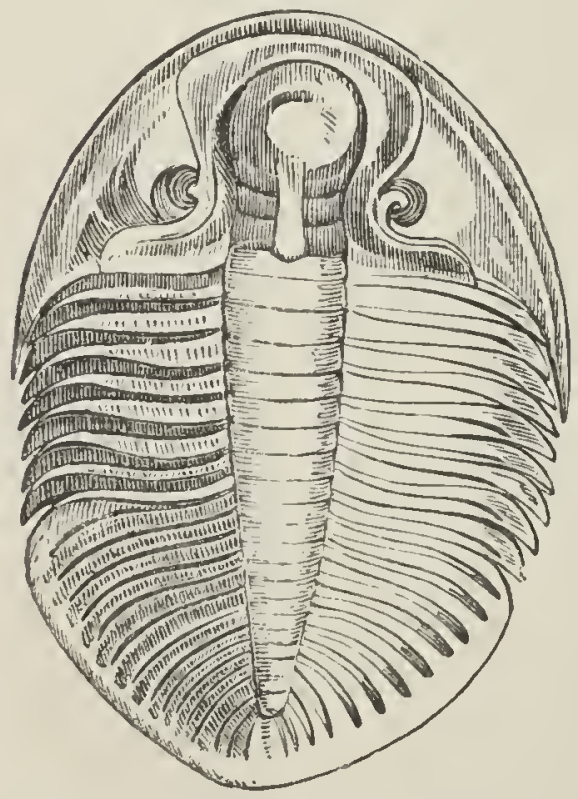

Ogygia Buchii, a Lozver Silurian Trilobite. apparatus connected with two spiral-shaped arms, extending from the margin of the mouth, and from which the order has received its name. So prominent does the order appear in this part of creation that an eminent geologist distinguishes the Lower Silurian period as the Age of Brachiopods.

The next most conspicuous fossil is a crustacean, also humble in its class. This is the Trilobite, a marine animal 
to which the wood-louse makes the nearest approach in general figure, but marked by two groovings along the length of the body, so as to present a tri-lobed form; hence the name. The king-crab (limulus), an animal of our present seas (Fig. 52), is, in an early stage of its existence, somewhat like the trilobite. It is surprising how many species and even genera of this form lived in the Silurian seas, and in what quantities their remains are found in various parts of the earth. The means of locomotion possessed by the animal are not known; but from its form we must suppose it to have lived at the bottom of the sea, having its eyes directed upwards and sideways. The latter

\section{FIG. 9.}

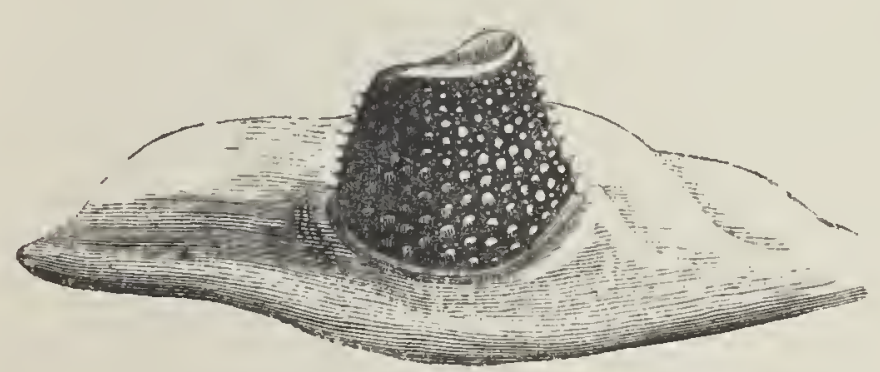

Facetted eye of Asaphres caudiatus.

organs presenting facets such as are seen upon similar animals of our era, we may be said to have a proof furnished to us by this humble creature, "that the water of those oceans and the supernatant atmosphere, was as transparent a medium at that time as it is at the present day, and that therefore no material permanent alteration can have resulted in either during the thousands of years which have elapsed since the creation of the animal world on this earth." 1 The trilobites stand low in the

'Emmerich on the Morphology of the Trilobites, Taylor's Sc. Mem., Aug. 1845. 
crustacea, nor are there any certain appearances of higher animals of that order (such as crabs, lobsters, \&c.) having yet been in existence.

Of univalve mollusks, which, generally speaking, rank above the bivalves, there are abundant remains. The first and humblest order, Pteropoda, most of which are naked, and therefore incapable of preservation in a fossil

FIg. Iо.

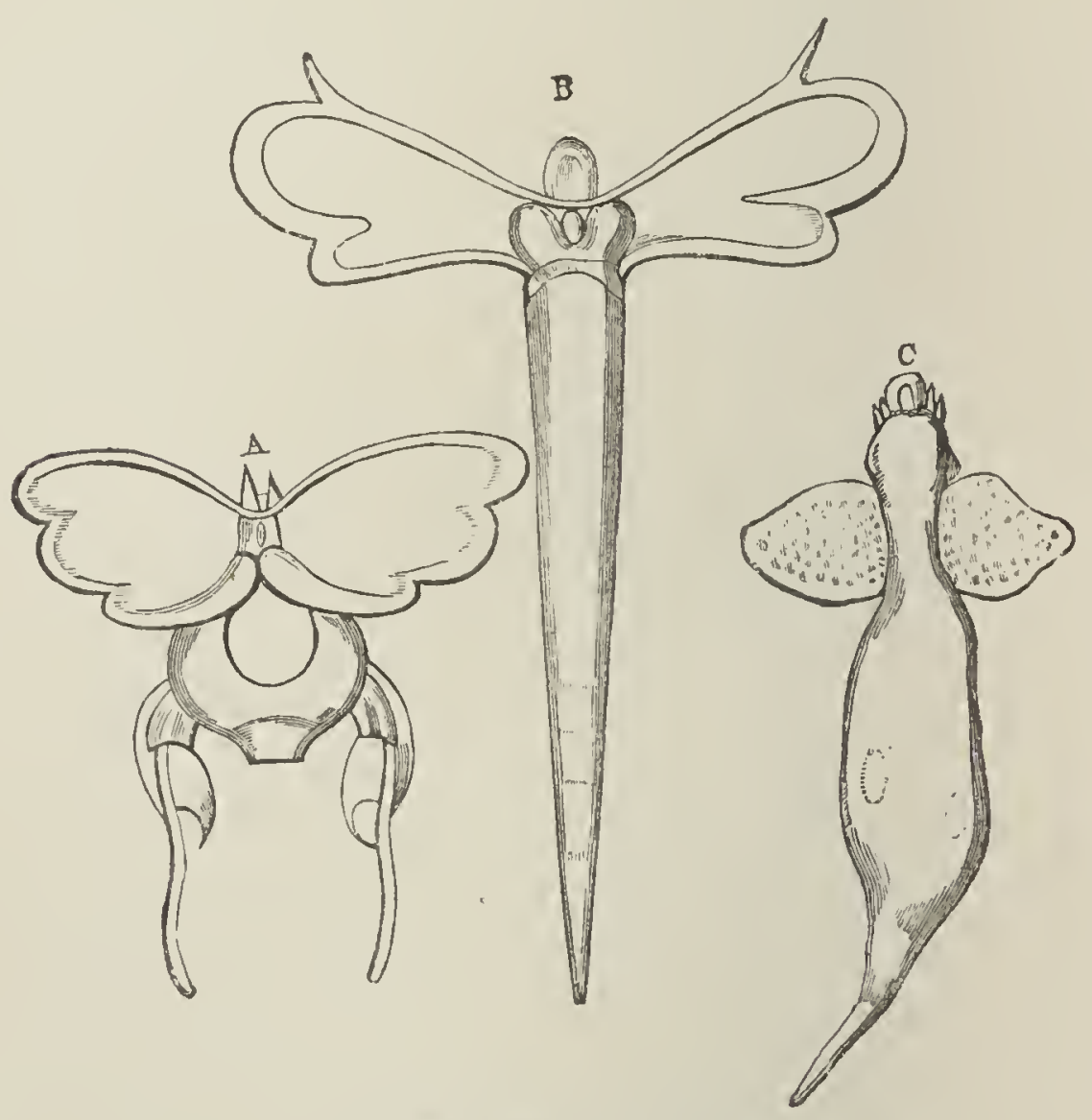

Existing forms of Pternpods.

A, Hyalea; B, Criseis; C, Clio.

state, appear only in a few slight conical shells, indicating an animal allied to the genus criseis, still common in the Mediterranean. Of the next, Gasteropoda, there are 
many fossil species. There are also representatives of the last class, Cephalopoda, amongst which are now found some of the highest of the invertebrate animals, as the nautilus, cuttle-fish, and poulp. The cephalopoda are,

FIG. II.

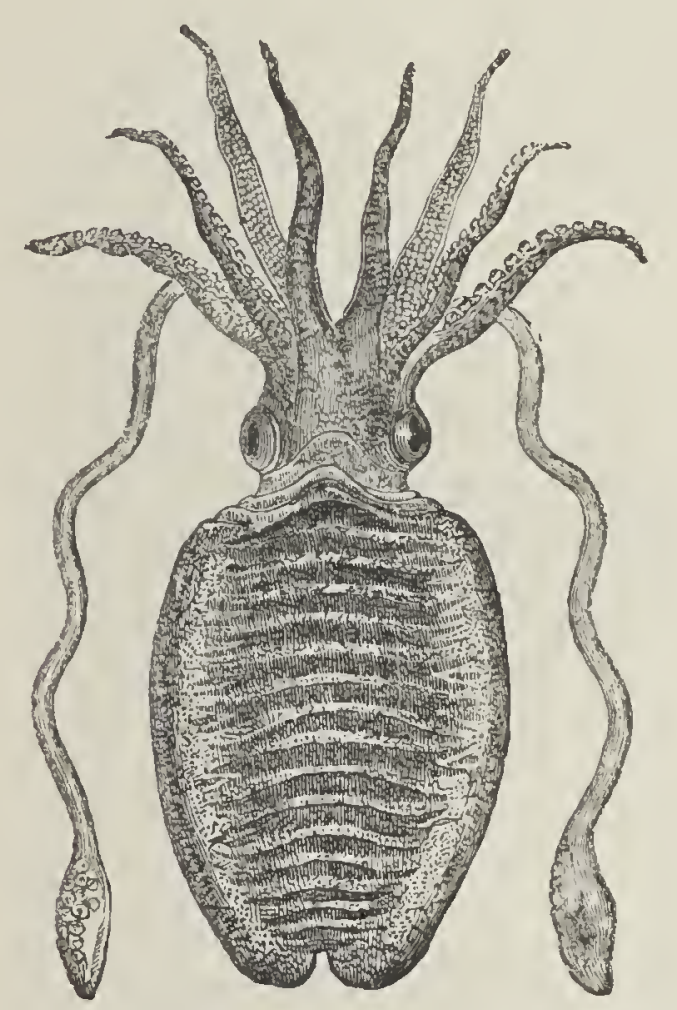

Sefia officinalis, or Common Cuttle-fish.

among invertebrate animals, what the feline and musteline animals are among the vertebrates, or the falcons among birds. They pursue a free-swimming life, with an organization powerfully adapted for making prey of the humbler marine animals. Naturalists regard them as having been eminently the police of those early ages, keeping down the teeming population of the Silurian seas. The genera which appear are, however, not the most exalted of their order, although many were of great 
size. Nor are they so abundant in the Lower Silurian period, either in species or individuals, as they after. wards became.

FIG. I2.

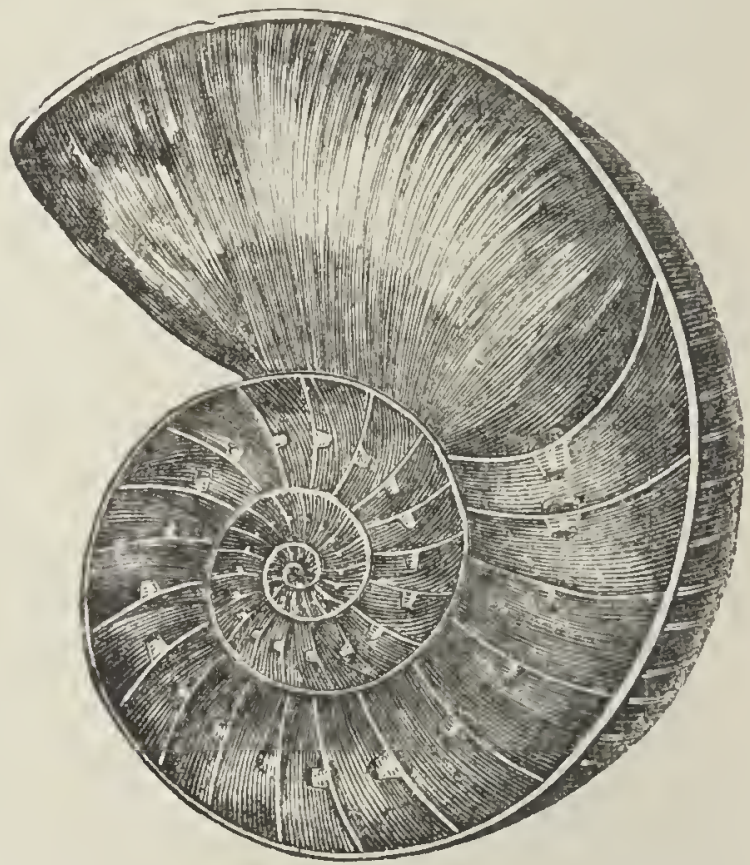

Shell of Nautilus pompilius, cut open to showe the chambors and the siphon.

FIG. 13.

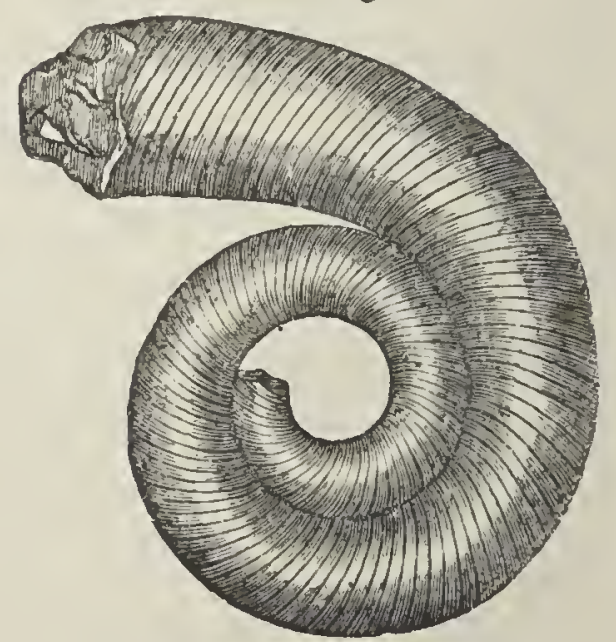

Lituites cornu-arietis, a Loz'er Silurian Cephalopod. 
Such in outline is the fauna of the Protozoic Period, or that portion of time represented by the Lower Silurian and Sub-Silurian rocks. We cannot believe that it presents us examples of all the genera of animals which existed in that age; and there is some force in the remark, that we generally see in it the products of deep seas only, and cannot know what other seas of shallow character may have produced. But, as far as positive evidence goes, we cannot but be sensible that the palæontology of the period indicates creation at a low stagepurely marine-destitute of fish, exhibiting families, generally speaking, low in their respective lines of gradation. ${ }^{1}$ And yet this was a state of things which lasted throughout a vast space of time, for the great thickness of the Lower Silurian strata can only be interpreted as the record of many ages. It is important to remark the coexistence of fucoids with the very oldest of yet discovered fossil animals. As animal life must depend primarily upon vegetation for support, we might have been sure beforehand that plants preceded, or were contemporaneous with, the animal. creation. Such, however, did not at one time appear as the order of fossils, and when, ultimately, fucoids were discovered in the earliest fossiliferous formations, it was felt that palæontology had come into a harmony with nature which was not to be dispensed with. ${ }^{2-}$

\section{${ }^{1}$ See Proofs and Illustrations, No. 6.}

2 In the Lower Silurians of Sweden, not only are there distinct impressions of such plants, but Professor Forchhammer speaks of courses of true coal, com. posed, as he thinks, of sea-weed, and gives an opinion that the alum-slate of that country. owes its combustible character to the carbon, sulphur, and potash derived from marine vegetation.-Murchison's Geology of Russia in Europe.

Mr. Daniel Sharpe has brought under the notice of the Geological Society the very remarkable fact of a coal basin from I000 to I 500 feet thick, existing in 
UPPER SILURIAN.

THE Upper Silurian formation, presenting in the ascending order in England the Wenlock shale, the Wenlock

FIG. I4.

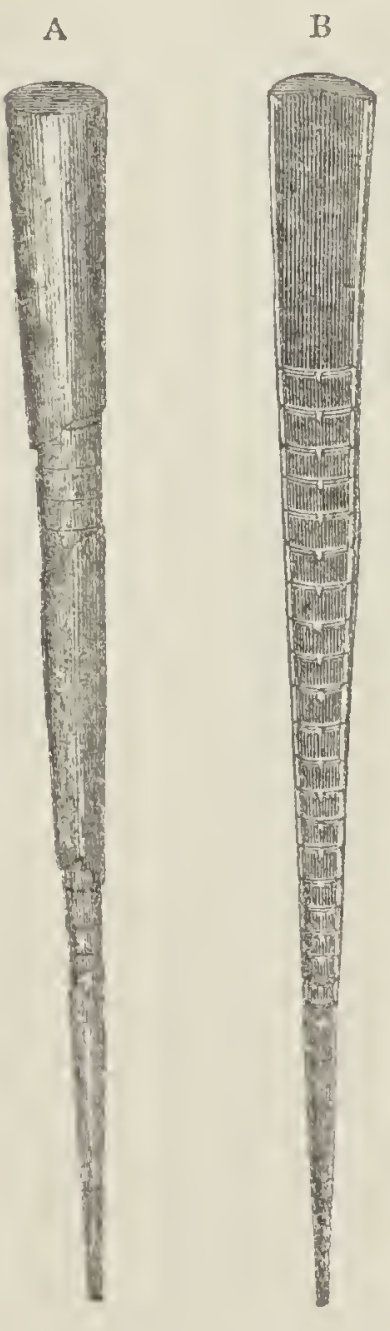

Orthoceratite

A, Exterior; B, Sec. tion, showing the chambers and siphuncle. limestone, the Lower Ludlow rocks, the Aymestry limestone, and the Upper Ludlow rocks, may be described as giving us a continuation of the fauna of the preceding formation, with some changes of species, and some additions. The brachiopod, the trilobite, and the orthoceratite (cephalopod) are everywhere characteristic fossils. It has been remarked by Sir Roderick Murchison, that in the Alleghany Mountains, in the hills of Herefordshire, and on the slopes of the Ural chain which divides Europe from Asia, we have remains of the same animal tribes connected with this formation. There are differences of species-that is to say, the fossils of different regions present certain minor peculiarities, but even this is only partial, and does not materially interfere with the general fact that there has been a remarkable uniformity of life in the

Portugal, below rocks characterised by their fossils as Lower Silurian. This coal bed contains plants generically, if not specifically, identical with the ferns of the carboniferous series; therefore inferring dry land and a land vegetation, in some parts of the earth, at this early period. 
primeval seas. In the present era, it is hardly necessary to say, the case is very different. Even seas so near as the Red Sea and Mediterranean present wholly different genera of mollusks. It has been thought that there might be a cause for the greater uniformity of life in those ages, in the greater uniformity of temperature, resulting from the as yet unspent heat of the surface, arising from the internal incandescence; but perhaps the more probable cause was simply the comparatively newness of life upon earth, and its little experience of those external agencies by which it is liable to be affected, and which, we shall see reason to believe, have conduced to the production of the many shades of variation which now mark the organic kingdoms.

Throughout the dense masses of the Lower Silurian formation, and the lower of the similar masses of the upper-each representing a long space of time-there are no indubitable remains of fish to be found. In the Aymestry limestone, at length, a few fragments appear, consisting mainly of spines or defences, and indicating some small individuals of the placoid family. This is a remarkable event, as it is, so far as we as yet know, the first appearance of vertebrated animals on the surface of the globe. $^{1}$

\section{DEVONIAN ERA.-FISHES ABUNDANT.}

WE now advance to a new chapter in this marvellous history-that of the Devonian era. The term Devonian 
System is applied to an important and conspicuous group of strata, overlying the Silurian, and largely developedfirst in the South of Devonshire (whence the name), and in Cornwall, South Wales, Herefordshire, Shropshire, and Worcestershire; also in Scotland, the valley of the Rhine, Russia, and the western states of America; besides, in all probability, many parts of the world as yet unexplored. In Scotland, the Great Grampian elevation, composed of granite and gneissic rock, is skirted by a dense formation of conglomerate and red sandstone, extending in a sweep from Dumbarton to Stonehaven, and so on to Morayshire, Ross, and Caithness. This passes by the general name of the Old Red Sandstone, which was at first used as an appellative for the system; but it has latterly been abandoned, as redness is not found to be a prevailing peculiarity of the strata in other countries. In Russia, a surface as large as the whole of Great Britain is occupied by this formation. It reaches a thickness of ten thousand feet in England.

The general forms of life prevalent in the Silurian era are continued in the Devonian, with the addition of a large development of the humblest vertebrate class-Fishes. There is here, as there was in the Silurians, an abundance of zoophytes, corallines, crinoids, crustaceans, and mollusks, but mostly presenting those inferior variations which naturalists regard as constituting distinct species; speaking strictly, out of about eight hundred so-called species of the Silurian epoch, one hundred pass into the Devonian formation, where, however, they gradually disappear, while new ones as gradually take their place. For such changes of species, adopting this word in the sense usually attached 
to it, geologists suggest causes in physical changes, as the rise of a sea-bottom by gradually filling up, or the intrusion of a new mineral infusion into the ocean, or one of a more decisive kind proceeding from such revolutions as are indicated by unconformableness in the strata. But on this point much obscurity at present rests; for, as our survey is extended into other countries, it is found that extensive changes of species occur without any apparent dependence on at least some of these causes; so that, in these instances, some other explanation remains to be sought for.

Corals (favosites, cyathophylla, stromatopora) are FIG. I 5.

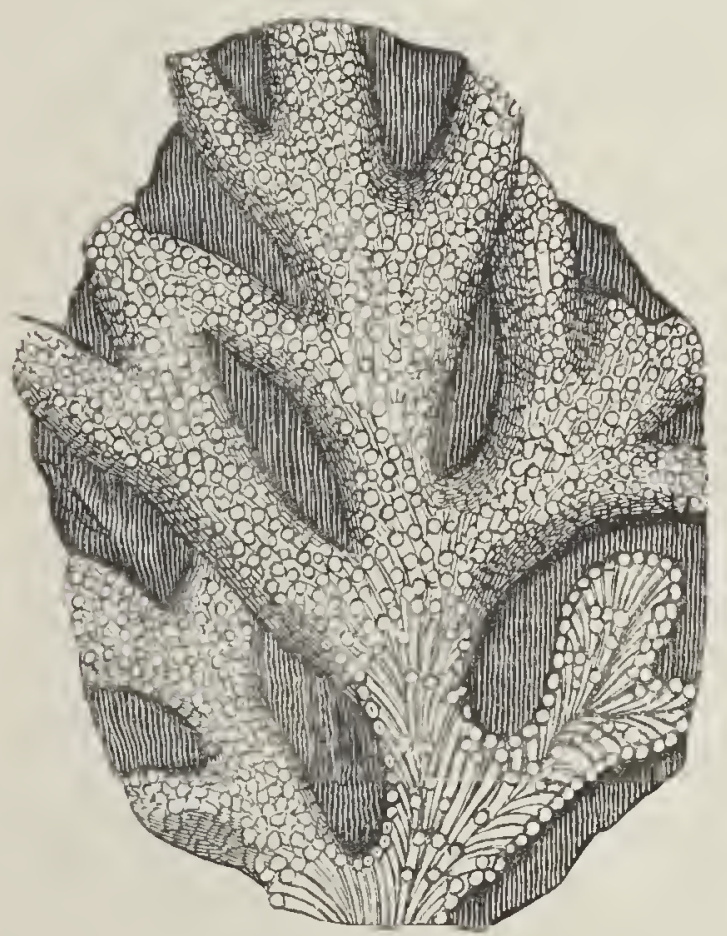

Favosites polymorpha.

amongst those genera which pass from the Silurians to the Devonians; they are so abundant, as in some places 


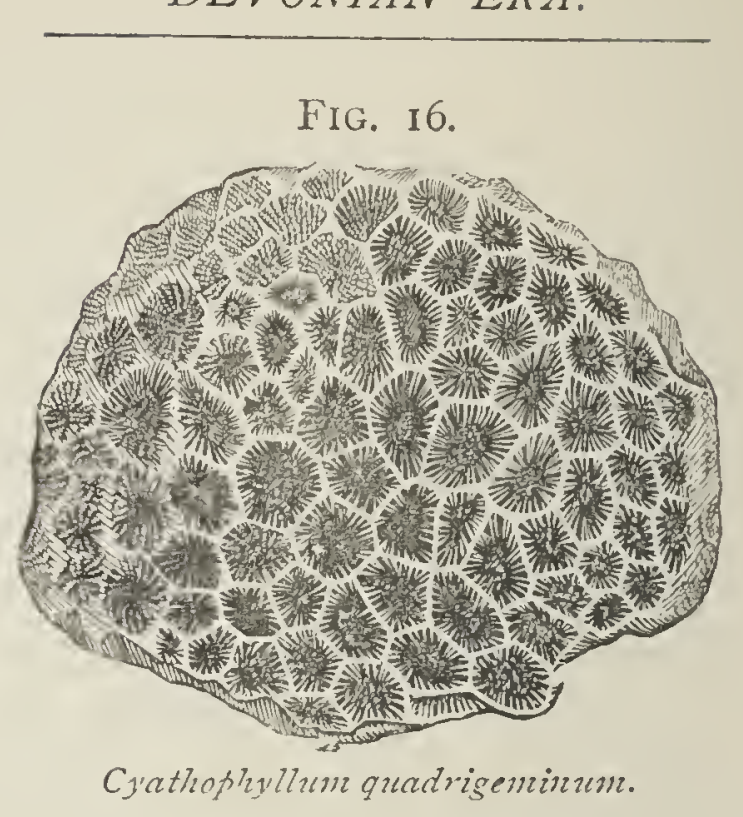

to constitute entire strata (Devonshire marbles). The crinoids and trilobites are also continued as families throughout this era. Of the latter we have a new species (brontes) supposed to have been not less than four feet

Fig. I 7 .

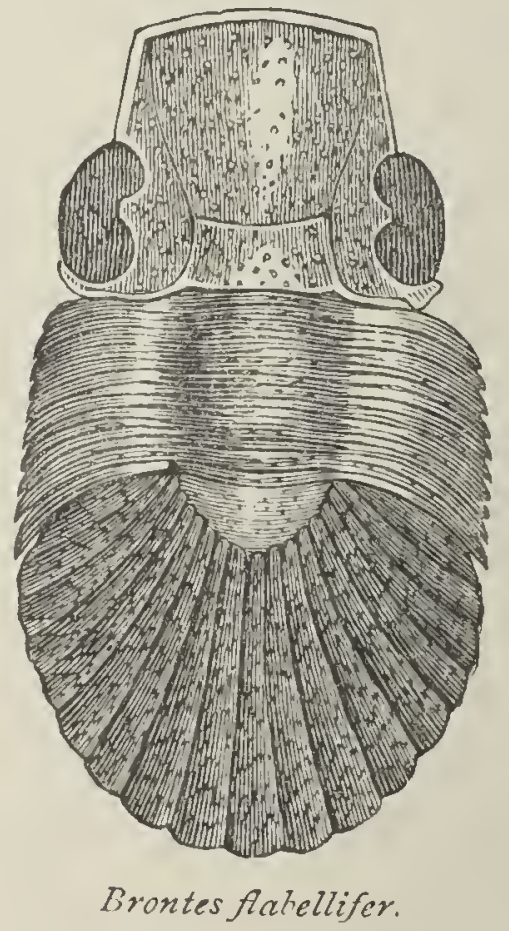


FIG. IS.
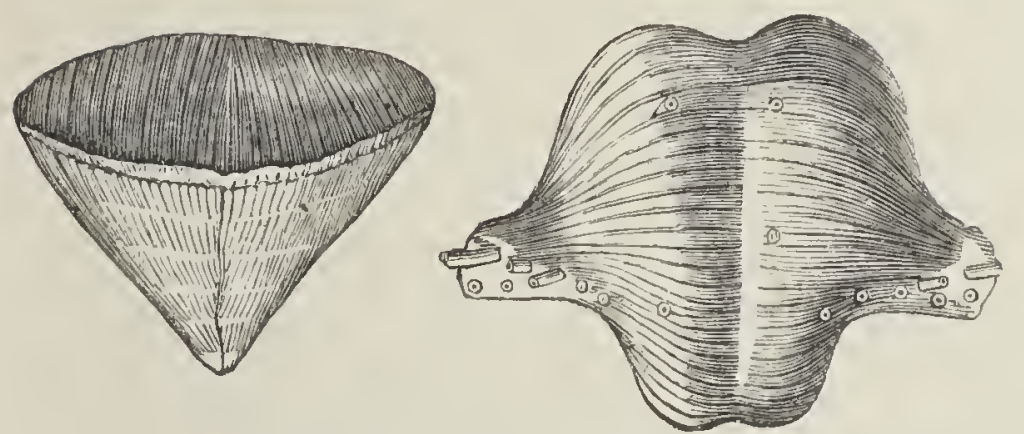

Devonian Brachiopods.

Fig. 18, Calceola sandalina; Fig. 19, Productus aculeatus.

long, and marked by several original features. Some of the new brachiopods are of a very peculiar shape (calceola and productus); amongst the gasteropods are some which approach existing forms. The lordly cephalopoda continue to be largely represented, but in a considerable change of form; for while the chief animals of this class

\section{FIG. 20.}

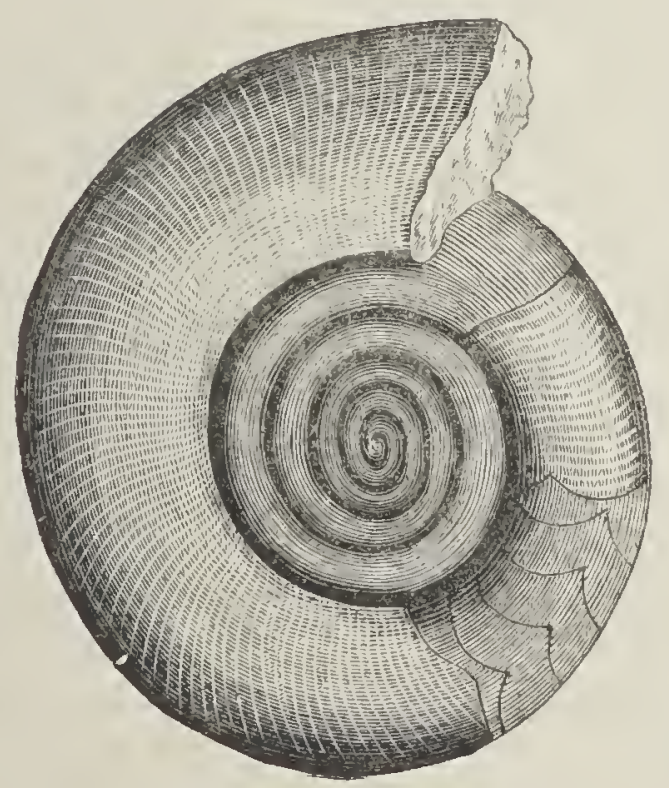

Clymenia Sedguickii. 
in the Silurians (orthoceratites) had a simple, straight, or slightly curved shell (Fig. I4), those new to the present era (as clymenia) had one forming a complete spiral.

The most remarkable circumstance connected with the Devonian formation, is its presenting us with an abundance of fish. A few faint traces of this class had, as we have seen, been presented at a late point in the Silurian formation. We are now to see such memorials of them in the Devonian formation as show that the seas of that era had in many places swarmed with such inhabitants. Professor Agassiz, to whom the investigation of the subject has chiefly been committed, has ascertained upwards of a hundred species of Devonian fish, to which number it is to be expected that many additions will yet be made.

In the present era, there are two leading divisions in the class of Fishes, those having an internal skeleton of bone, and those having this skeleton composed of cartilage. The osseous fishes are now many, and the cartilaginous few. In the Devonian era, it was different, for the cartilaginous fishes then predominated, and they formed a distinguished portion of the marine population, taking a leading part in that duty of keeping down the numbers of the lower animals, which, in the pre-Devonian ages was chiefly executed by the higher mollusca. The Devonian fishes are arranged by M. Agassiz in two orders, with a regard to their external covering, which that naturalist holds to be, in fishes, a reflection of the internal organization. In the one (placoids) it is of irregular enamelled plates, in the other (ganoids), regular enamelled scales, the first being not placed over each other, as scales are, but laid edge to edge, in the manner of a pavement. 
FiG. 2 I.

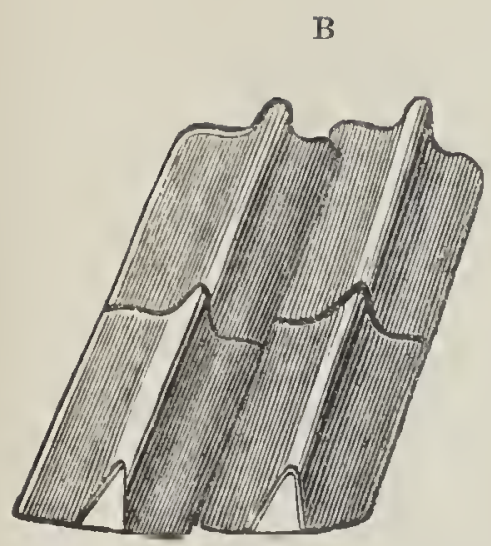

A

C

A, Placoid scale; B, C, Ganoid scales

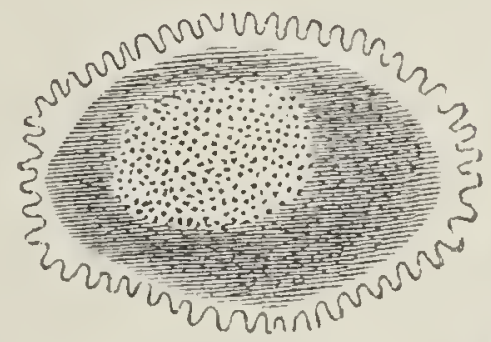

The cephalaspis has a longish tail-like body, inserted within the cusp of a large crescent-shaped head somewhat like a saddler's cutting-knife. The body is covered with

FIG. 22.
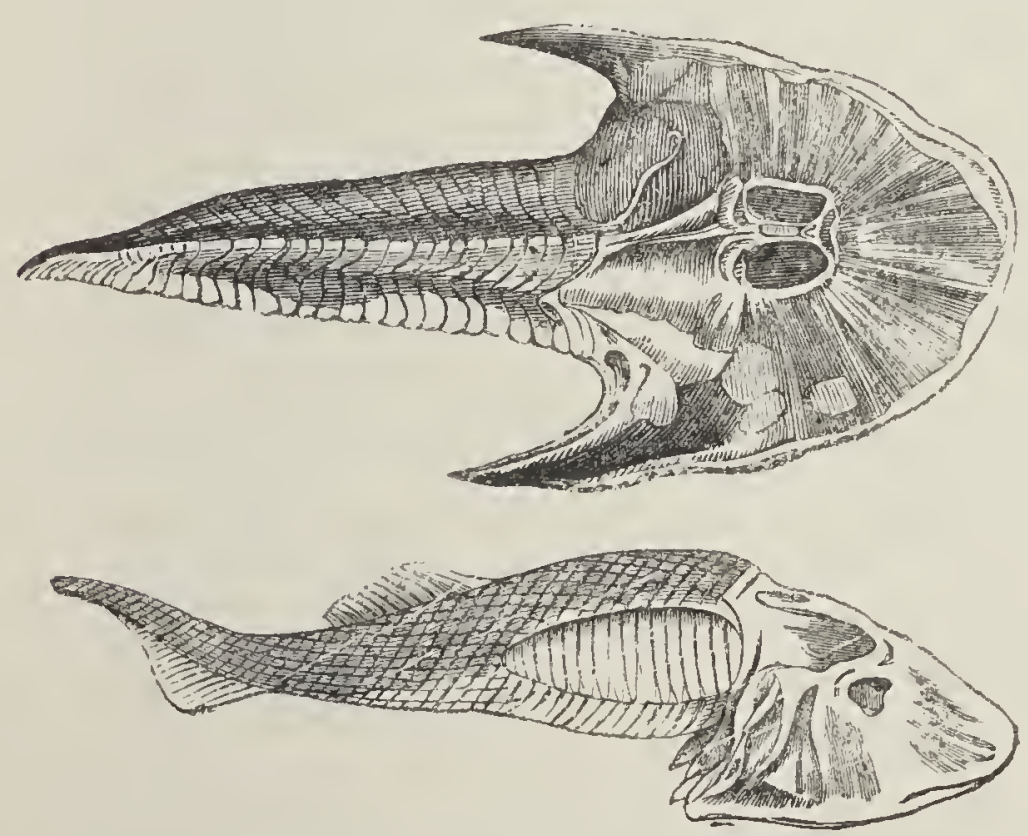

Cephalaspis Lyelii, as seen from atore, and from the side. 
strong plates of bone, enamelled, and the head was protected on the upper side with one large plate, as with a buckler-hence the name, implying buckler-head. A range of small fins conveys the idea of its having been as weask in motion as it is strong in structure. In the coccosteus, the outline of the body is of the form of a short thick coffin, rounded, covered with strong bony plates, and terminating in a long tail, which seems to have been the sole organ of motion. While the tail establishes this

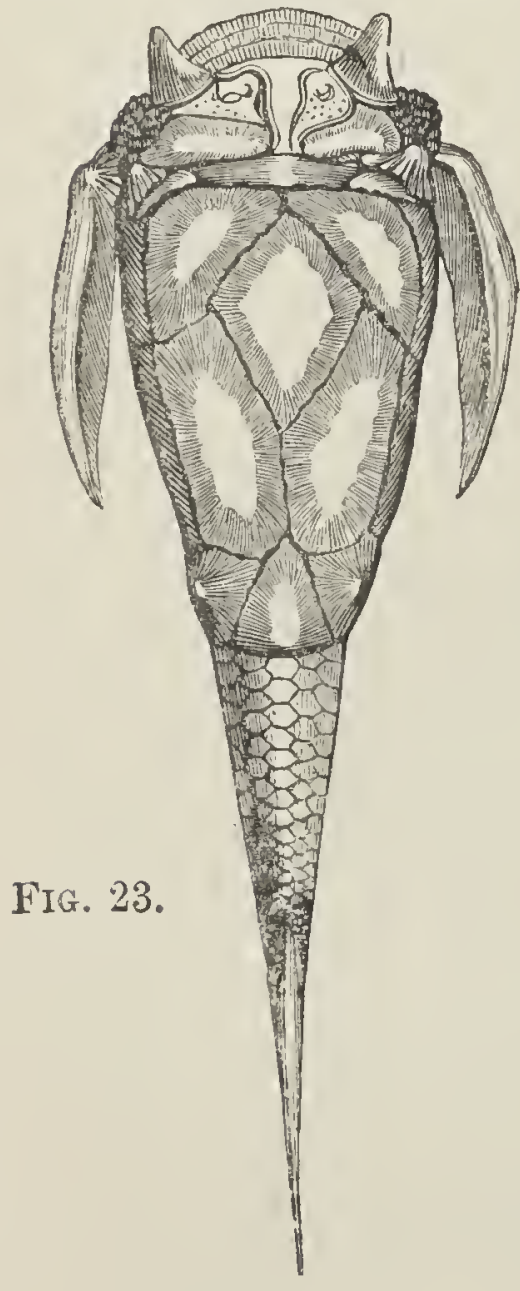

Pterichthys cornutus. creature among the vertebrata and the fishes, its teeth, chiselled, as it were, out of the solid bone of the jaw, like the nippers of a lobster, remind us of the invertebrate part of creation. The pterichthys has also strong bony plates over its body, arranged much like those of a tortoise, and has a long tail ; but its most remarkable feature, and that which has suggested its name, is a pair of narrow winglike appendages attached to the shoulders, which the creature is supposed to have erected for its defence when attacked by an enemy.

A group of ganoids seem to have been the police of their day, possessing a powerful development of sharp conical teeth situated on the margin of the 
jaws. One genus, the holoptychius, introduced near the close of the Devonian era, and passing up into the next, presents a flat oval form, measuring in one specimen thirty inches by twelve, with a covering of strong plates, wavily grooved and overlapping each other, the head forming only a slight rounded projection from the general figure. We here find another early and startling example, in addition to the brontes, of animals which may be called large. In the strata of this formation at Dörpat, there are gigantic bones, which were at first thought to belong to reptiles, but have since been ascertained to be remains of fishes, leading to the conjecture that the animals to which they appertained could not be less than thirty-six feet long. ${ }^{1}$

M. Agassiz has announced nine genera of sharks of the division Cestracion in the Devonians of Russia. It is in this voracious family that we see the placoids represented in modern seas ; the ganoids are all but unrepresented in our time. Of both classes, one invariable peculiarity has attracted much attention. "In all recent fish, with the exception of the shark family, the sturgeon, and the bony pike, the vertebral column terminates at the point where the caudal fin is given off, and this fin is expanded above and below the body, forming what is called a homocercal tail. In all those, without exception, which have been found in strata of the Palæozoic periods [placoids and ganoids,] the caudal fin is heterocercal, being formed of two unequal branches, the upper one expanded immediately from the vertebral column, while the lower one is

The head fountain of information on the early fishes is M. Agassiz's Poissons Fossiles, a splendid but not readily accessible book. For more popular descriptions, reference may be made to New Walks in an Old Field, by Hugh Miller, and to Jameson's Journal, July and October, I844. See also the excellent manual of Professor Ansted. 


\section{FIG. 24 .}

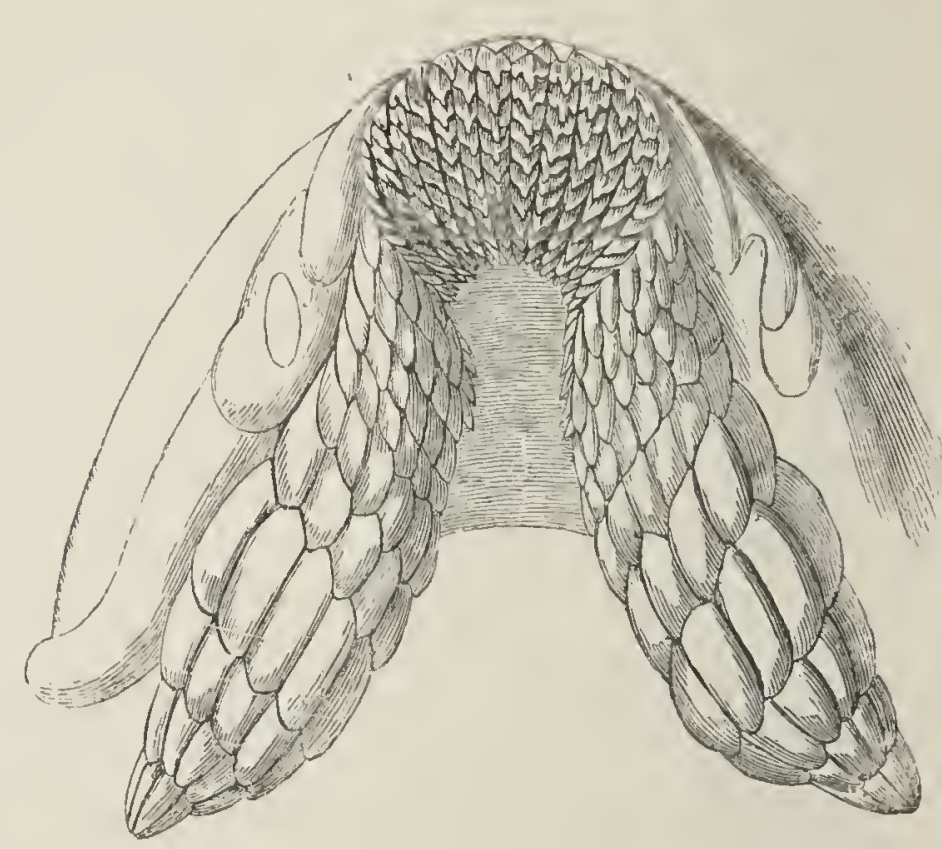

Lower Faw and Teeth of Cestracion Philippi, or Port-Fackson Shark.

given off at a point some distance from the extremity." 1 It is a remarkable fact, that this one-sided tail is a peculiarity in the more perfect fishes (as the salmon) at a certain stage in their embryonic history; as is also the inferior position of the mouth, peculiar to the early fishes. Moreover, in the early periods of embryonic life, there is no vertebral column, this organ being represented in embryos by a gelatinous cord, called the dorsal cord, which in maturity disappears as the vertebræ are formed upon it. M. Agassiz has satisfied himself that this was the nature of the organization of the early fishes, as it is that of the sturgeon of the present seas. ${ }^{2}$

An eminent geologist is of opinion that the species of

1 Ansted's Geology, i. 185.

${ }^{2}$ Some remarks on the grade of the cartilaginous fishes appear afterwards. 
FIG. 25.

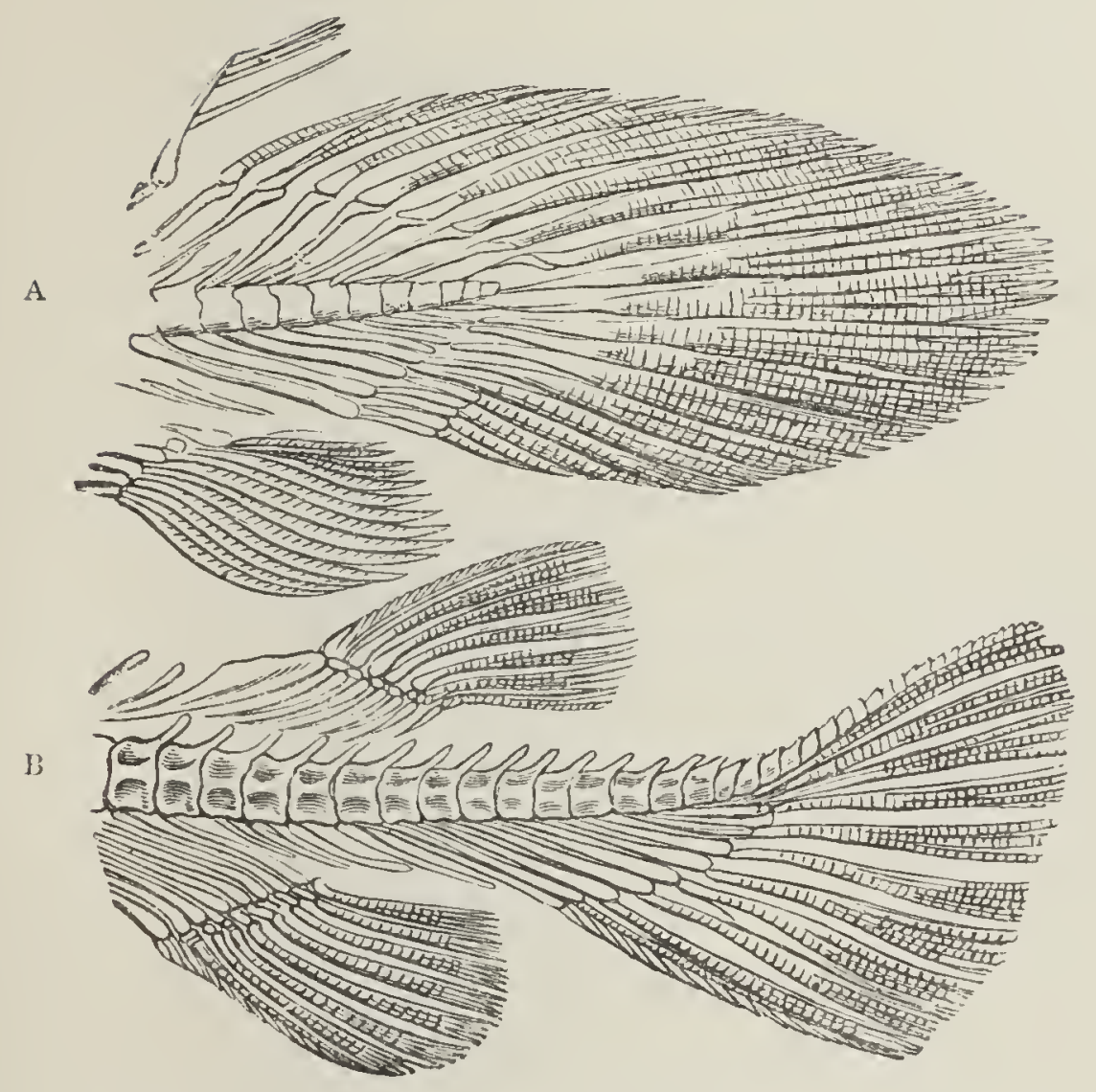

A, Homocercal Tail; B, Heterocercal Tail.

this era vary locally, as far as might be expected from what we see of the distribution of animal life in the present times. Nevertheless, throughout the distant parts of the earth where Devonian strata are found, the general characters of animal and also vegetable life are nearly the same. It is further observed, that whatever particular family is continued with little change through a succession of strata, is also amongst those most widely extended over the world. It was the opinion of $\mathbf{M}$. Brongniart, who distinguished himself by his investigation of vegetable fossils, that the fuci of these early seas indi- 
cate a higher temperature than now prevails at many of the places where they are found. He regarded this as a proof of the more equable diffusion of a tropical climate in ancient times, and distinctly attributes it to the action of the internal heat of the earth.

As yet-overlooking, for the present, certain partial and newly-announced instances-we meet with no traces of land plants. The hitherto esteemed exclusively marine character of the flora and fauna of the early ages was thought to betoken the non-existence of dry land. But there are reasons apart from the fossil history for believing that great masses had been exposed to the atmosphere in those ages. The earliest strata give token of vast disintegration. In our time, this process is usually seen taking place chiefly in the atmosphere, and at the point where land and water meet; in a much less activity below the surface of the ocean. It would thus appear likely that there was dry land in the eras of the earliest stratified formations, though, from whatever cause, it bore no vegetation and sustained no animals, or was only a scene of life in certain rare and favourably situated places.

CARBONIGENOUS ERA.-LAND PLANTS AND ANIMALS.

THE next group of rocks is called the Carboniferous Formation, from the remarkable feature of its numerous interspersed beds of coal. It commences with the beds of the mountain limestone, which, in some situations, as in Derbyshire and Ireland, are of great thickness, being alternated with chert, (a siliceous sandstone,) sandstones, 
shales, and beds of coal, generally of the harder and less bituminous kind, (anthracite,) the whole being covered in some places by the millstone grit, a siliceous conglomerate, composed of the detritus of the earliest formation. The mountain limestone, attaining in England to a depth of eight hundred yards, greatly exceeds in volume any of the primary limestone beds, and shows an enormous addition of power to the causes connected with animal life, by which this substance is supposed to have been produced. In fact, distinct remains of corals, crinoidea, and shells, are so abundant in it, as to compose threefourths of the mass in some parts.

Above the mountain limestone commence the more: conspicuous Coal Beds, alternating with sandstones, shales, beds of limestone, and ironstone. Coal is altogether composed of the matter of a terrestrial vegetation, transmuted by putrefaction of a peculiar kind, beneath the surface of water and in the absence of air. Some estuary shells, have been found in it, but few of pelagic origin, and no. remains of those zoophytes and crinoidea so abundant in the mountain limestone and other rocks. Coal beds exist in Europe, Asia, and America, and have hitherto been esteemed as the most valuable of mineral productions, from the important services which the substance renders in manufactures and in domestic economy. It is to be remarked, that there are some local variations in their arrangement. In France, they rest immediately on the granite and other primary rocks, the intermediate strata not having been found at those places. In other countries, coal beds are found in the Devonian formation, and even lower. 
Some features of the condition of the earth during the deposition of the carboniferous group, are explained with a clearness which must satisfy most minds. First, we are told of a time when carbonate of lime was formed in vast abundance along the shores and islands of the ocean, accompanied by an unusually large population of corals and encrinites; while in some parts of the earth there were pieces of dry land covered with a luxuriant vegetation. Next, we have a comparatively brief period of volcanic disturbance (when the conglomerate was formed). Then the causes favourable to the so abundant production of limestone, and the large population of marine radiata, decline, and we find the masses of dry land increase in number and extent, and begin to bear an amount of forest vegetation, far exceeding that of the most sheltered tropical spots of the present surface. The climate, even in the latitude of Baffin's Bay, was torrid; and the atmosphere has been supposed by some to have contained a larger charge of carbonic acid gas (the material of vegetation) than it now does. The forests or thickets of the period included no plants specifically the same with those now known upon earth. They mainly consisted of gigantic vegetables, many of which are not represented by any existing types, while others are akin to kinds, which, in temperate climes at least, are now only found in small and lowly forms. That these forests grew upon a Polynesia, or multitude of small islands, is considered probable, from similar vegetation being now found in such situations within the tropics.

With regard to the circumstances under which the masses of vegetable matter were transformed into succes- 
sive coal strata, there have been various opinions. From examples seen at the present day, at the mouths of such rivers as the Mississippi, which traverse extensive sylvan regions, and from other circumstances to be adverted to, it was suggested that the vegetable matter, the rubbish of decayed forests, was carried by rivers into estuaries, and there accumulated in vast natural rafts, until it sunk to the bottom, where an overlay of sand or mud would prepare it for becoming a stratum of coal. It is now generally believed that the vegetation first passed into the condition of a peat moss, that a subsidence then exposed it to be overrun by the sea, and covered it with a layer of sand or mud; that a subsequent uprise made the mud dry land, and fitted it to bear a new forest, which afterwards, like its predecessors, became a bed of peat ; that, in short, by repetitions of this process, the alternate layers of coal, sandstone, and shale, constituting the carboniferous group, were formed. It is favourable to this last view that marine fossils are rarely found in the bơdy of the coal itself, though abundant in the shale layers above and below it; also that in several places erect stems of . trees are found with their roots still fixed in the shale beds, and crossing the sandstone beds at almost right angles, showing that these, at least, had not been drifted from their original situations.

The plants of the carbonigenous period have been investigated with great care by several able naturalists, and about five hundred species have been ascertained. The living plants of our own era are at least 120,000 , and it is difficult to suppose the flora of that remote age to have been so much more limited. It must, however, 
be observed, that there are many conceivable circum. stances to account for the non-preservation or transmission of many of the plants of this era. The numerous fungi, and other lowly forms, could scarcely have left clear memorials of themselves in the rocks, or in the masses of coal; and it has even been ascertained by experiment, that some of the highest forms of vegetation perish with surprising quickness in water. If we might assume, nevertheless, that the plants actually ascertained, form in any degree a representation of the flora of this period, they would imply that the early terrestrial botany of our globe was greatly less varied than the present, and composed chiefly of plants of comparatively simple form and structure.

In the ranks of the vegetable kingdom, the lowest place is taken by plants of cellular tissue, and which have no flowers, (cryptogamia,) as sea-weeds, lichens, mosses, fungi, ferns. Above these, stand plants with vascular tissue, and bearing flowers, in which again there are two great subdivisions; first, plants having one seed-lobe, (monocotyledons,) and in which the new matter is added within, (endogenous - the cane and palm are examples;) second, plants having two seed-lobes, (dicotyledons,) and in which the new matter is added on the outside under the bark, (exogenous - the pine, elm, oak, and all the British forest-trees are examples:) these subdivisions also ranking in the order in which they are here stated. Now it is found that the predominant plants of the coal era are of the cellular and cryptogamic kind, while the dicotyledons are comparatively rare. There is, indeed, one exogenous family, which occurs in considerable numbers, 
and, perhaps, figured more conspicuously in the living woods of that era than in the dead coal-beds-namely, the conifers ; but this, again, is held as the lowest family of its class, having an imperfection in its flowering apparatus, which brings it into affinity with the cryptogamic forms. That many trees of higher families now existed, seems unlikely, when we learn that such trees occur in considerable numbers in subsequent formations, showing that there was nothing positively to forbid their being preserved in the coal measures, if they had then existed.

A conspicuous form in this era was the fern or breckan, of which about one hundred and thirty species have been ascertained as entering into the composition of coal. The ferns are plants which thrive best in warm, shaded, and moist situations. In tropical countries, where these conditions abound, there are many more species than in temperate climes, and some of these are arborescent, or of a tree-like size and luxuriance. The ferns of the coal strata have been of this magnitude, and that without regard to the regions of the earth where they are found. In the coal of Baffin's Bay, of Newcastle, and of the torrid zone, alike, are the fossil ferns arborescent, showing that in that era, the present tropical temperature, or one even higher, existed in very high latitudes.

In the swamps and ditches of England there grows a plant called the horse-tail, (equisetum, having a succulent, erect, jointed stem, with slender leaves, and a scaly catkin at the top. A second large section of the plants of the carboniferous era were of this kind, (equisetacee,) but, like the ferns, reaching the magnitude of trees. While existing equiseta rarely exceed three feet in height, and the 


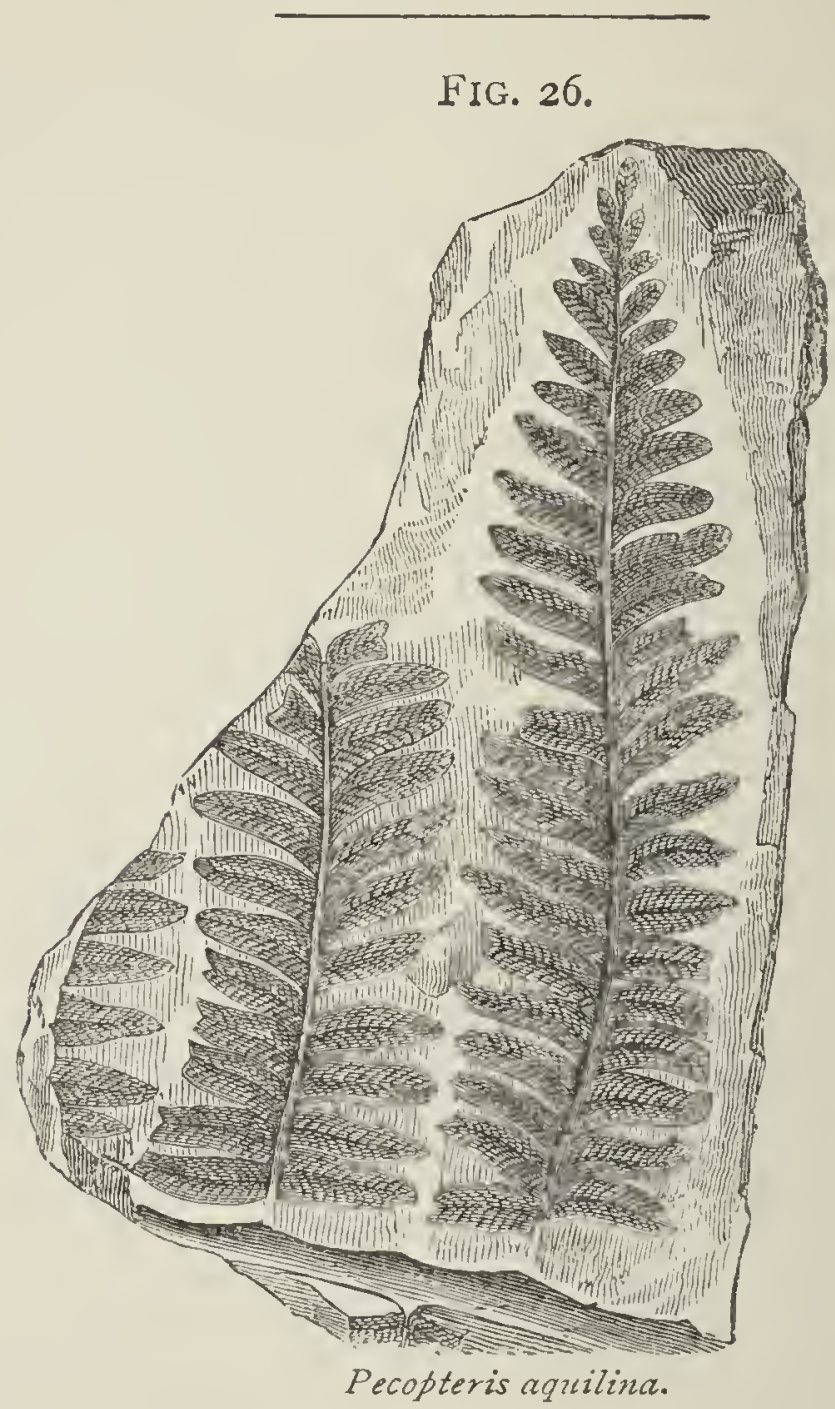

stems are generally under half an inch in diameter, their kindred, entombed in the coal-beds, seem to have been generally fourteen or fifteen feet high, with stems from six inches to a foot in thickness. It is to be remarked that plants of this kind (forming two genera, the most abundant of which is the calamites) are only represented on the present surface by plants of the same family : the species which flourished at this era gradually lessen in number as we advance upwards in the series of rocks, and disappear before we arrive at the tertiary formation. 
FIG. 27.

The club-moss family (lycopodiacea)

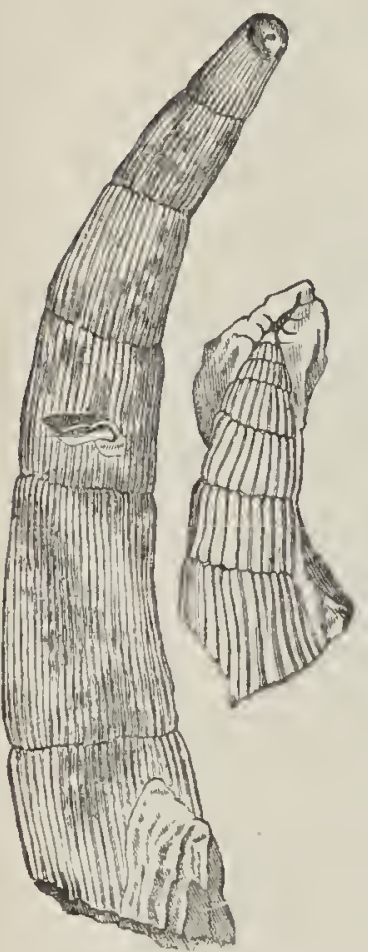

Calamites canneformis. are other plants of the present surface, usually seen in a lowly and creeping form in temperate latitudes, but presenting species which rise to a greater magnitude within the tropics. Many specimens of this family are found in the coal-beds; it is thought they have contributed more to the substance of the coal than any other family. Like the ferns and equisetaceæ, they rise to a prodigious magnitude. The lepidodendron (so the fossil genus is called, from the scaly exterior) has probably been from sixty-five to eighty feet in height, having at the base a diameter of about three feet, while the leaves

FIG. 28.

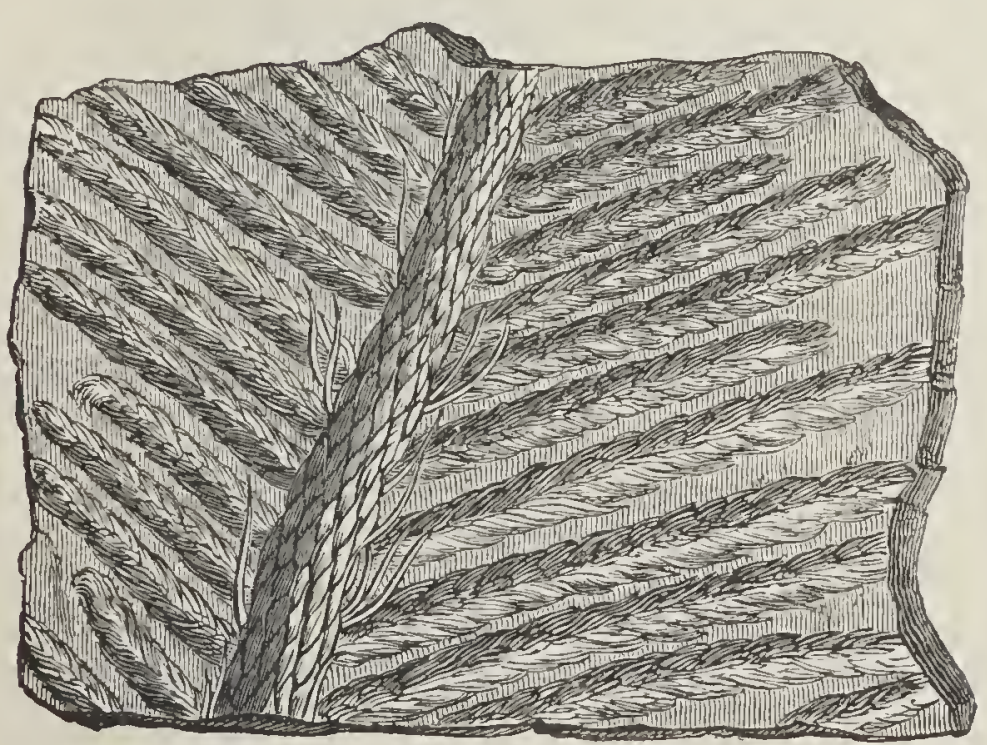

Lycofodites pinnatus. 
measured twenty inches in length. In the forests of the coal era, the lepidodendra would enjoy the rank of furs in our forests, affording shade to the only less stately ferns and calamites. The internal structure of the stem, and the character of the seed-vessels, show them to have been a link between single-lobed and double-lobed plants-a fact worthy of note, as it favours the idea of a progress in vegetable creation, in the line of an improved organization. It is also curious to find a missing link of so much importance in a genus of plants which has long ceased to have a living place upon earth.

The other leading plants of the coal era are without representatives on the present surface, and their characters are in general less clearly ascertained. Amongst the most remarkable is the sigillaria, of which large stems are

FIG. 29.

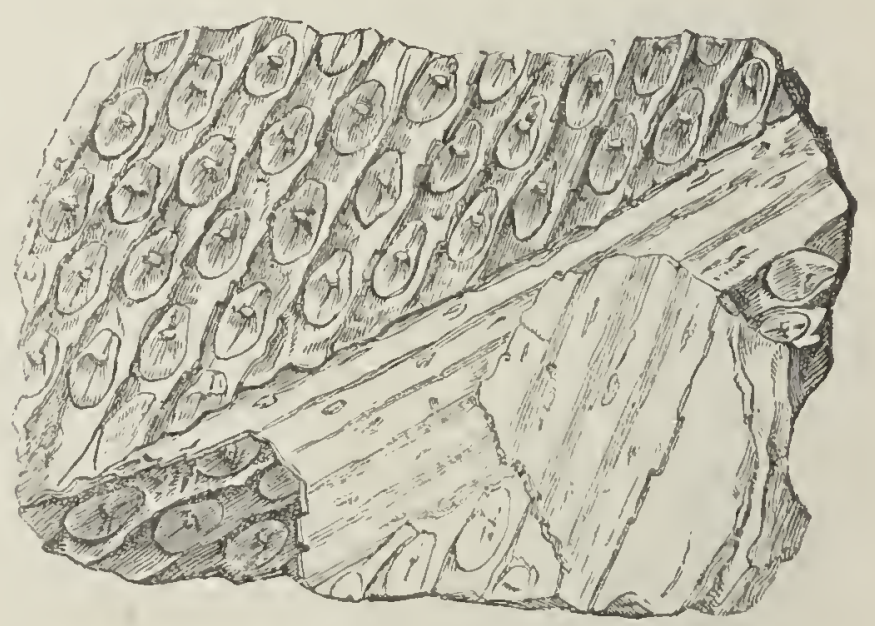

Sigillaric undulata.

very abundant, showing that the interior has been soft, and the exterior fluted, with separate leaves inserted in vertical rows along the flutings. Masses to which the 
term stigmaria is applied, were originally described as distinct plants, but are now generally regarded as fragments of the root and stem of sigillaria. Amongst monocotyledons were some palms, (flabellaria and noggerathia,) besides a few not distinctly assignable to any class.

The true conifers of the coal are comparatively rare, and are only as yet found in isolated cases, and in sandstone beds. One discovered in the Craigleith quarry, near Edinburgh, consisted of a stem about two feet thick, and forty-seven feet in length. Others were afterwards found, both in the same situation, and at Newcastle. Leaves and fruit being wanting, an ingenious mode of detecting the nature of these trees was devised by some naturalists residing in the northern capital. ${ }^{1}$ Taking thin polished cross slices of the stem, and subjecting them to the microscope, they detected the structure of the wood to be that of a cone-bearing tree, by the presence of certain "reticulations" which distinguish that family, in addition to the usual radiating and concentric lines. That particular tree was concluded to be an araucaria, a genus now found in Norfolk Island, in the South Sea, and in a few other remote situations. The conifers of this era may be said to form the dawn of dicotyledonous trees, to which, it has already been noticed, the lepidodendra are a link from the monocotyledons. The concentric rings of the Craigleith and other conifers of this era have been mentioned. It is interesting to find in these a record of the changing seasons of those early ages, when as yet there were no human beings to observe time and tide. The rings are clearly traced;

1 See Witham on the Internal Structure of Fossil Vegetables, I834. 
but it is observed that they are more slightly marked than is the case with their family at the present day, as if the changes of temperature had been within a narrower range.

Such (if we are to be allowed to rest with negative evidence) was the vegetation of the carbonigenous era, composed of forms low in the botanical scale, mostly flowerless and fruitless, but luxuriant and abundant beyond what the most favoured spots on earth can now show. The rigidity of the leaves of its plants, and the absence of fleshy fruits and farinaceous seeds, unfitted it to afford nutriment to animals; and, monotonous in its forms, and destitute of brilliant colouring, its sward probably unenlivened by any of the smaller flowering herbs, its shades uncheered by the music of birds, it must have been a sombre scene to a human visitant. But neither man nor any other animals were then in existence to look for such uses or such beauties in this vegetation. It was, however, serving another equally important end, storing up mineral masses which were in long subsequent ages to prove of the greatest service to the human race, even to the extent of favouring the progress of its civilization.

Instances of land vegetation previous to the Carbonigenous era have been spoken of as partial and newly announced. In the American lower Devonian rocks, some plants allied to ferns have been found. In Portugal, under strata even lower, there are coal beds, in which remains of ferns have been distinguished. In the American Silurians there has been found a plant allied to the lepidodendron, and in the same formation in England various indications of land vegetation are spoken of, 
though they have not, as far as the author is aware, been described. These facts are introduced here, instead of at any earlier part of our narration, on mere grounds of literary conveniency; it appearing inexpedient to make extensive alterations in the original structure of the work, on account of matters so isolated and perhaps scarcely as yet generally accepted. They may be regarded as standing in no inconsistency with the general strain of the palæontological history, but only like certain similar discoveries of animal remains and tracings, pointing to the general probability of an earlier origin for all the forms and grades of existence than was indicated by geology in its infant years.

The Carboniferous formation exhibits a scanty zoology compared with either those which go before, or those which come after. The mountain limestone, indeed, deposited at the commencement of it, abounds unisually in polypiaria, crinoidea, and mollusca; but when we ascend to the coal-beds themselves, the case is altered. We have then only a limited variety of shell mollusks, with fragments of a few species of fishes, and these are rarely or never found in the coal seams, but in the shales alternating with them. Among the fishes, the conspicuous form is the Sauroid family, which receives its name in consequence of a character of teeth, scales, and even osteology, resembling that of the Sauria, and evidently leading on to that section of reptiles. One of the most noted species is the Megalichthys Hibbertii, discovered by Dr. Hibbert Ware, in a limestone bed at Burdiehouse, near Edinburgh, and of which other specimens have been found in the coal measures of Yorkshire, and low coal 
shales of Newcastle. The enormous size of the animal is inferred from teeth belonging to it, not less than four inches long.

At this point are found the first traces of insects. The fossil remains of two species belonging to the family of curculionidæ, as well as some relics of neuropterous, orthopterous, and lepidopterous insects, and "a scorpionlike creature," have been described. For many years, no remains or traces of any animals superior in organization to fishes were discovered in the carboniferous system, and it was supposed that the next formation in the series marked the era of reptiles. Within the last few years, some scattered instances of reptilian life have been found in the coal era, and even in the Devonian,-a small batrachian in the old red sandstone of Morayshire (Fig. 30),-implying a closer succession of this grade of existence upon that of Fish, than had previously been observed.

It here becomes necessary to remark that the ingredients and arrangements of rocks, with fossil remains, do not form the sole materials of the history compiled by the geologist. He is equally contented when he can find an intelligible fact told by what may be called a writing of nature upon these stone tablets. So low as the bottom of the carboniferous system, slabs are found marked over a great extent of surface with that peculiar corrugation or wrinkling, which the receding tide leaves upon a sandy beach when the sea is but slightly agitated; and not only are these ripple marks, as they are called, found on the surfaces, but casts of them appear on the under sides of slabs lying above. The phenomena sug- 
FIG. 30 .

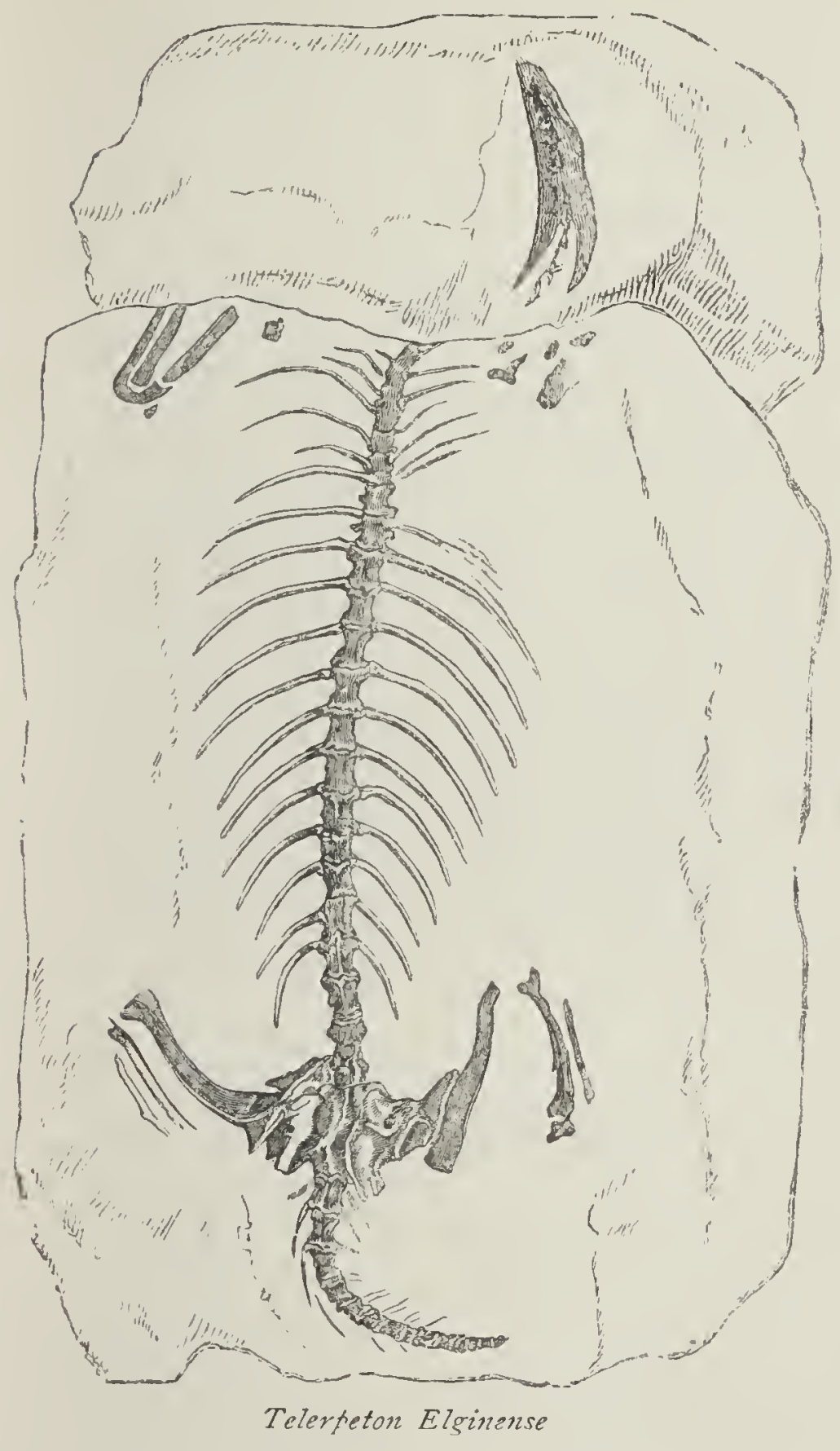

gest the time when the sand ultimately formed into these stone slabs was part of the beach of a sea of the car. bonigenous era; when, left wavy by one tide, it was 
covered over with a thin layer of fresh sand by the next, and so on, precisely as such circumstances might be expected to take place at the present day. Sandstone surfaces, ripple-marked, present themselves throughout

FIG. 3 I.

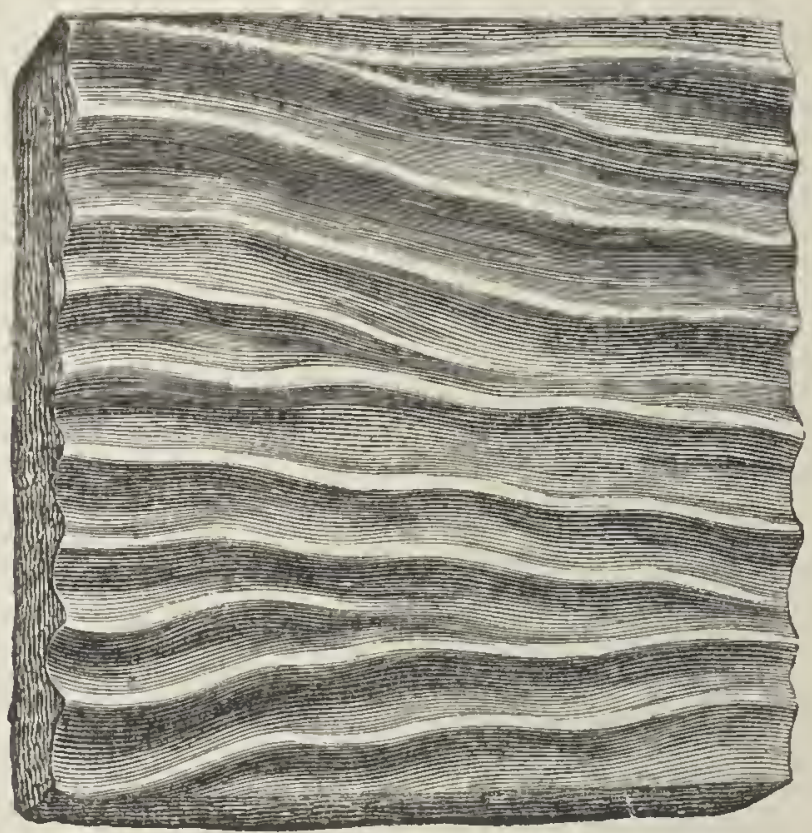

Slab of ripple-marked sandstone.

the subsequent formations: in those of the New Red, at more than one place in England, they further bear impressions of rain-drops which have fallen upon them-the rain, of course, of the inconceivably remote age in which the sandstones were formed. In the Greensill sandstone, near Shrewsbury, it has even been possible to tell from what direction the shower came which impressed the sandy surface, the rims of the marks being somewhat raised on one side, exactly as might be expected from a slanting shower falling at this day upon one of our beaches. These facts have the same kind of interest as 
FIG. 32.

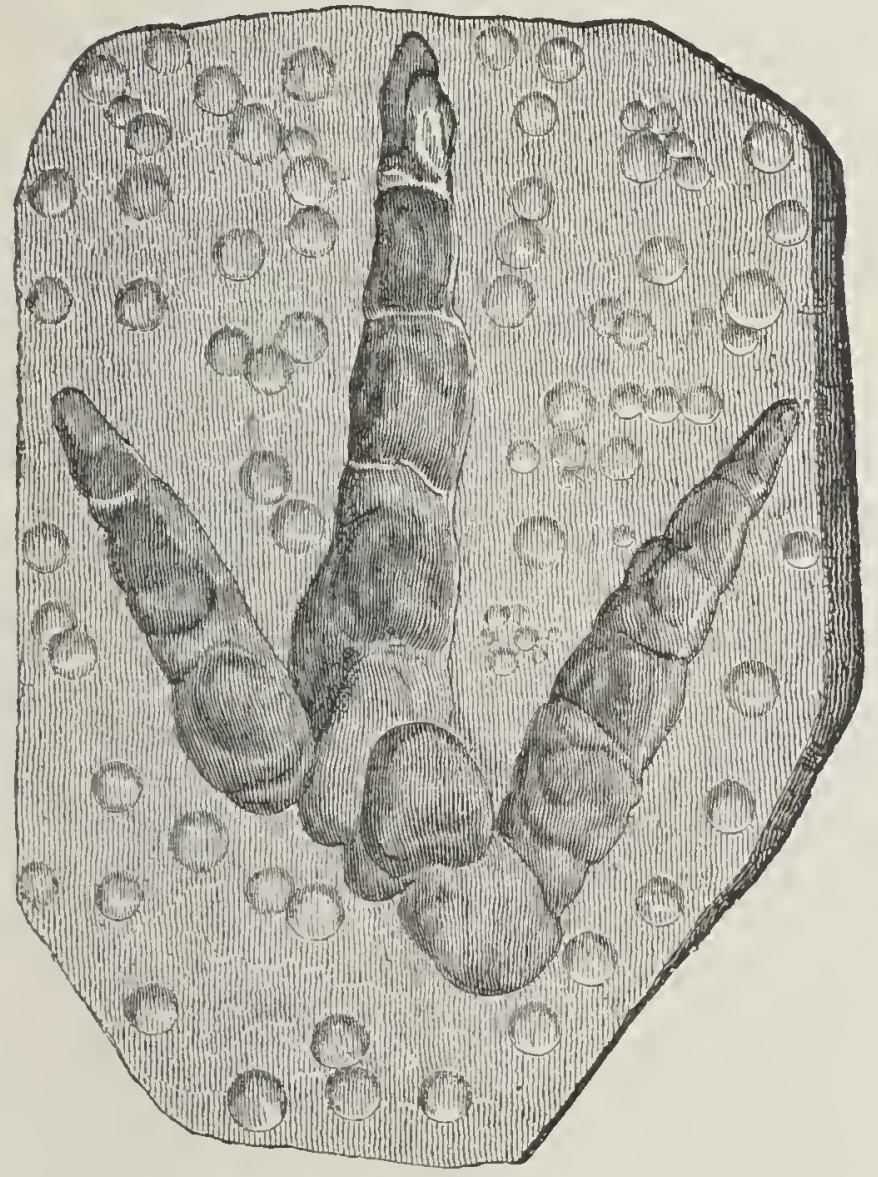

Slab of Sandstone (newered), showing impressions of rain-drops, and foot-print of bird.

the season-rings of the Craigleith conifers, speaking of the identity of the familiar processes of nature in those early ages with those of our own.

Hearing of memorials of this kind will prepare the reader to learn that the earliest intelligence we have respecting land-walking animals consists, in great part, of their mere footsteps, impressed on the wet sand or mud which afterwards became rock. Let no one undervalue such testimony. The fidelity of an impression from a foot, as certifying by what or whose foot the impression 
was made, is acknowledged in judicial procedure; and often has this kind of evidence fixed the opinion of judge and jury when every other has failed.

So much being premised, we proceed to remark that the earliest discovered traces of a reptilian population of the carbonigenous era consist of the mere footmarks of certain animals of that class upon the surfaces of a coarsegrained sandstone amongst the coal-beds of Westmoreland county, Pennsylvania. From an illustrated account of them in the American Journal of Arts and Sciences (April, 1845), it appears that these footmarks exhibit a ball, with five toe-marks, circular and elongated, placed in radiating fashion before it. In similar strata at another place, are footsteps of a different kind, resembling

FIG. 33 .

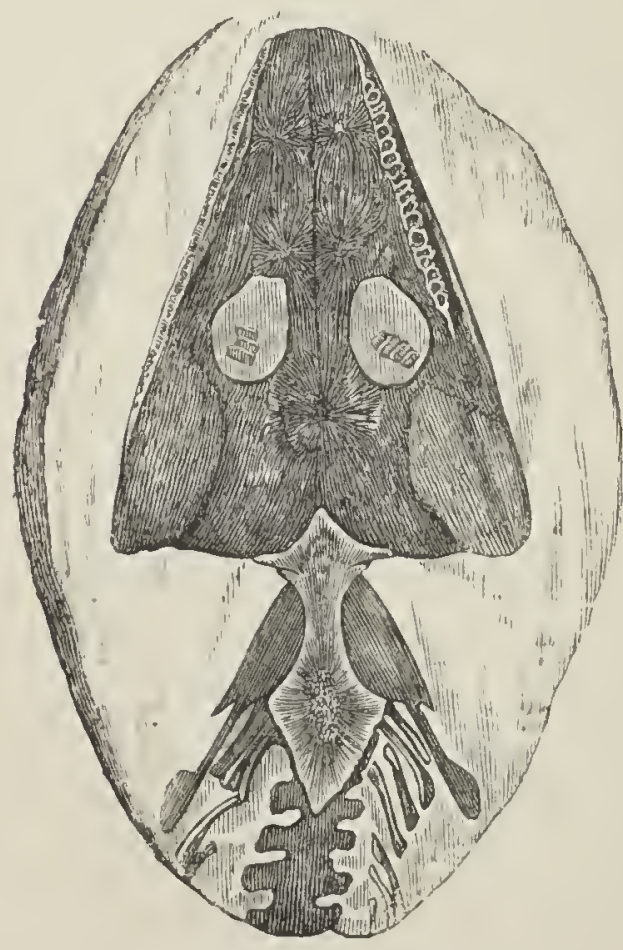

Archegeosanrus minor. the human hand, with the rudiment of a sixth toe, at the side opposite that presenting what passes for the thumb. More recently, actual remains of reptiles have been discovered in the coal formation in $\mathrm{Ba}$ varia. They are referred to a variety of Saurian species to which the general name of Archegeosaurus has been given, and which M. Von Meyer considers as having been allied to the Labyrinthodonts of a higher and later formation. The re- 
mains of one individual indicate an animal between three and four feet long; the teeth seem to have been of an advanced character for the class, that is, fixed in distinct alveoli, and the animals were furnished with weak limbs serving only to swim or creep. It may be remarked that the labyrinthodonts were at first thought to belong to the batrachian order (frogs and toads), but are now considered as members of the Saurian order, - that of which crocodiles andlizards are the modern representatives. They are supposed to have been "Saurians arrested in their development, on the level of the batrachians," furnishing "a proof that representatives of a permanent larva condition existed among the loricated reptiles of the ancient world, in the like manner as the sirens do among the recent batrachians." 1

Coal strata are nearly confined to the group termed the carboniferous formation. Thin beds are not unknown afterwards, but they occur only as a rare exception. It is therefore thought that the most important of the conditions which allowed of so abundant a terrestrial vegetation - whatever these were-had ceased about the time when this formation was completed.

The termination of the carboniferous formation is marked in some regions by symptoms of great disturbance. Coal-beds generally lie in basins, as if following the curve of the bottom of seas. There is no such basin which is not broken up into pieces, some of which have been tossed up on edge, others allowed to sink, causing the ends of strata to be in some instances many yards, and in a few, several hundred feet, removed from the corresponding

${ }^{1}$ Quarterly Journal Geol. Soc. Nov. 1848. 
ends of neighbouring fragments. These are held to be results of volcanic movements below, the operation of which is further seen in numerous upbursts and intrusions of fireborn rock (trap). That these disturbances took place about the close of the formation, and not later, is shown in the fact of the next higher group of strata being comparatively undisturbed. Other symptoms of this time of violence are seen in the beds of conglomerate which occur amongst the first strata above the coal. These, as usual, consist of fragments of the elder rocks, more or less worn from being tumbled about in agitated water, and laid down in a mud paste, afterwards hardened. ${ }^{1}$ It is to be admitted for strict truth, that in some parts of Europe the carboniferous formation is followed by superior deposits, without the appearance of such disturbances between their respective periods; but such cases apparently are exceptive.

\section{PERMIAN ERA.-REPTILES.}

IN this subordinate manner may be noticed a short series of strata, following, whether conformably or otherwise, upon the carboniferous formation, and to which a general name has been applied, from its being unusually well developed in the portion of Russia which formed the ancient kingdom of Permia. This sub-formation-comprehending in ascending order a group of sandstones, called with us the Lower New Red Sandstones, and

1 It must at the same time be admitted that conglomerate is, in many instances, simply a portion of the river alluvia of ancient times,-exactly resem. bling the gravel of our own era. 
amongst the Germans Rothe-todteliegende - a thick calcareous bed called with us the Magnesian Limestone, by the Germans Zechstein, - and some other strata-is, in respect of fossils, a continuation of the carboniferous system. With it, however, ends a range of animal forms which first appeared in the Silurians, and passed, with the changes which have been indicated, through the Devonian and Carbonigenous eras.

The total number of specific forms, which had been diminishing in the carbonigenous era, is in this still further reduced; one recent author says, from about a thousand to a hundred and sixty-six, of which only eighteen are common to the inferior strata. ${ }^{2}$ It appears as if, while some new species continued to present themselves, the animal kingdom was now generally undergoing a decay, for even specimens of particular families are less abundant than formerly. Instead, for example, of the hundred species of corals of the carboniferous formation, there were now only fifteen, and of these but three or four abundant. Of the numerous crinoidea of the past, but one now remained, and this is rarely found. The trilobite has now vanished, to appear no more. For hundreds of brachiopods, there were now only thirty, ten of them old. The cephalopods almost disappear at the very commencement of the Permian era.

It cannot at present be determined whether this diminution of fossils is owing to an actual reduction of the amount of life in the ancient seas, or only to some such simple cause as the occurrence of deposits which were 1 Literally Red Dead Liers; that is, strata of red colour, having no remains of living things in them.

2 Murchison's Geology of Russia in Europe. 
not favourable to the preservation of animal remains. It may even be that the principal cemeteries of the age have not yet been hit upon by research; for certainly this is neither the most extensively nor the most rigidly examined of the various formations, and we are made the more suspicious by finding that, at this part of the rock series, several important fossiliferous strata are present in one region and not in others. It has been ascertained, however, by Permian researches, that extensive changes of specific forms in the ancient seas were not, as has been supposed, necessarily and essentially connected with great physical disturbances; for both do we find that the unconformability of strata or memorials of disturbance between the carboniferous and Permian do not affect the fossils, and that a conformable succession of strata over the Permian is attended by a great-usually called a complete-change of species. At this termination of the Permian, it has become customary to close what is called the Palæozoic Period, or period of the most ancient forms of animal existence, on a presumption that a completely new set now enter upon the field. There seem, however, to be considerable reasons for doubting if any such decided change takes place at this point of time. Plants identical with species of the carboniferous formation are found in later formations (Trias of France and certain Liassic beds in the Alps). We have also seen that reptiles of a family hitherto supposed to commence in these superior formations are now discovered in the carboniferous beds. In that regular advance of life from inferior to superior classes there is here no interruption. Taking all things together, it seems the more 
reasonable supposition, that, notwithstanding conformableness of strata, a local suspension of deposits for a considerable time is indicated-a time during which the usual changes of species were proceeding, probably at their usual rate-and which was sufficient to present something like a complete change of forms when the deposits were re-commenced. ${ }^{1}$

In the Permian formation, besides the principal orders of animals which previously existed, there occur undoubted remains of the reptilian class. As yet, only a few such bones have been discovered in Zechstein of Thuringia in Upper Saxony, and in quarries near Bristol. By Professor Owen, who has carefully examined them, they are said tc be of the lacertilian or lizard order (specifically called by him palceosaurs, thecodonts, monitors, etc.), but for the most part of gigantic size, and differing from modern lizards in very remarkable characters of the vertebræ, teeth, and dermal plates. To them, as to all the reptiles of this and several subsequent great periods, belonged a fish-like form of the vertebral column, in as far as its component bones were biconcave, or shaped like a double

1 Murchison's Russia ; also Mr. Horner's address as president of the Geological Society, Feb. 1846.

Russia presents another notable example of a change of fossils in a comformable series of strata; that is, a series showing no record of volcanic disturbances. This takes place between the Devonian and Carboniferous formations. "The uppermost beds of the Devonian," says Sir R. Murchison, "loaded with Holoptychius and Onchus, Coccosteus, Placosteus, and Dendrodus, are at once conformably surmounted by strata containing the most universally diffused carboniferous types. In short, fishes identical with those of the Old Red Sandstone of Scotland are invariably surmounted by the Stigmaria ficoides and the large Producti of our British mountain limestone; and thus the examination of Russia has taught us, not only in this instance, but also in the overlying Permian succession, that the great changes in animal life have not been dependent on physical revolutions of the surface, but are distinct creations, independent of any proximate local causes; though I would by no means pretend to say that the grand operations of change which have affected the conterminous regions of Russia did not tend to produce these results." 
FIG. 34.

A B
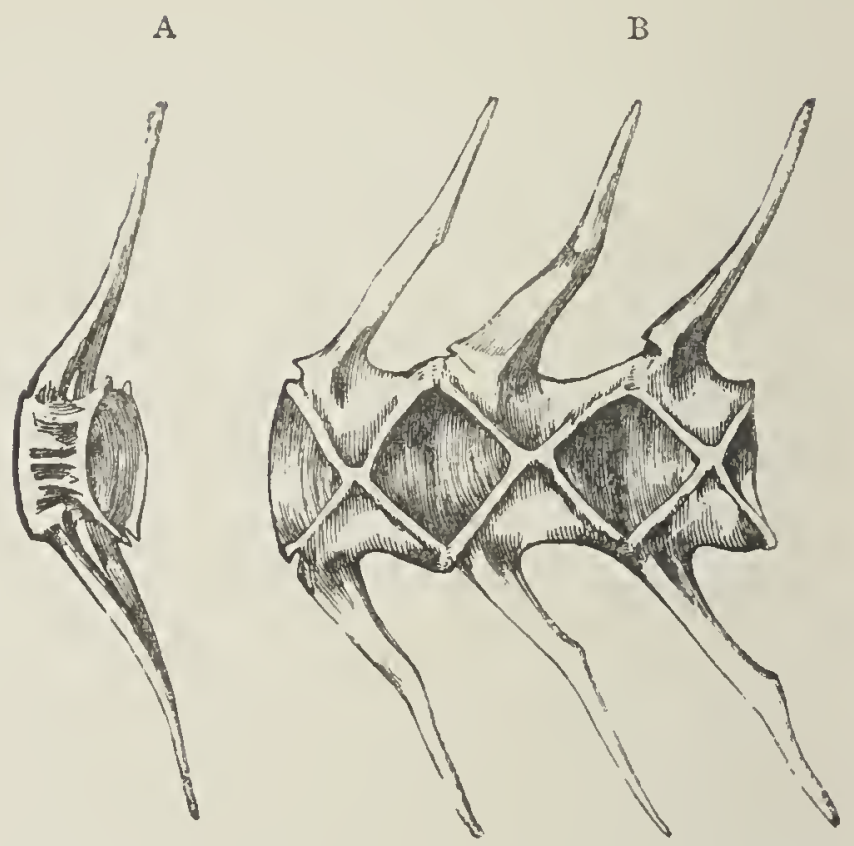

A, Obinque viene of the Vertebra of a Cod; B. Section of three connected vertebra, showing the intervertebral spaces.

egg-cup, a peculiarity regarded by this eminent anatomist as probably fitting the animal for partially marine habits. And that the full importance of this peculiarity of the early reptiles may be appreciated, the reader must be made aware that modern reptiles have a ball-and-socket form of the vertebræ-that is, a convexity at the one side fitting into the hollow of the adjacent bone; but this form only when they are mature animals, for in the embryotic state of the crocodile and of the frog the form has been ascertained to be biconcave, which gradually changes as the animal approaches perfection. The teeth of the thecodonts and palæosaurs were fixed in distinct sockets, like those of the modern crocodiles. In this respect, they were superior to the modern varanians, the 
nearest living tribes, which have the teeth imbedded in comparatively shallow cavities along the bottom of a groove in the jaw.

ERA OF THE TRIAS AND OOLITE.-REPTILES ABUNDANT.FIRST TRACES OF BIRDS AND MAMMALIA.

Geologists now apply the term Secondary Formation (once of wider application) to those strata intervening between the end of the Permian or close of what they call the Palæozoic Period, and the termination of the Chalk Series, afterwards to be described, at which place there is another and almost total change of specific forms. The first of these formations is called with us the Upper New Red Sandstone; it consists in England of only a group of strata of that kind, surmounted by some variegated marls. But on the Continent, below a stratum equivalent to these marls, there is one of limestone, bearing the name of the Muschelkalk, and full of shells. The system is there called Trias, on account of its thus consisting of a triple group of strata.

TRIAS.

The organic relics of this system are most abundant in the Muschelkalk. There we are presented with a great number of crinoids and shells, all differing in specific character from their predecessors of the same orders. The crinoid called, from its elegant lily-like shape, Encrinites Moniliformis, is a conspicuous fossil. The brachiopods, here almost extinct, are replaced by ostracea of various genera-a change from the animals of deep to those of 
Fig. 35. shallow seas. The univalve mollusks also 7. indicate a condition of the sea advancing towards that which exists near the present shores. In the new forms of cephalopoda are some marking their advanced character by their non-possession of a shell or stony skeleton. In this case, the existence of the animal is only betrayed by its horny mandible, constituting the fossils called rhyncholites.

There are in this system further and more decided traces of the Reptilian class. In the lower beds of the Upper New Red Sandstone, near Shrewsbury, we are introduced to a new lacertilian, presenting some remarkable characters, and named the Rhynchosaurus. From the few fragments of the animal which

\section{FIG. 36.}

A

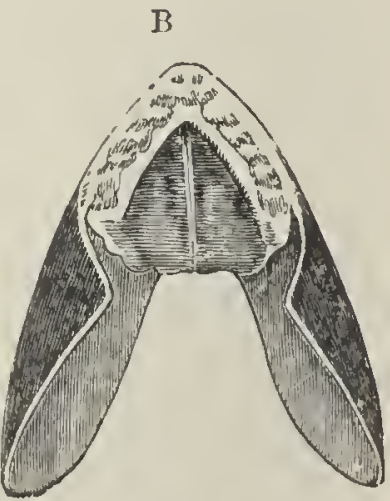

Encrinites moniliformis.

Rhyncholites.

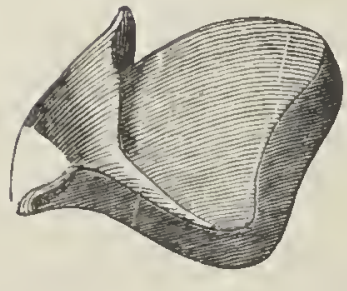

$A$, seen from the side; $B$, seen from above.

have been discovered, it would appear to have had a toothless head, resembling that of a bird, and enclosed 
FIG. 37.

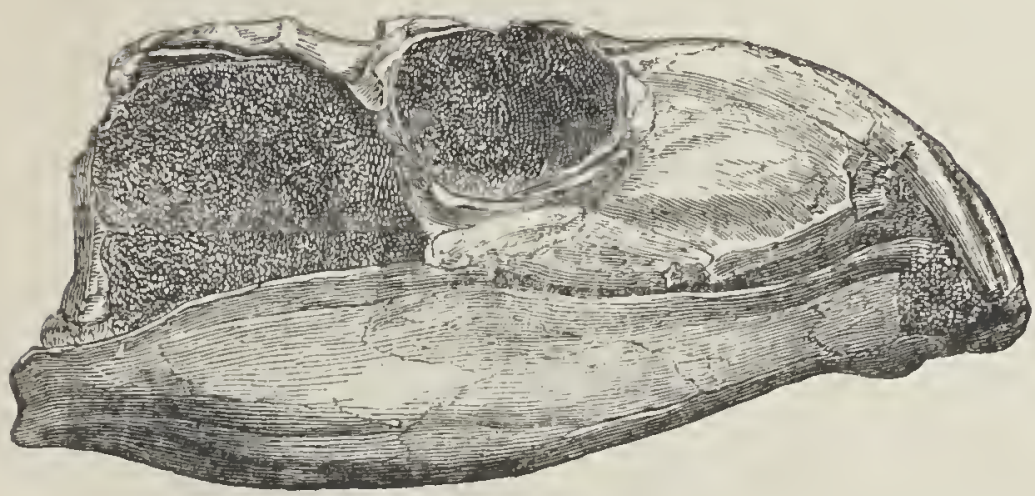

Skull of Rhynchosaurus.

in a bony sheath; also a hinder toe directed backwards, in which feature we also see an assimilation to the next higher vertebrate class. Footmarks, impressed in the way which has been described, and attributed to this animal, confirm the appearances presented by the extraordinary arrangement of its locomotive organs.

In the same beds occur a few bones, and a great number of footsteps, which Professor Owen has fixed as the double memorials of a group of animals, to which he has given (from the structure of their teeth) the name of Labyrinthodonts. As already mentioned, they were at first classed with the Batrachia-that order of reptiles to which the frog and toad belong; but they are now associated with the Saurians, though considered as only developed in that imperfect manner of which an example is presented by the Siren among the Batrachia. The labyrinthodonts were of the size of a large hog. Their footmarks, discovered alike in America and the elder continent, "bear a singular resemblance to the impression that would be made by the palm and expanded fingers and thumb of the human hand." But it is evident that 
FIG. 38 .

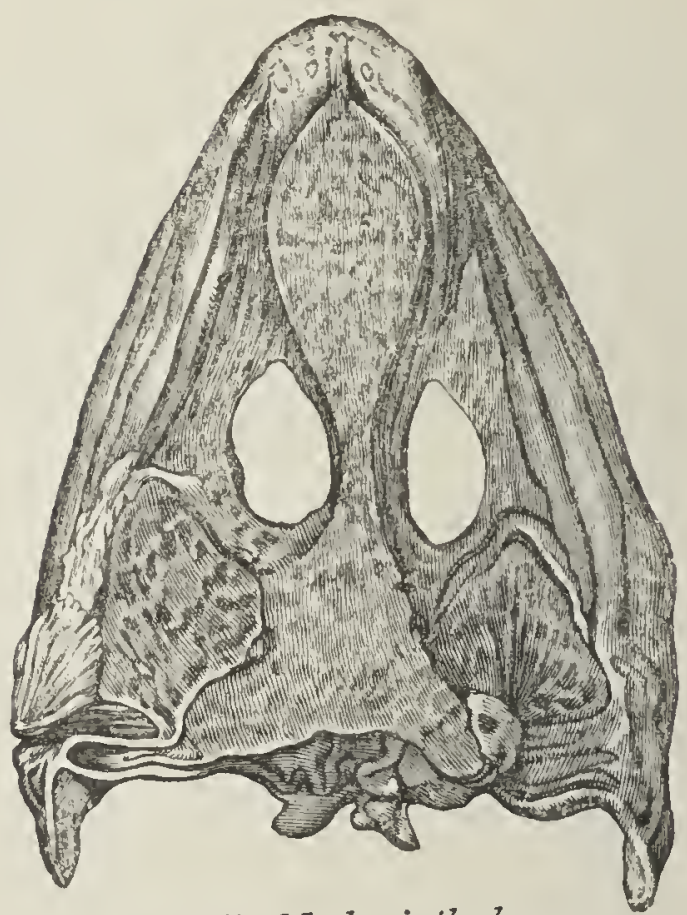

Skull of Labyrinthodon.

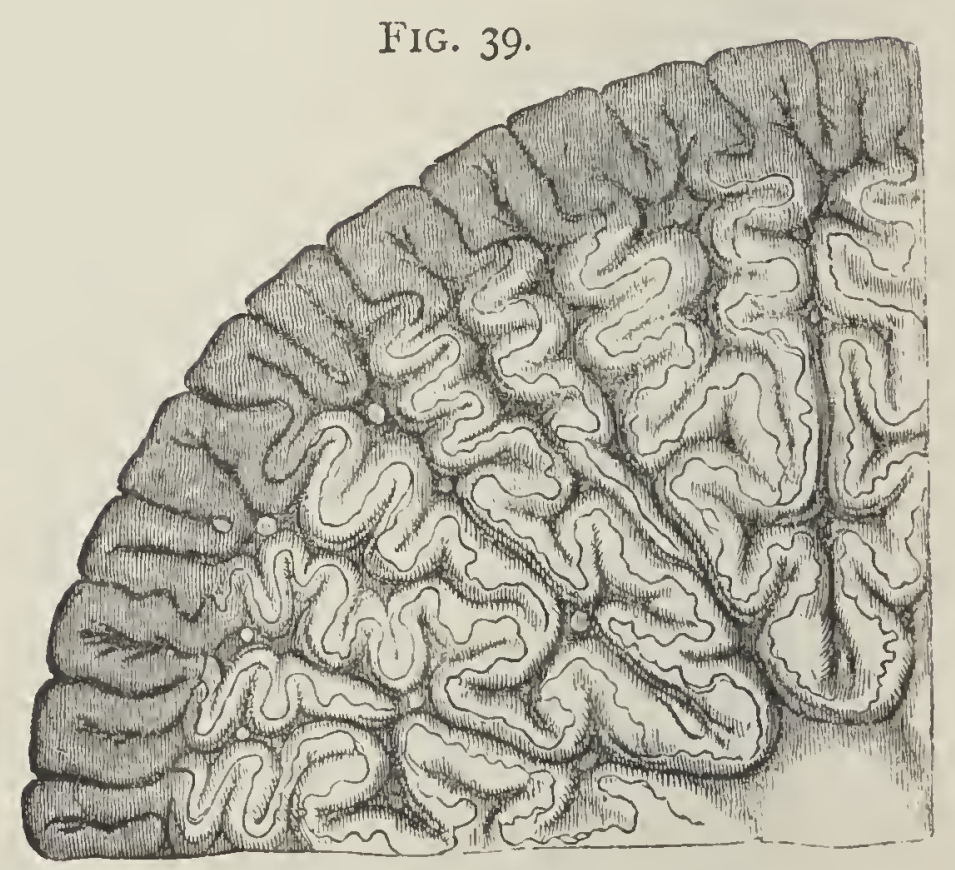

Portion of transierse section of Tooth of Labyrinthodon Faegeri. 
FIG. 40.

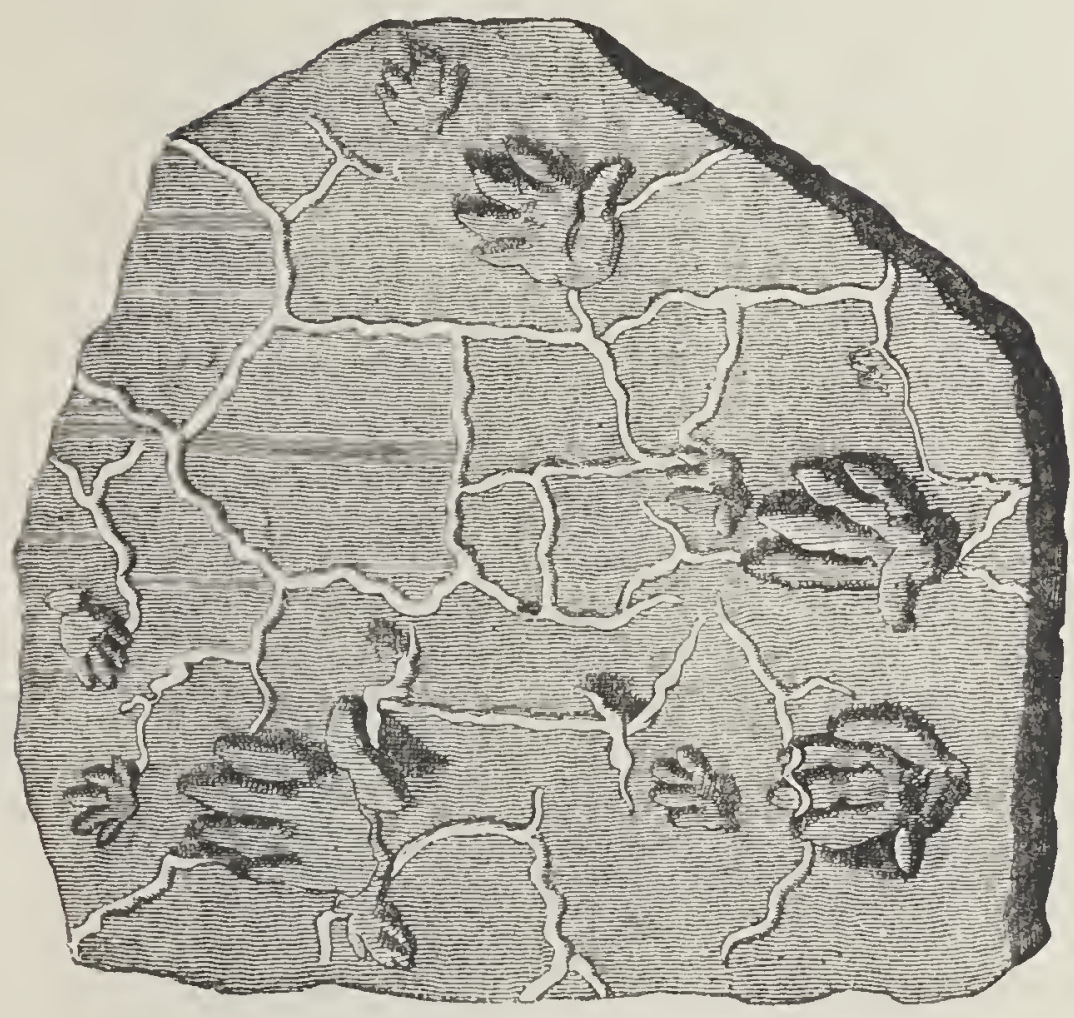

Foot-tracks of Labyrinthodon.

the fore extremities of the animal had been, like those of the kangaroo and some other genera, much smaller than the hinder, some specimens of which measure eight inches by five. These reptiles present affinities to the fish class, in their biconcave vertebræ and the formation and arrangement of the teeth. Their nostrils, being placed near the extremity of the head, indicate a partially marine habitat, such an arrangement being required to enable the animal to breathe while nearly altogether sunk in the water.

Quarries of the red sandstone of this system also present an abundance of footmarks attributed to tortoises, thus pointing to the contemporaneous existence of a third 
FIG. 4I.

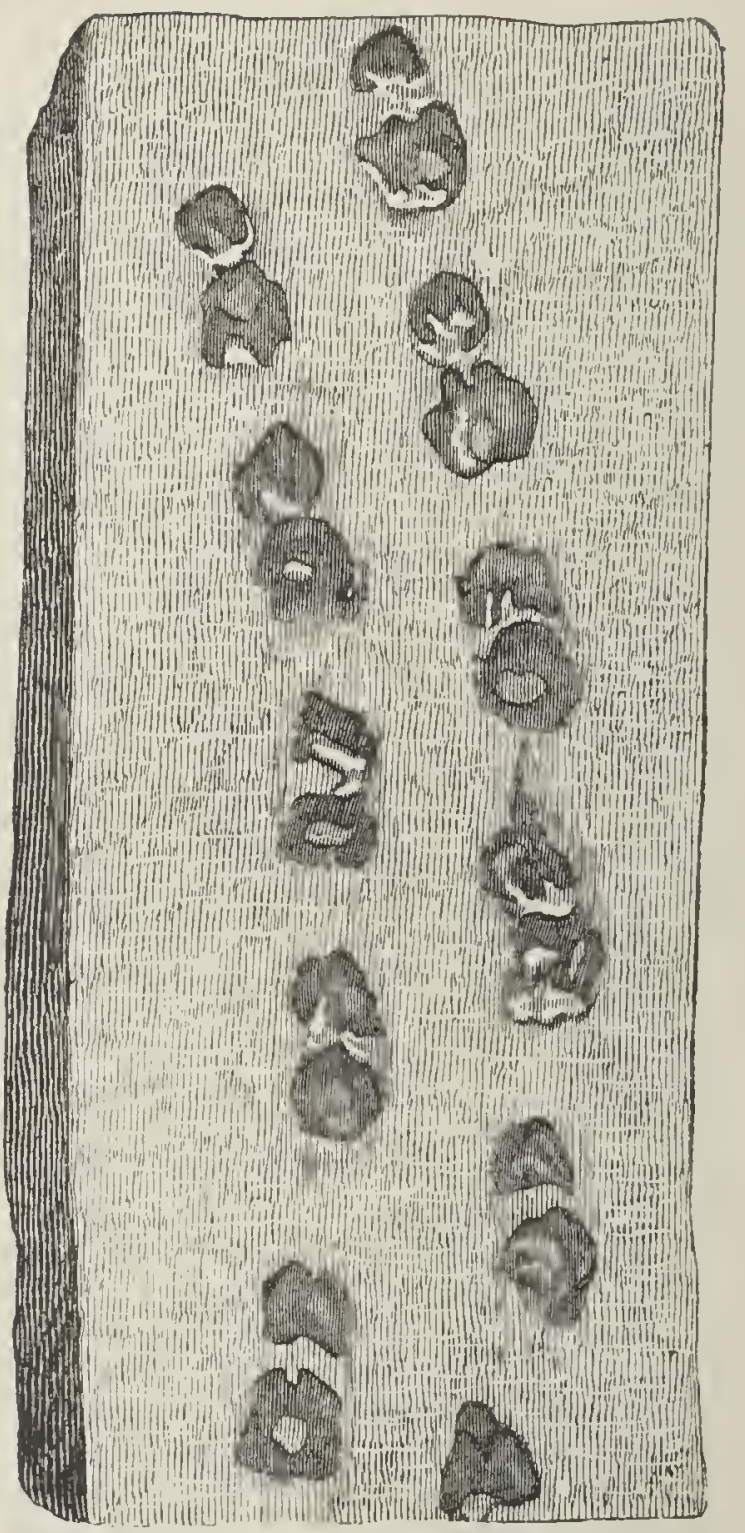

Footsteps of Turtles on Dezionian Sandstone of Elgin.

order of reptiles-the Chelonia. ${ }^{1}$ The first examples were discovered by the Rev. Dr. Duncan in the quarry of Corncockle Muir, Dumfriesshire, where the slabs incline

1 Footmarks of chelonian reptiles have recently been announced from the Devonian series. (Fig. 4I.) 
at an angle of thirty-eight degrees, and the footmarks are distinctly traced up and down the slope, as if, when the surfaces were those of a beach,-at, however, a lower inclination,- the animal had had occasion to pass only in that direction, in its daily visits to the sea. Some slabs similarly impressed, in the Stourton quarries, Cheshire, are further marked with a shower of rain which we know to have fallen afterwards, for its little hollows are impressed in the footmarks also, though more slightly than on the rest of the surface, the comparative hardness of a trodden place having apparently prevented so deep an impression being made.

It is in the celebrated Muschelkalk that, for the first time, we find examples of a group of reptiles which have excited more attention than perhaps any other extinct animals. The same group, it may be remarked, occurs in the English lias and subsequent formations: but the mere fact of writing in England should not make us postpone to that place an order of beings which we find earlier in another portion of what, geologically, may be regarded as but one great zoological province. These animals, called collectively Enaliosauria, or Marine Saurians, abounded throughout a long period of the earth's history, while mammalian life was yet hardly developed; but they disappeared in what we shall have to speak of as the Cretaceous Era. The Ichthyosaur, of which ten species have been distinguished, was an animal of marine habits and great bulk (reaching about thirty feet in length), in which to the form of the fish there were united, in a remarkable way, characters of animals higher in the scale. A body, framed upon a purely piscine vertebral column, 
FIG. 42.

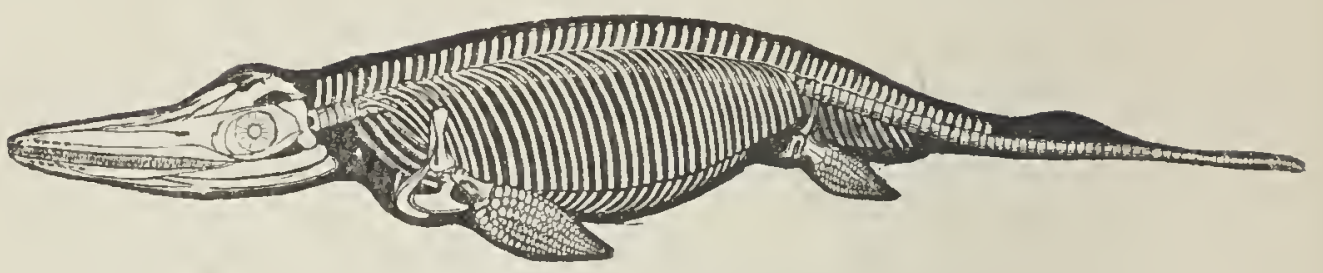

Skeleton of Ichthyosaums.

containing a huge voracious stomach, and terminating in a vertically expanded tail, in which respect it also preserved the fish character, was furnished with the head of a crocodile, and four fins approximating to the character of the paddles of the whale, but composed of a greater number of bones, and thus showing an affinity to the fins of fishes. Over all was a skin resembling that of the cetaceous animals. Nor should it be omitted that the sternum or breastbone presents a structure resembling that of the ornithorhynchus or duck-rat of Australia. The vast jaws of this animal having a stretch of seven

Fis. 43.

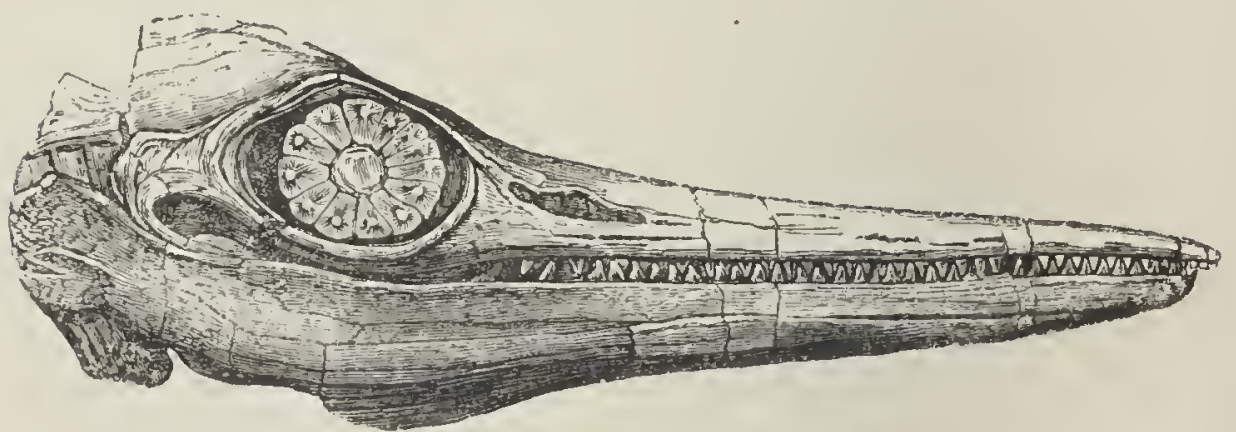

Skull of Ichthyosaurus fiatyodion.

feet; its eye resting in a socket eighteen inches in diameter, and defended by an apparatus of bony plates, like that of a bird of prey; the powerful range of teeth, and the position of the breathing apertures near the 
extremity of the snout; all speak to the naturalist of ferocious habits like those of the modern crocodile, to which the Ichthyosaur may be considered as a link from the predaceous fish. A curious light has been thrown upon these habits by the pellets voided by the animal, which have been found in great quantities in a fossilized state (coprolites). In these we find fragments not only of fish, but of reptiles, arguing that the animal must have been a destructive creature both to its own class and to that below it.

The genus next in importance is the Plesiosaurus, so called as being nearer to the Saurian character. This

FIG. 44.
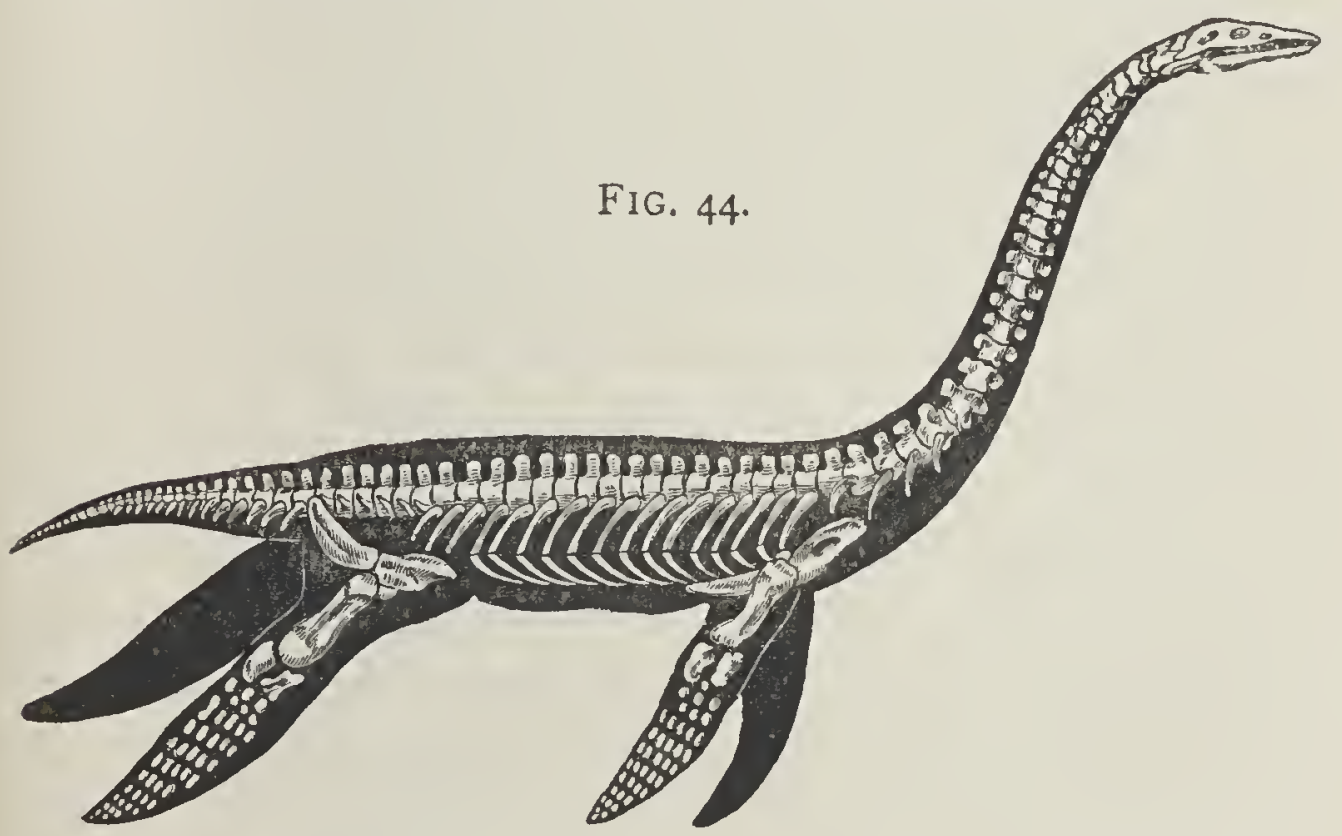

Skeleton of Plesiosnurus.

animal was under eighteen feet long, and altogether a feebler creature than the Ichthyosaur, which seems to have made it a prey. Yet it was itself one of the destructive potentates of the early seas. A body, generally fish- 
like, though framed on vertebræ presenting less concave ends, and which terminated in a short tail, serving only as a rudder, was furnished with a long neck and small head, together with four slender paddles, more cetacean than those of the Ichthyosaur. Moving, like that animal, quickly in the water, by means of the special organs designed for the purpose, the Plesiosaur would have a further advantage in its long, flexible, serpent-like neck; but the small size of the head, though there we find the same superior arrangement of teeth seen in the thecodonts, must have rendered it a much less formidable creature than that last described. Professor Owen regards it as fitted to live near shores and to ascend estuaries.

The attention of the geologists of the United States has been called to certain footmarks in the sandstone of the valleys of Connecticut (Fig. 32), indicative, as they think, of birds of the orders Grallatores (waders) and Rasores (scrapers). "The footsteps appear in regular succession on the continuous track of an animal, in the act of walking or running, with the right and left foot always in their relative places. The distance of the intervals between each footstep on the same track is occasionally varied, but to no greater amount than may be explained by the bird having altered its pace. Many tracks of different individuals and different species are often found crossing each other, and crowded, like impressions of feet upon the shores of a muddy stream, where ducks and geese

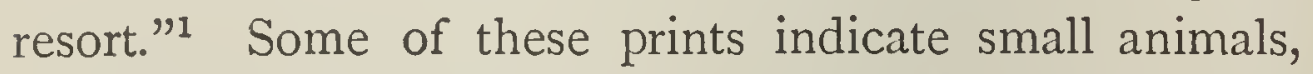
but others denote birds of what would now be an unusually

${ }^{2}$ Dr. Buckland (Bridgewater Treatise), quoting an article by Professor Hitchcock in the American Journal of Science, 1836. 
FIG. 45.

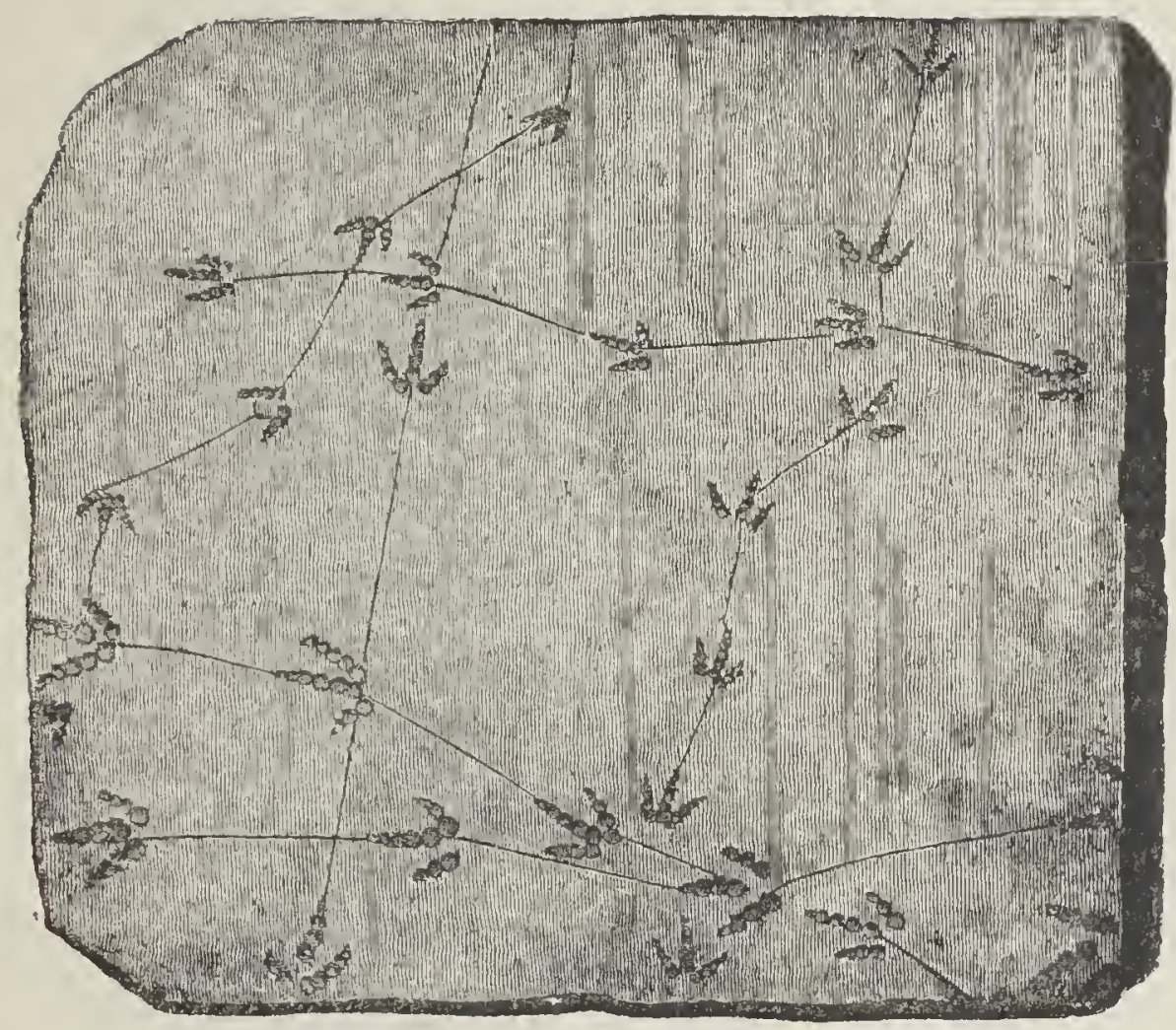

Impressions of Birds' feet on Sandstone.

large size, one having a foot fifteen inches in length, and a stride of from four to six feet. There are anomalies in the forms of some of the feet; but their being the vestiges of birds has for some years been generally admitted. There is, however, some uncertainty regarding the date of the rocks which present these memorials, for the phenomena of superposition only denote their being between the carboniferous and cretaceous formations, and an exact place is assigned them, merely upon the strength of the discovery that they present fish of certain genera never found above the Triassic series Along with distinctly ornithic footmarks are those of the Labyrintho- 
dont. Altogether, above thirty species of Triassic birds are made out from these tracings by American geologists. ${ }^{1}$

\section{OOLITE.}

The chronicles of this period consist of a series of beds, mostly calcareous, taking their general name (Oolite system) from a conspicuous member of them-the oolitea limestone composed of an aggregation of small round grains or spherules, and so called from its fancied resemblance to a cluster of eggs or the roe of a fish. This texture of stone is novel and striking. It is of chemical origin, each spherule being an aggregation of particles round a central nucleus. The oolite system is largely developed in England, France, Westphalia, and Northern Italy; it appears in Northern India and Africa, and patches of it exist in Scotland, and in the vale of the Mississippi. It may of course be yet discovered in many other parts of the world.

The series, as shown in the neighbourhood of Bath, is (beginning with the lowest) as follows: $x$. Lias, a set of strata variously composed of limestone, clay, marl, and shale, clay being predominant; 2. Lower oolitic formation, including, besides the great oolitic bed of central England, Fullers'-earth beds, Forest marble, and Cornbrash; 3. Middle oolitic formation, composed of two sub-groups, the Oxford Clay and Coral Rag, the latter

1 In 1847 , Professor Pleininger, of Stuttgard, published a description of two fossil molar teeth, referred by him to a warm-blooded quadruped, which he obtained from a bone breccia in Würtemburg, occurring between the lias and keuper. He regarded them as the teeth of a predacious mammal. Professor Owen has been unable to recognise the "affinity with any mammalian type, recent or extinct, known to him." 
being a mere layer of the works of the coral polype; 4 . Upper oolitic formation, including what are called Kimmeridge clay and Portland oolite. In Yorkshire there is an additional group above the lias, and in Sutherlandshire there is another group above that again. In the wealds (moorlands) of Kent and Sussex, there is, in like manner, above the fourth of the Bath series, another additional group, to which the name of the Wealden has been given, from its topographical situation, and which, composed of sandstones and clays, is sub. divided into Purbeck beds, Hastings sand, and Weald clay.

There are no particular appearances of disturbance between the close of the Trias and the beginning of the Lias and Oolite system, as far as has been observed in England. Yet there is a great change in the materials of the rocks of the two formations, showing that, while the bottoms of the seas of the one period had been chiefly arenaceous, those of the other were chiefly clayey and limy. And there is an equal difference between the two periods in respect of both botany and zoology. While the Permian and Triassic systems, with the single exception of the Muschelkalk, show comparatively scanty traces of life, those in the lias and oolite are extremely abundant, particularly in the department of animals, and more particularly still of sea mollusca. The distinguishing characters of the zoology appear to be uniform over a great space. "In the equivalent deposits in the Himalayan Mountains, at Fernando Po, in the region north of the Cape of Good Hope, and in the Run of Cutch, and other parts of Hindostan, fossils have been 
discovered, which, as far as English naturalists who have seen them can determine, are undistinguishable from certain oolite and lias fossils of Europe."1

The dry land of this age presented cycadea, "a beautiful class of plants between the conifers and palms, having a tall, straight trunk, terminating in a magnificent crown of foliage." 2 There were tree ferns, but in smaller proportion than in former ages; also equisetaceæ, lilia, and coniferæ. The vegetation was generally analogous to

FIG. 46 .

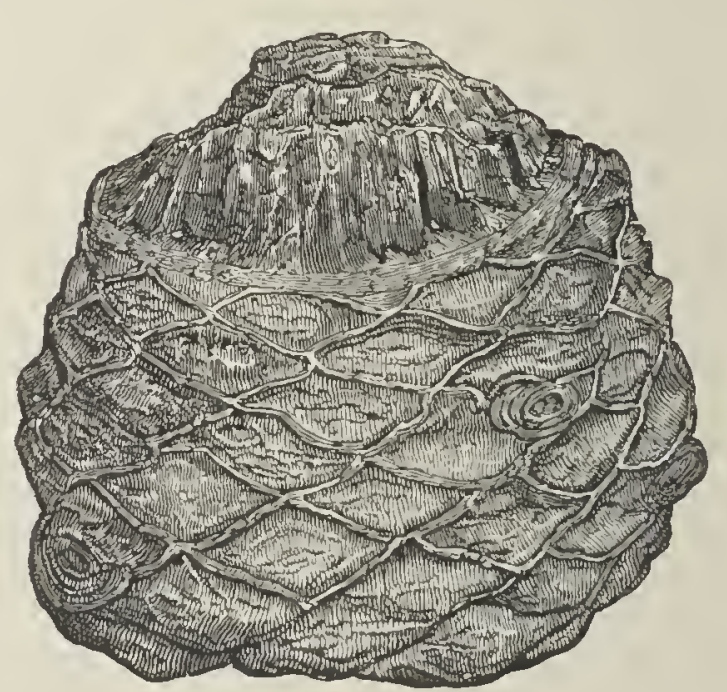

Trunk of Cycadites mesalobizyllus.

that of the Cape of Good Hope and Australia, which seems to argue a climate between the tropical and temperate. It was sufficiently luxuriant in this region of the globe to produce thin seams of coal, for there are such in the oolite formation of both Yorkshire and Sutherland, while in Virginia the oolite presents a coal-field with seams from thirty to forty feet thick. The sea, as
I Murchison's Silurian System.
2 Buckland, Bridgewater Treatise. 
FIG. 47.

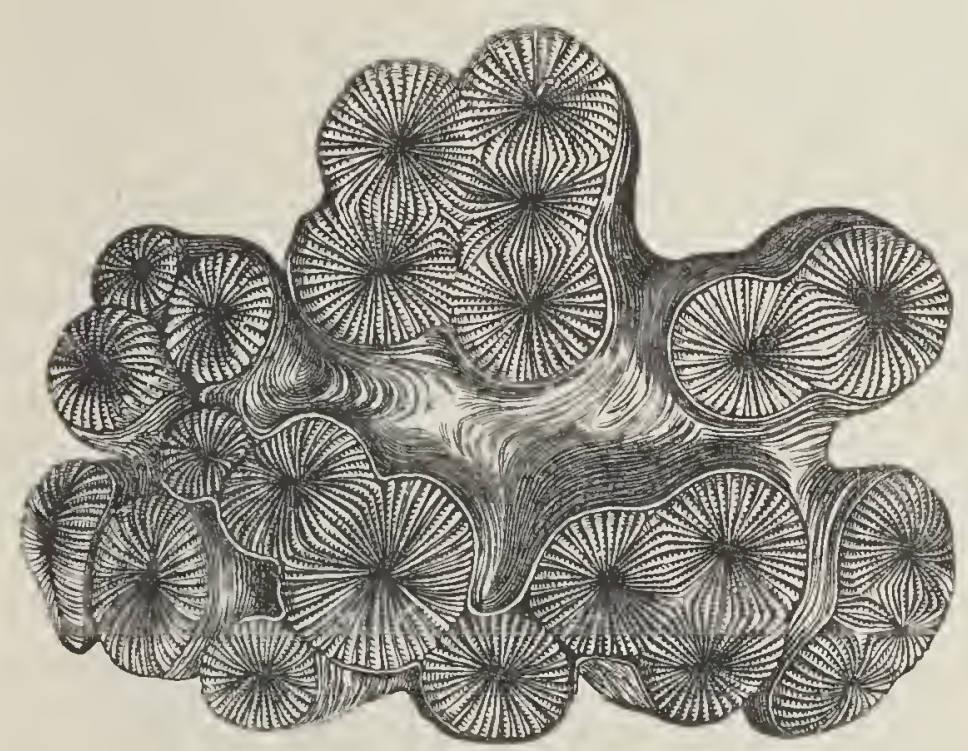

Thecosmilia gregaria, an Oolitic coral.

FIG. 43.

for ages Defore, contained algæ, of which, however, only a few species have been preserved to our day.

The lower marine animals present themselves in great abundance, and in some interesting varieties of form. Corals, scanty in the lias, reappear in the oolite in quantity sufficient, at some places, as we have seen, to constitute entire strata. The crinoids are

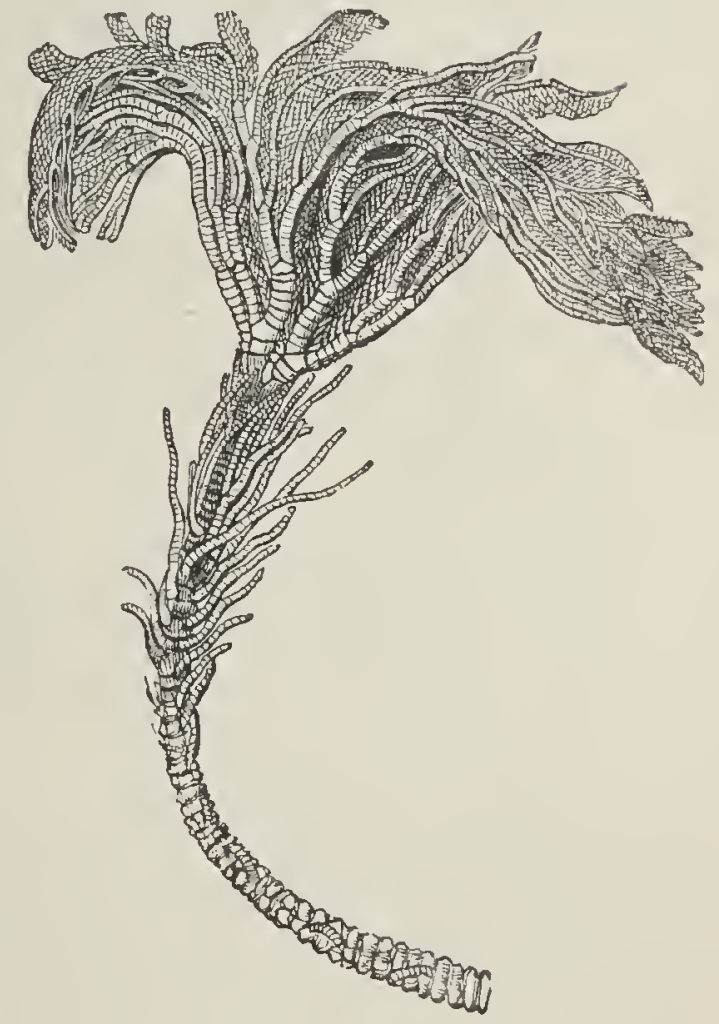

Pentacrinites briareis. 
also numerous, and amongst these are new genera showing an advance of organization from those of preceding systems. The pentacrinite, instead of a round, has a five-angled stalk, with an increased profusion of tentacula; it has also the superior character of a power to float about, and attach itself where it pleased. To this fossil of the lias succeed others of the same group in the oolite-comatula and ophiura-which are entirely free-

FIG. 49.

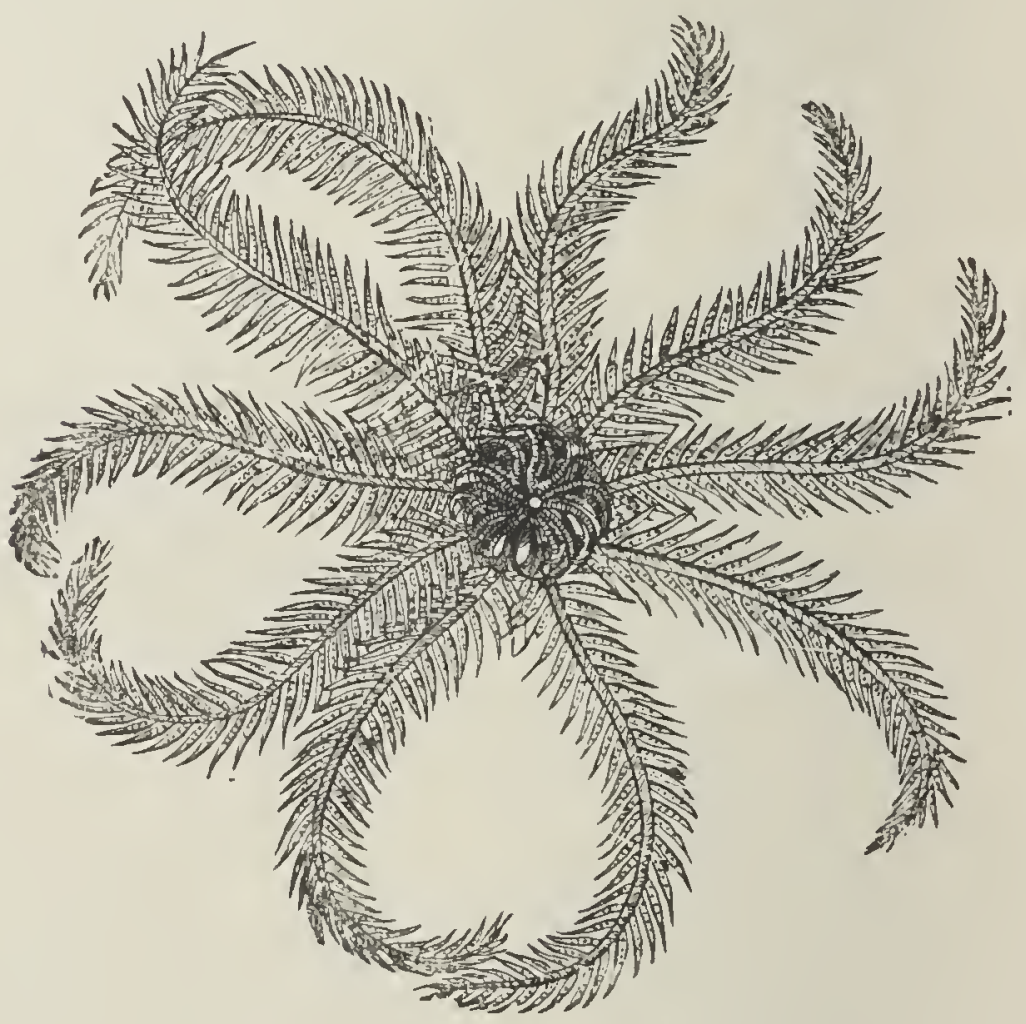

Comatula rosacca (recent).

swimming, thus supporting the general appearances of an advance of animal characters as we proceed from lower to higher formations. Here also appear other examples of the order to which the crinoidea belong 
(echinodermata) ; namely, the echinus, or sea-urchin, and the goniaster, which last is regarded as a link between the echinus and star-fish.

FIG. 50.

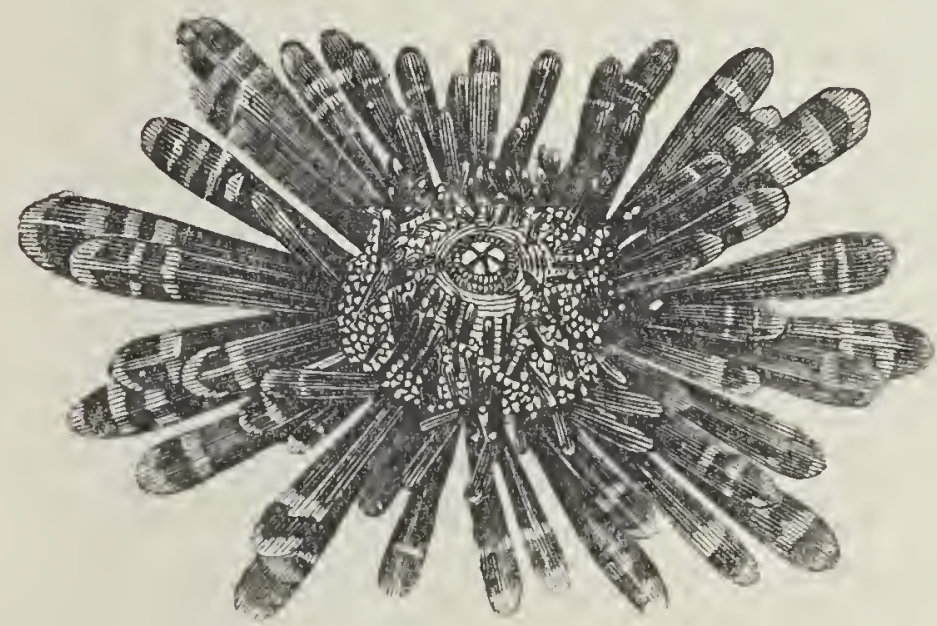

Echinus mammillatus (recent).

FIG. 5I.

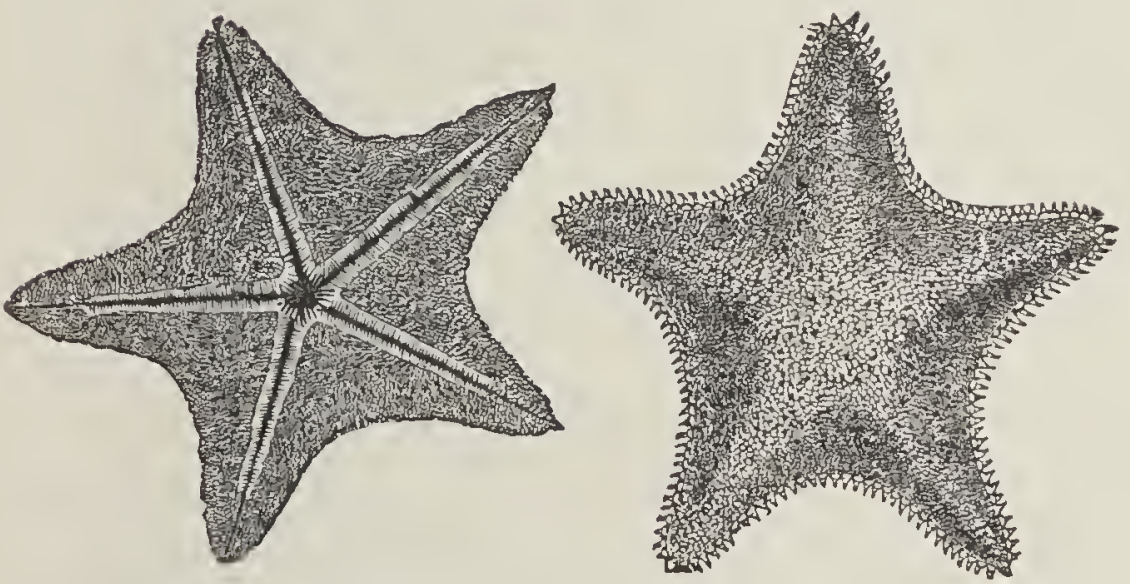

Goniaster equestris (recent).

Among the crustaceans of the oolite, a conspicuous place is due to the limulus, or king-crab, of which several species occur in this formation. This animal is re- 
FIG. 52.

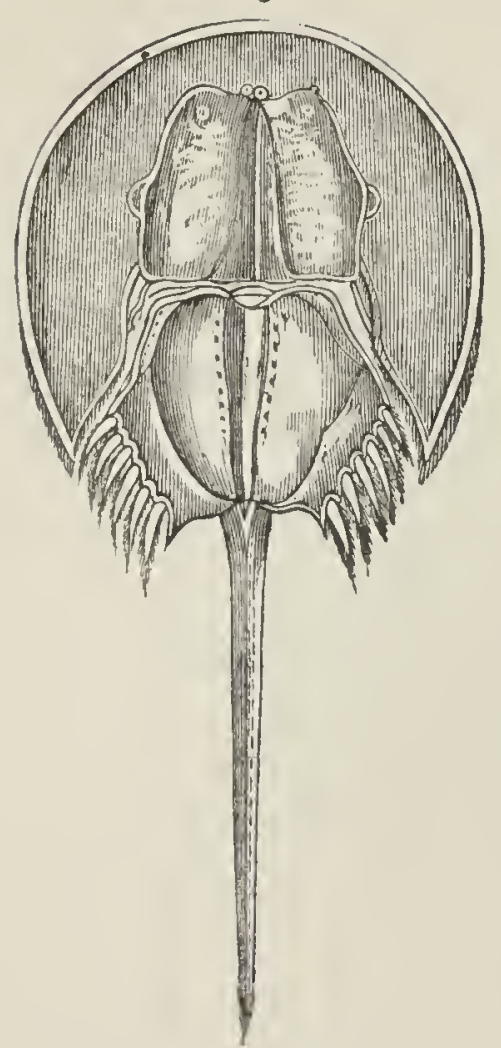

Limulues molnccanus (recent).

markable as in its embryotic state bearing a resemblance to the trilobite; and the appearance of the limulus at the time when the trilobite vanishes (the carbonigenous era), is spoken of by a distinguished geologist as "one of those beautiful links in natural history, of which the strata forming the earth's crust have afforded so many proofs." 1 Here also we have, in the eryon, an early example of the highest crustacean order (decapoda), and one to which the modern lobster and cray-fish belong. Insects resembling the dragon-fly have been found in the oolite.

FIG. 53 .
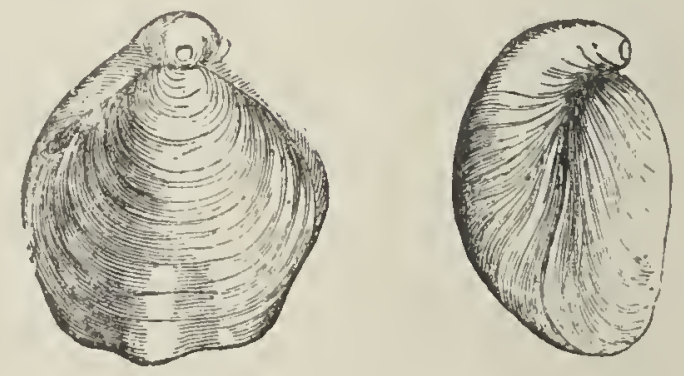

Terelratula biplicata.

The deeper oolitic seas were occupied by various species of terebratula, a brachiopodus mollusk remarkable as having lived in one form or another from the earliest

1 Murchison, Geology of Russia. 
FIG. 54.

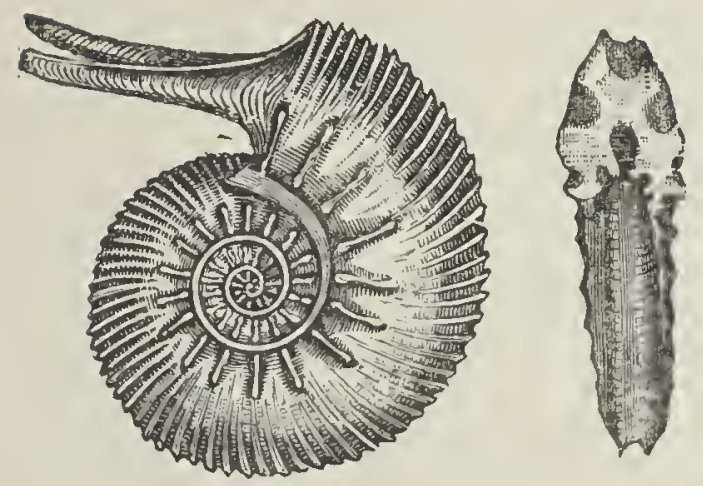

Ammonites fasoni.

to the present time. In the shallower seas were other bivalves. There was also abundance of all the univalve

FIG. 55 .

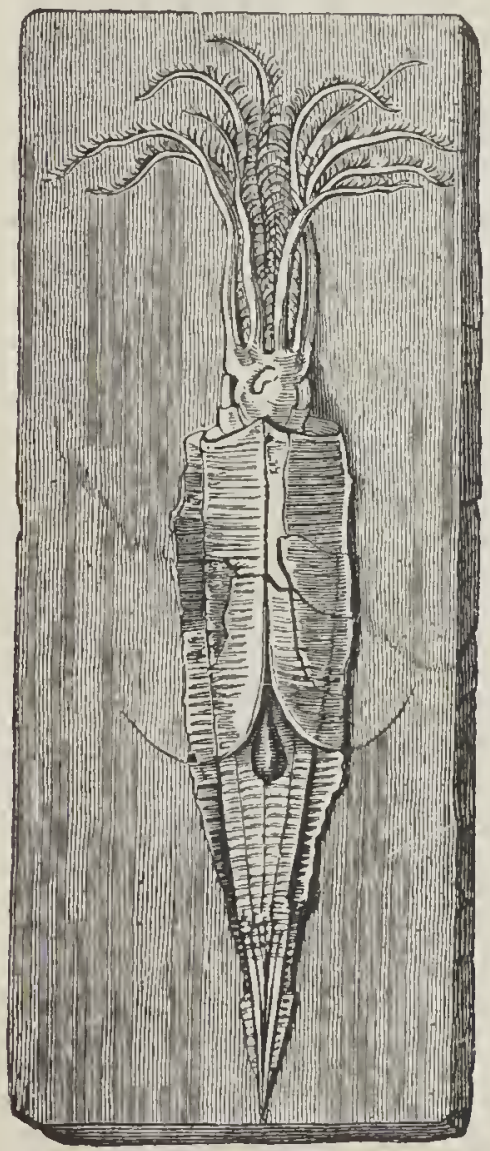

Belemnoteuthis antiquus.
FIG. $5^{6 .}$

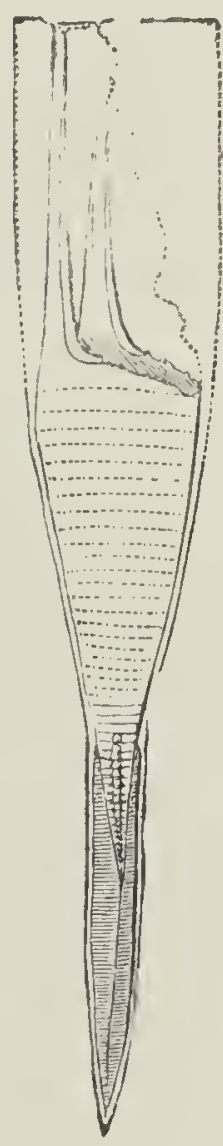

Belemnite. 
classes, Pteropoda, Gasteropoda, and Cephalopoda. In the last, we see an advance of characters among the ammonites and belemnites, which now appear in many varieties. The Belemnite, which belonged to the higher order of the class, those having only two branchiæ, calls for some particular notice. It is an elongated, conical shell, terminating in a point, and having, at the larger end, a cavity for the residence of the animal, with a series of airchambers below. The animal, placed in the upper cavity, sent its tentacula abroad over the summit of the shell, searching the sea for prey. The creature had an ink bag with which it could muddle the water around it, to protect itself from more powerful animals, and, strange to say, this has been found so well preserved, that an artist has used it in one instance as a pigment, wherewith to delineate the belemnite itself.

There are many fishes, some of which (acrodus, psammodus, etc.) are presumed, from remains of their palatal

FIG. 57 .

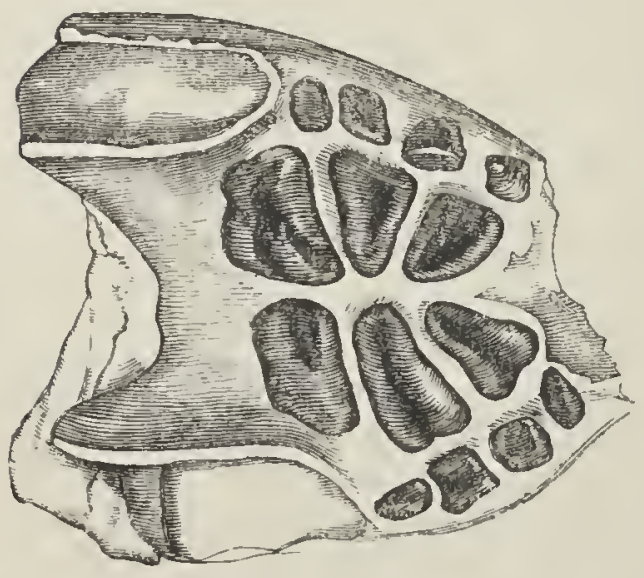

Palatal tecth of Placodus gigas, a Pychodont Ganoid. bones, to have been of the gigantic cartilaginous class (placoidean) now represented by such as the cestracion. It has been considered by Professor Owen as worthy of notice, that, the cestracion being an inhabitant of the Australian seas, we have, in both the botany and ichthyology of this period, an analogy to that continent. The pycno- 
donts (thick-toothed) and lepidoids (having thick scales) are other families described by M. Agassiz as extensively prevalent.

In the English lias there is a vast abundance of the enaliosauria which we have seen commence in the foreign Muschelkalk, and, in addition to these, specimens of Pterosauria, or Winged Saurians, a type of being, the most novel, perhaps, of all which the geological record has presented to us. The Pterodactyls, as the animals

FIG. 58.

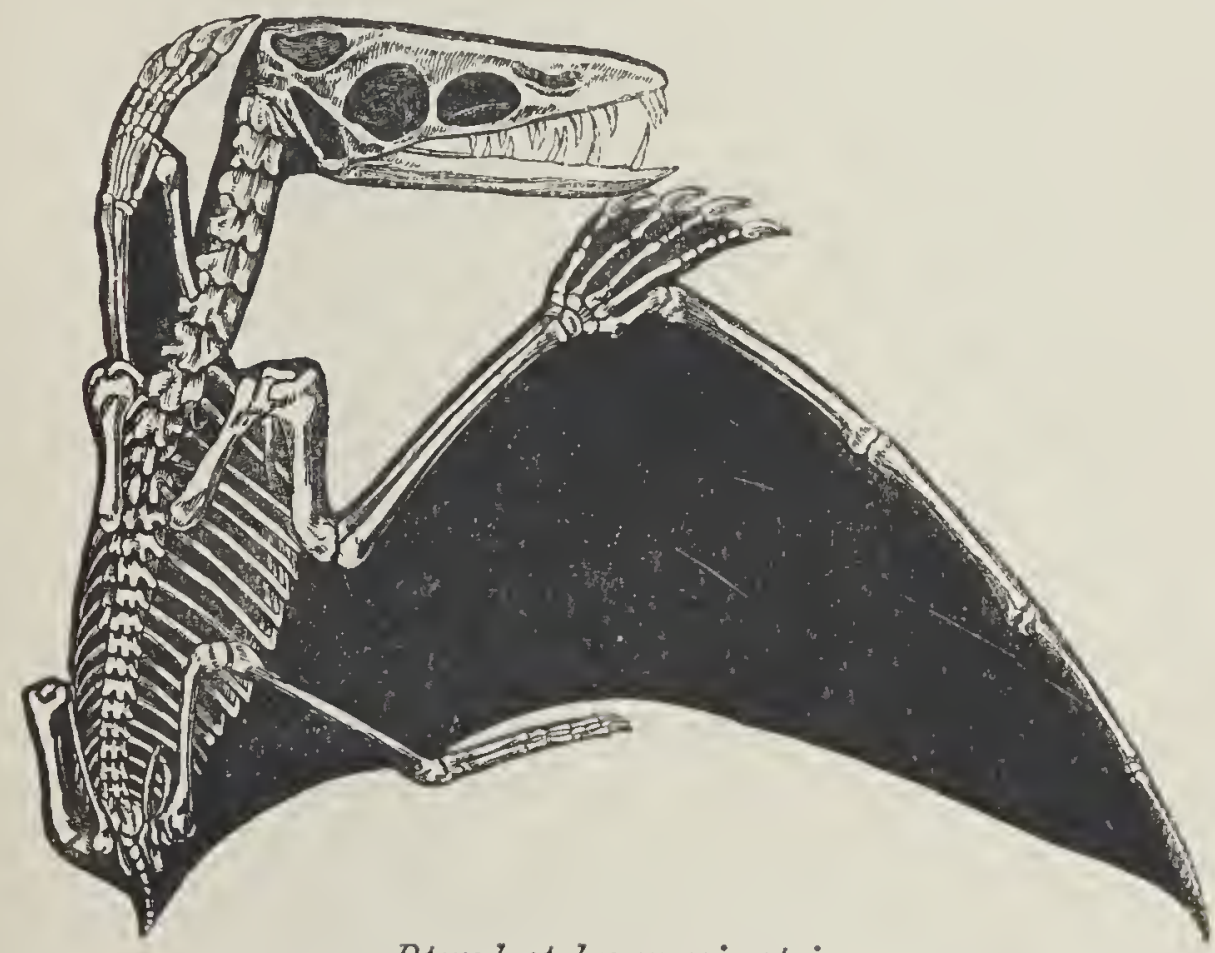

Pterodactvlus crassirostris.

of this character have been called, were saurians possessed of bat-like wings extended upon the fore-finger, by which the animal was enabled to pursue its way in the air. This genus became extinct in the time of the chalk formation. The only existing animal of which it may 
even remind us is the draco volans, or flying lizard, which has a membrane by which to support itself in leaping from tree to tree.

In the proper oolite, there is added an enaliosaurian (the Pliosaur) in which there is a very close approach made to the crocodilian order, but upon a scale of enormous magnitude, the animal having apparently been as large as the existing whales. Here, too, we find the true crocodilia largely developed, and five genera have been described, (Teleosaurus, Steneosaurus, Cetiosaurus, \&c.). The two first are like crocodiles of our own time in all respects, except a somewhat greater bulk, and certain peculiarities indicating more aquatic habits. The last derives its name from the approximation to the whale tribes seen in the form of its vertebræ. In this group there is a genus presenting ball-and-socket vertebræ, and thus proving its advanced character; but, strange to say, the concavity is in this case directed backwards, instead of forwards, which is the universal arrangement in similar cases in our era.

The first glimpse of the highest class of the vertebrate sub-kingdom-Mammalia-(overlooking the couple of mammalian teeth recently brought forward as having been found in a bone breccia at Würtemburg, between the lias and keuper) is obtained from the Stonesfield slate, where there have been found several specimens of the lower jaw-bone of a quadruped, evidently insectivorous, and inferred, from peculiarities of structure, to have belonged to the marsupial family (pouched animals). ${ }^{1}$ It

- Fragments attributed to a cetaceous animal, another humble form of the mammal class, have likewise been found in the great oolite, near Oxford. 


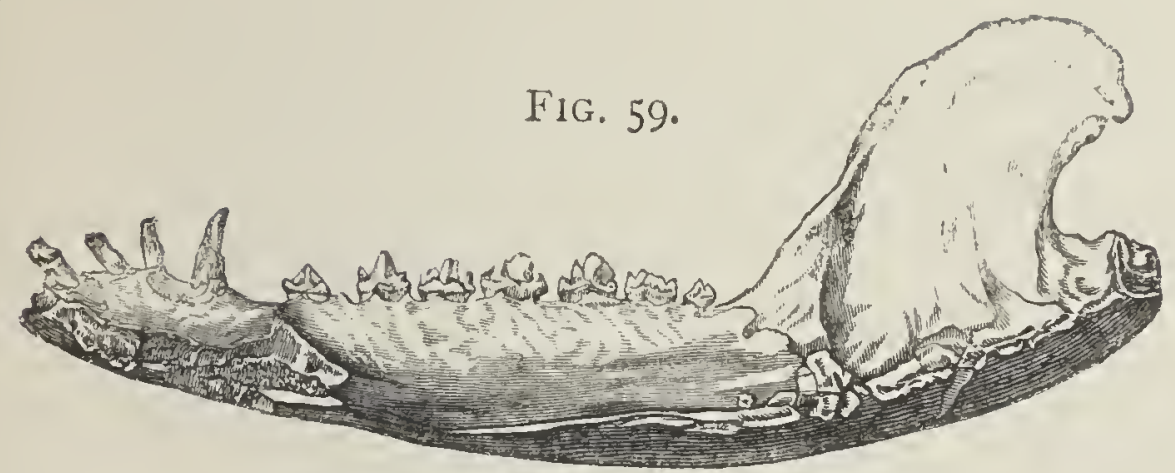

Lower Faze of Phascolotherium Bucklandii.

may be observed, although no specimens of so high a class of animals as mammalia are found earlier, that such may nevertheless have existed; the defect may be in our not having found them; but, other things considered, the probability is that heretofore there were no mammifers. It is an interesting circumstance that the first mammifers found should have belonged to the marsupialia, when the place of that order in the scale of creation is considered. In the imperfect structure of their brain, deficient in the organs connecting the two hemispheres-and in the mode of gestation, which is only in small part uterine-this family is usually regarded as only a little advanced above the character of the bird.

The highest part of the oolitic formation presents some phenomena of an unusual and interesting character, which demand special notice. Immediately above the upper oolitic group in Buckinghamshire, in the vicinity of Weymouth, and other situations, there is a thin stratum, usually called by workmen the dirt-bed, which appears, from incontestable evidence, to have been a soil formed, like soils of the present day, in the course of time, upon a surface which had previously been the bottom of the sea. 
The dirt-bed contains exuviæ of tropical trees, accumulated through time, as the forest shed its honours on the spot where it grew, and became itself decayed. Near Weymouth there is a piece of this stratum, in which stumps of trees remain rooted, mostly erect or slightly inclined, and from one to three feet high; while trunks of the same forest, also silicified, lie embedded on the surface of the soil in which they grew.

Above this bed lie those which have been called the Wealden, from their full development in the Weald of Sussex; and these as incontestably argue that the dry land forming the dirt-bed had next afterwards become the area of brackish estuaries or lakes partially connected with the sea; for the Wealden strata contain exuviæ of fresh-water tribes, besides those of the great saurians and chelonia. The area of this estuary comprehends the whole south-east province of England. A geologist thus confidently narrates the subsequent events: "Much calcareous matter was first deposited [in this estuary], and in it were entombed myriads of shells, apparently analogous to those of the vivipara. Then came a thick envelope of sand, sometimes interstratified with mud; and, finally, muddy matter prevailed. The solid surface beneath the waters would appear to have suffered a longcontinued and gradual depression, which was as gradually filled, or nearly so, with transported matter; in the end, however, after a depression of several hundred feet, the sea again entered upon the area, not suddenly or violently-for the Wealden rocks pass gradually into the superincumbent cretaceous series-but so quietly, that the mud containing the remains of terrestrial and fresh-water 
creatures was tranquilly covered up by sands replete with marine exuvir." I A subsequent depression of the same area, to the depth of at least three hundred fathoms, is believed to have taken place, to admit of the deposition of the cretaceous beds lying above.

From the scattered way in which remains of the larger terrestrial animals occur in the Wealden, and the intermixture of pebbles of the special appearance of those worn in rivers, it is also inferred that the estuary which once covered the south-east part of England was the mouth of a river of that far-descending class of which the Mississippi and Amazon are examples. What part of the earth's surface presented the dry land through which that and other similar rivers flowed, no one can tell. It has been surmised that the particular one here spoken of may have flowed from a point not nearer than the site of the present Newfoundland. Professor Phillips has suggested, from the analogy of the mineral composition, that anciently elevated coal strata may have composed the dry land from which the sandy matters of these strata were washed. Such a deposit as the Wealden almost necessarily implies a local, not a general condition; yet it has been thought that similar strata and remains exist in the Pays de Bray, near Beauvais. This leads to the supposition that there may have been, in that age, a series of river-receiving estuaries along the border of some such great ocean as the Atlantic, of which that of modern Sussex is only an example.

The zoology of the Wealden is chiefly remarkable for the additions which it makes to the list of reptiles presented

I De la Beche's Geological Researches, p. 344. 
in previous formations. Besides some new crocodilia (Suchosaurus and Goniopholis), and several chelonia (Tetrosternon, etc.), we have here the principal constituents of a group, which Professor Owen has described as a distinct order, under the name of Dinosauria, another form being the Megalosaurus of the oolite. These were terrestrial crocodile-like animals, with some features of organization recalling the lacertilia, and also such a massive and stately form of the extremities, as to remind us of the large land pachyderms. The animal last named, from twenty-five to thirty feet long, with an enormous muzzle furnished with strong teeth, must have been by far

FIG. 60.

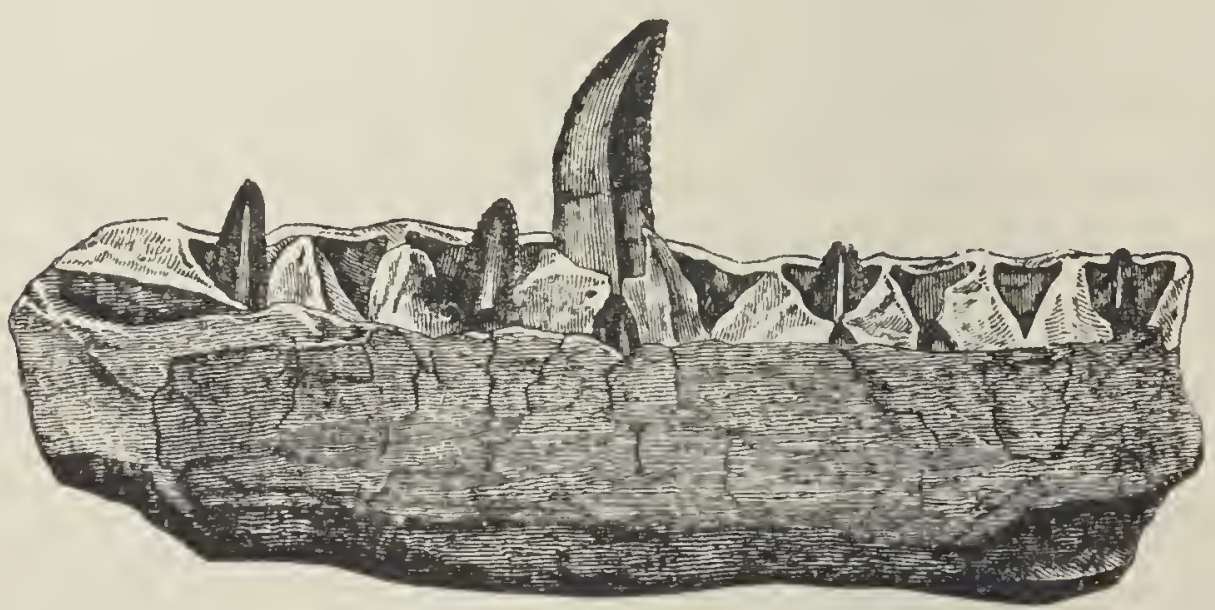

Portion of jaze of Megalosaurus.

the most formidable land creature of its age. The Iguanodon was an equally huge herbivorous reptile, which Dr. Mantell has shown, by a curious process of reasoning, to have possessed a tongue of prehensile character, like certain ruminant mammalia of our day. From the scapula or blade-bone of the remaining genus, the 
FIG. 6r.

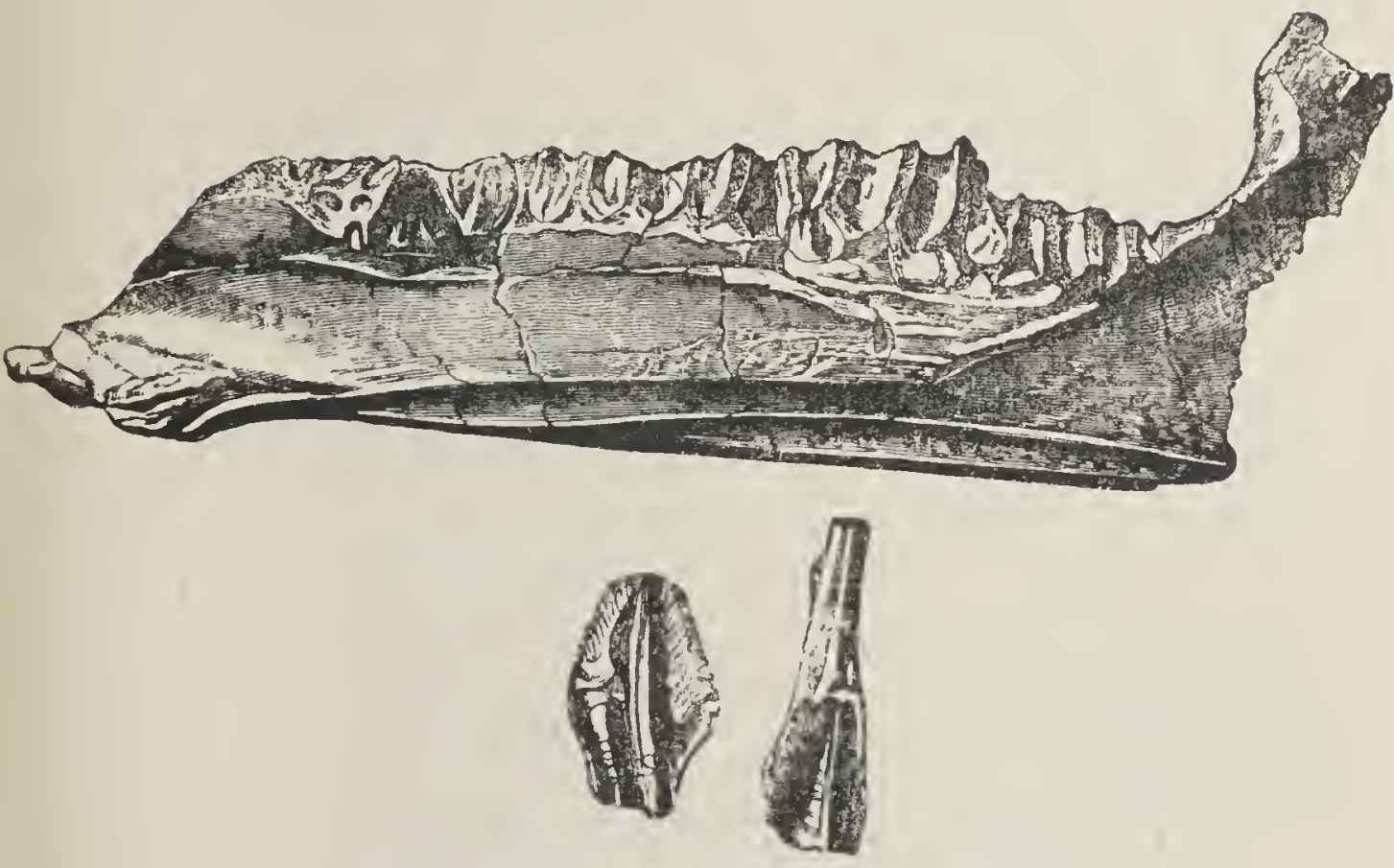

Portion of lower jazu and teeth of Iguanodon.

Hylcosaurus, the approximation of the whole of the dinosaurs to the mammalian type of structure has been inferred.

The imagination eagerly aspires to picture the world of the Oolitic Era, when there were scarcely any living creatures of more exalted character than reptiles. There were then vast tracts of dry land, as now; their surface bore a luxuriant vegetation of no mean kind. The meteoric agencies, the rise and fall of tides, were common phenomena of that time, as of the present. Day after day, through long drawn ages, the sun passed on his course. Night after night, the sparkling garniture of the sky looked down on this green world. But a being of superhuman intelligence, coming to examine our globe, 
would have seen all this existing only for fishes and still humbler creatures in the sea, and for reptiles, insects, and perhaps a few birds, and still fewer opossums, upon land. He would have beheld the tyrant sauria pursuing their carnivorous instincts upon the wave, upon the shore, and even in the air; huge turtles creeping along the muddy coasts ; still more huge megalosaurs traversing the plain; and with all this, the air filled with multitudes of insects. But no flocks would have met his eye upon the mountains, no herds quietly roaming in the valleys. He would encounter no tiger or elephant in the jungle. None of the smaller mammalian quadrupeds, as the dog, the genet, the hedge-hog, the hare, the mole, would have presented themselves. And not only were no human beings to be seen, but our supernatural visitant would know that this scene must lie spread out in perfect capability for their reception, during whole millenniums, before such beings were to exist; the stream flowing and glittering in the sun, but not to cheer the eye of man; the whole jocund earth spread out in unenjoyed beauty, as yet unwitting of the glory and the gloom which human impulses were to bring upon it. How strange to reflect on the contemplations of the supposed visitant! What a vast void! What a stretch of time before there was to be even a commencement to its proper filling! And yet the certainty that in good time, in the ripeness of the plans of the mighty Author, the higher animals were to come, and among the last the Creature of Creatures-who, in his infinity of device, was to turn it all to his use-the historical being of the world!

It has been supposed by some geologists, that there 
was a special adaptation of the earth at this time to its predominating tenants, as if it presented only low muddy coasts and marshes fit for the residence of reptiles. And it has been thought that this state of the earth is what led to the existence of so many reptiles. But all such speculations rest on insecure grounds. When we consider that the Age of Reptiles, as it has been called, is interposed between an age of fishes and an age of mammals, reptiles being also intermediate to these in the animal scale, we cannot but surmise that the fact depends on some organic law, rather than upon one in physical geography. An observation of some importance to this question is made by Mr. Darwin in his Journal. Describing the Galapagos islands in the Pacific Ocean, where turtles and lizards replace the herbivorous mammalia, and are the predominating forms of life, he says-" The geologist, on hearing this, will probably refer back his mind to the secondary epochs, when lizards, some herbivorous, some carnivorous, and of dimensions comparable only with our existing whales, swarmed on the land and in the sea. It is therefore worthy of his observation, that this archipelago, instead of possessing a humid climate and rank vegetation, cannot be considered otherwise than extremely arid, and, for an equatorial region, remarkably temperate."

\section{CRETACEOUS ERA.}

THE record of this period consists of a series of strata, in which chalk beds make a conspicuous appearance, and which is therefore called the Cretaceous System or formation. In England, a long stripe, extending from Yorkshire 
to Kent, presents the cretaceous beds upon the surface, generally lying conformably upon the oolite, and in many instances rising into bold escarpments towards the west. The celebrated cliffs of Dover are of this formation. It extends into Northern France, and thence north-westward into Germany, whence it is traced into Scandinavia and Russia. The same system exists in North America, and probably in other parts of the earth not yet geologically investigated. Being a marine deposit, it establishes that seas existed at the time of its formation on the tracts occupied by it, while some of its organic remains prove, that in the neighbourhood of those seas there were tracts of dry land.

The cretaceous formation in England presents beds chiefly sandy in the lowest part, chiefly clayey in the middle, and chiefly of chalk in the upper part, the chalk beds being never absent, which some of the lower are in several places. In the vale of the Mississippi, again, the true chalk is wholly, or all but wholly absent. In the south of England, the lower beds are (reckoning from the lowest upwards), I, Shankland or greensand, "a triple alternation of sands and sandstones with clay;" 2, Gault, "a stiff blue or black clay, abounding in shells which frequently possess a pearly lustre;" 3, Hard chalk; 4, Chalk with flints; these last two being generally white, but in some districts red, and in others yellow. The whole are, in England, about I 200 feet thick, showing the considerable depths of the ocean in which the deposits were made.

Chalk is a carbonate of lime, and the manner of its production in such vast quantities was long a subject of 
speculation among geologists. Some light seemed to be thrown upon the subject a few years ago, when it was observed, that the detritus of coral reefs in the present tropical seas gave a powder, undistinguishable, when dried, from ordinary chalk. It then appeared likely that the chalk beds were the detritus of the corals which lived in the oceans of that era. Mr. Darwin, who made some curious inquiries on this point, further suggested, that the matter might have intermediately passed through the bodies of worms and fish, such as feed on the corals of the present day, and in whose stomachs he has found impure chalk. This, however, cannot be a full explanation of the production of chalk, if we admit some more recent discoveries of Professor Ehrenberg. That master of microscopic investigation announces, that chalk is composed partly of "inorganic particles of irregular elliptical structure and granular slaty disposition," and partly of shells of inconceivable minuteness, "varying from the onetwelfth to the two hundred and eighty-eighth part of a line"-a cubic inch of the substance containing above ten millions of them! The chalk of the north of Europe contains, he says, a large proportion of the inorganic matter; that of the south, a larger proportion FIG, 62.
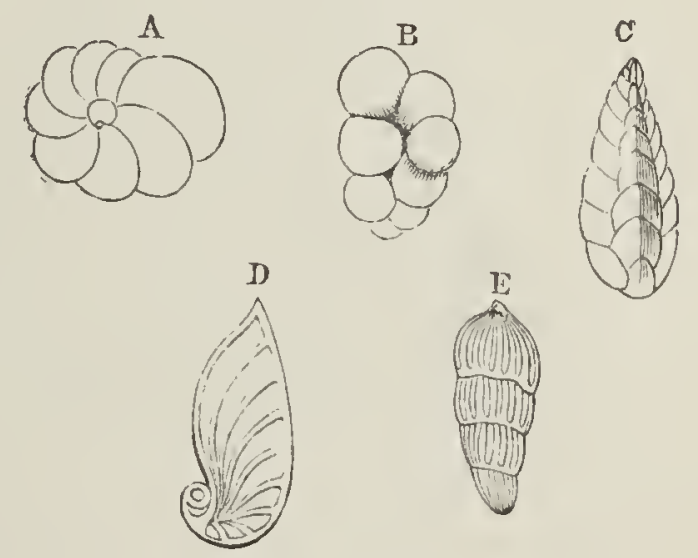

Calcareous-shelled Foraminifern. from the Chalk.

A, Rotalia; B, Textularia; C, Verneuilina; D, Cristellarin; E, Dentalina. 
of the organic matter, being in some instances almost entirely composed of it. The shells of some are calcareous, of others, siliceous. M. Ehrenberg has likewise detected microscopic sea-plants in the chalk.

FIG. 63.
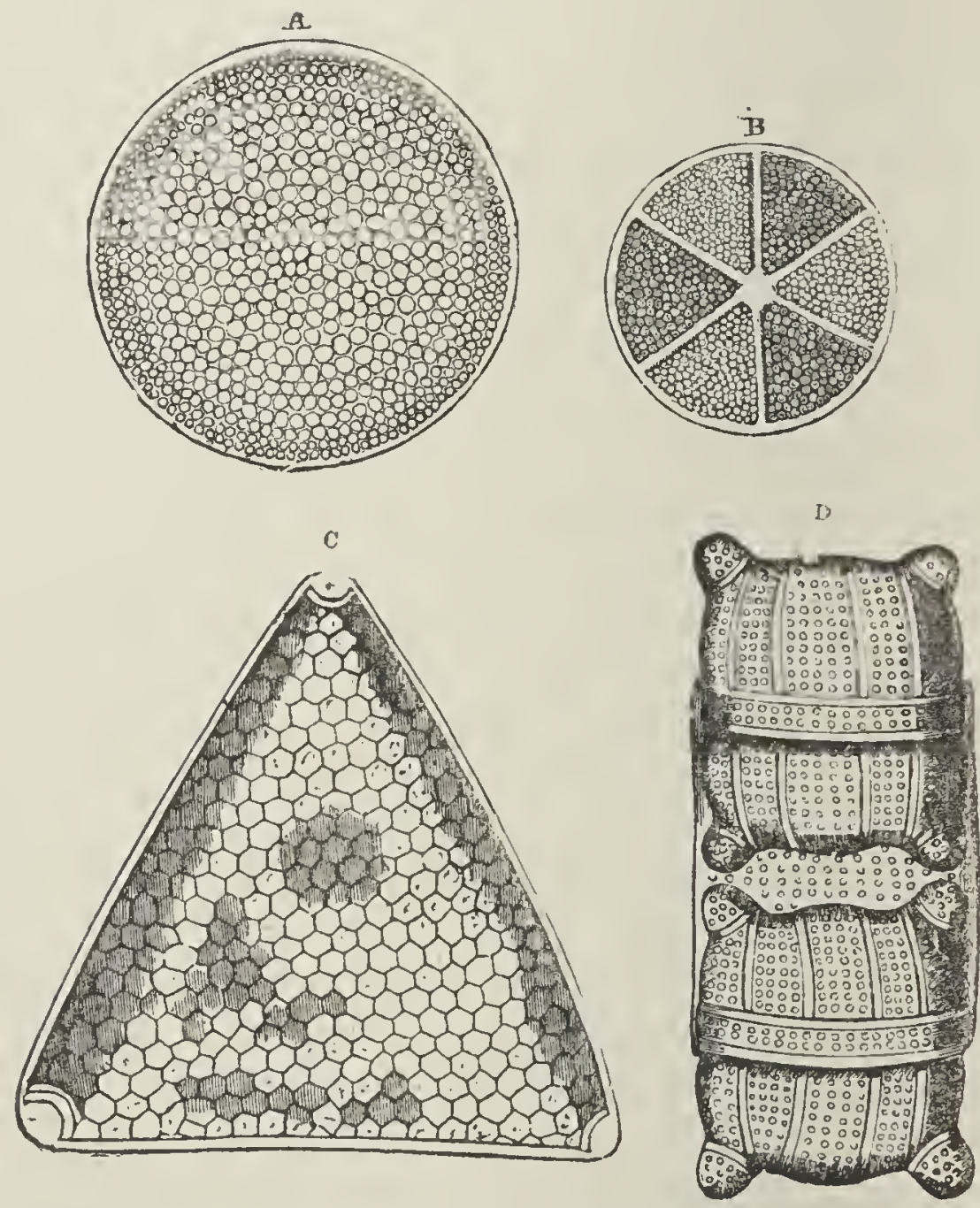

Siliceous shelled Infusoria.

A, Coscinadiscus; B, Actinocyclus; C, Triceratiun; D, Biddulphia

The distinctive feature of the uppermost chalk beds in England is the presence of flint nodules. These are 
generally disposed in layers parallel to each other. It was readily presumed by geologists that these masses were formed by a chemical aggregation of particles of silica, originally held in solution in the mass of the chalk. But whence the silica in a substance so different from it? Ehrenberg suggests that it is composed of the siliceous coverings of a portion of the microscopic creatures, whose shells he has in other instances detected in their original condition. ' It is remarkable that the chalk with flint abounds in the north of Europe; that without flints in the south; while in the northern chalk siliceous animalcules are wanting, and in the southern present in great quantities. The conclusion seems natural, that in the one case the siliceous exuviæ have been left in their original form: in the other, dissolved chemically, and aggregated on the common principle of chemical affinity into nodules of flint, probably concentrating, in every instance, upon a piece of decaying organic matter, as has been the case with the nodules of ironstone in the earlier rocks, and the spherules of the oolite.

What is more remarkable, M. Ehrenberg has ascertained that at least fifty-seven species of the microscopic animals of the chalk, being infusoria and calcareous-shelled polythalamia, are still found living in various parts of the earth. These species are the most abundant in the rock. Singly they are the most unimportant of all animals; but in the mass, forming as they do such enormous strata over a large part of the earth's surface, they have an importance greatly exceeding that of the largest and noblest of the beasts of the field. Moreover, these species have a peculiar interest, as the only specific types of that 
early age which have survived to the present day. While the specific features of all higher animals have been again and again changed since that period, these humble creatures have preserved the characters they then possessed-shall we say, through a continuing uniformity in the conditions under which they have lived, while all other animals have been exposed to circumstances productive of change?

All the ordinary and more observable orders of the inhabitants of the sea, except the cetacea, have been found in the cretaceous formation-zoophytes, radiaria, mollusks, crustacea (in great variety of species), and fishes in smaller variety. Down to this period, the placoid and ganoid fishes had, as far as we have evidence, flourished alone; now they decline, and we begin to find in their place fishes of two orders of superior organization, those which predominate in the present creation. These are osseous in internal structure, with corneous scales. The enaliosaurians disappear in this formation, while the land reptiles, so numerous in the two preceding periods, become much diminished in numbers. Of the latter, one of the most remarkable was the Mosasaurus, which seems to have held an intermediate place between the monitor and iguana, and to have been about twentyfive feet long, with a tail calculated to assist it powerfully in swimming.

Fuci abounded in the cretaceous seas, and confervæ are found enclosed in flints. Of terrestrial vegetation, as of terrestrial animals, the specimens in the European area are comparatively rare, rendering it probable that there was little dry land near. The remains are chiefly of ferns, 
FIG. 64.

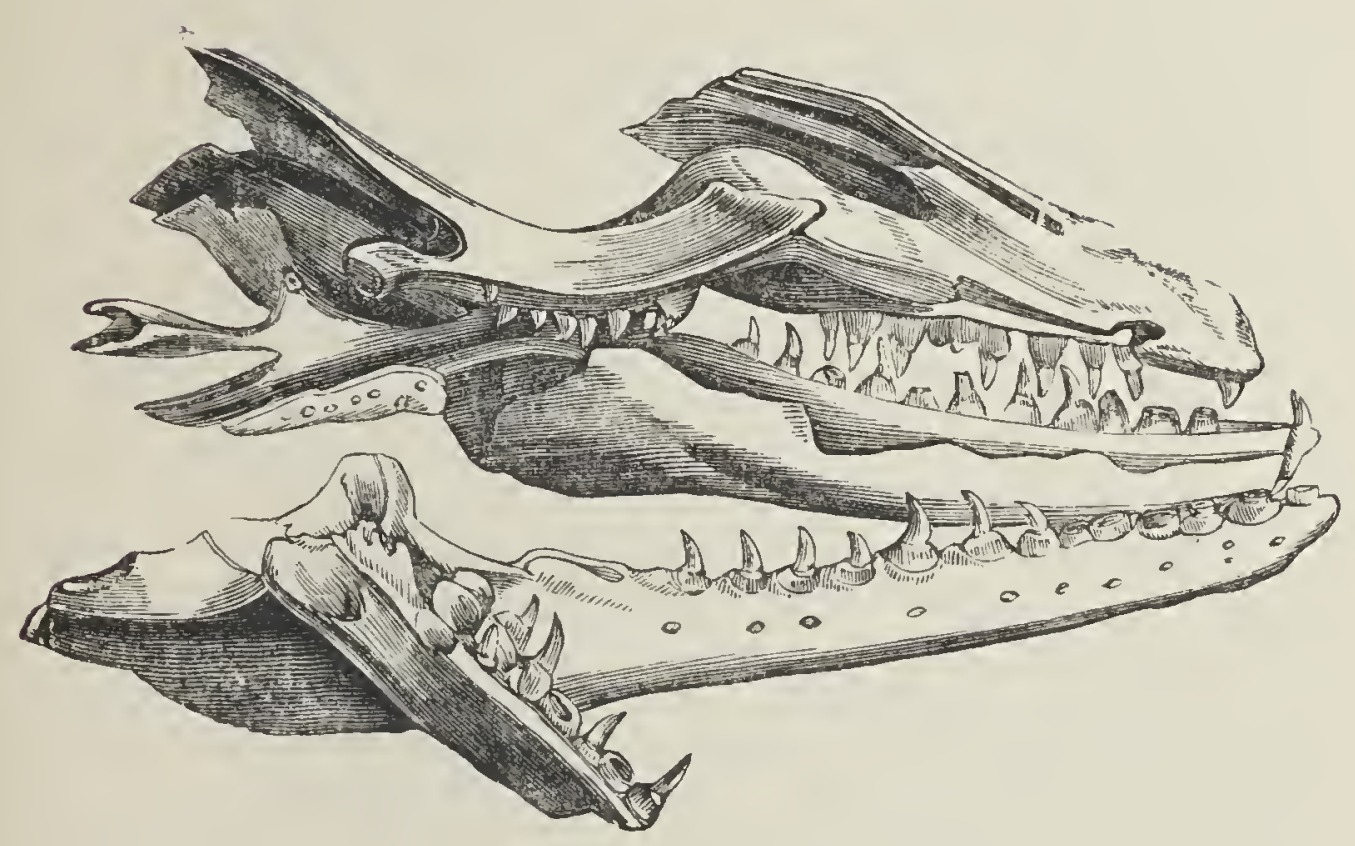

Skuli if Mosasaurus.

conifers, and cycadex, but in the two former cases we have only cones and leaves. There have been discovered many pieces of wood containing holes drilled by the teredo, and thus showing that they had been long drifted about in the ocean before being entombed at the bottom.

The series in America corresponding to this, entitled the Fermginous Sand formation, presents fossils generally identical with those of Europe, not excepting the fragments of drilled wood: showing that, in this, as in earlier ages, there was a parity of conditions for animal life over a vast tract of the earth's surface. To European reptiles, the American formation adds a gigantic one, styled the Saurodon, from the lizard-like character of its teeth.

We have seen that footsteps of birds have been 
announced from America, in the new red sandstone. Some similar isolated phenomena occur in the present formation. In the slate of Glaris, in Switzerland, corresponding to the English galt in the chalk formation, the remains of a bird have been found.

ERA OF THE TERTIARY FORMATION.-MAMMALIA ABUNDANT.

THE chalk-beds are the highest which extend over a considerable space; but in hollows of these beds, comparatively limited in extent, there have been formed series of strata-clays, limestones, marls, alternating-to which the name of the Tertiary Formation has been applied. London and Paris alike rest on basins of this formation, and another such basin extends from near Winchester, under Southampton, and re-appears in the Isle of Wight. A stripe of it passes along the east coast of North America, from Massachusetts to Florida. It is also found in Sicily and Italy, insensibly blended with formations still in progress. Though comparatively a local formation, it is not of the less importance as a record of the condition of the earth during a certain period.

The hollows filled by the tertiary formation must be considered as the beds of estuaries and gulfs, left at the conclusion of the cretaceous period. We have seen that an estuary, either by the drifting up of its mouth, or a change of level in that quarter, may be supposed to have become an inland sheet of water, and that, by another change of the reverse kind, it may be supposed to have become an estuary again. Such changes the Paris basin 
appears to have undergone oftener than once; for, first, we have there a fresh-water formation of clay and limestone beds; then a marine-limestone formation; next, a second fresh-water formation, in which the material of the celebrated plaster of Paris (gypsum) is included; then a second marine formation of sandy and limy beds; and finally, a third series of fresh-water strata. Such alternations occur in other examples of the tertiary formation likewise.

The end of the Secondary Formation, which we have just seen take place, presents in some respects a remarkable resemblance to the close of what is called the Palæozoic period in the Permian strata. Looking broadly at the specific forms of the next higher strata, they appear to have undergone a total change. Again do we now witness a difference of the shelly cephalopoda. There is also a gradual reduction, and finally a disappearance, of the specific forms of gasteropods, formerly abundant. It has heretofore been a belief of geologists, that at this point, as at the former, there was an entire renewal of life upon our planet; but several considerations forbid such a conclusion in the second as well as in the first instance. First, the specific forms are not wholly changed, for a few do pass into the next higher strata. Second, there is, in the higher formation, an apparent following of an order applicable to the whole palcontological history, as something under one law, seeing that birds and mammalia, the next classes in the vertebrate scale, are then added. In the words of Sir R. Murchison, who believes that a true geological passage may be found between the two formations, the upper secondary rocks-judging from many of 
their generic forms- "seem to have prepared the way for the sequence of the tertiary strata." For these reasons, the idea of an entire renovation of life at this time-what is commonly called a new creation - is not now maintained anywhere with confidence. The more rational explanation of the appearances is one suggested by actual facts observed in the strata; that the final cretaceous beds were deposited in seas more than usually deep, and which were therefore no proper habitat for the animals previously existing; that an interval of time afterwards took place, which is not represented by any strata which have been discovered; and that, by the time the tertiary formation commenced, the usual modifying influences having never ceased, the fauna had undergone such an amount of change as naturalists are accustomed to describe (their language being wholly arbitrary) as a renewal of species.

It is in perfect harmony with this view, that from the commencement of the Tertiaries, and as we ascend in the series, we find more and more specific forms identical with those still existing upon earth, as if we had now reached the dawn of the present state of the zoology of our planet. By the study of the shells alone, Sir C. Lyell has formed a division of the whole term into four sub-periods, to which he has given names with reference to the proportions which they respectively present of surviving species-first, eocene; second, miocene; third, older pliocene; fourth, newer pliocene. ${ }^{1}$ This division, however, is to be regarded as not safely applicable to the Tertiaries generally, except as a convenient means of indicating various portions of the series.

1 Lyell's Elements of Geology. 
The eocene period presents, in three continental groups, I 238 species of shells, of which forty-two, or 3.5 per cent., yet flourish unchanged. Some of these are remarkable enough; but they all sink into insignificance beside the mammalian remains, which the lower eocene deposits of the Paris basin present to us, showing that the land had now become the theatre of an extensive creation of the highest class of animals. Cuvier ascertained about fifty species of these, all of them long since extinct. About four-fifths are of the order Pachydermata, thick-skinned animals, to which our modern elephant, rhinoceros, horse, and pig, belong. Nearly the whole of these, however, belong to a family which is now confined to South America and Sumatra, namely, the tapir,-an animal of squat figure, and possessing a short proboscis, an inhabitant of the woods, and a herbivore, but of unsocial habits. It is curious to find that a family now so limited in its range, had formerly been distributed over France, England, and other parts of the earth. Naturalists have conferred the names, Palcotherium, Lophiodon, Coryphodon, \&c., upon the ancient extinct tapirs, which seem chiefly to differ from modern species in a few peculiarities of the constitution of the teeth, and in having three, instead of four, toes upon the fore feet. One British specimen seems to have been about a third larger than the modern animal.

Another section of the Paris eocene remains have served to reconstruct a family to which the general name Anoplotherium has been given, from regard to its deficiency of all offensive or defensive weapons. These are the first examples of bi-hooved animals as yet discovered upon 
FIG. 65 .

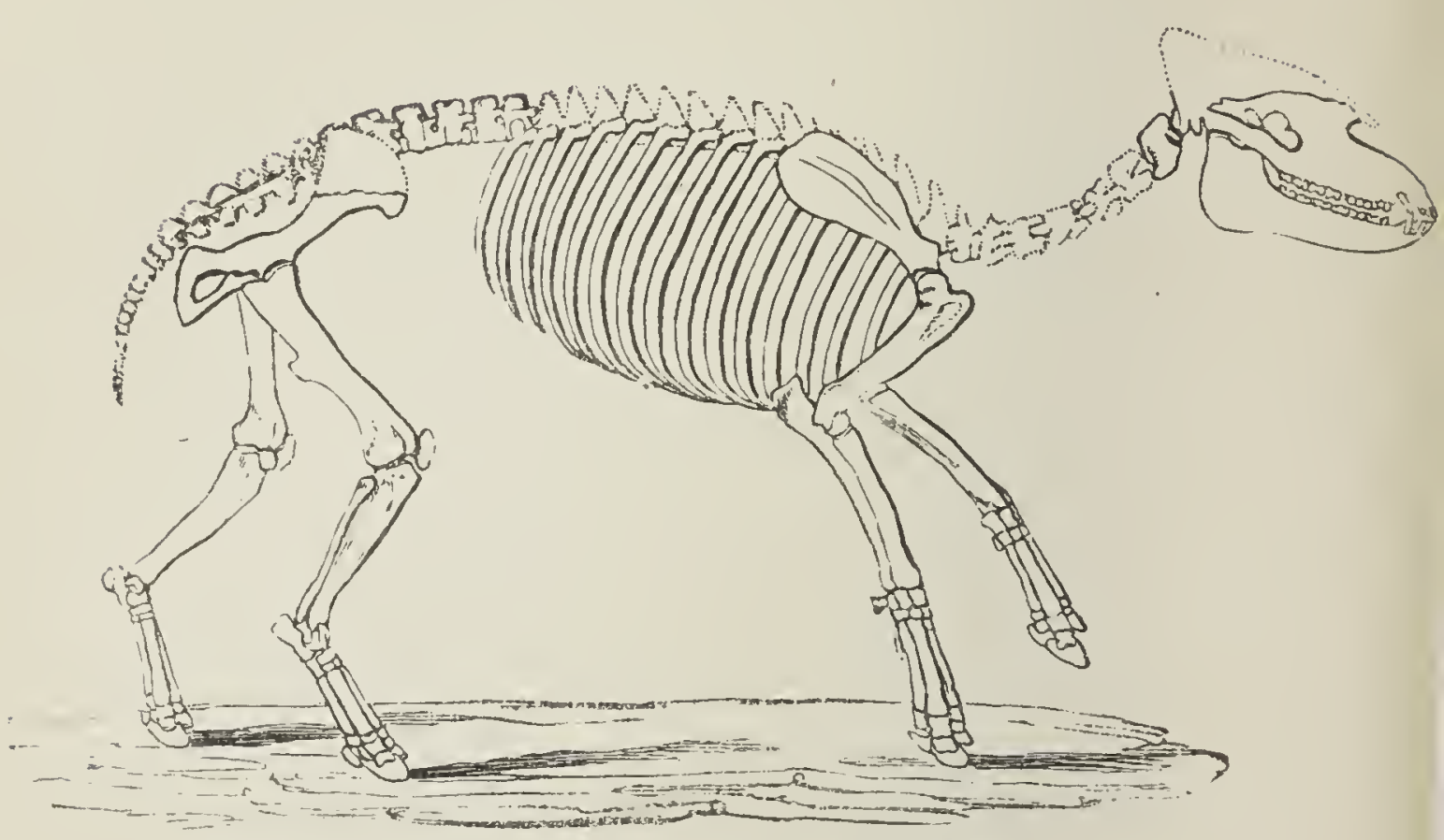

Skeleton of Palaotherium magnum.

earth; they were strictly herbivorous, and make a slight approach to the cervine or deer tribes. The common anoplothere was about the size of an ass, but less elevated from the ground, and with a tail of above three feet in length; it is supposed to have been of aquatic habits, and an expert swimmer and diver, but also given to browsing upon land. Associated with these we find the first example (chœropotamus) of an animal approaching to the hog tribe, being nearest to the peccary of South America.

We learn from the remainder of the Paris fossils, and from others found in the eocene, that the earth now possessed fresh-water reptiles; serpents of the size of a boa; natatorial, wading, and rapacious birds; rodents 
(dormouse and squirrel); species allied to the racoon, the genet, and fox; also bats and monkeys. Lastly, the oldest tertiaries of America present us with the Zeuglodon, a herbivorous whale resembling the dugong, having a stinted development of the extremities, but an enormous tail, and reaching altogether the length of a hundred feet.

In the miocene sub-period, the shells give eighteen per cent. of existing species, showing a considerable advance from the preceding era with regard to the inhabitants of the sea. The advance in land animals is less marked, but yet considerable. The predominating forms are still pachyderms, and the tapiroid animals continue to be FIG. 66.

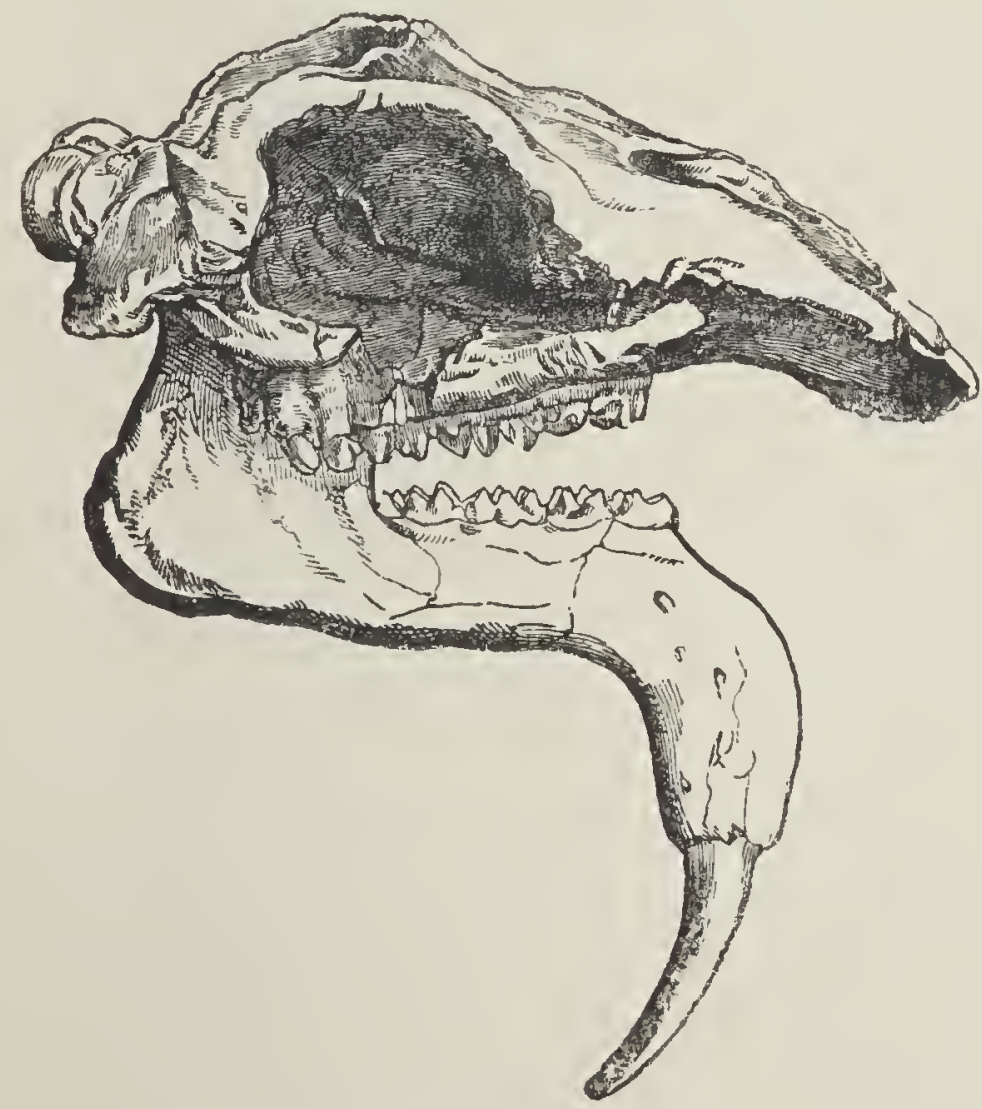

Skull of Dinotherizun. 
conspicuous. Here occur remains of the Dinotherium, a creature said to exhibit an affinity to the cetacea in the form of its head, and to the tapir in the character of its teeth. It is most distinguished by its huge size, being not less than eighteen feet long; it had a mole-like form of the shoulder-blade, conferring the power of digging for food, and a couple of tusks turning down from the lower jaw, by which it could have attached itself, like the walrus, to a shore or bank, while its body floated in the water. Dr. Buckland considers this and some similar miocene animals, as adapted to a semi-aquatic life, in a region where lakes abounded. Besides the tapirs, we have in this era animals allied to the glutton, the bear, the dog, the horse, the hog, and lastly, several felines (creatures of which the lion is the type); all of which are new forms, as far as we know. There was also an abundance of marine mammalia, seals, dolphins, lamantins, walruses, and whales.

The shells of the older pliocene give from thirty-five to fifty-those of the newer, from ninety to ninety-five per cent. of existing species. The pachydermata of the preceding era now disappear; but others enter upon the scene-elephantoid animals, the hippopotamus, rhinoceros, and horse. All of these bear a striking resemblance to pachyderms of the same families still existing. We have, in the mastodon and mammoth, which succeed each other in the strata, elephants variously distinguished from the present by peculiarities in their dentition, and hence considered as of different species. What is remarkable of these ancient animals is their having lived in countries so far beyond the present range of their 
FIG. 67.

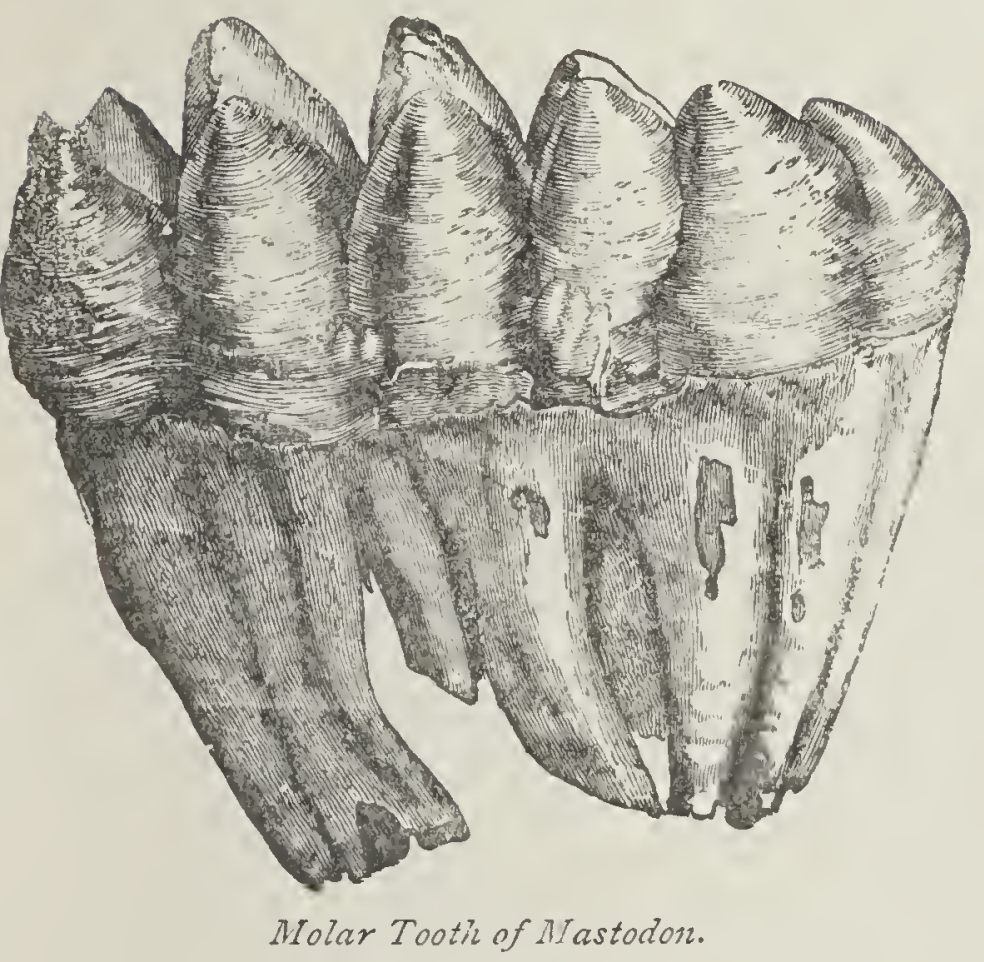

FIG. 68.

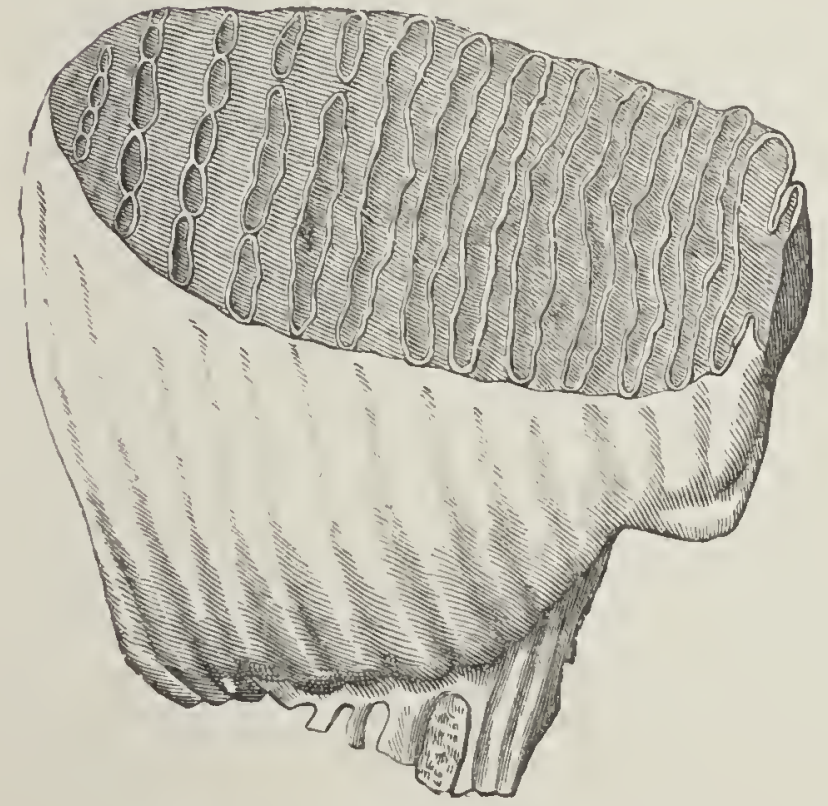

Molar Tooth of Asutw Filephan:. 
family, namely, throughout the whole temperate region of Asia and Europe (England not being excepted), and even so far north as the seventieth degree of latitude.

FIG. 69.

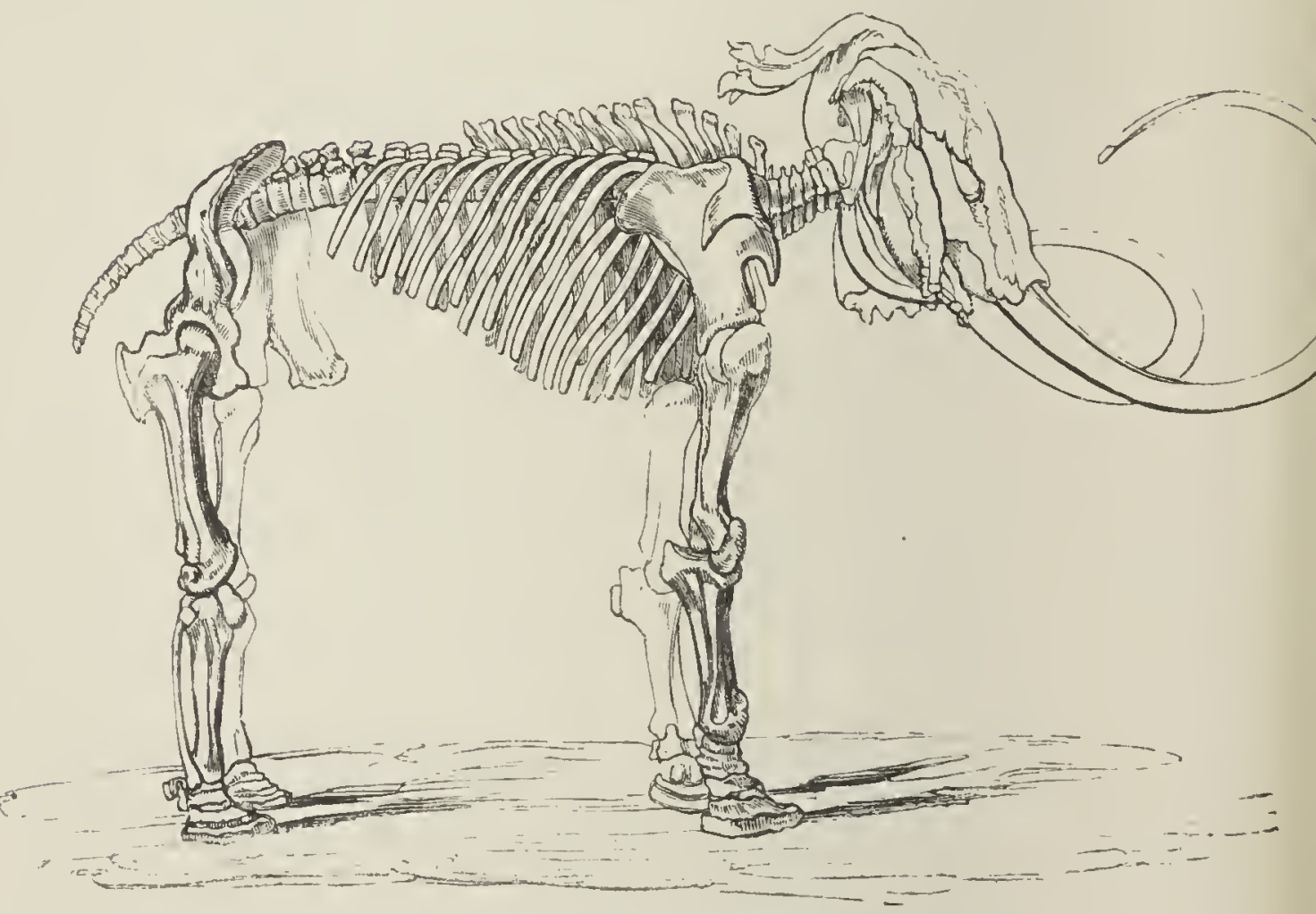

Skeleton of Mammoth.

The mammoth also inhabited North America. Its chief external peculiarity was a pair of long curved tusks extending forwards and upwards from the upper jaw. The numerous remains of the animal in the most superficial strata, and the discovery (in I80I) of a specimen with its flesh and hide entire in a mass of ice at the mouth of the Lena in Siberia, show that it must have lived down to comparatively modern times.

The pliocene gives many other new families. From 
remains which have been found, however fragmentary in many cases, there cannot be a doubt that all the principal mammalian forms, except the highest and a few others, now existed throughout the earth, and in species which only differed from those still living in slight peculiarities, chiefly of dentition. Bears, badgers, hyenas, and feline animals : moles and other insectivores; otters and weasels; the wolf and dog; then roamed for prey as now; besides an extinct felina, the machairodus, possessing teeth like curved saws. England had beavers and bears, little different from living species; only, one of the former family was of huge bulk. We also had the hippopotamus and rhinoceros. Oxen, deer, camels, etc., inhabited the great zoological province with which we are connected; and monkeys and apes passed far beyond the tropical regions to which they are now confined. In India, besides the pachyderms of the European eocene, there were ruminants in abundance (including an extraordinary one, of huge bulk, named the Sivatherium), carnivores, rodents, and insectivores. Here also were monkeys, of unusual bulk; but the most wonderful animal as yet discovered in this region was a tortorse, not distinguishable in any point of structure from a land species now living, but reaching the surprising length of eighteen feet. The discoveries among the tertiaries of South America have been of a not less interesting character, in as far as they equally show an approach to the existing zoological characters of that region. Dr. Lund, a Danish naturalist, presents us with a monkey, indicating the features of the platyrrhine or New World group; and the edentate order, which is still most peculiar to that region, is there 
I34 ERA OF THE TERTIARY FORMATION.

preceded by examples of vast size. In the megatherium, megalonyx, scelidotherium, and mylodon, we have a family of sloths, of elephantine magnitude, which lived by break-

FIG. 70.

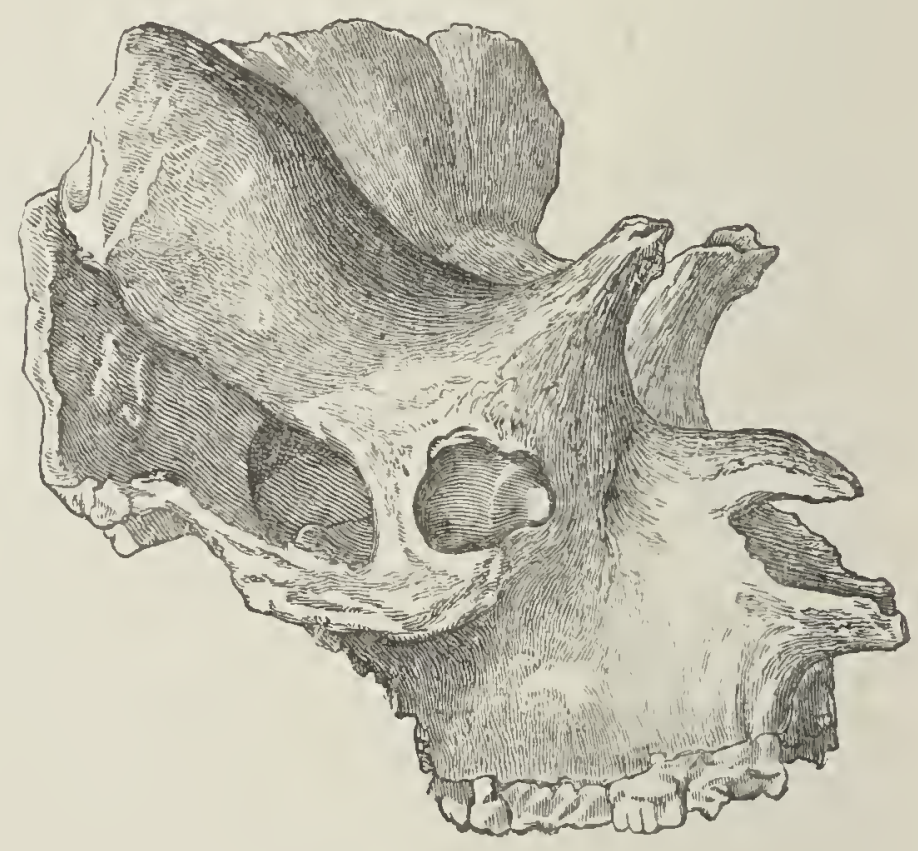

Skull of Sizatherium.

ing down and eating trees. The toxodon surprises us not less, being a proportionally huge member of the rodent order, - that order which now includes most of the smallest quadrupeds. ${ }^{1}$

One remarkable circumstance connected with the tertiary formation remains to be noticed,-the prevalence of volcanic action at that era. In Auvergne, in Catalonia, near Venice, and in the vicinity of Rome and Naples, lavas exactly resembling the produce of existing volcanoes are associated and intermixed with the lacustrine as

1 The tertiary mammalia are chiefly described from the beautiful work of Professor Owen, $A$ History of British Fossil Mammalia and Birds, 1845. 
well as marine tertiaries. The superficies of tertiaries in England is disturbed by two great swells, forming what are called anticlinal axes, one of which divides the London from the Hampshire basin, while the other. passes through the Isle of Wight, both throwing the strata down at a violent inclination towards the north, as if the subterranean disturbing force had waved forward in that direction. The Pyrenees, too, and Alps, have both undergone elevation since the deposition of the

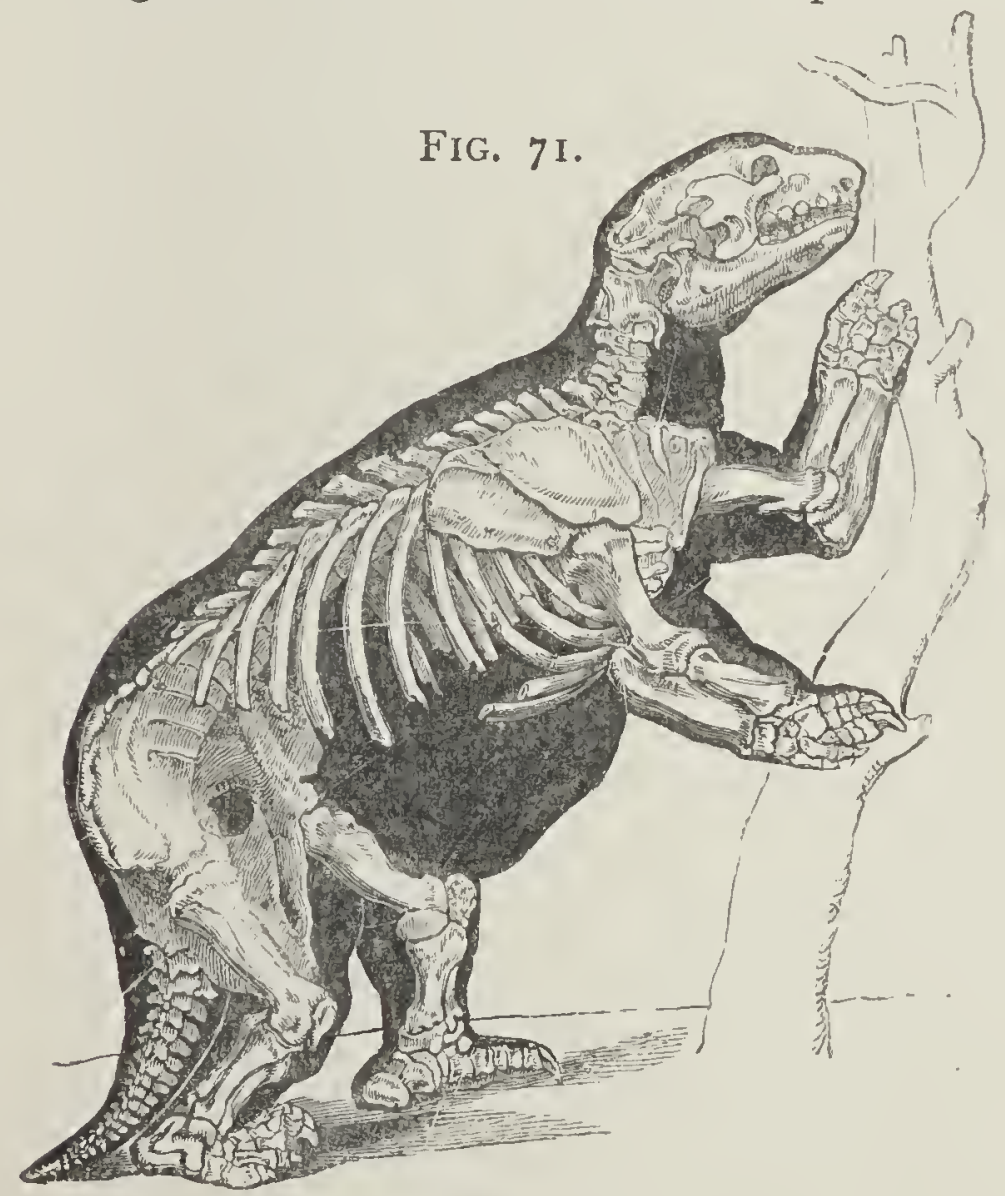

Skeleton of Mylodon.

tertiaries; and in Sicily there are mountains which have risen three thousand feet since the deposition of some of the most recent of these rocks. The general effect 
of these operations was of course to extend the land surface, and to increase the variety of its features, thus improving the capability of natural drainage, and generally adapting the earth for the reception of higher classes of animals.

ERA OF THE SUPERFICIAL FORMATIONS.-EXISTING SPECIFIC FORMS ABUNDANT.

WE have now completed our survey of the series of stratified rocks, and traced in their fossils the progress of organic creation down to a time which seems not long antecedent to the appearance of man. There are, nevertheless, memorials of still another era or space of time which it is all but certain did also precede that event.

The first that calls for notice is the phenomenon to which geologists have applied the term denudation. Great hitches and slips are detected in superficial strata,-such as, if left in their original state, must have caused considerable inequalities on the face of the country; yet all is found as smooth-the joinings are all as much reduced to a common level-as if some gigantic artificial force had been used for the purpose. Again, a great valley has been scooped out in the midst of sedimentary strata, leaving the edges of these facing each other from the opposite sides, with perhaps here and there an isolated mass starting up to the height of the two sides, being composed of matter which has resisted the agency by which the adjoining matter was removed. Here, it is thought, we see incontestable traces of the operation of moving water. The second fact we are called to notice is, that over the 
rock formations of all eras, in various parts of the globe, but confined, in general, to situations not very elevated, there is a layer of stiff clay, often of a blue colour, mingled with fragments of rock of all sizes, travel-worn, and otherwise, and to which geologists give, or till lately gave, the name of Diluvium, as being apparently the produce of some vast flood, or of the sea thrown into an unusual agitation. It seems to indicate that, at the time when it was laid down, much of the present dry land was under the ocean-a supposition which we shall see supported by other evidence. The included masses of rock have been carefully inspected in many places, and traced to particular parent beds at considerable distances. Connected with these phenomena are certain rock surfaces on the slopes of hills and elsewhere, which exhibit groovings and scratchings, such as we might suppose would be produced by a quantity of loose blocks hurried along over them by a flood, possibly one in which there were large rafts of ice. Another associated phenomenon is that called crag and tail, which exists in many places,namely, a rocky mountain, or lesser elevation, presenting on one side the naked rock, in a more or less abrupt form, and on the other a gentle slope. Finally, we may advert to certain long ridges of clay and gravel which arrest the attention of travellers on the surface of Sweden and Finland, and which are also found in North America, where, indeed, the whole of these phenomena have been observed over a large surface, as well as in Europe. It is very remarkable that the direction from which the diluvial blocks have generally come, the lines of the grooved rock surfaces, the direction of the crag and tail eminences, and 
that of the clay and gravel ridges-phenomena, it is to be observed, extending over the northern parts of both Europe and America-are mostly from the north and north-west towards the south and south-east. We thus acquire the idea of a powerful current, a commixture of water and ice, moving in a direction from north-west to south-east, carrying, besides mud, masses of rock which furrowed the solid surfaces as they passed along, abrading the north-west faces of many hills, but leaving the slopes in the opposite direction uninjured, and in some instances forming long ridges of detritus along the surface. These are curious considerations; and it has become a question of much interest, by what means, and under what circumstances, such a current was produced. But in the present state of our knowledge, all that can be legitimately inferred from the Diluvium, or, as it is now more generally called, Drift, is, that many portions of the northern nations of Europe and America were then under the sea, and that a strong current, producing certain mechanical results, set over them.

Connected with the Drift is the history of Ossiferous Caverns, of which specimens singly exist at Kirkdale in Yorkshire, Gailenruth in Franconia, and other places. They occur in the calcareous strata, as the great caverns generally do, but have in all instances been naturally closed up to the recent period of their discovery. The floors are covered with what appears to be a bed of the diluvial clay, over which rests a crust of stalagmite, the result of the droppings from the roof since the time when the clay bed was laid down. In the instances above specified, and several others, there have been found, under 
the clay bed, assemblages of the bones of animals, of many various kinds. At Kirkdale, for example, the remains of twenty-four species were ascertained-namely, pigeon, lark, raven, duck, and partridge; mouse, waterrat, rabbit, hare, hippopotamus, rhinoceros, elephant, weasel, fox, wolf, deer (three species), ox, horse, bear, tiger, hyena. From many of the bones of the gentler of these animals being found in a broken state, it is supposed that the cave was a haunt of hyenas and other predacious creatures, by which the smaller ones were here consumed. This must have been at a time antecedent to the floodings which produced the drift clay, since the bones are covered by a bed of that formation. It is impossible not to see here a very natural series of incidents. First, the cave is frequented by wild beasts, who make it a kind of charnel-house. Then, submerged in the current which has been spoken of, it receives a clay flooring from the waters containing that matter in suspension. Finally, raised from the water, but with no mouth to the open air, it remains unintruded on for a long series of ages, during which the clay flooring receives a new calcareous covering from the droppings of the roof.

Our attention is next drawn to the erratic blocks or boulders, which in many parts of the earth are thickly strewn over the surface, particularly in the north of Europe. Some of these blocks are many tons in weight, yet are clearly ascertained to have belonged originally to situations at a great distance. Fragments, for example, of the granite of Shap Fell are found in every direction around to the distance of fifty miles, one piece being placed high upon Criffel Mountain, on the opposite side 
of the Solway estuary; so also are fragments of the Alps found far up the slopes of the Jura. There are even blocks on the east coast of England, supposed to have travelled from Norway. The only rational conjecture which can be formed as to the transport of such masses from so great a distance, is one which presumes them to have been carried and dropped by icebergs, while seas existed upon the space between their original and final sites. Icebergs do even now carry off such masses from the polar coasts, which, falling when the retaining ice melts, must take up situations at the bottom of the sea, similar to those in which we find the erratic blocks of the present dry land.

While the diluvium and erratic blocks clearly suppose a part at least of the present land to have at a comparatively recent time been sunk to a considerable depth in the sea, there is another set of appearances which as manifestly show the steps by which the land was made afterwards to re-emerge from that element. These consist of terraces, which have been detected near, and at some distance inland from, the coast lines of Scandinavia, Britain, America, and other regions; being evidently ancient beaches, or platforms, on which the margin of the sea at one time rested. They have been observed at different heights above the present sea-level, from twenty to twelve hundred feet; and in many places they are seen rising above each other in succession, to the number of three, four, and even more. The smooth flatness of these terraces, with generally a slight inclination towards the sea, the sandy composition of many of them, and, in some instances, the preservation of marine shells in 
the ground, identify them perfectly with existing seabeaches, notwithstanding the cuts and scoopings which have at frequent intervals been effected in them by watercourses. The irresistible inference from the phenomena is, that the highest was first the coast line; then an elevation took place, and the second highest became so, the first being now raised into the air and thrown inland. Then, upon another elevation, the sea began to form, at its new point of contact with the land, the third highest beach, and so on down to the platform nearest to the present sea-beach. Phenomena of this kind become comparatively familiar to us, when we hear of evidence that the last sixty feet of the elevation of Sweden, and the last eighty-five of that of Chili, have taken place since man first dwelt in those countries; nay, that the elevation of the former country goes on at this time at the rate of about forty-five inches in a century, and that a thousand miles of the Chilian coast rose four feet in one night under the influence of a powerful earthquake, so lately as 1822 . Subterranean forces, of the kind then exemplified in Chili, supply a ready explanation of the whole phenomena, though some other operating causes have been suggested.

The idea of such a deep immersion of the land unavoidably suggests some considerations as to the effect which it might have upon terrestrial animal life. Some, regarding it as a complete submersion, argue that terrestrial life would be, on such an occasion, extensively, if not universally, destroyed. Nor was the idea of its universal destruction the less plausible, when it was believed that the present land animals are an entirely new set of 
species, introduced since the conclusion of the Tertiary Formation. It must now be owned that there are insurmountable objections to such an hypothesis. First, it is not true that the specific forms of the tertiary epoch have all of them disappeared. There are several-for example, a badger of the Miocene-which are not in the slightest degree distinguished from living species. Many reptiles, now living in India, have been proved to be coëval with the Himalayan Anoplothere, Mastodon, and Hippopotamus. Second, the specific distinctions alleged in a great number of cases between tertiary and existing animals are extremely slight, and such as we have no fixed principle by which to be assured that they mark new species, in the sense of a new creation. Finally, the tertiary animals of America indicate an approximation to the character of existing animals in that region, and tertiary animals of the other great continent equally approximate to those at present occupying it; showing that the demarcations of the present great zoological provinces had been already marked out, and have never been obliterated. There is therefore enough to justify us in believing that no entire submergence of the earth took place at the time of the Diluvium, though how nearly it might approach completeness we cannot say.

There are some other superficial formations, of less consequence on the present occasion than the diluviumnamely, lacustrine deposits, or filled-up lakes; alluvium, or the deposits of rivers beside their margins; deltas, the deposits made by great rivers at their efflux into the sea; peat mosses; and the vegetable soil. The animal remains found in these generally testify to a zoology on the verge 
of that now prevailing, or melting into it, there being included many species which still exist. In a lacustrine deposit at Market-Weighton, in the Vale of York, there have been found bones of the elephant, rhinoceros, bison, wolf, horse, felis, deer, birds, all or nearly all presenting peculiarities different from existing species, associated with thirteen species of land and fresh-water shells, " exactly identical with types now living in the vicinity." In similar deposits in North America, are remains of the mammoth, mastodon, buffalo, and other animals of extinct and living types. In short, these superficial deposits show precisely such remains as might be expected from a time at which the present forms of the animal world had been generally assumed, but yet so far remote in chronology as to allow of the dropping of many species, through familiar causes-perhaps we should only say the obliteration of many peculiarities called specific-in the interval. Still, however, several of the most important living species have left no record of themselves in any formation beyond what are, comparatively speaking, modern. Such are the sheep and goat, and such, above all, is our own species. We thus learn that, compared with many humbler animals, man is a being, as it were, of yesterday. 


\section{GENERAL CONSIDERATIONS}

\section{THE ORIGIN OF THE ANIMATED TRIBES.}

THus concludes the wondrous section of the earth's history which is told by geology. It takes up our globe at an early stage in the formation of its crust; conducts it through what we have every reason to believe were vast spaces of time, in the course of which many superficial changes took place, and vegetable and animal life was gradually evolved; and drops it just at the point when man was apparently about to enter on the scene. The compilation of such a history, from materials of so extraordinary a character, and the powerful nature of the evidence which these materials afford, are calculated to excite our admiration, and the result must be allowed to exalt the dignity of science, as a product of man's industry and his reason.

It is now to be remarked, that there is nothing in the whole series of operations displayed in inorganic geology, which may not be accounted for by the agency of the ordinary forces of nature. Those movements of subterranean force which thrust up mountain ranges and 
upheaved continents, stand in inextricable connexion, on the one hand, with the volcanoes which are yet belching forth lavas and shaking large tracts of ground, as, on the other, with the primitive incandescent state of the earth. Those forces which disintegrated the early rocks, and of the detritus formed new beds at the bottom of seas, are still seen at work to the same effect in every part of the globe. To bring these truths the more clearly before us, it is possible to make a substance resembling basalt in a furnace; limestone and sandstone have both been formed from suitable materials in appropriate receptacles; the phenomena of cleavage have, with the aid of electricity, been simulated on a small scale, and by the same agent crystals are formed. In short, the remark which was made regarding the indifference of the cosmical laws to the scale on which they operated, is to be repeated regarding the geological. A common furnace will sometimes exemplify the operation of forces which have been concerned in the production of a Giant's Causeway; and in a sloping ploughed field after rain, we may often observe, at the lower end of a furrow, a handful of washed and neatly deposited mud or sand, capable of serving as an illustration of the way in which Nature has produced the deltas of the Nile and Ganges. In the ripple-mark on sandy beaches of the present day, we see Nature's exact repetition of the operations by which she impressed similar features on the sandstones of the carbonigenous era. Even such marks as wind-slanted rain would in our day produce on tide-deserted sands, have been read upon tablets of the ancient strata. It is the same Nature-that is to say, God through or in the manner 
of nature-working everywhere and in all time, causing the wind to blow, and the rain to fall, and the tide to ebb and flow, inconceivable ages before the birth of our race, as now. So also we learn from the conifers of those old ages, that there were winter and summer upon earth, before any of us lived to liken the one to all that is genial in our own nature, or to say that the other breathed no airs so unkind as man's ingratitude. Let no one suppose there is any necessary disrespect for the Creator in thus tracing his laws in their minute and familiar operations. There is in reality no true great and small, grand and familiar, in nature. Such only appear, when we thrust ourselves in as a point from which to start in judging. Let us pass, if possible, beyond immediate impressions, and see all in relation to Cause, and we shall chastenedly admit that the whole is alike worshipful.

The Creator, then, is seen to have formed our earth, and effected upon it a long and complicated series of changes, in the same manner in which we find that he conducts the affairs of nature before our living eyes: that is, in the manner of natural law. This is no rash or unauthorized affirmation. It is what we deduce from the calculations of a Newton and a Laplace, on the one hand; and from the industrious observation of facts by a Murchison and a Lyell, on the other. It is a point of stupendous importance in human knowledge; here at once is the whole region of the inorganic taken out of the dominion of marvel, and placed under an idea of divine regulation which we may endlessly admire and trust in.

Mixed up, however, with the geognostic changes, and 
apparently as a final object connected with the formation of the globe itself, there is another set of phenomena presented in the course of our history-the coming into existence, namely, of a long suite of living things, vegetable and animal, terminating in the families which we still see occupying the surface. The question arisesIn what manner has this set of phenomena originated? Can we touch at and rest for a moment on the possibility of plants and animals having likewise been produced in a natural way; thus assigning immediate causes of but one character for everything revealed to our sensual observation; or are we at once to reject this idea, and remain content, either to suppose that creative power here acted in a different way, or to believe unexaminingly, that the inquiry is one beyond our powers?

Taking the last question first, I would reply, that I am extremely loath to imagine that there is anything in nature which we should, for any reason, refrain from examining. If we can infer aught from the past history of science, it is, that the whole of nature is a legitimate field for the exercise of our intellectual faculties; that there is a connexion between this knowledge and our well-being; and that, if we may judge from things once despaired of by our inquiring reason, but now made clear and simple, there is none of Nature's mysteries which we may not hopefully attempt to penetrate. To remain idly content to presume a various class of immediate causes for organic nature, scems to me, on this ground, equally objectionable.

With respect to the other question. The idea has several times arisen, that some natural course was 


\section{GENERAL CONSIDERATIONS RESPECTING}

observed in the production of organic things, and this even before we were permitted to attain clear conclusions regarding inorganic nature. It was always set quickly aside, as unworthy of serious consideration. The case is different now, when we have admitted law in the whole domain of the inorganic. There are even some considerations on the very threshold of the question, which appear to throw the balance of likelihood strongly on the side of natural causes, however difficult it may be to say what these causes were. The production of the organic world is, we see, mixed up with the production of the physical. It is mixed in the sense of actual connexion and dependence, and it is mixed in regard to time, for the one class of phenomena commenced, whenever the other had arrived at a point which favoured or admitted of it; life, as it were, pressed in as soon as there were suitable conditions, and, once it had commenced, the two classes of phenomena went on, hand in hand, together. It is surely very unlikely, a priori, that in two classes of phenomena, to all appearance perfectly co-ordinate, and for certain intimately connected, there should have been two totally distinct modes of the exercise of the divine power. Were such the case, it would form a most extraordinary, and what to philosophic consideration ought to be a most startling exception, from that which we otherwise observe of the character of the divine procedure in the universe. Further, let us consider the comparative character of the two classes of phenomena, for comparison may of course be legitimate until the natural system is admitted. The absurdities into which we should thus be led must 
strike every reflecting mind. The Eternal Sovereign arranges a solar or an astral system, by dispositions imparted primordially to matter; he causes, by the same majestic means, vast oceans to form and continents to rise, and all the grand meteoric agencies to proceea in ceaseless alternation, so as to fit the earth for a residence of organic beings. But when, in the course of these operations, fuci and corals are to be for the first time placed in those oceans, a change in his plan of administration is required. It is not easy to say what is presumed to be the mode of his operations. The ignorant believe the very hand of Deity to be at work. Amongst the learned, we hear of "creative fiats," "interferences," "interpositions of the creative energy," all of them very obscure phrases, apparently not susceptible of a scientific explanation, but all tending simply to this,that the work was done in a marvellous way, and not in the way of nature. Let the contrast between the two propositions be well marked. According to the first, all is done by the continuous energy of the divine will,-a power which has no regard to great or small: according to the second, there is a procedure strictly resembling that of a human being in the management of his affairs. And not only on this one occasion, but all along the stretch of geological time, this special attention is needed whenever a new family of organisms is to be introduced: a new fiat for fishes, another for reptiles, a third for birds; nay, taking up the present views of geologists as to species, such an event as the commencement of a certain cephalopod, one with a few new nodulosities and corrugations upon its shell, would, on this theory, require 
the particular care of that same Almighty who willed at once the whole means by which INFINITY was replenished with its worlds!

The question is here treated as one to be settled by philosophy. There are, however, objections of a different character to the idea of natural procedure in organic creation. Most minds are prepossessed by a more or less distinct conclusion in favour of organic creation by some kind of special exercise of divine power. This is the idea which first arose in the human family, being that which the unassisted mind is apt to form out of the appearances presented to it; precisely as, with respect to the motions of the heavenly bodies, the geocentric theory was that which the appearances first suggested, and therefore was first embraced by man. It took some time to introduce the heliocentric theory, even after it had been established by proof. So is there a force of prejudice to be overcome in this case, before any new hypothesis on the subject can expect to be fairly judged. It has even been said that to presume a creation of living beings as a series of natural events, is equivalent to superseding the whole doctrine of the divine authorship of organic nature. With such a notion infesting the mind, it must of course be almost hopeless that the question should be candidly entertained. There can, in reality, be no reason adduced for holding this necessarily following from the idea of organic creation in the manner of law, or by a natural method, any more than from a similar view of inorganic creation. The whole aim of science from the beginning has been to ascertain law; one set of phenomena after another has been 
brought under this conception, without our ever feeling that God was less the adorable creator of his own world. It seems strange that a stand should appear necessary at this particular point in the march of science. Perhaps if our ordinary ideas respecting natural law were more just, the difficulty might be lessened. It cannot be sufficiently impressed that the whole idea relates only to the mode in which the Deity has been pleased to manifest his power in the external world. It leaves the absolute fact of his authorship of and supremacy over nature, precisely where it was; only telling us that, instead of dealing with the natural world as a human being traffics with his own affairs, adjusting each circumstance to a relation with other circumstances as they emerge, in the mode befitting his finite capacity, the Creator has originally conceived, and since sustained, arrangements fitted to serve in a general sufficiency for all contingencies; himself, of course, necessarily living in all such arrangements, as the only means by which they could be, even for a moment, upheld. Were the question to be settled upon a consideration of the respective moral merits of the two theories, I would say that the latter is greatly the preferable, as it implies a far grander view of the divine power and dignity than the other. For one thing, it places the leading divine attribute of foresight in a much more sublime position. "If," says Dr. Buckland, contemplating the establishment of this doctrine- " if the properties adopted by the elements at the moment of their creation adapted them beforehand to the infinity of complicated useful purposes which they have already answered, and may have still further to answer, under 
many dispensations of the material world, such an aboriginal constitution, so far from superseding an intelligent agent, would only exalt our conceptions of the consummate skill and pozerer that could comprekend such an infinity of future uses under future systems, in the original groundwork of his creation."

It is now to be remarked that what has been ascertained of the actual history of organic beings upon earth, is in no respect out of harmony with this idea of their creation after the manner of law. We have scen that these did not come at once, as they might have been expected to do if produced by some special act, or even some special interposition of will, on the part of the Deity. They came in a long-extending succession, in an order, as would appear, of progressive organization; grade following grade, till, from a humble starting-point in both kingdoms, the highest forms were realized. Time, we sce, was an element in the evolution of Being, as it is in the reproduction of an individual at the present day. At the beginning of geological investigation, it was thought that some immediate external conditions ruled the appearance of particular classes of animals at particular times: as that the absence of dry land was the cause of the late commencement of terrestrial animals; that there being for a long time only reptilian land vertebrata, was owing to an overcharge of the atmosphere with carbonic acid-the store from which came the chief material of the abundant vegetation of the carbonigenous age; and so forth. But it is now seen that the progress of the animal world was, in its main features, independent of

2 See Proofs and Illustrations, No. 3. 
such circumstances. There was dry land for many ages before there were any land animals. The sea abounded in invertebrate animals, while as yet fish did not exist, though the conditions required for the existence of both are the same. The oolitic continents, where only reptiles roamed, could have equally supported mammalia, for which the atmosphere was then fully fitted, even upon the admission of the carbonic acid hypothesis, as the coal was by that time formed; yet mammalia came not. ${ }^{1}$ It was supposed at the dawn of true geology, that fresh creations of animals were connected with great physical revolutions of the surface; as if, at particular times, all had perished in storms of volcanic violence, and been replaced with a wholly new fauna. This idea is likewise passing away. It is now seen that changes in specific forms took place quietly in the course of time, while no volcanic disturbances are traceable. ${ }^{2}$ In short, it is always becoming more and more manifest that organic progress-both the specific changes in classes formerly existing, and the accession of new and higher classesdepended, not by any means wholly or immediately upon external circumstances, but in great part upon time. All this looks very unlike either special working or special willing on the part of the Creator, but, on the contrary, very like the simply natural procedure of things in the world of our own day.

There are some facts in the history of fossils, which it is difficult to reconcile with the idea of special creative effort, but which perfectly harmonize with that of 
a creation in a natural manner. It is admitted, for instance, that "the differences which exist between extinct faunas and the animals now living are so much greater in proportion as these faunas are most ancient." Passing downward in the formations and backward in time, we first find species identical with the present; next, only genera; afterwards, only families or orders. These are the words of naturalists; but the truth simply is, that in early formations, animals resembled the present in broad general characters; afterwards they resembled them in characters more particular; finally, they become identical. Always as we advance, the total mass of the animal creation puts on more and more of the appearances which it now bears. It may be asked if this does not seem to imply that the present system of things is essentially connected with the past; in which case, if the present is a natural system, we have an additional proof that the past was a natural system also. So also it is admitted that, however nearly the specific forms may experience an entire change from one formation to another, there are always resemblances and approximations between each two which are adjacent to each other. "If," says M. Pictet, an opponent of the views here advocated, "we compare two successive creations of one and the same epoch, such as the faunas of the five divisions of the cretaceous formation, we cannot fail to be struck with the intimate connexion they have zeith each other. The greater part of the genera are the same: a great part of the species are very closely allied and easily confounded. [Referring to two of these sub-formations, ] is it probable that the albian fauna had been completely annihilated, and then, by a new and 
independent creation, replaced by a fauna altogether new, and so similar to it? I am aware that these facts may be referred to the general plan of creation [that is, a supposed plan, according to which the divine power had operated in its special successive creative operations]; but is the mind entirely satisfied with this explanation?" We may echo the last question. Can we be content to assume-for, after all, it is assumption-that a series of miraculous creations was invariably to be in the manner of a piecing on and blending from one to another, when we have the alternative of presuming (grant it were to be left to presumption alone) that these connexions are only memorials of a natural law presiding over the development of the whole organic creation, and making it one and not many things? We can only wonder that a man learned in the subject can see such a difficulty as he has here stated, and find it more easily passed over than the bare fact that certain mammalia have not changed for three thousand years,-for such is the only difficulty he states on the other side.

It must further be recollected, that we are not only to account for the origination of organic being upon this little planet, third of a series which is but one of hundreds of thousands of series, the whole of which again form but one portion of an apparently infinite globe-peopled space, where all seems analogous. We have to suppose, that every one of these numberless globes is either a theatre of organic being, or in the way of becoming so. This is a conclusion which every addition to our knowledge makes only the more irresistible. Is it conceivable, as a fitting mode of exercise for creative intelligence, that it 
should be constantly paying a special attention to the creation of species, as they may be required in each situation throughout those worlds, at particular times? Is such an idea accordant with our general conception of the dignity, not to speak of the power, of the Great Author? Yet such is the notion which we must form, if we adhere to the doctrine of special exercise. Let us see, on the other hand, how the doctrine of a creation in the manner of law agrees with this expanded view of the organic world.

Unprepared as most men may be for such an announcement, there can be no doubt that we are able, in this limited sphere, to form some satisfactory conclusions as to the plants and animals of those other spheres which move at such immense distances from us. Suppose that the first persons of an early nation who made a ship and ventured to sea in it, observed, as they sailed along, a set of objects which they had never before seen-namely, a fleet of other ships-would they not have been justified in supposing that those ships were occupied, like their own, by human beings, possessing hands to row and steer, eyes to watch the signs of the weather, intelligence to guide them from one place to another-in short, beings in all respects like themselves, or only showing such differences as they knew to be producible by difference of climate and habits of life? Precisely in this manner we can speculate on the inhabitants of remote spheres. We see that matter has originally been diffused in one mass, of which the spheres are portions. Consequently, inorganic matter must be presumed to be everywhere the same, although possibly with 
differences in the proportions of ingredients in different globes, and also some difference of conditions. Out of a certain number of the elements of inorganic matter are composed organic bodies, both vegetable and animal: such must be the rule in Jupiter and in Sirius, as it is here. We, therefore, are all but certain that herbaceous and ligneous fibre, that flesh and blood, are the constituents of the organic beings of all those spheres which are as yet seats of life. Gravitation we see to be an all-pervading principle: therefore there must be a relation between the spheres and their respective organic occupants, by virtue of which they are fixed, as far as necessary on the surface. Such a relation, of course, involves details as to the density and elasticity of structure, as well as size of the organic tenants, in proportion to the gravity of the respective planetspeculiarities, however, which may quite well consist with the idea of a universality of certain types, such as we see exemplified upon earth. We come to comparative matter of detail, when we advert to heat and light; yet it is important to consider that these are universal agents, and that, as they bear marked relations to organic life and structure on earth, they may be presumed to do so in other spheres also. The considerations as to light are particularly interesting, for, on our globe, the structure of one important organ, almost universally distributed in the animal kingdom, is in direct and precise relation to it. Where there is light there will be eyes, and these, in other spheres, will be the same in all respects as the eyes of tellurian animals, with only such differences as may be necessary to accord with minor 
peculiarities of condition and of situation. ${ }^{1}$ It is but a small stretch of the argument to suppose that, one conspicuous organ of a large portion of our animal kingdom being thus universal, a parity in all the other organsspecies for species, class for class, kingdom for kingdom-is highly likely, and that thus the inhabitants of all the other globes of space bear not only a general, but a particular resemblance to those of our own.

It must be obvious, that, if organic beings are thus universally distributed, the idea of their having all come into existence through the power of God acting by the laws everywhere applicable, is strictly conformable to the principle suggested for our own limited sphere. As by one set of laws he produced all orbs, their motions and geognostic arrangements, so by another set of laws he may be supposed to have overspread them all with life. The whole productive or creative arrangements would thus appear in unity.

${ }^{1}$ The fishes that inhabit our own deep seas are circumstanced, as regards light, very much like the inhabitants of Uranus or Neptune.-Correspondent. 


\title{
PARTICULAR CONSIDERATIONS
}

\author{
RESPECTING
}

\section{THE ORIGIN OF THE ANIMATED TRIBES.}

Probability being shown as in favour of a natural mode of origin for living beings, it becomes necessary to inquire how far the notion is countenanced by the constitution of organic bodies, and if any trace is observable in organic nature of such a means and method on the part of its Creator.

To the generality of men of science, it either appears that the origin of the animated creation is an impenetrable mystery, or that, by reason of the invariable production of like by like in our age, we only can suppose for it an origin exceptive in its character from the ordinary procedure of the deity in nature. Nevertheless, there are many facts which very much favour the idea that a rise of life out of inorganic elements is within the scope of the natural operations of deity, albeit we cannot pretend to know much of the absolute character of life itself.

First, with regard to the constituents of organic bodies, it is found that they are merely a selection of the elemen- 
tary substances which form the inorganic or non-vitalized world. Carbon, oxygen, hydrogen, and nitrogen, are the chief. The first combinations of these in animals are into what are called proximate principles, as albumen, fibrin, \&c., out of which the animal body is composed. So far from there being anything peculiar or mysterious in these combinations, it is acknowledged that they are simply chemical. "It is now certain," says Dr. Daubeny, of Oxford, "that the same simple laws of composition pervade the whole creation; and that if the organic chemist only takes the requisite precautions to avoid resolving into their ultimate elements the proximate principles upon which he operates, the result of his analysis will show that they are combined precisely according to the same plan as the elements of mineral bodies are known to be." 1 A particular fact is here worthy of attention: "The conversion of fecula into sugar, as one of the ordinary processes of vegetable economy, is effected by the production of a secretion termed diastase, which occasions both the rupture of the starch vesicles, and the change of their contained gum into sugar. This diastase may be separately obtained by the chemist, and it acts as effectually in his laboratory as in the vegetable organization. He can also imitate its effects by other chemical agents." 2 The same writer elsewhere adds, "No reasonable ground has yet been adduced for supposing that, if he had the power of bringing together the elements of any organic compound, in their requisite states and proportions, the result would be any other

1. Supplement to the Atomic Theory.

${ }^{2}$ Carpenter on Life, Todd's Cyclopedia. 
than that which is found in the living body. Every fresh discovery," he says, "is tending to break down the barrier between the two classes of organic and inorganic bodies, as far as regards their chemical combination."1

It is much to know the elements of organic bodies, and tliat the first combinations of these are simply chemical. The powers by which these combinations take place are next to be inquired into. The predominant idea hitherto has been, that the vital affinities are of a totally distinct nature, depending upon a mystic something, to which the term vital principle was applied. But this idea is now on the decline. Admitting the vital affinities, as powers superseding and counteracting ordinary chemical affinities, it is seen that the idea of a distinct inscrutable principle on which they depend, is "both unsupported by evidence and useless in the explanation of facts." It is becoming evident that living structures result from the action of a multitude of natural forces in combination"gravity, cohesion, elasticity, the agency of the imponderables, and all other powers which operate both on masses and atoms." Professor Draper, of New York, in making this statement, says- "It is astonishing that in our days the ancient system which excludes all connexion with natural philosophy and chemistry, and depends on the fictitious aid of a visionary force, should continue to exist ; a system which at the outset ought to have broken down by the most common considerations, such as those connected with the mechanical principles involved in the

1 From the Prize Essay of Dr. Carpenter, ( 1838 ,) under the award of the professors of the Edinburgh University.

2 Alison's Principles of Physiology, quoted in the above Prize Essay.

$\mathrm{L}$ 
bony skeleton, the optical principles in the construction of the eye, or the hydraulic action of the valves of the heart." 1

So much for the combinations concerned in living bodies; but how shall we hope to see their forms brought under any relation to physical laws? On this point we have some illustrations in the phenomena attending the production of crystals, a class of bodies which has been said to stand between the inorganic and the organic. From the agency which has been employed by Mr. Crosse in making crystals formerly supposed to be of Nature's production alone, it is now incontestable that crystallization is dependent in some degree on electric agency, the special forms being the result of the peculiar nature of the constituent substance and the conditions under which the imponderable is applied. Here are obviously natural means concerned in producing forms almost as various as those of living beings, and equally determinate and regular. A certain community of cause in the two instances is indicated by the surprising resemblance which some examples of crystallization bear to vegetable forms. In some, the mimicry is beautiful and complete; for example, in the well-known one called the Arbor Diance. An amalgam of four parts of silver and two of mercury being dissolved in nitric acid, and water equal to thirty weights of the metals being added, a small piece of soft amalgam of silver, suspended in the solution, quickly gathers to itself the particles of the silver of the amalgam, which form upon it a crystallization precisely resembling a

Treatise on the Forces which produce the organization of Plants. New York, I844. 
shrub. Vegetable figures are also presented in some of the most ordinary appearances of the electric fluid. In the marks caused by positive electricity, or which it leaves in its passage, we see the ramifications of a

FIG. 72.

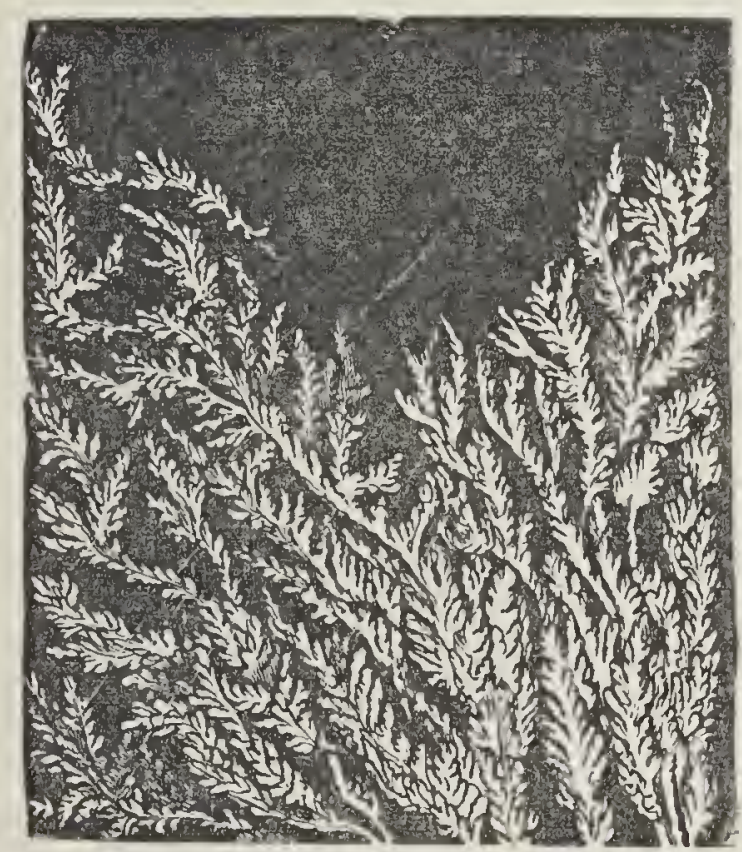

Crystallized Silver.

tree, as well as of its individual leaves; those of the negative, recal the bulbous or the spreading root, according as they are clumped or divergent. These phenomena seem to indicate that the electric energies have had something to do in determining the forms of plants. With regard to the resemblance of the ramifications of the branches and leaves of plants to the traces of the positive electricity, and that of the roots to the negative, it is a circumstance calling for especial remark, that the atmosphere, particularly its lower strata, is generally charged positively, while the earth is always charged 
negatively. The correspondence here is curious. A plant thus appears as a thing formed on the basis of a natural electrical operation - the brush realized. We can thus suppose the various forms of plants as determined under the operation of a law in electricity, variously affecting them according to their organic character, or respective germinal constituents. In the poplar, the brush is unusually vertical, and little divergent; the reverse in the beech: in the palm, a pencil has proceeded straight up for a certain distance, radiates there, and turns outwards and downwards; and so on. We can here see at least traces of secondary means by which the Almighty Deviser might establish all the vegetable forms with which the earth is overspread. ${ }^{1}$

We turn to the minutiæ of organic structure and embryology, as affording us some further illustrations of an instructive kind. It is now ascertained by microscopic research, that the basis of all vegetable and animal substances consists of nucleated cells; that is, cells having granules within them. Nutriment is converted into these

1 "6

the form of the route of free electricity is modified by the medium through which it passes, and also by the electrical state of such medium, or of that of the relative electrical conditions of two bodies between which it is transmitted. If the medium through which it passes possesses a very inferior conducting power, it is obvious that a certain momentum must be requisite to enable the fluid to force its passage to a given distance, and there will be a point at which the momentum of the fluid and the resistance of the body will exactly counterbalance each other; but so soon as the electricity has again accumulated to a sufficient degree to overcome the resistance, it will again force its way in another direction, until it arrives at another point of equilibrium. In this zuay zue may readily see the modus operandi of the electric fluid in imparting regular forms to bodies; and it is highly probable that its action in this respect extends to the vegetable kingdom, and perhaps operates even on animals, from the time in which they exist in the embryo state. . . . . Another fact, in support of the opinion that the distinctive forms of bodies are produced by electrical action, is, that crystals, and the twigs and leaves of vegetables, all terminate in points or sharp edges, so that the electrical action can proceed no further in increasing the growth, or, in other words, in propelling fresh portions of matter for the extension of the plant, or the crystal, beyond the pointed or edged terinination."-Leithead on Electricity, 1837 . 
before being assimilated by the system. The tissues are formed from them. The ovum destined to become a new creature, is originally only a cell with a contained granule. We see it acting this reproductive part in the simplest manner in the cryptogamic plants. "The parent cell, arrived at maturity by the exercise of its organic functions, bursts, and liberates its contained granules. These, at once thrown upon their own resources, and entirely dependent for their nutrition on the surrounding elements, develop themselves into new cells, which repeat the life of their original. Amongst the higher tribes of the cryptogamia, the reproductive cell does not burst, but the first cells of the new structure are developed within it, and these gradually extend, by a similar process of multiplication, into that primary leaf-like expansion which is the first-formed structure in all plants." the little cell becomes directly a plant, the full formed living being. It is also worthy of remark that, in the sponges, (an animal form,) a gemmule detached from the body of the parent, and trusting for sustentation only to the fluid into which it has been cast, becomes, without further process, the new creature. Further, it has been recently discovered by means of the microscope, that there is, as far as can be judged, a perfect resemblance between the ovum of the mammal tribes, during that early stage when it is passing through the oviduct, and the young of the infusory animalcules. One of the most remarkable of these, the volvox globator, can hardly be distinguished from the germ which, after passing through a long foetal

' Carpenter's Report on the Results obtained by the Microscone in the Study of Anatomy and Physiology, 1942 . 
progress, becomes a complete mammifer, an animal of the highest class. It has even been found that both are alike provided with those cilia, whose action, producing an appearance of revolving motion, is partly the cause of the

\section{FIG. 73 .}
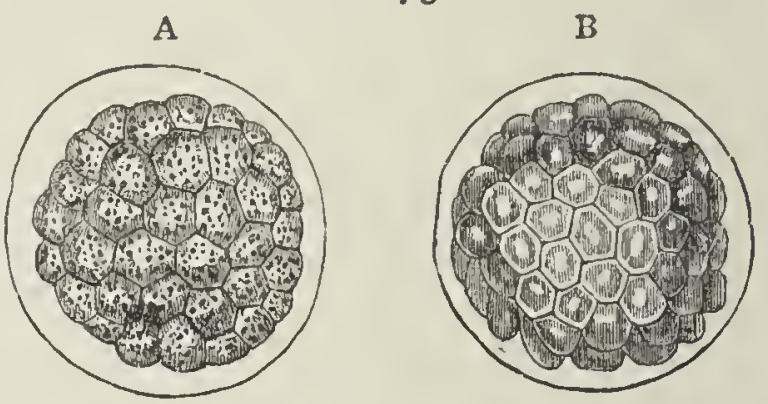

A. Early stage of Mammalian Ovum;-B, Young of Volvox Globator.

name given to this animalcule. These resemblances are the more entitled to notice, that they were made by various observers, distant from each other at the time. ${ }^{1}$ It has likewise been noticed that the globules of the blood are reproduced by the expansion of contained granules; they are, in short, distinct organisms multiplied by the same fissiparous generation. So that all animated nature may be said to be based on this mode of origin; the fundamental form of organic being is a cell, having new cells forming within itself, by which it is in time discharged, and which are again followed by others and others, in endless succession. It is of course obvious that, if these cells could be produced by any process from inorganic elements, we should be entitled to say that the fact of a transit from the inorganic to the organic had been witnessed in that instance; the possibility of the commencement of ani-

${ }^{1}$ See Dr. Martin Barry on Fissiparous Generation; Jameson's Journal, Oct. 1843. 
mated creation by the ordinary laws of nature might be considered as established. It was announced some years ago by Prevost and Dumas, that globules could be produced in albumen by electricity; but their experiments do not appear to have been confirmed. Though no such fact may have yet taken place, we see nevertheless how small a space requires to be filled up in order to make the connexion bewseen the inorganic and the organic complete.

Admitting, however, all these views regarding life and organization, the opponents of the present argument have still to say that a transition from the inorganic to the organic, such as we must suppose to have taken place in the early geological ages, is no ordinary cognizable fact of the present time upon earth: structure, form, life, are never seen to be imparted to the insensate elements; the production of the humblest plant or animalcule, otherwise than as a repetition of some parental form, is not one of the possibilities of science: if, then, we trace back the generations of organisms to the Silurian or any earlier epoch, and acknowledge the world of that time to have been one in which the present order of natural events was prevalent, we necessarily can see no natural origin for life and organization, and one by a special interference, or an interruption of the natural order of events, must be admitted.

Leaving for a future opportunity of comment the grand fallacy involved in this argument, as regards the conclusion in favour of a miraculous origin of life-this being an assumption of a fact equally contrary to experience-let us confine ourselves for the present to a few sentences of 
remark on the minor one of assuming as a necessity on our side that life should be shown as still capable of originating in the inorganic elements. There is certainly no express reason to suppose that, although life had been imparted by natural means after the first cooling of the surface to a suitable temperature, it would have continued thereafter to be capable of being imparted in like manner. The great work of the peopling of this globe with living species is mainly a fact accomplished; the highest known species came as a crowning effect thousands of years ago. The work being thus, to all appearance, finished, we are not necessarily to expect that the origination of life and of species should be conspicuously exemplified in the present day. We are rather to expect that the vital phenomena presented to our eye should mainly, if not entirely, be limited to a regular and unvarying succession of races by the ordinary means of generation. This, however, is no more an argument against a time when phenomena of the first kind prevailed, than it would be a proof against the fact of a mature man having once been a growing youth, that he is now seen growing no longer. We might consider the primitive production of species either as one phenomenon, of the nature of the development of an individual embryo, and that phenomenon as past, just as the individual creation is perfected at birth, or as expressly and wholly a consequence of conditions, which being temporary, the results were temporary also. From the occupation of all the great geographical provinces with a more or less full suite of the forms of life, a new development may have hardly any chance of being now drawn forth, and none of being advanced to any extent, even 
though the same life-creating laws be still in force. Or the operations of these laws might be observant of times, and those of rare occurrence, so that hundreds of human generations may pass without an opportunity of witnessing such effects. However, then, it may actually have been, assuredly the most rigid disproof of primitive creation as a fact of our time could be no conclusive argument against a natural creation at a time when the earth was vacant of all organic tenantry.

It is also going somewhat beyond legitimate bounds to assert positively that structure, form, and life are never now-a-days imparted to the insensate elements. It is very true that naturalists do not in general maintain the ancient doctrine of spontaneous, or, as it should rather have been called, non-parental generation. And I must at once admit that, having to look to the authority of others for my data, I do not feel entitled to rest with any confidence on that principle. While protesting, however, against its being supposed indispensably necessary to the present speculation, I may point out some of the difficulties which stand in the way of its being conclusively rejected, as well as some experiments which have resulted in its favour.

It is well known that vegetable life often appears in circumstances where the presence of seeds must be presumed as in the highest degree unlikely. It is a familiar fact that, on earth being thrown up from a great depth, as the bottom of a mine or well, or on a new surface being formed in any other way, a set of plants not always common in the district invariably springs up at the place.

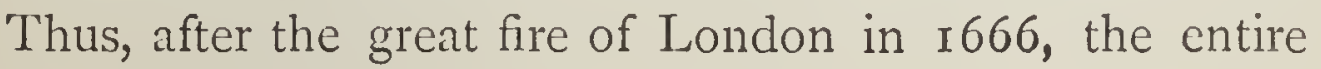


surface of the destroyed city was covered with such a vast profusion of a species of cruciferous plant, the Sisymbrium iris of Linnæus, that it was calculated that the whole of the rest of Europe could not contain so many plants of it. White, of Selborne, tells us that when old beech trees are cleared away, the naked ground in a few years becomes clothed with strawberry plants. It is well known that, whenever forest ground is cleared, young trees of a different and complementary nature spring up, and this without the ground being disturbed. A crop of white clover arising from a quantity of lime, where no such seeds were sown, is a familiar phenomenon; it was tried a few years ago in the centre of a wide moss, many miles from clover crops of all kinds, and with entire success. It is also known that, if a spring of salt water makes its appearance in a spot, at a great distance from the sea, the neighbourhood is soon covered with plants peculiar to a maritime locality,-plants which previous to this occurrence were entire strangers to the country. Again, when a lake happens to dry up, the surface is immediately usurped by a vegetation which is entirely peculiar, and quite different from that which flourished on its former banks. When the marshes of Zealand were drained, the Carex cyperoides was observed in abundance, and it is known that this is not a Danish plant at all, but peculiar to the north of Germany. In a work upon the useful mosses, M. de Brebisson states, that, a pond in the neighbourhood of Falain having been rendered dry during many weeks in the height of summer, the ground was immediately and entirely covered to the extent of many square yards by a minute compact green turf, 
formed of an imperceptible moss, the Phaseum axillare, the stalks of which were so close to each other, that upon a square inch of this new soil might be counted more than five thousand individuals of this minute plant, which had never previously been observed in the country. Some cryptogamic plants again are found only on particular artificial substances. The white mould on ink, for instance, is invariably the same, and yet different from any other fungus. Some are found only on certain animal substances, as parings of hoofs, horn, bone, \&c. Some are peculiar to hospitals, where they grow parasitically from the wounds of the patients; whole crops of them being sometimes found on the removal of the dressings. Sowerby, in his Fungi, gives us one peculiar to the modelling clay of sculptors. ${ }^{1}$ The ordinary way of accounting for these phenomena is to assume that the seeds of the plants either resided in a state of dor. mancy in the earth, or were brought to the spot by winds; but there is scarcely a single instance of living seeds being detected in earth brought up from mines or wells, and some of the seeds assumed to be transported through the air are too heavy for that purpose, not to speak of the unlikelihood that such seeds, granting they were transportable, should take root exclusively on a new surface, many miles from their native ground.

It has been shown by the opponents of this doctrine, that when a vegetable infusion is debarred from the contact of the atmosphere, by being closely sealed up or covered with a layer of oil, or only receives oxygen which

1 The range of facts here adduced is partly from the manuscript of an obliging correspondent, and partly from a brief article on Spontaneous Generation of Plants, in Jameson's Philosophical Journal, January, 1836. 
has passed through sulphuric acid, whereby all animal admixtures have been destroyed, no animalcules are produced; but can we be sure, in such circumstances, that we have not set aside some other simple condition requisite for a non-ex-ovo generation? Who can tell what effect such exclusion of air, or such mode of admitting oxygen, may have upon the operation of the imponderables in the case? To this I do not believe that any satisfactory answer could be given.

Heretofore the predominant doctrine has had a considerable difficulty with regard to the entozoa, or creatures which live within the bodies of others. These animals do, and apparently can, live nowhere else than in the interior of other living bodies, where they generally take up their abode in the viscera, but also sometimes in the chambers of the eye, the interior of the brain, the serous sacs, and other places having no communication from without. Some are viviparous, others oviparous. Of the latter it cannot reasonably be supposed that the ova ever pass through the medium of the air, or through the blood-vessels, for they are too heavy for the one transit, and too large for the other. Of the former, it cannot be conceived how they pass into young animals-certainly not by communication from the parent, for it has often been found that entozoa do not appear in certain generations of a human family, and some of peculiar and noted character have only appeared at rare intervals, and in very extraordinary circumstances. A candid view of the less popular doctrine, as to the origin of this humble form of life, is taken by a distinguished living naturalist. "To explain the beginning of these worms within the human 
body, on the common doctrine that all created beings proceed from their likes, or a primordial egg, is so difficult, that the moderns have been driven to speculate, as our fathers did, on their spontaneous birth; but they have received the hypothesis with some modification. Thus it is not from putrefaction or from fermentation that the entozoa are born, for both of these processes are rather fatal to their existence, but from the aggregation and fit apposition of matter which is already organized, or has been thrown from organized surfaces.

Their origin in this manner is not more wonderful or more inexplicable than that of many of the inferior animals from sections of themselves. . . . Particles of matter fitted by digestion, and their transmission through a living body, for immediate assimilation with it, or flakes of lymph detached from surfaces already organized, seem neither to exceed nor fall below that simplicity of structure which favours this wonderful development; and the supposition that, like morsels of a planaria, they may also, when retained in contact with living parts, and in other favourable circumstances, continue to live and be gradually changed into creatures of analogous conformation, is surely not so absurd as to be brought into comparison with the Metamorphoses of Ovid. . . We think the hypothesis is also supported in some degree by the fact, that the origin of the entozoa is favoured by all causes which tend to disturb the equality between the secerning and absorbent systems." 1 Here particles of organized matter are suggested as the germinal original of distinct and fully

1 Article Zoophytes, Encyclopædia Britannica, 7th edition. 
organized animals, many of which have a highly developed reproductive system. How near such particles must be to the inorganic form of matter, may be judged from what has been said within the last few pages. ${ }^{1}$

Seeing such reasons for believing the general dictum of the philosophical world on primitive generation to be at least inconclusive, we may be prepared to review without surprise or incredulity the well-known experiments of Mr. Crosse, which seemed to result in the production of a small species of insect in considerable numbers. This gentleman was pursuing some experiments in crystallization, causing a powerful voltaic battery to operate upon a saturated solution of silicate of potash, when the insects unexpectedly made their appearance. He afterwards tried nitrate of copper, which is a deadly poison, and from that fluid also did live insects emerge. Discouraged by the reception of his experiments, Mr. Crosse soon discontinued them; but they were some years after pursued by Mr. Weekes, of Sandwich, with precisely the same results. This gentleman, besides trying the first of the above substances, employed ferrocyanate of potassium, on account of its containing a larger proportion of carbon, the principal element of organic bodies; and from this substance the insects were

1 "Our increasing knowledge of the varied forms through which many of the lower tribes of animals and plants pass, between one true occurrence of the reproductive process and another, removes a great deal of the difficulty about the propagation of entozoa, \&c., which formerly existed. . . The whole subject of the entozoa has been worked out, within the last two or three years, by Siebold and Van Beneden, with the most wonderful success. They have followed the same species through a variety of forms, according to the animal in whose body the ovum is developed, the stage of development, and the part of the body; and they have removed all difficulty fin regard to the species examined) as to the doctrine of parental production. The cysticercus of the rat's liver becomes a tænia in the cat's intestine, and so on."-MS. Notes of a Physiologist. 
produced in increased numbers. A few weeks sufficed for this experiment, with the powerful battery of Mr. Crosse: but the first attempts of Mr. Weekes required about eleven months, a ground of presumption in itself that the electricity was chiefly concerned in the phenomenon. The changes undergone by the fluid operated upon, were in both cases remarkable, and nearly alike. In Mr. Weekes's apparatus, the silicate of potash became first turbid, then of a milky appearance; round the negative wire of the battery, dipped into the fluid, there gathered a quantity of gelatinous matter. From this Mr. Weekes observed one of the insects in the very act of emerging, immediately after which it ascended to the surface of the fluid, and sought concealment in an obscure corner of the apparatus. The insects produced by both experimentalists seem to have been the same, a species of acarus, minute and semi-transparent, and furnished with long bristles, which can only be seen by the aid of the microscope. It is worthy of remark, that some of these insects, soon after their existence had commenced, were found to be likely to extend their species. They were sometimes observed to go back to the fluid to feed, and occasionally they devoured each other. ${ }^{1}$

The reception of novelties in science must ever be regulated very much by the amount of kindred or relative phenomena which the public mind already possesses and acknowledges, to which the new can be assimilated. A novelty, however true, if there be no received truths with which it can be shown in harmonious relation, has little

1 See a pamphlet circulated by Mr. Weekes in 1842 . For a detail of further and more conclusive experiments, reference may be made to Explanations, forming a Sequel to Vestiges, \&sc. 
chance of a favourable hearing. In fact, as has been often observed, there is a measure of incredulity from our ignorance as well as from our knowledge, and if the most distinguished philosopher three hundred years ago had ventured to develop any striking new fact which only could harmonize with the as yet unknown Copernican solar system, we cannot doubt that it would have been universally scoffed at in the scientific world, such as it then was, or, at the best, interpreted in a thousand wrong ways in conformity with ideas already familiar. The experiments above described, finding a public mind which had never discovered a fact or conceived an idea at all analogous, were of course ungraciously received. It was held to be impious even to surmise that animals could have been formed through any instrumentality of an apparatus devised by human skill. The more likely account of the phenomena was said to be, that the insects were only developed from ova, resting either in the fluid, or in the wooden frame on which the experiments took place. On these objections the following remarks may be made. The supposition of impiety arises from an entire misconception of what is implied by an aboriginal creation of insects. The experimentalist could never be considered as the author of the existence of these creatures, except by the most unreasoning ignorance. The utmost that can be claimed for, or imputed to him is, that he arranged the natural conditions under which the true creative energythat flowing from the primordial appointment of the Divine Author of all things - was pleased to work in that instance. On the hypothesis here brought forward, the acarus Crossii was a type of being ordained from the 
beginning, and destined to be realized under certain physical conditions. When a human hand brought these conditions into the proper arrangement, it did an act akin to hundreds of familiar ones which we execute every day, and which are followed by natural results; but it did nothing more. The production of the insect, if it did take place as assumed, was as clearly an act of the Almighty himself, as if he had fashioned it with hands. For the presumption that an act of aboriginal creation did take place, there is this to be said, that, in Mr. Weekes's experiment, every care that ingenuity could devise was taken to exclude the possibility of a development of the insects from ova. The wood of the frame was baked in a powerful heat; a bell-shaped glass covered the apparatus, and from this the atmosphere was excluded by the fumes constantly rising from the liquid, for the emission of which there was an aperture so arranged at the top of the glass, that only these fumes could pass. The water was distilled, and the substance of the silicate had been sub jected to white heat. Thus every source of fallacy seemed to be shut up. In such circumstances, a candid mind, which sees nothing either impious or unphilosophical in the idea of a new creation, will be disposed to think that there is less difficulty in believing in such a creation having actually taken place, than in believing that in two instances, separated in place and time, exactly the same insects should have chanced to arise from concealed ova. ${ }^{1}$

The writer of the critique upon this work in the British and Foreign Medical Review, after saying that "none of the easy solutions which have been offered of the difficult problem presented by the appearance of this acarus, can be admitted," proceeds to make a few remarks much to the above purpose; and adds- "Not the least curious part of its (the acarus's) history is the series of metamorphoses which it undergoes before quitting the solution; these being entirely different 
It must nevertheless be kept in mind that we do not present the Crossian experiment and other alleged cases of primitive generation as undoubted facts, or as indispensable parts of the present hypothesis. Looking to the fact that the earth has long ago been planted with a full suite of species, from low to high, it is not likely that it is now in a condition to receive any accession to the number, except in the humblest and obscurest walks of the animated kingdoms, and under circumstances which do not perhaps often exist. While, therefore, we do not reject the alleged examples, but on the contrary think them favourable to our hypothesis, we do not attach to them a high degree of consequence. We are quite ready to fall back upon the phenomena adverted to at the beginning of this section, which merely go to prove that life and organization are essentially physical phenomena. It is, perhaps, quite enough, in the mean time, that we there see traces of the means and method adopted by the Creator in that part of his work.

from the very slight changes which other acari undergo after their emersion from the egg. Further, we believe it may be positively asserted, that in what. ever mode these acari are first generated, it is not from eggs; since, after they have escaped from the solution, they live in the neighbourhood, and readily breed; and their eggs, which we have ourselves seen, are quite large enough to have been readily visible in the solution, had they existed there."

The metamorphoses here adverted to will perhaps go some way to satisfy those who have objected that the acarus, belonging, as it does, to the articulata, is too high an animal to have been produced otherwise than from ova. 


\section{HYPOTHESIS OF THE DEVELOPMENT}

OF THE

\section{VEGETABLE AND ANIMAL KINGDOMS.}

WE have now seen arguments, of both a general and particular kind, for the simply natural origin of life upon our planet. But, whatever force may be allowed to these arguments, no attempt has as yet been made to show how, even if life originated in its first and humblest forms in this manner, it might have passed on, otherwise than by a series of divine acts of a character above or exceptive to the natural order of things, through that double series of higher forms terminating in the dicotyledons and mammalia, which we have seen rising throughout the geological ages, and leaving the earth occupied by its present organisms.

In now proposing to make such an attempt, I deem it necessary, for the sake of simplicity, to confine attention mainly to the animal kingdom, assuming that the vegetable department of nature, which starts from a common, or at least, contiguous basis, is sure to fall into any system which may be found applicable to the other.

It has already been shown, with abundant clearness, that there has been a progression of animal life upon the 
globe,-first, an era of invertebrate animals; second, a period during which fish were the sole vertebrate form of being; next, a time when reptiles are seen in addition, but without birds or mammalia; then a period when these last were added, but without man; and finally, the present era, in which that master species has existed in supremacy over all. This is a manifest stepping-on from one grade to another, and it is a fact which is only feebly disputed by one or two geologists, on the ground that we know of the absence of the higher animals at any period solely by negative evidence, all other students of this science seeing very well that, though in the geological record there must be many blanks, there can be none extending to whole sub-kingdoms and classes.

It is equally clear, and can now be asserted on the authority of the first naturalists of the age, that, in all the conspicuous orders of animals, there have been, in the progress of time, strong appearances of a progress of forms, from the more simple to the more complex, from the more general to the more special, the highest and most typical forms being always attained last. It cannot be pretended, in all cases, that we have an unbroken and perfect series, exhibiting these gradations, for the Stone Book is one wanting many leaves; but in the orders that have been best preserved, there is such a well-marked succession leading on from one degree of organization to another, that the general fact of a progress in all the orders is not to be doubted. Thus the examples of the cephalopodous, gasteropodous, and bivalve orders of mollusca found in the Silurian formation, are all of them of humble character, standing low, as it were, in their re- 
spective lines of development. These were succeeded in the higher formations by superior genera. It is the same with the well-marked line of the echinodermata, the crinoid of the Silurians leading gradually on, through a fine series of intermediate forms, to the echinus of the Oolite. The cartilaginous are succeeded by the osseous fishes, and in the cartilaginous order itself there is a progress in the series of genera. The characters of the saurian reptile first make a sort of dawn in a family of fishes; then there are species half fish, half reptile; after which comes a succession of forms ending in true crocodiles. In the plants of the early world, as far as they are known to us, the same progress may be traced in the broad features of the succession.

In this revelation of organic history there are some circumstances which must be kept in mind. One is that the initial genera of the various orders, though always of humble organization comparatively, are not always liable to be described as positively so. They are always perfect animals; in many instances they are of large bulk as compared with other genera of their own orders, and are sometimes not without traits of organization calculated to excite our admiration. It is perfectly evident, in all of them, that they have been well fitted by creative wisdom for the part they had to play in the field of life. There is need for these remarks, to prevent the reader from rushing to the supposition that there has been a very gradual transition of forms, - that the first animals of all the various orders were very small and ill-fashioned, and so forth. Such preconceptions, not being verified by the fact, only tend to bewilder us regarding the actual 
character of that progression of forms which meets us in the pages of the geologist. It must be taken for what it exactly is, and that, as far as we can see, is not a pure, simple series of equal transitions, but a plurality of lines, in which there have either been some comparatively wide leaps, or else certain intermediate species which have been lost to observation. Those whose prejudices lead them to dispute the broad fact of progressive organization, generally rest their objections on points of that kind, either assuming that such are necessary to the idea of progress, or finding that they have been incautiously sanctioned by the advocates of that doctrine. ${ }^{1}$

Leaving for a future section the particulars of the animal scale, which will there lend us further illustration, it may now be observed that, while the external features of the various creatures are so different, there has been traced, throughout large groups of them, a fundamental unity of organization, as implying, with respect to these groups, that all were constructed upon one plan, though in a series of improvements and variations, giving rise to the special forms, and bearing reference to the conditions in which each animal lives. Starting from the primitive germ, which, as we have seen, is the representative of a particular order of full-grown animals, we find all others to be merely advances from that type, with the extension

${ }^{1}$ See Proofs and Illustrations, -No. 5, The Lower Silurian System is the record of an era of invertebrate animals; No. 6 , The genera of the Lower Silurian era are humble in their respective lines; No. 7, The early fishes were low both with regard to their class as fishes and the order to which they belong (cartilagines); No. 8, In all the orders of fossil animals there is an ascending character from first to last; No. 9, There is a succession from low to high types in fossil plants, from the earliest strata in which they are found to the highest; No. тo, The comparatively large bulk of some of the early fossil animals is to be regarded as a mark of their inferiority in the scale. 
of endowments and modifications of form which are required in each particular case; each form, also, retaining a strong affinity to that which precedes it, and tending to impress its own features on that which succeeds.

This principle is partly matter of familiar observation. It is obvious to all, that an ordinary mammalian quadruped has a strong analogy of form to the human being; its head, its forelegs, its hinder extremities, have each their representative parts in our frame. But the ordinary observer is surprised to learn how much further the principle is carried. For example, the hind leg of the horse looks very different from one of our limbs, in as far as it seems to have a knee presented backwards, and possesses no toes. In reality, the part of the horse corresponding to our knee is high up near the body of the animal, and the hock corresponds to our heel. It has toes, moreover; but they are sunk in the hollow of a hoof, which serves as a shield to that part. The horse, the dog, and many other quadrupeds, may be said to walk upon their toes (hence called digitigrade): others, as the bear and badger, present the whole foot to the ground, as man does (hence called plantigrade). Thus, too, the wing of the bird contains bones representing those of our arm, though modified for so different a purpose. The paddles of the whale tribes and seals are other curious modifications of a member substantially the same. The bat, again, has the bones of its hand developed to an unusual extent, so as to become a frame for the membrane by which it flies: in the extinct pterodactyle, the same purpose was chiefly served by a development of the forefinger alone. The fundamental 
resemblance which lurks below various appearances is often startling. Thus, the giraffe, with its long neck, has, in that part, no more bones than are to be found in the neck of the elephant and pig, which hardly seem to have a neck

\section{FIG. 74 .}

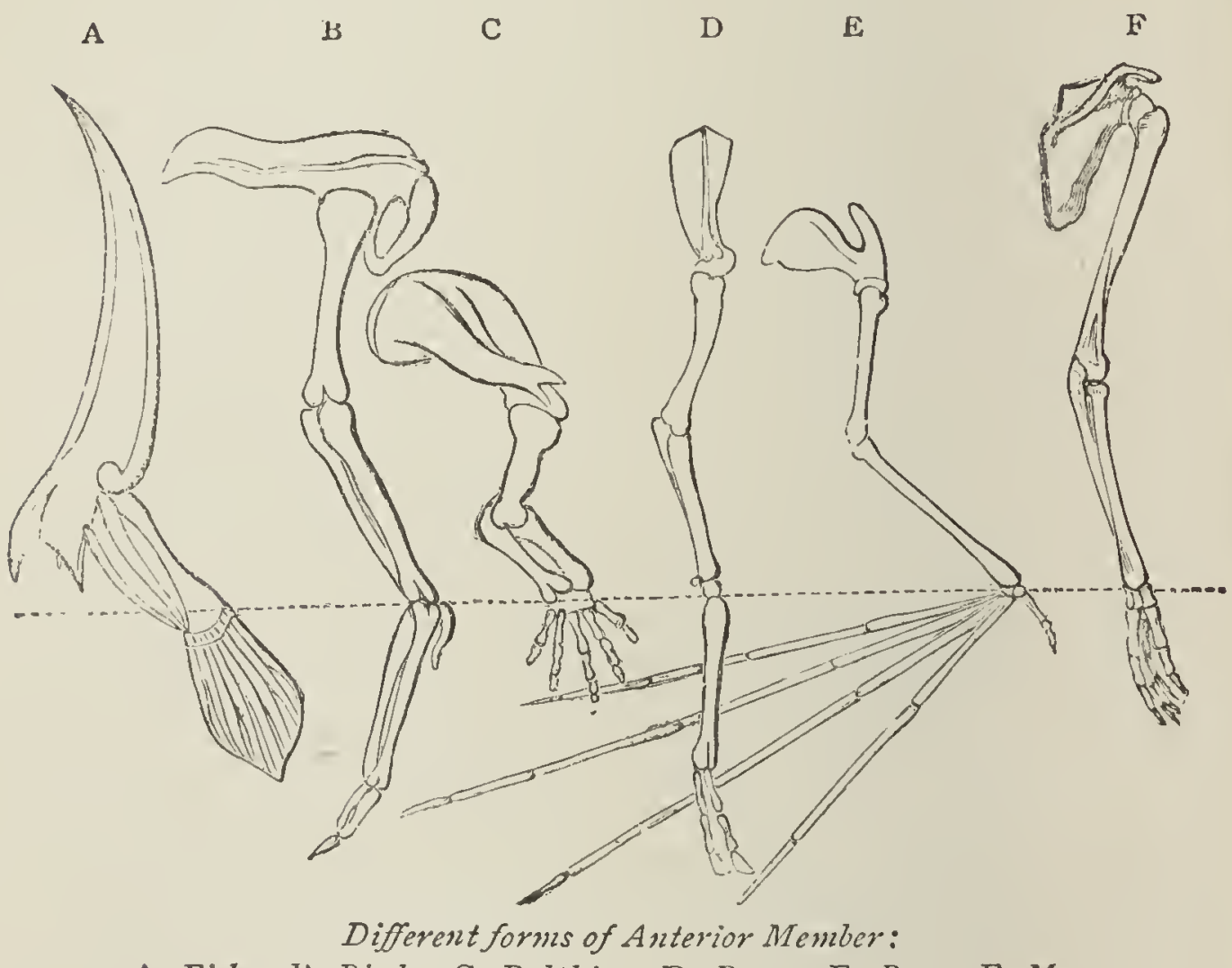

A, Fish;-D, Bird;-C, Dolphin;-D, Leer;-E, Bat;-F, M1an.

at all. The cervical vertebræ are but seven in every one of the mammalian animals. Sometimes, an organ appears entirely wanting in one family, as feet in the serpent tribes, a pelvic region in the whale, the wing in the bird called the apteryx; and yet it is not truly wanting. Usually, some rudiment of it appears, as if nature had been willing to give it, but had kept it back from a complete develop- 
ment, as knowing it to be not needed in that instance. On this ground, the notion of a much ridiculed philosopher of the last century, respecting a human tail, may be said to be not quite without foundation. Between the fifth and sixth week a tail exists in the human embryo; it then goes back; but still in the mature subject its elements are seen clumped up in the bone at the bottom of the spine, the os coccygis.

Unity of organization becomes the more remarkable when we observe that the corresponding organs of animals, while preserving a resemblance, are sometimes put to different uses. For example, the ribs become, in the serpent, organs of locomotion; and the snout is extended, in the elephant, into an instrument serving all the usual purposes of an arm and hand.

It is equally remarkable that there should be, in the original plan of the animal structure, a double set of organs, one or other of which is selected for development according to the needs of the particular animal. Thus there are in the plan both gills and lungs, two wholly distinct kinds of respiratory apparatus, the one being designed for a watery and the other for an atmospheric medium. The mammalia, as creatures destined to breathe the air, are furnished with lungs; but, at an early stage of the foetal progress, this is not the case. They have at that time a branchial apparatus. Afterwards, this goes back, and the lungs are developed from a different portion of the organism. Lungs, on the other hand, are possessed by certain fishes in a rudimental form; it is the well-known air-bladder of those fishes, which are understood to profit by it, as an additional means of floating. So, also, the 
baleen of the whale and the teeth of the land mammifer are different organs. The whale, in embryo, shows the rudiments of teeth; but, not being wanted, they are not developed, and baleen is brought forward instead.

But the most remarkable circumstance attending the law of unity of organization is, that an organ is sometimes developed to a certain extent, but wholly without use. ${ }^{1}$ This organ will, perhaps, be seen serving a purpose in a particular family of animals; but we advance into an adjoining or kindred family, and there find a rudiment of the same organ, which, owing to the different conditions of this new set of creatures, is of no kind of service. Thus, some of the serpent tribes possess rudimentary and totally useless limbs. In other instances, a portion of organization necessary in one sex is also presented in the other, where it is not necessary. For example, the mammæ of the human female, by whom these organs are obviously required, also exist in the male, who has no occasion for them. It might be supposed that in this case there was a regard to uniformity for mere appearance sake; but that no such principle is concerned, appears from a much more remarkable instance connected with the marsupial animals. The female of that tribe has a process of bone advancing from the pubes for the support of her pouch, and this also appears in the male marsupial, which has no pouch, and requires none.

I"I think it would be more correct to say, 'without apparent use.' A very strong case has been made out by Mr. Paget, in his Hunterian Lectures at the College of Surgeons, in favour of the rudimental development of organs being necessary to withdraw from the blood some element of nutrition, which, if retained in it, would be positively injurious, -like a retained excretion. (See Carpenter's Human Physiology, p. r95). This does not in the least interfere with the author's argument, but is, in fact, only a confirmation of it, carrying back the anity to the formative fluid."-MIS. Notes of a Phy'siologist. 
The same law of unity may be recognised in the vegetable kingdom. Amongst phanerogamous plants, a certain number of organs are always present, either in a developed or rudimentary state; and those which are rudimentary can often be developed by cultivation. Flowers which bear stamens on one stalk and pistils on another, can be caused to produce both, or to become perfect flowers, by having a sufficiency of nourishment supplied to them. So, also, where a special function is required for particular circumstances, nature provides for it, not by a new organ, but by a modification of a common one. Thus, for instance, some plants destined to live in arid situations, require to have a store of water which they may slowly absorb. The need is arranged for by a cup-like expansion round the stalk, in which water remains after a shower. Now the pitcher, as this is called, is not a new organ, but simply the metamorphosis of a leaf.

It is thus proved, with regard to the constituent beings of large sections of the animal kingdom, that they are bound up in a fundamental unity, however various in degree of endowment and in the purposes which they serve in the world. They may be said to stand in a connexion resembling that in which the planets are placed by the third law of Kepler. And the inference with regard to their origin is the same. Precisely as it is impossible to suppose a separate exertion or fiat of Almighty Power for the formation of the Earth, wrought up as it is in a complex dynamical connexion, first with Venus on the one hand and Mars on the other, and secondly with all the other members of the system, so is 
it impossible to conceive the same power using particular means for the production of a particular animal species, an individualized fraction, as it now appears, in a vast system which would not be complete without it, and into whose adjacent parts it melts by the finest shadings. Supposing, for a moment, that each species had been distinct in its origin, these shadings would have been unnecessary; and there would at least have been a strong probability against a unity of organization being adopted as part of the plan. In that case, abortive or rudimentary organs must have been considered as a kind of blemishthe thing of all others most irreconcilable with that idea of perfection which a general view of nature irresistibly attributes to its Author. If, on the other hand, we admit that the animal kingdom was framed under the operation of a general law, we see in the shadings and the organic unity something not only harmonious with, but essential to, the system. Rudimentary organs, too, appear but as harmless peculiarities of development, and interesting evidences of the manner in which the Divine Author has been pleased to work.

It must be easy to see how this class of facts bears on the great question. Organisms we know to have been produced, not at once, but in the course of a vast series of ages: here we now see that they are not a group of individually entire things accidentally associated, but parts of great masses, nicely connected, and integral in their respective totalities. Time, and a succession of forms in gradation and affinity, become elements in the idea of organic creation. It must be seen that the whole phenomena thus pass into strong analogy with those attending 
the production of the individual organism. This leads us to consider facts attending the embryonic development of animals.

First surmised by the illustrious Harvey, afterwards illustrated by Hunter in his wonderful collection at the Royal College of Surgeons, Embryonic Development has latterly become a science in the hands of Tiedemann, St. Hilaire, and Serres. For some years its primary propositions were these: $\mathrm{I}$. The embryos of all animals are not distinguishably different from each other; 2 . Those of all animals pass through a series of phases of development, each of which is the type or analogue of the permanent configuration of tribes inferior to it in the scale. The latter proposition was asserted to be more particularly true of departments of the organization, as the nutritive system, the vascular system, the nervous system, \&c., each of which is destined for a peculiar degree of develop. ment in different groups of animals, according to their several needs. It is now seen that, while the first proposition remains as originally stated, the second must be modified. The whole truth may be thus set forth:-

All organisms, vegetable as well as animal, commence with a simple cell, of which it is impossible to tell in any case to what form it is destined to advance. A series of changes takes place. First, of an animal embryo, we can distinguish whether it is destined for the radiate, molluscous, articulate, or vertebrate sub-kingdom. Take an embryo of the vertebrate sub-kingdom, we next trace in it the change which will determine whether it is to belong to the fish, reptile, bird, or mammal class. Take an embryo of the mammal class, the characters of the particular order are 
next determined. Afterwards, those of family, genus, species, sex, and individual are evolved in succession. Thus, in the words of Von Bär, who first enunciated the doctrine, "A heterogeneous or special structure arises out of one more homogeneous or general, and this by a gradual change." Thus, also, it must be clearly seen, the embryo of each grade of being passes through the general conditions of the embryos of the grades beneath it. As an illustration. "There is no essential difference between the vertebral column of the early embryo of man, and that of an embryo fish; the evolution of the nervous centres begins in both upon the same plan; so also does that of the circulating apparatus. . . ." Some illustrations of this principle, as far as applicable to special parts of the organization, as the circulatory and nervous systems, are presented in the diagrams annexed, Figs. 75 and 76.

There are even cases in which the embryo of the higher animal may be said to pass through a comparatively mature condition of a grade beneath it. This happens where an animal comes forth from the egg before its development is completed, but in a condition that fits it for an independent existence. We have notable examples in the insects, whose young first appear in the inferior annelidan form (larva), and in the batrachian reptiles, whose progeny are fish for the first few weeks of life (tadpoles). It is not, indeed, pretended that the larva of the insect is a perfect annelid, or that the tadpole is a perfect fish. There is an embryonic character in both cases. Still they are "essentially" annelid and fish. 
When we trace the history of what has been called "the general life of the globe," as far as that has been ascertained by geological research, we find something very like the same plan as that which is followed in "the individual life of every one of the forms of organized being which now people it."-(Carpenter.) We see clearly that there has been a succession from invertebrate to vertebrate; then, in the vertebrate, from the fish to the reptile, from the reptile to the bird and mammal; in the mammal, finally to man. That there has also been an advance in each stirps or series of animals, is abundantly evident. In connexion with advance of grade, there appears to have

\section{FIG. 75 .}

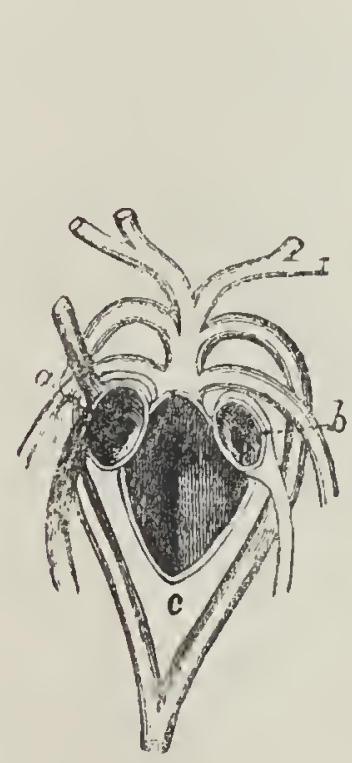

$\mathrm{B}$

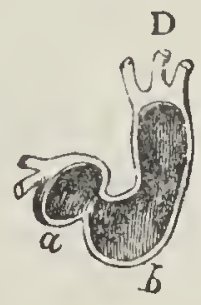

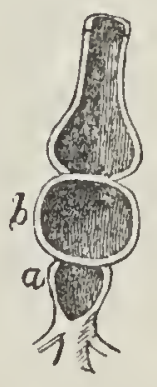

A

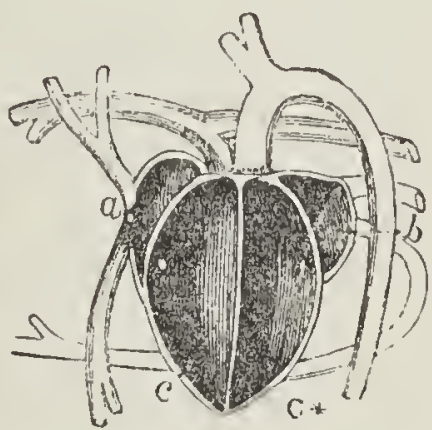

C

Diagram of the Principal Forms of the Heart:

A, Heart of Fish; a, single auricle; $b$, single ventricle:-B, Heart of Reptile; $a$, right auricle; $b$, left auricle; $c$, single ventricle:-C, Heart of Mammal; $a$, right auricle; b, left auricle; c, right ventricle; $c^{*}$, left ventricle:$\mathrm{D}$, enbryonic heart of MIanmal, corresponding in developincnt with that of Fish. 
been a progression from general to special characters. It has been pointed out that the Cystidea, an early echinodermatous form, presents "a combination of the distinctive

FIG. 76 .

A

L

C
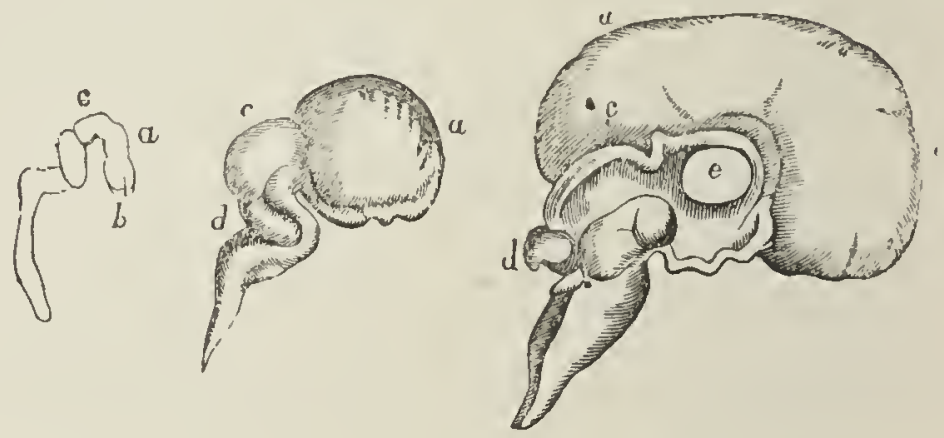

D
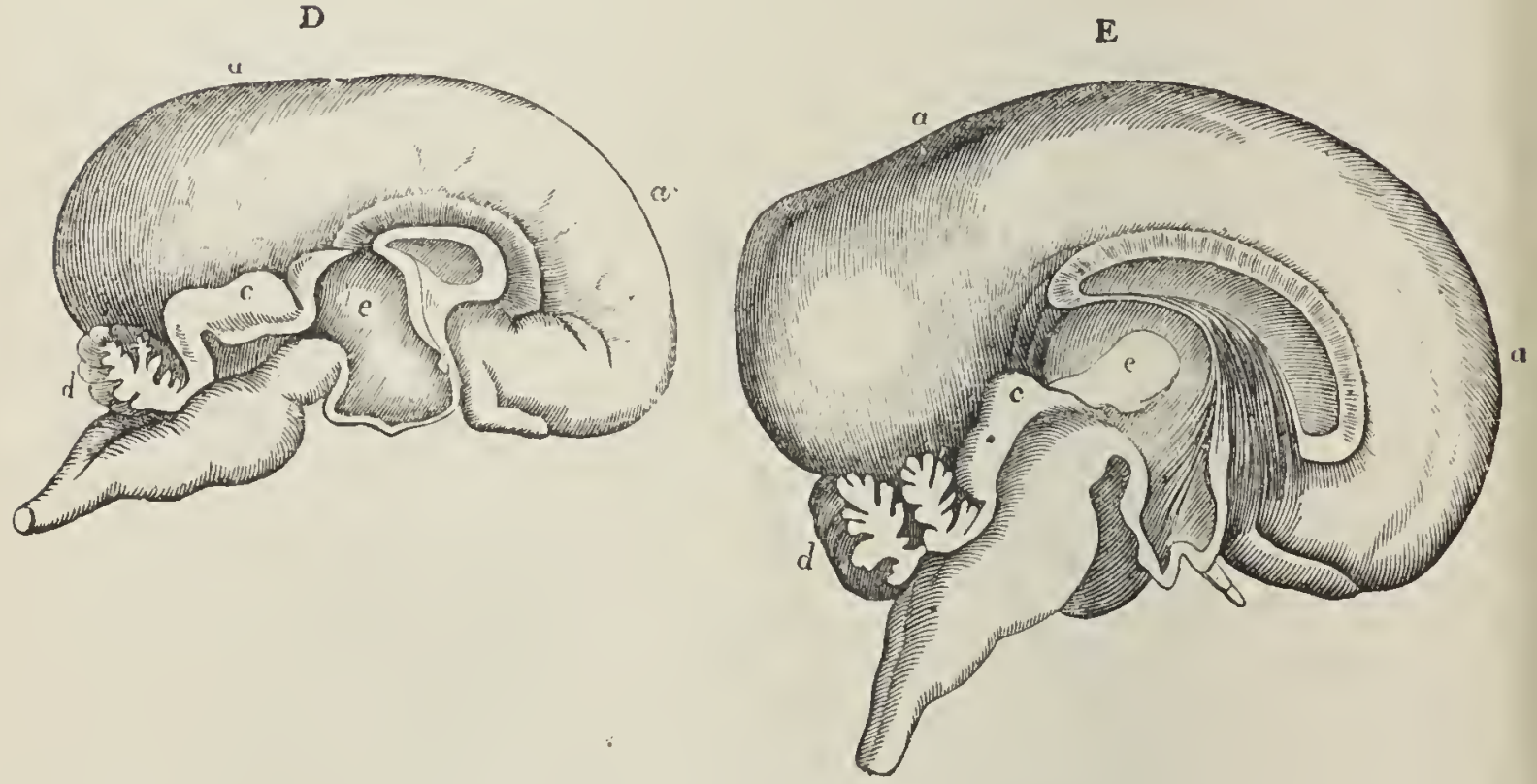

Successire Stages of Derclotment of the Human Brain.

A, at the 7 th weck; $a$, rudinent of hemispheres; $b$, corpora striata; $c$, corpora quadrigenina; $d$, cerebellum:- $\mathrm{B}$, at the I2th week:- $\mathrm{C}$, at the I5th week; $e$, optic thalamus:- D, at the 2Ist week:-E, at the 27 th rueek. - In the relative proportions of the principal parts of the Human Brain at these successive periods, there is a very close correspondence to the proportions presented by the corresponding parts of the Brains of Fishes, Reptiles, Birds, and the lozver Mammalia. 
characters of the remaining groups" of echinodermata. The earliest Cephalopods were not the most typical. The first Fishes exhibit a remarkable assemblage of characters, some leading to the invertebrate grade, others rising towards the reptilian form, while the more typical fishes came afterwards. "When we look at the earliest forms of reptilian life, of which we have any cognizance, we find them to present very remarkable combinations of the characters which are now distributed among different groups. Thus the Labyrinthodon of the Triassic formation appears to have been essentially Batrachian in its structure, but to have possessed some characters of the Crocodilian order. And the same formation contains remains of reptiles, which, while essentially Saurian in their general structure, had the horny mandibles, and probably many other characters of the Chelonia. In the early history of the class Mammalia, so far as known to us, the same general plan may be traced. The only order that is distinctly recognisable by remains preserved in the secondary strata, is that of Marsupialia, which has much in common with the Oviparous Vertebrata. Near the commencement of the Tertiary epoch, remains of Pachydermata are abundant; but these were for the most part different from those of the present epoch, containing combinations of characters which are now distributed among several distinct families, and presenting also a closer approximation to the herbivorous cetaceans on the one hand, and to the ruminants on the other, than is exhibited by any existing species of the order. So among the early Edentata we meet with a group now entirely 
extinct, which connected that order with the massive pachyderms."1

The history of fossil plants, as far as known, exhibits traces of the same law; "the characteristic flora of the coal formation appearing to have been chiefly composed of coniferæ, which constitute a connecting link between the Phanerogamia and Cryptogamia; and of these coniferæ, while some may have been nearly allied to existing forms, the great majority appear to have presented such a combination of the characters of the coniferæ with those of the higher cryptogamia, as no existing group exhibits."

Now it must be at once admitted, that we do not possess such an intimate and exact knowledge, either of the history of life on the globe or of the embryonic history of an individual organism of the highest rank, as to entitle us to say that there is a perfect resemblance between the two. As far, however, as we know of both, there is a very striking resemblance, and every addition to our knowledge helps towards establishing a complete one. On this point, one of the first of living naturalists has lately thus expressed himself :- "Nothing can be more gratifying than to trace the close agreement of the general results derived from the study of the structure of animals, with the results derived from the investigation of their embryonic changes, or from their succession in geological times. Let anatomy be the foundation of a classification, and, in the main, the frame thus devised will agree with the arrangement introduced from embryological data. And again this series will express the chief features of the order 
of succession in zuhich animals were gradually introduced upon our globe." 1

As examples and illustrations:-The Comatula, a freeswimming star fish, (Fig. 49,) is, at one stage of its early progress, a crinoid-that is, a star-fish fixed upon a stalk

\section{FIG. 77.}

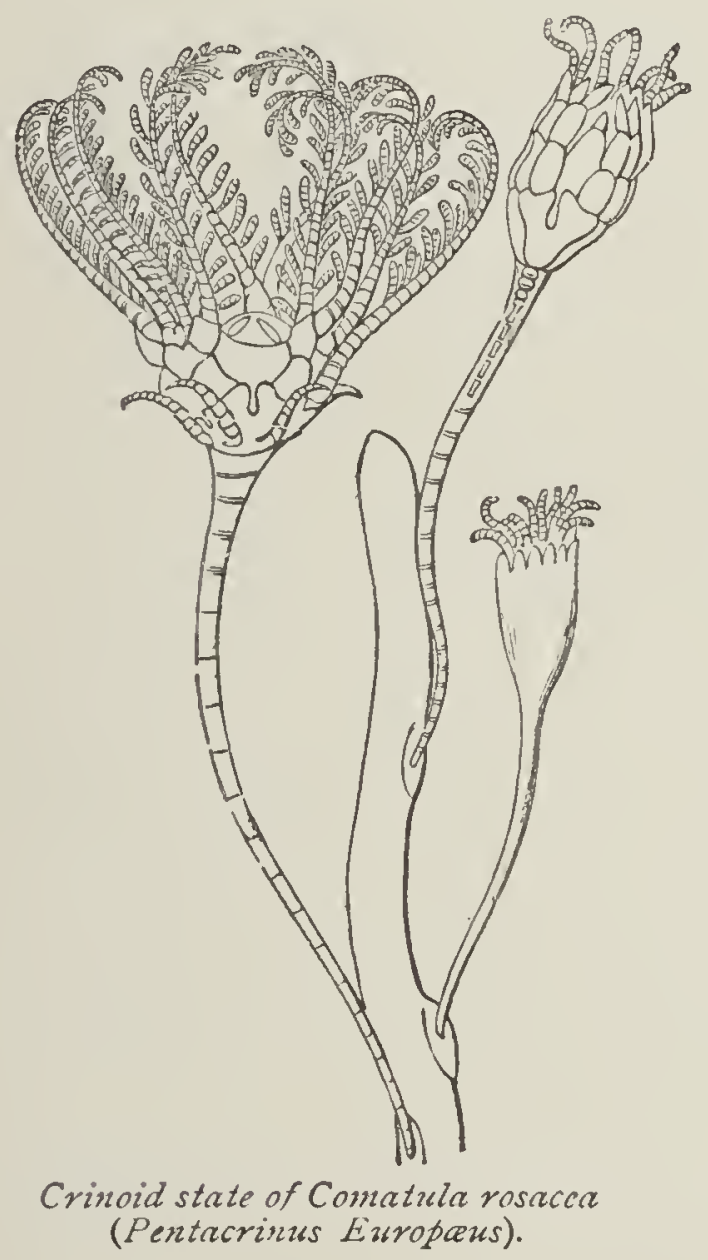

at the bottom of the sea. It advances from the form of one of the lower to that of one of the higher echinodermata. The animals of its first form were, as we have seen,

'Agassiz's work on Lake Superior. Boston, U.S. 1850. 
among the most abundant in the earliest fossiliferous rocks: they began to decline in the New Red Sandstone era, and they were succeeded in the Oolitic age by animals of the form of the mature comatula.-The higher Crustacea, as the crab and lobster, at their escape from the ovum, resemble the perfect animal of the inferior order entomostraca, and pass through the forms of transition which characterize the intermediate tribes of

FIG. 78.
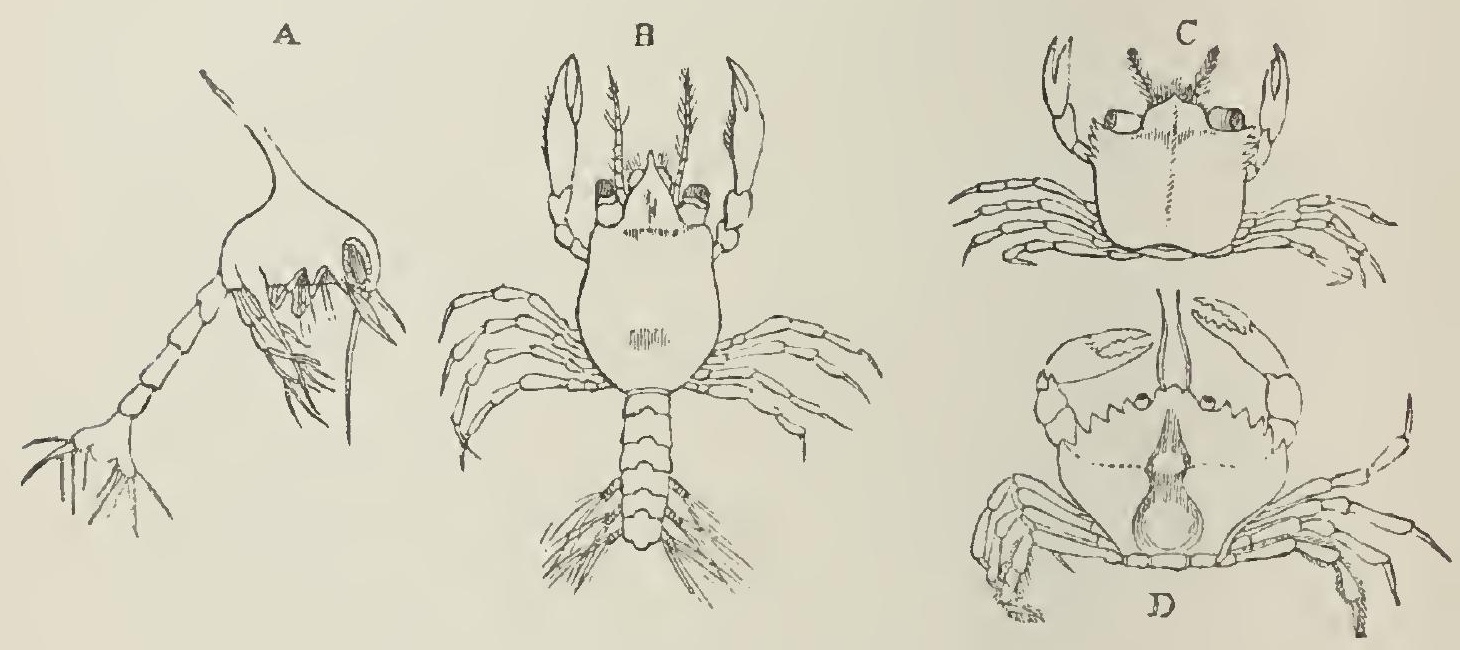

Metamorphoses of Crab.

A, first stage; $\mathrm{B}$, second stage; $\mathrm{C}$, third stage, in which it begins to assume the adult form; D, perfect form.

crustacea. The earliest crustacea on the globe were entomostracous, and the crab and lobster did not make their appearance till the Triassic epoch.-The Cirripede is a high articulate animal, and the sessile cirripede is superior to the pedunculated, "the sessile being apparently the perfection of this line of being." The embryo cirripede passes through a distinctly entomostracan form. We 
should therefore expect that the cirripedes should appear after the entomostraca, and the sessile after the pedunculated. It is so. The cirripedes do not enter upon the stage till the Oolitic era; and, while the pedunculated first appear in the Stonesfield slate, and are conspicuous in the chalk, the sessile are not seen till the tertiary.The Insects pass through a distinct metamorphosis, being, at an early period of their fotal existence, essentially annelidans or worms. In the geological record, annelidan forms occur in the Silurian age, the full insect not till the carboniferous. One great section of the insects go through a more perfect metamorphosis than the other, having at one time the form of an inactive pupa which takes no nourishment, but passes through many, though gradual, changes. Now it is exceedingly curious that, while the insects of least perfect metamorphosis (Ametabola) are first detected in the carboniferous age, and become prominent in the Jurassic, those of most perfect metamorphosis (Metabola) did not enter on the scene till afterwards. Agassiz likens the Ametabola to the cryptogamia, and the Metabola to flowering plants, and adds that "it is well worthy of remark that among plants the cryptogamic, and among insects the Ametabolous, first appeared upon our earth." So much for the Invertebrate sub-kingdom.

When we proceed higher, we find the examples become even more remarkable. Take the White-fish, one of the most highly organized of its class, which, in mature life, has a bony skeleton, an equally forked tail (Fig. 25), and a mouth in the front of its head. When it first comes forth from the egg, the vertebræ are cartilaginous, the 
caudal fin unequally forked, and the mouth transverse and underneath its head, resembling generally the mature cartilaginous fish. Now, as we have seen, the cartilaginous fishes existed long before there were any possessing osseous skeletons. Take the Frog: it is at its birth a tadpole, with external branchiæ and other organs fitting it to live in the water. It is, in short, essentially a fish. We should therefore expect that fishes should have existed before frogs, which the geological record fully testifies.

Such are a few of the more prominent facts tending to establish a parity or identity of plan between the succession of animals on the earth, and the stages of embryonic development in those which have last come upon the scene. This parity becomes the more striking, from those very peculiarities which have been felt as most puzzling in both. Some steps in the march of fossils have been thought to be so inconsistent with the idea of a general progress of life, as to cause many to repudiate that idea entirely. A distinct conception of embryonic development ought to reconcile them to it. We must take into view that, besides the vertical movement of the embryo through grades of being, there is a kind of lateral advance from the more general to the more special. The characters of the fœtal animal are at one time more comprehensive than they afterwards become. We should, therefore, in the assumption of a perfect parity in the two sets of phenomena, expect that the first fishes, while the lowest, should also partake of the characters of other vertebrate, and even of certain invertebrate orders, which appears to be precisely the case with those of the Old 
Red Sandstone. The Cephalaspids, while, in their external skeleton, leaning to the crustacea, were, as a distinguished physiologist has remarked, "shaped like the tadpoles of Batrachia; the breathing organs and chief parts of the alimentary apparatus were aggregated with the proper viscera of the cranial cavity in an enormous cephalic enlargement; the rest of the trunk was for locomotion, and dwindled to a point. The position of the anal fin proves the vent to have been situated, as in tadpoles, immediately behind the cephalic abdominal expansion. In the. Pterichthys, the mouth was small and inferior, as in the young tadpole; and there are long fin-like appendages, projecting from the sides of the cephalic enlargement, like the external gills of the Batrachian and Selachian larvæ."1 Other examples of this curious analogy have already been enumerated from the pages of another eminent physiologist. The subject is as yet in much need of elucidation; but the leading idea has certainly been made tolerably clear.

Now it will occur to all who can approach this subject without prejudice, that, if there be a real identity of character in the two sets of phenomena, there is in that fact a great improbability that the two sets of phenomena have been produced by two different kinds of causesthat the development of a particular organism is a natural phenomenon, but that the development of the whole animal or vegetable kingdom has taken place under different conditions. It must appear, on the contrary, highly likely that the producing, ruling, and guiding cause

1 [Professor Owen?] Quarterly Review, Sept. I851. 
operated in the same manner in the two cases. Neither can it be irrational to suggest that embryonic development shadows forth the principle which was employed or followed by the Uncreated, in filling the earth with the organic creatures by which it is inhabited.

Does it not now appear as if the clouds were beginning to give way, and the light of simple unpretending truth about to break in upon the great mystery? In the first place, however, let us remember that, in such speculations, the explanation which is most simple, and which makes the least demand upon the puerile emotion of wonder, is always, other things being equal, the most acceptable. In physiology, particularly, a phenomenon of slow and gradual movement must ever have an advantage over one which consists in a great and sudden effect, because all the observable processes in physiology are of the former character. Supposing that the reproduction of living beings - say, for example, trees - were, from the invisibility of the seed, amongst the unsolved problems of sciencesuppose that, every part of the process being inscrutable prior to the appearance of the young plant above the soil, it were assumed and held forth, that plants were produced all at once, whether by natural or non-natural forces, would it not be felt as a great relief from the unsatisfactory state in which this explanation would leave us, if a Schleiden or a Brown were at length to announce that he had detected the process of germination, a process of slow and gradual steps, each one leading on to another? Would not even a well-supported hypothesis as to the deposition of seed, the penetration of sap, the expansion and bursting of the germ, and the sprouting forth of the 
stalk, be greatly preferable to remaining under some hazy, unsupported notion as to a miracle being required for every individual plant? It is, then, as, in addition to all special evidences in its favour, the simplest explanationas an explanation involving slow and gradual movement, such as we usually see in nature-as an explanation appealing to and allying itself with science, instead of resting on a dogmatic assumption of ignorance, that I bring forward on this momentous occasion the principle of PROGRESSIVE DEVELOPMENT.

The proposition determined on after much consideration is, that the several series of animated beings, from the simplest and oldest up to the highest and most recent, are, under the providence of God, the results, first, of an impulse which has been imparted to the forms of life, advancing them, in definite times, by generation, through grades of organization terminating in the highest dicotyledons and vertebrata, these grades being few in number, and generally marked by intervals of organic character which we find to be a practical difficulty in ascertaining affinities; second, of another impulse connected with the vital forces, tending in the course of generations, to modify organic structures in accordance with external circumstances, as food, the nature of the habitat and the meteoric agencies, these being the "adaptations" of the natural theologian. We may contemplate these phenomena as ordained to take place in every situation, and at every time, where and when the requisite materials and conditions are presented-in other orbs as well as in this-in any geographical area of this globe which may at any time arise-observing only the variations due to 
difference of materials and of conditions. The nucleated vesicle is contemplated as the fundamental form of all organization, the meeting-point between the inorganic and the organic - the end of the mineral and beginning of the vegetable and animal kingdoms, which thence start in different directions, but in a general parallelism and analogy. This nucleated vesicle is itself a type of mature and independent being, as well as the starting point of the fotal progress of every higher individual in creation, both animal and vegetable. We have seen that, the proximate principles or first organic combinations being held, and in some instances proved, as producible by the chemist, an operation which would produce in these the nucleated vesicle is all that is wanting effectually to bridge over the space between the inorganic and the organic. Remembering these things, it does not seem, after all, a very immoderate hypothesis, that a chemicoelectric operation, by which germinal vesicles were produced, was the first phenomenon in organic creation, and that the second was an advance of these through a succession of higher grades, and a variety of modifications, in accordance with laws of the same absolute nature as those by which the Almighty rules the physical department of nature.

Leaving the first of these supposed processes to rest upon the arguments which have been adduced with regard to a possible transition from the inorganic to the organic, as a natural fact, we have two things to be accounted forfirst, grade; and, second, external peculiarities. It may be asked, Can we believe that a fish may advance to be a reptile, and a reptile to be a bird-being a distinct step 
onward in complexity of organization-and that particular organs are capable of being modified, so as to suit external conditions,- for example, the bill of a bird to the picking up of food in shallow waters, or the throat of the foetal marsupial to the reception of the mother's milk without a danger of choking.

With regard to grade, it must be admitted at once that, in Nature's government, there is no observable appearance of such promotions. But it may be asked, if, supposing such events to be within the scope of nature, we are necessarily to expect to see them take place, or even to hear of them having been recorded? To settle this question, let us first inquire into the proportion of the number of these grades to the space of time believed to be represented in the fossiliferous series of rocks. Mr. Lyell tells us that the space between our sun and some of the remote starclusters, of which the distance to Sirius (not less than nineteen millions of millions of miles) is but a fraction, may no more than compare with the space of time which has probably elapsed since the origin of the coralline limestone over which the Niagara is precipitated at the Falls. Now, the number of grades of what may be called the first degree (transitions from class to class) passed through by the vertebrata since their origin in the early rocks is, at the utmost, three. Such a leap in organic progress has, therefore, only taken place once in many millions of millions of years. If such be the case, all chance of such grade transitions being witnessed within the four thousand years of historical humanity becomes so attenuated as scarcely to have an existence. As to the possible occurrence of such unusual events in the midst of a series 
which appears fixed and regular, let us call forward an illustration from the Ninth Bridgezuater Treatise of Mr. Babbage. The reader is requested to suppose himself seated before the calculating machine, and observing it. It is moved by a weight, and there is a wheel which revolves through a small angle round its axis, at short intervals, presenting to the eye successively a series of numbers engraved on its divided circumference.

Let the figures thus seen be the series, I, 2, 3, 4, 5, \&c., of natural numbers, each of which exceeds its immediate antecedent by unity.

"Now, reader," says Mr. Babbage, "let me ask you how long you will have counted before you are firmly convinced that the engine has been so adjusted, that it will continue, while its motion is maintained, to produce the same series of natural numbers? Some minds are so constituted, that after passing the first hundred terms, they will be satisfied that they are acquainted with the law. After seeing five hundred terms few will doubt, and after the fifty thousandth term the propensity to believe that the succeeding term will be fifty thousand and one, will be almost irresistible. That term will be fifty thousand and one; and the same regular succession will continue; the five millionth and the fifty millionth term will still appear in their expected order, and one unbroken chain of natural numbers will pass before your eyes, from one up to one hundred million.

"True to the vast induction which has been made, the next succeeding term will be one hundred million and one; but the next number presented by the rim of the wheel, instead of being one hundred million and two, is 
one hundred million ten thousand and two. The whole series from the commencement being thus,--

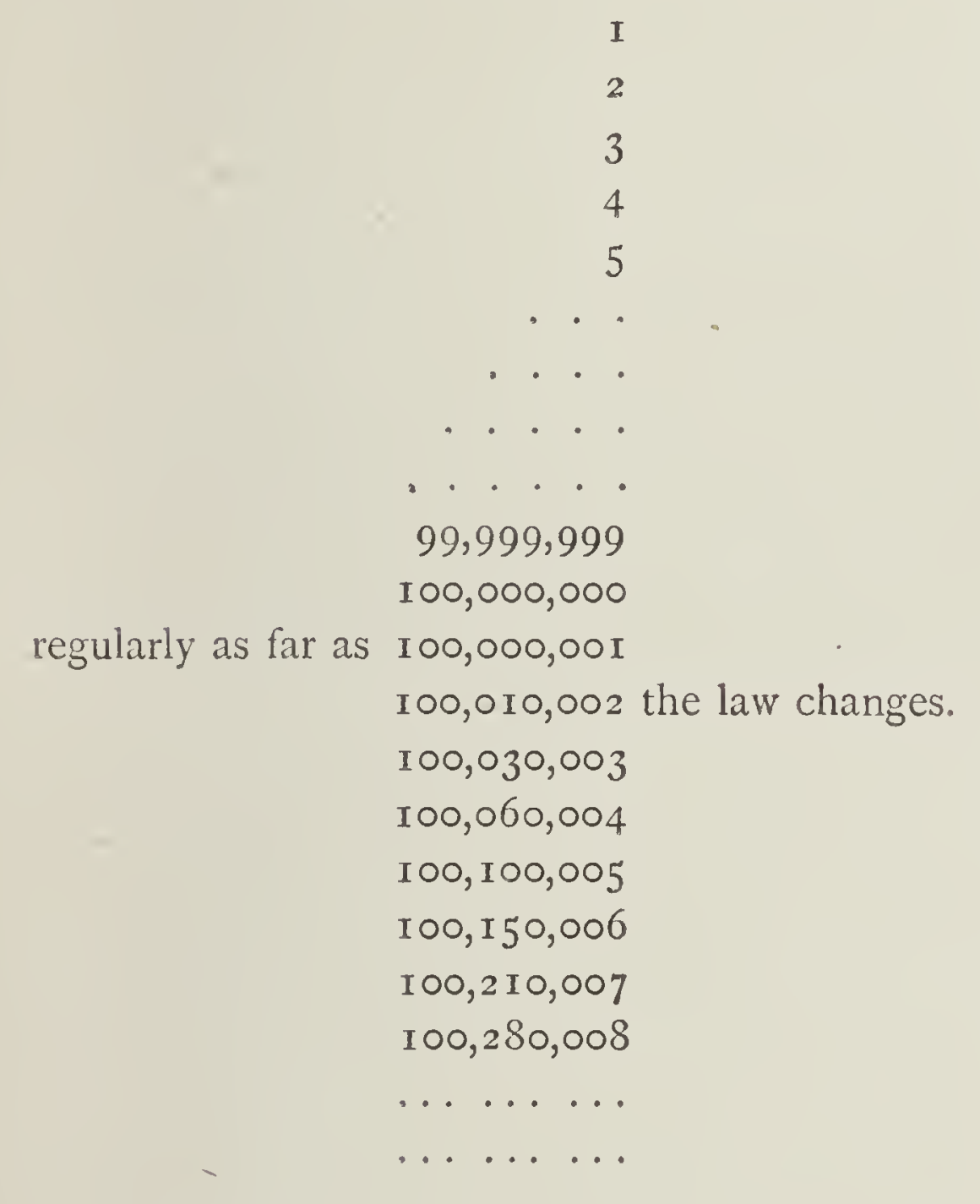

"The law which seemed at first to govern this series failed at the hundred million and second term. This term is larger than we expected by 10,000 . The next term is larger than was anticipated by 30,000 , and the excess of each term above what we had expected forms the following table:- 


$$
\begin{array}{r}
10,000 \\
30,000 \\
60,000 \\
100,000 \\
\text { I } 50,000
\end{array}
$$

being, in fact, the series of triangular numbers, ${ }^{1}$ each multiplied by ro,ooo.

"If we now continue to observe the numbers presented by the wheel, we shall find, that for a hundred, or even for a thousand terms, they continue to follow the new law relating to the triangular numbers; but after watching them for $276 \mathrm{I}$ terms, we find that this law fails in the case of the 2762 nd term.

"If we continue to observe, we shall discover another law then coming into action, which also is dependent, but in a different manner, on triangular numbers. This will continue through about 1430 terms, when a new law is again introduced, which extends over about 950 terms, and this, too, like all its predecessors, fails, and gives place to other laws, which appear at different intervals.

1 The numbers I, 3, 6, I0, I5, 21, 28, \&c., are formed by adding the successive terms of the series of natural numbers thus:

$$
\begin{aligned}
I & =I \\
I+2 & =3 \\
I+2+3 & =6 \\
I+2+3+4 & =10, \text { \&c. }
\end{aligned}
$$

They are called triangular numbers, because a number of points corresponding to any term can always be placed in the form of a triangle; for instance:

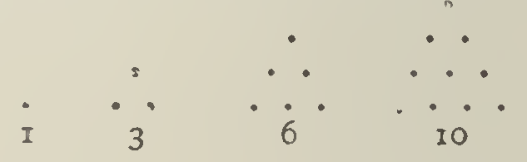


"Now it must be observed that the laze that each number presented by the engine is greater by unity than the preceding number, which law the observer had deduced from an induction of an hundred million instances, was not the true law that regulated its action, and that the occurrence of the number 100,010,002 at the 100,000,002nd term was as necessary a consequence of the original adjustment, and might have been as fully foreknown at the commmencement, as was the regular succession of any one of the intermediate numbers to its immediate antecedent. The same remark applies to the next apparent deviation from the new law, which was founded on an induction of $276 \mathrm{I}$ terms, and also to the succeeding law, with this limitation only-that whilst their consecutive introduction at various definite intervals, is a necessary consequence of the mechanical structure of the engine, our knowledge of analysis does not enable us to predict the periods themselves at which the more distant laws will be introduced."

It is not difficult to apply the philosophy of this passage to the question under consideration. Let us remember that the gestation of a single organism is the work of but a few days, weeks, or months; but the gestation (so to speak) of a whole creation is a matter involving the enormous spaces of time which have been described. Suppose that an ephemeron, hovering over a pool for its one April day of life, were capable of observing the fry of the frog in the water below. In its aged afternoon, having seen no change upon them for such a long time, it would be little qualified to conceive that the external branchiæ of these creatures were to decay, and be replaced by internal lungs, that feet were 
to be developed, the tail erased, and the animal then to become a denizen of the land. Precisely such may be our difficulty in conceiving that the advance of plants and animals by generation to a higher type of being is a possibility of nature. Granting that, during the whole time which we call the historical era, there have been no movements of this kind, nor even any of the less rare transitions in which only specific modifications are concerned, we know the historical era to be only an infinitesimal portion of the entire age of our globe. We do not know what may have happened during the ages which preceded its commencement, as we do not know what may happen in ages yet in the distant future. All, therefore, that we can properly infer from the apparent fixity of organic forms is, that such is the ordinary procedure of nature in the time immediately passing before our eyes. Mr. Babbage's illustration enables us to understand how this ordinary procedure may be subordinate to a higher law which in proper season interrupts and changes it.

We have seen that gestation consists of two distinct and independent stages-one devoted to the development of the new being through the conditions of the inferior types, or, rather through the corresponding first stages of their development; another perfecting and bringing the new being to a healthy maturity, on the basis of the point of development reached. It becomes very clear, that the protraction of the more general condition, at some given stage, till a higher special point was reached-overleaping, as it were, the intermediate space-is all that is necessary for an advance from one grade of being to another. 
We may never see an example of the working of the actual law which is supposed to be capable of producing such an advance of grade; but something approaching to it in effect has been observed. Sex is fully ascertained to be a matter of development. All beings are, at one stage of the embryotic progress, neuter; a certain number of them are afterwards advanced to be of the more powerful sex. The ingenious Huber first made us aware of an instance, in a humble department of the animal world, of arrangements being made by the animals themselves for adjusting the law of development to the production of a particular sex. Amongst bees, as amongst several other insect tribes, there is in each community but one true female, the queen bee, the workers being false females or neuters; that is to say, sex is not carried on in them beyond that early point where no special determination is to be seen, the result being, as might be expected, sterility. The preparatory states of the queen bee occupy sixteen days; those of the neuters, twenty; and those of males, twenty-four. Now, it is a fact, settled by innumerable observations and experiments, that the bees can so modify a larva, which otherwise would result in a worker, that, when the perfect insect emerges from the pupa, it is found to be a queen or true female. For this purpose they enlarge its cell, make a pyramidal hollow to allow of its assuming a vertical instead of a horizontal position, keep it warmer than other larvæ are kept, and feed it with a peculiar kind of food. From these simple circumstances, leading to a shortening of the embryotic condition, results a creature different in form, and also in dispositions, from what 
would have otherwise been produced. Some of the organs possessed by the worker are here wanting. We have a creature "destined to enjoy love, to burn with jealousy and anger, to be incited to vengeance, and to pass her time without labour," instead of one "zealous for the good of the community, a defender of the public rights, enjoying an immunity from the stimulus of sexual appetite and the pains of parturition; laborious, industrious, patient, ingenious, skilful; incessantly engaged in the nurture of the young, in collecting honey and pollen, in elaborating wax, in constructing cells and the like!paying the most respectful and assiduous attention to objects which, had its ovaries been developed, it would have hated and pursued with the most vindictive fury till it had destroyed them!" I It may be observed that there is, from the period of oviposition, a destined distinction between the sexes of the young bees. The queen lays the whole of the eggs which are designed to become workers, before she begins to lay those which become males. But the condition of her reproductive system evidently governs the matter of sex, for it is remarked that when her impregnation is delayed beyond the twenty-eighth day of her entire existence, she lays only eggs which become males.

We have here, it will be admitted, a most remarkable illustration of the principle of development, although in an operation limited to the production of sex only. Let it not be said that the phenomena concerned in the generation of bees may be very different from those concerned in the reproduction of the higher animals.

${ }^{1}$ Kirby and Spence's Introduction to Entomology. 
There is a unity throughout nature, which makes the one case an instructive reflection of the other. ${ }^{1}$

We shall now see an instance of development operating within the production of what approaches to the character of variety of species. It is fully established that a human family, tribe, or nation, is liable, in the course of generations, to be either advanced from a mean form to a higher one, or degraded from a higher to a lower, by the influence of the physical conditions in which it lives. The coarse features and other structural peculiarities of the negro race only continue while these people live amidst the circumstances usually associated with barbarism. In a more temperate clime, and higher social state, the face and figure become greatly refined. The few African nations which possess any civilization exhibit forms approaching the European; and when the same people in the United States of America have enjoyed a within-door life for several generations, they assimilate to the whites amongst whom they live. On the other hand, there are authentic instances of a people originally well-formed and good-looking, being brought, by imperfect diet and a variety of physical hardships, to a meaner form. It is remarkable that prominence of the jaws, a recession and diminution of the cranium, and an elongation and attenuation of the limbs, are peculiarities always produced by these miserable conditions, for they indicate an unequivocal retrogression towards the type of the lower animals.

$1 \mathrm{M}$. Hampe has observed in the creeping willow (salix repens) that twigs above the water blossom as females, whilst those twigs which have been in the water, and subsequently blossomed when the water dried up, had only male blossoms. This seems a case analogous to that of the determination of sex by the bees, and may be held as an additional proof of the power of circumstances to affect development to very important results. 
Thus we see nature alike willing to go back and to go forward. Both effects are simply the result of the operation of the law of development in the generative system.

Let us trace this law also in the production of certain classes of monstrosities. A human fœtus is often left with one of the most important parts of its frame imperfectly developed; the heart, for instance, goes no further than the three-chambered form, so that it is the heart of a reptile. There are even instances of this organ being left in the two-chambered or fish-form. Here we have apparently a realization of the converse of advance of grade, so far, at least, as one organ is concerned. Seeing a complete specific retrogression in one point, how easy it is to suppose a simply natural process, reversing the phenomenon, and making a fish mother develop a reptile heart, or a reptile mother develop a mammal one. It is no great boldness to surmise that a superadequacy of force in the measure of this under-adequacy (and the one thing seems as natural an occurrence as the other) would suffice in a natatorial bird to give it as a progeny the ornithorhynchus, or might give the progeny of an ornithorhynchus the mouth and feet of a true mammalian, and thus complete at two stages a passage from one class to another.

Perhaps, with the bulk of men, even those devoted to science, the great difficulty is, after all, in conceiving the particulars of such a process as would be required to advance a fish into a reptile. And yet no difficulty could well be less substantial, seeing that the metamorphosis of the tadpole into the frog - a phenomenon presented to our observation in countless instances every spring-is, in part 
at least, as thoroughly a transmutation of the fish organization into the reptile, as the supposable change of sauroid fishes into saurian reptiles could ever be. It is different, as being only a process in ordinary generation; but it realizes, as for as the necessary organic changes are concerned, the hypothetic view of an advance of one grade of animal forms into another. There is another fact connected with the reproduction of the batrachian order of reptiles, that, when the young are enclosed in a dark box sunk in a river, with holes through which the water may flow, the animals grow, but never undergo their destined change: they become gigantic tadpoles, and the reptile characters are not developed. Here the progeny of a reptile literally becomes a fish, and transition of species is thoroughly realized, although in retrogression. And this is an instance in which the whole animal is concerned. Now surely no one will deny that that which we see nature undo she is able to do, and might be seen doing, if the proper occasion were to occur, or were the requisite attendant conditions realized.

So much with regard to grade. Let us now consider the principle of modifability - that part of the hypothesis to which we are to look for an account of the external variations and adaptations of animals.

Here we are directly opposed by the prevalent doctrine among naturalists, that species is intransible, and has so continued during all the time that scientific observation has existed. ${ }^{1}$ There is a certain variability, they admit,

I Dr. Carpenter says, "Although the life of all organized beings commence. in the simplest and most general type of organic structure, so that there is no perceptible distinction between their germs, yet we see that each germ must have a certain capacity of development peculiar to itself; since it is a general law of 
in organisms, throughout successive generations, and for this variability external conditions may account; but such variations show a disposition to give way, when the original conditions are resumed, or when the changed individual is mingled in alliance with the original stock. There is therefore a fixed and immutable character which we call species, and which can only be traced to an origin differing as an event from the procedure of nature in our own time. I trust to be able to show that this doctrine is in such a condition with regard to facts, and has of late been obliged by facts to make so many shifts in its assumptions, that it is not entitled to the respect usually assigned to it.

The doctrine theoretically attaches the term species to every organism which manifests the same peculiarities throughout a series of generations. Practically, without waiting to watch successive generations, or where, from the extinction of the organism, this may be impossible, naturalists give the appellation to every organism which presents a plurality of individuals similarly marked. Very small peculiarities suffice. A particular spot on the wing of a butterfly constitutes it a distinct species. The Golden Plover of Australia was so reckoned, and got the name of Xanthocheilus, from only having a small portion of

organic development that like produces like. However varied may be the series of forms through which the parent passes, the offspring repeats these with the greatest exactness; and the whole scheme of development may be described as one in which the primordial cell is tending towards the attainment of the perfect form and condition of its parent." I would venture to remark that, without seeing the germ of a particular being maintain the tendency to the parental form in the nidus of an animal specifically different from its parent, we are not entitled to assume that it has "a certain capacity of development peculiar to itself." Its capacity of development may be quite indefinite, and only bound down to the attainment of the parental form by being kept and nourished by the parent. 
yellow in the commissure of its bill. At the same time, in palæontology, such a peculiarity as an extra-plication in the enamel of a fossil pachiderm's tooth, is sufficient to obtain a specific name for that animal, and constitute its origin a separate miracle. With equal facility, naturalists of this predominant order make up groups of species into genera, and groups of genera into families and tribes.

Suppose the doctrine were to be taken according to the practice, we should possess a fact speaking strongly against fixity of species. It has been pointed out by an eminent botanist that, amongst the latest fossil plants, are poplars, pines, birches, and hornbeams, like those now existing, but not the same. Thus one species has replaced another in even comparatively recent times. It may be asked, if the same change of species has not been going on since? The vague descriptions of ancient botanists forbid our speaking confidently of the intermediate ages. But look to the present time. In districts examined narrowly at no distant day, new species are continually being found by new investigators. It will be said that these are owing to the acuteness of modern observers. But this is begging the whole question. "We do not know," says our author, "that we are entitled to assert, that botanists were so mole-eyed thirty years ago, that their quick-sighted successors have been able to add twenty-five per cent. to the number of ascertained species growing at their own doors." 1 Grant, then, that the peculiar plants in question really are species, the probability undoubtedly is, that they are newiy formed

' Gardeners' Chronicle, July I I, I846. 
species, true examples of that very phenomenon which the superstition of science would hold to be a supernatural event.

Still, take the doctrine according to the practice, and let us see how it stands with regard to certain facts recently ascertained. Amidst all the dogmatism which has been indulged in on this subject, the assumed distinction of species has given way in numberless instances, both in the vegetable and animal kingdoms. In botany, the wider distinction of genus, and even that of whole tribes, has proved in some cases fallacious. According to Dr. Lindley, "So entirely in the simplest forms of Thallogens [an assemblage embracing sea-weeds, fungi, and lichens] is all trace of series missing, that in some of them their reproductive matter has been regarded by certain writers as altogether of an ambiguous nature. In their opinion, it is even uncertain whether this matter will reproduce its like, and whether it is not a mere representation of the vital principle of vegetation, capable of being called into action either as a Fungus, an Alga, or a Lichen, according to the particular conditions of heat, light, moisture, and medium, in which it is placed; producing Fungi upon dead or putrid organic beings; Lichens upon living vegetables, earth, or stones; and Algæ where water is the medium in which they are developed. Kützing endeavours to maintain the following propositions connected with this subject:- Ist, the formation of organic matter can only take place by means of the previously dissolved elements of other organic principles; 2nd, simple globules, such as Cryptococcus, Palmella, and Protococcus, can give birth to different 
formations, according to the influence of light, air, and temperature; 3 rd, we must regard all the forms of lower algæ as vegetations of a very simple structure, and distinguish them from each other, notwithstanding that in certain circumstances they may raise themselves to vegetations of a higher form; for, in other circumstances, they can exist and multiply independently; 4th, the same formation may be produced by primitive formations of altogether different kinds." "It has been said," adds Dr. Lindley, "that Algæ are aquatics, while Lichens and Fungi are terrestrial; but Fungi will develop in water, when they assume the form of Alge." 1 Undoubtedly eight so-called genera of fungi are now set down as only variations of one plant (Thelephora sulphurea), arising from peculiar conditions of culture.

Even in higher departments of the vegetable kingdom, the revolutions have been very remarkable. In a recent memoir on the Coniferæ, six so-called species of pine are wound up into one. The cowslip, primrose, oxlip, and polyanthus, which were always regarded as distinct species, are now found to be producible from one set of seeds, under various conditions; they are radically one plant. So also "the clove, pink, and carnation are only varieties of a flower growing among the ruins of some of our old castles, the Dianthus caryophyllus." The artichoke of the garden and the cardoon (a kind of thistle) of the South American wild, are held as distinct species in all botanical works; yet the artichoke, in neglect, degenerates into the cardoon. ${ }^{2}$ The ranunculus aquatilis and the ranunculus hederaceus

1 The Vegetable Kingdom, 8vo, r846, p. 5 .

2 Darwin's Journal of a Voyage Round the World. 
are, in like manner, set down as distinct species; but behold the secret of their difference! While the former plant remains in the water, its leaves are all finely cut, and have their divisions hairy; but when the stems reach the surface, the lcaves developed in the atmosphere are widened, rounded, and simply lobed. Should the seeds of this water-plant fall upon a soil merely moist without being imundated, the result is the ranunculus hederaceus-the presumed distinct specics-with short stalks, and none of the leaves divided into hairy cut work! ${ }^{1}$ 'To come to a more familiar instance. The various bread-forming grains, wheat, barlcy, oats, rye, are found to be resolvable into one. If wheat be sown in Junc, and mown down so as not to be allowed to come to car till the next season, the product will be found to consist partly of rye or some other of the cercals. Oats have in like manner been transformed into rye, barley, and even wheat. 'Till a recent period, this phenomenon was doubted; but it has been tested by experiment, and reported on by so many credible persons, that it can no longer be rejected. ${ }^{2}$ And it appcars, that poorness of soil has the same effect as mowing down. Onc observer states that, in a ficld of wheat, near Lucerne, he saw ears rescmbling barlcy, but with grains similar to rye, growing from the same stem

\section{'Lamarck's Philosophie Zoologique.}

2 "I have had occasion to make a careful comparison of the textures of the seed-conts of the corn-grains; and 1 find such a marked difference between those of wheat, barley, and onts, that 1 cannot yet believe in theirmutual convertibility, until this has been established on more satisfactory evidence. For it is a rule that has hitherto been found to hold good most uniformly, that intimate structure is far more constant than external form, and is a better test of affinities and differences: e.g., among all the varieties of apple, there is the same intimate structure; so also among all the varieties of ferr; and these never approximate one another, notwithstanding the approximations in the appearance, form, and flavour of these fruits."-MS. Notes of a P'hysiologist. 
with ears of wheat. ${ }^{1}$ Dr. Lindley, who publishes these facts, acknowledges there being no theoretical improbability in such transformations, seeing that, "in orchidaceous plants, forms just as different as wheat, barley, rye, and oats, have been proved by the most rigorous evidence to be accidental variations of one common form, brought about no one knows how, but before our eyes, and rendered permanent by equally mysterious agency." ${ }^{2}$ It is more than probable that the greater number of what may be called the domesticated plants, are unsuspected variations of others, which, growing wild, are recognised as different species. One noted instance of such transition has been detected in our different kinds of cabbage, savoy, broccoli, and cauliflower. They are all common descendants of a plant which is sometimes found growing wild upon our sea-shores, the Brassica oleracea-a transition which no one can appreciate till he has compared the tough slender stem and small glaucous leaf of the original, with the stout fleshy stem and large succulent leaves, sometimes gathered into a heart several feet in circumference, which he will find in the most familiar of the cabbages.

${ }^{1}$ Gardeners' Chronicle, 1846 , p. I 8 . The witness in this case signs himself, C. Wayth, Bursted House, Maidstone. See p. Ioz of the same volume; also the Gardeners' Chronicle for August and September, 1844, where an experiment by Lord Arthur Hervey is recorded. See, further, the Magazine of Natural History, new series, i. 574, and Reports of Ray Society, r846, p. 38r.

2 After these facts had been presented in several editions of the present work, challenged on merely speculative grounds, but never truly shaken, botanists were astonished, in 1852 , by the announcement of $M$. Fabre, that an experiment conducted by him during twelve years with the wild grass Egilops ovata, had resulted in its transition into true wheat, "of such quality as was not excelled on the neighbouring farms." The philosophical consequence deduced by the Gardeners' Chronicle of Dr. Lindley, is that "faith in those lower classes of botanical distinctions which have been said to represent permanent natural differences, is gone." "Rye," says this writer, "is less different from wheat than is ægilops, and may very well be another ægilopian form. So again of barley, the wild state of which is just as uncertain; we may now expect that some clever experimenter will trace it to an origin as surprising as that of wheat." 
What respect, it may be asked, can we attach to the doctrine of intransibility of species, when we find its adherents wrong in so many instances? Admit their explanation, that a mere mistake has been made in calling

FIG. 79.

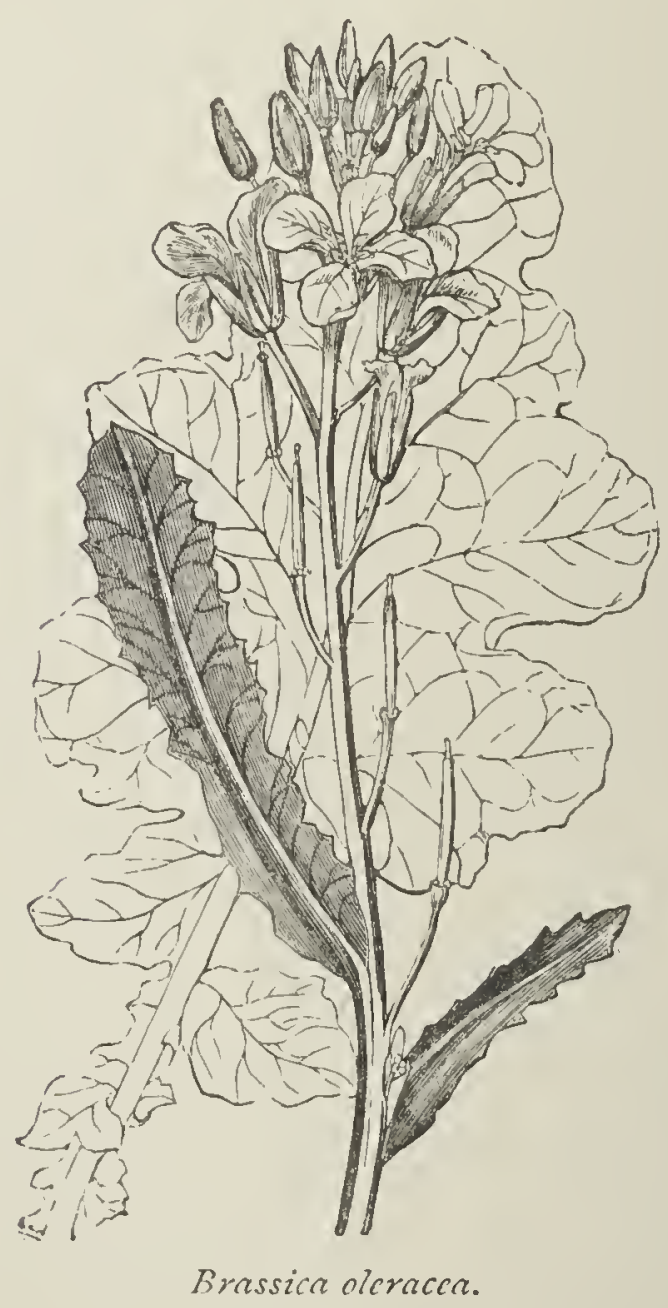

that species which was only variety, what guarantee can we have for the fixity of any so-called species, when it has given way in such instances? What is species, if it cannot be fixed upon such a vast assemblage as the Thal- 
logens, or even the progeny of the Thelephora sulphurea? Of the believers in species as a fixed thing, can we now believe that they know anything about it? Apart from all theorising about the absolute character of the thing called species, do not these facts show a transibility and intercommunion of forms totally at variance with those general opinions as to fixity which now reign in the scientific world?

In the animal kingdom, we have fewer illustrations of modifiability of transition; but they tend to exactly the same effect. I shall here pass over the succession of forms which appears in common infusions. Neither shall I enter into the particulars of a late curious investigation by a Danish naturalist, which results in showing alternative forms in the succession of certain animals low in the scale, including the medusa; that is, as it were, A giving birth to $\mathrm{B}, \mathrm{B}$ to $\mathrm{C}$, and $\mathrm{C}$ to $\mathrm{A}$ again. ${ }^{1}$ Such matters are as yet obscure, however highly they may promise in time to illustrate this question. Let us rather look to departments of this kingdom which come broadly under the observation of naturalists. In the mollusca there occurs a modifiability of a most remarkable nature. Fresh-water species of these, exposed to brackish water, assume, where able to survive the change, characters in the exterior form of the shell proper to their marine congeners, and involving differences from the original animal much greater than is usually sufficient with naturalists to constitute a distinction of species, if not of tribe or family. Many years ago, Pennant remarked the singular modification of stomach which the common trout appears to have under-

'Steinstrup on Alternate Generation, published by the Ray Society. 
gone in the lakes of the county of Galway, in consequence of feeding on shell-fish. The integument has become as thick as the gizzard of a bird, manifestly in consequence of an effort of nature to accommodate herself to the peculiar food of the animal. So also, when a common gull was fed upon corn, the parietes of the stomach were found, on examination after death, to be thickened. ${ }^{1}$ The peculiar forms of the mandibles of birds are grounds of specific distinction; yet it is now ascertained that these are variable under particular conditions as to food. It has been tried with confined birds; and even in a wild state there occur individuals strangely modified in this respect, the magpie, woodpecker, and rook, having all been found with the crossed mandibles of the loxia. ${ }^{2}$ Look also at the changes from the wild animals to those domesticated ones which are known to be descended from them. "When the eggs of the wild goose," says Professor Low, "are taken, and the young are supplied with food in unlimited quantity, the result is remarkable. The intestines, and with them the abdomen, become so much enlarged, that the animal nearly loses the power of flight, and the powerful muscles which enabled him in a wild state to take such flights, become feeble from disease, and his long wings are rendered unserviceable. The beautiful bird that outstripped the flight of the eagle, is now a captive without a chain." Another change is the transition from grey to white plumage. In the domestication of the pig, the author last quoted admits that there are reductions of the number of teeth, and variations of the number of the dorsal, lumbar, sacral,

1 Yarrell's Birds, iii. 57I.

2 Magazine of Natural History, vii. 57. 
and caudal vertebræ, producing differences greater than what are usually regarded as sufficient to constitute species. But the most striking observations on this subject are those of M. Roulin, made during a residence of several years in Columbia, relative to the races which had been introduced there in a domesticated state by the early voyagers, and allowed to run wild during the three centuries which have since elapsed. As an example, the hog: "Wandering all day in the wood, this animal has lost nearly all marks of servitude; its ears have become erect, its head broadened, and raised at the upper part, and its colour has been rendered permanent." It has, in short, returned to a strict resemblance to the wild boar of France. The cow, also, from the cessation of the practice of milking, has lost the abundant flow of milk which is found in her species in Europe: to get milk from her at all, it is necessary that her calf should be left with her. M. Roulin arrived at the following conclusions:- that animals naturalized in new countries undergo durable changes, bringing their organization into accordance with the climates in which they are destined to live; and that habits of independence soon make the domestic species resume the characters of the wild species from which they have sprung. We have here, it will be owned, equal proof that the tuskless hog of our farmyards is the same animal which roams the forest in formidable state and armature, as that the wild boar is the same with the domestic pig.

It is difficult, after what has now been seen, to regard the idea of species or specific distinction as descriptive of a fact in nature; it must be held as merely applicable 
to certain appearances presented, perhaps transiently, to our notice. The history of the question seems to be this. Naturalists, starting with a limited fund of observation,mainly, indeed, consisting of the remark which the most superficial observation supplies, that like usually produces like,-lay it down as an axiom that species is a determinate thing. In a little time, certain modifiabilities are observed. To maintain the axiom intact, these are called varieties. Afterwards, much greater variabilities are witnessed, even to the dissolution of genera among the cryptogams and cereals, and the community of algæ and fungi-water and land plants. Still, to keep the axiom whole, these are held in doubt, or relegated to a place in the elastic region of the varieties. Such is the stage which we have now attained. But this is a process the reverse of philosophical: it is to start with a theory, and then make facts succumb to it. Were the process reversed and the facts taken first, we should see that a great modifiability exists in organic nature, especially in the humbler departments of the two kingdoms. ${ }^{1}$ And seeing that this modifiability presents itself within the scope of a very limited experience, it might safely be

${ }^{1}$ It is a very curious fact that, whilst the lower classes of living beings are more capable than the higher of bearing the deprivation of these vital stimuli, they are at the same time more liable to alterations in their own structure and development, in consequence of variations in the degree of the agency of these, and of other causes external to themselves. Thus the forms of the lower tribes of plants and animals are liable to be greatly affected by the conditions under which they grow ; and these also modify their degree of development. It seems as if the formative power were less vigorous in the lower than in the higher classes; so that the mode in which it manifests itself in the former is more dependent upon external influences; whilst in the latter, it either predominates over them, causing the regular actions to be performed, or gives way altogether. The same principle applies to the early condition of the higher organisms; their embryoes, like those beings of permanently-low type which they resemble in degree of development, being liable to be affected by modifying causes, which the perfect beings of the same kind are able to resist.-Carpenter's General Physiology, 185 r. 
Inferred that something much greater would be detected, if our range of experience were extended, especially since the world presents us with results, which can only be naturally accounted for in this manner. It is here a fact to be specially remarked, that the greatest variability, the most striking instances of transition or intercommunion of forms, are offered in the lower grades of being. In these departments of nature, generation is rapid and abundant, in comparison with the reproduction of the higher forms. What requires perhaps a century in the one case (say a series of three generations) will be accomplished in a day in the other. Nothing, therefore, seems more natural than that phenomena connected with the reproduction of the higher animals should require a much longer time to be evolved than those connected with the lower. The time may be, in the one case, such as to fall within our range of observation (and this range, as far as scientific accuracy is concerned, is but a day), while in the other case it may be, and indeed, on a just comparison, we should expect it to be, beyond even the whole space of what is called the historical era. Such is precisely the point to which the present theory would lead us. We see that permanency of specific distinctions in the higher organisms might sink, as it has done in so many of the lower, if we had as long a time to observe their reproductive history, as would, in embryology, be equivalent to the space of time during which we have observed the humbler creatures. We see this persistency, and think it fixed, exactly as men have hitherto seen the solar position in the universe. We advance among the stars at the rate of two millions of millions of miles a year; but astronomers tell us that it would take 
ninety millions of years to enable us to pass through the whole, even at this rapid rate. Well, therefore, might the unassisted eye and unexamining intellect presume the place of the solar system to be fixed, for it is evident that no human tradition could record changes indicating the translation. Yet we do pass on to Hercules, although forty centuries failed to remark the circumstance. So may specific distinctions in the higher animals have been changed in the course of the vast periods which geology shows to have elapsed since the commencement of organization upon earth, although, during that inappreciable segment of the great cycle which has passed since man woke to the mysteries of nature, no single transition of the kind might have been observed. The whole case reminds us greatly of the objection which stood against the earth's motion from the days of Aristarchus downwards, that there ought in that case to be an observable parallax. As there was no observed parallax, because the earth's orbit is an insignificant space in comparison with the distance of the stars, so is our observation of animal changes insufficient to show transitions of species in the higher grades of the kingdom, because it is a mere span in comparison with the vast ages actually concerned in the phenomenon.

A similar principle of explanation applies to the alleged tendency of variety to be obliterated. While it is only to be expected that a single animal showing an originality of form will fail to impress it on its posterity, if it be absorbed in alliance with animals possessing no such peculiarities, there is no reason to believe that a variety uniting with a creature like itself will not have descendants of its own 
character. We judge on this question in the midst of a fully-peopled world; but we must cast back our minds to a time when it was only in the course of being filled with living things. We must think of a time when, for example, over large portions of the surface mountain tracts were rising, perhaps beside low and marshy grounds, or when forests began to spread over extensive regions. Here a new field of existence is presented. The fecundity of nature has ordained that her creatures shall ever be pressing upon the verge of the local means of subsistence. A colonizing principle accordingly comes into play. On such an occasion, it might be that individual wading birds began to advance into dry grounds and woods, elected to the new life perhaps by some of those varieties of appetency which occur in all tribes; thus exposing themselves to new influences, and ceasing to experience those formerly operating, until, by slow degrees, in the course of a vast space of time, the characters of the pheasant tribe were evoked. ${ }^{1}$ Here, it will be at once perceived, re-absorption of peculiarities was not likely to occur ; for the field of colonization, so to speak, was sufficiently wide to allow of the new families wandering farther and farther away from the original grounds and the ancestral tribes, while return was prevented by the full population continually pressing behind. Altogether, this presents a very different view of varieties from that which is commonly presented, when we see a single

1 A correspondent states that he has seen a variety of the goldfinch marked by strong distinguishing characters, - considerably larger size, more graceful form, and much richer and more lustrous plumage, - which, bird-catchers say, occurs frequently as a progeny of the ordinary bird. The distinctions of this animal are greater than those held in many instances as specific; there seems no room to doubt in such an instance that pairs so peculiar might, in fresh ground of their own, give rise to a race which naturalists would call a separate species. 
peculiar individual standing in the midst of, and necessarily allying itself to, the original stock. The process of variation as a consequence of changed conditions and appetencies being left unchecked, and that for a vast space of time, we obtain at length creatures fixedly peculiar; that is, however, creatures which merely appear so, because there is no replacing them in the former conditions in this densely-peopled globe, and, though there were, the retrogression to the anterior forms would require a space of time beyond the range of human observation.

It may now be remarked, that, in this hypothetic variability, the possibility of re-union may, and in all probability does, depend upon the degree of similarity which still exists in the different individuals, supposing them to be members of the same stirps or line of being, for I believe that no others are capable of intermixture. As has been remarked by a venerable naturalist - "Many bulbous roots that have been increased during a long succession of years by offsets, become absolutely incapable of bearing seed; and it is not more strange that plants which in different soils and climates have diverged from the original form of the first created individual, should refuse to bear seed by the one which has departed most widely, and yet produce it readily by another, which still agrees with it in some important points." 1 Admit this, and the grand basis of specific distinction, the possibility of intermixture, can no longer be laid hold of. Plants and animals of one line are only to be expected to unite, which being of one grade of organization, are also

'Letter of the Dean of Manchester in Gardeners' Chronicle, July I8, I846. 
sufficiently near to each other in those peculiarities liable to modification from external causes, on which the socalled distinctions of species are grounded. ${ }^{1}$

The illustrations of our hypothesis are now closed. We have seen that, even judging from short spaces of time, there is a great and incontestable modifiability of organic forms, - -so great as to have absorbed the presumed distinctions of species in many noted instances. It appears that this modifiability, by some hidden law, immediately obeys external conditions. It has also been seen that, though no transition from grade to grade was ever observed to take place, the means and mode by which it might naturally happen are not concealed from us; they are pictured before our eyes in the metamorphosis of the tadpole, and even practically exemplified in a narrow degree in the natural history of the bee. It has been shown that no organism is independent, but all stand in "a web of intimate relation," undeniably indicating that their origin is one connected phenomenon. It has been seen that the higher animals, when their organization is examined, are only improvements upon the lower-advanced forms of the same beings; and the same holds good regarding plants. In conformity, too, with this gradation of forms, is the succession of the actual animals throughout the geological ages;-a fact most important-a piece of actual tangible evidence, bearing wholly, when taken in connexion with proofs of other kinds, in favour of the natural origin of species. When, in addition to all this, we learn that life is believed by many men of science to spring occasionally, 
even now, from inorganic elements-when we find that, moreover, it is generally admitted by that class of men to be in itself a simply natural phenomenon, it seems difficult to resist the impression that vestiges, at least, are seen of the manner and method of the Creator in this part of his work. It appears to be a case in which rigid proof is hardly to be looked for. But such evidences as exist, are remarkably consistent and harmonious. The theory pointed to comports with everything else which we have learned accurately regarding the history of the universe. Science has not one positive affirmation on the other side. Indeed, the view opposed to it is not one in which science is concerned; it appears as merely one of the prejudices formed in the non-age of our race, and which it becomes the manhood of humanity to dismiss. For the history, then, of organic nature, I embrace, not as a proved fact, but as a rational interpretation of things as far as science has revealed them, the idea of Progressive Development. We contemplate the simplest and most primitive types of being, as giving, under a law to which that of like-production is subordinate, birth to a type superior to it in compositeness of organization and endowment of faculties; this again producing the next higher, and so on to the highest. We contemplate, in short, a universal gestation of nature, analogous to that of the individual being; and attended as little by circumstances of a startling or miraculous kind, as the silent advance of an ordinary mother from one week to another of her pregnancy. We see but the chronicle of one or two great areas, within which the development has reached the highest forms. In some others, as Australia and the 
islands of the Pacific, devclopment appears to have not yet passed through the whole of its stages, because, owing to the comparatively late uprise of the land, the terrestrial portion of the development was there commenced more recently. It would commence and proceed in any new appropriate area, on this or any other sphere, exactly as it commenced upon our area in the time of the earliest fossiliferous rocks, whichever these are. Nay, it perhaps starts every hour with common infusions, and in similar humble theatres, and might there proceed through all the subsequent stages, granting suitable space and conditions. Thus simple-after ages of marvelling-appears Organic Creation, while yet the whole phenomena are, in another point of view, wonders of the highest kind, being the undoubted results of ordinances arguing the highest attributes of foresight, skill, and goodness on the part of their Divine Author.

This seems the proper place at which to remark more particularly, that the course of organic nature is not invariably forward. It has its ebbs as well as its flows, though the general movement is to be contemplated as onward. As a normal arrangement in the case of the species, the animal may be better provided by nature in its youth than afterwards; for example, many marine mollusks are at first fitted for a free-swimming life, but, as they attain maturity, lose their limbs, and become sessile. Such is a proceeding of nature, and we must take it as we find it. ${ }^{1}$ It throws an interesting light on

1 "The possession of locomotive power, at some period of life, by beings that are fixed, or nearly so, during the whole remainder of their existence, is a very general occurrence among Plants as well as Animals, and is evidently destined to prevent the overcrowding of any particular type in one spot. Locomotion is not ith 
some of the objections which have been urged against the present hypothesis, showing, for instance, how a gradetransition in that general gestation of nature which has been spoken of, might, in some of the series of beings, present us with animals comparatively high in some respects, to be followed by species in which, owing to the adaptive process, some of the higher features were reduced or erased. It is very curious that this recession of animals at their maturity to a lower range of qualities and an inferior mode of existence, and this recession of animals in the geological series (for example, the coming of saurians without distinct teeth, after the thecodonts which possessed that feature), have been presented together as objections to the theory of Progressive Development, without its being seen that the one fact suggests an explanation of the other, making out a support, instead of establishing a difficulty, for that view of the history of animated nature.

Early in this century, M. Lamarck, one of the most distinguished of modern naturalists, suggested that the gradation of animals depended upon some general law which it was important for us to discover. So far he was right; but the theory which he consequently formed with regard to the causes of the varieties of animated being,

itself a character of elevation; for it is presented by the zoospores of the simplest Algæ, and by the gemmules of Sponges and Zoophytes, which are propelled by ciliary movement. As in the case of other functions, elevation is marked by the development of organs specially set apart for the purpose. Perhaps the most curious instance of absolute recession is shown in the metamorphosis of the Cirrhipeds, which in their young state have not only distinct locomotive members, but also eyes, resembling those of Entomostracous Crustacea, but which lose these when they settle down for adult life. Here, as in the case of the curious larva of Star-fish, Echinida, \&c., it is obvious that the object of the peculiar endowments of the embryonic form is the dispersion of the individuals." - MIS. Notes of a Physiologist. 
was so far from being adequate to account for the facts, that it has had scarcely a single adherent. What M. Lamarck chiefly grounded upon was the well-known physiological fact, that use or exercise strengthens and enlarges an organ, while disuse equally atrophies it. He conceived that, an animal being brought into new circumstances, and called upon to accommodate itself to these, the exertions which it consequently made to that effect caused the rise of new parts; on the contrary, when new circumstances left certain existing parts unused, these parts gradually ceased to exist. Something analogous was, he thought, produced in vegetables, by changes in their nutrition, in their absorption and transpiration, and in the quantity of caloric, light, air, and moisture which they received. This principle, with time, he deemed sufficient to have produced the advance from the monad to the mammal. His illustrations were chiefly of the following nature. The bird which is attracted to the water by the necessity of seeking there its food, wishes to move about on the surface of the flood, and for this purpose strikes out its toes. Through the consequent repeated separations of the toes, the skin uniting them at the roots is extended, and at length becomes webbed. In like manner, the shore-bird which has no desire to swim, but has to approach the water for food, is constantly subject to sink in the mud. The bird, disliking this, exerts all its efforts to lengthen its legs; the result is, that, by continual habit for many generations, the legs of this order do at length become long and bare, as we see them. The error of the theory is in giving this adaptive principle too much to do. What undoubtedly is effectual in modifying 
the exterior peculiarities of animals, was obviously insufficient to account for the great grades of organization. In the present day, we have superior light from geology and physiology, and hence comes the suggestion of a process analogous to ordinary gestation for advancing organic life through its grades, in the course of a long but definite space of time, with only a recourse to external conditions as a means of producing the exterior characters. It must nevertheless be acknowledged that the germ of this natural view of the history of the animated world is presented in the work of Lamarck. ${ }^{1}$

The idea that any of the lower animals were concerned in the origin of Man, is usually scouted by unreflecting persons as derogatory to human dignity. It might in the same way seem a degradation to a full-grown individual, to contemplate him as having once been a helpless babe upon his mother's knee, or to trace him farther back, and regard him as an embryo wherein no human lineaments had as yet appeared. All organic things are essentially progressive: there would be no end to perplexity and misjudgment, if we were to take each up at its maturity, and hold it as made ridiculous by the consideration of what it was in its earlier stages:- the grandeur of the oak, for instance, lost in the idea of its once having been an acorn;

a "If I received the Development hypothesis as a generally true expression of facts, I should still feel at liberty to unite with it the Lamarckian hypothesis. For the tendency of all recent physiological investigation has been to show that the nutritive processes may be influenced in a very remarkable degree by states of mind; and I cannot question the fact, that these do not merely affect the individual, but that states of mind on the part of the parent affect the develop. ment of the offspring. I cannot doubt that what have been termed the spon. taneons variations of animals are frequently, if not always, due to conditions, mental or physical, operating upon the parent either before, or at the time of, conception, or during gestation."-MS. Notes of a Physiologist. See upon this question the Article "Varieties of Mankind," in the Cyclopædia of Anatomy and Physiology, vol, IV., pp. I304, I305. 
the nobleness of a Washington, or the intense intellectual force of a Bonaparte, sunk in recollections of their schoolboy-days. In nature much will appear humble by contrast, but to a healthy mind nothing will appear contemptible. When we look in a right spirit into her mysteries, we discover only the manner in which her Master is pleased to work, and all then appears beautiful exceedingly. Thus it has never occurred to any physiologist to love or admire his race the less, because he knew that the human organization has to pass through stages of reproduction, the earlier of which are not to be distinguished from those of the invertebrate animal. So need it never be imputed as a degradation to mankind, that the force and tendencies of their illustrious nature once lay imperfectly developed in some humbler form of being. One source of the prejudice here to be contended with, rests in our associations with the word ancestry. From seeing our immediate seniors possessed of venerable qualities, we naturally incline to venerate an ancestry; we presume its constituent elements to be something superior to ourselves. When called upon, therefore, to place any of the inferior orders of being in this relation, a shock unavoidably follows. But here the error lies in transferring our ideas of the qualities of a sire or grandsire to a collective ancestry. The elder people of the earth are in reality its children, and we are its true senate. The feeling due to early generations, is the half-pitying benevolence which we daily bestow upon childhood. It follows that the still earlier generations antecedent to the perfection of the human type, ought to be regarded with an extension of this same feeling-the modification of it which humane natures 
daily manifest in their treatment of the inferior animals. Our children, it may be said, are the representatives of the first simple and impulsive men of the earth: the lower animals represent the earlier pre-human stages of life. The right conception of the case is, that in these stages we are not to look for what is venerable, but, on the contrary, for what is humble and elementary. We are to expect but the primitice of man's masterful life-something not even ascending to the dignity of "the infant mewling in its nurse's arms." If thus prepared, we should experience no shock on hearing that the human form was preceded genealogically by others of humbler aspect. A deep moral principle seems involved in the history of the origin of man. He is the undoubted chief of all creatures, and as such may well have a character and destiny in some respects peculiar and far exalted above the rest; but it appears that his relation to them is, after all, one of kindred. Along with his authority over them, he bears from nature an obligation to abstain from wantonly injuring them, and as far as possible, to cherish and protect them. Good men feel this duty, as if it were a command from a source above themselves. It seems to them, that if the helplessness of childhood calls for kind and gentle treatment, much more does the essentially weaker character of the dumb creature. And if the innocence of infancy is touching, still more so is the even more harmless character, which (overlooking carnivorous instincts implanted in certain families for a wise purpose) attaches to the lower animals. It is common, under the influence of prejudice, to do gross injustice to the characters of these denizens of nature's common. We do not 
sufficiently reflect on their respectable qualities. Yet we must go to the dog for a type of the virtue of fidelity, and to the bee for that of industry. The parental affection of many animals is not below, if it is not considerably above, that of human mothers. Man nowhere exemplifics the virtue of patience, in the practical perfection in which we see it in the horse and many other creatures which become the slaves of his convenience. Nowhere does he display that perfect moderation in wants. Alas for man's boasted superiority--in how many respects does it fail beside the unassuming merits of the mere commonality of nature! 


\section{AFEINITIES AND GEOGRAPHICAL DISTRIBUTION OF ORGANISMS.}

All truth being self-consistent, we might expect that this view of the history of organic nature, if sound, would accord with a just classification of Plants and Animals, supposing such to exist. It is certainly very desirable that our hypothesis could have been subjected to this test; but it cannot be, for naturalists are as yet only struggling towards true classifications in both kingdoms. We may, nevertheless, make some inquiry into at least the general lineaments of that order which has long been alleged to exist in animated nature, with a view to ascertaining how far any such order agrees with a genealogical system.

The result of any investigations which I have been able to make, is, that there is an order in animated nature, but that it has hitherto been much misunderstood. We see some pointing to that "chain of being," or series of ascending forms, which has long been supposed to extend between the animalcule and the human being. It has been on the other hand successfully shown that beings do not form "a single and continuous series;" that it is "impossible to place all living animals in such 
an order that we may always pass from one species to another by following a decrease in perfection." "On the one hand, there are classes of animals so insulated, that nothing connects them with others." "On the other, there are types of organization which are absolutely indivisible, and of which the most perfect beings are superior to the mean of another type, while the most imperfect are inferior to it." A solution for the difficulty may be found, if we contemplate the animal kingdom (and, by consideration of parity, we may presume the vegetable also) as consisting of a plurality of series going on side by side with each other, but not all to the same point in the scale. Nor is this merely a hypothetical view of the animal kingdom. It is strongly pointed to by some of the most interesting discoveries in embryology. It is supported by several important considerations regarding the general characters of particular series. It likewise harmonizes with that order of fossils, which may be said to form a sort of rude outline of the history of organization upon earth. Finally, such reformation as this new view calls for in classifications, is accordant in its general demands with all those recently effected by the greatest naturalists, by which external and comparatively accidental characters are overlooked, and only the more essential affinities regarded. If it goes beyond the march of living naturalists, it goes in the direction in which they are going, and over ground to which I belicve they must quickly come, whether they adopt a genealogical view of the organic world or not.

The divisions of the animal kingdom, as we find them in Cuvier, are partly into grades, with a regard to dignity 
of organization-first into Vertebrata (having an internal skeleton) and Invertebrata, and afterwards into such divisions as these of the vertebrata-namely, Mammalia, Birds, Reptiles, Fishes. In these grades are comprehended animais of very various character,-animals which only agree in this particular of a community of grade or rank. But other divisions in the common classifications are into groups or series of animals closely allied to each other in form, and of one general character,-as, for cxample, the cephalopoda, the echinodermata, the crustacea. The one kind of division may be said to be transverse, the other longitudinal. Such a diversity gives rise to a suspicion that there is something wrong, something out of accordance with nature. And so it is. The true fundamental divisions are entirely of the latter kind-longitudinal; there only do we find persistence of characters; the other so-called divisions are only the marks of stages which the true divisions, the Stirpes of being, have reached in their respective courses. It is nevertheless necessary, in the meantime, to keep the existing classification in view, and to use its language, in order that my own views may be intelligible.

Cuvier divided the Invertebrata into three great masses, the Radiata, the Articulata, and Mollusca. Of these, the two last appear as co-ordinate, though distinct from each other; while the Radiata, again, may be considered as forming a kind of basis for the whole kingdom.

The Radiata are all of them animals of exceedingly simple structure, mostly inhabitants of the waters, many of them propagating not by ova, but by division of their bodies, or by the throwing out of little bud-like 
excresences. In this lower region are comprehended the Infusory animalcules, Internal Parasites (Entozoa), Sponges, Polyps, Sea-nettles (Acalepha), and some other obscure classes. Some of these appear to be distinct and independent series, which advance no further; such, in particular, are the internal parasites, which necessarily do not pass to any higher grade, because they have no sphere for further development. Others form the roots, as it were, of higher families.

There are two admitted methods of investigating the affinities of beings. One is to observe the connexion between the forms of the mature organisms; another is to examine the embryotic progress, and watch the succession of forms there presented. It is ascertained that no animal, in the course of its development, passes through the forms of all the animals meaner than itself. For example, the sea-nettle is at one time like the monad, an infusory animalcule, and then like the polyp; the mollusk is successively like the monad and polyp, but never like the sea-nettle. The articulate animal, again, is never like the polyp or sea-nettle, but proceeds at once from the monad form to that of the worm. This Professor Owen calls being "obedient to the law of unity of organization only in its monad stage." 1 The fact has been held as a difficulty in the way of the doctrine of unity; but perhaps it is only one of the same nature with that intimated regarding the assumed scale of being. I see animals classed by their affinities in distinct lines, or series, which I regard as stirpes or races. I would therefore expect the unity of organization to be liable to 
some such limitation as Mr. Owen points out. Is it not, in reality, that each stirps has a unity of organization for

FIG. So.

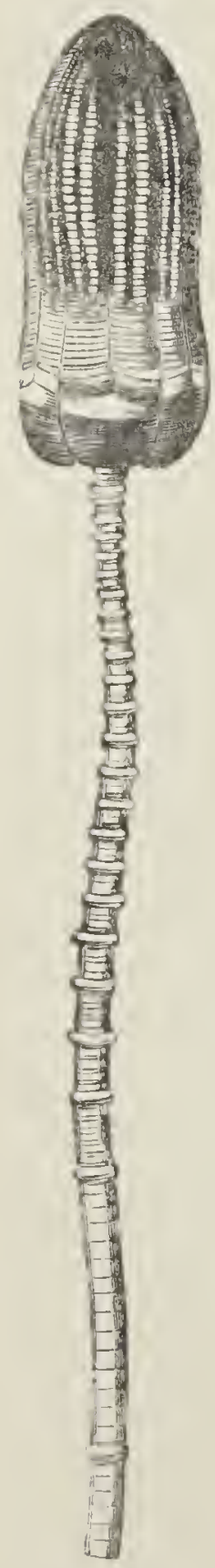

Encrinites moniliformis.

itself, or, in other words, that there is such a unity only as far as each particular series of animals is concerned? These breaks in unity, and the breaks in the chain of being, are but one thing: they are only disturbances to our preconceived ideas, not to a true view of nature drawn from its realities.

I shall not attempt to place all these obscure animals in genealogical series. The state of zoological science demands that such an effort should be postponed. Let us limit our attention to one class, the Echinodermata, or star-fishes, which are perhaps improperly ranked with other Radiata, seeing that their character is so much superior. In general highly organized, and enjoying free movement at the bottom of the sea, these animals are signally destructive. Admitted to be in their lower forms intimately allied to the Polyps, they probably start in some portion of that extensive order. One of their earliest forms is the Encrinus or stone-lily, a group of animals of which we have seen many varieties flourishing in the early seas, but which are now nearly extinct. The creature consisted of a stomach and mouth, surrounded by long tentacles or arms, placed upon the top of a stalk fixed to the sea-bottom, the whole being composed of numberless minute calcareous plates, con- 
nected by gelatinous substance. In more advanced forms of the same order (as the Comatula and the extinct Marsupite), the body and arms desert the stalk, and betake themselves to a free-swimming life; but, as has been

FIG. 8I.

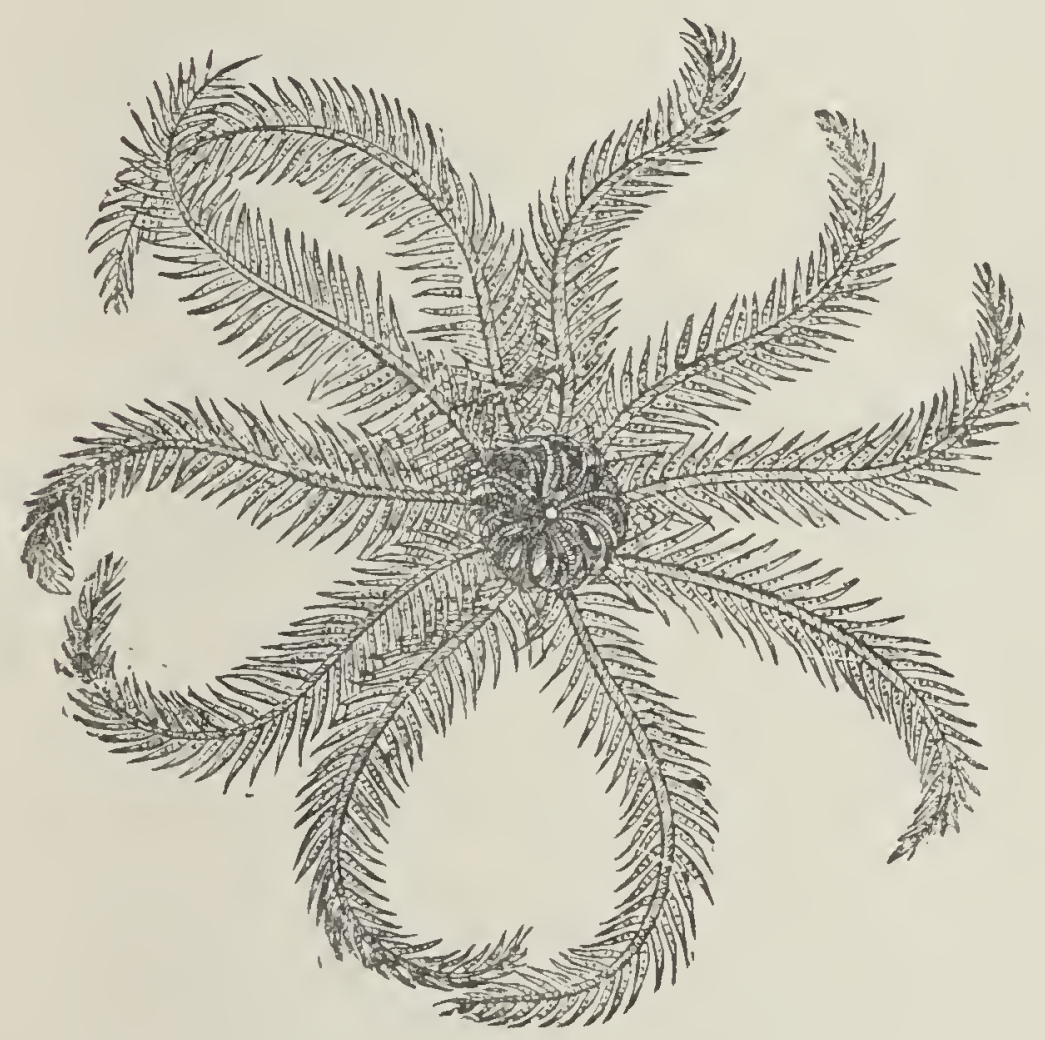

Comatula rosncea (recent).

elsewhere mentioned (page I 95), the young comatula lives for a time as an encrinus; that is, upon a stalk. Seeing that the same animal, in an earlier embryotic stage, represents a polypidom, it is probable that in the polypiaria is the origin of the echinodermatous line: it is first the polypidom, then the encrinus, then the freeswimming comatula or feather-star, the last being one 
of the most graceful animals in existence. In the higher genera of the latter family, the tentacles are shortened and reduced in number. In the Ophiurce, there are only

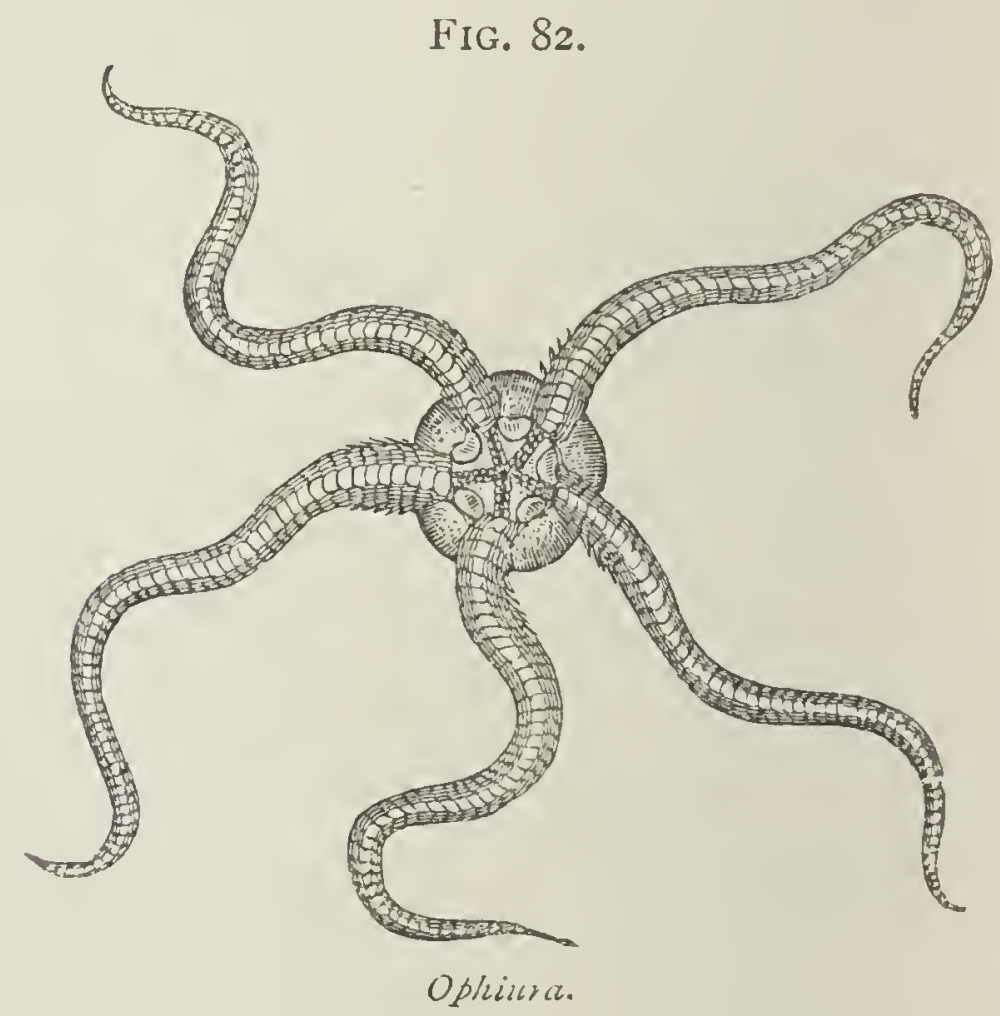

five long and simple rays projecting from the central body. Afterwards, in the Asteriada, or true star-fishes, the central part dilates step by step, until it fills up the interstices between the rays, and the form becomes a pentagonal disk. From this there is a clear passage to the Echinus or sea urchin, which is merely a spheroidal animal in a calcareous case, from which numberless spines and tentacles project, for locomotion and the collection of food. This form again becomes elongated into the cylindrical soft-bodied Holothuria, with a circle of tentacles at the oral extremity; thence the transition is easy to 
FIG. 83 .

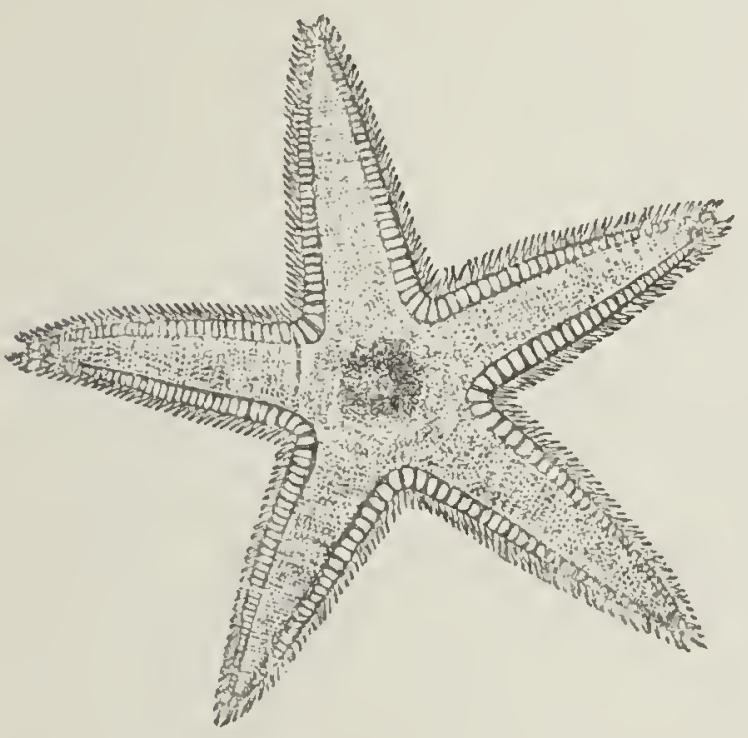

Astrias aurautiaca.

the genus Fistularida, animals externally worm-like, and possessing the rudiment of a heart, with red blood in the arteries. The reader cannot fail to have been struck by the greater number of forms passed through in this

FIG. 84.

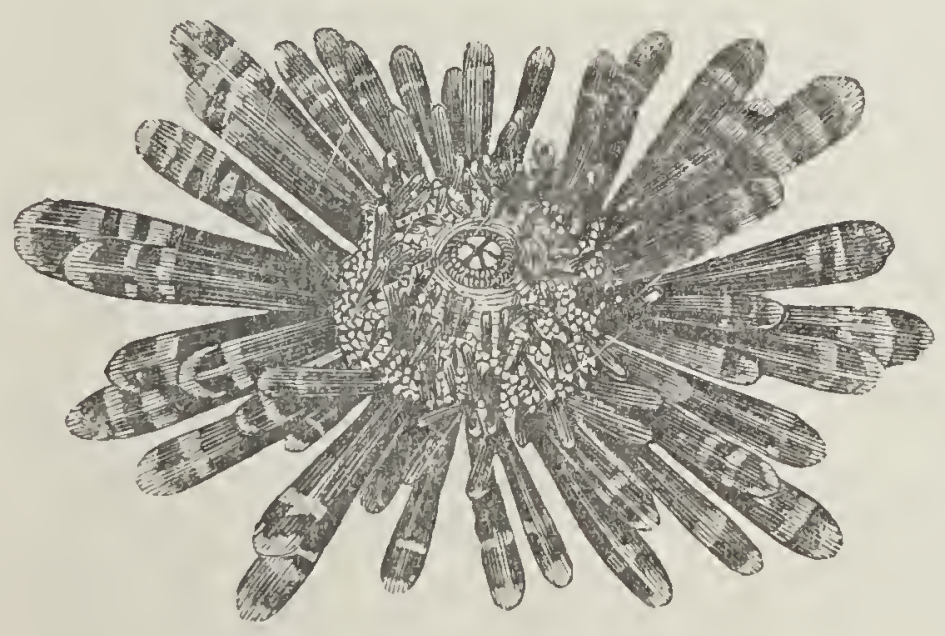

Echinus mammiliatus (recent). 
FIG. 85 .

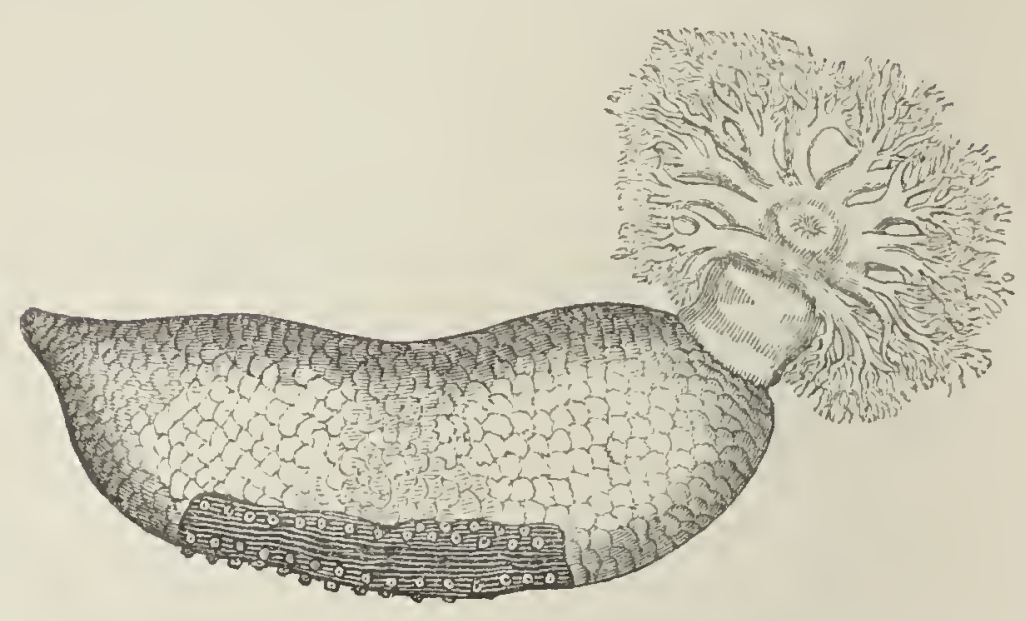

Holothuria phantapus.

line, in comparison with any other, before leaving the radiate sub-kingdom; but, in reality, the echinodermata, though of radiated form, are much superior to the rest of that division in their organization,

FIG. S6.

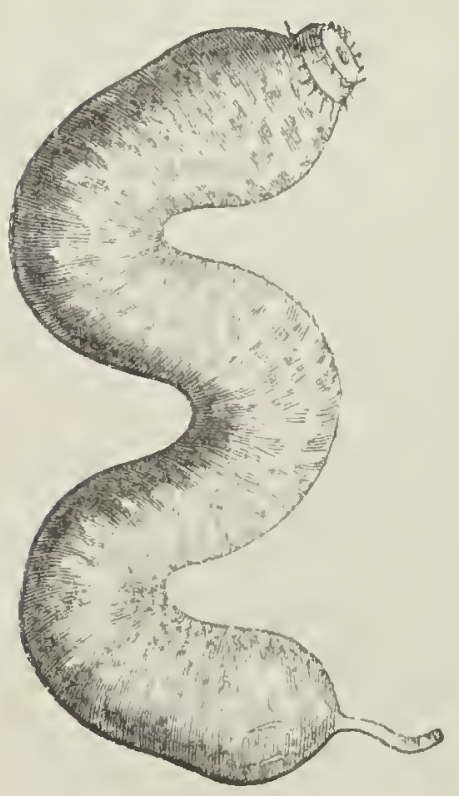

Eckiurus vulgaris. which is, if not complicated in the asual sense of naturalists, full of extremely curious minute work. Their whole destiny seems to be of a high kind; for in the stone record their line of forms stands parallel with others, in which the whole of the three lowest sub-kingdoms are passed through. Polypiarian animals and Encrinites appear in the Silurian and many subsequent formations; at the commencement of the carbonigenous era, the latter are so abundant that we walk over large tracts of country, 
where the rocks beneath our feet are almost wholly composed of their remains. The Asteriadæ appear in the upper Silurians, and are but faintly seen until the Lias, when they become conspicuous. In the Oolite, the Echinidæ make their appearance. These are the last which we could expect to be preserved in rocks, as the higher families possess no hard parts; otherwise we might perhaps have seen the succession of this class of fossils continued into the Holothuriæ and Fistularidæ. It cannot fail to be noticed how well the progression of forms agrees with the order of their appearance in the geological ages.

The ground is now cleared for the two grand series of Invertebrate animals, and first of the Articulata. These are generally described as animals "composed of a succession of rings, formed by the skin or outward integument, which from its hardness constitutes a kind of external skeleton;" one class, however, the Annelides, have no hard investment. The pedigree of the Articulata is very brief. The embryo in most classes passes at once from the monad to the worm form, and then the articulate character is assumed. It can therefore scarcely be said that the radiate sub-kingdom comes before the articulate, though the one is lower in organization than the other. There is indeed reason to believe that the great classes of the Articulata are distinct stirpes, the commencement of each of which is little more than a step from the inorganic form of matter. This may seem inconsistent with the maxim, Natura per saltum ritil agit; but maxims must be obedient to facts, not facts to maxims, and we may deem that a leap which in reality is none.

That the Annelides (worms) are the humblest of the 
articulate animals, there is now no doubt; for the character of red blood, which was attributed to them by Cuvier, and held as a mark of great though anomalous elevation, has been explained satisfactorily as a mistake, being merely a hue possessed by the fluid element of the blood, and not due to red corpuscles, as in the vertebrata.

FIG. 87.

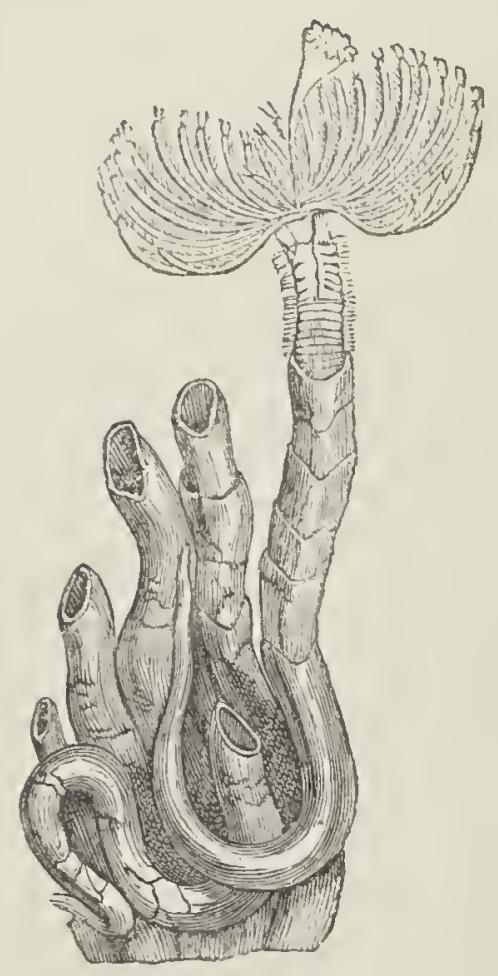

Group of Serpula, with the branchial tufts of one of them expanded.

Four leading forms in this class are described. Of the Tubicolida, or those inhabiting tubes, the Serpula is an example. It forms for its habitation, usually upon some sea-immersed stone, an irregularly twisted calcareous tube, out of which it presents, floating in the water, a fan-like branchial apparatus, of beautiful colours. The second order, Suctoria, is represented by the well-known leech; the third by the earth-worm; the fourth by the sea-mouse (aphrodita). In all of these groups we see distinct advances in organization, and this is traceable in some in an interesting conformity with changes of scene and mode of life, from fixed situations to free movement in the sea, from thence to the shore, and thence again to the land. From the Nais, for example, a simple marine worm which at the recess of tide burrows in the sand, there is a clear passage to the common earth-worm, which adopts a similar retreat 
on land, and comes to the surface when rain is falling. The fourth order, Dorsibranchiata, so called because of gill tufts ranged along the back, have an equally clear affinity, implying ancestral relationship to certain land animals, which, however, naturalists at present regard as an independent class. The Nereis, a well-known dorsi-

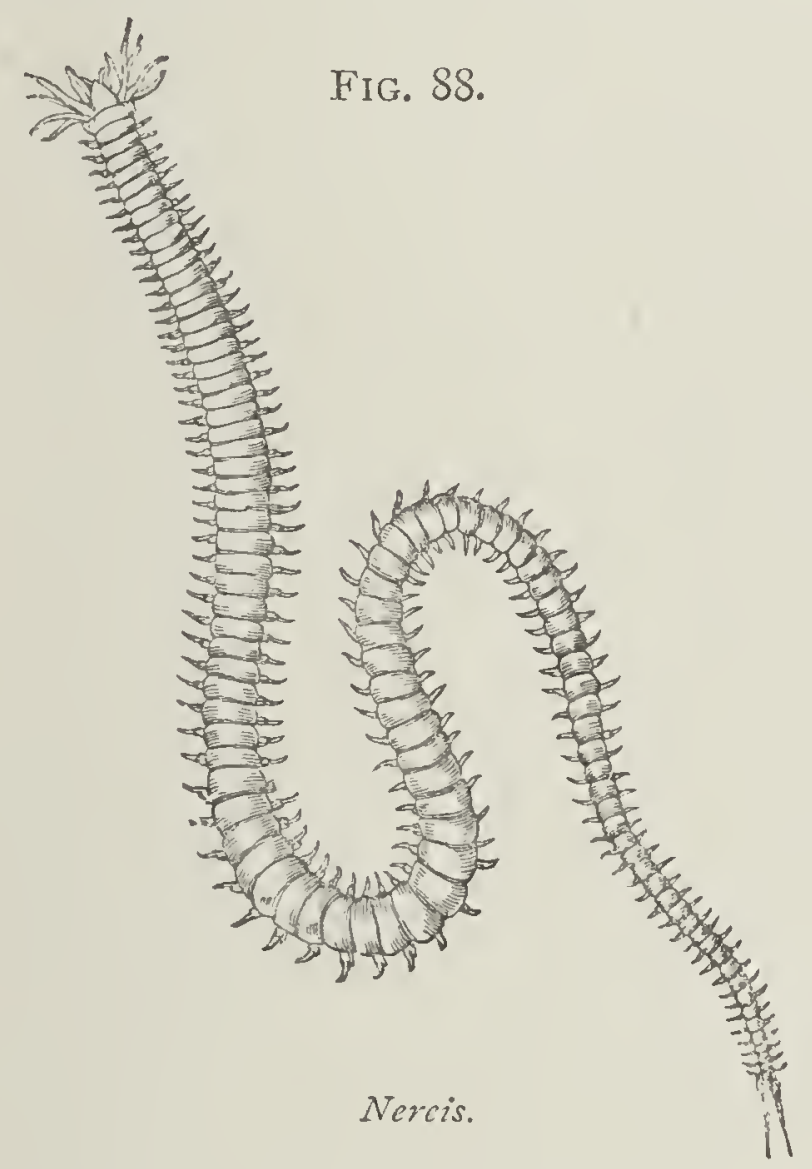

branchiate, is an animal of great length, composed of a consecutive series of rings, each having a couple of processes at each side, which are used as oars for propelling the body through the water. One species is four feet long, and consists of several hundred segments. By conversion of the water-breathing apparatus into one fitted for aërial respiration, an increase of firmness and density to the 
external integument, and the development of a couple of limbs for each ring of the body, we see the nereis, as it were, transmuted into the Myriapod. ${ }^{1}$ Here, however, there may be more than one line of passage; for the two great families of the myriapods, the Iulidx and Scolopendridæ, are diverse in character, the former being

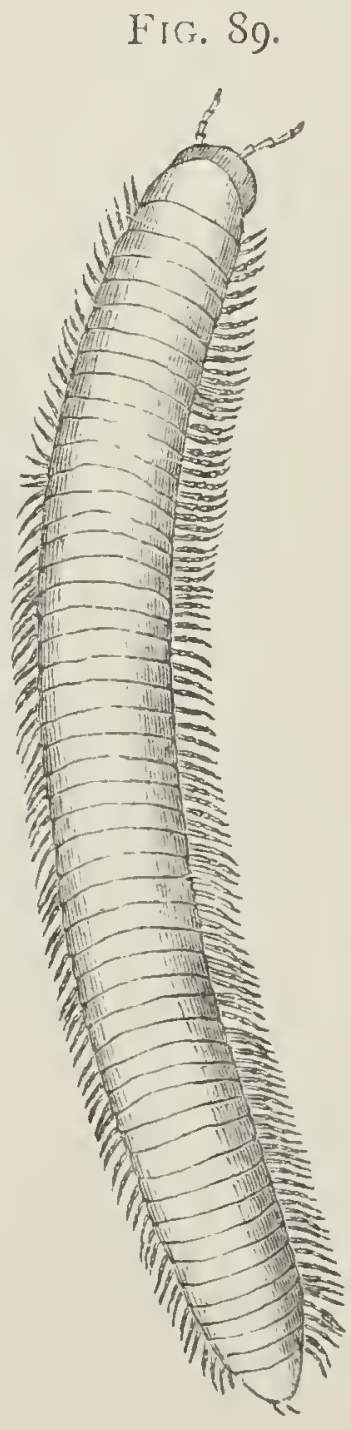

FIG. 90.

Izulus.

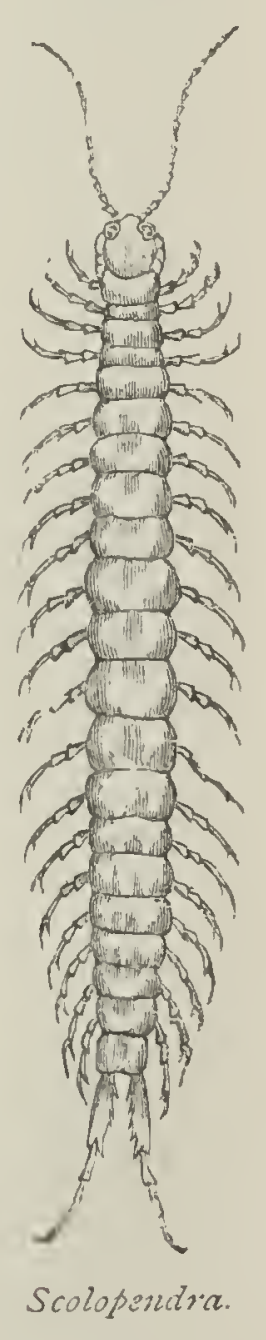

1 See the presumed steps of conversion fully described in Professor Rymer Jones's Animal Kingdom, p. 224. 
vegetable feeders, the latter carnivorous, and it appears as a rule in the genetic system, that true carnivores are always apart. Confining our view to the Scolopendridæ, we see a remarkable continuity of character and habits transmitted to them from the presumed marine ancestor (nereis), allowing for the altered medium of existence. The scolopendra is an animal furnished with powerful destructive organs; and, living under stones and the bark of trees, and in fissures generally, it is his custom to wind insidiously along, and dart upon any little animal which comes in his way. Of the nereides, on the other hand, we are told that they "usually live in the excavations of littoral rocks, in the hollows of sponges, in the interstices of the radicles of thalassiophytes, under stones, and in general in all bodies which present fissures more or less profound. . . . They all appear to feed upon animal substances. . . . M. Bosc tells us they live upon polypi and small worms, on which they throw themselves, by darting the anterior part of their body, which they have first contracted."

The next articulate class demanding attention is the Crustacea, animals in which the annular sections are covered with a calcareous shell, and provided with jointed limbs, the respiratory apparatus being branchial; all are aquatic, except some of the higher genera, which occasionally adventure upon the land. They are in two great groups, Entomostraca and Malacostraca, the former being the simpler, and exclusively aquatic. Emmerich considers the Trilobites which figure so conspicuously in the early rocks, as between the two divisions, but most nearly allied to the first; whence it would appear that the crustacea 
which make so early an appearance in the rock series, are humble animals, only preceded in their own subkingdom by a group which, from their slight forms, might be ill-adapted for preservation in strata exposed after deposition to a high temperature. The geological history of the crustacea tallies in other points with their gradation. In the triassic epoch come the Macruri, which prevail to the present time; afterwards, in the tertiary era, come the Brachyura. These are the fossil orders which have been best studied, and it is M. Agassiz who says, "they succeed each other in the series of formations in the order of their organic gradation." The same naturalist remarks "the intimate analogy between these different types and the phases of the embryonic development of the crustacea, which MM. Rathke and Erdl have afforded us the means of becoming acquainted with." 1 As elsewhere observed, the young of the decapoda are of the entomostracous form, and thus denote a passage of the one from the other.

In one family of the crustacea, there is a striking illustration of what is here set forth as the true history of species. This is the family to which the well-known hermit-crabs (Paguri) belong, distributed extensively in the tropical American islands, and upon our own coasts. Animals of this kind live in molluscan shells deserted by

1 "Resting upon the characters derived from the nervous system, which in the crabs is concentrated into a few masses, zoologists have generally considered these animals as higher than the lobsters, in which the nervous ganglia remain more isolated. Now, as far as we know, the embryos of brachyuran crustacea, that is, of crabs, are all macrural in their shape; that is to say, they resemble at an early age the lobsters more than their own parents; and again, lobster-like crustacea prevailed in the middle ages of geological times, during the triassic and oolitic periods, that is, before crabs were created, as we find no fossils of that family before the tertiary period."-Agassiz on Lake Superior, x850, p. 197. 
FIG. 91.

A

Is

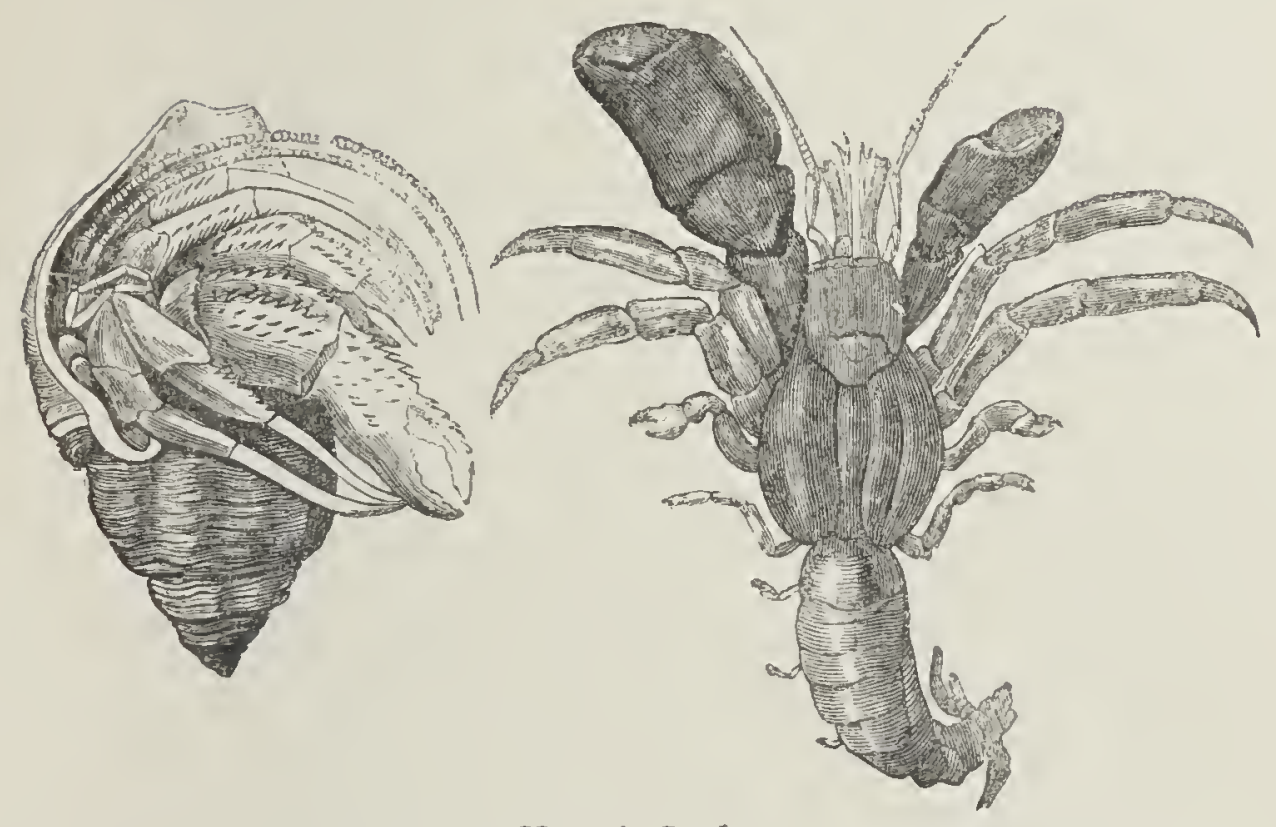

Hermit Crabs.

A, Enclosed in shell of Whelk;-B, The animal removed from its protective covering.

the proper tenants. They select one at the first for their residence, and afterwards, as they increase in size, they remove to larger ones. With the hind part of the body inserted in the hollow shell, they present the head and feet outwards. They move about in the shallow water, upon the shore, and even upon dry land, with great freedom, dragging their adopted mansion after them. A very slight examination of these animals shows that they are adapted by special peculiarities for this kind of life. In the common British hermit-crab, the third and fourth pairs of locomotive limbs are of small size, being buried wholly within the shell, where they are applied to the columellar fold, as a means of fastening the animal in the recess. Farther in, and also employed in fastening 
the body to the shell, is the caudal part, with two holders developed for this express purpose, and as rough as a file. The hold is still further secured in some species by rows of suckers along the abdomen. Add to all this, that for want of room at the mouth of the shell, only one of the pincer claws is well developed, usually the right, while only the two front pairs of feet are used for locomotion, and we see that, whethér we take these crabs as a species, a genus, or a family, their ordinary form-that thing which naturalists regard as immutable, and as originally the effect of a special creative effort-is in direct relation to the existence and forms of turbinate shells formerly possessed by a different class of animals, - which must therefore have existed before the hermit-crabs. It may be well to mark the credulity to which the adherents of immutability must here be reduced. They must believe that the Creator, having a particular regard to the fact of molluscan shells lying useless on the shore, formed, by special care or fiat, a family of crabs to occupy them. They must believe that the roughness of the caudal appendages, the development of suckers along the abdomen, the reduction of the two hind pairs of limbs, and the left pincer-claw, were all subjects for this special care, and were beyond the power of what an eminent geologist calls "vulgar nature." Surely the Deus ex machin $\hat{a}$ was never more remarkably exemplified. See, on the other hand, how these facts are accounted for on the development theory. According to this new light, the hermit-crabs are simply a portion of some greater section of the crustacean class. Their peculiarities are modifications from the parent form, brought about in the 
course of generations, in consequence of an appetency which had led these creatures to seek a kind of shelter in turbinate shells. They are as truly creatures of the Great God, as if they had been made in the manner of a human artist modelling a figure. But the means were inherent natural forces in the constitution of the original tribe, tending, in generation, to accommodate organic form to physical circumstances.

The next class in general rank is the Insecta, a wonderfully varied group, yet all agreeing in having thirteen segments and three pairs of legs; all, moreover, respiring by means of tracheæ or tubes permeating the body, -an arrangement having reference to their peculiar mode of locomotion, which, in the majority of species, is by flight through the air. The fact of the greater number of insect genera passing in their larva state, through the annelidan or myriapodous form, points to these classes as their genetic origin; yet this is a point on which the benefit of further investigation is desirable. In the case of the Arachnida (mites and spiders), which are placed at the head of the articulate class, no humbler form is traceable in the embryo; it is therefore impossible to assign them any pedigree. Can it be possible that the arachnida, or these with the insecta, have sprung almosi or wholly at once from inorganic elements? On this subject, it is impossible to make any positive affirmation; but it certainly is remarkable that in no department of the animal kingdom besides the infusoria and entozoa, have there been more frequent appearances of an aboriginal commencement of life than in the insecta. The acarus, so often produced from certain solutions, 
where ova were rigidly excluded, is a lowly member of the arachnida.

We now come to the Mollusca, a portion of the animal kingdom, the importance of which, in point of numbers, and the part they play in creation, none but students of zoology could fully appreciate. The infinite variety of bivalve and univalve shells presented upon our own coasts, and brought from all parts of the world, will convey some idea of the multitude of forms comprehended under this sub-kingdom. The whole mass is, after all, resolvable into three divisions; one of them comprising headless mollusks in bivalve shells; the other two, headed mollusks in univalve shells (some, however, of all the three divisions being naked). The whole sub-kingdom appears to have a very brief genesis in the radiata, the only preceding forms in embryo being the infusorial and polypian. Here, too, as in the Articulata, we find that we must start at a point very near the fountain-head of organic existence.

In the headless division, naturalists place three subdivisions, called by them classes, in the following rank, according to ascending grade of organization-Tunicata, Brachiopoda, and Lamellibranchiata. The two latter are the shell-fish of popular observation, headless, and mostly sessile, or destined to spend their lives in fixed positions. The Tunicata are similar in all essential respects, except in being of humbler organization, and inclosed, not in shells, but in a cartilaginous or coriaceous integument, whence their name. It thus appears that the Brachiopoda, which are the predominant fossils of the lower Silurian era, are the first animals we meet with in this line, having 
FIG. 92.

$\Lambda$

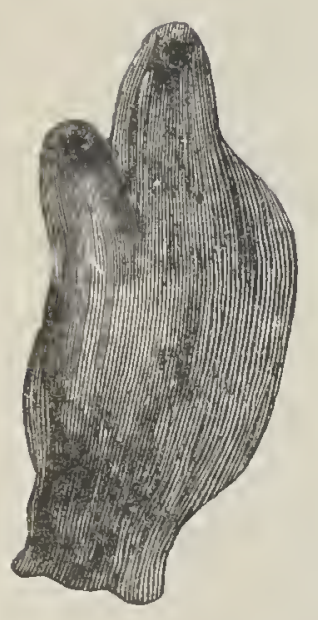

B

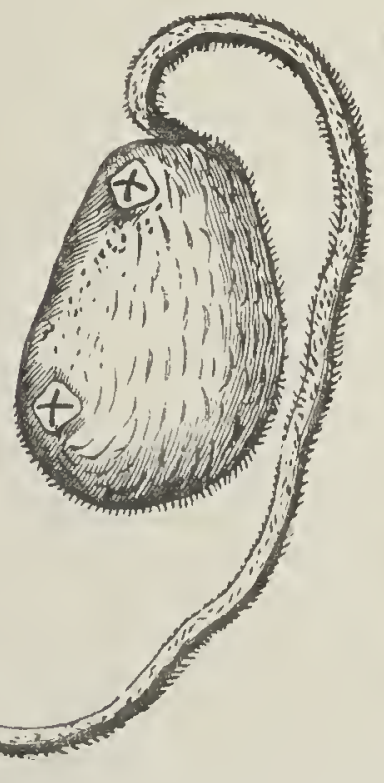

c

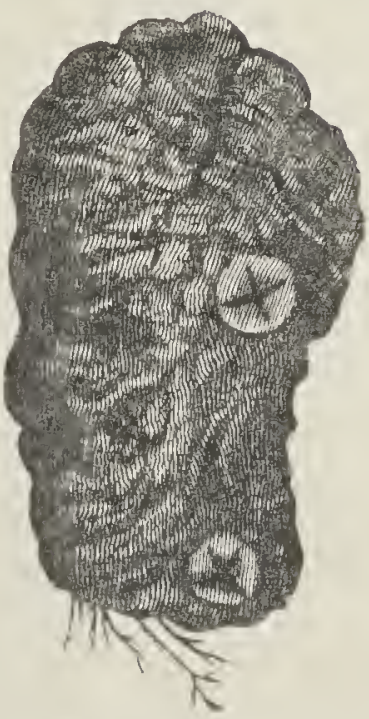

Various forms of Tunicated Mollusca:-A, Ascidia; B, Boltenia; C, Cynthin.

parts capable of commemorating their existence. While the Brachiopoda are generally inhabitants of deep seas, the Lamellibranchiata, among which are included the oyster, mussel, and other testacea, affect the beds of shallow seas, whence they spread in a variety of genera, towards shores, the mouths of rivers, and into fresh

A

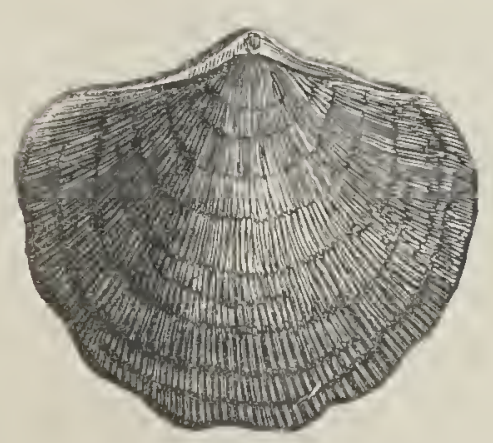

FIG. 93 .

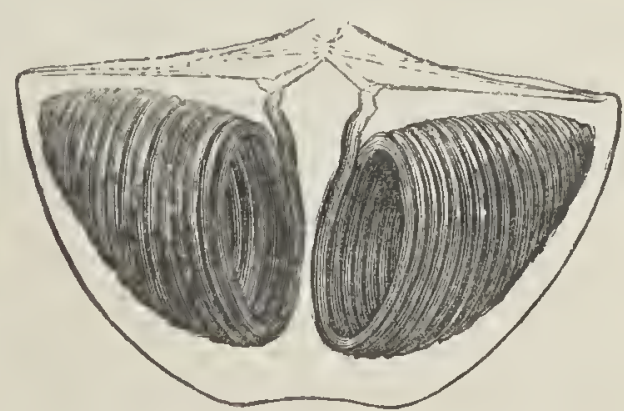

A, Terebratula reticularis; B, Interior of Spirifer hystericus. $\mathrm{R}$ 
water. The Lamellibranchiates are higher than the preceding class; they are the first bivalves which possess a true hinge (Fig. 94). It is also remarkable that, with the decline of the brachiopods, at an early point in the secondary formation, rises the lamellibranchiate family. There is here, therefore, an improvement in organization,

\section{FIG. 94 .}

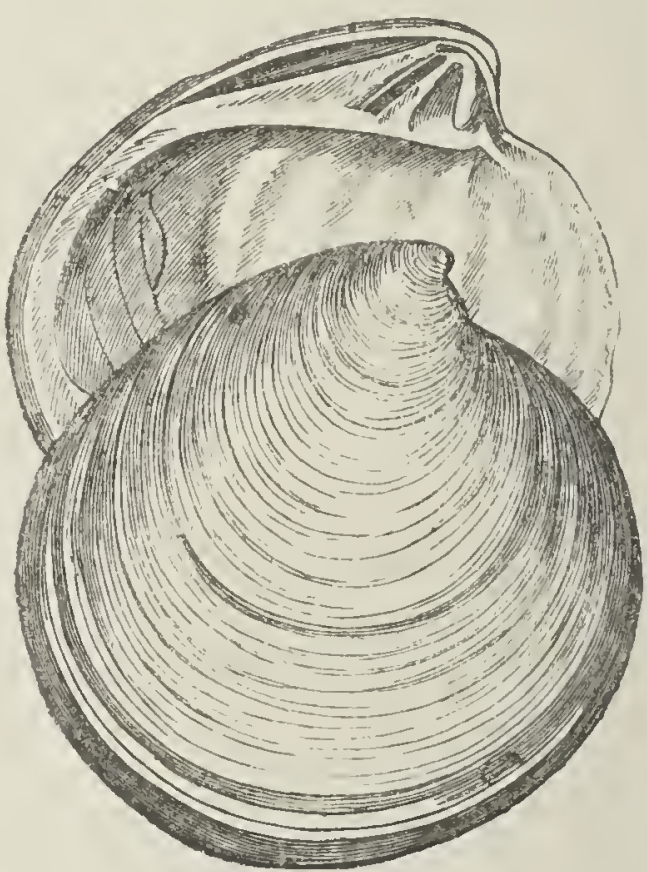

Cytheren concentrica.

an advance in habitat landward, and a succession of existence in the geological ages, all in harmonious connexion. Nor is this all. The lamellibranchiata are again divisible into monomyaria and dimyaria, the former having one adductor muscle, and the latter two; the former, moreover, being intermediate, between the branchiopods and dimyaria in respect of non-symmetrical form. Norc', in the Geological Chronicle, the monomyaria 
succeed the brachiopods as an abundant and predominating form, and are succeeded again, in that respect, by the dimyaria. This beautiful harmony between the fossil history of the acephalous mollusks and their order in progressive organization, is expressly declared by M. Agassiz.

The three highest molluscan classes, univalved, possessing heads, and with hardly an exception destined for independent locomotion, stand apart from the bivalve orders; generally superior in organization, as beseems their higher destiny, but not on that account to be held as an advanced form in the same genealogy. The lowest univalve class-called the Pteropoda, from their mode of progression by a couple of wing-like membranes projecting from the neck-may be described as marine slugs, generally of small size, many of them naked, others protected by a very delicate shell, which swim through the ocean in vast multitudes; one species (clio) being in such abundance in the circumpolar ocean as to form the chief food of the whale. Professor Edward Forbes expresses his opinion that the larva of the pteropod will yet most likely be found to resemble an ascidian polype; inferring a very brief descent from the starting-point of life in its class.

The Gasteropoda - a class of many families and genera, including limpets, whelks, cowries, snails, \&c.-have comparatively a high organization, the nervous system being more concentrated, the nutritive more elaborate; but yet are of sluggish habits, usually moving by alternate contractions and expansions of a fleshy disk placed upon their stomachs, whence the name of the class. Many of the gasteropods are naked, others possessed of but slender 
FIG. 95 .

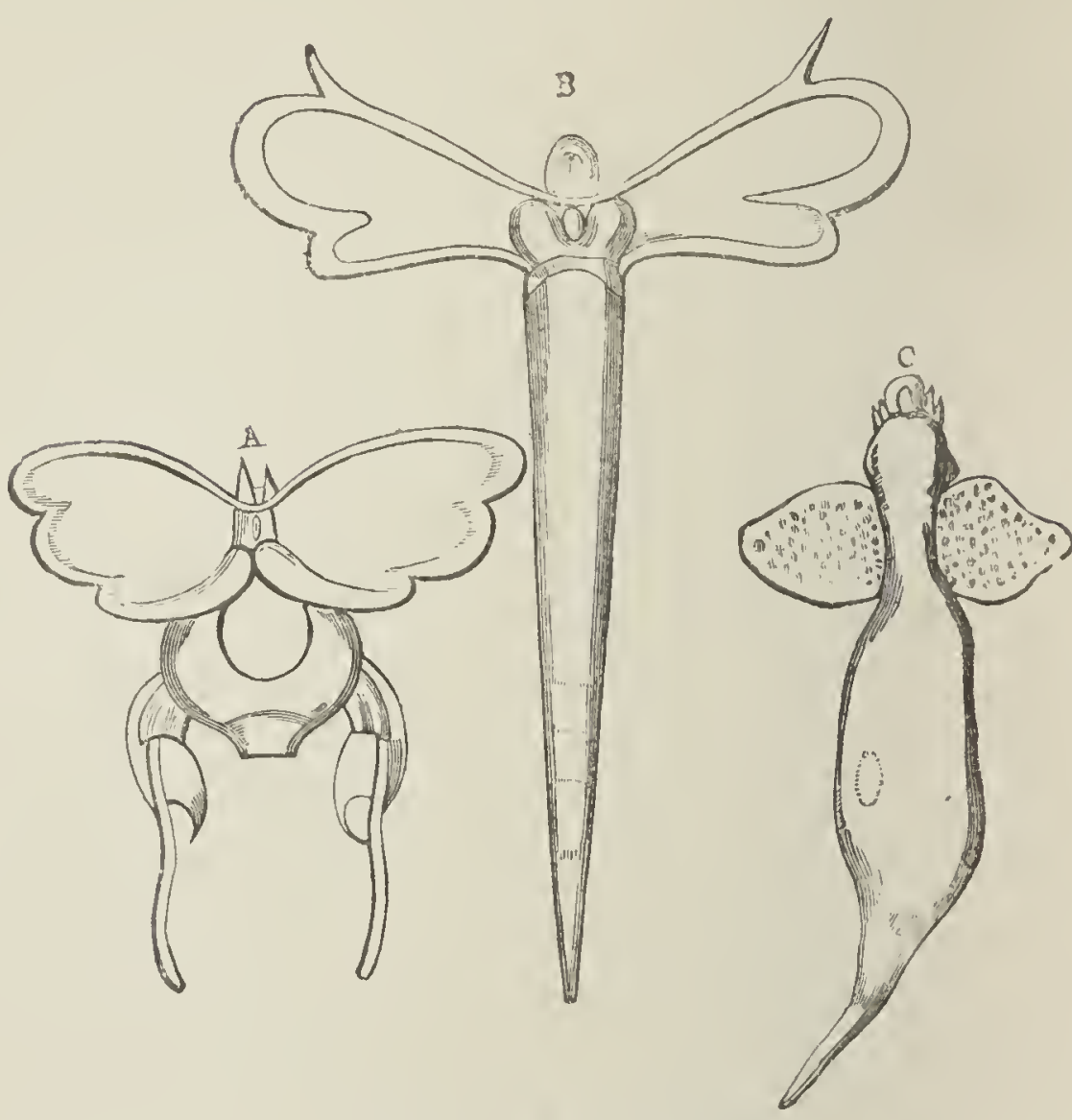

Existing forms of Pteropols.

A, Hyalca; B, Criseis; C, Clio.

protection. A large proportion are vegetable feeders, the marine species battening upon sea-weed, the terrestrial species upon herbage and fruit; the rest are flesh-eaters, but the general character of the Gasteropoda as a class is harmless, like that of the herbivorous mammalia. A clear gradation of forms passes through some of the families, from the simple cone of the limpet to the spiral of the snail (Fig. 97). The descent of the class appears to be from some families of the preceding; for "they all,' says a minute observer of nature, "commence life under 
FIG. 96.

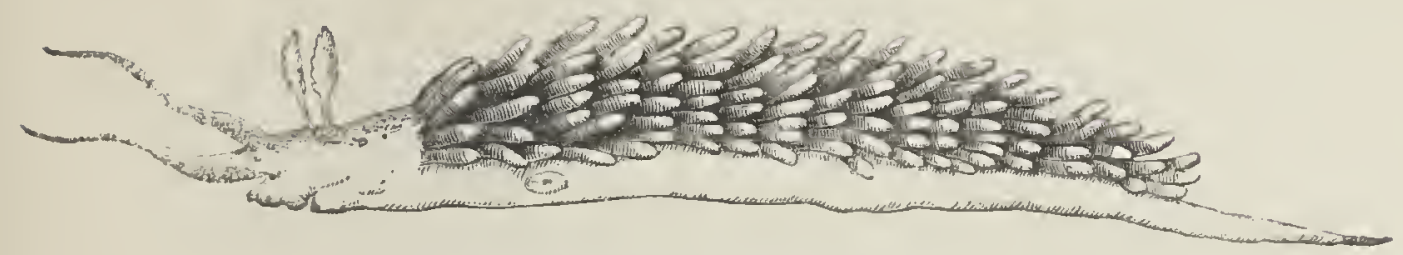

Eolis Inca, a Naked Gasteropod.

the same form, both of shell and animal ; namely, a very simple spiral, helicoid shell, and an animal furnished with two ciliated wings or lobes, by which it can swim

FIG. 98.
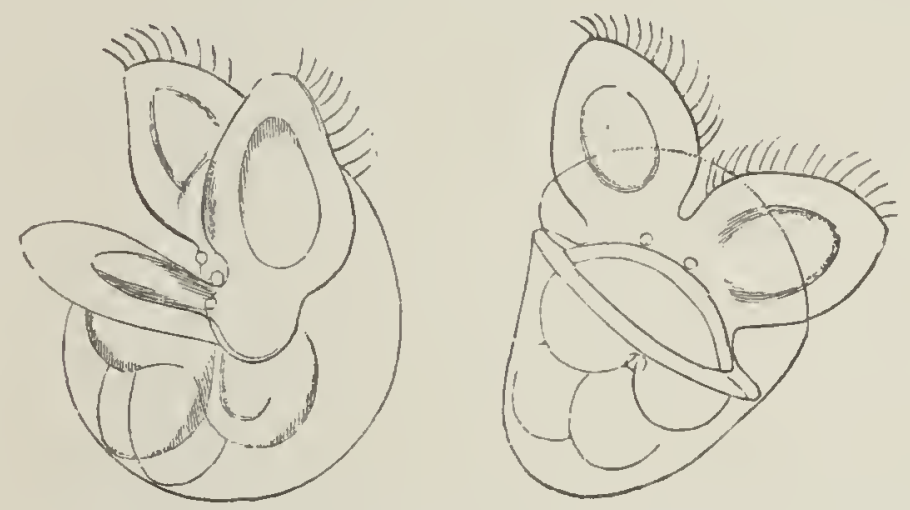

Embryoes of Nudibranchiate Gasteropods.

freely through the fluid in which it is contained. At this stage of the animal's existence, it corresponds to the permanent state of a Pteropod." 1

In the univalve mollusks, as in the bivalves, it clearly appears that the humblest families are destined to a fixed place in the depths of the ocean. As we advance through the higher groups, we find, in parallel steps

I Professor Edw. Forbes, in Jameson's Journal, xxxvi. 326. 
with an improvement in the organs of animal life, an advance in the sphere of existence to a life on the surface of the ocean, to fresh water, and even to dry

FIG. 97 .

A

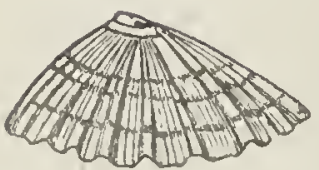

13

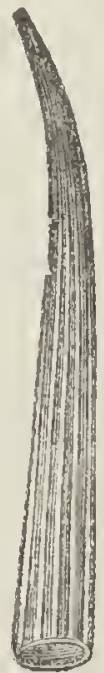

E

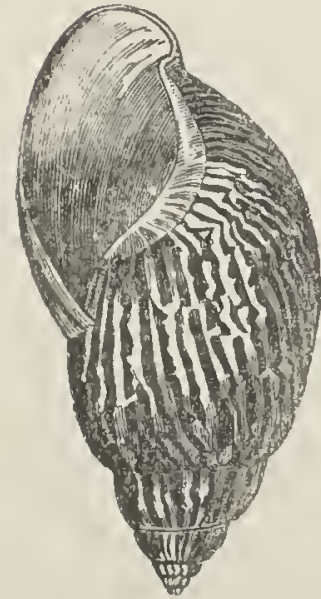

C
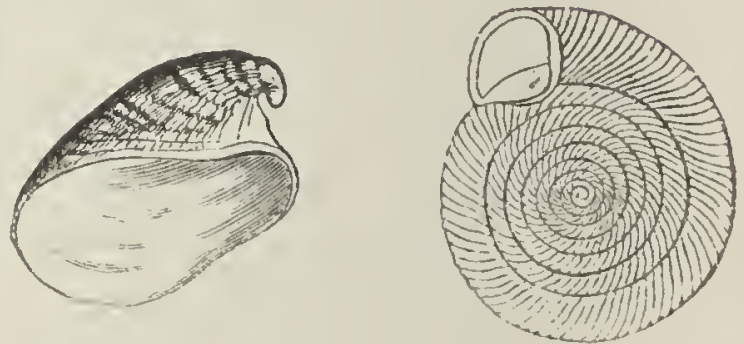

F

(

H

Various forms of Gasteropodous Shells:

A, Patella; B, Dentalinu; C, Pileopsis; D, Helix; E, Achatina; F, Sigaretus; G, Vermetus; H, Scalaria. 
$\mathrm{h}$

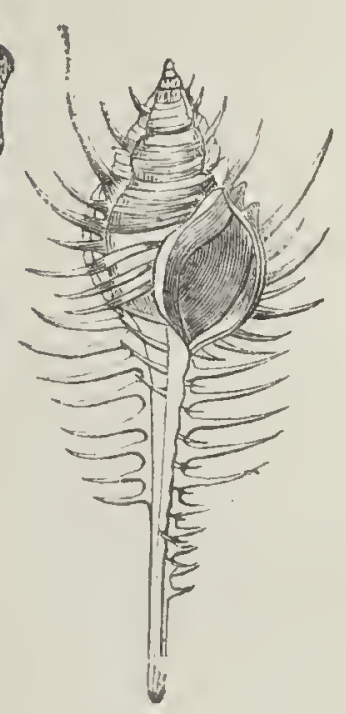

Various forms of Ginsteropoduus Shells:

I, Neriner; K, Inrex; L, Voluta.
L

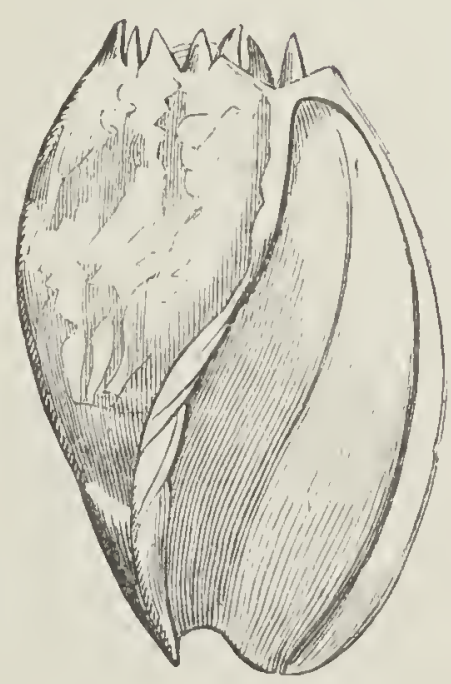

land. The humble Helicidae (snails), a family of the Gasteropoda, are the first animals which we encounter as adventuring upon the firm surface of the globe. And it is interesting to remark, in this progression, the requisite change in the mode of respiration-namely from branchix, the apparatus necessary in aquatic life, to a vascular air-sac, the first form of lungs-the proper breathing organ of terrestrial animals.

In the peculiarly destructive Cephalopoda, we recognise the highest organization of which the molluscan form appears capable; it includes the orthoceratites, ammonites, belemnites, etc. of the rock systems, and the nautilus and cuttle-fish of the present era. Their descent is probably from the carnivorous families of the pteropoda; for "the 
nucleus of their shells," says the naturalist last quoted, "is a spiral univalve, similar in form to the undeveloped shells above alluded to [those of the embryo gasteropods]; and it is yet to be seen whether all cephalopoda do not commence their existence under a spiral-shelled pteropodous

FIG. 99.

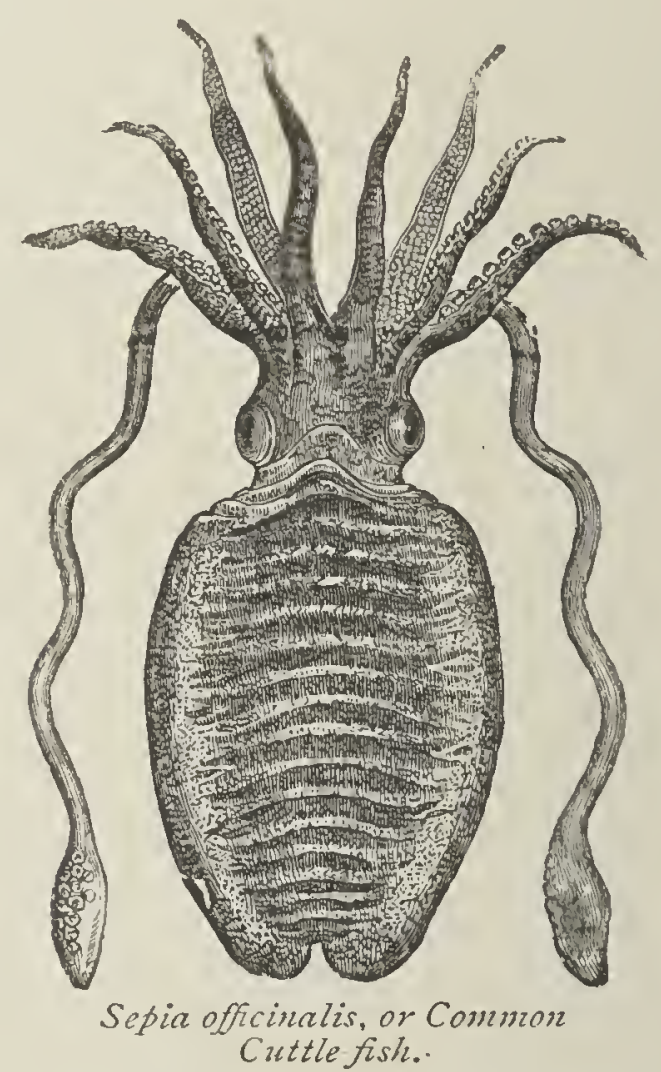

form." It has also been remarked, that "the shells of two species [pteropoda] afford indications of a transition towards the cephalopoda; one resembling in its straight conical form the belemnite and many other extinct genera of that class, and the other having a partially-formed chamber at the lower closed extremity; and similar evidence is afforded by their internal structure." 1 This

${ }^{1}$ Carpenter's General Physiology. 
genealogy, if it shall be affirmed, will afford an important illustration of the geological history, because it will show that cephalopoda might be expected to make their appearance as early in the rock series as any other mollusks possessing parts equally fitted to commemorate

FIG. 100.

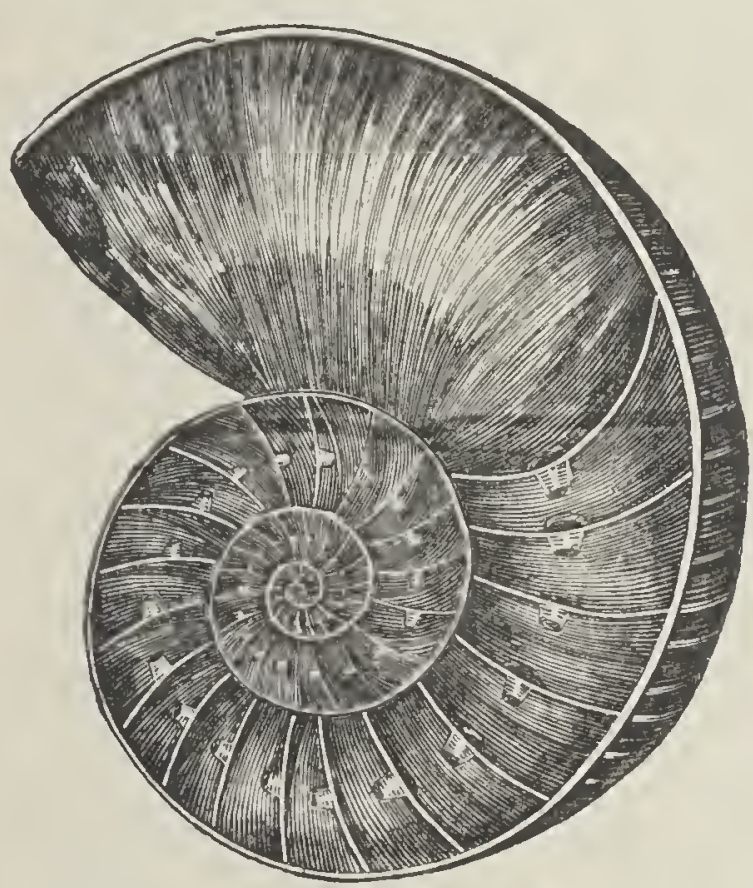

Shell of Nantilus pompilius, cut open to show the chambers and the siphon.

their existence. These animals are to be supposed as an ultimate form, reached, not through the medium of all the lower molluscan orders, but only of one; and with respect to that one, it so happens that, though possessing hard parts of such delicacy as to have little chance of preservation, relics of it have been discovered as far down as any cephalopodous remains. ${ }^{1}$ This con-

1 See page 50 of this volume. 
temporaneity of the cephalopoda with the gasteropods and brachiopods, it may be remarked, would be in harmony with what we know of the economy of nature with respect to the destructive animals. They seem to bear a relation to those upon which they are destined to prey, and to be a necessary accompaniment to them. Hence they would require to be upon a different genetic line-which actually appears, in every advance of the animal kingdom, to be the case-and developed contemporaneously with the weaker tribes, the fertility of which would otherwise produce complete anarchy. Granting, then, this pedigree for cephalopoda, it would be no anomaly in our theory, although remains of mollusks inferior to them should never be found lower down in any part of the earth.

The cephalopods, though so highly organised in comparison with the gasteropods, do not advance, like these, to land forms, with apparatus for aërial respiration. They are, as a class, restricted to a pelagic life, admitting of occasional appearances on the surface of the ocean. Their respiratory system is accordingly branchiate, yet with marks of grade which are worthy of observation. It is, in the words of Professor Owen, a law determining animal rank, that "increased number [of parts] irrespective of correlative structure, in an organ of the animal body, is ever a mark of its inferiority." By this test, the nautilus, with its four branchiæ, sinks below the belemnite and the cuttle-fish with only two; and such is the basis of a division of the cephalopoda. In the whole of this order, however, there is a remarkable advance of the nervous system, though only to the effect of enabling the animal to supply itself with food by conquest over the inferior 
tribes. The nervous centres, which in lower mollusca were only protected by coverings which also served to cover the rest of the body, now become of sufficient importance to have a special protection, in the form of cartilaginous plates, which naturalists interpret as the rudiment of an internal skeleton. In this way, the cephalopoda approach the borders of the vertebrate sub-kingdom.

This remarkable class of animals affords in its details some evidences in favour of the development theory. In the early rocks of America, as in those of England, the humble form of a straight or slightly curved shell prevails. Curved shells increase afterwards. There are also tolerably distinct appearances of a transition of forms in the genera of clymenia, goniatite, and ceratite, which make their appearance in this succession in the rock formations. The dibranchiate belemnites commence in the oolitic epoch, ushering in the sepiæ, the highest of all the cephalopodous orders, and which have since continued to exist.

It is worthy of remark that, in the succession of rocks, the forms of the cephalopoda change much more abruptly than appears to be the case with other less organized mollusca; that is, there are more decided as well as more frequent examples of what geologists call change of genera in this class than in others. This is only one of the many proofs of law in these phenomena. On the supposition of interferences, why should there be entire renewals of some sets of animals and not of others? On the theory of law, we only see each line of organic being undergoing the modifications appropriate to its special 


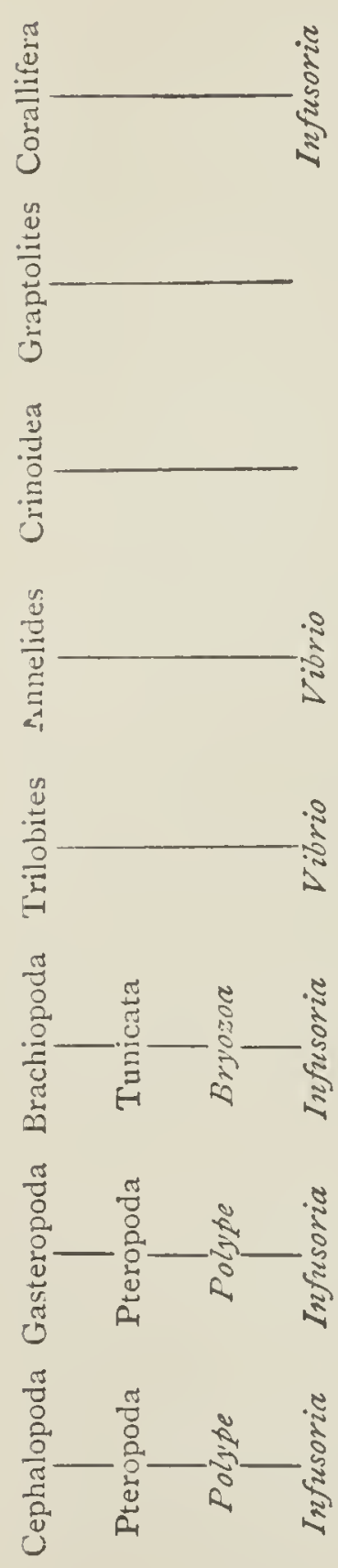

constitution, in connexion with the efficacy upon that constitution of external conditions.

When we consider the Invertebrate animals in this arrangement, the advances made in portions of the Animal Kingdom, before the end of the Silurian era, appear in a very different light from what they do while we entertain the erroneous notion that there is but one chain of being. The annexed tabular view will make this readily and abundantly plain. Those animals which, though hypothetically concerned in the genealogy, are not actually found in a fossil state, but for whose nonappearance as fossils, reasons are given, are expressed in italics.

In looking among the animals of one class for the point of connexion by which it is joined to the next above, we must not invariably expect to find what we are wanting in the highest species, for these are often the heads of branches. On the contrary, it appears, in many instances, in the lower species. And this is the more worthy of being pointed out, as the supposition of something different has supplied one of the stumbling. 
blocks of the development theory. In all the classes, for instance, which have terrestrial as well as marine species, the nexus to the next grade of being is among the latter, which are invariably the inferior. And thus it is that no transition of the kind here under our attentionthat is, none of the greater grade transitions-takes place out of the aquatic medium which has here been regarded as analogous to that of all individual embryos.

We now proceed into the Vertebrata, of which the Fishes compose the lowest class. Here, with a skeleton, are red blood and a double-chambered heart; but the blood is still cold, and the respiration is carried on by branchiæ, the animals being wholly designed for aquatic existence.

Of the transitions or transmutations implied by the development theory, the greatest or most violent are those few which took place in the passage from the invertebrate animals to fishes, from fishes to reptiles, and from these to the higher classes. This we might expect, as at such points the phenomenon had nothing to do with external circumstances, but wholly depended on the internal development-force,-each stage being one of that limited number of periods, into which the longenduring gestation of nature may be supposed to have been divided. Here, accordingly, we may expect to find the affinities less distinct than elsewhere; and yet at all of them some connexions are visible, leaving the general fact of the transition indubitable.

Between the invertebrate animals and the fishes, the junction is tolerably clear at one point. This is where the cephalopodous mollusks connect with such fishes as 
the myxine or hag, and the lamprey. These fishes are wormlike in shape, with only a rudimental skeleton in the form of a horny or gelatinous cord. They have a suctorial leechlike mouth, with numerous small teeth, by

\section{FIG. IOI.}

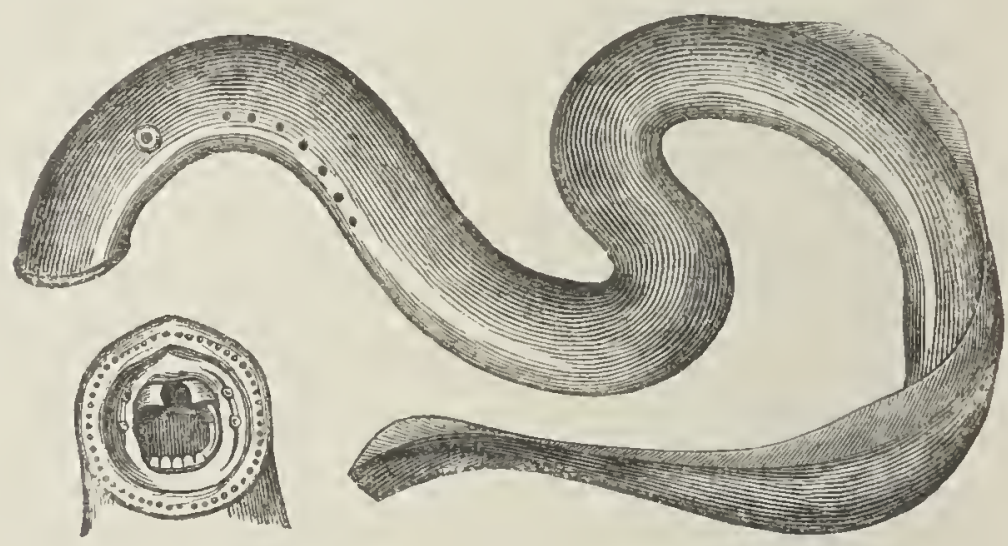

A

Lamprey:-A, its circular suctorial mouth.

which they fasten upon living animals for sustenance. The affinity to the cephalopods is fully admitted. It is seen in the nature of the skeleton, in the character of the investing skin which ejects a copious secretion whenever the animal considers itself in danger, in the power of respiring through the gill apertures without any dependence for that function on the mouth, and in the eight free filaments seen in some species extending forward from around the mouth,- "representing," as Professor Owen remarks, "the eight ordinary arms of the Cephalopoda Dibranchiata, but arrested in their development by reason of the preponderating size of the caudal extremity of the body, which now [that is, in the fish] forms the sole organ of locomotion." The lancelot, one of this 
family, is so extremely humble in organization, that Pallas mistook it for a limax (a gasteropodous mollusk), and it has only of late been finally established among the fishes. Some difficulty has been experienced in seeing true affinity between the baglike figure of the mollusk and the cylindrical elongated form of the fish; but it has been suggested that the mollusk is, as it were, the fish doubled-in or inverted upon itself : hence the end of the alimentary canal so near to the mouth. The inversion reversed or undone, makes the fish. These appearances of propinquity are most interesting. If they do not indicate genealogical connexion, it is difficult to account for them. On any other supposition, how should such peculiarities of organization be seen exactly at this point in the animal scale? The fishes here spoken of are not discovered in a fossil state. For this their want of hard parts unfitted them; but they are classed with the Chondroptergii, or cartilaginous fishes, which, we have seen, are amongst the first found in the ascending series of rocks. The affinity and the geological succession are therefore in perfect harmony. It is important to remark the progress from entirely soft animals, to an order bearing cartilaginous plates to protect a rudimental brain; from these, again, to an order having a skull and vertebral column of cartilage; a series of advances entirely conformable to phenomena seen in individual development. Nor is it to be overlooked that the presumed progeny exhibit, in their voracious character, and the functions they serve in nature, a perfect family likeness to their ancestry. The cartilaginous fishes were the chief police for keeping down the redundant life of the Devonian and Carboni- 
ferous seas, as the cephalopoda had been at an earlier stage of the existence of the globe.

The approach made by the annelides to some of the humbler forms of fish ${ }^{1}$ indicates another passage from the invertebrate into the vertebrate animals; and this passage may have taken place in the Upper Silurian or Devonian era, for annelides are ascertained to have previously existed. Perhaps some of the less destructive of the early cartilagines - the Lepidoids were such an inoffensive family - have had such an origin.

It might be suggested, as an inquiry worthy of the attention of zoologists, whether the echinodermal line has not given rise to the more recently developed fish families, - those which enter upon the field in the cretaceous era. If the fistularidæ make, as appears, so near an approximation to the lowest bearers of the vertebrate type, it is not easy to see how any preconceived ideas regarding the order of sub-kingdoms to be passed through should stand in the way, especially after so many traces of similar (apparent) irregularity. The geological history of the animals in question is favourable to the conjecture, for the echinoderms are amongst the most conspicuous and important forms antecedent to the chalk era. Looking, indeed, at the enormous abundance of crinoidea in the carboniferous rocks, one can hardly avoid the idea, that this peculiar form was destined for some important ultimate history. It might be suggested that the orders by which the fish class is thus entered, are those placed by Cuvier at

1 "It is rather "the approach made by some of the humbler forms of fish to the Annelides.' . . . The lancelot has many striking points of conformity to the Annelides."-MS. Notes of a Physiologist. 
the bottom of the osseous fishes, the Lophobranchii and Plectognathi, which indicate their nearness to the invertebrate type by many features attaching to some or all of them, as imperfection and slow hardening of the skeleton, deficiency of ribs and fins, low and embryotic forms of mouth, dentition, and gills ; the Lophobranchii, moreover, hatching their young in a pouch below the tail, after the manner of a family of animals equally low among the mammalia.

In the present state of this inquiry, it is impossible to give an entire genealogical tree of Being. Much must remain obscure and unindicated. Even of what is set forth, some parts must be held liable to correction under better light. Enough, however, is done for the present object, if such fragments of the great composite chain be shown, as afford proof that there is such a thing in nature, and that the idea of genetic succession of advancing forms is in harmony with it. The fishes form one of the obscurer portions of the animal kingdom. The classifications of Cuvier and Agassiz are neither of them admitted to be natural; it is therefore not to be expected that any general student should be able to display the class in all its genetic relations, however confident he may be, from what he sees elsewhere, that such relations exist. We find, however, three advances made to its lower confines from the invertebrata-namely, by the cephalopodous mollusks, by the annulose animals (annelides), and by the echinodermata. And we see advances made in its upper confines to the next higher class, the Reptilia, which succeed it in the strata and chronology of the earth, as in organization. 
It is also sufficiently clear, that the succession of fishes upon our globe was in conformity with the embryonic development of the individual fish of a high order. This has been denied; but against all inferior authorities, that of M. Agassiz must on such a point be held incontestable. $\mathrm{He}$ expressly affirms it as proved "that the embryo of a fish during its development, the class of living fishes in its mumerous families, and the fish type in its planetary history, in every respect go through analogous phases." The want of substantial vertebræ in the Devonian fishes is found in the last gradation of the class of fishes, among the Cyclostomes. He has reason to think that the internal case for the brain in the Devonian fishes was cartilaginous. So it is in the sturgeon, so it is in all embryos. Certain arrangements of the fins, as well as the heterocercal tail, and the inferior position of the mouth, complete these curious and impressive analogies.

The Reptiles to the cold blood of the fish add a higher circulatory organization, as also lungs for aërial respiration; all of them (for exceptions are only apparent) are oviparous. Amidst the confusions of existing classifications, it is possible to trace three leading divisions, of which the tortoise, the lizard, and the frog, are the several representatives,-namely, the Chelonia, the Sauria, and the Batrachia. Cuvier makes a fourth order of the serpents; but Merrem and other naturalists contend that these are but a reduction from the lacertine portion of the sauria.

The Chelonia are remarkable for the boxlike case in which most of them are enclosed, - a peculiar development of the ribs of the animal, and which forms an 
admirable means of passive defence. They are animals of inert faculties, but great tenacity of life, and, generally speaking, the most harmless of all the reptiles, many of them feeding exclusively on vegetable substances. Destitute of teeth, they exhibit, like the birds, only a horny armature of the jaw, and even this is, in one genus, replaced by skin only.

The Chelonia are for the most part tropical animals, being seldom seen beyond the 2 oth degree of latitude. Within that range, however, the marine species are remarkable for the long voyages they annually undertake, for the purpose of depositing their eggs. It is also found, from our stony records, that the Chelonia were much more widely diffused over the earth in the ages of the oolite and tertiary, than they are now.

The marine chelonia-Turtles (Chelones)-demand the first notice. To this group belong the largest existing specimens of the order; some of them reach six and even seven, feet in length, and weigh seven or eight hundred pounds. All of them have extremities modified into paddles, for marine progression, with the toes enveloped in the membrane, and a very slight development of claws; but there is a natural division of the chelones in respect of habits and even of organization. One sub-group, amongst which is the common Green Turtle, so well known for its palatable qualities, is composed of species altogether herbivorous and of gregarious and innocent habits. These animals may be seen in herds at the bottom of the sea, quietly browsing on the weeds growing there. Sometimes they enter the mouths of large rivers, and are occasionally seen to make 
their way ashore, apparently in search of food. Their plates are discoidal, laid edge towards edge, with intervals of cartilage, by which their bodies have a certain flexibility. Another sub-group comprises turtles of carnivorous habits, active, and when attacked, fierce; examples are seen in the Loggerhead Turtle, which has the plates arranged as above, and the Hawksbill, in which they are imbricated, or laid edge over edge; the latter being the animal which furnishes the arts with the elegant substance called Tortoise-shell. Finally, there is a genus, also of carnivorous habits, - the Sphargis or Coriaceous Turtle,in which the exterior is not composed of shell, but of a leathery skin, having seven tuberculated ridges passing lengthwise along the back. These carnivorous genera have a more powerful form of mouth than the rest, and in some the claws are more marked. Thus armed, the Loggerhead, for example, will defend itself from a man with courage and ferocity; will snap a walking cane in twain with one effort of its jaws, and not let go anything it has seized until its own life is extinct. These genera live upon mollusca, crustacea, and fishes; and even the young crocodiles are liable to the attacks of the loggerhead. The progression of all the turtles in their proper element is rapid. M. Audubon says- "The Green and Hawkbilled, in particular, remind you by their celerity, and the ease of their motions, of the progress of a bird in the air."

In all the remaining chelonia, the paddle-form of the extremities is exchanged for legs and feet, the latter furnished with claws.

The River Tortoise (Tryonices), conspicuous tenants 
of the Ganges and Euphrates, the Niger and Nile, the Mississippi and Ohio, are next in size to the turtles, some being three feet long. With an imperfect development of the osseous case, they are enveloped in a soft skin, which has caused them to be often denominated Soft Tortoises. The feet are palmated for swimming, and the toes exhibit three claws. These animals are of fierce and energetic character, living upon fishes and reptiles, and not scrupling to attack the young alligators. They dart out their head at their prey with inconceivable rapidity, and tear it with their sharp-edged beaks and claws, after the manner of the predaceous birds.

The Emydes, sometimes called Fresh-water Tortoises, sometimes Marsh Tortoises, are of many various species, haunting lakes, marshes, and small rivers in Asia, Africa, Australia, but more particularly America, where the proper habitat is most largely presented. They have shelly cases, which in youth exhibit the imperfect closing peculiar to the turtles, but afterwards become complete. Certain species can, by flexures in the case, close-in their head, tail, and feet, so as to set enemies at defiance. The feet are palmated, and provided with five claws before and four behind. A remarkable rapidity of movement distinguishes this family, which devours not only aquatic worms, insects, mollusks, and small reptiles, but carrion. Among the emydes are species, such as Cistudo Carolina and Emys Muhlenburgii, which tend to a land life, and have the feet less palmated than the rest. There are also genera, Pyxis and Kinyxis, the one belonging to the Old World, the other to the New, which are regarded as connecting links between the emydes and land tortoises. 
Several aquatic genera of remarkable forms are not yet settled in any definite place in our systems. One of these, the Emysaura Serpentina (Fig. I02), which has a large head and a crocodilian tail, lives in the North American rivers, feeding on fish and small birds. Another, Chelys Fimbriata, or Matamata, with hardly any tail, has a large neck and snouted head, in which the mouth opens crosswise; it belongs exclusively to the rivers of Guiana. Mr. Swainson makes of these genera a group, to which he gives the name of Chelydrida.

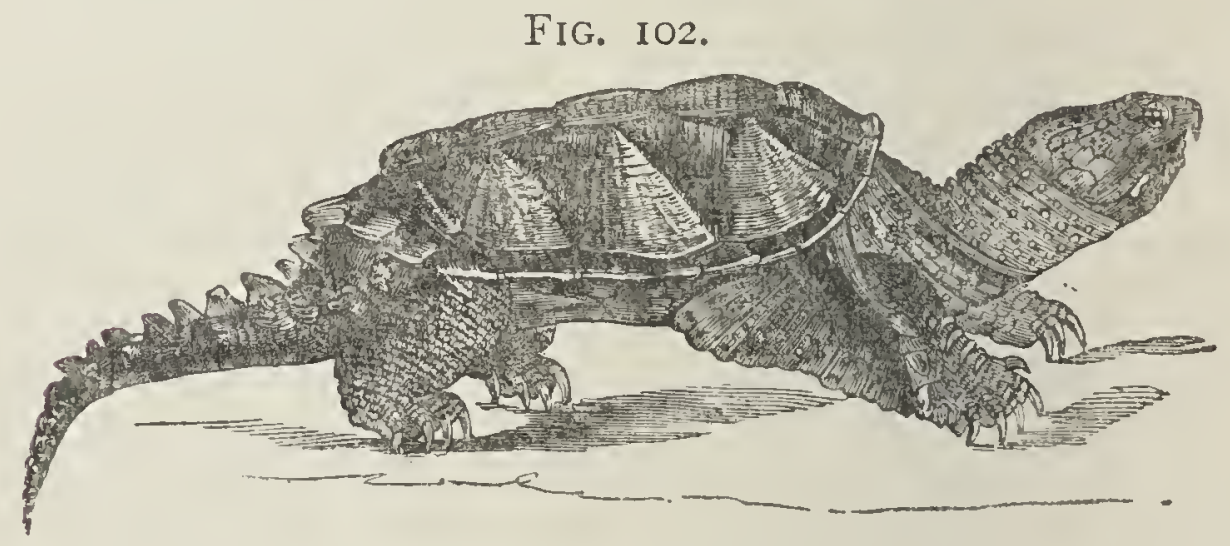

Enzysaura Serpentina.

Last are the Land Tortoises (Testudines), in which, with a perfect osseous case, there are extremities formed entirely for land progression, terminating in rounded callous stumps, with indistinct unguiculate toes. These animals are found in tropical regions all over the earth. Generally they are of small size; but in the Galapagos Islands Mr. Darwin found them several feet in length, and we know that in the tertiary era there were species in India of colossal proportions. The greater number of the land tortoises are vegetable feeders, and similar in 
disposition to the herbivorous turtles. A small group of species, already adverted to, stand apart, as exhibiting immediate affinities to the emydes.

Seeing the various characters of the Chelonia, and keeping in view the principles of the genealogical system, we have good reason for believing that two or more stirpes exist in this order of animals. The herbivorous species of sea and land undoubtedly form portions of one family, the transition from the one to the other being attended by little besides a slight conversion of the extremities, a maturing of the development of the osseous case, and that reduction of bulk which is everywhere seen in terrestrial advances from marine originals. Another stirps, perhaps starting in the coriaceous turtle, involves the Tryonices, or Soft Tortoises, which may be regarded as having merely passed from a marine to a fluviatile life, as has been done in many other instances. The Emydes, for which an original may be found in some of the other carnivorous turtles, constitute another line terminating in certain land species. On the Chelydes it would perhaps be premature to speculate. In our investigations in this order, it is highly instructive to mark the improvement in the filling-up of the interstices of the osseous frame, as we advance from the marine and fluviatile species. These interstices are seen in the youth of the emydes and land-tortoises, but as age advances, they are obliterated. But what is in them a youthful and transient character, is permanent in the former animals, marking clearly their precedence in the genealogical scale.

No better word than SAURIA seems attainable for the greatly varied order which next occurs, a combination of 
all the loricate and squamate reptiles. The crocodile, the lizard, and serpent, will suggest the principal forms to those least acquainted with zoology. They are extensively distributed over the earth, but chiefly in warm climates, and, being for the most part disliked by man, they are usually seen to decline as the human population advances. Of the three great reptilian orders, they may be considered the most carnivorous and destructive, though few are of great strength. In the time of the secondary formation, it was different. Huge saurians then traversed both sea and land, the undoubted masters of the animal world. Now, excepting in the crocodile family, and a few of the serpents, bulk and strength have alike departed from the order.

The Crocodilia form a distinct and well-marked family, comprehending the several genera of the common Crocodile, distributed in Africa, India, and America, the Alligators and Caimans of North America, and the Gavial, peculiar to India. All of these are well known to be animals of large size, living in rivers, fierce and carnivorous, and serving a useful end in devouring the dead animals which are usually floated in great quantities down the continental streams. Their exterior presents "distinct series of bones of moderate size, embedded, as it were, in the substance of the skin, and covered externally with a thick cuticle;" hence the term loricata, or mailed, which has been applied to them. The head is large, with an enormous gape, and some arrangements in respect of teeth, nostrils, and gullet, which appear admirably adapted for an animal requiring to catch its prey in the water. The origin of this reptilian family is to be sought amongst 
the great aquatic saurians of the secondary formation; the ichthyosaur, in particular, whose head is entirely crocodilian, while its general organization is fish-like. Afterwards, connecting links occur in the teleosaur, steneosaur, etc.

The remaining sauria present various forms tolerably distinguished from each other, but which are usually comprehended under the general term lacertine, the lizard being regarded as their type. First, and nearest to the crocodiles, may be cited the Varanida, a group composed of the Ouran or varan of the Nile, the Monitors of both worlds, the Tupinambis, and other genera; animals living upon small reptiles and insects, chiefly frequenting land, but also occasionally haunting the banks of rivers. The varan is so like the crocodile, and makes such an approach to it in bulk, that the Egyptians believe it to spring from an egg of that animal which has been hatched in dry earth. The skin of the varanians is "furnished with enchased scales, which are tuberculous, projecting, rounded upon the head as well as upon the back and sides, always distributed in rings or circular bands, parallel under the belly and round the tail." The teeth are planted in a furrow, and curve backward. Next may be mentioned the Lacertida, or True Lizards, of which the only living examples are small insect-eating animals, in a great variety of specific forms, scattered over the warm and temperate countries of the Old World; the least repulsive of all reptiles, often indeed of beautiful form and colouring. In intimate alliance with them may be placed the Geckos, which are of nocturnal habits, and the Chameleons, which again are inhabitants of trees, all of these being likewise 
insectivorous. In palæontology, the lacertian animals date from an earler time than any other Sauria. The huge extinct Monitors of the Thuringian Zechstein, the thecodonts of the nearly contemporary dolomitic conglomerate of Redland near Bristol, were among the patriarchs of these families. The Mosasaurus, the Geosaurus, and the Megalosaurus, were likewise huge early specimens of this division of the sauria. Finally, we have the Iguanide, the most harmless of all the Sauria, being generally restricted to a vegetable diet; to this family belong the anolis, stellio, dragons, basilisks, and other species.

The serpents (Ophidia) are usually placed as a distinct order of reptiles; such was the arrangement of Cuvier; but Merrem and several other modern naturalists of high character, place them in connexion with the squamate sauria; and there, undoubtedly, natural classification requires that they should be. From those sauria to the ophidia, there is such a series of transitional forms in the scinks and chalcidx, where we see the body gradually becoming elongated and more serpentiform, and the limbs diminishing away to mere rudiments, that it is impossible to assign exact limits to the various genera. We may even see in the perfect varanians a preparation for this new form. In these animals the bones of the head have, in part, that looseness of structure and adherence which is carried to so remarkable an extent in the serpents, which, being obliged to take their prey entire, could not otherwise swallow it. The varanians, too, move in a serpentine manner, using their long tail to aid their progression, and to enable them the better to leap upon their prey; 
peculiarities in which they greatly resemble the serpents. In the last lacertilia, the ribs are increased in number, the two pairs of limbs are removed farther and farther from each other, and become small and weak; in some species the anterior, and in other the posterior pair, alone remain; until at last they are reduced to mere rudiments

FIG. I03.

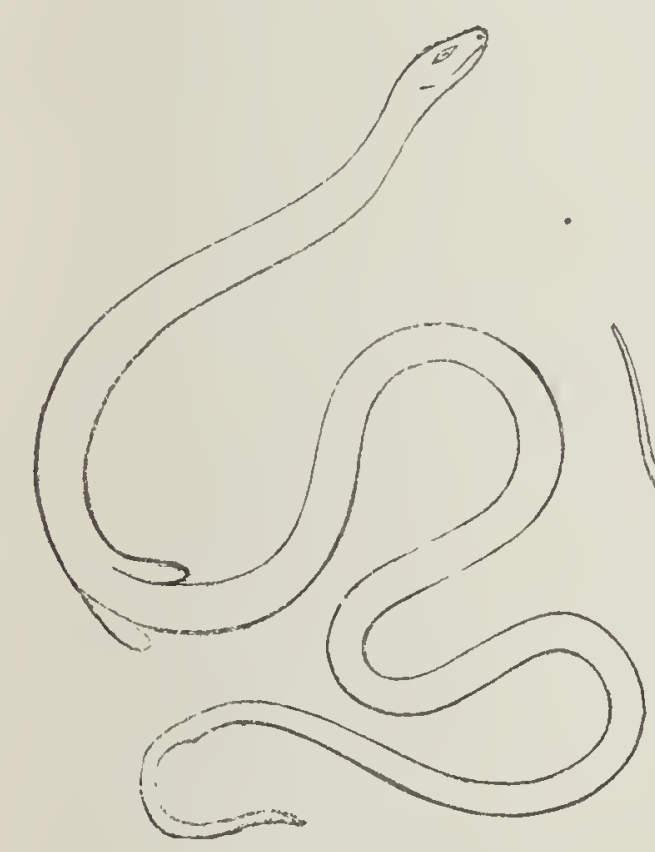

Dimanzs.
FIG. IO4.

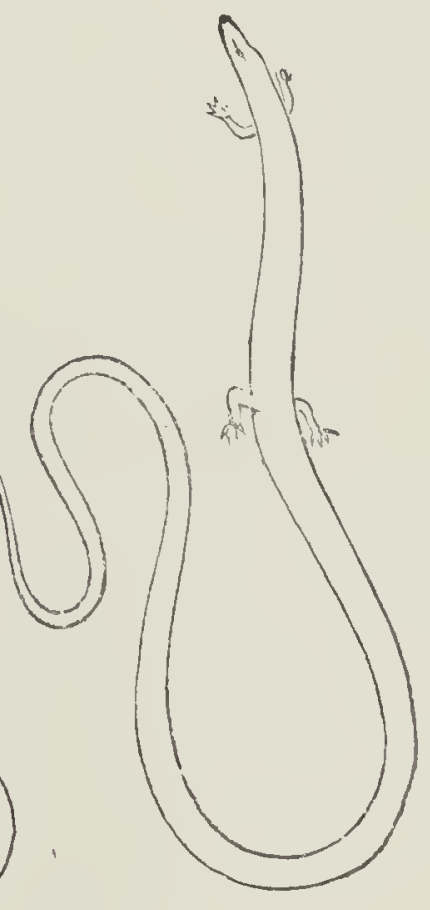

Seps.

which do not appear above the skin. The common slowworm is an example of a lacertilian in this state. At the same time, to suit the necessities of a body considerably attenuated, one of the lungs is gradually shrunk up, until at length, in the true serpent, only a vestige of it remains. Such is the actual history of the great serpent families-reductions from the lacertilia, to suit a life 
generally skulking and furtive; and there could not well be a more lively illustration of the doctrine of the transformation of animals. It furnishes a strong proof of the readiness of nature for reduction as well as advance, according as circumstances shall dictate. Many existing serpents are much larger than any existing lacertilia, the parent family; but it must be remembered that the early lizards were of enormous bulk. Geology speaks in harmony with this view of the genesis of the uphidia, no fossil serpent occurring in the secondary formation, where all the other reptilian forms so greatly abounded. Such harmonies may always be expected, where the true track of natural investigation has been arrived at.

A naked moist skin, sometimes smooth, sometimes covered with papillæ or tubercles, is the only universal character of the third division of the Reptiles - the Batrachia, so called from the Greek word for a frog, as that animal is the most conspicuous example of the order. The animals of this order are also remarkable for coming into active existence in a fish form (the tadpole), and passing in the course of active life through one of those metamorphoses which in the other animals are undergone before birth. They realize, as has been said, before our eyes, one of the grade transitions presumed by the development theory. In some species, certain portions of the organization are arrested at the fish stage, and so continue through life.

The frogs and toads (Ranida) are the batrachians most universally diffused over the earth and most familiarly known. They are harmless creatures, generally of small size, living upon slugs and insects, which they catch by 
darting out their long soft tongue, the end of which is, for this purpose, covered with a viscid fluid. They hibernate in mud or water, thus living a long time, not only without food, but without aërial respiration, a proof of the low organic character of these animals. The frogs spend much of their time in water; some assume a partially arboreal life, and have certain peculiarities in the feet which assist them in climbing. The toads are more terrestrial in their habits; but all alike have to propagate in the water, where their shell-less eggs are deposited in long strings, a single mother producing upwards of a thousand young. Some foreign species of the ranidæ greatly exceed ours in size; but, in comparison with the two other reptilian orders, the batrachian may be said to consist of little animals. Teeth are wanting in most of the toads, and they are developed on a humble scale in the frogs. The whole of the ranidæ are destitute of tail ; neither have their toes any armature, excepting a horny sheath in a few species. They are also devoid of ribs, or present at the most rudiments of such bones.

The ungainly form of the toad has caused it to be no favourite with our race, and given rise to many reports against it, particularly one respecting its venomous qualities, which is quite false. A French naturalist remarks that, if we could behold the frog without prejudice, we should see in it an animal uniting an elegant form with light and slender limbs, adorning the banks of the rivulet with its pleasing colours, (only less variable in some species than those of the chameleon,) and animating the scene with its light and lively gambols. The croaking noise of the frog is proverbial; this is changed in the 
love season to a soft and plaintive note. A modern writer says, "A traveller towards the desert shores of the Caspian and the Volga would imagine that he heard of a sudden, in the evening, a joyous assembly of men and women laughing very heartily. $\mathrm{He}$ approaches; the inextinguishable laughter redoubles among the rocks, and, to his astonishment, he finds that it proceeds from an assembly of enormous black toads, celebrating their nuptial rites." 1

Although the frogs and toads are now, generally speak ing, small animals, we must recollect that such has not always been the case. The Batrachia, whose footsteps occur in the carbonigenous era, and at a somewhat later date, must have been as large as good-sized hogs. It may at the same time be remarked that, if this was the utmost size attained by batrachia in the era of the secondary formation, they were then, as now, relatively much smaller than the saurian order, of which several reached the length of thirty, forty, and even, it is believed, seventy feet.

A second division of batrachia is composed of animals of which the salamander is the type; hence called Salamandrida. In them the tail is largely developed: in other respects, as in their reproductive history, they resemble the preceding division, the water-newts being analogous to the frogs, and the land-salamanders to the toads. They also resemble the ranidæ in habits; but one remarkable species, the Menopoma of the Ohio and Alleghany rivers, which reaches two feet in length, is more fierce and carnivorous than any of the frogs or 
toads. The salamandridæ are extensively diffused over the earth; they generally are small animals, but one species, Sieboltia, which inhabits a lake upon a basaltic mountain in Japan, is three feet in length, and fossil species are found in the schists of Eningen (miocene formation), which must have been of nearly twice this measurement. The fluid which exudes from the salamanders, as from other batrachia, is probably what has given rise to the vulgar notion that these animals can resist the action of fire.

The remaining batrachia are isolated species, generally limited in locality, and all of them retain in their maturity some portion of the fish character. The Amplizuma, an eel-like animal, two or three feet long, which is found in stagnant pools in the more southern of the United States, has apertures in the sides of the neck, the last vestige of the gillstructure. Deep underground, in waters never visited by daylight, resides the blind Proteus, which continues to have entire gills branching from the neck throughout the whole of life, and only depends in a less degree upon lungs. With four short and feeble limbs, it departs little from the form of the fish. The Sirens, which inhabit marshes in Carolina, have no hind limbs, and only rudiments of the anterior pair. In the

FIG. I05.

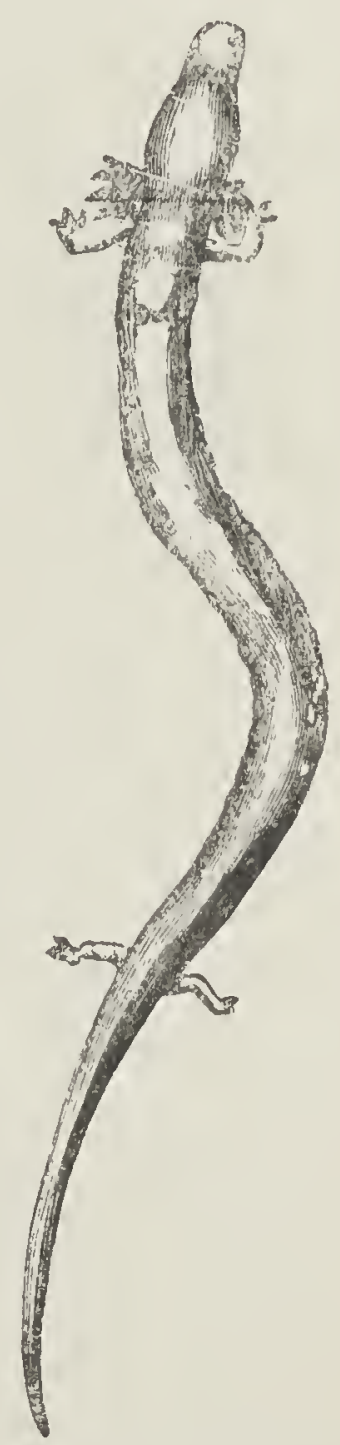

Protens Anguineus. 
North American lakes is the Menobranchus, with constant gills, and four very small limbs: it sometimes attains the length of three feet. Another of these gilled batrachia is the Axolotl of the Mexican lakes, the flesh of which is esteemed a delicacy.

FIG. 106.

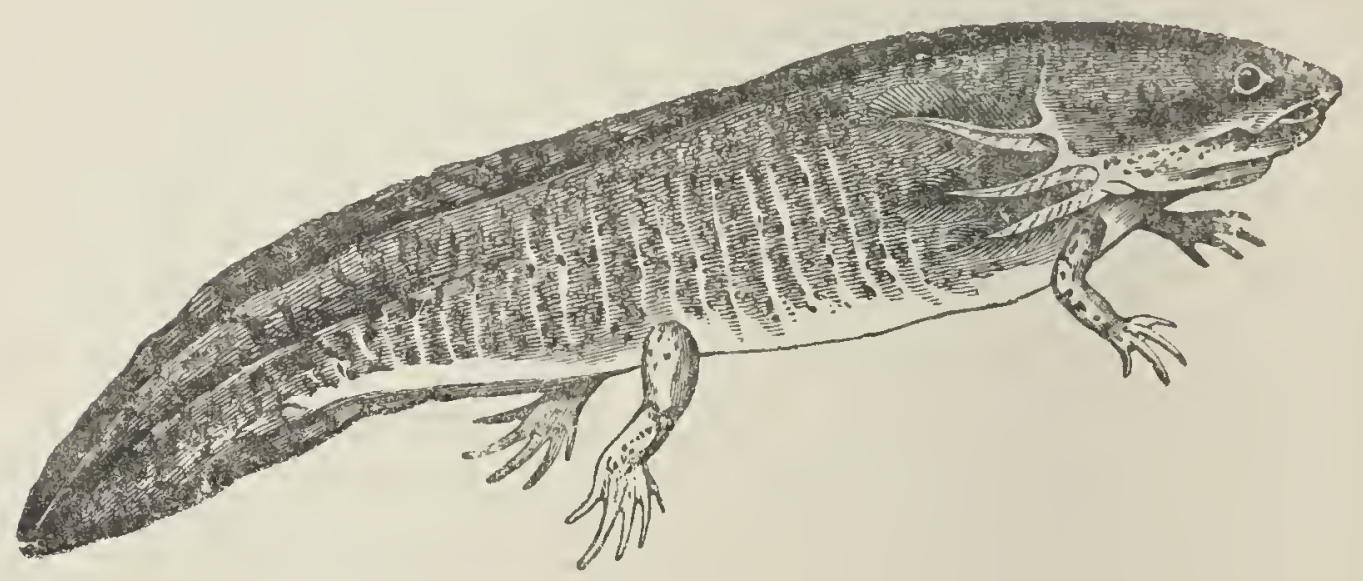

Axolotl.

The reduction of limbs in some of these latter species reminds us of the lacertilian animals on the approach of that family to the serpent form. It is not therefore surprising to learn that there is a genus of undoubted batrachians which are wholly serpentine in figure, that is, without limbs, and also possessed, like the serpents, of unequal lungs. These are the Cecilia, or blind-worm, and kindred species, all of them inhabitants of warm countries; usually of a very attenuated form, and about two feet long. Till lately, the cecilia was ranked with serpents; but its passing through a metamorphosis, united to a consideration of its naked skin, has at length assigned it to the present order. Vegetable matters, as 
well as mud and sand, have been found in the stomachs of the ceciliadæ.

The batrachia have a particular value on the present occasion, as, although probably but the relics of an order once containing many more genera, and some of these much larger in bulk, they present unequivocal affinities to the grade below them, and also striking affinities amongst themselves, while their reproduction supplies a faithful picture of the principal phenomenon concerned in the development theory. Several genera, by retaining portions of the fish character, make the descent of the whole from fishes still more apparent. Professor Owen has shown that not merely in the retention of gills, but in peculiarities of teeth, can the nearness of some of the batrachia to fishes be distinguished. The Ranidæ appear to compose two kindred lines; the toads, in their more terrestrial habits, may be said to make a greater advance than the frogs. In the Salamandridæ, there are also traces of at least two lines: amongst them, from smooth skins, and aquatic habits, to tuberculated skins and land habits, we pass through a well-knit chain of affinities. In the other Batrachia, we see only detached developments from the neighbouring fish-form, which we may suppose, in some instances at least, to have been prevented from advancing into new forms by the circumstances in which they are placed.

With this account of the Reptiles, the geological history of the class, as far as it goes, appears in harmony. First, it is after fish that reptiles occur in time, as it is after fish that they stand in organization. Early in the Carbonigenous era, after fishes had existed for the space of two 
entire formations, there arises a family assuming a trace of reptilian character, in an inner row of Saurian teeth. The Sauroid fishes, as they are called, increase and multiply, and, several ages thereafter,-in the Muschelkalk, - the Enaliosauria, or fish-crocodiles (ichthyosaur, \&c.) are presented, in which the passage to the reptile is clear and distinct. Before this event in the saurian line, a similar and more effectual transition had taken place in another animal series, resulting in those specimens of the lacertilian order which are found in the Keuper. In this instance, our records are meagre, and it is therefore not surprising that specimens uniting the fish with the reptile, as is done by the enaliosauria, are not as yet found. But still the general affinity to the fish-character, as well as a certain degree of aquatic habit, is shown in the biconcave vertebre of these early lizards. Of what has been remarked as to the late occurrence of serpents, it is not necessary to make repetition.

The next class above the Reptiles is that of BIRDS, in which warm blood makes its first appearance, and which are marked by various other traits of superiority, particularly in the nervous system, though an oviparous mode of reproduction is still maintained. It is a class comprehending a vast number of families, adapted to different spheres of existence and habits; some predaceous and sanguinary, others innocent and supported by a vegetable dict; some adapted for living upon the water, others upon the land; some designed to dwell upon the ground, others upon trees; yet exhibiting, throughout the whole, and under every variety of external adaptation, a much greater unity of structure than any other class of equal 
importance. Unusually clear chains of affinity run through the class, one genus melting into another by the nicest shadings; and yet, from the unfortunate principle of classification assumed by naturalists-in which the most external characters are taken as the chief basis of arrangement-there is no class presented to us in a more confused manner.

The first true division of the Birds is into three stirpes; one whose food consists chiefly of vegetable matters; another which live wholly upon flesh; a third which, as compared with either of the preceding, may be said to be omnivorous. The starting point with all three is in the Swimming Birds (Natatores of Cuvier), where the organization is admittedly the humblest, and to which an approximation from the Turtles has long been acknowledged. In this order, as it is called by Cuvier, there are some genera which present the typical bird-form in a strikingly imperfect manner, the feet being placed so far behind the centre of gravity that the animal walks no better than a seal, while the anterior extremities-short, and in some instances, scaled, rather than feathereddo not serve for flight, but are used exactly like the paddles of the marine turtles in propelling the body through the water: often for several hundred yards under it. There is some reason for believing that the Birds are derived solely from one order of the Reptiles, and that this is the cause of their more concentrated unity of structure. The affinity to that inferior class is certainly less clearly shown than are the affinities which pervade the class itself; but it may be asked if we can be sure that the transition from class to class was always to give inter- 
mediate forms, or that these, if given, were necessarily to be preserved, either as living species or as fossils? The Chelonia present a sufficient variety of characters to have been the sole parentage of the Bird class; many being fierce and carnivorous, while others are vegetable feeders and of gentle character. They are now chiefly tropical, while the swimming birds are hyperboreal; but the secondary and tertiary formations show that the chelonia were once much more widely distributed than they now are.

The first of the great stirpes is that which gives us the birds most important of all to us-the domestic poultry. Its root appears in certain of the natatorial families, the Divers (Colymbida), Grebes, etc. These are Swimmers native to the Arctic Ocean, though accustomed to migrate southward in winter. They are immediately followed by the Mergansers, Ducks, Geese, Swans, (Anatide,) and the Phalleropes (Phalleropida), Gallinules, and Coots (Lobipedida), which still preserve the aquatic habits, and the webbed or lobated feet necessary for progression in the water, but tend more to residence in rivers and other inland waters. In these, however, we see a clear separation into three subdivisions, one composed of the Mergansers and Ducks, which live in great part upon animal matters, another comprising the Geese and Swans, which are purely vegetable feeders, and a third embracing the Gallinules and Coots, whose diet is mixed.

The hypothetic history of these animals is so distinct, that it might almost be set down as a series of recorded events. Their tendency, in consequence of tastes in aliment, was to advance along rivers and the shores of lakes, to those adjacent low grounds where vegetable food, 
worms, and insects are to be found. They landed, we may say, either upon sandy beaches, or upon those low shores which, in the early ages of the world, antecedent to a time of cultivation, were wholly covered with marshes. On came the tide of population behind; it behoves them to spread landward for subsistence. The consequence was a modification of the hitherto natatorial forms of these birds, to suit a strolling life upon soft sands and in marshes. The webbing of the toes shrunk, being no longer required for swimming; the toes were elongated, so as to give support upon a yielding ground or bottom; the tarsi were also lengthened, to raise the body of the bird above the shallow water in which it walked: at the same time the animal acquired a greater length of neck and of bill to enable it to feed in these waters. The result is-the Wading Birds (Grallatores of Cuvier); merely a transformation of their swimming progenitors. In some parts of the earth, however, the regions adjacent to the sea were not marshes, but extensive sandy plains, presenting means of subsistence somewhat scantier, but still not to be neglected. The consequence was a branch of the swimmers, adapted by length and strength of limbs for that rapid progression from one place to another which is required by animals placed on extensive wastes. This branch comprises the Running Birds (Cursores), the Ostrich in Africa, the Emeu and Cassowary of Australia, the Rhea of America, the Apteryx of New Zealand; characterized by an extinction of the hind toe, which is not needed in their field of existence, and a reduction of the wings for the same reason in a modified degree, with, however, an approximation to 
mammalian characters, in the hair-like appearance of the feathers, the presence of a diaphragm in the visceral cavity, and other structural minutiæ.

The three subdivisions of the first stirps are with tolerable distinctness seen, passing each into its several progeny among the waders. Looking at once to external features, and to habits and characters, we readily select, as the descendants of the anatine birds, the Ardeidee (Herons, Spoonbills, and Storks), the most brilliantly plumaged of the Waders, as the Ducks are of the Swimmers, and equally addicted to a foul kind of animal diet, being, as is well known, amongst the most active scavengers of eastern and other cities. The anserine birds claim a progeny in the Gruide (Cranes), whose form of head, and the position of the eye, as well as the elevation of the hind toe upon the leg, remind us of that family, while their constancy to a pure vegetable diet is equally conspicuous. The Phalleropes, Gallinules, and Coots, reappear in a variety of forms, possibly forming inferior divisions or branches, yet evidently all much allied, the Rallide (Rails), Otida (Bustards), partially cursorial in figure, the Charadriade (Plovers), and the Scolopacide (Snipes, Sandpipers, and Curlews). All of these birds are mixed feeders, of gentle and timid character, with a tendency to walking power, which in some instances enables the animal to escape more surely by threading the brake than by flight. This last property may be connected in some way with the form of the feet shown by the grebes, phalleropes, rails, and other genera of the subdivision, these being not webbed, like those of the other swimming birds, but 
lobated; that is, having a separate lobe expanded along the sides of each toe.

The origin of all the bird-life as yet spoken of, was that ocean which we now see beating the northern shores of the two great continents. There, almost exclusively, is the nativity of these Swimmers; there do they yet live in sea and air-darkening abundance. Swimming birds, corresponding to them, scarcely exist anywhere in southern oceans; there is but one development of anatine birds in that quarter, in the geese and cereopsis of Australia. The rise of wading descendants was the consequence of a spread inland; that is, harmonizing with that system of animal migration which the swimming birds are still seen practising. Pursuing our hypothetic history, this movement of bird-life soon overpassed the borders of rivers, lakes, and marshes, and came to elevated, dry, and sylvan grounds; and a necessity for other modifications then arose.

At least two of the subdivisions had descendants suited to the new fields of existence. The cranes, spread as far south as India, there gave forth, as a great colony for its rich woods, the equally beautiful and useful Pheasant family (Phasianide), comprising the trained peacock, the jungle-fowl, and common poultry; in central America, in like manner, they presented the corresponding genera of turkeys and currassows. Thus came those useful domestic birds, some of which have been our servants as long as man has had a history, and which have entered so much into our common associations and literature. From them, again, proceeded the Pigeons (Columbida) whose beauty and innocence are even more 
endearingly present to us. To those who know only the common fowl and the ordinary pigeon of our country, it may be difficult to suppose such a connexion; but in India, the native seat of the family, the forms of the dove are numerous, and amongst them are species (for example, Geophilus Nicobarensis) which are evidently intermediate.

The game-birds, grouse, partridges, quails, \&c. (Tetraonida) appear as descendants of the rails and bustards, appropriate to the heathy moorland and mountain. So ends the first great stirps of the class of Birds.

Some general principles are clearly to be observed in the genealogy. Each subdivision preserves its own character, particularly as to food, through all the transformations which it undergoes. Thus the anserine birds, the cranes, and the poultry and pigeons, are all of them innocent vegetable-feeding animals. There is also an invariable diminution of size of body from the oceanic original to the inland descendants; for example, the anserine birds sink in the cranes, these fall off again in the poultry, and these again in the pigeons. At the same time, intelligence and the tendency to domesticity always increase.

The Second great stirps is composed of birds destined by their organization and dispositions to act as destructives over the rest. Its chief subdivision commences in a swimming family (Procellaride), of which the huge Albatross, with its ten-feet expanse of wings and its great hooked bill, is an example. The tendency of this family, as determined by the temptation of food, was not generally to low shores, but to cliffy wildernesses. Accordingly, it has no intermediate stilted forms, unless 
a solitary species, the Secretary of India and the Mauritius, be an exception. It may be regarded as passing at once into the majestic Eagle, the grandest of all birds, and a terrible image of unrelenting destructiveness. Some of the aquiline genus, as the Osprey, still haunt the shores and rivers, while others take up their abode in inland and generally Alpine grounds, frequenting the plains only for the sake of prey. The Kites and Buzzards show an affinity, as of descent, to the Eagles. Another subdivision presents, in suite, the Falcons (including hawks), and the Owls (Strigida), the latter being addicted to living near the haunts of men and pursuing prey by night. A link between the two is seen in the peregrine falcon, both in its owlish visage and its inclination to live in tall buildings. Another swimming family, composed of the Pelicans and Cormorants (Pelicanida), gives rise to the Vultures; and thus is completed the raptorial stirps.

The Third stirps is in some respects the most remarkable of all. It spreads out into a much greater variety of species than either of the other two; it is diffused over every country of the globe. On the whole, it may be described as omnivorous, though some genera are exclusively flesh-eaters, and even distinguished by their predaceous and sanguinary character. Hopping is a prevailing, though not exclusive, mode of progression. In the land genera, the foot is adapted for grasping or perching; whence the term Insessores is applied to them. The birds are generally, though not in every instance, remarkable for their wariness and vivacity; some are noted for their chattering and imitative powers; some of 
the most advanced genera attract attention by their beautiful song.

The stirps starts with the Gulls (Laride), an oceanic tribe distributed over the whole world, of active flying habits, generally of pure white plumage, presenting a variety of species, some of which, as the Terns, tend to a river life, and are of a swallow-like form. The mental character of the gulls does not stand high in our estimate; but we often do injustice in this respect to the sea-birds, believing that to be stupidity which is only unconsciousness of danger arising from the habitat being remote from human haunts. Mr. Edmondstone of Zetland speaks of the "characteristic inquisitiveness and vivacity" of many of the gulls, being the very qualities to be expected in the patriarchs of this stirps. Certain species, as the Skua, are predaceous and fierce, and the Glaucous Gull is a well-known attendant upon sailing vessels for the sake of offal. Like the crows, the gulls attack and devour; they will quickly eat up a dead whale. The common gull, again, comes to land in cultivated regions, and follows the plough in search of what it may turn up. It is not unworthy of notice, considering how this stirps is generally distinguished in respect of voice, that a particular species of the Laridæ is known, from its peculiar cry, by the name of the Laughing Gull.

Though the Gulls are upon the whole a whitish race, there are species presenting an admixture of black. This should prepare us in some degree to hear the crows (Corvida) presented as the immediate successors of the Gulls, more especially as one of the family-the Pie-is chequered, and white crows sometimes occur as 
exceptions to the rule. But the immediate dependence of the colour of plumage upon conditions is one of the most familiar facts of the philosophical naturalist; and the changes in this respect which individual birds undergo in their moultings before attaining maturity, might well reconcile us to the most startling transitions in this external character.

Intelligent, wary, social, omnivorous, though some tend more to flesh-eating than others, the Crow family is everywhere well marked; everywhere are they an object of marvel and curious study to our species, to whom it almost appears as if their voices were a kind of speech. In the genealogy of animals, their place is extremely important, for to scarcely any has so vast and various a progeny been given. It clearly appears that various crows, the Raven, Rook, Jay, Pie, etc., are the heads of so many distinct families, which have assumed various sub-characters in different regions of the globe, according as they were affected by external conditions; "a mighty maze, but not without a plan."

Taking the predaceous corvidæ first-they start in the Raven of the old world, and misnamed Black Vulture of America, the largest of all the species; animals keenscented, cautious, yet fierce, and which do not scruple even to attack some of the larger mammalia. In our continent, we see the raven and carrion crow followed by the hooded crow, which, being only a reduced image of its predecessor, will without much difficulty pair with the former, and produce a prolific offspring.

The crows are classed by naturalists as Conirostres; that is, having a conical beak. The beak is, nevertheless, 
considerably curved in the predaceous species, so as to approach the hooked form: in the American carrion crow it is as decidedly hooked as that of any raptorial bird. This should prepare us for hearing of series of birds descended from the predaceous crows, with that reduced kind of raptorial beak which having a curve and a notch or tooth in the upper mandible, gives them in classification the name of Dentirostres. One of these genera is the Shrikes or Butcher Birds (Laniade), a numerous and widely-diffused assemblage, living upon the smaller birds and insects, the former of which the shrike sticks, when killed, upon thorns, as a butcher hangs up meat in his stall; hence the name of the genus. From the shrikes also proceed certain genera of eminently insectivorous habits, and some of which, in accordance with that kind of prey, have the reduced form of beak called fissirostral, accompanied by a great width of gape-namely, the Swallows, Swifts, and Martins, (Hirundinide); the Nightjars and Goatsuckers (Caprimulgida), which, feeding by night, are to the swallows what the owls are to the falcons; also the Fly-catchers (Muscicapida), a genus so near to the shrikes in aspect, that several of the species have been classed by various naturalists in that group.

From the shrikes, moreover, if we can trust to an admitted affinity, come the Thrushes and Blackbirds (Merulide), whose fine song has blinded us in some degree to their destructive habits; as also certain corresponding birds of other countries, the Breves of India and Australia, the Water Owsel of Europe; the Mocking Bird, Water Thrush, and Ant Thrush of America. The Lyre-birds of Australia are also in strong affinity to the 
thrushes. Here it may be remarked, that the blackbird, as well as the crow, occasionally produces a white offspring, thus returning as it were to the primitive type.

The meruline family have an extensive progeny in the warblers' (Sylviade), nightingale, stonechat, blackcap, redbreast, redstart, etc., which are specially inhabitants of the groves and thickets, and devourers of insects. The affiliation here is peculiarly distinct: M. Vieillot remarks, "a spotted warbler is to my eye nothing but a thrush in miniature." With the thrushes are also connected the wagtails (Motacillida); in the American water thrush this affinity is exhibited very strongly.

The Chough or Red-legged Crow (Fregilus), an omnivorous genus, of familiar habits, may, from the admitted affinity, be set down as the undoubted progenitor of the Starlings and Pastors (Sturnida), a family in favour with the human species on account of their intelligence, sprightliness, and fine song. "They appear," says Mr. Swainson, "as a smaller kind of crows, which they very much resemble in manners and structure." Allied to the starlings, and probably an offshoot from some local genus, are the Pique-bœufs (Buphagida) of Africa, which gave occasion to a remark of some importance in the present speculation. These birds derive their food from the parasitic larvæ contained in the skins of ruminant animals, upon whose backs accordingly they take their meals, holding on by their cramp-iron-like feet, and using a forceps-like beak to squeeze out their food. The bird is fitted in a peculiar manner for this mode of existence; its claws are the most hooked of all birds' claws, overlooking only the birds of prey. It is curious thus to find 
a bird fitted for a life in intimate connexion with other animals, which we know did not come into existence till after the commencement of birds. Upon the common theory, it would be necessary to believe that the piqueboeuf was called into existence by a special fiat in connexion with the greater phenomenon of the origin of ruminant animals. It almost looks like derision to ask if this be credible, especially when we consider that the pique-bœuf is, in reality, not a bird standing in a solitary distinction of characters, but only a kind of starling adapted to special habits. Yet the reigning opinion of naturalists, if true to itself, can in no way escape from the absurdity to which this question reduces them.

Near to the starlings, but perhaps only by collateral relationship, is an important genus, numerous in both Europe and North America, the Larks (Alaudide), a ground-inhabiting, seed-eating, innocent race, endeared to us by the habit so noted in certain species of rising high in the air, and there pouring out their beautiful and joyful songs. There are many varieties of the Lark, adapted to life upon shores, in fields, and amongst the woods. They possess a remarkably strong conical beak for husking seeds, and which they occasionally employ even in breaking nuts for the sake of the kernels. Perhaps with the larks should be associated the pipits or titlings. The Buntings (Emberizidce), comprising the yellow-hammer, ortolan, etc., are a comparatively untuneful variation from the larks, having a shorter bill, with a palatal knob, but generally similar habits, insomuch that they are often caught in the same net. From them again we pass to the Sparrows (Passeres), so widely diffused 
and so well known, and to the Finches (Fringillide), the latter an extensive group of field birds, comprehending the goldfinch, chaffinch, linnet, canary, cross-bill, etc. The most conspicuous external feature of this series of birds is a hind claw of unusual length and straightness. All are conirostral.

The Cuckoo is from many features entitled to a place in or about this portion of the corvine stirps, though its zygodactyle foot has caused it to be classed by naturalists in their purely artificial order of Scansores or climbers. It is prevalent over the whole world, including Australia, and is everywhere noted for its habit of placing its eggs in the nests of other birds, that its young may be hatched and brought up by them. As is well known, the rearing of a young cuckoo in a nest costs the life of all the foster mother's own progeny. Here occurs another difficulty of a remarkable kind, for those who maintain that each species has been the result of a special fiat; for how irreconcileable is it with all our ideas of immediate or special arrangement, that a particular species can only be continued by such a sacrifice! The fact is, that the cuckoo is obliged by its constitutional character to stay an unusually short time in the northern regions where it produces its young. In our country its normal stay is only from the middle of April to the beginning of July. Belated in its approach to the nursing regions, it is obliged to make use of the nests of other birds, which it finds ready built. What is worthy of notice, it employs the nests of its own nearest relations, the larks, pipits, finches, sparrows, etc., an arrangement we may suppose to be connected in some way with the early history of the whole 
group of species-a family or clan sacrifice, as it were, for the benefit of a less fortunate member. Thus, it will be observed, when we take the whole group together, as only variations produced by certain natural laws from one stock, the parasitical reproduction of the cuckoo sinks into that character which alone we can reconcile with the rest of the providential scheme,-a trivial exceptive evil in the midst of much that appears, and undoubtedly is, very good.

The Jay is said by Professor Macgillivray to connect the crows with the Tits (Paride), a varied genus of notedly crow-like characters.

From the Nutcracker, another of the smaller crows, come the Woodpeckers (Picida), which present merely a modification of the corvine structure to suit an insecteating life amidst growing timber. The woodpeckers, for this purpose, have turned back the outer toe, so as to be able to climb and cling to the stems of trees; the beak has been at the same time elongated, to enable them to search in the crevices of the timber for insects. They are spread into all the quarters of the globe. It is interesting to observe the kindred nature of the parent species: the nutcracker is often observed to climb the bark of trees : it uses the beak to split open nuts; and, as in the woodpecker, the middle feathers of the tail have been found worn in consequence of its climbing habits. In near affinity to the woodpeckers, but perhaps only in cousinship, not in descent, we must place the Creepers (Certhiadce), nuthatch, hoopoe, wren, \&c.; smaller birds, which have the toes in the usual arrangement, but are not less dexterous in making their way along the bark of 
trees and searching it for their favourite food. The Trogons of India, Africa, and America, and the kindred Todies, of the first of these countries and Jamaica, also appear to be of the woodpecker connexion. If we might judge by the structure of the tongue, we should place the Humming Birds of America in the same branch of the corvine genealogy: they eat insects, although they are certainly more peculiarly fitted to draw an innocent aliment from the juices of those flowers whose dyes they themselves rival. Corresponding to them in the Old World are the Honey-eaters of Australia and Sun-birds of India and Africa. Those remarkable looking birds, the Hornbills (Buceride), natives of India and Africa, are another off-shoot of the great corvine nest, most probably from the Carrion crow, which, in feeding, those of Africa at least resemble. They are gregarious, noisy birds, generally of large size, with feet short for perching, their habit being to reside in trees. The tendency of the crow tribe to noise, or the exercise of voice, has led in this genus to a development which forms their most conspicuous feature, namely, a hollow protuberance, blown out, as it were, like a bag, upon the top of the upper mandible, and which serves as a sounding board to increase the vociferation which the bird delights to utter. In immediate descent from these birds appear the Plantain-eaters (Musophagida), which, however, are re* stricted to Africa.

The Toucans of Tropical America (Ramphastida) are another branch of the corvine family. They live in deep forests, much after the manner of the woodpeckers, using their enormous beaks and barbed tongues in searching 
out eggs and nestlings in the hollows of trees. Singular as the beak appears in this instance, it is seen to be expressly suited for the objects which the bird wishes to accomplish. Let us not wonder too much at a growth so extraordinary, or be too eager to set it down as a feature separating this bird hopelessly from all the rest of the corvine family. Naturalists daily see such modifications of this instrument, as make it very easy to understand how the animal, tempted by food in peculiar situations, came to have its beak adapted to the purpose of obtaining it. The same remark will serve on our introducing the Parrots (Psittacida) as another family of the corvine stirps, some of whose special qualities, particularly garrulity and imitativeness, they possess in an extraordinary degree. They are distributed throughout the intertropical countries of both hemispheres, as well as Australia and New Zealand. Eminently arboreal in habits, in them we see the perfection of the scansorial or zygodactyle form of the foot, the outer toe being turned completely behind.

In the stone record there are, as is well known, few entries of birds; but such as there are, bear a general correspondence with this view of the genealogy of the class. The Connecticut footsteps chiefly point to tribes which stand early in the pedigree, namely, species allied in structure to the snipes and plovers. Others, from their gigantic size, have been thought only referable to struthious birds-an equally early off-shoot from the aquatic order. Some few are more dubiously assigned to rasorial birds. With regard to the absence, here or at an carlier period, of swimming birds, let it be considered that the 
phenomena are extremely local and limited; also, that the spot investigated is a portion of an ancient shore, a haunt of wading rather than of swimming birds. Recently, indeed, it has been announced that one of the birds indicated by the footmarks was a swimming birda fulica, or coot; but, as all such announcements require confirmation, little can be founded upon this, more especially as a footprint resembling that of a finch was spoken of at the same time. In rocks posterior to the Connecticut footmarks, but within the secondary formation, occur three bird fossils, one referred to the snipe family, another to the albatross, and the third to the swallow; the majority being thus applicable to early portions of the genealogy. When we at length come into the tertiary formation, we find, in the eocene, a vulturine bird: soon after which ornitholites, as they are called, become of greater abundance; and "here," says Mr. Strickland, "as in every other department of the animal kingdom, we perceive a rapid approximation to the fauna, which is characteristic of the period in which we live." ${ }^{1}$

Finally, we have to inquire into the connexions between the lower vertebrate classes and the highest, the MamMALIA. Naturalists place the Birds between the Reptiles and Mammals; yet in some respects the birds are not truly intermediate. We are the less to be surprised on finding that the principal mammal orders appear to be immediately connected with the Reptiles, while only the lowest come through the Birds. As usual in transitions from class to class, which in general are the leaps of the

1 Report on the Progress and Present State of Ornithology, by H. E. Strickland; British Association, I 844 . 
development process, the passage from reptile and bird to mammal is obscure; only indicated in a few stray facts. Perhaps the fossil blank at the conclusion of the cretaceous era has helped to keep light from this subject. Still we have enough to bear us out in saying, that, as the fishes connect with reptiles, and these with birds, so do reptiles and birds together connect with mammalia; thus placing the general fact of the continued advance of animal life from its lowest to its highest point beyond a doubt.

The first glimpse of the mammalian type presented by geological research, is in the Cetiosaur, a huge reptile of the Oolite nearly allied to the marine sauria, but exhibiting in the form of the larger vertebræ a clearer affinity to the whale tribes. In connexion with this fact, the physiologist tells us, that in the manatus and dugong, specimens of these tribes, there is a dense texture of bone, and an absence of medullary cavities, assimilating their skeleton to the reptiles, which class they further resemble in the loose connexion of the bones of the head. It would thus appear, in this grand instance, as in all others, that the starting point of the superior class was in the marine and consequently earliest examples of that below ; for the trunk of the genealogical tree of Being is short compared with the branches.

The passage from the Birds to the Mammalia connected with them happens (for accident in the preservation of species and the discovery of fossils is much concerned in the case) to be more manifest. Somewhat unexpectedly -but Nature must be taken as we find her-it is the humblest mammalian orders, which come through this protracted channel. They are the Dirging Edentata 
(armadillos, ant-eaters, pangolins, etc.), the Insectivora (moles, hedgehogs, etc.), and Rodentia (mice, squirrels, hares). By all modern comparative anatomists, it is allowed that these show, in their osseous structure, imperfect dentition, and humble character of brain, an affinity to birds. There is, however, another order of animals, which can hardly be considered as fully mammalian in character; Implacental Mammalia they may at the best be called; and which are even nearer to the bird character than the three orders above enumerated. These are the Monotremes and Marsupials; animals now

FIG. 107.

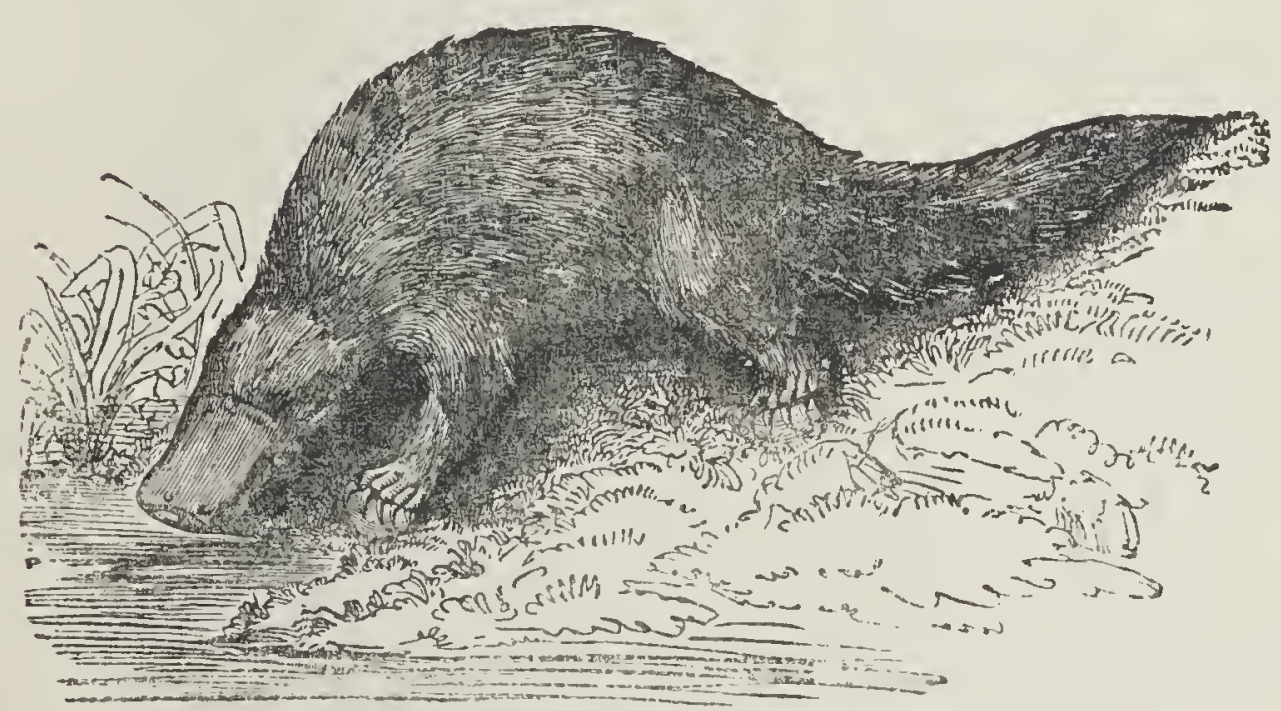

Ornithorhynchus.

almost restricted to Australia, but which were formerly more widely distributed. In the brain and other parts of the organization, they are decidedly bird-like. But this is not all; for in the only surviving monotremes, the Ornithorhynchus and Echidna, we see the bill and web-feet of the swimming-bird still unchanged, the former animal being 
a semi-rodent, and the latter a semi-insectivore. Here is a gradation most remarkable, the point reached being only, as it were, half-way towards the higher form of existence. It is also very remarkable to find amongst the more numerous marsupials, genera recalling the rodent and the insectivorous forms, as if these were only further advances along similar lines.

Reverting to the genealogy of the higher orders of Mammalia, we find ourselves introduced by the cetiosaur and the remark as to the osteology of the dugong, into the confines of the marine or fish-like order of their class. In this group of animals, what first strikes us is that, while united by a common medium of existence, and some peculiarities fitted thereto, they are otherwise extremely various, as much so indeed as all the land mammalia together. The whale, the dolphin, the seal, are animals fully as different from each other as the panther and the elephant, the deer and monkey. Naturalists now begin to say that the Carnivora (lions, bears, genets, shrews) are represented in the seals, and the great pachyderms in the whales; - the ruminants, also, in the herbivorous cetes (manatus and dugong). Obscure as is our knowledge of the aquatic mammals, this relation is indubitable, but its real character has never been read. It becomes quite intelligible when we arrive at the idea of a genealogical system; but in no other way, to all appearance, can it be explained.

The aquatic mammals are not properly one distinct order, nor two either. They merely form the initiatory stages of certain terrestrial orders, - a cross section, as it were, at the bottom of those orders, and part of the com- 
posite chain by which they are connected with the reptiles.

The first of these terrestrial orders is that of the Carnivora: it starts in the seals (Phocida). We see in that family genera bearing a positive resemblance to both the ursine and the feline tribes, and respectively called in consequence sea-bears and sea-lions. It is also of importance in the case of the bears, that there are genera (such as the arctic bear) geographically adjacent to the haunts of the phocal tribes, partly similar in their semiaquatic habits, and also akin in the low (plantigrade) organization of their hind extremities. From the bearsstartling as it may appear-proceed the Canidae (wolf, fox, $\operatorname{dog}$ ), in which there is at once an improvement in form (digitigrade) and an advance in intelligence. Let not prejudice resist this pedigree. We must remember that the dog is still a carnivorous animal, and, in the wild state, a ferocious one. But the almost identity of teeth, and the fact of the bear and dog having proved fruitful, are the facts on which the genealogy chiefly rests.

A third carnivorous line, which may be called the Musteline, is clearly traceable from the seal called the Otaria, through the sea-otter, the river-otter, and so on to the shrews and musteline animals in general. One, in which the succession is not so distinctly seen, embraces the Viverrine animals, including the hyæena, procyon, genet, ichneumon, etc.

The alliance of the Pachydermata to the whales is fully admitted by modern zoologists, being seen in the thick and naked skin, the gigantic body, massive bones, and even the variable and irregular teeth, peculiar to the 
latter animals. Here it is also important to observe that some of the pachyderms nearest to the whales in bulk, as the hippopotamus and rhinoceros, are partly aquatic in their habits. Even the elephants and tapirs are but one step further on to terrestrial habits, seeing that they chiefly haunt the savannahs and jungles adjacent to great rivers. The Equidae (horse, ass, quagga, onager) and the Suida (pig, babyroussa, peccary) are pachyderms adapted to inland situations, reduced in bulk, but improved in organization. Their respective parentages in the bulkier families may be left for future decision.

The herbivorous cetes, dugong, manatus, and walrus, form the basis of the great order Ruminantia, to which they are allied in their gregarious habits and large bulk, as well as in their food. ${ }^{1}$ This order presents two distinct subdivisions-the Bovida (aurochs, bison, buffalo, ox), leading on by such intermediate forms as the ovibos or musk-ox to the sheep; and the Cervidae (elk deer), leading on to the goat; the animals of low and alluvial grounds thus, as usual, passing into smaller species adapted to more inland and elevated situations.

The last mammalian order is that which Linnæus called Primates, comprehending, however, not only the monkeys and lemurs, and the Cheiroptera or bats, but the Sloths (Bradypodida); which Cuvier, merely from their want of certain teeth, placed elsewhere. ${ }^{2}$ For this order ther $\epsilon$

1 A different position was assigned to the herbivorous cetes in the fifth edition. Since then, the balance of evidence appears to me decidedly for the arrangement above indicated.

2 The sloths have been raised from association with the ant-eaters and armadillos to the Primates, by a French naturalist, in consideration of the complete nature of the fore-arm, the head of the radius being round and apt for rotation; also from the thorax being rather wide than deep, and from the form of the 
remains (with a long interval) a basis in the Delphinida, the last and smallest of the cetacean tribes. This affiliation has a special support in the brain of the Dolphin family, which is distinctly allowed to be, in proportion to general bulk, the greatest amongst mammalia, next to the oran-outang and man. We learn from Tiedeman, that "each of the cerebral hemispheres is composed, as in man and the monkey tribe, of three lobes-an anterior, a middle, and a posterior ;" and these hemispheres "present much more numerous circumvolutions and grooves than those of any other animal." Here it might be rash to found anything upon the ancient accounts of the dolphin -its familiarity with man, and its helping him in shipwreck and various marine disasters, although it is difficult to believe these stories to be altogether without some basis in fact. There is no doubt, however, that the dolphin evinces a predilection for human society, and charms the mariner by the gambols which it performs beside his vessel. The first steps from this aquatic family are perhaps not to be seen upon earth. It appears as if we

trunk in its lower part. Mr. Owen is opposed to the translation; but it is sup. ported by Mr. Edward Newman, a living zoologist of the first character. The following are Mr. Newman's reasons :-

"The face of the sloth is round, short, and remarkable for its almost human expression, a character even more observable in this animal than in the majority of monkeys. The structure of the skull and teeth also exhibit some approaches to the monkeys, but none to the ant-eaters. The size, figure, and general external appearance is that of a monkey. The mammæ are two only, and these are pectoral. The feet are always used as hands for grasping and climbing, and never as feet for walking or running on the ground. The sloth spends his time entirely in trees, among the branches of which he travels with wonderful rapidity."System of Nature, 1843 .

The Physiologist who has supplied some MS. notes on these pages here remarks : "The characters enumerated above are rather adaptive than essential. In the most essential characters, those of the nervous and generative systems, the sloths are very low. Moreover, they are intimately connected with the Mylodon, Megatherium, etc., which have many reptilian affinities." 
had to take up the lines in decidedly inland species-the Monkeys and Sloths, which are sylvan; the Bats, which are partially aërial; and man, who is geographically universal. For the Sloths alone, do we discern any trace of intermediate species. These appear distinctly enough in the fossil megatherium and megalonyx. ${ }^{1}$ The want of the rest is not a formidable difficulty, for it appears, generally, that the species hovering between sea and land, or those adapted to live upon shores and low grounds, are most liable to become extinct. Hence it is that the tapirine and elephantine animals are visibly fading from the face of the earth. Thus has the anoplothere perished, while the llama survives. It cannot fail to be remarked that the geological history of the mammalia is, as far as we obtain from it any distinct ideas, in conformity with these views regarding their classification. The marsupials and aquatics appear early, even before the cretaceous era. After the long blank which that formation represents, what are the animals found predominant in the beginning of the tertiary? The great pachyderms and cetacea, particularly manatidæ. The dog, horse, and other culminating species of the various lines, come comparatively late, the sheep and goat not at all; man also is absent, till the most recent formations.

We cannot but regard with profound interest the question respecting our own immediate ancestry. The

1 It was suggested that the megatherium might exhibit an alliance to the armadillos by a bony armour. Mr. Newman (System of Nature) expresses his dissent to this notion, because "the dorsal vertebræ want those lateral processes so essential to the support of a weighty osseous carapace. I should rather fancy him a sloth in all his characters, with a round monkey-like face, an awkward gait, shaggy hair, pectoral mammæ, \&c. Megalonyx, Mylodon, and (if distinct) Dr. Harlan's Oryctotherium Missouriense, evidently approach Megatherium, and unite in forming a group of animals, \&c." 
mind immediately refers to the simial family, whose form, size of brain, and general characters make so manifest an approach to our own. Yet it may be doubted if the particular species whence the human family was derived, has ever come under the attention of naturalists. It seems, judging from analogy, as if a larger species than any as yet described, were required, for this place in the tree of being. It may here be observed that of all the reptilian orders, the batrachian is that which has best pretensions to a place in the pedigree of the Primates. "It is singular," says Dr. Roget, "that the frog, though so low in the scale of vertebrated animals, should bear a striking resemblance to the human conformation in its organs of progressive motion." It is the only animal besides man with a calf to its leg. It evidently " is making," says Dr. Roget, "an approximation to the higher orders of mammalia." The frog, however, is but a humble off-shoot of the main line terminating in the Primates. In these things the superficial thinker will only see matter of ridicule: the large-hearted and truly devout man, who puts nothing of nature away from him, will, on the contrary, discover in them interesting traces of the ways of God to man, and a deeper breathing of the lesson, that whatever lives is to him kindred.

Our view of the animal kingdom is now completed, and I venture to claim for it the character of being, with all necessary and unavoidable imperfections, the only approach yet made to a truly natural classification. Proceeding everywhere upon obvious affinities, most of them admitted by zoologists, or else upon equally acknowledged 
facts in the doctrine of embryology, it presents an arrangement in almost every point conformable to palrontology, or the geological history of animals upon earth. Nay more; so far is that history from being irreconcileable with any assumed progress of animated being from simple to complex forms, that I would now say, any discoveries violently altering it, or doing more than filling up its blanks, would be at issue with the true plan of being, and a source of doubt with regard to the whole of our hypothesis of creation.

It now appears that we may regard the animal kingdom (and by analogy the vegetable also) as composed of series of forms, each usually taking an origin in the lower subkingdom, and afterwards passing through higher grades, but not in every case through all, until the highest is reached. It appears that the grand matrix of organic being is the sea, though this is not to be held as excluding fluids of lesser mass, and different character, from their share in this phenomenon. Regarding the ocean as the grand medium of life, we see what may be called trunk lines of being passing through it, as high as the mammalia, with terrestrial families shooting off at various points, or forming the terminations or "capitals" of the main lines, passages, however, being observed in some instances to have taken place on land. Two principles are thus seen at work in the production of the organic tenants of the earth-first, a gestative development pressing on through the grades of organization, and bringing out particular organs necessary for new fields of existence; secondly, a variative power connected with the will and dispositions in animals, re-acted upon 
by external conditions, and working to minor effects, though these may sometimes be hardly distinguishable from the other. Everywhere along the central scale of organization, the land has been, as it were, a temptation or provocation to new and superior forms adapted for inhabiting it. We might almost regard the progression as the result of an aspiration towards new and superior fields of existence, as from the deep sea to the shallow or river embouchure, from the shore to the bank, from that again to the higher ground in the interior. He may not yet be held as a very fanciful naturalist, who would regard the megatherium as eager to climb the tree which he could only shake, and thus producing a progeny fitted to do that which was the object of his wishes,-or the rock-nose whale, which loves to rest its head on rocks beside the beach, as wishful of that mode of life which was at length vouchsafed to a more highly developed descendant. Such too may be found to be the true principle of perfectibility in nature-a continual, though it may be an irregularly shown tendency to press on to better and better powers,-an indefinite improvableness, which may work, as in seconds, in the individual, or strike hours in the species.

Within the last twenty-five years, Mr. Macleay, and other naturalists, have presented a classification of animals on a numerical system of grouping. The prevalent opinion amongst them was, that the true divisions and subdivisions were in groups of five: thus, five subkingdoms, five classes of vertebrata, five orders of the class mammalia, and so on, the general character of each class being represented in a corresponding order, and the 
same character being further reflected even in the families or genera into which the orders were subdivided. There were striking appearances of a basis of truth in this theory, though in the excessive ardour of its first advocates, it was carried to a pitch of refinement in which nature was lost sight of, and the whole was greatly marred by the notion that all the groups arranged themselves in circles. Acknowledging the value of the theory as, with all its faults, a great step in philosophical zoology, I shall proceed to show what have an appearance of being true grounds for some such arrangement of the animal kingdom.

The Birds present the clearest traces of a determinate grouping, with an analogous sub-grouping. We see three great divisions; first, birds of solitary, predaceous, carnivorous habits; second, birds of gregarious habits, accustomed to walking on the ground, slow of movement, large of bulk, generally granivorous, and harmless; third, birds which are, generally speaking, omnivorous, rapid of movement, comparatively of small bulk, not merely gregarious, but social, often marked by garrulity, imitative power, cunning, and mischievousness. The eagle and vulture mark the first; the common fowl, pigeons, and game birds, the second; the crow, pie, parrot, thrush, lark, sparrow, the third. As for subgroupings, it would be rash to attempt precision; but certainly in the second, the geese, cranes, gallinæ, and pigeons, with their peculiarly innocent characters, might stand as representatives of the group itself, while the more carnivorous ducks, herons, and plovers appear in analogy to the predaceous or first group, and the rails to 
the third. In the third group, again, the three are not less strikingly represented by the following in succession-the shrikes and warblers, - the larks and sparrows, - the parrots, toucans, pies, starlings, \&c.

If we start from the birds with these three general characters in our mind, we shall find that the reptiles fall under them in this order; - the Sauria-the Chelonia-the Batrachia. So do the Mammalia, after we have laid aside those which appear as lateral offshoots through the birds. They rank thus :- the Carnivora-the Herbivora (using this term to include pachyderms, equidæ, and ruminants) -and the Primates. Thus, again, analyse the Carnivora, and it seems allowable to regard the viverrine and musteline animals as representing the order itself, and the Ursidæ and Canidæ in their bulk and comparative innocence of character as standing for the herbivora, while the Primates are reflected in the Felinæ, to which belongs a remarkable clutching power. ${ }^{1}$ In the Herbivora we may regard such animals as the pig and rhinoceros as representing the carnivores, the ruminants as representing the innocent group, and the equidæ, with their rapid movements and familiar character, as standing appositely to the third. So also, in the third, the batsthe sloths-and the apes-appear in precisely the same series of relations. Whether there be still another grade of sub-analogies, I will not take it upon me to pronounce.

It may here be remarked that this system is not affected by any determination which may be arrived at

1 "The Felinæ appear as the typical carnivores, while the viverrine and musteline animals must be regarded as aberrant."-MS. Notes of a Physiologist. 
with regard to the genealogy of the birds; for these, whether descended from one order of reptiles or all three, would exhibit the same groupings. It may also be remarked that their supposed descendants, the Edentata, Rodentia, and Insectivora, conform to the relations as thus collocated. The Fish must not yet be speculated upon; but in the Mollusca, I am tempted to think that the relations apply in this order-Cephalopoda-Gasteropoda-Cochifera.

Even with those relations here indicated, we acquirefirst the idea of three great strands of organic being, each composed of three inferior strands, respectively representing the principal lines, and which probably were the true genealogical series of our system. Verily, it would give us a curious conception of organic nature, if we could satisfy ourselves that, like chemistry, it had a mysterious foundation in mathematical proportions. Threes under threes, each subordinate three reflecting the ternity to which it belongs, and all others! Such an idea is obviously favourable to the development theory, as arguing a unity in animated nature and the definite character of its entire constitution. It suggests how, under the flowing robes of nature, where all looks arbitrary and accidental, there is an artificiality of the most rigid kind. The Natural appears to sink into and merge in a higher Artificial. To adopt a comparison more apt than dignified, we may be said to be placed here as insects in a garden of the old style. Our first unassisted view is limited, and we perceive only the irregularities of the minute surface, and single shrubs which appear arbitrarily scattered. But our view at 
length extending and becoming more comprehensive, we begin to see parterres balancing each other, trees, statues, and arbours placed symmetrically, and that the whole is an assemblage of parts mutually reflective. It can scarcely be necessary to point to the inference hence arising with regard to the origination of nature in some Power, of which man's mind is a humble and faint representation. The insects of the garden, supposing them to be invested with reasoning power, and aware how artificial are their own works, might, of course, very reasonably conclude that, being in its totality an artificial object, the garden was the work of some maker or artificer. And so also, when we attain a knowledge of the artificiality which is at the basis of nature, must we conclude that nature is wholly the production of a being resembling, but infinitely greater than ourselves.

By the same light we are enabled to see more clearly than ever the providential arrangement with respect to the various characters of animals: some to draw nutriment directly from the vegetable kingdom; others to keep the numbers of these in check, and prevent their carcasses from cumbering the earth-to be, in fact, a medium for returning their constituent substances to the atmosphere from which these were originally extracted by the vegetation; others again destined to a higher and more intelligent enjoyment than either, and turning animal as well as vegetable substances to their use. It is most interesting also to trace by this light the perseverance of characters and habits, and even of points in organization, from grade to grade. The Iguanodon, the huge reptile 
of the Wealden, has lately been inferred on good grounds by Dr. Mantell to have "possessed a large prehensile tongue and fleshy lips, capable of being protruded and retracted, and which must have formed most efficient instruments for seizing and cropping the foliage and branches of ferns, cycadex, and coniferous trees;"--an ipplication of facts of the organization we see kept up in those herbivorous mammalia (cattle and horses, for example), which we may presume to be merely an advance on the same line of existence. Travelling in the East, we might see the gavial acting as the scavenger of the Ganges, and the dog serving the same purpose in the neglected streets of great cities: the latter, a descendant of the line of being of which the former is an offshoot, merely serves on land the purpose served by his relative in the river. The vulture corresponds amongst birds, and the shark amongst fishes, to the dog amongst the mammalian carnivora: behold all of these animals furnished alike with the most acute powers of smell, for the discovery of their prey. A living naturalist speaks thus of the resemblance of the parrots to the monkeys:- "There can be little doubt that the parrots, among birds, emulate the monkeys among placentals: they eat all kinds of food they can procure; they obtain it in the same situations; they seek it in the same way,-by climbing,-for a parrot actually climbs like a monkey; it does not leap or run like other birds; but, like a monkey, or more especially a lemur, climbs slowly and solemnly from bough to bough: its toes are placed two and two, presenting an exact analogy to the opposable thumb of the Primates; and its foot is constantly used as a hand for conveying food to the mouth: its 
chattering voice is also similar; and, in the gift of speech, it rivals man himself: its large brain and peculiar tact in imitation are still additional similarities. I should, therefore, place the genus Psittacus as one of the Primates among birds." 1 The explanation is easy: the monkeys either are the descendants of the line which at an earlier period gave parrots, or the parrots come from a sub-line representing the monkeys in their greater line. In the same way, the pig is the relative or analogue of the duck, the bullock of the turkey, the squirrel of the monkey, the furtive springing cat of the equally furtive springing serpent, and so forth. Strange thus to trace in the humble and ancient animal a prophecy of the higher and more recent; the cephalopod, for example, foreshowing the shark-the shark the saurian, the saurian the vulture and mammalian carnivore. It is curious to observe in each line through all grades a continuity of character. Thus the most remarkable power of the Primates, that of grasping, is seen in the peculiar power from which the insessorial birds take their name, as well as in the extraordinary grasping faculty which is exercised under peculiar circumstances by the Batrachia. The long vermiform body and stealthy movements of the serpent foretel the similar characteristics of the musteline animals. Equally curious to see the migratory habits of the chelonia re-produced in the migratory habits which attach both to birds and to the ruminants: thus the voyage of three thousand miles which the turtle will make in order to lay her eggs on Ascension Island, the vast vernal flight of the swallow from Africa to England for incubation, the

1 Newman's System of Nature. 
roaming disposition of the hyperborean deer and the American bison, are all kindred phenomena, comprehended under one law of their gracious Creator: each race and sub-race true from first to last to its allotted instincts.

A result of very profound interest may be expected from the perfect development of this view of the system of nature; it will enable us to see with tolerable distinctness the status of man as one of the vessels of life. Even from the sketch now before us, we may draw some curious inferences. It appears that the stirps which terminates in the Primates, is one which may be considered as central between the other two, combining characters from both, along with characters of its own. Its central sub-line is eminently eclectic, and particularly in its food, uniting the carnivorous instincts of the bats, on the one hand, with the phytophagous habits of the sloths, on the other. Sociality, vocality or the use of voice, a prehensive use of the extremities, imitativeness, drollery, sagacity, all form characteristics generally applicable to this line of animals. In the reptilian grade, and perhaps in inferior grades also, they are rather below than above their fellows; but in the mammalian stage, they suddenly ascend to a pre-eminence, not by superior strength, but by greater relative magnitude of brain, by agility, and by the use of the hand. The signal superiority of the human species is thus prepared for and betokened in the immediately preceding portions of the line: it might have been seen, ere man existed, that a remarkable creature was coming upon the earth. The advance, nevertheless, which man 
makes above his immediate predecessors is very great; the highest of these cannot rank above an infant of our species in sagacity or morale.

This advance is no isolated fact. In each of the other sub-lines, there is what may be called a crowning species, greatly superior to its immediate ancestry, and these are the most distinguished of all animals. In the herbivorous stirps, the sub-carnivorous line is topped by the pig, the sub-herbivorous by the sheep, the subcentral by the horse. In the carnivorous stirps, the subherbivorous is topped by the dog, the sub-central by the cat. The horse, dog, and cat, so eminent for their sagacity and usefulness, are in this peculiar manner analogues to man, whom they serve so faithfully. A signal superiority, however, belongs to him as the centre and apex of all; the undoubted king and lord of this portion of animated nature. His greatness - considering him merely as a unit in the animal kingdom - lies primarily in the concentration of qualities which he derives from this situation. $\mathrm{He}$ is not an animal solely herbivorous, or solely carnivorous; solely innocent, or solely destructive. He has all these characters and habits, with the addition of others proper to his own family. There is great virtue in this principle of concentration, or, as it may rather be called, this universality of character. We see that an intensity of it marks all the greatest individuals of our species, such as Shakespeare and Scott, of whom it has been observed that they must have possessed within themselves, not only the poet, but the warrior, the statesman, the philosopher, and the man of affairs, and who, 
moreover, appear to have had the mild and manly, the moral and impulsive parts of our nature, in the finest balance.

When the naturalists of modern times began to inquire into the geographical distribution of plants and animals, they quickly found that the prevalent notion of their dispersion from one common centre was untenable. From facts observed by them, they have latterly concluded that, so far from this being the case, there are many provinces of the earth's surface occupied by plants and animals almost wholly peculiar, and which must accordingly have had a separate origin. Professor Henslow, of Cambridge, speaks of no fewer than forty-five such provinces for the vegetable kingdom alone.

A botanical or zoological province is generally isolated in some manner,-either as an island in the midst of a wide ocean,-as, for example, St. Helena, or the Isle de Bourbon-or as a portion of a continent separated from the rest either by a range of high mountains, or by the boundaries of a climate. It is also found that elevation of position comes to the same effect with regard to vegetation as advance in latitude; so that, as we ascend a lofty mountain in a tropical country, we gradually pass through zones exhibiting the plants of kinds appropriate to temperate and arctic regions. Even the neighbourhood of a salt marsh, however remotely placed amongst grounds of a different kind, exhibits plants appropriate to such a soil.

Fewer distinct zoological regions are enumerated, but perhaps only in consequence of imperfect observation. 
Here, however, the evidences against communication of organisms from one region to another are even more decided. If, however, it was surmised that the organisms of isolated regions had been communicated from other countries, and merely modified in their new abodes, the disproof of the conjecture would be more positive with regard to the zoology of the question than the botany. For, while it might appear possible that seeds have been floated even five hundred miles to a new soil like that of the Isle de Bourbon, how can we account, by such a supposition, for the existence there of bats, reptiles, and other animals, the progenitors of which could never have swum so far for the sake of a change of residence? This island, be it remarked, is of volcanic origin, and known to have become dry land at a comparatively recent period.

The two great continents of the earth are the first zoological divisions of its surface. The animals as well as plants of the old and new world are specifically different, with very few exceptions; that is, they are different in the degree which naturalists agree to consider as sufficient to establish distinct species. But even North and South America present different animals. We also find that the animals in the north and south of Asia are different, and that most of the African species are distinct from those of Asia.

The differences are in some instances so great as to be held by naturalists as generic. Beyond this point, however, there are parities or identities. We see, for instance, in all these various regions, feline animals, ruminants, pachyderms, rodents, etc. Thus, for the lion and tiger of 
Asia, we have a different lion and the panther in Africa, the jaguar in South America, and the puma ranging from Brazil to Canada. Instead of the elk of Northern Europe, and the argali of Siberia, we have, in North America, the moose deer and mountain sheep. Asia and Africa have elephants, to which the extinct mammoth and mastodon of Northern Europe and North America are parallels; and it now appears that even the horse, of which there are several varieties in the old world, was abundant in the new, at a period long antecedent to the introduction of the present breed by the colonists. Australia has its emeu, Africa its ostrich, and America her rhea, all similar animals, though specifically different. We find simiæ planted in three great regions-Southern Asia, Western Africa, and equinoctial America, but all of different character, those of America being peculiarly distinct in their want of the opposable thumb, and of callosities in the seat, as also in the use of the tail as a prehensile instrument. Australia has only a few very unimportant mammalian animals of her own besides the marsupials, which are represented by a few species in America; but to the Southern part of the latter continent are confined the whole family of the sloths. Africa, in like manner, has exclusive possession of the giraffe. To Northern America belongs a great number of genera of birds quite peculiar to it, and also a greater number and variety of the rodents than are found in any other parts of the earth. Similar facts could be stated respecting other classes of animals; but I limit attention to the mammalia as being the most restricted in number and the best known. 
Some principles governing the parity and variation of the organisms spread over different regions have been observed. It is found, for instance, that there is more uniformity between two masses of land which are both in the north or south hemisphere, albeit divided by wide oceans, than between two portions of one continent extending into both of these hemispheres. North America is zoologically less allied to South America, than it is to Northern Europe. An island, however far apart, is apt to show zoological features reflective of those of the nearest continent. Two countries, again, divided only by a narrow sea, have usually the same flora.

Some principle affecting the development of the higher animals can also be detected in connexion with geological chronology. Startling as it may appear, we are now assured that the present great continent comprising Europe, Asia, and Africa, has been, with minor changes in the relative position of sea and land, one theatre of organic being since the commencement of the existence of land animals upon the surface of the earth; that is to say, there has been, on one part or another of this geographical area, an uninterrupted chain of living forms from an early period in the secondary formation. This is the zoological province whose history is presented by the geologist; it is the oldest we are acquainted with. There are, however, some isolated regions which are known with certainty to have been in a condition of dry land for a less space of time. Such are the volcanic islands, of which the Isle of Bourbon is an example. Such also are the Galapagos Islands, placed in the Pacific, above five hundred miles from South America. Now it is remarkable in such 
regions to find the mammalia either wholly wanting or in very small numbers.

Australia itself - a fifth great section of the habitable globe-appears to be one of these regions of an incomplete zoology. It is well known to have no native mammalia besides that humble implacental kind which are nearly peculiar to it, and a few rodents and bats. Professor Owen remarks how the fishes of the oolitic era-acrodus, psammodus, etc.-with the contemporary mollusks (trigoniæ and terebratulæ), which served these fishes for food, are represented in the living cestracion which swims the Australian seas, with exactly the same sea mollusks to yield them sustenance. "Araucarix and cycadeous plants likewise," he says, "flourish on the Australian continent, where marsupial quadrupeds abound, and thus appear to complete a picture of an ancient condition of the earth's surface, which has been superseded in our hemisphere by other strata and a higher type of mammalian organization." I

Such being the facts of the case, we are to inquire: whether they best agree with the hypothesis of an origin of organisms by special Divine exertion, or that of their origination in Divine power working in the manner of natural law; and also, if the latter supposition appear preferable, how far the facts agree with the plan of animated nature delineated in the preceding pages.

It is remarkable at the very first, that there is any variety of species in different regions, more especially as the species of one region usually thrive when transplanted to another of generally similar character in point of soil

1 British Fossil Mammalia and Birds, p. 69 
and climate. Had organisms been produced by special attention-taking this according to any ideas we can form of it-we might rather have expected to see identica! plants in similar countries. It will not avail here to attribute the variation to the cultivation of variety as a principle on the part of the Divine Disposer, for the differences evidently follow no such principle, being of various intensities in near and in remote situations. In this consideration, there is a great obstacle to the reception of the special-exertion hypothesis. It seems much more likely that organisms took their rise in germs springing from inorganic elements; which germs being different in accordance with such slight local differences in the combination of the elements as physical studies inform us of, and the external conditions attending their development being also locally different, the resulting vessels of life were various accordingly. Such variations of result are exactly of a piece with hundreds of other simply natural events-for example, the difference of animals born at one birth; and similar natural causes are therefore presumable for them.

The facts respecting the geographical distribution of organisms are in perfect harmony with the plan of their origin, which, from the geological history, the principles of organic development, and their external affinities, has here been sketched. The plan necessitates the facts of distribution, which the other hypothesis does not. First, a development of vegetable organisms, we shall say, taking place in the sea, it is exactly what we would expect, that they should spread upon the neighbouring shores in every direction, and that we should thus, for 
example, have one flora surrounding the Mediterranean,- which is the fact. So it is also likely that islands should botanically and zoologically partake of the character of the neighbouring continents. In regions, on the other hand, sufficiently distant to be involved in the influence of diverse foci of life, we are to expect differences proportioned to the difference of original elements, and also of conditions attending the development of the various lines: there we may only expect to see such ultimate parities attained as those between the emeu of Australia and the rhea of America, or the jaguar and puma of the latter continent and the tiger of Asia. Here it is important to observe that the cetacea and the marine birds in the neighbourhood of the different continents, present less variation than do the land mammals and birds: they have advanced less way along the lines, and have been less exposed to the conditions productive of external variations. In the case of a well-defined zoological region, such as the northern parts of North America, we see the indigenous animals expressly confined to those families which our plan sets forth as springing from the marine tribes above adverted to. There is the polar bear, with his various progeny, the brown bear, black bear, the wolf, fox, and dog; these from a phocal ancestry. The sea-otter, sprung from an allied stock, gives birth to the few musteline. animals which dwell in these dreary regions. Then we have herbivorous cetes, giving rise to the moose deer and musk ox, these again being the progenitors of the goat and sheep. And, finally, we have the unusually numerous rodents from the aquatic birds, which nowhere are seen in greater numbers than on the borders of the 
Arctic Ocean. Such, with the mole, is the whole show of mammalia in this province: it is, it will be observed, of a limited kind; but it is interesting to remark that it presents nearly all the animals of that class, which we have supposed, from their affinities, to be descended from the marine families of which there is such abundance upon the adjacent ocean. And, supposing this ocean to be the berceau of these land animals, we can easily see why they should be more akin to the terrestrial mammalia of Northern Europe than to those of South America. The Northern Ocean, spreading in one character of climate along the confines of the two first regions, enables a set of maritime animals which may have come into existence in any part of it, to spread into the two continents alike-the same bear, nearly the same ruminants, and so forth; but, if the Southern Ocean have possessed, as is likely from its distance, a different development of animal life from the Northern, and be supposed as sending off terrestrial animals in like manner into South America, the interposition of several great zones of different climate stands forth as a sufficient reason why there should not have been the same communication of zoological forms in that case to the hyperborean seas, as there was from those laving North America to those which dash upon Scandinavia, Russia, and Siberia.

The hypothesis is equally applicable to the imperfect developments of life upon the more recently raised lands, such as the Galapagos islands and Australia. Development is a matter of time, and in the case of these regions, the full time has not yet elapsed. It is therefore exactly 
what we might expect, upon the natural hypothesis, that, in these regions, animal life should have yet hardly reached the mammalian stage, the point which was attained in our elder and greater province about the time of the oolite. ${ }^{1}$ On the other hand, no rational cause for this imperfect zoological show can be presented in consonance with the plan of special exertions.

1 See this argument more fully elucidated in Explanations, a Sequel to the Vestiges, Ec. 


\section{EARLY HISTORY OF MANKIND.}

THE human race is known to consist of numerous nations, displaying considerable differences of external form and colour, and speaking, in general, different languages. This has been the case since the commencement of written record. It is ascertained that the external peculiarities of particular nations do not change rapidly. While a people remain upon one geographical era, and under the influence of one set of conditions, they always exhibit a tendency to persistency of type, insomuch that a subordinate admixture of various type is usually obliterated in a few generations. The investigations of Dr. Prichard have nevertheless made it tolerably clear $^{1}$ that external peculiarities are of a more superficial and accidental nature than was at one time supposed. One fact is at the very first extremely startling, that there are nations, such as the inhabitants of Hindostan, apparently one in descent, which nevertheless contain groups of people of almost all shades of colour, and likewise discrepant in other of those important features on which much stress has been laid. Some other facts, which may be stated in brief

'See Prichard's Researches into the Physical History of Man ; also his smaller work, the Natural History of Man. 
terms, are scarcely less remarkable. In Africa there are Negro nations, - that is, nations of intensely black complexion, as the Jolofs, Mandingoes, and Kafirs,-whose features and limbs are as elegant as those of the best European nations. While we have no proof of Negro races becoming white in the course of generations, the converse may be held as established, for there are Arab and Jewish families of ancient settlement in Northern Africa, who have become as black as the other inhabitants. There are also facts which seem to show the possibility of a natural transition by generation from the black to the white complexion, and from the white to the black. True whites (apart from Albinoes) are not unfrequently born among the Negroes, and the tendency to this singularity is transmitted in families. There is, at least, one authentic instance of a set of perfectly black children being born to an Arab couple, in whose ancestry no such blood had intermingled. This occurred in the valley of the Jordan, where it is remarkable that the Arab population in general have flatter features, darker skins, and coarser hair, than any other tribes of the same nation. ${ }^{1}$

The style of living is ascertained to have a powerful effect in modifying the human figure in the course of generations, and this even in its osseous structure. About two hundred years ago, a number of people were driven by a barbarous policy from the counties of Antrim and Down, in Ireland, towards the sea-coast, where they have

'Buckingham's Travels among the Arabs.

A brief notice, by the Rev. Lansdown Guilding, St. Vincent, of a Negro couple in that parish, having, amongst other children, one as fair as an European, with European features, white hair, and blue eyes, is inserted in the Magazine of Natural History, vii. 589. 
ever since been settled, but in unusually miserable circumstances, even for Ireland; and the consequence is, that they exhibit peculiar features of the most repulsive kind, projecting jaws with large open mouths, depressed noses, high cheek-bones, and bowed legs, together with an extremely diminutive stature. These with an abnormal slenderness of the limbs, are the outward marks of a low and barbarous condition all over the world; it is particularly seen in the Australian aborigines. On the other hand, the beauty of the higher ranks in England is very remarkable, being in the main as clearly a result of good external conditions. "Coarse, unwholesome, and illprepared food," says Buffon, "makes the human race degenerate. All those people who live miserably are ugly and ill-made. Even in France, the country-people are not so beautiful as those who live in towns; and I have often remarked that in those villages where the people are richer and better fed than in others, the men are likewise more handsome, and have better countenances." He might have added, that elegant and commodious dwellings, cleanly habits, comfortable clothing, and being exposed to the open air only as much as health requires, cooperate with food in increasing the elegance of a race of human beings.

Attention has lately been attracted by a curious physiological speculation, having for its object to show that some of the broader features of the great families of mankind are expressly connected with the principle of development. It points out that the brain of one of the most favoured specimens of humanity, after completing the series of animal transformations, passes through the 
characters in which it appears in the Negro, the American, and the nations of Northern and Eastern Asia (sometimes comprehensively called Mongolian), and finally assumes that perfect character which it bears in the superior nations comprehensively called Caucasian by Cuvier. The face partakes of these alterations. "One of the earliest points in which ossification commences is the lower jaw. This bone is consequently sooner completed than the other bones of the head, and acquires a predomi. nance, which, as is well known, it never loses in the Negro. During the soft pliant state of the bones of the skull, the oblong shape which they naturally assume approaches nearly the permanent shape of the Americans. At birth the flattened face, and broad smooth forehead of the infant, the position of the eyes rather towards the side of the head, and the widened space between, represent the Mongolian form; while it is only as the child advances to maturity, that the oval face, the arched forehead, and the marked features of the true Caucasian become perfectly developed." 1 It appears, in short, that the leading characters of the various races of mankind are simply representations of particular stages in the development of the highest or Caucasian type. The Negro exhibits permanently the imperfect brain, projecting lower jaw, and slender bent limbs of a Caucasian child some considerable time before the period of its birth. The aboriginal American represents the same child nearer birth. The Mongolian is an arrested infant newly born. In harmony with these views is the opinion now beginning to be announced by ethnologists, that

${ }^{1}$ Lord's Popular Physiology, explaining observations by M. Serres. 
some nations have passed in the course of ages through the three leading forms of skull, beginning with what is called the prognathous, a narrow shape of the head with a prominent jaw, proper to savage tribes; afterwards advancing to a pyramidal form, which is usually found among nomadic or pastoral races, in conformity with their assuming that mode of life; and finally exhibiting in a comparatively civilized state an arched form of skull. ${ }^{1}$

On the whole, it results from inquiries into what is called the physical history of man, that conditions, such as climate and food, domestication, and perhaps an inward tendency to progress under tolerably favourable circumstances, are sufficient to account for all the outward peculiarities of form and colour; so that these can only at the utmost serve as proofs of the distinctness of races, if supported by more decisive evidence.

The inquiries of the philologist have supplied such evidence. It is seen that the language of a people, liable as it is to change, is a much more permanent possession than a form of head or a hue of the skin. It is a profound expression of the idiosyncrasy of a people, not easy to be obliterated or disguised. There are upon earth between three and four thousand languages, perhaps for the most part as distinct from each other as French, English, German, but, like these, exhibiting relationships which at once enable us to decide on the relationships of the nations to which they belong. A relationship amongst languages is shown in the community of words or roots of words. This is the kind of relationship with which we are most familiar, but it is one liable to some

1 See Dr. Prichard's Natural History of Man. 
obscurity, as it may either happen that all or nearly all traces of a common vocabulary have perished between nations known to be akin, or there may be a community of words that is only the result of accident. By far the most certain test of an affinity between languages is the trace of a common character or analogy in their grammatical structure and in their laws of combination-what has been well called the mechanism of speech. This is both a more immediate and distinct expression of intellect, and one which tends to be more permanent. Now it is found that, amidst all the diversities of tongues, relations in the laws of their formation can be established from one to another, till we come to reckon six plans of language, if such a phrase may be used, amongst which no sort of community can be shown, leading to the supposition that they have originated in entire independence of one another, and are each expressive of the idiosyncrasy of a distinct family of mankind. ${ }^{1}$ This distinction, as it happens, is tolerably in harmony with a classification of mankind into five varieties, which Cuvier determined on from a consideration of broad external characters, but which has now of course lost much of its value.

The first group of nations, according to the philological arrangement, comprehends the Indians, Persians, and nearly the whole of the people of Europe, being the chief section of the Caucasians of Cuvier. "There is," says Dr. Prichard, "internal evidence in the IndoEuropean languages, sufficient to prove that they grew

1 See Report on Ethnology, by Dr. Prichard, in the publication of the British Association for 1847 . 
by gradual dialectic development out of one common matrix. Any person who considers, with competent knowledge of these languages, the nature of their relations to each other, the fact that their original roots are for the most part common, and that in the great system of grammatical inflection pervading all these languages there is nothing else than the varied development of common principles, must be convinced that the differences between them are but the result of the gradual deviation of one common language into a multitude of diverging dialects; and the ultimate conclusion that is forced upon us is, that the Indo-European nations are the descendants of one original people, and consequently. that the varieties of complexion, form, stature, and other physical qualities which exist among them are the results of deviation from an original type." The leading members of this family of languages are the Sanskrit, or ancient written language of India, the Persian, the Greek, the old Epirotic or Illyrian, the old Italic, comprehending the Latin, Umbrian, Oscan, etc., the old Prussian, including the Lettish and Lithuanian, the Germanic, to which belongs the English, the Slavonian prevalent over Russia, Poland, Bohemia, and the Christian countries of Europe subject to the Turks; finally, the Celtic, which now lives only in a few districts of France and the British Islands.

The second great family, the Syro-Arabian, refers to the languages of ancient Chaldea, Palestine, and Arabia, besides various dialects spoken in and around Abyssinia and Egypt. The ancient Hebrews, the Phonicians, and the Carthaginians, spoke kindred tongues belonging to this stem. 
The term Ugro-Tartarian has been applied by Dr. Prichard to a group of nations in northern Asia, sometimes called the Five Nomadic Races, with which must be associated certain nations scattered in distant parts of the globe, as the Turks, Hungarians, Finns, and Laplanders in Europe, and various obscure tribes in Eastern as well as Southern Asia. The chief nations of this stock are the Mongolians, Tungusians, Tartars, and Turks. It is a stock which has never shown any considerable tendency to civilization: yet it was a horde of this people whom Attila conducted on his conquering course through Europe, and by other offshoots were the empires of China, Hindostan, and Byzantium overturned. It would appear that they are comparatively a very ancient portion of mankind. India possessed an aboriginal population of this stock, who appear to have been driven into the Dekhan and Ceylon, or only left amongst the mountains. The Iberians or Cantabrians of Spain are discovered from the remains of their language (the Basque) to have been of this race. Of the same connexion were the Jotuns of the north of Europe. And these appear as the relics of European aborigines, who must have regarded the Celts and the Germanic tribes as invaders of their territories. Nouns incapable of variation of any kind, and the use of suffixes to make up for this want, are the leading features of the Ugro-Tartarian languages, besides a peculiar euphonic principle depending on the use of only vowels of certain sets in the same words. By such features it is that modern philologists can trace to their origin and confidently classify tribes who have for ages been nestling in obscure nooks of the 
earth. On such ground it is believed by some that the Celtic population of the British Islands has sustained at an early period an infusion of Lappish blood.

The fourth family of languages is the Chinese, which comprehends the tongue spoken by the Chinese people, the language of Thibet, and the Indo-Chinese idioms. The distinguishing features of the Chinese language are, its consisting altogether of monosyllables, and being destitute of all grammatical forms, except certain arrangements and accentuations, which vary the sense of particular words. It is also deficient in some of the consonants most conspicuous in other languages, $\mathrm{b}, \mathrm{d}, \mathrm{r}, \mathrm{v}$, and $\mathrm{z}$; so that this people can scarcely pronounce our speech in such a way as to be intelligible: for example, the word Christus, they call Kuliss-ut-oo-sut. The Chinese, strange to say, though they early attained to a remarkable degree of civilization, and have preceded the Europeans in many of the most important inventions, have a language which resembles that of children, or deaf and dumb people. The sentence of short, simple, unconnected words, in which an infant amongst us attempts to express some of its wants and its ideas - the equally broken and difficult terms which the deaf and dumb express by signs, as the following passage of the Lord's Prayer:--" Our Father, heaven in, wish your name respect, wish your soul's kingdom providence arrive, wish your will do heaven earth equality," etc.-these are like the discourse of the refined people of the so-called Celestial Empire. An attempt was made by the Abbé Sicard to teach the deaf and dumb grammatical signs; but they persisted in restricting themselves to the simple signs of ideas, leaving 
the structure undetermined by any but the natural order of connexion. Such is exactly the condition of the Chinese language.

Africa, exclusive of the northern parts, which have been referred to as occupied by Syro-Arabian nations, is possessed by races generally of black complexion and at a low stage in civilization, but more various in their colour and in their barbarism than is usually supposed. Guinea and some of the neighbouring districts are the true seat of the entirely black or Negro tribes, who have become so well known to us in their native simplicity by their representatives, the slave population of the West Indies and North America. The Kaffirs, in the South of Africa, are of superior form and more vigorous character, with only a brown complexion. The Fulahs and Mandingoes are mountaineer races, who have spread from Senegambia along the coast and far into the interior. They have formed states, practise commerce, and little of the Negro form is seen in them. In civilization and in external appearance, the northern African nations make a gradual transition towards the Syro-Arabian races which are found in that region. The languages, however, are considered as distinct. These, throughout the whole of Africa, excepting the districts occupied by Syro-Arabian races, are, as far as known, believed to be of one character, not so low as the monosyllabic Chinese, and not so highly inflected as the Indo-European, but at a point of development apparently between the two.

Crossing the Pacific, we come to the last great family in the languages of the aboriginal Americans, which have all of them features in common, proving them to con- 
stitute a group by themselves, without any regard to the very different degrees of civilization which these nations had attained at the time of the discovery. The common resemblance is in the grammatical structure as well as in words, and the grammatical structure of this family is of a very peculiar and complicated kind. The general character in this respect has caused the term Polysynthetic to be applied to the American languages. A long manysyllabled word is used by the rude Algonquins and Delawares to express a whole sentence: for example, a woman of the latter nation, playing with a little dog or cat, would perhaps be heard saying, "kuligatschis," meaning, "give me your pretty little paw;" the word, on examination, is found to be made up in this manner: $k$, the second personal pronoun; uli, part of the word wulet, pretty; gat, part of the word wichgat, signifying a leg or paw; schis, conveying the idea of littleness. In the same tongue, a youth is called pilape, a word compounded from the first part of pilsit, innocent, and the latter part of lenape, a man. Thus, it will be observed, a number of parts of words are taken and thrown together, by a process which has been happily termed agglutination, so as to form one word, conveying a complicated idea. There is also an elaborate system of inflection; in nouns, for instance, there is one kind of inflection to express the presence or absence of vitality, and another to express number. The genius of the language has been described as accumulative; it "tends rather to add syllables or letters, making further distinctions in objects already before the mind, than to introduce new words." ${ }^{\text {Yet it }}$

'Schoolcraft. 
has also been shown very distinctly, that these languages are based in words of one syllable, like those of the Chinese and Polynesian families; all the primary ideas are thus expressed: the elaborate system of inflection and agglutination is shown to be simply a farther development of the language-forming principle, as it may be calledor the Chinese system may be described as an arrestment of this principle at a particular early point.

Dr. Prichard alludes to a mixture of somewhat vague notions, partly derived from physical theories, and partly from history, or rather from mythology, which refers the origin of human races to high mountainous tracts. "The tops of mountains," he says, "first emerged above the surface of the primeval ocean, and, in the language of some philosophical theorists, first became the scene of the organizing life of nature. . . . Geological theories give their part to render these notions popular; not only the late speculations of the Count de Buffon, and the learned Bailly, but the opinions of ancient philosophers, who maintained, before the time of Justin and Pliny, that the mountains of High Asia must have been the part of the world first inhabited by men; inasmuch as that region must have been first refrigerated in the gradual cooling of the surface of our planet, and first raised sufficiently above the surface of our ocean." It may be remarked that, in the progress of geology, the evidences of the sea having once covered various parts of the earth to a considerable height, are become so familiar, that no one now doubts of such a phenomenon, however difficult it may be to account for the emergence of the land from the enveloping waters. Assuredly, no such submersion could 
have been total, as in that case there could not have been that unbroken march of animal life and progressive organization of which the crowning results are now presented on the surface of the earth. But there may have been, as appears from marine remains and formations in many situations, a submergence sufficient to deluge all the lands which are now less than fifteen hundred feet above the level of the sea. When this was the state of the earth, a map of it would have presented one large island, stretching from east to west athwart what has since become Asia, an archipelago where the Alps and the Scandinavian and Ural mountains now exist, another large island in intertropical Africa, and one or two similar though less extensive tracts in America.

Now, it has been seen that the philologist speaks of six human families, so decidedly different in language, that there is reason to suspect their being of different origins, albeit identical in species. On such a point it is impossible as yet to speak with firmness; but certainly, as such researches advance, the idea of a single origin for the species is always appearing less tenable, nor does the opposite hypothesis involve anything contradictory to science. Without undertaking to pronounce on the subject, it may be allowable for us to inquire how the notions adverted to by Dr. Prichard, in their new form of a sextuple focus of human population, agree with the geological views which have been noticed, and with the indications of ancient tradition.

Central Asia is well known as a highly elevated tableland, sending rivers to the northern and southern oceans, as well as to the seas of Okhotsk and Japan. The 
northern portion of this great plateau is a pastoral region, where the Tungusians, Mongolians, and Turks, nomadic races belonging to our third family, have from time immemorial fed their numerous flocks. To this focus is traced by affinity of language, and of physical and moral characters, a fourth race, the Ugorian or Finnish, which is now found to the north-west, and far removed. A fifth, the Bhotiza, are a mountain people on the northern borders of Hindostan. We have likewise seen that traces of an aboriginal people of this family exist in Spain on the one hand, and the Dekhan on the other. What is mai.lly to be remarked is, that, while portions of the family have wandered into countries of lower level, a great portion of it is still in possession of one large section of the tableland of Central Asia. We still find there a possible cradle for this peculiar family of mankind.

Of the Indo-European variety, the Asiatic branch is divided into two principal stems, the Indians and the Persians. Dr. Prichard speaks of them as arising from two principal foci at no great distance from each other, in the southern portion of the same table-land. In the north-west part of the region between the Himalaya and Vindhya mountains, in countries watered by the Saraswati, "the earliest traditions of the Brahmins place the ancestors of the Indian race. . . . There," says the learned ethnologist, "the Hindoos had the seat of their early national existence twenty-five centuries before the Christian era, and thence they appear gradually to have spread, under the hierarchy of the Brahmins and their two royal dynasties, descendants of the sun and moon, over the different provinces of Rajputána, Ayodhya, 
Saurasktra, and further eastward to Indraprest'ha, or Delhi, and to Magadha and the Gangetic provinces." $\mathrm{He}$ adds, "to the westward of the Indus, not far from Bamian or from Balkh, was the country which the earliest traditions of the Persians point out as the primeval seat and paradise of their race."

With regard to the Chinese, or that vast family of mankind spreading along the coast from the Ganges to the Hoang-ho, and even farther northward, Dr. Prichard says-and the importance of using his language on the occasion must be obvious-"With the rivers which descend from the high country of Central Asia, and from their diverging waters on all sides, after traversing extensive regions of lower elevation, into the remote ocean, these nations appear also to have come down, at various periods, from the south-eastern border of the Great Plateau; in different parts of which tribes are still recognised, who resemble them in features and in language." The Chinese proper were originally, according to their own historians, a small horde of barbarians, who wandered about the foot of the high mountains of the Thibetan border of China, without settled dwellings, clothed in skins, and ignorant of the use of fire. "They appear," says Dr. Prichard, "to have descended along the valley of the Hoang-ho, from the high countries situated to the northward of Shenshi, in the plains of which province we first discover them in the dawning of history wandering with their herds, and similar in their habits to the nomadic nations of high Central Asia.

The migration took place at an early, but unascertained period, probably somewhat more than two thousand years 
before the Christian era." Thus we see that this family of mankind also touches upon the Great Asiatic Plateau, and, like the preceding, has traditions tracing its origin to that region.

The territory which ancient history represents as in the possession of the Syro-Arabian races is comparatively limited; but it adjoins on the north to the Euxine and Kurdistan, another portion of the skirts of the Asiatic table-land.

From the African and American families we have no report as to their primeval history; but in the centre of the great regions occupied by each, we see a vast tableland, which may have been its first seat, and from which there may have been a spreading out into lower regions, as seems to have been the case in Asia.

It therefore appears that, if, at a time when the sea was relatively to the land two thousand feet higher than at present, six centres of human population had been established, four of them on various parts of the Asiatic table-land, one on that of Central Africa, and another on either the Andean or Mexican table-land, the phenomena of their subsequent diffusion in the course of the time during which the sea was subsiding, and the dry land enlarging, might have been expected to be precisely what we have seen. That such is, indeed, a near approach to the actual history of primeval humanity, seems far from unlikely. It is a circumstance worthy of special note, that Europe is regarded by all ethnologists as a region which has been colonized from Asia. If there had existed in Europe a language-distinguished variety of mankind, having no connexion with any table-land, it 
would have been a serious deduction from the probability of this hypothesis. But Europe being at once a low, therefore a comparatively recently-exposed region, and one which has notoriously received its people in successive migrations from the east, is a relation of facts obviously favourable to the view here set forward. An important zoological fact perfectly harmonizes with it, that in near local connexion with the three great table. lands in question are the three seats of the Quadrumana on earth,-the order of animals with which the human race is most in affinity.

It will be well, however, to keep in mind that philo. logical researches do not as yet enable us to pronounce authoritatively whether mankind have had one origin, or three, or six. It only appears that the six families enumerated, besides many peculiar external features, are distinguished by languages so entirely set apart from each other by the principle of their construction, that no kind of connexion amongst them can be imagined as existing at least from the time when they began to form a speech; and it appears as by far the most probable supposition that they are portions of the same species developed in different parts of the globe. The hypothesis may in the meantime be set up as that most worthy of attention, and which it now befits Science to seek to prove or disprove.

It is one of those things necessary to complete our view of the world as wholly under law, that civilization should appear to be capable of arising in a natural manner. The tendency of the uninstructed mind is to suppose supernatural causes for such phenomena, and there are even educated persons whose habits of thinking predispose 
them to take similar views. By one of these it has lately been argued, that facts are in favour of a supernatural origin for civilization. We see, says this authority, many examples of nations falling away from civilization into barbarism, while, in some regions of the earth, the history of which we do not clearly know, there are remains of works of art far superior to any which the present unenlightened inhabitants could have produced. The appearances are therefore in favour of a decline from some great and wide-spread civilization of early times. To this it may be answered, that these appearances are partial, compared with what we know from history of an advance and an extension of civilization from early times. The decadences from civilization in such regions as Medea or Greece are only such local instances of failure or suppression as might be expected when civilization was cradled amidst nations generally barbarous, and who had an interest in attacking their wealthier neighbours. This, at least, were as legitimate an inference from the facts which are known. But it is also alleged that we know of no such thing as civilization being ever self-originated. It is always seen to be imparted from one people to another. This is considered as demanding the inference that there has been no time without civilization; consequently, that civilization was the earliest condition of man. If the facts were as alleged, we should no more be entitled to come to this conclusion, than we should be to suppose that there never was a time without a church, because for many ages we have seen one continually kept up by apostolic ordination. Obviously it is not to be expected that we should know of any of the ancient 
nations originating civilization amongst themselves, for history commences when they are already somewhat advanced in that course. As to the instances in which it has been seen to be imparted, these may be true, without necessarily implying that there was not a natural origin of civilization in some of the earlier nations. It may be questioned, however, if these instances are in themselves true. The efforts made to trace the civilization of Central America to Egypt and other countries, have all signally failed. There is even a fallacy in supposing that, because Greece, for example, obtained certain kinds of knowledge and forms of art from Egypt, its whole civilization was descended from that and similar quarters. There are characteristic features in all civilizations, which support the idea that they are usually for the most part original. There is not only this peculiarity, but there is an isolatedness in some civilizations, which tallies much better with the theory of their independent than their imparted origin. When it is said that civilization is never seen to arise without aid from external sources, an affirmation is made on very imperfect grounds. It appears that civilization does sometimes rise in a manner clearly independent, amongst a horde of people generally barbarous. A striking instance is described in the laborious work of Mr. Catlin on the North-American tribes. Far placed among those which inhabit the vast region of the north-west, and quite beyond the reach of any influence from the whites, he found a small tribe living in a fortified village, where they cultivated the arts of manufacture, realized comforts and luxuries, and had attained to a remarkable refinement of manners, insomuch as to be 
generally called "the polite and friendly Mandans." They were also more than usually elegant in their persons, and of every variety of complexion between that of their compatriots and a pure white. $U_{p}$ to the time of $\mathrm{Mr}$. Catlin's visit, these people had been able to defend themselves and their possessions against the roving bands which surrounded them on all sides; but, soon after, they were attacked by small-pox, which cut them all off except a small party, whom their enemies rushed in upon and destroyed to a man. What is this but a repetition, on a small scale, of phenomena with which ancient history familiarizes us-a nation rising in arts and elegancies amidst barbarous neighbours, but at length overpowered by the rude majority, leaving only a Tadmor or a Luxor as a monument of itself to beautify the waste? What can we suppose the nation which built Palenque and Copan to have been, but only a kind of Mandan tribe, which chanced to have made its way farther along the path of civilization and the arts, before the barbarians broke in upon it? The flame essayed to rise in many parts of the earth; but there were strong agencies working against it, and down it accordingly went, times without number; yet there was always a vitality in it, nevertheless, and a tendency to progress, and at length it seems to have attained a strength against which the powers of barbarism can never more prevail. The state of our knowledge of uncivilized nations is very apt to make us fall into error on this subject. They are generally supposed to be all at one point in barbarism, which is far from being the case, for in the midst of every great region of uncivilized men, such as North America, there are nations partially refined. 
The Jolofs, Mandingoes, and Kafirs, are African examples, where a natural and independent origin for the improvement which exists is as unavoidably to be presumed as in the case of the Mandans. ${ }^{1}$ We find that Mrs. Somerville, in her excellent little work on Physical Geography, speaks without hesitation of the "spontaneous civilization" which has arisen among both the African and the South-American nations.

1 The view of civilization here controverted is to be found in Archbishop Whately's Lectures on Political Economy. In Additions to the fifth edition of his Grace's Elements of Rhetoric, the fact respecting the Mandans is controverted, on the grounds that there is no proof of their originally having been savages, or of the same race with the other North Americans, or of their civilization not having been introduced from without. Mr. Catlin is also represented as stating in private that he presumed the Mandans, from their external appearance, to be a distinct race. Their distinctness and the independent origin of the civilization I am represented as having assumed, contrary to all logical science. I would reply briefiy, that censure on the last point, were it just, would come ill from one who is willing wholly to assume, in this case, the opposite position. It is not just, however; for where the Mandans, as his Grace supposes, the remains of a civilized people, introduced from without, they ought to have had a distinct language, which is not pretended. External peculiarities are precisely those which civilization modifies, and they therefore tell not in the case. Then as to Mr. Catlin's privately expressed admission, it is sufficient to refer to his own words, quoted at a later portion of my text, where he expressly attributes the improvement of the Mandans to the external circumstances to which $I$ in part trace all civilization. Unprompted, unprejudiced, untampered-with testimony, such as we find in Mr. Catlin's book, seems to me worth considerably more than anything on the opposite side of a merely theoretical nature.

Sir C. Lyell, in his Travels in North America, speaking of the original people of America, conveys views in which I concur.

"Although," he says, "the various tribes remained in general as stationary in all matters requiring intellectual effort, as in their nautical contrivances, we behold with surprise certain points, of which Mexico was the most remarkable, where an indigenous and peculiar civilization had been developed, and had reached a high degree of perfection. However much we may admire their architecture, their picture-writing, and historical records, it is their astronomical science in particular, as Mr. Prescott observes, which was disproportioned to their advancement in other walks of civilization. They had fixed the true length of the tropical year, with a precision unknown to the great philosophers of antiquity, which could only be the result of a long series of nice and patient observations.

To ascribe the civilization of the Toltecs to an Asiatic origin, while it is admitted that there was no correspondence or relationship between their language and that of any known European nation, appears to me a baseless hypothesis, however true it may be that the aboriginal Americans had derived some hints from foreign sources. . If, then, a large continent can be inhabited by hundreds of tribes, all belonging to the same race, and nearly all remaining for centuries in a state of apparently hopeless barbarism, while two or three of them make a start in their social condition, and in the arts and sciences; if these same nations, when brought into contact with Europeans, relapse and retrograde until they are scarcely distinguishable in 
The most conclusive argument against the original civilization of mankind is to be found in the fact that we do not now see civilization existing anywhere except in certain conditions altogether different from any we can suppose to have existed at the commencement of our race. To have civilization, it is necessary that a people should be numerous and closely placed; that they should be fixed in their habitations, and safe from violent external and internal disturbance; that a considerable number of them should be exempt from the necessity of drudging for immediate subsistence. Feeling themselves at ease about the first necessities of their nature, including self-preservation, and daily subjected to that intellectual excitement which society produces, men begin to manifest what is called civilization; but never in rude and shelterless circumstances, or when widely scattered. Even civilized men, when transferred to a wide wilderness, where each has to work hard and isolatedly for the first requisites of life, soon show a retrogression to barbarism: witness the plains of Australia, as well as the backwoods of Canada and the prairies of Texas. Fixity of residence and thickening of population are perhaps the prime requisites for

intellectual rank from the rude hunter tribes descended from a common stock; what caution ought we not to observe when speculating on the inherent capacities of any other great member of the human family. The negro, for example, may have remained stationary in all hitherto explored parts of the African continent, and may even have become more barbarous when brought within the influence of the white man, and yet may possess within his bosom the germ of a civilization as active and refined as that of the golden age of Tezcuco."-ii. 38.

Mrs. Somerville, in her work on Physical Geography, (2 vols. 1848 ,) takes her place in opposition to Dr. Whately. She says, "A spontaneous civilization has arisen in various parts of Southern and Tropical Africa, in which there has been considerable progress in agriculture and commerce." Again,--"Some of the native South American nations have spontaneously made considerable progress in civilization in modern times." 
civilization, and hence it will be found that all civilizations as yet known have taken place in regions physically limited. That of Egypt arose in a narrow valley hemmed in by deserts on both sides. That of Greece took its rise in a small peninsula, bounded on the only land side by mountains. Etruria and Rome were naturally limited regions. Civilizations have taken place at both the eastern and western extremities of the elder continentChina and Japan on the one hand; Germany, Holland, Britain, France, on the other,- -while the great unmarked tract between contains nations decidedly less advanced. Why is this, but because the sea in both cases has imposed limits to further migration, and caused the population to settle and condense? - the conditions most necessary for social improvement. Even the simple case of the Mandans affords an illustration of this principle; for Mr. Catlin expressly, though without the least regard to theory, attributes their improvement to the fact of their being a small tribe, obliged, by fear of their more numerous enemies, to settle in a permanent village, so fortified as to insure their preservation. "By this means," says he, "they have advanced further in the arts of manufacture, and have supplied their lodges more abundantly with the comforts and even luxuries of life than any Indian nation I know of. The consequence of this," he adds, "is, that the tribe have taken many steps ahead of other tribes in manners and refinements." These conditions can only be regarded as natural laws affecting civilization. ${ }^{1}$ It is

I The problem of Chinese civilization, such as it is-so puzzling when we consider that they are only, as will be presently seen, the child race of mankindis solved when we look to geographical position producing fixity of residence and density of population. 
also necessary for a civilization that at least a portion of the community should be placed above mean and engrossing toils. Man's mind is subdued, like the dyer's hand, to that it works in. In rude and difficult circumstances, we unavoidably become rude, because then only the inferior and harsher faculties of our nature are called into exercise. When, on the contrary, there is leisure and abundance, the self-seeking and self-preserving instincts are allowed to rest, the gentler and more generous sentiments are evoked, and man becomes that courteous and chivalric being which he is found to be amongst the upper classes of almost all civilized countries. These, then, may be said to be the chief natural laws concerned in the moral phenomenon of civilization. If I am right in so considering them, it will, of course, be readily admitted that the earliest families of the human race, although they might be simple and innocent, could not have been in anything like a civilized state, seeing that the conditions necessary for that state could not have then existed. Let us only for a moment consider some of the things requisite for their being civilized,--namely, a set of elegant homes ready furnished for their reception, fields ready cultivated to yield them food without labour, stores of luxurious appliances of all kinds, a complete social enginery for the securing of life and property,-and we shall turn from the whole conceit as one worthy only of the uninstructed mind.

Language is a gift so peculiar to man, and in itself so remarkable, that there is a great inclination to surmise a miraculous origin for it; although there is no proper ground, or even support, for such an idea in Scripture, 
while it is clearly opposed to everything else we know with regard to the providential arrangements for the creation of our race. Here, as in other cases, a little observation of nature might have saved much vain discussion. The real character of language itself has not been thoroughly understood. Language, in its most comprehensive sense, is the communication of ideas by whatever means. Ideas can be communicated by looks, gestures, and signs of various other kinds, as well as by speech. The inferior animals possess some of those means of communicating ideas, and they have likewise a silent and unobservable mode of their own, the nature of which is a complete mystery to us, though we are assured of its reality by its effects. Now, as the inferior animals were all in being before man, there was language upon earth long ere the history of our race commenced. The only additional fact in the history of language, which was produced by our creation, was the rise of a new mode of expression-namely, that by sound-signs produced by the vocal organs. In other words, speech was the only novelty in this respect attending the creation of the human race. No doubt it was an addition of great importance, for, in comparison with it, the other natural modes of communicating ideas are insignificant. Still, the main and fundamental phenomenon, language, as the communication of ideas, was no new gift of the Creator to man; and in speech itself, when we judge of it as a natural fact, we see only a result of some of those superior endowments of which so many others have fallen to our lot through the medium of a' superior organization.

The first and most obvious natural endowment con- 
cerned in speech is that peculiar organization of the larynx, trachea, and mouth, which enables us to produce the various sounds required. Man started at first with this organization ready for use, a constitution of the atmosphere adapted for the sounds which that organization was calculated to produce, and, last, but not least. a mental power prompting to, and giving directions for, the expression of ideas. Such an arrangement of mutually adapted things was as likely to produce sounds as an Eolian harp placed in a draught is to give forth tones. It was unavoidable that human beings so organized, and in such a relation to external nature, should utter sounds, and also come to attach to these conventional meanings, thus forming the elements of spoken language. The great difficulty which has been felt, is to account for man going in this respect beyond the inferior animals. There could have been no such difficulty, if speculators in this class of subjects had looked into physiology for an account of the superior vocal organization of man, and had they obtained a true science of mind to show man possessing a faculty for the expression of ideas which is only rudimental in the lower animals. Another difficulty has been in the consideration that, if men were at first utterly untutored and barbarous, they could scarcely be in a condition to form or employ language-an instrument which it requires the fullest powers of thought to analyze and speculate upon. This difficulty comes strangely from those who can see none in the miraculous imparting of a full vocabulary to beings as yet possessing but a portion of the ideas which an entire language represents. But, in reality, it is not necessary to suppose 
the fathers of our race as early attaining to great proficiency in language; and, in the second, language itself seems to be amongst the things least difficult to be acquired, if we can form any judgment from what we see in children, most of whom have, by three years of age, while their information and judgment are still very imperfect, mastered and familiarized themselves with a quantity of words, infinitely exceeding in proportion what they acquire in the course of any subsequent similiar portion of time.

Discussions as to which parts of speech were first formed, and the processes by which grammatical structure and inflections took their rise, appear in a great measure needless, after the matter has been placed in this light. The mental powers could readily connect particular arbitrary sounds with particular ideas, whether those ideas were nouns, verbs, or interjections. As the words of all languages can be traced back into roots which are monosyllables, we may presume these sounds to have all been monosyllabic accordingly. The clustering of two or more together to express a compound idea, and the formation of inflections by additional syllables expressive of pronouns and such prepositions as of, by, and to, are processes which would or might occur as matters of course, being simple results of a mental power called into action, and partly directed, by external necessities. This power, however, as we find it in very different degrees of endowment in individuals, so would it be in different degrees of endowment in nations, or branches of the human family. Hence we find the formation of words, and the process of their composition and gram- 
matical arrangement, in very different stages of development in different races. The Chinese have a language composed of a limited number of monosyllables, which they multiply in use by mere variations of accent, and which they have never yet attained the power of clustering or inflecting; the language of this immense nation-the third part of the human race-may be said to be in the condition of infancy. The aboriginal Americans, so inferior in civilization, have, on the other hand, a language of the most elaborately composite kind, perhaps even exceeding, in this respect, the languages of the most refined European nations. These are but a few out of many facts tending to show that language is in a great measure independent of civilization, as far as its advance and development are concerned. ${ }^{1}$ Do they not also help to prove that cultivated intellect is not necessary for the origination of language?

Facts daily presented to our observation afford equally simple reasons for the almost infinite diversification of language. It is invariably found that, wherever society is at once dense and refined, language tends to be uni-

1 The following is an extract from The Progress of Ethnology, by J. Russell Bartlett, Corresponding Secretary of the American Ethnological Society, New York, 1847. It is preceded by a statement, that the American Missionaries on the Gaboon river, have framed a grammar of the Roongwee language-i.e., the language of those parts. "It is one of the most perfect languages of which they have any knowledge. It is not so remarkable for copiousness of words, as for its great and almost unlimited flexibility. Its expansions, contractions, and inflexions, though exceedingly numerous, and having, apparently, special reference to euphony, are all governed by grammatical rules, which seem to be well established in the minds of the people, and which enable them to express their ideas with the utmost precision. How a language so soft, so plaintive, so pleasant to the ear, and at the same time so copious and methodical in its inflexions, should have originated, or how the people are enabled to retain its multifarious principles so distinctly in their minds as to express themselves with almost unvarying precision and uniformity, are points which we do not pretend to settle. It is spoken coastwise nearly two hundred miles, and perhaps with some dialectic differences it reaches the Congo river. How far it extends into the interior is not satisfactorily known." -Report, British Association, I847, p. I74. 
form throughout the whole population, and to undergo few changes in the course of time. Wherever, on the contrary, we have a scattered and barbarous people, we have great diversities, and comparatively rapid alterations of language; insomuch that, while English, French, and German, are each spoken with little variation by many millions, there are islands in the Indian archipelago, probably not inhabited by one million, but in which there are hundreds of languages, as diverse as are English, French, and German. It is easy to see how this should be. There are peculiarities in the vocal organization of every person, tending to produce peculiarities of pronunciation: for example, it has been stated that each child in a family of six gave the monosyllable, fly, in a different manner, (eye, fy, ly, \&c.) until, when the organs were more advanced, correct example induced the proper pronunciation of this and similar words. Such departures from orthoepy are only to be checked by the power of example; but this is a power not always present, or not always of sufficient strength. Robert Moffat, in his work on South Africa, states, without the least regard to hypothesis, that amongst the people of the towns of that great region, "the purity and harmony of language is kept up by their pitchos or public meetings, by their festivals and ceremonies, as well as by their songs and their constant intercourse. With the isolated villages of the desert it is far otherwise. They have no such meetings; they are compelled to traverse the wilds, often to a great distance from their native village. On such occasions, fathers and mothers, and all who can bear a burden, often set out for weeks at a time, and leave their children to the 
care of two or three infirm old people. The infant progeny, some of whom are beginning to lisp, while others can just master a whole sentence, and those still further advanced, romping and playing together, the children of nature, through the live-long day, become habituated to a language of their oum. The more voluble condescend to the less precocious, and thus, from this infant Babel, proceeds a dialect composed of a host of mongrel words and phrases, joined together without rule, and in the course of a generation the entive character of the language is changed." I It has been stated, that in like manner the children of the Manchester factory workers, left for a great part of the day, in large assemblages, under the care of perhaps a single elderly person, and spending the time in amusements, make a great deal of new language. I have seen children in other circumstances amuse themselves by concocting and throwing into the family circulation entirely new words; and I believe I am running little risk of contradiction when I say that there is scarcely a family, even amongst the middle classes of this country, who have not some peculiarities of pronunciation and syntax, which have originated amongst themselves, it is hardly possible to say how. All these things being considered, it is easy to understand how mankind have come at length to possess between three and four thousand languages, all different at least as much as French, German, and English, though, as has been shown, resemblances suggesting community of origin are observable in groups of them.

What has been said on the question whether mankind 
were originally in a state of civilization or otherwise, will have prepared the reader for understanding how the arts and sciences, and the rudiments of civilization itself, took their rise amongst men. The only source of fallacious views on this subject is the so frequent observation of arts, sciences, and social modes, forms, and ideas, being not indigenous where we see them now flourishing, but known to have been derived elsewhere: thus Rome borrowed from Greece, Greece from Egypt, and Egypt itself, lost in the mists of historic antiquity, is now supposed to have obtained the light of knowledge from some still earlier scene of intellectual culture. This has caused to many a great difficulty in supposing a natural or spontaneous origin for civilization and the attendant arts. But, in the first place, several stages of derivation are no conclusive argument against there having been an originality at some earlier stage. In the second, such observers have not looked far enough, for, if they had, they might have seen various instances of civilizations which it is impossible, with any plausibility, to trace back to a common origin with others; such are those of China and America. They would also have seen civilizations springing up, as it were, like oases among the arid plains of barbarism, as in the case of the Mandans. A still more attentive study of the subject would have shown, amongst living men, the very psychological procedure on which the organization of civilization and the arts and sciences depended.

These things, like language, are simply the effects of the spontaneous working of certain mental faculties, each in relation to the things of the external world on which it 
was intended by creative Providence to be exercised. The monkeys themselves, without instruction from any quarter, learn to use sticks in fighting, and some build houses-an act which cannot in their case be considered as one of instinct, but of intelligence. Such being the case, there is no necessary difficulty in supposing how man, with his superior mental organization, (a brain five times heavier,) was able, in his primitive state, without instruction, to turn many things in nature to his use, and commence, in short, the circle of the domestic arts. He appears, in the most unfavourable circumstances, to be able to provide himself with some sort of dwelling, to make weapons, and to practise some simple kind of cookery. But, granting, it will be said, that he can go thus far, how does he ever proceed further unprompted, seeing that many nations remain fixed for ever at this point, and seem unable to take one step in advance? It is perfectly true that there is such a fixation in many nations; but, on the other hand, all nations are not alike in mental organization, and another point has been established, that only when some favourable circumstances have settled a people in one place, do arts and social arrangements get leave to flourish. If we were to limit our view to humbly-endowed nations, or the common class of minds in those called civilized, we should see absolutely no conceivable power for the origination of new ideas and devices. But let us look at the inventive class of minds which stand out amongst their fellowsthe men, who, with little prompting or none, conceive new ideas in science, arts, morals - and we can be at no loss to understand how and whence have arisen the 
elements of that civilization, which history traces from country to country throughout the course of centuries. See a Pascal reproducing the Alexandrian's problems at fifteen; a Ferguson making clocks from the suggestions of his own brain, while tending cattle on a Morayshire heath; a boy Lawrence, in an inn on the Bath road, producing, without a master, drawings which the educated could not but admire; or look at Solon and Confucius, devising sage laws, and breathing the accents of all but divine wisdom, for their barbarous fellow-countrymen, three thousand years ago-and the whole mystery is solved at once. Amongst the arrangements of Providence is one for the production of original, inventive, and aspiring minds, which, when circumstances are not decidedly unfavourable, strike out new ideas for the benefit of their fellow-creatures, or put upon them a lasting impress of their own superior sentiments. Nations, improved by these means, become in turn foci for the diffusion of light over the adjacent regions of barbarism-their very passions helping to this end, for nothing can be more clear, than that ambitious aggression has led to the civilization of many countries. Such is the process which seems to form the destined means for bringing mankind from the darkness of barbarism to the day of knowledge and mechanical and social improvement. Even the noble art of letters is but, as Dr. Adam Ferguson has remarked, "a natural produce of the human mind, which will rise spontaneously, wherever men are happily placed;" original alike amongst the ancient Egyptians and the dimly monumented Toltecans of Yucatan. "Banish," says Dr. Gall, "music, poetry, painting, sculpture, architecture, all the arts 
and sciences, and let your Homers, Raphaels, Michael Angelos, Glucks, and Canovas, be forgotten, yet let men of genius of every description spring up, and poetry, music, painting, architecture, sculpture, and all the arts and sciences, will again shine out in all their glory. Twice within the records of history has the human race traversed the great circle of its entire destiny, and twice has the rudeness of barbarism been followed by a higher degree of refinement. It is a great mistake to suppose one people to have proceeded from another on account of their conformity of manners, customs, and arts. The swallow of Paris builds its nest like the swallow of Vienna, but does it thence follow that the former sprung from the latter? With the same causes we have the same effects; with the same organization we have the manifestation of the same powers." 


\section{MENTAL CONSTITUTION OF ANIMALS.}

No clear ideas have as yet been entertained by the generality of even educated men, with regard to the mental constitution of animals. The very nature of this constitution is not as yet generally known or held as ascertained. There is, indeed, a notion of old standing, that the mind is in some way connected with the brain; but the metaphysicians insist that it is, in reality, known only by its acts or effects, and they accordingly present the subject in a form which is unlike any other kind of science, for it does not so much as pretend to have a basis in nature. There is a general disinclination to regard mind in connexion with organization, from a fear that this must interfere with the cherished doctrine of the spirit of man, and lower him to the level of the brutes. A distinction is therefore drawn between our mental manifestations and those of the lower animals, the latter being comprehended under the term instinct, while ours are collectively described as mind, mind being again a received synonyme with soul, the immortal part of man. There is here a strange system of confusion and error, which it is most imprudent to regard as essential to religion, since candid investigations of nature tend to show its untenableness. There is, in reality, nothing to prevent our regarding man as being specially, in accordance 
with his position as the head or chief of all animals, endowed with an immortal spirit, at the same time that his ordinary mental manifestations are looked upon as simple phenomena resulting from organization, those of the lower animals being phenomena absolutely the same in character, though developed within narrower limits. ${ }^{1}$ What has chiefly tended to take mind, in the eyes of

I"Is not God the first cause of matter as well as of mind? Do not the first attributes of matter lie as inscrutable in the bosom of God-of its first author-as those of mind? Has not even matter confessedly received from God the power of experiencing, in consequence of impressions from the earlier modifications of matter, certain consciousnesses called sensations of the same? Is not, therefore, the wonder of matter also receiving the consciousness of other matter called ideas of the mind, a wonder more flowing out of and in analogy with all former wonders, than would be, on the contrary, the wonder of this faculty of the mind not flowing out of any faculties of matter? Is it not a wonder which, so far from destroying our hopes of immortality, can establish that doctrine on a train of inferences and inductions more firmly established and more connected with each other than the former belief can be, as soon as we have proved that matter is not perishable, but is only liable to successive combinations and decombinations?

"Can we look farther back one way into the first origin of matter than we can look forward the other way into the last developments of mind? Can we say that God has not in matter itself laid the seeds of every faculty of mind, rather than that he has made the first principle of mind entirely distinct from that of matter? Cannot the first cause of all we see and know have fraught matter itself, from its very beginning, with all the attributes necessary to develop into mind as well as he can have from the first made the attributes of mind wholly different from those of matter, only in order afterwards, by an imperceptible and incomprehen. sible link, to join the two together?

". . . [The decombination of the matter on which mind rests] is this a reason why mind must be annihilated? Is the temporary reverting of the mind, and of the sense out of which that mind develops, to their original com. ponent elements, a reason for thinking that they cannot again, at another later period and in another higher globe, be again recombined, and with more splendour than before? . . . . The New Testament does not, after death here, promise us a soul hereafter unconnected with matter, and which has no connexion with our present mind-a soul independent of time and space. That is a fanciful idea, not founded on its expressions, when taken in their just and real meaning. On the contrary, it promises us a mind like the present, founded on time and space; since it is, like the present, to hold a certain situation in time, and a certain locality in space; but it promises a mind situated in portions of time and of space different from the present: a mind composed of elements of matter more extended, more perfect, and more glorious: a mind which, formed of materials supplied by different globes, is consequently able to see farther into the past, and to think farther into the future, than any mind here existing : a mind which, freed from the partial and uneven combination incidental to it on this globe, will be exempt from the changes for evil to which, on the present globe, mind as well as matter is liable, and will only thenceforth experience the changes for the better which matter, more justly poised, will alone continue to experience : a mind which, no longer fearing the death, the total decomposition, to which it is subject on this globe, will thenceforth continue blest and immortal."-HOPE, on the Origin and Prospects of Man, $183 \mathrm{x}$. 
learned and unlearned, out of the range of nature, is its apparently irregular and wayward character. How different the manifestations in different beings! how unstable in all! - at one time so calm, at another so wild and impulsive! It seemed impossible that anything so subtle and aberrant could be part of a system, the main features of which are regularity and precision. But the irregularity of mental phenomena is only in appearance. When we give up the individual, and take the mass, we find as much uniformity of result as in any other class of natural phenomena. The irregularity is exactly of the same kind as that of the weather. No man can say what may be the weather of to-morrow; but the quantity of rain which falls in any particular place in any five years is precisely the same as the quantity which falls in any other five years at the same place. Thus, while it is absolutely impossible to predict of any one Frenchman that during next year he will commit a crime, it is quite certain that about one in every six hundred and fifty of the French people will do so, because in past years the proportion has generally been about that amount, the tendencies to crime in relation to the temptations being everywhere invariable over a sufficiently wide range of time. So also, the number of persons taken in charge by the police in London for being drunk and disorderly in the streets, is, week by week, a nearly uniform quantity, showing that the inclination to drink to excess is always in the mass about the same, regard being had to the existing temptations or stimulations to this vice. Even mistakes and oversights are of regular recurrence, for it is found, in the postoffices of large cities, that the number of letters put in 
without addresses is year by year the same. Statistics has ascertained an equally distinct regularity in a wide range, with regard to many other things concerning the mind, and the doctrine founded upon it has lately produced a scheme which may well strike the ignorant with surprise. It was proposed to establish in London a society for ensuring the integrity of clerks, secretaries, collectors, and all such functionaries as are usually obliged to find security for money passing through their hands in the course of business. A gentleman of the highest character as an actuary spoke of the plan, in the following terms :- "If a thousand bankers' clerks were to club together to indemnify their securities, by the payment of one pound a year each, and if each had given security for $500 l$., it is obvious that two in each year might become defaulters to that amount, four to half the amount, and so on, without rendering the guarantee-fund insolvent. If it be tolerably well ascertained that the instances of dishonesty (yearly) among such persons amount to one in five hundred, this club would continue to exist, subject to being in debt in a bad year, to an amount which it would be able to discharge in good ones. The only question necessary to be asked previous to the formation of such a club would be, - may it not be feared that the motive to resist dishonesty would be lessened by the existence of the club, or that ready-made rogues, by belonging to it, might find the means of obtaining situations which they would otherwise have been kept out of by the impossibility of obtaining security among those who knew them? Suppose this be sufficiently answered by saying, that none but those who could bring satisfactory testimony to their 
previous good character should be allowed to join the club; that persons who may now hope that a deficiency on their parts will be made up and hushed up by the relative or friend who is security, will know very well that the club will have no motive to decline a prosecution, or to keep the secret, and so on. It then only remains to ask, whether the sum demanded for the guarantee is sufficient?"1 The philosophical principle on which the scheme proceeds, seems to be simply this, that amongst a given (large) number of persons of good character, there will be, within a year or other considerable space of time, a determinate number of instances in which moral principle and the terror of the consequences of guilt will be overcome by temptations of a determinate kind and amount, and thus occasion a certain periodical amount of loss which the association must make up.

This statistical regularity in moral affairs fully establishes their being under the presidency of law. Man is seen to be an enigma only as an individual: in the mass he is a mathematical problem. It is hardly necessary to say, much less to argue, that mental action, being proved to be under law, passes at once into the category of natural things. Its old metaphysical character vanishes. This view agrees with what all observation teaches, that mental phenomena flow directly from the brain. They are seen to be dependent on naturally constituted and naturally conditioned organs, and thus obedient, like all other organic phenomena, to law. And how wondrous must the constitution of this apparatus be, which gives us consciousness of thought and of affection, which makes us

'Dublin Review, Aug. 1840. 
familiar with the numberless things of earth, and enables us to rise in conception and communion to the councils of God himself! It is matter which forms the medium or instrument-a little mass which, decomposed, is but so much common dust; yet in its living constitution, designed, formed, and sustained by Almighty Wisdom, how admirable its character! how reflective of the unutterable depths of that power by which it was so formed, and is so sustained!

In the mundane economy, mental action takes its place as a means of providing for the independent existence and the various relations of animals, each species being furnished according to its special necessities and the demands of its various relations. The nervous system-the more comprehensive term for the organic apparatus on which this action depends - is variously developed in different classes and species, and also in different individuals, the volume or mass bearing a general relation to the amount of power. Passing over the humblest orders, where nervous apparatus is so obscure as hardly to be traceable, we see it, in the nematoneura of Owen, ${ }^{1}$ in filaments and nuclei, the mere rudiments of the system. In the articulata, it is advanced to a double nervous cord, with ganglia, or little masses of nervous matter at frequent intervals, and filaments branching out towards each side; the ganglia near the head being apparently those which receive nerves from the organs of the senses; and this arrangement is only less symmetrical in the mollusca. Ascending to the vertebrata, we find a spinal cord, with a brain at the upper extremity, and

1 Including rotifera, entozoa, echinodermata, \&c. 
numerous branching lines of nervous tissue, an organization strikingly superior; yet here, as in the general structure of animals, the great principle of unity is observed. The brain of the vertebrata is merely an expansion of the anterior pair of the ganglia of the articulata, or these ganglia may be regarded as the rudiment of a brain, the superior organ thus appearing as only a further development of the inferior. There are many facts which tend to prove that the action of this apparatus is of a nature allied to electricity, a modification of that surprising agent, which takes magnetism, heat, and light, as other subordinate forms, and of whose general scope in this great system of things we are only beginning to have a faint conception. It has been found, for example, that simple electricity, artificially produced, and sent along the nerves of a dead body, excites muscular movement. Nor is this a very startling idea, when we reflect that electricity is almost as immaterial as ever mind was supposed to be. It is a thing perfectly intangible, weightless,-well described by modern philosophers as a force rather than a substance,-and yet an actual existence in nature, as is sufficiently proved by its effects. So also may its ally mental action be intangible, immaterial, and yet a real existence, and ruled by the Eternal through His laws. ${ }^{1}$

1 If mental action is electric, the proverbial quickness of thought-that is, the quickness of the transmission of sensation and will-may be presumed to have been brought to an exact measurement. The speed of light has long been known to be about 192,000 miles per second, and the experiments of Professor Wheatstone have shown that the electric agent travels (if I may so speak) at least as rapidly, thus showing a likelihood that one law rules the movements of all the "imponderable bodies." Mental action may accordingly be presumed to have a rapidity equal to one hundred and ninety-two thousand miles in the second-a rate evidently far beyond what is necessary to make the design and execution of any of our ordinary muscular movements apparently identical in point of time, which they are. 
Common observation shows a great general superiority of the human mind over that of the inferior animals. Man's mind is almost infinite in device; it ranges over all the world; it forms the most wonderful combinations : it seeks back into the past, and stretches forward into the future; while the animals generally appear to have a narrow range of thought and action. But so also has an infant but a limited range, and yet it is mind which works there, as well as in the most accomplished adults. The difference between mind in the lower animals and in man is a difference in degree only; it is not a specific difference. All who have studied animals by actual observation, and even those who have given a candid attention to the subject in books, must attain more or less clear convictions of this truth, notwithstanding the obscurity which prejudice may have engendered. We see animals capable of affection, jealousy, envy; we see them quarrel, and conduct quarrels in the very manner pursued by the ruder and less educated of our own race. We see them liable to flattery, inflated with pride, and dejected by shame. We see them as tender to their young as human parents are, and as faithful to a trust as the most conscientious of human servants. The horse is startled by marvellous objects, as a man is. The dog and many others show tenacious memory. The dog also proves himself possessed of imagination, by the act of dreaming. Horses, finding themselves in want of a shoe, have of their own accord gone to a farrier's shop where they were shod before. Cats closed up in rooms, will endeavour to obtain their liberation by pulling a latch or ringing a bell. A monkey, wishing to get into a parti- 
cular tree, and seeing a dangerous snake at the bottom of it, watched for hours till he found the reptile for a moment off his guard; he sprang upon it, and, seizing it by the neck, bruised its head to pieces against a stone; after which he quietly ascended the tree. We can hardly doubt that the animal seized and bruised the head, because he knew or judged there was danger in that part. It has several times been observed that in a field of cattle, when one or two were mischievous, and persisted long in annoying or tyrannizing over the rest, the herd, to all appearance, consulted, and then making a united effort, drove the troublers off the ground. The members of a rookery have also been observed to take turns in supplying the needs of a family reduced to orphanhood. All of these are acts of reason, in no respect different from similar acts of men. Moreover, although there is no heritage of accumulated knowledge amongst the lower animals, as there is amongst us, they are in some degree susceptible of those modifications of natural character, and capable of those accomplishments which we call education. The taming and domestication of animals, and the changes thus produced upon their nature in the course of generations, are results identical with civilization amongst ourselves; and the quiet, servile steer is probably as unlike the original wild cattle of this country, as the English gentleman of the present day is unlike the rude baron of the age of King John. Between a young, unbroken horse, and a trained one, there is, again, all the difference which exists between a wild youth, reared at his own discretion in the country, and the same person when he has been toned down by 
long exposure to the influences of refined city society. Of extensive combinations of thought, we have no reason to believe that any animals are capable-and yet most of us must feel the force of Walter Scott's remark, that there was scarcely anything which he would not believe of a dog. There is a curious result of education in certain animals, namely, that habits to which they have been trained, in some instances become hereditary. For example, the accomplishment of pointing at game, although a pure result of education, appears in the young pups brought up apart from their parents and kind. The peculiar leap of the Irish horse, acquired in the course of traversing a boggy country, is continued in the progeny brought up in England. This hereditariness of specific habits suggests a relation to that form of psychological manifestation usually called instinct; but instinct is only another term for mind, or is mind in a peculiar state of development; and though the fact were otherwise, it could not affect the conclusion, that manifestations such as have been enumerated are mainly intellectual manifestations, not to be distinguished as such from those of human beings.

More than this, the lower animals manifested mental phenomena long before man existed. While as yet there was no brain capable of working out a mathematical problem, the economy of the six-sided figure was exemplified by the instinct of the bee. The dog and the elephant prefigured the sagacity of the human mind. The love of a human mother for her babe was anticipated by nearly every humbler mammal, the carnivora not excepted. The peacock strutted, the turkey blustered, and the cock 
fought for victory, just as human beings afterwards did, and still do. Our faculty of imitation, from which so much amusement is derived, was exercised by the mocking-bird; and the whole tribe of monkeys must have walked about the pre-human world, playing off those tricks in which we see the comicality and mischiefmaking of our own character so curiously exaggerated.

The unity and simplicity which characterize nature, give great antecedent probability to what observation seems about to establish, that, as the brain of the vertebrata generally is only an advanced condition of a particular ganglion in the mollusca and crustacea, so are the brains of the higher and more intelligent mammalia only further developments of the brains of the inferior orders of the same class. Or, to the same purpose, it may be said, that each species has certain superior developments, according to its needs, while others are in a rudimental or repressed state. This will more clearly appear, after some inquiry has been made into the various powers comprehended under the term mind.

One of the first and simplest functions of mind is to give consciousness-consciousness of our identity and of our existence. This, apparently, is independent of the senses, which are simply media, and, as Locke has shown, the only media, through which ideas respecting the external world reach the brain. The access of such ideas to the brain is the act to which the metaphysicians have given the name of perception. Gall, however, has shown, by induction from a vast number of actual cases, that there is a part of the brain devoted to perception, and that even this is subdivided into portions 
which are respectively dedicated to the reception of different sets of ideas, as those of form, size, colour, weight, objects in their totality, events in their progress or occurrence, time, musical sounds, etc. The system of mind invented by this philosopher-the only one founded upon nature, or which even pretends to or admits of that necessary basis-shows a portion of the brain acting as a faculty of comic ideas, another of imitation, another of wonder, one for discriminating, or observing differences, and another in which resides the power of tracing effects to causes. There are also districts of the brain for the sentimental part of our nature, or the affections, at the head of which stand the moral feelings of benevolence, conscientiousness, and veneration. Through these, man stands in relation to himself, his fellow-men, the external world, and his God; and through these comes most of the happiness of man's life, as well as that which he derives from the contemplation of the world to come, and the cultivation of his relation to it, (pure religion.) The other sentiments may be briefly enumerated, their names being sufficient in general to denote their functions-firmness, hope, cautiousness, self-esteem, love of approbation, secretiveness, marvellousness, constructiveness, imitation, combativeness, destructiveness, concentrativeness, adhesiveness, love of the opposite sex, love of offspring, alimentiveness, and love of life. Through these faculties man is connected with the external world, and supplied with active impulses to maintain his place in it as an individual and as a species. There is also a faculty (language) for expressing by whatever means, (signs, gestures, looks, conventional terms in speech,) the ideas 
which arise in the mind. There is a particular state of each of these faculties, when the ideas of objects once formed by it are revived or reproduced, a process which seems to be intimately allied with some of the phenomena of photography, when images impressed by reflection of the sun's rays upon sensitive paper are, after a temporary obliteration, resuscitated, on the sheet being exposed to the fumes of mercury. Such are the phenomena of memory, that handmaid of intellect, without which there could be no accumulation of mental capital, but an universal and continual infancy. Conception and imagination appear to be only intensities, so to speak, of the state of brain in which memory is produced. On their promptness and power depend most of the exertions which distinguish the man of arts and letters, and even in no small measure the cultivator of science.

The faculties above described - the actual elements of the mental constitution-are seen in mature man in an indefinite potentiality and range of action. It is different with the lower animals. They are there comparatively definite in their power and restricted in their application. The reader is familiar with what are called instincts in some of the humbler species, that is, an uniform and unprompted tendency towards certain particular acts, as the building of cells by the bee, the storing of provisions by that insect and several others, and the construction of nests for a coming progeny by birds. I can regard this quality as nothing more than a mode of operation peculiar to the faculties in a humble state of endowment, or early stage of development. The cell-formation of the bee, the house-building of ants and beavers, the web- 
spinning of spiders, are but primitive exercises of constructiveness, the faculty which, indefinite with us, leads to the arts of the weaver, upholsterer, architect, and mechanist, and makes us often work delightedly where our labours are in vain, or nearly so. The storing of provision by the bees is an exercise of acquisitiveness, a faculty which with us makes rich men and misers. A vast number of curious devices, by which insects provide for the protection and subsistence of their young, whom they are perhaps never to see, are most probably a peculiar restricted philo-progenitiveness. The common source of this class of acts, and of common mental operations, is shown very convincingly by the melting of the one set into the other. Thus, for example, the bee and bird will make modifications in the ordinary form of their cells and nests when necessity compels them. Thus the alimentiveness of such animals as the dog, usually definite with regard to quantity and quality, can be pampered or educated up to a kind of epicurism, that is, an indefiniteness of object and action. The same faculty acts limitedly in ourselves at first, dictating the special act of sucking ; afterwards it acquires indefiniteness. Such appears to be the real nature of the distinction between what are called instinct and reason, upon which so many volumes have been written without profit to the world. All faculties are instinctive, that is, dependent on internal and inherent impulses. This term is, therefore, not specially applicable to either of the recognised modes of the operation of the faculties. We only, in the one case, see the faculty in an immature and slightly developed state; in the other, in its most 
advanced condition. In the one case it is definite, in the other, indefinite, in its range of action. These terms would perhaps be the most suitable for expressing the distinction.

In the humblest forms of being, we can trace scarcely anything besides a definite action in a few of the faculties. Generally speaking, as we ascend in the scale, we see more and more of the faculties in exercise, and these tending more to the indefinite mode of manifestation. And for this there is the obvious reason in providence, that the lowest animals have all of them a very limited sphere of existence, are born only to perform a few functions, and enjoy a brief term of life, and then give way to another generation, so that they do not need much mental power or guidance. At higher points in the scale, the sphere of existence is considerably extended, and the mental operations are less definite accordingly. The horse, dog, and a few other animals, noted for their serviceableness to our race, have the indefinite powers in no small endowment. Man, again, shows very little of the definite mode of operation, and that little chiefly in childhood, or in barbarism, or idiocy. Destined for a wide field of action, and to be applicable to infinitely varied contingencies, he has all the faculties developed to a high pitch of indefiniteness, that he may be ready to act well in all imaginable cases. His commission, it may be said, gives large discretionary powers, while that of the inferior animals is limited to a few precise directions. But when the human brain is congenitally imperfect or diseased, or when it is in a state of infancy, we see in it an approach towards 
the character of the brains of some of the inferior animals. Dr. J. G. Davey states that he has frequently witnessed, among his patients at the Hanwell Lunatic Asylum, indications of a particular abnormal cerebration, which forcibly reminded him of the specific healthy characteristics of animals lower in the scale of organization ; $^{3}$ and every one must have observed how often the actions of children, especially in their moments of play, and where their selfish feelings are concerned, bear a resemblance to those of certain familiar animals. Behold, then, the wonderful unity of the whole system. The grades of mind, like the forms of being, are mere stages of development. In the humbler forms, only a few of the mental faculties are traceable, just as we see in them but a few of the lineaments of universal structure. In man the system has arrived at its highest condition. The few gleams of reason, then, which we see in the lower animals, are precisely analogous to such a development of the fore-arm as we find in the paddle of the whale. Causality, comparison, and other of the noble faculties, are in them rudimental.

Bound up as we thus are by an identity in the character of our mental organization with the lower animals, we are yet, it will be observed, strikingly dis-

1 Phrenological Journal, xv. 338.

One of the brightest minds of our age, the Rev. Sidney Smith, held precisely the same views respecting the mental constitution of man which are presented in the text :- " Nature," says he, "has not formed man totally different from other animals, but rather added to his brain new organs. She has not, in his case, pulled down the fabric of sentient being, and reconstructed it upon a totally different plan. All that she has done has been to add to the original edifice Corinthian capitals and Doric columns; bestowing reason, not to supersede, but to guide, direct, and perfect his animal nature. We may rest assured, therefore, that whatsoever principles, in the shape of instincts, are given to animals for their preservation and protection, are also instincts in man; and that what in them is a propensity or desire, is not in him anything else." 
tinguished from them by this great advance in development. We have faculties in full force and activity which the animals either possess not at all, or in so low and obscure a form as to be equivalent to nonexistence. Now these parts of mind are those which connect us with the things that are not of this world. We have veneration, prompting us to the worship of the Deity, which the animals lack. We have hope, to carry us on in thought beyond the bounds of time. We have reason, to enable us to inquire into the character of the Great Father, and the relation of us, his humble creatures, towards him. We have conscientiousness and benevolence, by which we can in a faint and humble measure imitate, in our conduct, that which he exemplifies in the whole of his wondrous doings. The existence of faculties having a regard to such things is a good evidence that such things exist. The face of God is reflected in the organization of man, as a little pool reflects the glorious sun.

The affective or sentimental faculties are all of them liable to operate whenever appropriate objects or stimuli are presented, and this they do as irresistibly and unerringly as the tree sucks up moisture which it requires, with only this exception, that one faculty interferes with the action of another, and operates instead, by force of superior inherent strength or temporary activity. For example, alimentiveness may be in powerful operation with regard to its appropriate object, producing a keen appetite, and yet it may not act, in consequence of the more powerful operation of cautiousness, warning against evil consequences likely to ensue from the desired in- 
dulgence. This liability to flit from under the control of one feeling to the control of another, constitutes what is recognised as free will in man, being nothing more than a vicissitude in the supremacy of the faculties over each other.

It is a common mistake to suppose that the individuals of our own species are all of them formed with similar faculties-similar in power and tendency-and that education and the influence of circumstances produce all the differences which we observe. There is not, in the old systems of mental philosophy, any doctrine more opposite to the truth than this. It is refuted at once by the great differences of intellectual tendency and moral disposition to be observed amongst a group of young children, who have been all brought up in circumstances perfectly identical--even in twins, who have never been but in one place, under the charge of one nurse, attended to alike in all respects. The mental characters of individuals are inherently various, as the forms of their persons and the features of their faces are; and education and circumstances, though their influence is not to be despised, are capable of entirely altering these characters, where they are strongly developed. That the original characters of mind are dependent on the volume of particular parts of the brain and the general quality of that organ, is proved by induction from an extensive range of observations, the force of which must have been long since universally acknowledged, but for the unpreparedness of mankind to admit a functional connexion between mind and body. The different mental characters of individuals may be presumed from analogy to depend on the same 
law of development which we have seen determining the forms of being and the mental characters of particular species. This we may conceive as carrying forward the intellectual powers and moral dispositions of some to a high pitch, repressing those of others at a moderate amount, and thus producing all the varieties which we see in our fellow-creatures. Thus, a Cuvier and a Newton are but expansions of a clown; and the person emphatically called the wicked man, is one whose highest moral feelings are rudimental. Such differences are not confined to our species; they are only less strongly marked in many of the inferior animals. There are clever dogs and wicked horses, as well as clever men and wicked men; and education sharpens the talents, and in some degree regulates the dispositions of animals, as it does our own.

There is, nevertheless, a general adaptation of the mental constitution of man to the circumstances in which he lives, as there is between all the parts of nature to each other. The goods of the physical world are only to be realized by ingenuity and industrious exertion; behold, accordingly, an intellect full of device, and a fabric of the faculties which would go to pieces or destroy itself if it were not kept in constant occupation. Nature presents to us much that is sublime and beautiful; behold faculties which delight in contemplating these properties of hers, and in rising upon them, as upon wings, to the presence of the Eternal. It is also a world of difficulties and perils, and see how a large portion of our species are endowed with vigorous powers, which take a pleasure in meeting and overcoming difficulty 
and danger. Even that principle on which our faculties are constituted-a wide range of freedom in which to act for all various occasions-necessitates a resentful faculty, by which individuals may protect themselves from the undue and capricious exercise of each other's faculties, and thus preserve their individual rights. So also there is cautiousness, to give us a tendency to provide against the evils by which we may be assailed; and secretiveness, to enable us to conceal whatever, being divulged, would be offensive to others or injurious to ourselves, - a function which obviously has a certain legitimate range of action, however liable to be abused. The constitution of the mind generally points to a state of intimate relation of individuals towards society, towards the external world, and towards things above this world. No individual being is integral or independent; he is only part of an extensive piece of social mechanism. The inferior mind, full of rude energy and unregulated impulse, does not more require a superior nature to act as its master and its mentor, than does the superior nature require to be surrounded by such rough elements on which to exercise its high endowments as a ruling and tutelary power. This relation of each to each, produces a vast portion of the active business of life. It is easy to see that, if we were all alike in our moral tendencies, and all placed on a medium of perfect moderation in this respect, the world would be a scene of everlasting dulness and apathy. It requires the variety of individual constitution to give moral life to the scene.

The indefiniteness of the potentiality of the human faculties. and the complexities which thus attend their 
relations, lead unavoidably to occasional error. If we consider for a moment that there are not less than thirty such faculties, that they are each given in different proportions to different persons, that each is at the same time endowed with a wide discretion as to the force and frequency of its action, and that our neighbours, the world, and our connexions with something beyond it, are all exercising an ever-varying influence over us, we cannot be surprised at the irregularities attending human conduct. It is simply the penalty paid for the superior endowment. It is here that the so-called imperfection of our nature resides. Causality and conscientiousness are, it is true, guides over all; but even these are only faculties of the same indefinite potentiality as the rest, and partake accordingly of the same inequality of action. Man is therefore a piece of mechanism, which never can act so as to satisfy his own ideas of what he might be-for he can imagine a state of moral perfection, (as he can imagine a globe formed of diamonds, pearls, and rubies,) though his constitution forbids him to realize it. There ever will be, in the best-disposed and most disciplined minds, occasional discrepancies between the amount of temptation and the power summoned for regulation or resistance, or between the stimulus and the mobility of the faculty; and hence those errors, and shortcomings, and excesses, without end, with which the good are constantly finding cause to charge themselves. There is at the same time even here a possibility of improvement. In infancy, the impulses are all of them irregular; a child is cruel, cunning, and false, under the slightest temptation, but in time learns 
to control these inclinations, and to be habitually humane, frank, and truthful. So is human society, in its earliest stages, sanguinary, aggressive, and deceitful, but, in time, becomes just, faithful, and benevolent. To such improvements there is a natural tendency, which will operate in all fair circumstances, though it is not to be expected that irregular and undue impulses will ever be altogether banished from the system.

It appears surprising that beings are born into the world, whose organization is such that they unavoidably run into vicious courses; such are the persons said to have the criminal type of brain. A great mystery besets us when we consider individuals as being determinately invested with evil tendencies by a special act of creative power. Under a system in which the Deity is regarded as acting by general arrangements, a light breaks upon us. It is a law of organization, that emotions much indulged in produce a change in the constitution of the being indulging in them. His character is so far changed, and this quality becomes liable to hereditary descent. It may reappear either in his own immediate offspring, or some more remote descendant; for hereditary qualities often pass over intermediate generations. Thus, one human being has his organization determined to vice merely because of the ill-controlled feelings of a parent or other predecessor. God no more expressly decreed the mean form of his brain than he expressly decreed the excesses which led to it. We have seen that it is for wise ends that God leaves our moral faculties to an indefinite range of action: the general good results of this arrangement are obvious; but excep- 
tions of evil are inseparable from such a system, and this is one of them. To come to particular illustrationwhen a people are oppressed, or kept in a state of slavery, they invariably contract habits of lying, for the purpose of deceiving and outwitting their superiors, falsehood being a refuge of the weak under difficulties. What is a habit in parents, becomes an inherent quality in children. We are not, therefore, to be surprised when a traveller tells us that black children in the West Indies appear to lie by instinct, and never answer a white person truly, even in the simplest matter. Here we have secretiveness roused in a people to a state of constant and exalted exercise : an over-tendency of the nervous energy in that direction is the consequence, and a new organic condition is established. This tells upon the progeny, which comes into the world with secretiveness excessive in strength and activity. All other evil characteristics may be readily conceived as being implanted in a new generation in the same way. And sometimes not one, but several generations may be concerned in bringing up the result to a pitch which produces crime. It is, however, to be observed, that the general tendency of things is to a limitation, not the extension of such abnormally constituted beings. The criminal brain finds itself in a social scene where all is against it. It may struggle on for a time, but it is sure to be overcome at last by the medium and superior natures. The disposal of such beings will always depend much on the moral state of a community, the degree in which just views prevail with regard to human nature, and the feelings which accident may have caused to predominate at a particular time. 
Where the mass was little enlightened or refined, and terrors for life or property were highly excited, malefactors have ever been treated severely. But when order is generally triumphant, and reason allowed sway, men begin to see the true case of criminals-namely, that while one large section are victims of erroneous social conditions, another are brought to error by tendencies which they are only unfortunate in having inherited. Criminal jurisprudence then addresses itself less to the direct punishment, than to the reformation and caretaking of those liable to its attention. And such a treatment of criminals, it may be further remarked, so that it stop short of affording any encouragement to crime, (a point which experience will determine, is evidently no more than justice, seeing how accidentally all forms of the moral constitution are distributed, and how thoroughly mutual obligation shines throughout the whole frame of society-the strong to help the weak, the good to redeem and restrain the bad.

The sum of all we have seen of the psychical constitution of man is, that its Almighty Author has destined it, like everything else, to be developed from inherent qualities, and to have a mode of action depending immediately on its own organization. Thus the whole appears complete on one principle. The masses of space are formed by law; law makes them in due time theatres of existence for plants and animals; sensation, disposition, intellect, are all in like manner developed and sustained in action by law. It is most interesting to observe into how small a field the whole of the mysteries of nature thus ultimately resolve themselves. The inorganic has been thought to 
have one final comprehensive law, GRAvitation. The organic, the other great department of mundane things, rests in like manner on one law, and that is-DEvELOPMENT. Nor may even these be after all twain, but only branches of one still more comprehensive law, the expression of a unity, flowing immediately from the One who is First and Last. 


\section{PURPOSE AND GENERAL CONDITION OF THE ANIMATED CREATION.}

WE have now to inquire how this view of the constitution and origin of nature bears upon the condition of man 'lpon the earth, and his relation to supra-mundane things.

That enjoyment is the proper attendant of animal existence is pressed upon us by all that we see and all we experience. Everywhere we perceive in the lower creatures, in their ordinary conditions, symptoms of enjoyment. Their whole being is a system of needs, the supplying of which is gratification, and of faculties, the exercise of which is pleasurable. When we consult our own sensations, we find that, even in a sense of a healthy performance of all the functions of the animal economy, God has furnished us with an innocent and very high enjoyment. The mere quiet consciousness of a healthy play of the mental functions - a mind at ease with itself and all around it-is extremely agreeable. This negative class of enjoyments, it may be remarked, is likely to be even more extensively experienced by the lower animals than by man, at least in the proportion of their absolute endowments, as their mental and bodily functions are much less liable to derangement than ours. To find the world constituted on this principle is only 
what in reason we should expect. We cannot conceive that so vast a system could have been created for a contrary purpose. No averagely constituted human being would, in his own limited sphere of action, think of producing a similiar system upon an opposite principle. But to form so vast a range of being, and to make being everywhere a source of gratification, is conformable to our ideas of a Creator, in whom we are constantly discovering traits of a nature, of which our own is a faint and far-cast shadow.

It appears at first difficult to reconcile with this idea the many miseries which we see all sentient beings, ourselves included, occasionally enduring. How, the sage has asked in every age, should a Being so transcendently kind, have allowed of so large an admixture of evil in the condition of his creatures? Do we not at length find an answer to a certain extent satisfactory, in the view which has now been given of the constitution of nature? We there see the Deity operating in the most august of his works by fixed laws, an arrangement which, it is clear, only admits of the main and primary results being good, but disregards exceptions. Now the mechanical laws are so definite in their purposes, that no exceptions ever take place in that department; if there is a certain quantity of fluid matter to be agglomerated and divided and set in motion as a planetary system, it will be so with hair'sbreadth accuracy, and cannot be otherwise. But the laws presiding over meteorology, life, and mind, are necessarily less definite, as they have to produce a great variety of mutually-related results. Left to act independently of each other, each according to its separate 
commission, and each with a wide range of potentiality to be modified by associated conditions, they can only have effects generally beneficial. Often there must be an interference of one law with another; often a law will chance to operate in excess, or upon a wrong object, and thus evil will be produced. Thus, winds are generally useful in many ways, and the sea is useful as a means of communication between one country and another; but the natural laws which produce winds are of indefinite range of action, and sometimes are unusually concentrated in space or in time, so as to produce storms and hurricanes, by which much damage is done; the sea may be by these causes violently agitated, so that many barks and many lives perish. Here, it is evident, the evil is only exceptive. Suppose, again, that a boy, in the course of the lively sports proper to his age, suffers a fall which injures his spine, and renders him a cripple for life. Two things have been concerned in the case : first, the love of violent exercise, and second, the law of gravitation. Both of these things are good in the main. Boys, in the rash enterprises and rough sports in which they engage, are only making the first delightful trials of a bodily and mental energy which has been bestowed upon them as necessary for their figuring properly in a scene where many energies are called for, and where the exertion of these powers is ever a source of happiness. By gravitation, all moveable things, our own bodies included, are kept stable on the surface of the earth. But when it chances that the playful boy loses his hold (we shall say) of the branch of a tree, and has no solid support immediately below, the law of gravitation unre- 
lentingly pulls him to the ground, and thus he is hurt. Now it was not a primary object of gravitation to injure boys; but gravitation could not but operate in the circumstances, its nature being to be universal and invariable. The evil is, therefore, only a casual exception from something in the main good.

The same explanation applies to even the most conspicuous of the evils which afflict society. War, it may be said, and said truly, is a tremendous example of evil, in the misery, hardship, waste of human life, and misspending of human energies, which it occasions. But what is it that produces war? Certain tendencies of human nature; as keen assertion of a supposed right, resentment of supposed injury, acquisitiveness, desire of admiration, combativeness, or mere love of excitement. All of these are tendencies which every day, in a legitimate extent of action, produce great and indispensable benefits to us. Man would be a tame, indolent, unserviceable being without them, and his fate would be starvation. War, then, huge evil though it be, is, after all, but the exceptive case, a casual misdirection of properties and powers essentially good. God has given us the tendencies for a benevolent purpose. He has only not laid down any absolute obstruction to our misuse of them. That were an arrangement of a kind which he has nowhere made. But he has established many laws in our nature which tend to lessen the frequency and destructiveness of these abuses. Our reason comes to see that war is purely an evil, even to the conqueror. Benevolence interposes to make its ravages less mischievous to human comfort, and less destructive to human life. Men begin 
to find that their more active powers can be exercised with equal gratification on legitimate objects; for example, in overcoming the natural difficulties of their path through life, or in a generous spirit of emulation in a line of duty beneficial to themselves and their fellow-creatures. Thus, war at length shrinks into a comparatively narrow compass, though there certainly is no reason to suppose that it will be at any early period, if ever, altogether dispensed with, while man's constitution remains as it is. In considering an evil of this kind, we must not limit our view to our own or any past time. Placed upon the earth with faculties prepared to act, but inexperienced, and with the more active propensities necessarily in great force to suit the condition of the globe, man was apt to misuse his powers much in this way at first, compared with what he is likely to do when he advances into a condition of civilization. In the scheme of Providence, thousands of years of frequent warfare, all the so-called glories which fill history, may be but a subordinate consideration. The chronology of God is not as our chronology. See the patience of waiting evinced in the slow development of the animated kingdoms, throughout the long series of geological ages. Nothing is it to him that an entire goodly planet should, for an inconceivable period, have no inhabiting organisms superior to reptiles. Progressive, not instant effect, is his sublime rule. What, then, can it be to him that the human race goes through a career of impulsive acting for a few thousand years? The cruelties of ungoverned anger, the tyrannies of the rude and proud over the humble and good, the martyr's pains, and the vatriot's despair, what are all these but incidents of an 
evolution of superior being which has been pre-arranged and set forward in independent action, free within a certain limit, but in the main constrained, through primordial law, to go on ever brightening and perfecting, yet never, while the present dispensation of nature shall last, to be quite perfect!

The sex passion in like manner leads to great evils. Providence has seen it necessary to make very ample provision for the preservation and utmost possible extension of all species. The aim seems to be to diffuse existence as widely as possible, to fill up every vacant piece of space with some sentient being to be a vehicle of enjoyment. Hence this passion is conferred in great force. But the relation between the number of beings, and the means of supporting them, is only on the footing of general law. There may be occasional discrepancies between the laws operating for the multiplication of individuals, and the laws operating to supply them with the means of subsistence, and evils will be endured in consequence, even in our own highly favoured species. But against all these evils, and against those numberless vexations which have arisen in all ages from the attachment of the sexes, place the vast amount of happiness which is derived from this source-the basis of the whole circle of the domestic affections, the sweetening principle of life, the prompter of all our most generous feelings, and even of our most virtuous resolves and exertionsand every ill that can be traced to it is but as dust in the balance. And here, also, we must be on our guard against judging from what we see in the world at a particular era. As reason and the higher sentiments of 
man's nature increase in force, this passion is put under better regulation, so as to lessen many of the evils connected with it. The civilized man is more able to give it due control; his attachments are less the result of impulse: he studies more the weal of his partner and offspring. There are even some of the resentful feelings connected in early society with love, such as hatred of successful rivalry, and jealousy, which almost disappear in an advanced state of civilization. The evil springing, in our own species at least, from this passion, may therefore be an exception mainly peculiar to a particular term of the world's progress, and which may be expected to decrease greatly in amount.

With respect, again, to disease, so prolific a cause of suffering to man, the human constitution is merely a complicated but regular process in electro-chemistry, which goes well, and is a source of continual gratification, so long as nothing occurs to interfere with it injuriously, but which is liable every moment to be deranged by various external agencies, when it becomes a source of pain, and, if the injury be severe, ceases to be capable of retaining life. It may be readily admitted that the evils experienced in this way are very great; but, after all, such experiences are no more than occasional, and not necessarily frequent-exceptions from a general rule of which the direct action is to confer happiness. The human constitution might have been made of a more hardy character; but we always see hardiness and insensibility go together, and it may be of course presumed that we only could have purchased this immunity from suffering at the expense of a large portion of that delicacy 
in which lie some of our most agreeable sensations. Or man's faculties might have been restricted to definitiveness of action, as is greatly the case with those of the lower animals, and thus we should have been equally safe from the aberrations which lead to disease; but in that event we should have been incapable of acting to so many different purposes as we are, and of the many high enjoyments which the varied action of our faculties places in our power; we should not, in short, have been human beings, but merely on a level with the inferior animals. Thus, it appears, that the very fineness of man's constitution, that which places him in such a high relation to the mundane economy, and makes him the vehicle of so many exquisitely delightful sensations-it is this which makes him liable to the sufferings of disease. It might be said, on the other hand, that the noxiousness of the agencies producing disease might have been diminished or extinguished; but the probability is, that this could not have been done without such a derangement of the whole economy of nature as would have been attended with more serious evils. For example--a large class of diseases are the result of effluvia from decaying organic matter. This kind of matter is known to be extremely useful when mixed with earth in favouring the process of vegetation. Supposing the noxiousness to the human constitution done away with, might we not also lose that important quality which tends so largely to increase the food raised from the ground? Perhaps (as has been somewhere suggested) the noxiousness is even a matter of special design, to induce us to put away decaying organic substances into the earth, where they 
are calculated to be so useful. Now man has reason to enable him to see that such substances are beneficial under one arrangement, and noxious in the other. He is, as it were, commanded to take the right method in dealing with them. In point of fact, men do not always take this method, but allow accumulations of noxious matter to gather close about their dwellings, where they generate fevers and agues. But their doing so may be regarded as only a temporary exception from the operation of mental laws, the general tendency of which is to make men adopt the proper measures. And these measures will probably be in time universally adopted, so that one extensive class of diseases will be altogether or nearly abolished.

Another large class of diseases spring from mismanagement of our personal economy. Eating to excess, eating and drinking what is noxious, disregard to that cleanliness which is necessary for the right action of the functions of the skin, want of fresh air for the supply of the lungs, undue, excessive, and irregular indulgence of the mental affections, are all of them recognised modes of creating that derangement of the system in which disease consists. Here also it may be said that a limitation of the mental faculties to definite manifestations (vulgo, instincts) might have enabled us to avoid many of these errors; but here again we are met by the consideration that, if we had been so endowed, we should have been only as the lower animals are,wanting that transcendently higher character of sensation and power, by which our enjoyments are made so much greater. In making the desire of food, for example, with 
us an indefinite mental manifestation, instead of the definite one which it mainly is amongst the lower animals, the Creator has given us a means of deriving far greater gratifications from food (consistently with health) than the lower animals generally appear to be capable of. He has also given us reason to act as a guiding and controlling power over this and other propensities, so that they may be prevented from becoming causes of malady. We can see that excess is injurious, and are thus prompted to moderation. We can see that all the things which we feel inclined to take are not healthful, and are thus exhorted to avoid what are pernicious. We can also see that a cleanly skin and a constant supply of pure air are necessary to the proper performance of some of the most important of the organic functions, and thus are stimulated to frequent ablution, and to a right ventilation of our parlours and sleeping apartments. And so on with the other causes of disease. Reason may not operate very powerfully to these purposes in an early state of society, and prodigious evils may therefore have been endured from diseases in past ages; but these are not necessarily to be endured always. As civilization advances, reason acquires a greater ascendancy; the causes of the evils are seen and avoided; and disease shrinks into a comparatively narrow compass. The experience of our own country places this in a striking light. In the middle ages, when large towns had no police regulations, society was at frequent intervals scourged by pestilence. The third part of the people of Europe are said to have been carried off by one epidemic. In London, in 1685 , one in twenty-three died annually, a proportion which has since sunk to one in 
forty. The improvement of human life during the last two ages is shown in a comparison of the Northampton tables of mortality compiled by Dr. Price, with those prepared a few years ago by Mr. Finlayson. Modern tables still show a prodigious mortality among the young in all civilized countries-evidently a result of some prevalent error in the usual modes of rearing them. But to remedy this evil there is a sagacity of the human mind, and the desire to adopt any reformed plans which may be shown to be necessary. By a change in the management of an orphan institution in London, during the last fifty years, an immense reduction in the mortality took place. We may of course hope to see measures devised and adopted for producing a similar improvement of infant life throughout the world at large.

In this part of our subject, the most difficult point certainly lies in those occurrences of disease where the afflicted individual has been in no degree concerned in bringing the visitation upon himself. Daily experience shows us infectious disease arising in a place where the natural laws in respect of cleanliness are neglected, and then spreading into regions where there is no blame of this kind. We then see the innocent suffering equally with those who may be called the guilty. Nay, the benevolent physician who comes to succour the miserable beings whose error may have caused the mischief, is sometimes seen to fall a victim to it, while many of his patients recover. We are also only too familiar with the transmission of diseases from erring parents to innocent children, who accordingly suffer, and perhaps die prematurely, as it were for the sins of others. After all, how- 
ever painful such cases may be in contemplation, they cannot be regarded in any other light than as exceptions from arrangements, the general working of which is beneficial.

With regard to the innocence of the suffering parties, there is one important consideration which is pressed upon us from many quarters-namely, that moral conditions have not the least concern in the working of the physical laws. These arrangements proceed with an entire independence of all such conditions, and desirably so, for otherwise there could be no certain dependence placed upon them. Thus it may happen that of two persons ascending a piece of scaffolding, the one a virtuous, the other a vicious man, the former, being the less cautious of the two, ventures upon an insecure place, falls, and is killed, while the other, choosing a better footing, remains uninjured. It is not in what we can conceive of the nature of things, that there should be a special exemption from the ordinary laws of matter, to save this virtuous man. So it might be that of two physicians, attending fever cases in a mean part of a large city, the one, an excellent citizen, may stand in such a position with respect to the beds of the patients as to catch the infection, of which he dies in a few days, while the other, a bad husband and father, and who, unlike the former, only attends such cases with selfish ends, takes care to be as much as possible out of the stream of infection, and accordingly escapes. In both of these cases man's sense of good and evil- his faculty of conscientiousnesswould incline him to destine the vicious man to destruction and save the virtuous. But the Great Ruler of 
Nature does not act on such principles. He has established laws for the operation of inanimate matter, which are quite unswerving, so that when we know them, we have only to act in a certain way with respect to them, in order to obtain all the benefits and avoid all the evils connected with them. He has likewise established moral laws in our nature, which are equally unswerving, (allowing for their wider range of action, ) and from obedience to which unfailing good is to be derived. But the two sets of laws are independent of each other. Obedience to each gives only its own proper advantage, not the advantage proper to the other. Hence it is that virtue forms no jrotection against the evils connected with the physicai laws, while, on the other hand, a man skilled in, and attentive to these, but unrighteous, and disregardful of his neighbour, is in like manner not protected by his attention to physical circumstances from the proper consequences of neglect or breach of the moral laws.

Thus it is that the innocence of the party suffering for the faults of a parent, or of any other person or set of persons, is evidently a consideration quite apart from that suffering.

In short, the whole question of evil, a puzzle throughout all ages, only becomes explicable when we receive and study the system of a mundane government in the manner of law. There is no need for considering it as a detraction from either the power or the goodness of God. The dispensation under which we live has been constituted by him on the principle of law; but this is not necessarily to imply that either his goodness or his powe1 
is to stop at this point. That such, however, is the character of the pageantry of worldly events now passing, is the only idea we can arrive at when we approach the question without prejudice. How else should it be that in any case the guilty flourish and the innocent suffer? How else should it be that men often endure bitter woe and pain while prosecuting the noblest objects? How else should we ever see so simple an event as the following, which meets my eyes in the journals, while these sheets pass through the press :-A multitude of poor Irish emigrants are embarked in a canal boat, about to leave their native district for a port whence they are to sail for America. At the moment of parting, they crowd to one side, to shake hands for the last time with their friends. The vessel is over-balanced and turned upon its side. Of the multitude thrown into the water, seven are taken up dead. Here an action rather amiable and laudable than otherwise, leads to the loss of life,-a pure evil, unmixed with good. It is impossible to imagine such a transaction occurring under the immediate direction of the Deity; it would be profaning human nature to attribute any such act to the immediate command or interference of a man. But there is no difficulty in understanding how such occasional evils should take place in the course of a chain of causes which only proceed in consequence of a general impulse designed in the main for good.

Evil, indeed, is one of the strongest proofs that could be desired for the reality of this system. We see it in one of its most familiar forms in the destructive animals. An innocent little bird in the claws of the 
cruel hawk-a poor stag grasped by the ruthless boaa lamb in the fangs of the wolf-can we imagine a form of misery greater than is exhibited in these animals? Yet millions of such creatures perish in this manner annually, and have so done since long before there existed a human heart to pine or break with its more sentimental, but not less real wretchedness. Upon no theory can this be understood except upon that of an economy governed by general laws. The carnivorous animals are simply the police and undertakers of the inferior creation, preventing their too great increase, and clearing off all such as grow weakly and die, ere they can become in any degree a burden to themselves or a nuisance to other creatures. For these functions the destructive tribes have been expressly organized, and their organization of course is of divine appointment. Constituted as we are, we cannot suppose a plan involving so much suffering to have been adopted except with a view to that independency, or completeness within itself, which is here argued for as the manner in which the Deity's operations on earth are revealed to us. He has endowed the families which enjoy his bounties with an almost indefinite fecundity, that enjoyment may be as widely diffused as possible; but the limitation of the results of this fecundity within the line necessary according to circumstances, were no right immediate employment for himself. The object is accomplished, in a befitting manner, by his ordaining that certain other animals shall have endowments sure so to act as to bring the rest of animated beings to a proper balance. And the object is accomplished well; insomuch that we never hear of any 
but the most partial and transient discrepancy between the volume of inferior animal life and the power appointed for its regulation. Even in this sad chapter of nature, we are forced to acknowledge that, upon the theory of a divine action in the manner of law, everything is very good.

- Nor are any of the ordinary evils of our world altogether unmixed. God, contemplating apparently the unbending action of his great laws, has established others which appear to be designed to have a compensating, a repairing, and a consoling effect. Suppose, for instance, that, from a defect in the power of development in a mother, her offspring is ushered into the world destitute of some of the most useful members, or blind, or deaf, or of imperfect intellect, there is ever to be found in the parents and other relatives, and in the surrounding public, a sympathy with the sufferer, which tends to make up the deficiency, so that he usually is in the long run not much a loser. Indeed, the benevolence implanted in our nature seems to be an arrangement having for one of its principal objects to cause us, by sympathy and active aid, to remedy the evils unavoidably suffered by our fellowcreatures in the course of the operation of the other natural laws. And even in the sufferer himself, it is often found that a defect in one point is made up for by an extra power in another. The blind come to have a sense of touch much more acute than those who see. Persons born without hands have been known to acquire a power of using their feet for a number of the principal offices usually served by those members. I need hardly say how remarkably fatuity is compensated by the more than 
usual regard paid to the children born with it by their parents, and the zeal which others usually feel to protect and succour such persons. In short, we never see evil of any kind take place, where there is not some remedy or compensating principle ready to interfere for its alleviation. And there can be no doubt that in this manner suffering of all kinds is very much relieved.

We may, then, regard the globes of space as theatres designed for the residence of animated sentient beings, placed there with this as their first and most obvious purpose-to be sensible of enjoyments from the exercise of their faculties in relation to external things. The faculties of the various species are very different, but the happiness of each depends on the harmony there may be between its particular faculties and its particular circumstances. For instance, place the small-brained sheep or ox in a good pasture, and it fully enjoys this harmony of relation; but man, having many more faculties, cannot be thus contented. Besides having a sufficiency of food and bodily comfort, he must have entertainment for his intellect, whatever be its grade, objects for the domestic and social affections, objects for the sentiments. $\mathrm{He}$ is also a progressive being, and what pleases him to-day may not please him to-morrow; but in each case he demands a sphere of appropriate conditions in order to be happy. By virtue of his superior organization, his enjoyments are much higher and more varied than those of any of the lower animals; but the very complexity of circumstances affecting him renders it at the same time unavoidable, that his nature should be often inharmoniously placed and disagreeably affected, and that he 
should therefore be unhappy. Still, unhappiness amongst mankind is the exception from the rule of their condition, and an exception which is capable of almost infinite diminution by virtue of the improving reason of man, and the experience which he acquires in working out the problems of society.

To secure the immediate means of happiness, it would seem to be necessary for men first to study with all care the constitution of nature ; and, secondly, to accommodate themselves to that constitution, so as to obtain all the realizable advantages from acting conformably to it, and to avoid all likely evils from disregarding it. It will be of no use to sit down and expect that things are to operate of their own accord, or through the direction of a partial deity, for our benefit; equally so were it to expose ourselves to palpable dangers, under the notion that we shall, for some reason, have a dispensation or exemption from them: we must endeavour so to place ourselves, and so to act, that the arrangements which Providence has made impartially for all may be in our favour, and not against us; such are the only means by which we can obtain good and avoid evil here below. ${ }^{1}$ And, in doing this, it is especially necessary that care be taken to avoid interfering with the like efforts of other men, beyond what may have been agreed upon by the mass as necessary for the general good. Such interferences, tending in any way to injure the body, property, or peace of a neighbour, or to the injury of society in

1 The doctrine of the natural laws as affecting human welfare is clearly and satisfactorily explained in Mr. Combe's Essay on the Constitution of Man, to which and to the excellent works of Dr. Andrew Combe, may be ascribed no small share of that public movement towards improved sanitary regulations which is one of the most gratifying features of our age. 
general, tend to reflect evil upon ourselves through the re-action which they produce in the feelings of our neighbour and of society, and also the offence which they give to our own conscientiousness and benevolence. On the other hand, when we endeavour to promote the efforts of our fellow-creatures to attain happiness, we produce a re-action of the contrary kind, the tendency of which is towards our own benefit. 'The one course of action tends to the injury, the other to the benefit, of ourselves and others. By the one course, the general design of the Creator towards his creatures is thwarted; by the other it is favoured. And thus we can readily see the most substantial grounds for regarding all moral emotions and doings as divine in their nature, and as a means of rising to and communing with God. Obedience is not selfishness, which it would otherwise be-it is worship. The merest barbarians have a glimmering sense of this philosophy, and it continually shines out more and more clearly as men advance in intelligence. Nor are individuals alone concerned here. The same rule applies as between one great body or class of men and another, and also between nations. Thus, if one set of men keep others in the condition of slavesthis being a gross injustice to the subjected party, the mental manifestations of that party to the masters will be such as to mar the comfort of their lives; the minds of the masters themselves will be degraded by the association with beings so degraded; and thus, with some immediate or apparent benefit from keeping slaves, there will be, in a far greater degree, an experience of evil. So also, if one portion of a nation, engaged 
in a particular department of industry, grasp at some advantages injurious to the other sections of the people, the first effect will be an injury to those other portions of the nation, and the second a re-active injury to the injurers, making their guilt their punishment. And so when one nation commits an aggression upon the property or rights of another, or even pursues towards it a sordid or ungracious policy, the effects are sure to be redoubled evil from the offended party. All of these things are under laws which make the effects, on a large range, absolutely certain; and an individual, a party, a people, can no more act unjustly with safety, than I could with safety place my leg in the track of a coming wain, or attempt to fast thirty days. We have been constituted on the principle of only being able to realize happiness for ourselves when our fellow-creatures are also happy; it is therefore necessary that we both do to others only as we would have others to do to us, and endeavour to promote their happiness as well as our own. There is even a higher law, which has long been announced, but never acted on to any considerable extent, that our greatest happiness is not to be realized by each having a regard for himself, but by each seeking primarily to benefit his fellow-creatures. When man comes to have confidence in his own nature, he will begin to act on this principle, and the result will be a degree of happiness such as we only see at present faintly shadowed forth in the purest and sweetest charities of family life-a happiness from which there will be no class exceptions.

The question whether the human race will ever advance 
far beyond its present position in intellect and morals, is one which has engaged much attention. Judging from the past, we cannot reasonably doubt that great advances are yet to be made; but if the principle of development be admitted, these are certain, whatever may be the space of time required for their realization. A progression resembling development may be traced in human nature, both in the individual and in large groups of men. The individual is in childhood under the influence of the propensities and instinctive aptitudes; in youth, he is swayed by marvellousness, the love of the beautiful, the imagination: in full maturity, he passes under (comparatively) the domination of reason. In perfect analogy, a nation is at first impulsive and unreasoning; afterwards it is conducted by the second class of sentiments (the age of mythologies, hierocracies, man and idea worships); finally, its institutions approximate to careful regard for what is convenient and profitable, under the control of justice and humanity. The advance of knowledge favours the progress of the moral conditions, and in improved moral conditions knowledge becomes more sound. In tolerably favourable circumstances, this tendency onward never fails to make itself visible; and it is evident that, though many nations seem nearly stationary, and others appear to retrograde, there is always a progress in some place, so that no long space of time ever elapses without showing, upon the whole, a certain advance. By the work of our thoughtful brains and busy hands, we modify external nature in a way never known before. Under the operations of tillage, of mechanism, of building, making, and inventing; of those applications of natural powers and 
forces which human wit turns to account in so many ways; of all the results of social experience, of knowledge, and of arrangement; the earth tends to become a much serener field of existence than it was in the earlier ages of man's history. Its progress in this respect may not be clearly seen at a particular time, through the obscuring effect of temporary and accidental causes; but that the tendency of the physical improvements wrought by man upon the surface, and of the mechanic movements which he invents for the saving of his own labour, is to improve the daily comforts, and allow room for the intellectual and moral advancement of earth's children, cannot be denied without something like flying in the face of Providence itself. These improvements, then, thus partly wrought out by the exertions of the present race, I conceive as at once preparations for, and causes of, the possible development of higher types of humanity,-beings less strong in the impulsive parts of our nature, physical nature giving less matter for that nature to contend with and subdue to its needs,-more strong in the reasoning and the moral, because there will be less of the opposite to give these marring or check,-more fitted for the delights of social life, because society will then present less to dread and more to love.

The history and constitution of the world have now been hypothetically explained, according to the best lights which a humble individual has found within the reach of his perceptive and reasoning faculties. We have seen a system in which all is regularity and order, and all flows from, and is obedient to, a divine code of laws of unbending operation. We are to understand from what 
has been laid before us, that man, with his varied mental powers and impulses, is a natural problem, of which the elements can be taken cognizance of by science, and that all the secular destinies of our race, from generation to generation, are but evolutions of a law statuted and sustained in action by an All-wise Deity. To some, before just reflection, it appears as a dreary view of the divine economy of our world, as if it placed God at an immeasurable distance from his creatures, and left them without refuge or remedy from the numberless ills that "flesh is heir to," and which no one can hope altogether to escape. But in reality, God may be presumed to be revealed to us in every one of the phenomena of the system, in the suspension of globes in space, in the degradation of rocks and the upthrowing of mountains, in the development of plants and animals, in each movement of our minds, and in all that we enjoy and suffer, seeing that, the system requiring a sustainer as well as an originator, $\mathrm{He}$ must be continually present in every part of it, albeit $\mathrm{He}$ does not permit a single law to swerve in any case from its appointed course of operation. Thus we may still feel that $\mathrm{He}$ is the immediate breather of our life and ruler of our spirits, that we may, by rightly directed thought, come into communion with him, and feel that, even when his penal ordinances are enforced upon us, his hand and arm are closely about us. Nor is this all. It may be that, while we are committed to take our chance in a natural system of undeviating operation, and are left, with apparent ruthlessness, to endure the consequences of every collision into which we knowingly or unknowingly come with each of its regulations, there 
is a system of mercy and grace behind the screen of nature, towards which we stand in a peculiar class of relations, which is capable of compensating for all casualties endured here, and whose very largeness is what makes these casualties a matter of indifference to God. For the existence of such a system, the actual constitution of nature is indeed a powerful argument. The reasoning may proceed thus:- the system of nature assures us that benevolence is a leading principle in the Divine Mind. But that system is at the same time deficient in a means of making this benevolence of invariable operation. To reconcile this to the character of the Deity, it is necessary to suppose that the present system is but a part of the whole, a stage in a Great Progress, and that the Redress is in reserve. Another argument here occursthe economy of nature, beautifully arranged, and vast in extent as it is, does not satisfy even man's idea of what might be; he feels that, if this multiplicity of theatres for the exemplification of such phenomena as we see on earth were to go on for ever unchanged, it would not be worthy of the Being capable of creating it. An endless monotony of human generations, with their humble thinkings and doings, even though liable to a certain improvement, seems an object beneath that august Being. But the mundane economy might be very well as a portion of some greater phenomenon, the rest of which was yet to be evolved. Our system, therefore, though it may at first appear at issue with other doctrines in esteem amongst mankind, tends to come into harmony with them, and even to give them support. I would say, in conclusion, that, even where the two above arguments may fail of $\mathrm{B} B$ 
effect, there may yet be a faith derived from this view of nature sufficient to sustain us under all sense of the imperfect happiness, the calamities, the woes, and pains of this sphere of being. For let us but fully and truly consider what a system is here laid open to view, and we cannot well doubt that we are in the hands of One who is both able and willing to do us the most entire justice. Surely in such a faith we may well rest at ease, even though life should have been to us but a protracted malady, or though every hope we had built on the secular materials within our reach were felt to be melting from our grasp. Thinking of all the contingencies of this world as to be in time melted into or lost in some greater system, to which the present is only subsidiary, let us wait the end with patience and be of good cheer. 
PROOFS, ILLUSTRATIONS, AUTHORITIES,

ETC. 



\section{PROOFS, ILLUSTRATIONS, AUTHORITIES,}

ETC.

THE scientific facts on which this work is founded, and many of the ideas and phrases of the author, having been for controversial purposes contradicted and misrepresented, he has been induced to set all these matters in a clear light by quotations from the writings of reputable naturalists and others, so that they may nolonger be the subject of doubt among unlearned readers. It is scarcely necessary to say that the number of authorities could easily have been extended; but the author has been content to limit himself to pronouncements which chance to be given forth in brief forms and popularly intelligible language. He has also been induced to enter into a discussion of the arguments of some of his more noted opponents, with a view to expose the singularly hollow and fallacious grounds on which these are for the most part based.

\section{NATURAL LAW.}

On the subject of natural law, the following extracts will probably help to dispel certain prejudices which have been formed with regard to the conclusions aimed at in the present work:-

"The order we see, not only implies intelligence in its first conception, but power by its continued existence; or, in other words, it is the same being who enacts and executes the law." Dugald Stewart.

"There is a mistake concerning the idea which the term law expresses in physics, wherever such an idea is made to take the 
place of power, and still more of an intelligent power, and as such to be assigned for the cause of anything, or of any property of anything, that exists. . . . A law presupposes an agent, for it is only the mode according to which an agent proceeds; it implies a power, for it is the order according to which that power acts. Without this agent, this power, which are both distinct from itself, the law does nothing, is nothing."-Paley.

"When we assert a perpetual divine agency, we readily acknowledge that matters are so contrived as not to need a divine interposition in a different manner from that in which it had been constantly exerted. And it is most evident that an unremitting energy displayed in such circumstance, greatly exalts our idea of God, instead of depressing it; and therefore, by the way, is so much the more likely to be true." -Doddridge.

"The term law expresses the conditions of action of the properties of matter. The Divine Creator of the universe 'has, by creating his materials, endued with certain fixed qualities and powers, impressed them in their origin with the spirit, not the letter of his law, and made all their subsequent combinations and relations inevitable consequences of this first impression.' [Herschel's Preliminary Dis. course.] In our study of the phenomena of nature, it is our object to ascertain their laws by the inquiry into the conditions under which the occurrences present themselves; and a law deduced from this source is nothing more than a general expression of the conditions common to a certain class of phenomena, leading us to the belief that, under the same conditions, the same phenomena will constantly occur." $-W . B$. Carpenter.

"Our belief in the uniformity of nature, which leads us to seek for a common cause when a number of similar phenomena are presented to our observation, is based, not only on experience, but upon the conviction which every believer in the existence of the Deity feels of this immutability. If it were otherwise, we should be led by analogy only to infer the existence of law and order where none is evident; but the mind which is once satisfied of the existence of a Creator, possesses a moral certainty that to Him must belong a consummate wisdom which shall contrive the attainment of every end by the best adapted means, -an omnipotence which shall have 
all the means at full command,--and an omniscience which shall foresee in every action, not only its immediate, but its remotest consequences. To imagine, therefore, that the plan of the universe, once established with a definite end, could require alteration during the continuance of its existence, is at once to deny the perfection of the Divine attributes; whilst, on the other hand, to suppose, as some have done, that the properties first impressed upon matter could of themselves continue its actions, is to deny all that revelation teaches us regarding our continued dependence on the Creator. Let it be borne in mind, then, that when a law of physics or of vitality is mentioned, nothing more is really implied than a single expression of the mode in which the Creator is constantly operating on inorganic matter, or on organized structures."-Ibid.

\section{THE LAPLACIAN COSMOGONY.}

"There is a great difference between inventing laws of nature to account for classes of phenomena, and merely endeavouring, in conformity with known laws, to conjecture what collocations, now gone by, may have given birth to individual facts still in existence. The latter is the strictly legitimate operation of inferring from an observed effect, the existence, in time past, of a cause similar to that by which we know it to be produced in all cases in which we have actual experience of its origin. This, for example, is the scope of the inquiries of geology; and they are no more illogical or visionary than judicial inquiries, which also aim at discovering a past event by inference from those effects which still subsist. . . . We can conclude that a man was murdered, although it is not proved by the testimony of eye-witnesses, that a man who had the intention of murdering him was present on the spot. It is enough if no other known cause could have generated the effects known to have been produced. . . . The celebrated speculation of Laplace, now very generally received as probable by astronomers, concerning the origin of the earth and planets, participates essentially in the strictly inductive character of modern geological theory. . . . . The known laws of matter authorise us to suppose that a body which is constantly giving out so large an amount of heat as the sun is, must 
be progressively cooling, and that by the process of cooling it must contract ; if, therefore, we endeavour, from the present state of that luminary, to infer its state in a time long past, we must necessarily suppose that it extended as far as we can trace those effects which it would naturally leave behind on retiring; and such the planets are. These suppositions being made, it follows from known laws that successive zones of the solar atmosphere would be abandoned; that these would continue to revolve round the sun with the same velocity as when they formed part of his substance; and that they would cool down, long before the sun himself, to any given temperature, and consequently to that at which the greater part of the vaporous matter of which they consisted would become liquid or solid. The known law of gravitation would then cause them to agglomerate in masses, which would assume the shape our planets actually exhibit; would acquire, each round its own axis, a rotatory movement; and would in that state revolve, as the planets actually do, about the sun, in the same direction with the sun's rotation, but with less velocity, and each of them in the same periodic time which the sun's rotation occupied when his atmosphere extended to that point; and this also M. Comte has, by the necessary calculations, ascertained to be true, within certain small limits of error. There is thus, in Laplace's theory, nothing hypothetical: it is an example of legitimate reasoning from a present effect to its past cause, according to the known laws of that cause; it assumes nothing more than that objects which really exist, obey the laws which are known to be obeyed by all terrestrial objects resembling them." -J. S. Mill: System of Logic.

3. THERE WAS DRY LAND LONG BEFORE THE OCCURRENCE OF THE FIRST FOSSILS OF LAND PLANTS AND ANIMALS.

"So far as we can ascertain, the depths of the ocean are the spots where rocks are deposited and formed, whilst the dry land and the sea-shore are the places where they are destroyed and wasted away. There is not any known process now acting, by which the rocks existing in the depths of the ocean could be disintegrated and their detritus formed again into new rocks. Any ancient sedimentary 
deposit therefore implies not only the existence of a sea in which its materials were deposited, but of a land from which they were derived, and rivers and currents by which they were carried down to that sea and spread out over its channel."-Professor Nicol, of Cork, Quarterly Journal Geological Society, Aug., I848.

Professor Ramsay and Mr. Aveline, of the Geological Survey, "infer from the unconformability of the Caradoc and Wenlock deposits, in connexion with the old coast-line of the Longmynds and Bishop's Castle series, that both at Builth and Bishop's Castle, the older rocks rose above the level of the sea at the time when the Caradoc sandstone was formed, this land becoming gradually depressed during the deposit of the Wenlock and Ludlow rocks. Thus this dry land became covered by thousands of feet of sands and mud mingled with remains of marine animals."-President's (De la Beche) Address to Geol. Soc., I 849.

4. THERE ARE SPECIES COMMON TO DIFFERENT FORMATIONS, AND AN UNBROKEN SUCCESSION OF ANIMAL LIFE FROM THE BEGINNING TO THE PRESENT EPOCH.

"There can be no doubt that fossil species pass from one formation into another, from one period into the next. . . . No further proof of this need be required, than that the most experienced zoologists and botanists, and even the most decided opponents of this view, Agassiz and D'Orbigny, after examining the original specimens adduced in proof, have themselves unconditionally admitted it. . . . Almost every one knows certain forms of Terebratula biplicata from the oolite and the chalk, which cannot be distinguished from each other in any constant manner. Edward Forbes declares expressly that he has found the Terebratula caput-serpentis of the white chall, of the upper tertiary strata, and of the present seas; and the Echino. cyamus pusillus in the eocene, miocene, pliocene strata, and living, perfectly identical. Ehrenberg mentions-even after the exclusion of all the tertiary strata erroneously joined to the chalk-a still very considerable number of infusoria and foramenifera as occurring in the chalk, in the tertiary formations, and living ; and D'Orbigny, in 
agreement with this, declares that he cannot distinguish the Dentalina communis and Rotalina zmbilicata of the Paris white chalk, either from the tertiary or from the living species of the Mediterranean; and in regard to the latter especially, that after the most minute comparison he cannot find any distinction. He himself quotes five cephalopods and three foramenifera in the green sand (gault) and in the chalk. Agassiz himself cites Lamma elegans in calcaire grossier, Middle Tertiary, Molasse, and Upper Tertiary, and Cytherea leonina in the Middle Tertiary and Molasse. That a great number of tertiary specimens pass into the present creation, is not only admitted by all palæontologists, with two or three exceptions, but has also been specially proved by us in our review of Agassiz's memoir, 'Sur les especes reputées identiques ;' and among other things, by showing partly that the specific distinctions which Agassiz adduced between specimens of certain species from the two positions, and partly that the identity of geological position which he assumed for the genuine Cyprina Islandica in Sicily as quaternary instead of tertiary, did not exist. . . . R. Owen has recognised, in the English (newer pliocene) tertiary strata, forty species of mammalia, thirty of which still exist."-Bronn on Palcontological Statics, translated in Quar. Jour. G. S. Nov. I 849 .

Dr. Mantell concludes "that throughout all geological time the changes on the earth's surface, and the appearance and extinction of peculiar types of animals and plants have been governed by the same physical and organic laws; that the paroxysmal terrestrial disturbances, though apparently in the earlier ages involving larger areas, and operating with greater energy than the volcanic and the subterranean action of modern times, did not affect the established order of organic life upon the surface of the globe, and that, throughout the innumerable ages indicated by the sedimentary formations, there was at no period a greater anomaly in the assemblage of certain types of the animal and vegetable kingdoms than exists at the present time."-President's (De la Beche) Address, 1848.

"Mr. Davidson communicated [to the Geological Society of France] a detailed memoir of the Brachiopods of the Upper Silurian System of England, the result of his labours in the districts where these rocks are found, and among local collections. He considers it as now 
recognised that many species have lived through the Silurian system, and have even been perpetuated beyond it. . . . Respecting generic distinctions, Mr. Davidson observes as probable, that as we advance, and lacunes are filled up, distinctions will become more and more arbitrary . . . genera approximating to each other by a multitude of intermediate species, some possessing the external forms of one genus with certain internal characters of another, so that there is much difficulty in assigning them their true place."-President's (De la Beche) Address, 1849.

On the skirts of the Venetian Alps are equivalents of the cretaceous series of our country, graduating upward into "nummulitic accumulations," which Sir R. Murchison refers to the age of the lowest tertiary or eocene rocks. Two or three species of Gryphæa are common to the rocks equivalent to the cretaceous series and the nummulitic accumulations, thus, zoologically connecting the secondary with the tertiary formations.

"From the accidental circumstance of the tertiary rocks having been made known to us by the labours of such men as Cuvier and Brongniart, working around such a seat of science as Paris, a desire to perpetuate very marked distinctions between the cretaceous and supra-cretaceous accumulations has not unnaturally been experienced." A reluctance has been long experienced "at considering the accumu. lations of mud, sand, gravel, calcareous, or other matter, of the one time as a mere sequence of those of the other, and the breaks in this sequence in particular areas as no more than other breaks in the general deposits of other geological times, even in the same areas. We are not to suppose that all the rivers of the world suddenly ceased to transport detritus into lakes and seas; that the breakers no longer wore away the coasts, or that animal and vegetable life was entirely destroyed; because we find a break in the sequence of accumulations in a particular portion of the earth's surface. We have now learned by the progress of our science, to account for such long breaks, and among other things, that dry land cannot fail to show them, when such dry land, after submergence, is covered by marine deposits, and is again upraised above the water." - President's (De la Beche) Address, 1849. 
5. THE LOWER SILURIAN FORMATION IS THE RECORD OF AN ERA OF INVERTEBRATE ANIMALS.

"The absence of even the lowest of the vertebrata in the inferiot Silurian rocks, an absence which is total, so far as can be inferred from the researches of geologists in all parts of the world, gives them a true Protozoic character; and this condition of things was mentioned by the author as a strong reason for concluding, that the epoch in question was the earliest in which animal life was developed."Abstract of a Paper by Sir R. Murchison: Report Brit. Assoc. I844 (p. 54).

"The most assiduous researches in various regions where the earlier groups of fossils have been widely spread, have failed in detecting anywhere a zone of higher antiquity than the Upper Ludlow, in which the remains of fishes are embedded. . . . These few traces of fishes being detectable only at the close of the first long era of primeval life, it follows that the Silurian deposits as a whole are prominently separated from all those which succeeded, by the invertebrate character of their very numerous fossil animals, among which the cephalopods that so abound, probably performed the duties of the fishes, and were the scavengers of the pristine seas." Sir R. Murchison, Dec. 1852. See Proceedings of Geol. Soc. ix. I7.

See afterwards the refutation of a whole chapter-full of false rumours of vertebrate life in the Lower Silurians and lower portion of the Upper Silurians.

6. THE GENERA OF THE LOWER SILURIAN FORMATION ARE HUMBLE IN THEIR RESPECTIVE LINES OF GRADATION.

"As a general result of the inquiries hitherto made, it may be stated that the palæozoic animals belong, for the most part, to the lower division of the different classes."-Agassiz: Principles of Zoology, 1848 .

Corallines. - "Among the earlier forms are those of the genera Aulopora and Catenipora, all belonging to the group of lowest organization among coralline bodies." - Ansted: Picturesque Sketches of Creation, 1847. 
Echinodermata. - The Cystidea, "the primitive form of animals of this class."-De Verneuil. "Form the extreme verge of an entire group of Radiaria, the Cario-crinus indicating the way in which the passage from Cystidea to Crinoidea may have taken place."-Von Buch: quoted in Quar. Jour. Geol. Soc. Nov. I848. "The figure (Caryocystites granatum) exhibits the structure of the stony case in one species; and the annexed figure (Caryocrinus ornatus) shows the step by which this ancient family, apparently the first introduced, passed on to the higher organization of the modern star-fish."Ansted: Pic. Sketches Creation, p. 34.

Acephalous Mollusks. - "The bivalves or Acephala are numerous [in the palæozoic rocks], but for the most part belong to the Brachiopoda, that is to say, to the lowest division of the class." - Agassiz: Princ. Zoology, p. 192.

"The Brachiopoda exhibit an internal organization extremely simple, compared with that of the other bivalves."-Ansted.

Crustacea.- "The Articulata of the Palæozoic age are mostly Trilobites, animals which evidently belong to the lower order of the Crustaceans. There is an incompleteness and want of development in the form of their body, that strongly reminds us of the embryo among the crabs."-Agassiz: Prin. Zool. p. 193.

"It appears that none of the orders [of Crustacea] usually classed as of the highest organization occur in the Silurian strata."-Professor Phillips: Mem. Geol. Survey, ii.

"Almost all the genera of Trilobites seem to be the prophetic images, in a gigantic form, of the different types the Crustacea present in their embryonic state." - Agassiz, at the Scientific Meeting at Charlestown, 1850.

Cephalopoda. - "They all bore a much greater resemblance to the nautilus than the cuttle-fish, and in this respect seem to exhibit the same peculiarity that has already been so often alluded to, namely, the usual introduction of groups of species possessing the lower organization of their tribe in the earliest formed strata of the earth." Ansted: Pic. Sk. Creation, p. 42.

"It may perhaps be inferred as a general result, that the abundance 
of cephalopodous life in these strata is inversely as their antiquity; that the series of these animals was more and more diffused and augmented in number as time elapsed, till the termination of the Silurian deposits."-Professor Phillips: Menn. Geol. Survey, ii.

"Among the higher mollusca, a prominent place in the earlier formations was occupied by that group which presents the least development of the distinctive characters of the Cephalopod class, and which has much in common with the testaceous Gasteropods."Carpenter: Gen. Physiology. \& 345.

7. THE EARLY FISHES WERE LOW, BOTH WITH RESPECT TO THEIR CLASS AS FISHES, AND THE ORDER TO WHICH THEY BELONG (CARTILAGINES.)

"The Sturgeon and the White-fish are two very different fishes; yet, taking into consideration their external form and bearing merely, it might be questioned which of the two should take the highest rank; whereas the doubt is very easily resolved by an examination of their anatomical structure. The White-fish has a skeleton, and moreover a vertebral column composed of firm bone. The Sturgeon, on the contrary, has no bone in the vertebral column, except the spines and apophyses of the vertebræ. The middle part or body of the vertebra is cartilaginous; the mouth of transverse and under the head; and the caudal fin is unequally forked, while in the White-fish it is equally forked.

"If, however, we observe the young White-fish just after it has issued from the egg, the contrast will be less striking. At this period the vertebræ are cartilaginous, like those of the sturgeon; its mouth also is transverse, and its tail undivided; at that period the Whitefish and the Sturgeon are therefore much more alike. But this similarity is only transient ; as the white-fish grows, its vertebræ become ossified, and its resemblance to the Sturgeon is comparatively slight. As the Sturgeon has no such transformation of the vertebræ, and is in some sense arrested in its development, while the White-fish undergoes subsequent transformation, we conclude that, compared with the White-fish, it is really inferior in rank."

"[The fishes of the early period] all exhibit certain characteristic 
features which are very interesting in a physiological point of view. They all have a broad head, and a tail terminating in two equal lobes. What is still more curious, the best preserved specimens show no indications of the bodies of vertebræ, but merely the spinous processes; from which it must be inferred that the body of the vertebra was cartilaginous, as it is in our Sturgeons. . . . We thence conclude that these ancient fishes were not so fully developed as most of our fishes ; being, like the Sturgeon, arrested, as it were, in their development; since we have shown that the Sturgeon, in its organization, agrees, in many respects, with the Cod or Salmon in their early age."-Agassiz: Principles of Zoology.

Agassiz says - "Life, in animals, is manifested by two sorts of functions : viz., First, the peculiar functions of animal life, or those of relation, which include the functions of sensation and voluntary motion; those which enable us to approach and perceive our fellow beings and the objects about us, and to bring us into relation to them : second, the functions of vegetative life, which are nutrition and reproduction; those, indeed, which are essential to the maintenance and perpetuation of life."

He says elsewhere-" As a general result of the observations which have been made up to this time, on the embryology of the various classes of the Animal Kingdom, especially of the Vertebrates, it may be said that the organs of the body are successively formed in the order of their organic importance, the most essential being always the earliest to appear. In consequence of this law, the organs of vegetative life, the intestines and their appurtenances, make their appearance subsequently to those of animal life, such as the nervous system, the skeleton, etc."

He makes the same announcement in other terms- "in most animals the organs of animal life are precisely those which are earliest formed in the embryo; whereas those of vegetative life, such as the heart, the respiratory organs, and the jaws, are not distinctly formed till afterwards."-See Prin. Zoology, § 59, 31 8, 322.

Agassiz has laid it down as a principle, that the characters in embryology, the organic gradation of animals, and the appearance of the animals in the succession of ages as displayed by geology, are all in conformity. 
Assuming this to be true, and keeping in view that the nervous system appears in the embryo before the circulatory, respiratory, and other organs of vegetative life, which of the class of fishes should we expect first to be presented on the scene? Undoubtedly, those which have the nervous system in greatest vigour-the cleverest fishes, so to speak. And this is the fact.

M. Agassiz, in his Recherches sur les Poissons Fossiles, expresses his full conviction of a harmony between the succession of ichthyic types and their relation to the geological formations to which they belong. "It may, indeed," he says, "be affirmed that the closest connexion exists between the principal types of this class and the epoch of their successive development. We have only to glance at the tables of species characteristic of the formations, which I published at the end of vols. 2, 3, 4, and 5 of my work, to be convinced that each order, and even each family, follows a particular progression; that there is, in regard to each group, a beginning and an apogée in its develop. ment ; that by turns they terminate by becoming extinct, if they go back to a remote antiquity, or by acquiring a considerable extension in the present creation, if their appearance dates only from a recent epoch."

Some of the Cartilaginous Fishes present characters in the nervous and reproductive systems which the osseous fishes do not possess. A few are viviparous, and manifest an affection for their offspring. On these grounds, an assumption has been built, that the fishes commence with the highest forms. The occurrence of cestraceons in the Upper Silurians is particularly insisted upon as evidence for this conclusion. Nevertheless, the general inferiority of the cartilagines seems tolerably well established. It is well known that no family of the animal kingdom is equally high in all points of structure and endowment, and that many forms, generally humble, have characteristics of a comparatively elevated kind. There are features of even the human organization which would place our race below some of the inferior animals, if these were to be made an exclusive criterion. The partial superiority possessed by certain cartilaginous genera seems partly to relate to their place in creation as destructives: they have a welldeveloped nervous system to enable them to conquer their prey (see Explanations, pp.49-56). That the nervous system determines the 
character of the reproductive system is an admitted law in physiology (see Owen, Philosophical Transactions, $\mathbf{1}$ S34, p. 359). To find, then, some of these cartilagines exhibiting a generative system superior to other fishes, is no true difficulty in our course. On the very same ground, the star-fishes (radiata), where the sexes are in different individuals, are superior to the annelides (articulata), which present "an andrcgynous combination of simple ovaria and testes;" yet no one would think of describing the radiata generally as superior to the articulata. Or the polypes might be said to be superior to the star-fishes, because in some of them "the digestive canal presents an œsophagus, a gizzard, a glandular stomach, and an intestine," while the latter animals have only "a radiated sac with one aperture." Yet, does any one, for that reason, think of placing the polypes above the star-fishes?

Professor Agassiz remarks* that of the five families of palæozoic fish, the Cephalaspides, that family which recedes most from the ordinary form of other fishes, are of least duration, being confined to the Old Red Sandstone; the Acanthodians are next in this respect, coming down no later than the coal formation.

Yet " the different genera of the Cephalaspides already show a gradation, although faintly marked, in their conformation becoming more and more perfect. It is thus that, on the one hand, the winged appendages of the Pterichthys and Pamphractus are lost in the Coccostei and Cephalaspis, where they are replaced by ordinary fins; while, on the other hand, there is an evident approximation between the Coccostei and the broadly cuirassed genera of the family of Celacanthes, such as Asterolepis and Bothriolepis. The thick and short form of the Pterichthys and the very incomplete development of their fins, evidently show that they were fishes of little agility, living in shoals in mud, moving sluggishly, and destined to become the prey of others. Among the Cephalaspides [genus of this name] the broad shield with which they are covered, and their eyes situated on the upper side, indicate the same mode of life; but in them the trunk becomes more moveable, and the tail, the most powerful instrument of motion, is furnished with fins, and becomes fit to

* Monographie des Poissons Foissiles, \&c.

C C 
execute the most rapid motions. The Coccostei, finally, were evidently, even at this step in the gradation, voracious fishes, as is shown by their conical sharp teeth, and their long flat and flexible tail."

The gradation is even indicated as going on to the family of Celacanthes. "There is no doubt," pursues M. Agassiz, "a wide interval between this and the formidable armature of the Bothriolepis and the needle-like teeth of Dendrodes (Asterolepis); but it will be admitted that there is an advance towards the rapacious character in the family of Cephalaspides, and if we join to this the structure of the plates, the resemblance of the granulated scattered points of the Coccostei to the asterisks of the plates of asterolepis, we will soon be convinced that it is not necessary to take a long step to advance from the Coccostei to the cuirassed Celacanthes."

8. IN ALL THE ORDERS OF ANCIENT ANIMALS, THERE IS AN ASCENDING GRADATION OF CHARACTER FROM FIRST TO LAST.

"The agreement between the zoological affinities and the geological division of types in the series of formations is so striking, especially in certain classes which have of late been the object of particular study, that I think it may now be laid down as a fact, that systematic classifications which are not, at the same time, the expression of the succession of families in the order of time, can no longer be considered as expressing the real affinities existing among the animals which they embrace. The most fortunate approximations which naturalists have attempted at different epochs, have received striking confirmation by modern palæontological discoveries, and that often when those to whom we owe them were unconscious of it. These results are so striking, that even now, in some classes of animals, the knowledge of fossils, and their order of succession, may serve as a guide to correct the zoological system, just as, on the other hand, the advanced state of our anatomical knowledge will lead us to a correct determination of the geological age of certain deposits, even although we should not discover in them any fossil species identical with those of 
well-determined formations of the same era."-Agassiz: Monographie des Poissons Fossiles.

"I venture to say that the time will come when the relative age of fossils, within certain limits, will be as satisfactory a guide in assigning them their normal position in a natural system, as the facts derived from the study of their structure-so intimate are the connections existing between all parts of the wonderful plan displayed in creation."-Agassiz: Proc. of Am. Assoc. for Adv. of Science at Charleston, 1850. Jameson's Jour. April, I $8_{5}$ r.

Polypiaria.- "Amongst the most simply organized of the Silurian species, and amongst those found in the beds of oldest date, are the fossils called graptolites, which seem to have been the horny skeletons of animals not unlike those which are often met with on the coral and sea-weeds of our own coast. . . . Polyps, as animals of this humble class are called, appear to have been among the first of created beings, and are also those which have been changed least since the period of their original introduction up to the present time. Their extreme simplicity of structure would enable them to live through many changes, since they could adapt themselves to altered zonditions of temperature and position, at times when almost every other animal was destroyed; and accordingly, in the species of them found fossil, there is far less difference from existing nature than is the case with any other creatures. These little corallines, and the larger and more important group of true corals, as they commenced existence so early, seem also to have been comprised within a very limited number of natural families, and some particular species probably extend completely through the whole number of beds of the first great epoch."-Ansted: Pic. Sketches of Creation.

Foramenifera. - "A group of minute shelled animals belonging to the sub-kingdom Acrita ; marine, inhabiting sea-weeds and the seabottom; generally free, but sometimes attached to shells, corals, \&c. Animal gelatinous, occupying a calcareous shell, which is formed of a succession of cells or chambers, arranged in a straight, spiral, or agglomerated manner. The cells communicate one with another by one or more apertures, or by a narrow neck or tube, through which 
the animal matter is continued from cell to cell," etc. "Each new articulation produced by gemmiparous generation."

Only twelve species are described as belonging to formations before the Permian-and chiefly to the mountain limestone. A few specimens in the Permian.

"The presence of so few species in the earlier formations tends to strengthen the remark made by M. D'Orbigny, that the Foramenifera appear to have been subject to a somewhat regular progression both in character and number, the simple forms occurring in the early formations, and that but rarely, and the most complicated not until the cretaceous, tertiary, and recent epochs, and then with profusion." - King's Monograph of Permian Fossils, Palconto. graphical Society.

Echinodermata.- "The relations of the living and fossil types of the class of Echinoderms now appear in the most evident manner. The Crinoidea are the prototype of the whole class. Not only does geology show this, but also what we know of the first states of some species of this family equally confirms it. We may even say that the Crinoidea present us with a kind of synthesis of all the families of this class, by the different forms they assume; for example, in the Cystidea which remind us of the Echinidæ, or in the Melocrines, which make a near approach to the Asterix. It is only the Holothuriæ which seem to be exclusively confined to the present creation, and this family is precisely that which occupies the highest rank among the Echinoderms; while the Crinoidea, which occur at the lower part of this series, would appear to be the first; then come the Asteriæ; already numerous in the triassic formations; and finally, the Echinidx, whose greater development characterises the jurassic, cretaceous, and tertiary formations."-Agassiz: Monographie des Poissons Fossiles.

"The Crinoidea of the Palæozoic period, though very numerous, exhibit but little variety of type; and in the complete enclosure of the body by polygonal plates, they present a closer approximation to the Cystidea than do the Crinoidea of the secondary period, in which the variety of forms is much greater."-Carpenter's Gen. Phy's. $\$ 345$. 
Crustacea.- "The Trilobites, which are unquestionably the most ancient type of the class Crustacea ... do not go beyond the coal formation, when they are replaced by gigantic Entomostraca, which are in some degree the precursors of the Macruri. . . . The Macruri prevail from the Triassic epoch to the present creation; while the Brachyura are essentially Tertiary. . . It follows from this hasty glance that the types whose affinities have been best studied, such as the Trilobites, Macruri, and Brachyura, succeed each other in the series of formations in the order of their organic gradation." Agassiz: Monographie des Poissons Fossiles.

Cirrhopoda. -According to the development hypothesis, the Cirrhopoda should be placed in the upper department of the crustacea. The young go through a distinct metamorphosis, having, after their liberation from the egg, a form resembling that of the Entomostraca. "Four stages have been described by Burmeister as being presented by the animal subsequently to its emersion from the egg. In the first it is possessed of no hard covering, has two long antennæ and three pairs of arms tipped with bristles, by which it freely moves through the water ; and it is believed to be furnished with eyes. At a subsequent time the animal fixes itself by its antennæ, and the shell, of leathery consistence, begins to be formed in one piece at the back of the body; and at this period the eyes are very distinct and brilliant. In the third stage, the divisions of the shell begin to appear, and it more completely encloses the animal, at the same time becoming more solid by the deposition of calcareous matter. Soon after the animal completely fixes itself, the old integuments, together with the antennæ and eyes, are thrown off. The fourth stage is that in which the development is completed."-Carpenter. Comparative Physiology, 1839 .

The Cirrhopoda are in two divisions. "One division, the Balani (acorn-shells) have the bases of their pyramidal shells fixed upon rocks or other large masses of matter; whilst the Lepades (barnacles) attach themselves to floating bodies by a membranous tube, sometimes of considerable length."-Carpenter. That the latter or pedunculated cirrhopods are the inferior family may be speculatively inferred from the fact of their fixing power being of a less determined 
character than that of the other, the sessile habit being apparently the perfection of this line of being. That the Balani display an affinity to the decapod crustacea, and the Lepades to the Entomostraca, is an opinion of Mr. J. V. Thomson of Cork, who has distinguished himself by his researches in the development of the Cirrhopoda.

Now, such being the elevated position of the Cirrhopoda as an order, and such being at least speculatively the comparative character of its two great divisions, it is very remarkable to find no fossil cirrhopoda before the oolite formation, and that though pedunculated cirrhopods begin then, and make a large appearance in the chalk, none of the sessile family are presented till the tertiary.

"The oldest known pedunculated cirripede is a Pollicipes, discovered by Professor Buckman in the Stonesfield slate, in the Lower Oolite. . . . I have not as yet heard of any cirripede having been as yet discovered in the Upper Oolite, or in the Wealden formation. During the deposition of the great Cretaceous System, the Lepadidæ arrived at their culminant point; there were then three genera, and at least thirty-two species, some occurring in every stage of this system. . . . I believe that very many more will yet be discovered.

"No true Sessile Cirripede has hitherto been found in any Secondary formation: considering that at the present time many species are attached to oceanic floating objects, that many others live in deep water in congregated masses, that their shells are not subject to decay, and that they are not likely to be overlooked when fossilized, this seems one of the cases in which negative evidence is of considerable value. . . . Sessile cirripedes are first found in Eocene deposits, and subsequently, often in abundance, in the later Tertiary formations. These cirripedes now abound so under every zone, all over the world, that the present period will hereafter apparently have as good a claim to be called the Age of Cirripedes, as the Palæozoic period has to be called the Age of Trilobites." Charles Darwin: Monograph of Fossil Lepadida, 1851 .

Arachnida and Insecta. - Two species of Coleoptera and some Arachnida, particularly a scorpion, have been found in the Car- 
boniferous formation; also a neuropterous insect resembling a Cordalio and another of the same order related to the Phasmidx.

One shale bed in the Lias (Gloucestershire) is charged with wingcases of coleoptera along with some nearly entire beetles, of which the eyes are preserved. "Throughout an extensive district, several bands of this lias have been termed Insect Limestone, in consequence of the great number of such fossils, no less than 300 specimens of hexapods having been obtained, comprising both wood-eating and herb-devouring beetles of the Linnæan genera, Carabas, Elater, and others, besides Grasshoppers [Hemiptera], and detached wings of Dragon-flies and May-flies, or insects referable to the Linnæan genera Libellula, Ephemera, Hemerobius, and Panorpa [Neuroptera], the whole assemblage being no less than twenty-four families."Lyell, I85r.

Professor Heer thinks it probable "that lepidopterous insects were first created in the tertiary period, because the only well determined specimens of that order yet known to palæontologists have come from tertiary strata." $-I d$.

Our fossil insects are too few to allow of our bringing them forward with any confidence; but it is meanwhile remarkable that they are first-seen so long after the Crustacea, to which they are superior in organization, and that even amongst themselves the lowest families appear first.

That insects are above Crustacea is affirmed by Professor Agassiz. "In every respect," says he, "insects, considered as a whole class, are more highly organized [than Crustacea], their higher types assuming a division of the body into three distinct regions, - - undergoing also far more extensive metamorphosis, and assuming finally an aërial mode of respiration, to which the Crustacea do not reach. Silliman's American Journal, Ec., I85o.

Agassiz classes Arachnida and Myriapoda with true insects, considering them as only lower degrees of development- "the Myriapoda representing in a permanent state of development, and with the structure of true insects, the form of their caterpillars; the spiders, with their cephalic and thoracic regions united into a cephalo-thorax, representing their crysalis in a permanent state of development." In consideration of these embryonic particulars, he 
deems Myriapoda as the lowest type, the Arachnida next, and the true insects highest, the sucking tribes being amongst these last the most elevated.

"If we now," he says, "consider the insects proper, we shall find here again a strict accordance with the results we have already derived from the investigation of the lower classes, - namely, that the more intimate connection with the mainland and aerial mode of existence indicates a higher degree of development than an aquatic mode of life and between animals living in water, that fluvialite types must rank higher than marine." He goes on- "Having already acknowledged the superiority of the sucking insects over the chewing tribes, we cannot fail to perceive that the Neuroptera, which must be considered as the lowest, inasmuch as their body still preserves the elongated form of worms, are aquatic in their larval condition and have even external gills as their respiratory organs during that period. Next Coleoptera, among which also we find aquatic larvæ, and a number of terrestrial types; and highest the Orthoptera, which undergo a less extensive, but entirely terrestrial development, whilst Hymenoptera have a more diversified metamorphosis, and assume even in their larval condition in some of their types, the higher forms which characterise the larvæ of Lepidoptera.

"Among the sucking insects we begin again with various aquatic types or aquatic larval forms - next rise to Diptera, with other aquatic larval conditions, but a constant aërial mode of life in the perfect state, and finally to the type Lepidoptera, in which all the larvæ are terrestrial, and even highly organized in their earliest state in the higher groups." . . .

Few and scattered, we may repeat, as the fossil insects are, it is certainly striking, after M. Agassiz's view of the gradations of the class, to find Arachnida, Coleoptera, and Neuroptera first in the series of rocks, and Lepidoptera not occurring till the Tertiary. Nor is negative evidence here quite despicable, when we see that from the bed of the lias called the Insect Limestone no fewer than twenty families have been taken, and yet among them all none superior to Neuroptera and Coleoptera.

"The great class of Insects, which furnishes four-fifths of the existing species of the Animal Kingdom, has two chief divisions. 
In the one (the Ametabola) we have an imperfect, in the other (the Metabola) a perfect metamorphosis; that is, in the former there is no quiescent pupa state, and the metamorphosis is accompanied by no striking change of form; in the latter there is an inactive pupa that takes no nourishment, and so great a change of form that only by watching the progress of the metamorphosis can we recognise the pupa and the imago as being the same animal. The Metabola correspond, as it were, to the flowering plants; the Ametabola to the Cryptogamia. It is well worthy of remark that among plants the Cryptogamic, and among insects the Ametabolous, first appeared upon our earth. The most ancient forests, composed of tree-ferns, club-mosses, and equiseta, were inhabited by Locusta and Blatte, the first of insects. There have not yet been found in the carboniferous and triassic rocks any traces of insects that can be with certainty referred to any of the other insect orders. . ...

"The Ametabolous insects also play the chief part in the Jurassic period. Here they appear as very large Locusts and Dragon-flies, the latter belonging to the Asschnide (including the Gomphi) and the Agrionidæ, as a few Termites and a long series of beaked insects.

"This is the case also in the succeeding period, that of the Chalk, in which neither Butterflies, nor Bees, nor Hymenoptera generally, have been found. The Beetles, on the other hand, occur in somewhat larger proportion.

"In this cretaceous period there existed islands rising from the sea and chiefly wooded with fir-trees, bearing also Palms, Dragon-trees, and tree-like Lilies, together with which the first dicotyledonous trees occur. These, however, appear to have been as yet very few in number, it being only in the following period, the tertiary, that they became plentiful, forming from this time an essential proportion of the vegetable kingdom. In company with the creation of dicotyledonous trees and phanerogamic herbs, the Insect-world appears to have been first developed at this period in all its orders and in more manifold forms. Whilst at present we are acquainted with only I 26 species of insects altogether, from the earlier geological periods; from the two tertiary localities of CEningen and Radoboj I know of about 443 species. Among these are present all the seven orders of recent insects, but, nevertheless, in different numerical proportions to those 
of the existing faunæ. In these the Ametabola form about $0^{\cdot 10}$, the Metabola 0.90 [as to individual specimens]. Of the CEningen and Radoboj species, 124 belong to the Metabola, and 319 to the Ametabola, the former making more than a third. We see, therefore, that at this period the Ametabola were much more numerous in proportion than the Metabola, although not more in the mass, as in former geological periods." - Heer on the History of Insects, Leonhard und Bronn's Jahrb. f. Miner. u. s. w. I850. Translated in Q.J. Geol. Soc. Nov. i 850.

Professor Heer intimates a connexion between the creation of the various kinds of insects and the rise of conditions fit for their existence. With regard to the scarcity of insects in the early times, he says"Nor need we wonder, if we consider that at present also our Lycopodia and Equiseta harbour no insects, and the Filices very few. The hosts of insects, therefore, that live on the flowers and their honey, on the fruits and seeds, could not at that time have been in existence, the vegetable world being then destitute of flowers and fruits."

The Bees and Butterflies appear in the tertiary, in very few forms. "In the existing creation only," he says, "have these insect types been developed in their full richness of form and splendour of colour; and this may be the better understood, inasmuch as in the tertiary period the land was almost entirely occupied with woody plants and forests, and offered but few herbaceous flowering plants from which the Butterflies and Bees could derive their nourishment."

"Among the Metabola we first meet with the Flies." "The Nemocera were the first to appear, and were followed a little later by the Brachocera," the other and greater division of Diptera. Heer remarks that the Nemocera might be the first to appear, because of their suitableness to woods and thickets, and to damp and watery places. "Everything points to the fact that, in the tertiary period, the land was chiefly occupied by tree-like plants; and, further, the many species of willow and poplar, as also the swamp cypress (Taxodium), point to extensive swainps and morasses. . . . Such damp woodlands were probably the favourite resorts of the numerous Pachydermata of that age." The Brachocera, again, live chiefly on flowering and herbaceous plants.

"The water-beetles, as also the land-beetles, commenced with the 
more incomplete forms - the vegetable feeders, and only at a later period were the more highly-organized carnivorous water-beetles brought into existence."

Acephala.—"The Acephala afford us a not less striking example of these relations between the organic characters of a well-characterized zoological group, and the time of the appearance of its different types. In order to show this connection more distinctly, I may be permitted to premise a few general observations on this class. Mr. Owen was the first to show that the Brachiopods ought not to be regarded as a separate class, but that they may be conveniently arranged on the same line with the Monomyaires and the Dimyaires. To prove this assertion by new arguments, I have only to bring to mind that these fundamental sections of the class of Acephala are closely allied to each other by the connexion of their principal forms, and by their respective position in the midst of the ambient elements, as I have shown in my memoir, Sur les moules de Mollusques Vivans et Fossiles, to which I refer. I shail here merely state that the Brachiopods exhibit an inverse symmetry when compared with that of the regular Dimyaires. In the former the right and left sides are of very different conformation, and the animal is constantly lying on one of its sides, and the sides have been very generally and erroneously regarded as the dorsal and ventral regions. The anterior and posterior extremities, on the contrary, are shaped with the most perfect symmetry; that is to say, in other words, the front and hinder part of the animal cannot be distinguished, while its sides show a marked difference. In the Monomyaires in general, and among the Ostracer in particular, we observe a conformation intermediate between that of the Brachyopods and that of the Dimyaires; the sides are still very different, but now one of the edges appears as the anterior extremity of the body, and the animal, still adhering in the case of oysters, has no longer, in all the genera, the absolutely lateral position of the inferior types; witness the Pectens, which swim freely. Lastly, among the Dimyaires the bilateral symmetry attains to full perfection, and, at the same time, one of the extremities of the body is sensibly characterized as the anterior. The animal then assumes a position more or less vertical, the head in advance, and the relation of its organs 
with the surrounding media are analogous to those of other symmetrical animals.

"These connexions are fully justified by the order of the succession of Acephala in the series of formations. Of all modern palæontolo. gists, M. de Buch is the individual who has studied the Brachiopods with the greatest care; and it is to his works above all others that I refer for the detailed study of the facts, the principal results of which I am about briefly to state. In the most ancient formations, we find nothing but Brachiopods, but in such profusion, and in forms so varied, that in their abundance and diversity, they scarcely yield to the Acephala of the tertiary formations, in which the Brachiopods have almost entirely disappeared, to be replaced by an innumerable quantity of species of different genera, belonging, for the most part, to the order of Dimyaires. To make up for this, the intermediate formations afford a remarkable assemblage of Brachiopods, Mono. myaires, and Dimyaires, the more interesting from this, that the Dimyaires with non-symmetrical sides still exceed in number those which are perfectly regular, and thus become connected with the Monomyaires and Brachiopods which, at the era when they existed alone, gave to the acephalous faunas the singular character of want of symmetry in the sides, combined with a very remarkable symmetry before and behind."-Agassiz: Monographie des Poissons Fossiles.

Gasteropoda._" The absence even in the coal-measures of landshells is a singular, and if I mistake not, a significant fact. The known living species of the genera Helix, Cyclostoma, Bulimus, Achatina, Pupa, and Clausilia, exceed 2000 in number; and not one of these genera, nor any of the pulmoniferous mollusca, such as Lymnæus, Planorbis, Physa, etc., have as yet been detected in any one of the primary strata from the Silurian to the Permian inclusive. . . Some few shells of the coal-measures have been referred to the genus Unio, and others to an annelid allied to Spinorbis, and called Microconchus, probably an inhabitant of brackish water." Sir Charles Lyell, I85I.

Fresh-water mollusca of the genera Cyclas and Unio have been found in the marl-stones and shales of the Lias in Gloucestershire and other parts of the West of England. 
Planorbis and Lymnæus, as well as Valvata, Physa, and Melania in abundance (pulmoniferous mollusca), were found by Professor E. Forbes in the Purbeck beds, which are supposed to be of the Oolite age.

No helices yet detected so early. If I may take Bartlett's Index Geologicus as a guide, there seem to be no land shells till the postpleistocene era.

The organic gradation of the Gasteropoda is precisely in this order. "What," says Professor Agassiz, "is the respective position of the marine families, of the fluviatile families, and of the terrestrial families? . . . The natural gradation established by their structure, agrees with their natural connexion with the elements in which they live, in the order which I have assigned to these, the types of Gasteropoda which are lowest being exclusively marine,-the highest equally fluviatile and terrestrial; and among these the fluviatile ranking immediately above the marine, and the terrestrial ranking highest."-Silliman's Journal, May, 1850.

Cephalopoda.-The first division which Professor Owen has made in the Cephalopola is into Tetrabranchiata and Dibranchiata (having four branchix and two branchiæ). The Tetrabranchiata are placed by him lowest, by virtue of the law " that increased number, irrespective of co-relative structure in an organ of the animal body, is ever a mark of inferiority."-Lectures on the Invertebrate Animals.

The earliest cephalopods were tetrabranchiate. None of the dibranchiate appear till the Lias, the commencement of the Secondary Formations.

Among the tetrabranchiates, which are the earliest?

In the remarkable example of the Silurian formation, which has been so well explored by M. Barrande, in Bohemia, after one series in which there are trilobites, cystidex, etc., there is another, containing with these and other fossils, fragments of orthoceratites, being the first appearance of the cephalopodous order. In the next stage again are an enormous variety of the same genus, from 95 to Ioo species, together with various nautili and lituites. In the same formation in the state of New York, after a fossiliferous series without any appearance of the cephalopoda, there is one (Calciferous 
Sandstone), containing some small orthoceratites; then another (Chazy Limestone), containing some examples of the same fossil, but nuch larger; then still another, containing orthoceratites eight or ten feet long, etc. In the various examples of the Silurian formation in the British Islands, the order of the appearance of the ortho. ceratites is nearly the same. "The Orthoceratites, apparently the first, as it is the simplest, form of the multilocular shell," says Professor Ansted.

And how, after this, proceeds the march of cephalopodous life? Agassiz answers - "The Orthocera of the oldest periods precede the curved Lituites, which in their turn are followed by the circumvolute Nautilus. "Here we have," he says, "a natural gradation of a series of progressive types."-Address to Amer. Assoc. for Advan. of Science, 1849. This may be stated more in detail. "The cephalopodous animals, whose remains are most abundantly distributed in the older Palæozoic rocks, had their numerous chambers not twisted round a central axis, as in the nautilus, but placed one over another in a position more or less approaching the vertical; and not less than eighty species of these have been determined. The straight form of the shell is best known by the generic name Orthoceratite; but the names Lituite, Phragmoceratite, Cyrthoceratite, and Gomphoceras are also applied to distinguish differences of form, chiefly marked by the axis of the chambers being more or less curved; the chambers of none of them, however, being twisted into a complete spiral."-Ansted: Introduction to Geology.

Dr. Carpenter says- "Among the higher mollusca, we find that a prominent place in the earlier formations was occupied by that group which presents the least development of the distinctive character of the cephalopod class, and which has much in common with the testaceous Gasteropods. . . . The paucity of remains of typical Gasteropods, at the same period. . . remarkable; and some of those forms which are most abundant (e.g. Euomphalus and Bellerophon) present indications of close affinity to Cephalopods. So that it would seem as if the Nautiloid type is really to be regarded as having occupied the place at that period, not merely of the order above [fishes], but also (in part) of the order below; its decline and almost complete disappearance during the Secondary epoch, being coincident with 
the multiplication of the forms of more typical Gasteropods and of the higher Ccphalopods."

Professor Owen divides the Tetrabranchiata into Nautilidæ and Ammoniticlx. The fossils already spoken of are of the Nautilidx, and sufficient authority has been adduced to show that they are the lower of the two families. The higher family of Ammonitidæ does not make its appearance till the Lias. There are, however, intermediate forms. In the Devonian formation occurs Clymenia, which forms a link with the Goniatite of the mountain limestone, a fossil approximating, if not fully belonging to the Ammonite family. The distinctions are chiefly in the form of the septa or walls which divide the chambers of the shells. A living palæontologist says- "As we ascend in the Palæoozoic series, we find that various of the primitive genera and species disappear, and are succeeded by other forms, distinct from, but closely allied to them; which, in their turn, are lost."-Edzuards: Monograph of Eocene Mollusca.

"On passing into the Mesozoic (secondary) series, a marked change takes placc. Of the eight genera constituting the family of the Nautilidæ which lived during the Palæozoic epoch, Orthoceras and Nautilus alone survive; and of the long series of species belonging to the latter genus, whose remains are found in the carboniferous formations, every one disappears; but an immense array of Ammonites starts into existence, with septa at first comparatively simple, but becoming more complicated in structure in the succeeding formations." -Edreards.

We now come to the Dibranchiate Cephalopods. Professor Owen divides them into two tribes, the Decapoda, which, besides eight sessile arms round the mouth, have two tentacula placed one on each side, and the Octopoda, which have the eight arms, but want the two tentacula. He places the former lowest. "The Decapodous tribe," he says, "is that which is most nearly allied to the Tetrabranchiate order. This affinity is not only indicated by the additional number of external arms, and the frequent development of an internal circular series of eight short labial tentacles, but by several internal characters; as the single oviduct and detached glands for secreting the nidimentum; the valve of the funnel; the laminated rudiment of a chambered shell in the Cuttle-fish, and the fully developed cham- 
bered and siphoniferous shell of the Belemnites and Spirula. The observations of Peron and Lamarck having proved that the animal of the Spirula possesses eight short arms and two long tentacles, all provided with acetabula like the sepia, we regard it as the type of the first family of the Decapodous tribe, or that which immediately succeeds the Tetrabranchiata."-Cyclop. of Phys. Art. Cephalopoda.

In short, and in plainer terms, Professor Owen has placed the Decapodous tribe lowest, next the Tetrabranchiates, and the Spirula as the low'est of its tribe.

And how is it that the Dibranchiates commence in the series of formations? It is with the Belemnites, allied to the Spirula, the type nearest the Tetrabranchiates. These appear in the Lias, and their family "appear to be the sole representatives of the Dibranchiate Cephalopods throughout the whole of the Secondary Epoch."-Edwards. With the conclusion of that epoch perish all the survivors of the Tetrabranchiata, excepting only the Nautili, which continue to the present time.

During the tertiary epoch, the Cephalopoda are as remarkable for their rarity as they were formerly for their abundance. Two genera belonging to the family of Belemnitidæ occur in the beds of the Paris basin and in the Eocene formation of England. There are also two species of Argonaut from the new tertiary formations on the continent. This is the first appearance of the Octopoda, the highest tribe, on the field of life.

Fishes._- "It is no argument against the views that naturally arise out of the summary of the facts of Palæontology as they are now known, to urge that 'the fish and reptiles of the secondary rocks are as fully developed in their organization as those now living.'-(Sir Charles Lyell.) . . . One of the leading distinctions amongst animals is the position of the skeleton; the great binary division of Lamarck into vertebrata and invertebrata was based upon this distinction; and Cuvier's supplementary labours, which made us better acquainted with the real nature and value of the invertebrate groups, have served in the main to confirm the reality of the great characteristic manifested in the internal or external position of the skeleton.

"We have already adverted to the fact, that no completely ossified 
vertebra of a fish had been discovered in the strata of the Silurian and Devonian period. Those strata are of enormous extent, and have been most extensively investigated. As regards the internal skeleton, these primeval fishes were less fully developed than those of the tertiary and existing seas.

[Their external or dermal skeleton] was not only developed in excess, as compared with the great majority of recent fishes, but presented in its form and structure a closer analogy to the exoskeletons of invertebrata than that of any known fish which possesses the same system of hard parts well calcified. In the Pterichthys, Pamphractus, and Coccosteus, e. g., of the Old Red Sandstone rocks of Scotland, the exo-skeleton presents the form of large plates, either symmetrical, or articulated symmetrically by straight sutures, like the shell of the lobster. The large calcified dermal shield which protected the head of the Cephalaspis, has often been mistaken for that of a trilobite of the division A saphus. These, of course, are but analogies; and the invertebrate-like condition of the skeletons of the known palæozoic fishes was doubtless associated with a general plan of organization essentially vertebrate and piscine. But we can never hope to arrive at the truth, as it respects the course of creation on this planet, if we voluntarily shut our eyes to the fact and the bearing of these analogies.

"The contrasted states of the exo and endo-skeletons described by the Hunterian Professor in the Microdon radiatus of the secondary epoch, may have been associated with as advanced a development of the soft parts, as we find in the few ganoidal fishes that exist at the present day; but, the lower embryotic condition of the vertebrate skeleton being demonstrated, not only in that but in many other contemporary ganoids, it cannot be admitted that 'the fish of the secondary rocks are as fully developed in their organization as those now living.'

"To the arguments against that succession on which Sir Charles Lyell founds his statements, that no ichthyic type is more elevated than the cartilaginous fishes of the Upper Silurian group, and that the fish of the secondary rocks are as elevated as any now living, we will finally reply by recalling the remarks which the study of those ancient fossil fishes has elicited from the great founder of fossil $\mathrm{DD}$ 
ichthyology. Besides the incomplete development of the back-bone, M. Agassiz points out other striking traits of an embryonic character. The cephalaspids of the old red sandstone were shaped like the tadpoles of Batrachia; the breathing organs and chief parts of the alimentary apparatus were aggregated with the proper viscera of the cranial cavity in an enormous cephalic enlargement; the rest of the trunk was for locomotion, and dwindled to a point. The position of the anal fin proves the vent to have been situated, as in tadpoles, immediately behind the cephalic-abdominal expansion. In the Pterichthys, the mouth was small and inferior, as in the young tadpole; and there are long fin-like appendages, projecting from the sides of the cephalic enlargement, like the external gills of the Batrachian and Selachian larvx."-[Professor Owen?] Quarterly Review, Sept. I 85 I.

"It was not till the time of the chalk formation that the two other orders, the Ctenoïd and the Cycloïd, which almost exclusively prevail in the present creation, made their appearance. The first types of these orders belong for the most part to extinct genera allied to our Clupere ancl Tunnies. In this epoch fresh-water fish were still wanting. The fishes of the tertiary epoch are much more nearly related to those of our own times; a great number belong to genera now existing : we find true Tunnies, true Cluper, true Anchovies, true Smelts, and fresh-water fishes well characterised, such as Pikes, Leucisci, Tenches, Loaches, Gudgeons, etc., but neither Trouts nor Salmon."-Bib. Unio. de Génève, No. 100, Article on Agassiz's Recherches.

9. THERE IS A SUCCESSION FROM LOW TO HIGH TYPES IN FOSSIL PLANTS, FROM THE EARLIEST STRATA IN WHICH THEY ARE FOUND, TO THE HIGHEST.

On fossil plants the highest authority is M. Adolphe Brongniart. He has presented to the Institute his final views "on the Chronological Exposition of the Periods of Vegetation and the different Floras which have succeeded each other on the Earth's Surface."

In this paper, he remarks "the predominance, in the most ancient periods, of acrogenous-cryptogamous vegetables (Ferns and Lycopo. 
diace () ; later, the predominance of gymnospermous dicotyledons (Cycadere and conifere), without any mixture hitherto of angiospermous dicotyledons; and in the last place, during the chalk formation, the appearance and speedy predominance of angiospermous vegetables, both dicotyledons and monocotyledons."

In the first period, which he calls the Reign of Acrogens, gymnosperms, a superior type, come in (sigillaria, naggerathice, and asterophyllitec); but the sigillarix would appear to predominate in the middle and superior beds, and the asterophyllites, and particularly the annullaria, are found much more abundantly in the superior beds : "it is the same with the Coniferce, and it is only in the superior beds of St. Etienne, Autun, etc., that branclies have been found, at least in France."

"The gymnosperms," he elsewhere says, "show themselves in unusual forms, and sometimes so anomalous, that we are in doubt whether to place them in this or the preceding department [that of acrogenous cryptogams] ; such are the asterophylliteæ."

M. Brongniart holds as doubtful most of the alleged instances of plants of the carboniferous era found below the zone of the coal formation. One carboniferous formation in the neighbourhood of Oporto, which appears of very ancient date, since it is covered by beds containing fossil animals characteristic of the Silurian formation, contains some impressions of plants, and these impressions all of ferns (thus exclusively Acrogens).

The Flora of the carboniferous period contains, according to $\mathrm{M}$. Brongniart, only about 500 well-determined species of plants, scarcely a twentieth part of the number now flourishing on the face of the globe. "This number of species, moreover, corresponds to a long period during which diverse species succeeded each other, so that we may admit with much probability that never more than I00 species existed simultaneously. We thus perceive what was the poverty and especially the uniformity of this vegetation.

"Does this vegetation, thus reduced to the forms which we are led to consider as the most simple and least perfect, owe this special nature to a first phase of development in the organization of the vegetable kingdom, which had not yet attained the perfection which it afterwards reached; or is it owing to the influence of the physical 
conditions under which the surface of the earth was then placed? These are questions we cannot answer.

"I shall merely remind the reader that I have already pointed out the analogy which this predominance of Acrogenous Cryptogams establishes between the vegetation of the first period, and that of the small islands of the equatorial and southern temperate zone, in which the maritime climate reaches its highest degree. However, this predominance is not such as to entail, as during the carboniferous period, the exclusion of phanerogamous vegetables, and this complete exclusion would seem more favourable to the idea of a gradual development of the vegetable kingdom."

"All that we at present know of the vegetation of the globe at the period of the earliest known fossiliferous deposits is that it was of that more simple or less developed kind which characterises the tribes growing in the sea.

"The most ancient terrestrial Flora with which palæontologists have any real acquaintance is that of the carboniferous period; and this contains coniferæ, which, although by no means the lowest of the phænogamous class, are still far from being ranked among the highest. Whether some of the fossil coal plants are referable to the family of true Palms, is a point as yet not clearly determined. . . . O Of the 500 species of coal plants to which the critical and scrupulous investigations of Adolphe Brongniart have restricted the fossil evidences, one half at least are ferns, and the greater part of the remainder are gymnosperms . . . none of the oxogens of Lindley or dicotyledonons angiospermis of Brongniart, which comprise four-fifths of the living Flora of the globe, have yet been discovered in the coal measures. It must be remembered, too, when the value of negative evidence is called in question, that the whole of Europe does not produce more than fifty species of ferns-only one fifth of the number that have left their remains in our coal strata; and accordingly $\mathbf{M}$. Brongniart has called the Flora of the carboniferous and Permian strata, the 'age of Acrogens.'

"In the strata from the triassic to the Purbeck, inclusive, plants of the family of Zamia and Cycas, together with coniferæ, predominated in Europe far more than anywhere now on the globe in 
corresponding latitudes, and this fauna Brongniart calls the 'age of Gymosperms.'

"Now we presume it will be admitted that Cryptogamia, Phæno. gamia, Gymnosperms, and Dicotyledonous Angiosperms constitute a succession and a progressive one."-[Professor Owen?] Quarterly Reviezv, Sep. r851.

Dr. Carpenter, treating of the doctrine of the passage from the more general to the more special, says of the geological history of the vegetable kingdom- "So far as our present information extends, it is fully in harmony with the above doctrine; the characteristic Flora of the coal formation appearing to have been chiefly composed of Conifere, which constitute a connecting link between the Phanerogamia and Cryptogamia; and of these coniferæ, while some may have been nearly allied to existing forms, the great majority (Sigillaria, Lepidodendra, Calamites, etc.) appear to have presented such a combination of the characters of the coniferæ with those of the higher Cryptogamia, as no existing group exhibits."-Gen. Physio. $\log y, \mathrm{r} 85 \mathrm{r}$.

IO. THE COMPARATIVELY LARGE BULK OF SOME OF THE EARI,Y FOSSILS IS TO BE REGARDED $\Lambda$ S A MARK OF THEIR INFERIORITY IN THE SCALE.

In a paper on "The Natural Relations between animals and the Elements in which they live," (Silliman's Amer. Four. May, 1850.) Professor Agassiz first proves that, in any particular order, the marine families are lowest in the scale, the fluviatile (if any) next, while the land families rank highest. He shows also that there is a diminishing gradation of bulk from the marine to the fluviatile and land genera. He therefore speaks of our so frequently finding, throughout the animal kingdom, "that the lower condition of structure and development is manifested in a more bulky body."* From all this it follows that, in any order of animals, as the chephalopodous mollusks or the

* "Is there any proof that the largest Pachyderms are of the lowest organiza. tion? [That they were so is asserted in Explanations: a Sequel to the Vestiges, $\mathcal{E}^{\circ}$. ] I believe there is not the shadow of any proof for this assertion."-Professor Sedgivick: Preface to the 5 the ed. of Disconrse on the Studies at Cambridge. Sedgruick againsi Agassiz! 
cartilaginous fishes, which has been represented from the protozoic to the present age, the early and humbly developed families should be of comparatively large size.

Among the early cephalopods there are some very large; one in the Black River limestone of New York State, which cannot have been less than ten feet long. Many of the early cartilaginous fishes are also large.

The asterolepis, an early ganoid, on which Mr. Hugh Miller has written a volume to prove its being a fish of high organization, was as bulky, according to this author, as a large porpoise. "Thus," he says, "in the not unimportant circumstance of size, the most ancient ganoids yet known, instead of taking their places, agreeably to the demands of the development hypothesis, among the sprats, sticlklebacks, and minnows of their class, took their place among its huge basking sharks, gigantic sturgeons, and bulky sword-fishes. They were giants, not dwarfs."

So much the worse for Mr. Miller's opposition to the development hypothesis, if Professor Agassiz (perhaps the most philosophical of living zoologists) is to be trusted. The development hypothesis would, according to that philosopher, demand bulk in the initial animals of each line, and it is much beholden to Mr. Miller for the help he has thus given it, while doing his best, certainly under great difficulties, to show its baselessness.

\section{VARIABILITY OF SPECIES.}

The following remarks occur in a series of papers in the Phytologist, being from the pen of a distinguished botanist, Mr. H. C. Watson :-

"We seem to be justified in asserting that our knowledge of the present events in nature, taken by itself, should incline us to a conclusion which is directly adverse to the theory of 'progressive development,' or 'transition of species,' yet, without affording us any actual disproof of that theory. It is otherwise when our range of thought embraces the vastly wider space of time, the events of which are investigated by geologists. There we find ample evidence to justify the conclusion that different species succeeded each other. And no better mode of accounting for this succession has been sug- 
gested, than the hypothesis that one species passed into another, under changing external conditions. Supposing this transition of species to have taken place very gradually, and through a long series of descents, it would not require more rapid change (from central types into varieties, and from a less variety into a greater), than we see actually occurring in the production of varieties at the present period of the earth's history. Could we ascertain that some varieties will continue to vary from their central type through many successive descents, and that, as they become less similar to their original central type, the tendency of 'like to produce like' will overpower and supersede the tendency to revert to the original central type ;in this case, we might hold the 'transition of species' to be a theory founded on facts."

An eminent naturalist of the United States makes some observations tending to the same point:- "Although we may not," he says, "be able artificially to produce a change beyond a definite point, it would be a hasty inference to suppose that a physical agent, acting gradually for ages, could not carry the variation a step or two farther; so that, instead of the original (we will say) four varieties, they might amount to six, the sixth being sufficiently unlike the earlier ones to induce a naturalist to consider it distinct. It will now have reached the limit of its ability to exist as the former species, and must be ready either to develop a new dormant organic element, or die; if the former is effected, the osculating point is passed, and the species established upon the few individuals that were able to survive the shock. If the physical revolution supposed to be going forward is arrested or recedes, the individuals which had not passed the culminating point remain as a fifth variety, or relapse towards their former station; whilst the few which have crossed the barrier remain permanently behind it, even under the partial retrogression of the causes to which they owed their newly-developed organization. We may suppose some species and individuals to be more able to pass than others, and that many become extinct from inability to accomplish it. Under this point of view, a hiatus, rather than a regular passage, is regarded between a species, and that whence it is supposed to be derived, just as two crystals may occur, nearly identical in composition, but without an insensible gradation of 
intermediate forms, the laws, both of organic and inorganic matter, requiring something definite: whence the rarity of hybrids and monsters, themselves subject to established laws."-Professor Haldeman's Enumeration of Recent Freshwater Mollusca, Boston Journal of Natural History, January, I844.

Barton, in his Lecture on the Geography of Plants (1827), gives the following remarks from the "Flora Lapponica" of Wahlenberg:- "It is not easy to decide in every case whether the specific differences of plants are invariable or not; and I do not blush to avow, that my observation in regions varying as to soil and climate, have led me to form an opinion differing essentially from that of the greater number of botanists. A naturalist, who has visited only level countries, such as Northern Germany, can scarcely imagine how variable are the appearances of plants in mountainous districts. He frames for himself certain specific characters, and, by their help, supposes that he can determine between different species in any part of the world; and, in order completely to satisfy himself on the subject, he raises a few specimens in his garden. But I do not hesitate to affirm that conclusions so drawn are not fit to be put in competition with the extraordinary transitions observable in many parts of Lapland. Who has ever been able to bring back to their original form the monstrous productions of our gardens? When, therefore, I assert that the Woolly-leaved willow [Salix lanata] is sometimes found with leaves perfectly entire-sometimes serrated, sometimes round, sometimes spear-shaped, sometimes downy, sometimes perfectly smooth-I merely state the result of my own unquestionable experience, which I cannot consent to overlook, for the sake of pleasing the fancies of botanists."

A correspondent adds a number of facts and remarks from high authorities favourable to the hypothesis of variability of plants.

"'Algx,' says M. Fries, the Swedish botanist, (cent. vii. 669,) 'which are rnuch more extended in their native element, when exposed to the air, contract, and become lichens.' Thus nostoc muscornm becomes collena limosum; and Sir J. E. Smith has even decided that Licken pygmaa, when growing under water, is an alga, but when above, a lichen. (Loudon's Encyc. of Plants, p. 978.) This plant (fucus py'smaus of Eng. bot.) generally grows on rocks 
washed by high tides, and its character varies with its situation and its liability to submersion.

"'Algæ, lichens, and the collateral orders of fungi,' says Professor Lindley (Loudon's Encyc., p. 948), 'may be said to exhibit the lowest stage of vegetable development . . . . indeed, it seems that each is resolvable into the other,' \&c. (ib. p. 924). 'Of the former, many are considered by some botanists to be animalculæ, and others to be the seedling plants of mosses.' Thus in Eng. Botany, as to Conferva stipitata, Confer. striatula, C. taniaformis, Sir J. E. Smith pronounces himself unable to decide upon their animal or vegetable nature, 'even at the risk of being charged with not knowing a coralline from a conferva.' He considers them as 'intermediate links between the two kingdoms.' Not only is our garden cabbage derived from a sea-side plant, entirely different from a cabbage in appearance; but the same plant, Brassica oleracea, is also the original of the Swedish turnip. (Limnaus Eng. Bot., Bras. Oler.)

"'The vegetable and animal kingdoms have,' say Kirby and Spence, "their land debateable, occupied by those 'productions moyennes'-to use a term of Bonnet's - which are, as it were, partly animal and partly vegetable,' (iv. 370) . . . . ' 'but a more striking analogy has been traced between the insects that undergo a metamorphosis and the vegetable kingdom .... . there are circumstances which afford some ground for supposing that the substance of the insect and the vegetable partakes of the same nature; at least approximates more nearly than that of the insect and vertebrate animal (v. 3, 59).' The development of insects is by no means undeviating, and is capable of being much modified by circumstances. In addition to the striking instance of change of sex, in the development of a second queen-bee, it may be remarked, that in the pupa state insects are sometimes so matured as to be capable of continuing their race. Dr. Leach gives (from a communication by Sir Joseph Banks) a very interesting account of a spider which, having lost five of its legs, from a zueb-zueaver became a hunterthese legs it afterwards reproduced, though they remained shorter than the others. - Linn. Trans. xi. 393.

"In addition to your remarks on the cow-the wild original of 
this animal possesses large lachrymal fossa in the cranium, which in the domesticated animal are entirely wanting. In Hungary and Sweden, there exists a remarkable variety of solidungular pig, 'being single-hoofed like the horse'-(the cloven-foot is given by Moses as a specific mark of distinction). Linnæus has selected the form and nature of the teeth as a distinguishing characteristic of the higher mammalia; yet Blumenbach and others have observed a peculiar conformation of teeth in several Egyptian mummies, human ones, where the incisor teeth, instead of presenting their usual sharp cutting edge, were thick, short, and flat, resembling the molars; and the canine teeth only distinguishable from the bicuspides by their situation. (Rees's Cyclop. Art. Cranium, by Lawrence.) A similar structure has also been observed in the teeth of the Esquimaux and Greenlanders.

"The camel's capacity of enduring thirst is an acquired habit, depending upon its training, and adapts itself to the animal's adopted mode of life. 'In Egypt,' says Burckhardt (Notes on the Bedouins and Wahabys, 4to, r830), "where he drinks daily of the Nile, the period of privation cannot be extended beyond a day; on the high but moist table-lands of Anatolia, it is two days; over Arabia generally, it is four days; while in the route between Egypt and Senaar, they will continue nine days without water, though they suffer severely.' Burckhardt treats the often-repeated account of lilling the camel for the sake of the water in its stomach as a fable. This animal, indeed, has not, as is generally stated, any peculiar structure in the form of a sack, or fifth stomach, to enable it to sustain long-continued privation of water. John Hunter, who dissected a camel, states that he could find no more than four stomachs, the usual number in ruminating animals; and Sir E. Home, who assisted at the dissection, and prepared the different stomachs for exhibiting their structure (now in the Hunterian Museum), could discover no separate reservoir for water. Either, then, this does not exist, or it is developed in the course of education, and by the creature's habitual necessities. . . .

"The offspring of the goat and ewe possess perfect powers of reproduction; the same may be observed of hybrids between the canary bird and the goldfinch, chaffinch and bullfinch, yellow- 
hammer and sparrow. The progeny in all these cases are prolific, and breed not only with the parent stock, but with each other. So also the domestic fowl and the pheasant, the partridge and the guinea-fowl. White, of Selborne, gives us a description and figure of a bird, shot at Lord Stowell's, which he considered as a hybrid between a pheasant and a pea-fowl.

"The following not less remarkable or interesting fact was related to us by $\mathrm{Mr}$. M'Nab-viz., that he had sown the seeds of Ilex balearica, from which he had produced the common holly. He had also raised from the seeds of the tender Madeira holly (Ilex perado), a variety identical with that known as Hodgin's holly; and although the offspring of a tender parent, yet, like Hodgin's variety, it was also quite hardy. We regard these as extremely interesting and curious facts. We have here the Ilex balearica reverting back into the type of the genus, the common English holly, and this, too, although an exotic, and acknowledged species; while in the case of the Ilex perado, a plant scarcely deserving the name of half-hardy, it produces an offspring not only wholly different and unlike itself, but, what is far more remarkable, the progeny are hardy, while the parent is tender.'-Gardener's and Farmer's Joumal, Sept. 9, I848, p. I64. Article-Notes on a Gardening Tour. By the Editor."

When we consider the importance attached in predominant systems to minute peculiarities of the teeth as indications of distinctness of species, it becomes curious to learn the variability attaching to this department of organization in the human subject, as above remarked upon. It appears that, among a quantity of human remains found by Dr. Lund in the province of Minas Geraes, in Brazil, many of the heads present "the incisor and molar teeth exactly alike." The same peculiarity has been observed, not only in Egyptian mummies, but in heads raised from Celtic, Roman, and Saxon tumuli, in our own country. Of one found in 1838 , in a barrow on the Berkshire Downs, the teeth in the usual place of the incisors were "of an irregular solid oval form, strongly coated with enamel, and in every respect like the natural molars." The bicuspids were also molars.' Mr. Roach Smith, in his Collectanea Antiqua, notices such teeth as frequently occurring in the ancient Celtic barrows of Britain.-Letter of R. H. Allnutt, Medical Gazette, I845, p. 867. 
If the human race be of one species, yet have teeth so different, it may be asked of Professor Owen, how should fossil equidx be distinct species with dentine peculiarities of smaller amount? Why a different rule in the two cases?

I2. ANSWERS TO OBJECTIONS.

\section{Mr. Hugh Miller.}

Mr. Miller formally entered the field as an objector to the present work in IS49, when he published a volume entitled, Footprints of the Creator, or the Asterolepis of Stromness. He is a most ingenious and interesting person; his merits as an investigator of the fossils of the Old Red Sandstone are great; his literary powers of illustration are such as to require no allowance to be made for his early circumstances and education in any court of criticism; further, he is an earnest and upright man. I therefore give him on general grounds my respect; but I cannot admit that his book, ingenious, pains-taking, and eloquent as it is, makes the slightest impression on the arguments for a natural history of creation.

Mr. Miller acquits the Development Hypothesis of the vulgar charge brought against it, of involving atheism. He admits that "God might as certainly have originated the species by a law of development, as he maintains it by a law of development ;" which I humbly think is going nearly as far as myself, seeing that I have done nothing more than suggest the probability of some such method having been followed by the Creator, after showing facts in the history of nature which give the idea some countenance. Mr. Miller, however, goes on to say, that there are "beliefs in no less degree important to the moralist or the Christian, than even that of the being of a God, which seem wholly incompatible with the development hypothesis." He thinks it infers, either that "all the vitalities, whether those of monads or of mites, of fishes or of reptiles, of birds or of beasts, are individually and inherently immortal and undying, or that human souls are not so." He continues-"If, according to the development theory, the progress of the first Adam was an upward progress, the existence of the second Adam . . . is simply a meaningless anomaly," etc. My answer 
is that hundreds of the now admitted facts of science, including many of geology itself, have been objected to on similar grounds, yet have made their way, and been ultimately found not irreconcileable with the doctrines on which the objections were based. Mr. Miller himself says, it is " not improbable that for every year during which man has lived upon earth, the Pterichthys and its contemporaries may have lived a century." Can he conscientiously say that he is not here advancing something which, in the eyes of nine-tenths of Christendom, is destructive of the authority of that record on whose infallibility the truth of Christianity rests? As a British Christian of the year I 800 , would he not have condemned any one who made such a declaration as this which he now, in $\mathrm{I} 849$, puts forth in perfect security? Until he can answer these questions in the negative, I must protest against any such mode of discussing a purely scientific question.

Mr. Miller takes, from a low part of the Old Red Sandstone formation, a fossil fish, the Asterolepis, on which he proposes to try the question, whether the earliest fishes were low in the scale, as the development hypothesis requires. It is, he says, "the oldest organism yet discovered in the most ancient geological system of Scotland in which vertebrate remains occur." In several chapters he minutely describes the parts which he has discovered of this animal ; showing so much curious work in its structure, as doubtless must prepare the bulls of his readers for the final assertion, that, "instead of being, as the development hypothesis would require, a fish low in its organization, it seems to have ranged on the level of the highest ichthyic-reptilian families ever called into existence." "Instead of taking their places," he also declares, "agreeably to the demands of the development hypothesis, among the sprats, sticklebacks, and minnows of their class, [these ancient ganoids] took their place among its huge basking sharks, gigantic sturgeons, and bulky swordfishes." It is lamentable to think how many well-meaning people must have responded with joy to these conclusions, while the fact is that the hundred pages of clever writing and vivid illustration in which they have been prepared for are merely an example of labour thrown away.

In the first place, while it is acknowledged by Mr. Miller that 
there are fossil fish in a lower formation, the fact, if it were one, that these Old Red Sandstone fish are not quite at the base of their class is of absolutely no importance. It will be found that his acknowledgment on this point is only made with a liberality somewhat unfortunate for himself.

In the second place, the Asterolepis and its contemporaries were low fish. This is the admission of one whom Mr. Miller loves to quote, Professor Agassiz, who (see Proofs, Illustrations, \&\%c., No. 7) expressly says of the fishes of the early period, "They were not so fully developed as most of our fishes, being, like the sturgeon, arrested, as it were, in their development." On the point of large bulk, which Mr. Miller speaks of as most important to mark the high character of these ganoids, take a decision from the same great naturalist : he says (see Proofs, Illustrations, E ${ }^{\circ}$., No. 10), "The lower condition of structure and development is manifested in a more"bulky body." As to the fine work which Mr. Miller shows to have been expended on the dermal plates of the ancient ganoids, the same course of illustration and argument would make out the encrinites moniliformis a high animal, or place the butterfly above the bird on account of its curiously-formed wing. It is perhaps no great discredit to $\mathrm{Mr}$. Miller, who is not a naturalist, to have proceeded on such false grounds; but it is somewhat remarkable that naturalists should have allowed his work to be four times printed, without giving a hint for the warning of his readers, while the most trivial mis-statements of the present work, albeit in general not at all bearing on its conclusions, have been held up as destructive of its credit.

Mr. Miller's sixth chapter is one which he must now review with so much mortification, that, notwithstanding the taunting tone in which it is written, a magnanimous adversary would speak of it with tenderness.

At the time when this work first appeared, one large fossiliferous series at the bottom of the scale, namely, the Lower Silurian, had yielded no remains of fish, though it had been long and diligently explored. This, though a negative fact, was one of some importance to the development hypothesis, and was noticed accordingly. Some writers on the other side adopted the expedient of slumping the Lower and Upper Silurians together, and telling the ignorant public 
that vertebrated animals, the highest type of being, was found in the very lowest formation. It never could have been apprehended from anything said by these gentlemen, that the Lower Silurians constituted a distinct formation, three thousand feet thick, and representative of an immense stretch of time. I was therefore constrained to speak more emphatically of the long invertebrate era of the Lower Silurians. "It is still customary," I said, "to speak of the earliest fauna as one of an elevated kind. When rigidly examined, it is not found to be so. IN THE FIRST PLACE, IT CONTAINS NO FISH. There were seas supporting crustacean and molluscan life, but utterly devoid of a class of tenants who seem able to live in every example of that element which supports meaner creatures. This single fact, that only invertebrate animals now lived, is surely in itself a strong proof that, in the course of nature, time was necessary for the creation of the superior creatures." I thought proper to use some categorical language, to prevent my opponents from any longer blinking or misrepresenting this fact.

Objectors, feeling that to slump the two formations, would no longer serve their purpose, were exceedingly anxious to discover some remains of fish below the Upper Silurians, or even in the senior portions of those Upper Silurians where as yet no such fossils had been detected. A temporary gratification of their wishes was in store for them. Ichthyic fossils from the Wenlock Limestone were announced by Professor Sedgwick in 1845; he was sure of his fact, for he had "seen" the fossils." They were in such quantity, that seven species were determined. Next, Sir Roderick Murchison wrote to Mr. Miller in 1847: "The Lower Silurian is no longer to be viewed as an invertebrate perior; for the Onchus (species not yet determined) has been found in the Llandeillo flags and in the Lower Silurian rocks of Bala." This relic was determined to be a fish spine by "a very competent authority," and, according to Mr. Miller, we owed the important fact to "one of the most cautious and practised geologists of the present age, Professor Sedgwick." At the same time, it was stated that Professor Phillips had found remains of a fish in the Wenlock Shale, a position lower than the Wenlock

\footnotetext{
* Edinburgh Review, July, 1845 .
} 
Limestone. About the same level, similar relics had been cliscovered in America. Thus a great array of instances of fish in the Lower Silurians and lower portions of the Upper Silurians was made up, to the assumed confusion of the advocates of the development hypothesis. Mr. Miller penned an eloquent chapter on the subject, speculating on the size and character of the animals, and not failing to apologise for the tediousness to which he was condemned by his adherence to facts, he being in this respect at a great disadvantage in comparison with the ingenious theorist who has only a fancy picture to make up.

Will it ever be beliered by the readers of Mr. Miller's ingenious book, that not one of the "facts" on which he is so fearful of being tedious, is a fact at all? From "a very competent authority,"* we learn that the seven species of fish from the Wenlock Limestone, believed in by Professor Sedgwick, because he had "seen" them, turn out to have been found in the debris of a quarry of that rock, where it is admitted they had most probably been dropped from the pocket of some workman who had obtained them in a neighbouring quarry of a higher formation! $\dagger$ The Onchus spine from the Bala Limestone had been entered by the government surveyors, as a fragment of fish, after only a "cursory examination;" it proves to be, "in reality, half the rostral shield of a trilobite!" "Its resem. blance to an Onchus was due merely to its being broken in half and obscured by stone." In like manner, the spine from the Llandeillo flags, certified as such by "one of the most cautious and practised geologists of the present age," has been declared to be nothing but a piece of "a new genus of Asteroid Zoophyte," something lower in creation than even the Bala spine proved to be! While these vexing discoveries have been in progress, Professor Phillips has withdrawn his authority from the remains in the Wenlock Shale, and the low position assigned to the American specimen by Mr. Miller has not been sustained. In short, the whole of this chapter, which Mr. Miller feared would be tedious from its adherence to "sober fact," ought to be the most amusing (and I am afraid it really is so)

* J. W. Salter, in Journal of Geol. Soc., May, 185 I. † This is Mr. Salter's conjecture. 
in his whole book, seeing that it consists only of the purest fictions, the fictions of over-hasty science.

In his fourth edition (I85I) Mr. Miller inserts a note announcing that the supposed ichthyic remains from the Bala Limestones have "proved, on closer investigation, to be spurious." So much he had then discovered. But coprolites had been found in that ancient group of rocks, bearing witness to the existence of vertebrata in those ancient seas. In reality, there have been only found, in the Llandeillo rocks, "certain rounded black substances," which "suggested the idea of coprolites,"* and in which a large proportion of phosphate of lime is detected. An inference from chemical science respecting an object standing so far out from the region where there are any cognate facts to support it, will not of course go a great way with ordinary philosophers; but such facts have a peculiar value for opponents of the development hypothesis, and we may of course expect to find this kept by them fully in view.

Mr. Miller has not yet, however, exhausted his traces of vertebrate life in the Lower Silurians. "The course of discovery," says he, "has added greatly more to the evidence previously accumulated against the Lamarckian than it has withdrawn. The track of a quadruped has recently been found imprinted on a Lower Silurian sandstone in North America."

It is very unfortunate for evidence of this kind, that it is only added to be immediately after withdrawn. The Canada slabs with chelonian tracks reigned for a time in 1851 . Professor Owen, when he had seen only a few, gave his opinion that the peculiarities "pointed to the Reptilia," and he "inclined to refer them to a species of Terrapene or Emydian Tortoise." The President of the Geological Society gave his countenance to this idea in his annual address of that year. To find that not merely fish, but reptiles, had lived coevally with the hitherto supposed protozoic mollusks and trilobites, was a discovery even exceeding the wishes of such men as Mr. Miller. More slabs, however, came to England; some whispers of doubt began to circulate; and the learned Hunterian Professor was induced in spring 1852 , to give the whole subject a new and

\section{* Mr. Salter's paper, loc. cit.}

E E 
more searching investigation. The result appears in a most ingenious and laborious paper, presented, with many excellent illustrations, in the Quarterly Journal of the Geological Society. Mr. Owen there arrives at the conclusion that the foot-tracks are not chelonian, but cristacean, thus leaving that early age still invertebrate!

Now I am far from saying that remains of fish may not yet be discovered in the Lower Silurian formation;* but, in the meantime, it stands as a remarkable fact, that the formation, though much explored, and though lower organisms have been found in it in vast numbers, has not yet yielded any examples of this vertebrate type. And surely, while we admit that such negative evidence can never be equal to positive in value, there must be some limit to our inferior appreciation of that kind of proof. It ought surely to be remembered that, if there be not fish in that formation, we never can have any but negative proof of the fact. Shall we not then set some value upon that kind of evidence?

The various announcements of fossil fish below the Wenlock limestone have ended in such discredit to all concerned, that comment on the subject is unnecessary. It seems fair, however, to hint that the eagerness and facility which have been shown in admitting facts against the development hypothesis, even when they were of that isolated character which is most apt to excite suspicion, scarcely comports with the caution which men of science so loudly demand. It may be asked, is there only to be caution in admitting facts which contribute to the support of a hypothesis? Is heedless haste to be allowable where the hunting down of a hypothesis is in view? If so, it is proper that the public should be made aware of it, so as to be on their guard against too readily believing that obnoxious generalizations are disproved. For my own part, I must claim for the future the right to be somewhat slower than heretofore in accepting facts which are hurried before the world, as subversive of the development hypothesis.

* It is nevertheless remarkable that the admitted evidence of fish even in the Upper Silurian formation has sustained a diminution, rather than an addition, since the first publication of this work in 1844 . See papers in the Journal of the Geological Society for February, 1853 , in which a great number of the so-called ichthyic fossils of that formation are detected as being fragments of crustaceans, leaving barely a representation of this vertebrate type in any portion of the Silurians. 
Not content with what he had done to prove the high rank of the Asterolepis, Mr. Miller employs the three succeeding chapters in an attempt to obtain a high place in the scale for the Placoid fishes. He first employs much ingenuity and some amount of original observation in an attempt to establish that the rank of fishes should be determined, not by the osseous, but by the nervous system. $\mathrm{He}$ next brings forward some adroit argument against the principle, that "what is a mark of immaturity in the young of one set of animals, is a mark of inferior organization in the adult forms of another set." An entire chapter is devoted to the explication of a principle of degradation which appears in the succession of the animal types, the footless serpent, for example, coming after the strong-limbed reptiles, - the inferior fishes also, according to his classification, coming last. The conclusion he arrives at is, of course, that embryotic development affords no true key to the history of creation, for they do not present similar phenomena.

It is impossible to follow Mr. Miller through all the illustrations by which he labours "to make the worse appear the better reason." But it is not necessary. While, from anything that appears in his book, it might be supposed that the doctrines on which our hypothesis is founded are mere dreams entertained by an unknown author, and a few other men of no mark or authority, they are in reality sanctioned by naturalists of the highest repute. It seems to be only necessary to point to the opinions of some of these men, as being sufficient to prove that Mr. Miller's views, not mine, are those which should be regarded as novel and heterodox. Let the reader, then, be referred in the first place to our Proofs, Illustra. tions, \&c., No. 7, where he will find Professor Agassiz affirming that the cartilaginous fishes are inferior to the osseous. "These ancient fishes," he says, "were not so fully developed as most of our fishes, being arrested, as it were, in their development." Can anything be plainer than this? In an article in the Quarterly Review for September, I85I, designed to refute some of the views of Sir Charles Lyell, the writer, universally understood to be an anatomist of the highest rank, says, "In relation to the circumstances in which they lived, palreozoic fishes were as perfect as their successors; but, in comparison with these successors, they were less 
fully dcvelopcd." It need scarcely be remarked that twenty chapters from a mere working geologist and littérateur like Mr. Miller could not stand against such a declaration from such a quarter.

As to the general fact of a harmony between individual develop. ment and the development of animal life as manifested by geology, which Mr. Miller takes upon him to reject, it is affirmed as positively as words may speak by Professor Agassiz. The learned naturalist refuses to see in this remarkable parity the history which we have endeavoured to read off from it; but as to the fact of the parity itself he has no hesitation whatever. It must be for Mr. Miller's readers to say which authority they are willing to accept, Mr. Miller or Professor Agassiz.

We consider the early fishes as forming by no means the clearest part of this narration; but we are not without hope that the remarkable fact of their high nervous system, and other points of superiority, on which Professor Sedgwick and Mr. Miller have expatiated-straws to drowning controversialists-may yet be explained on some principle in entire conformity with that parity just spoken of between the fœtal history of an individual and the entire history of creation. We can see some prospect of this result in the fact that in the individual development, the organs subserving the functions of animal life, make their appearance before those which subserve the functions of vegetative life. As the nervous system belongs to the former, it seems as if we were to expect, in a march of animals representing the stages of fœtal development, that those possessing for their order or family most intellect should come first. We do not say that such is the explanation of the mystery; but we think that a candid examination of such points in transcendental physiology might, in the hands of such a man as Professor Owen, lead to some interesting results, and probably of a cast favourable to the development hypothesis.

The chapter on Degradation is expected to tell against that hypothesis, because it is assumed that the hypothesis necessarily infers an unfailing advance in all the lines of life, whereas, in the explanation presented in the Vestiges, allowance has, on the contrary, been made for what may be called partial recessions, or what appear such, under the influence of external circumstances. What 
is there set forth is, that there have been decided developmental advances from one grade of animal dignity to another, as from invertebrate to vertebrate, ichthyic to reptilian, reptilian to ornithic and mammalian, and in certain inferior gradations, all this under an inherent independent impulse, but that in special points of organization, there was an adaptability under the influence of external agencies-though taking effect through the medium of reproduction-which had caused considerable minor modifications, liable to be described as a degradation. Thus, for example, some animals of the lizard order might resort to a furtive life in the grass, and in time become better adapted to that field of existence, the limbs shrinking up in the course of generations, for want of exercise; and when we see certain ophidians with the mere remains of a pair of limbs dangling from the sides, but of no use, do we not see something very like a penult stage of the very process here hinted at? This work has been proclaimed as anti-scientific in its whole tendency, while that of Mr. Miller has been somewhat officiously patronized and applauded on opposite grounds; but I humbly think that there is here something much more lilie a scientific explanation of a natural fact, than in mystic allusions to a state of "ever-sinking degradation" in animal life, as something analogous to the history of a race which "long since separated into two great classes-that of the "elect angels,' and that of 'angels that kept not their first estate." "The reader will find in the text (p. 232) a further explanation of these so-called degradations, not merely in conformity with, but in strong support of, the hypothesis of development.

Mr. Miller's tenth chapter opens with a discussion of the evidence from the Silurian mollusks. He misrepresents my argument from the humble character of the Brachiopoda, and insists on the high standing of the Cephalopoda. It is enough for the setting aside of this part of Mr. Miller's opposition, merely to point to the authorities (Proofs, \&c., No. 6.) for both the brachiopoda and cephalopoda of that age being low in their respective orders.

He adds one remark on these brachiopoda, that they "consisted of much larger and more important animals, than any which the group contains in the present day. It [the group] has yielded to what geological history shows to be the common fate, and sunk into 
a state of degradation and decline." Mr. Miller's anxiety to make out a deterioration of the works of the Almighty seems so great, that I am afraid the truth will make him somewhat uncomfortable. He must nevertheless be again reminded that comparative bulk, which he rashly assumes as a mark of dignity, is unequivocally affirmed by Professor Agassiz as an indication of inferiority.

The remainder of the chapter is an eloquent exposition of what Mr. Miller considers as the proper view to be taken of the palæozoic flora. I cannot withhold my admiration from the ingenuity of illustration and beauty of language exhibited in this pleading, even while I must condemn it as wholly unsound. The highest authority on the subject (Proofs, \&c., No. 9.) fully bears out the view of the facts taken in the Vestiges, and even favours the inference drawn from the facts in favour of the development hypothesis. Mr. Miller chiefly insists on two particulars. Adverting to the rarity of land plants below the coal, he endeavours to account for it by saying"The fossil botanist, on taking leave of the lower Carboniferous beds, quits the land, and sets out to sea; and it seems in no way surprising that the specimens which he there adds to his herbarium should consist mainly of Fucacece and Confervece. The development hypothesis can borrow no support from the simple fact, that, while a high terrestrial vegetation grows upon dry land, only algæ grow in the sea." Can Mr. Miller seriously expect that we are to be content with this quiet assumption, that there was no dry land before the Carbonigenous era? I refer him to very sufficient authorities (Proofs, \&c., No. 3.) for a contrary opinion. The fact is, that the long continued existence of dry land throughout the enormous ages represented by the Silurian and Devonian formations, without leaving us any certain evidence of a land vegetation, is one of the preachings of geology most confounding to writers on Mr. Miller's side of the question.

But then, and this is the second particular, he has discovered a lignite, which he supposes to be Araucarian, in the Lower Old Red of Cromarty. This is the subject of much fine writing. It is an "unfallen Adam "-the "olive-leaf of Noah's dove,"-a whole forest scene is engendered by it in the imagination of this prose poet. "A true wood at the base of the Old Red Sandstone, or a true placoid 
in the limestones of Bala, very considerably beneath the base of the Lower Silurian system, are zuntozvard misplacements for the purposes of the Lamarckian." Oh, luckless word and bootless boast! The "true placoid" of the Bala limestones, which turns out to be "a new genus of Asteroid Zoophyte" (as shown a few pages back), is indeed an untoward misplacement-for Mr. Miller and those who led him to believe that it was a placoid fish. Taught by this misadventure that an Anti-Lamarckian is by no means infallible, when he rushes from one isolated and hastily-observed fact to a great conclusion, I claim a right to pause before admitting this lignite, lest it also should prove to be a "misplacement." The fossils of fish, which Professor Sedgwick so exultingly announced from the Wenlock limestone, and which he could not doubt because he had "seen" them, turned out to have been found, not in the rock, but in the loose debris of a quarry, where it was most likely they had been dropped by some workmen who had brought them from another place! When we turn to Mr. Miller's account of the circumstances under which the lignite were discovered, we certainly do not find any strong assurance against a similar mistake. "I found it," he says, "partially embedded, with many other nodules half disinterred by the sea, in an ichthyolitic deposit, a few hundred yards to the east of the town of Cromarty, which occurs more than four hundred yards over the great conglomerate base of the system!" We at least owe him thanks for his candour in the statement of the history of this fossil.

The next chapter, entitled "Superposition not Parental Relation," is in a jocular strain, and may perhaps raise a smile, partly at the author's expense, for wit is not his forte, but will scarcely in any candid mind produce a conviction. He supposes a low plain near the sea, containing marine remains, with those of some reptiles and birds, and covered by peaty mould, containing fragments of trees, the remains of a monkey, and over that the wreck of a human form. He supposes a ditch cut in this formation, presenting the fossils in ascending succession, and a would-be philosopher arguing from the succession, that the series of animals represented by the remains had stood in a parental relation to each other. And we are further informed that this is the infidel view of the matter, in opposition to the doctrine that "the Author of All created both land pro. 
ductions and sea productions at the 'times before appointed,' and "determined the bounds of their habitation."

Now, in the first place, there is nothing in the view of creation presented in the present work which stands in contrast to the doctrine that God created the living things of the world. The question is about something more special-the manner how. Apparently, however, it is not for the author of such a work to hope, that his views will be taken on his own showing. And yet Mr. Miller, at starting, had been candid enough to admit that the development hypothesis did not involve atheism.

In the second place, the illustration of the ditch and its fossils breaks down from want of true parity. It happens that, in the true geological " ditch," we see a series of animals in a rough way resembling not only their ascent in the scale of the zoologist, but also the progress of the higher individual in the process of reproduction. When the facts involved in these lines of investigation are modestly presented as vestiges of the manner in which God may have effected the peopling of the earth, it is humbly conceived that nothing truly ridiculous has been done, much less anything irreligious. It would be easy to show further differences of no small magnitude between the premises in the two cases; but I cannot condescend to take further trouble with an argument which seems to trust for its force chiefly to the foolish laughter which it may raise, or the unreflecting bigotry which it may excite.

At the end of this chapter, Mr. Miller refuses me the privilege of supposing that, prior to the Silurian era, there were lower and humbler forms of life, the remains of which have not been detected, or which may not have been preserved. He admits that Sir Charles Lyell and others take this view; but in the question connected with it I can have "no legitimate stake." "It is to Geology, as it is known to be, that the Lamarckian has appealed, - not to Geology as it is not known to be." "His appeal to the unknown serves but to show how thoroughly he feels that the actually ascertained evidence bears against him." This seems a hard law. It looks particularly so when the fact is that, if my opponents had not made rash and ultimately unjustified attempts to deprive me of an invertebrate era, and given representations of the grade of the earliest fossils which seemed 
opposed to the development hypothesis, I should have had comparatively little temptation to point to possible earlier fossils. Now that my original assertion of an invertebrate era stands triumphant over a hundred ignominious assaults, and the disingenuousness of my opponents in misrepresenting the earliest "actually ascertained evidence " is exposed, I am comparatively independent of possible earlier fossils. But, supposing this had not been the case, can it be seriously said that I have no "legitimate stake" in the question? If, in descending through the formations, we find them all fossiliferous till we arrive at one which is non-fossiliferous, but which has evidently been subjected to an agency notoriously calculated to destroy traces of organic matter, is the surmise, so natural in the case, that this formation may, in its original state, have been fossiliferous too, to be legitimate to all but me? I must profess myself unable to see how any rule of controversy can sanction such partiality. Mr. Miller says, my appeal was to geology as it is known to be. Well, and what is geology as it is known to be but the entire code of doctrine entertained at the present moment by its best expositors? If some geologists of reputation inferior to none, hold fast by the belief that there probably were fossils below the Silurians, is not the fact of some consequence, and am I not entitled to refer to it? Further, if, as is the case, another geologist of equal reputation (Sedgwick) believes he has found a formation lower than the Silurian, and discovers in it remains of animals of an exceedingly humble character, and no others, is not such a fact also fairly available to me? In denying me these privileges, Mr. Miller says nothing of the privilege he assumes of ignoring possible fossils, when it suits his convenience in this controversy to do so. He does not scruple in all cases to speak of the earliest "actually ascertained" and generally admitted fossils as if they were positively and conclusively the first, overlooking that many believe them not to have been the first; and many of his most plausible arguments are based on this deliberate assumption of what constitutes "Geology as it is known to be." He is at least consistent. It is precisely from one who takes more than justice to him. self, that we should expect a denial of justice to another.

In the twelfth and part of the thirteenth chapters, Mr. Miller treats of what he calls the Lamarckian hypothesis of the origin of 
plants, or rather the idea thrown out in this book, and which had also (unknown to me) been propounded in the mystic pages of Oken, that the vegetation of the earth had its origin in the sea. He considers it as necessary to this theory that there should be intermediate species on the borders of seas, or where salt and fresh-water meet; which he says is not the case-he finds no such thing in a particular inlet in Orkney, where there is a very gradual transition from salt to fresh-water. It seems to me a narrow ground on which to debate so great a question, and I must confess that till botanists of good authority have given their opinions, I cannot consent to take Mr. Miller's statements as conclusive even about the facts. I therefore place this question in suspense, feeling the more justified in doing so that the phytological part of the organic creation has never been prominently brought forward in this work or its sequel, but on the contrary held as subordinate to any rule which could be established for the animal kingdom.

Mr. Miller proceeds to try the aim and purpose of the present work by a reference to the experience argument of Hume and Laplace. Because of my having a preference for law as against miracle, he holds me as risking all upon the argument of these two writers, though I never made any reference to it. He assumes that I objected to creation by miracle, as contrary to invariable experience; and here, says he, is transmutation of plants shown by the Lake of Stennis to be " not only contrary to an invariable experience, but opposed to all testimony" - "a mere idle dream." In Mr. Miller's words, the experience argument of Hume "is quite sufficient to establish the fact that there can be no real escape from belief in acts of creation never witnessed by man, to processes of development never witnessed by man; seeing that a presumed law beyond the cognizance of experience must be as certainly rejected, on the principle of the argument, as a presumed miracle beyond that cognizance." Nay, he holds that the belief in the miracle is preferable, for the whole force of the anti-miracle reasoning fails to disprove the possibility of miracles, and only goes to this, that they are not to be credited upon report, or otherwise than on the strength of our own senses; - that is, the argument only tries to show an imperfection in our own minds-an imperfection, however, which has not been found to exist 
in intellects of the highest class, such as that of Dr. Chalmers, and those of Butler and Locke. We may, in short, be assured of a miracle from proper testimony; but of a law we can know nothing but from experience, and one contrary to experience is no law at all. Therefore "the argument of Hume and Laplace is perfect, as such, when directed against the development visions of Lamarck."

Mr. Miller must pardon me when I say that it is contrary to all the controversial codes I am acquainted with, to make one writer answerable for the arguments of another, to which he never referred, and of which he never made any use. Against every thing like a trial of my views by those of Hume and Laplace, I protest, as I like. wise do against the injustice committed by Mr. Miller of mixing up this work with the comparatively vague and unsatisfactory speculations of De Maillet, Lamarck, and Oken.

I might content myself with this general protest; but I am, nevertheless, willing to show how experience really bears on this question.

Grant that we have certain miracles sufficiently attested, and which are therefore believed by the Lockes, the Butlers, and the Chalmerses, it remains to be asked if they form, on the doctrine of experience, any proof for a miraculous mode of creation. Mr. Miller speaks of "the great moral purpose God intended by them." Locke, I find, characterises them as "the credentials of a messenger delivering a divine religion." They notedly had a special purpose in view concerning human affairs. Being in their very nature exceptional,-in the words of Locke, "operations contrary to the fixed and established laws of nature," -it does not appear to me that, in their most unqualified reception, they favour the idea that a process extending through a vast stretch of time, the origination of one enormous section of what we now call nature, a process which in the main took place before humanity existed at all, so as to be in any way affected by it, was also of the character of miracle. It rather seems to me that this process belonged to that fixed course of nature which it is necessary for a miracle to interrupt or violate, in order to be a miracle.

On the other hand, experience has this reference to a theory of organic creation in the manner of law. It presents to us a system of order or of law-that system of which miracles are but transient 
interruptions. "Where is the man among the cultivators of science," says Professor Sedgwicl;, "who denies that the whole of nature (material and moral) is under the dominion of law and order?" If, then, we are to decicle in what manner the world was conducted in the ages during which organic beings were coming into existence, by the rule of experience, we must pronounce that it was in the manner of law and order. This is a conclusion which it seems impossible to evade. It is the very heart and strength of the present work. How does it affect Mr. Miller? Law is admittedly the rule of nature, miracle the exception-an exception which we only know of by historical means, and as having reference to a particular end connected with human affairs. Whether was organic creation most likely to have been so normal or so exceptional? As a lover of science, I cannot but blush in asking one of its intelligent cultivators such a question.

It suits Mr. Miller's purpose to overlook this general and fundamental argument, and assume that the question for experience to try is, whether there be a law upon earth for the transmutation of species. On the strength of what experience can show against that, he affects to believe that the whole question can be at once settled. Now the real position of the development hypothesis is this. It being granted that the world is one of law and order, and consequently that organic beings must have originated in accordance with some law, it becomes us as reasonable beings to look about through nature, in order to see if there be any such law still in operation, or even any traces of its operation in a past age. We hear of many men who have believed it to be proved that living beings have originated from inorganic elements in our own age; but this is a doctrine not generally received, and we cannot found much upon it. We see, however, that undeniably organic beings have appeared on the eaath in a certain order generally suggesting a progress from low to high, and this throughout a long succession of ages; we also see a remarkable parity between these stages of progress and the succession of forms through which one of the highest animals passes in its foetal history; awaking the idea of a general gestative development for animal life, as being that law of which we are in quest. Here we do not pretend to have proved the existence 
of the law. But we contend that, if anyone has thoroughly received the doctrine which experience points to, of there having been some law concerned in the case, he will, if he is docile to reason, deem this provisional or hypothetical view of creation, - -standing in so strong analogy to processes actually exemplified in nature-borne out by the positive discoveries of geology-considerably preferable to a hypothesis of miraculous creative acts which has no known facts in its favour whatsoever, and stands in no traceable relation to anything known in the frame of the universe. He may think that, by our hypothesis-the only one which even claims an affinity to nature-he has been allowed to see the veritable footprints of the Creator, while in the other he only can see an incoherent dream. That many have thus rightly read the present work, its author cannot doubt, after the reception it has met with. But there is certainly something discouraging in the fact, that its ostensible opponents have all, through voluntary or involuntary blindness, mis-stated its leading arguments, as well as done their best to misinterpret nearly all the facts of nature by which these arguments are illustrated.

\section{Professor Sedgzvick's Preface, \&oc.}

The hostility of this gentleman to the present work was first shown in a long article in the Edinburgh Reviezv (July I845), written in a passionate tone, and adducing many facts and reasonings which the learned professor evidently expected to have an overwhelming effect. The author was nevertheless able to enter defences in a volume entitled Explanations, \&c., which met with a favourable reception from the public. His main work, moreover, has evidently not been quite crushed by the blow of the professor, for it has since then passed through many editions, and still maintains its original popularity. Feeling apparently that the article in the Review had not accomplished the desired end, Mr. Sedgwick has done our work the honour of writing between three and four hundred additional pages against it, and these he has presented as a set of incrustations spon a reprint of his small treatise, $A$ Discourse on the Studies of the University of Cambridge, which now therefore appears much like a 
simple mollusk bearing thrice its own weight in balani, serpulæ, and other inferior organisms. I must spare the reader the tedium of discussing such of these annotations as refer to particular points in science, as the nebular hypothesis, the grade of the cartilaginous fishes, and other matters in palæontology, content to believe that enough has been done in the Proofs, \&c., to support my own views against those of the Woodwardian professor. It will be sufficient here to meet Mr. Sedgwick on a few of his leading arguments.

The learned professor asks if we have any proof of specific trans. mutations in the living world, and answers by saying that "ive have not the shadow of any proof of them." He admits "there are varieties - the limits of species are not well known .... as an inevitable consequence, naturalists have made many blunders . ... but the mistakes of naturalists alter not the laws of nature. ... Not so much as one true specific change has ever been brought about, so as to raise the progeny of any known animal to a higher grade in the organic scale." (p. xxv.)

It would be obliging if Mr. Sedgwick would explain how, if the limits of species are not well known, he comes to be so sure that there is no such thing as specific transmutations. He looks to naturalists for the data on which he makes this so confident affirmation: if naturalists are so liable to make mistakes about species, how can he justify such confidence? And how is he so well aware of the laws of nature, and how can he so well define their operations, inclependently of those blundering naturalists? If he cannot answer these questions satisfactorily, I must take leave to consider him as very far from being entitled to find fault with the reasoning of the work in dispute, or to pronounce in any manner upon the subject.

No specific transformations! It may be that there are certain forms and grades which are not seen to be over-passed in the living world. It has never been alleged by the author of the Vestiges, as absolutely necessary to his theory, that such phenomena should now be witnessed. It has been, on the contrary, admitted that the time for them may be past. It has nevertheless been pointed out that a very remarkable degree of modifiability exists in organic beings of all grades, but especially the lower. And this has been laid hold of as favourable 
to the doctrine of organic development, for if a great variation can take place in the short period during which scientific observation has existed, it is quite clear that a greater still may have taken place in one of the vast spaces of time forming the epochs of the geologist. It is asked by the impartial public, how great is the degree of variation now occasionally observed to take place. They would learn nothing on the subject from Professor Sedgwick, beyond an ingenious hint that such things are confined to "dark corners of the animal kingdom," which every other person of his degree of intelligence in scientific matters knows is not true. Having elsewhere treated the subject pretty fullly, we shall content ourselves here with one case, taken from a part of the organic world by no means obscure. There is a wild grass named the Egilops ovata, and there is another well known plant called wheat. They are totally unlike each other, and naturalists have classified them not only as distinct species, but of distinct genera. Well, M. Fabre, in the course of twelve seasons, by merely selecting particular plants for reproduction, has converted the agilops into wheat. Here is a fact fully attested, and which no naturalist, as far as I am aware, rejects. The reader will judge of the value of the declaration that there is not the shadow of a proof of specific transformations, when he thus hears of one which may be styled generic; a stride ten times wider.-See Vestiges: chapter entitled Hypothesis of the Development of the Animal and Vegetable Kingdoms; also Proofs, Illustrations, \&c., No. II.

No proof of specific transmutations! Ay, scores of them, if we only could fix down naturalists to the species they have announced. It is only true that there are no specific transmutations in the same sense as it is true that no Quakers are ever brought to the gallows. Whenever species are transformed into each other, the naturalist concludes that they were not distinct species, but only varieties of one. "Species," in short, represents an idea in his mind, and everything inconsistent with this is a "mistake." Convenient philosophy, where formulæ of thought go first, and facts coming after are forced to square with them. Mr. Sedgwick knows the laws of nature by intuition, and with great complacency assures us that the mistakes of naturalists will not alter them.

About twenty pages of his preface are occupied with an account of 
the views of Dr. Clark of Cambridge, regarding animal development, the main drift of which is to show that the higher animal does not in embyro pass through stages corresponding to the character of the lower animals.

In opposition to the views of Dr. Clark of Cambridge, who has not been much heard of beyond the walls of that university, and to the conclusions of Mr. Sedgwick, who is neither an anatomist nor a naturalist, take those of the highest living authority on such subjects, Professor Agassiz. "Nothing can be more gratifying," he says, "than to trace the close agreement of the general results derived from the study of the structure of animals with the results derived from the investigation of their embryonic changes, or from their succession in geological times. Let anatomy be the foundation of a classification, and, in the main, the frame thus devised will agree with the arrangement introduced from embryological data. And again, this series will express the chief features of the order of succession in which animals were gradually introduced upon our globe."-Lake Superior, p. 197.

It appears, however, that some of the views which were prevalent regarding embryonic changes at the time when this work first appeared, are now given up, and I have therefore brought forward, in the present edition, an amended view of this subject : see chapter entitled Hypothesis of the Development, \&c. Professor Sedgwick will find that the amended view only brings the phenomena of development into a more perfect conformity with the history of species upon the earth, and so far strengthens the general argument of the present work.

The learned Professor occupies nearly a hundred pages in discoursing on the geological record of life, and, while admitting "a progressive development of organic structures," in a historical sense, denies that "the animal remains of our successive groups of strata are presented to us in such an order as to suggest a theory of natural development by transmutation from one organic form to another." "Are the Genera and Families of the old world," says he, "so illdefined as to pass one into another by insensible gradations? Are the organic intervals between the different orders and classes of the Animal Kingdom so far interpolated by new forms of nature as to 
lose all semblance of reality and permanence, and to show that all our systematic lines of separation are but the artifices of immature knowledge-that Order may spring from Order, and Class from Class, in the way of natural generation? Do the organic types of the old world follow one another chronologically, in such a manner as to arrange themselves on any conceivable organic scale, whether simple or complicated? To all such questions I can do no more than return a most decided negative."

The organic phenomena of geology are, by Mr. Sedgwick's own admission, "widely separated, broken, and disjointed." We can therefore scarcely expect to find in them the minute shades of gradation he assumes as necessary for a theory of transmutation. The theory, however, expressly leads to the expectation of considerable intervals of organic character between one grade of the animal kingdom and another, and it is not therefore surprising to find such breaks in the palæontological record. It is nevertherless true that many investigators fully equal in reputation to Professor Sedgwick, or any of those whom he brings forward on his own side, do show a succession of forms in certain orders, so as to make a very conceivable organic scale as regards those orders. We have just seen that Professor Agassiz avows his belief that "the chief features of the order of succession in which animals were gradually introduced upon our globe" are conformable both to a true classification of animals, and the embryonic changes undergone by the highest. In our Proofs and Illustrations, nearly every order of the Invertebrata is thus exhibited, upon authority of the highest kind, in the most perfect connexion with geological time. When the candid reader has perused these examples, he will be enabled to appreciate the intellectual probity of Professor Sedgwick, in alleging that the advocates of development can only give a semblance of truth to their theory "by reconstructing, hypothetically, a chain of being out of the organic fragments of the old world," etc.

It may be well, moreover, for the reader to bear in mind that the doctrine here condemned receives a certain degree of support from Professor Sedgwick himself. It will be found that, in another part of his pamphlet, he expresses his belief that "the origin of the organic world was determined by law," partly on the ascertained historical 
development of the forms and functions of organic life during successive epochs, which seems to mark a gradual evolution of Creative Power, manifested by a gradual ascent towards a higher type of being." So he negatives on one page the question, "Do the organic types of the old world follow one another chronologically in such a manner as to arrange themselves on any conceivable organic scale, whether simple or complicated?" And he admits, on another, "a development of forms and functions" throughout geological time, marking "a gradual ascent to a higher type of being." What can we understand from all this, but that, "widely separated, broken, and disjointed" as the phenomena of geology are, he is unable to deny that there is an order in them after all? Verily, he is the most obliging of controversialists, for if he denies any essential fact of his author at one place, he is pretty sure to give it his sanction at another, and a little trouble in the re-arrangement of his ideas is enough to bring him into tolerable harmony with the theory he condemns.

"On a scheme like this [of development] there is," says Professor Sedgwick, "neither sobriety in nature's movements, nor constancy in her laws." It "calls on us to believe in a series of miracles (for what is a miracle but a violation of the ordinary course of nature?); and it puts our language out of all true co-ordination with our knowledge. We use the word law to define the ascertained orderly movements in nature, whether animate or inanimate; and the successive changes we contemplate are connected in our minds under the ideas of material cause and material effect. But the moment we are led to speculate on the beginning of things-whether it be the beginning of a solar system, or the beginning of some new order of organic life-we are inevitably led to a conception of the First Cause, and we define the fact now under contemplation by the word creation."

I throw upon Mr. Sedgwick, and all who adhere to him, the philosophical infamy of resorting to miracle. My aim has been, is, and must be, with unswerving consistency, to maintain that in nature the Deity manifests, and has ever manifested himself as a God of order, natural laws being simply expressions of his will. We see these "orderly movements" in the present time; this is admitted on all hands. The question is, whether the commence- 
ment of any particular series of phenomena was an orderly movement also. Mr. Sedgwick says, when we are led to speculate on such things, we are "inevitably led to the conception of the First Cause," etc. Why the First Cause then any more than in the present movements? The mental process he speaks of may be "inevitable" in a mind of such calibre as his; on that point I am disposed to be very tolerant. At the same time, with all modesty, it does not seem to me difficult to get a little farther, and see that what we think the starting of a series of natural phenomena may have only been a new evolution of some previous or larger series, merely a stage in progress, while Professor Sedgwick's necessary idea of a creation not by law is only a somewhat happy example of the form of logic called begging the question.

One word more: he speaks of the idea of the commencement of animal life after the manner of the development hypothesis as implying a violation of the ordinary course of nature, because no such developments take place now; but if the following of generation after generation and a constant like-production be the ordinary course of nature at present, the fact itself of the starting of life was something different from that course, which must accordingly be to that extent liable to modification, in the conception of all who speculate on the subject. For Mr. Sedgwick, then, to talk contemptuously of any effort to fill up this gap in our knowledge as something interfering with the sobriety of nature's movements and the constancy of her laws, when he himself is forced by the same "fact" to imagine, what we equally do not see in living nature, the coming forward of the First Cause in some unusual manner, some manner different from the ordinary processes of nature, is surely a singular example of controversial effrontery, if it be not one rather of gross blindness and ignorance.

I had said at this place that surely such a train of reasoning or socalled reasoning, could impose upon nobody. But it seems right to recal the remark, when we reflect on the ground of objection to the development hypothesis which is commonly heard of among English naturalists. When the idea of an introduction of species into the world by development or modification is talked of, these gentlemen quietly set it aside with the remark, that it cannot have been the 
case, because there are no such phenomena as the starting of new life or passage from one form to another now, and the question is to be determined by experience. It never occurs to them to apply the same rule to the sole alternative idea of an introduction or modification of life by some miraculous mode. They find no such phenomenon as that now; yet, forgetting their own rule, they argue for it. No doubt, Professor Sedgwick rightly calculates the nature of his audience.

In one section of his preface, Professor Sedgwick discusses what he calls my "adopted philosophy," describing under this term the system of materialism in its grossest form, and raving against its professors with the virulence of a religious fanatic of the lowest school. I repudiate, as heartily as himself, this philosophy, and deny his ability to prove that my propositions, more than any others in science, necessarily lead to any such system of belief.

He then describes his own creed. The material world is manifestly conducted under a system of unvarying order. "Orderly movements and combinations in the animal world imply some corresponding laws, but different laws from those out of which spring the movements of dead and inorganic matter." Man is "governed by new laws;" "in his moral and intellectual attributes, he is widely separated from all other parts of the living world, and far above them." Thus "not one law, but many laws;" yet "all implying a unity of will in the great central and sustaining Power of the universe : and we thus ascend to a conception of one great Intelligent Cause, ruling over all nature, dead, sensitive, moral, and intellectual."

In the present work, it has constantly been maintained that the laws of nature appear as the expressions of a Will external to the world, leading us to the conception of a divine originator and ruler of all things.

The material and chemical laws are largely concerned in even the human constitution. Admitting, however, that there is a different law presiding over our moral nature, it is still a law. It still fixes thought and feeling as a department of nature, taking them wholly out of the region of the miraculous. God has appointed an order for the action of our intellectual and moral being, as another has been appointed for the arrangements and movements of the planetary 
bodies, and so on. Mr. Sedgwick himself makes at another place the full admission that "the mind and morals of man are under the regulation of fixed laws." Where, then, is the difference between us? Evidently in some perverse inference which he persists in making as a necessary deduction from our hypothesis, but with which it is no more justly chargeable than are his own views, or any other proposition of modern science. Some illustrations of this weakness in the logical power presently appear.

We find him going on to attempt, for the end which he has in view, the establishment of a difference between the material and moral laws. The former, he says, give certainties; the latter only probabilities. "The effects of a moral law admit of palliation or change, aggravation or diminution: not so can we change a material or mechanical law." "I affirm, then, that the moral conduct of man (whatsoever it may be in the eye of God) is not, like the movements of the heavenly bodies, bound up in the conception of a constant, undeviating law."

I answer-If "the mind and morals of man" are, as Professor Sedgwick admits, "under the regulation of fixed laws," the palliations and aggravations here spoken of must be determined by merely the mutual action and re-action of the laws themselves, as has been explained in my chapter on the Mental Constitution of Animals. To talk as if zue could change a moral law is absurd. Mechanical and chemical laws are, however, liable to be modified in their results by each other, precisely as the moral laws are. So in every way the professor fails. After such admissions as he has made, to come to such a "then" as we find in the above sentence shows a degree of severity in logic which he may be assured I am far from envying.

Strange to say, after all, Mr. Sedgwick admits the premises for the only positive conclusion aimed at in the Vestiges. He says- "If it be affirmed that the origin of the organic world was determined by law, we believe the proposition true-partly on the strength of what seems a sound analogy; for if the organic world be governed by law, we cannot believe that it commenced without law;-partly on its obvious adaptation to the existing laws of the organic world;-partly also on the ascertained historical development of the forms and functions of organic life during successive epochs, which seems to 
mark a gradual evolution of Creative Power manifested by a gradual ascent towards a higher type of being. But_—"

It cannot fail to be observed by any one who has comprehended the true scope of the Vestiges, that, in saying, "If the organic world be governed by law, we cannot believe that it commenced without law," Professor Sedgwick gives his sanction to the grand doctrine of that work, and abandons its true opposite of a creation by miraculous interference. We need not here stop to consider how far he is selfconsistent. Enough for the meantime, that he fully approves that doctrine which mainly we endeavour to advance, and does this partly, even, by the same arguments as those on which we proceed-for, of course, when we have settled that organic creation was a series of natural events, it matters comparatively little as to the special events themselves, whether they be such as the Development Hypothesis suggests or some other. I, for my part, have no such particular affection for that hypothesis as to be unwilling to give respectful consideration to any other that may be suggested: only, so long as it stands alone, I am willing to entertain it.

He goes on- "When it is affirmed that the successive parts of the great organic sequence are related to one another only in the way of material cause and material effect, we test the proposition by an appeal to facts and experiments-the last appeal on all questions of natural science-and on the strength of this appeal we deny the truth of the asserted proposition." . . . " "Those who exclude from their creed all conception of a personal and intelligent God of nature, must believe that dead, inanimate matter may, without external aid, and by its own inherent powers, work itself into what is vital, sensitive, and intellectual." The professor then goes on to argue for the existence of God from the law and order and harmony in the world, from the proofs of adaptation, wisdom, and goodness, and from reflections on our own internal consciousness.

It here fully appears that the real objection of the learned professor to the Vestiges is a bugbear formed in his own mind. It is nowhere affirmed in that work, that "the successive parts of the organic sequence are related to one another only in the way of material cause and effect." Cause and effect of any such peculiar character are never once alluded to there. The whole of the phenomena of 
the external world are regarded as originating in and dependent upon the will of God - the moral as well as material phenomena, the phenomena by which a globe was peopled, as well as those by which the population of a globe is sustained. This is what we have seen Mr. Sedgwick himself affirm. It is something over and above, a delusion of his own brain, with which he fights. It takes the form of a perfectly arbitrary distinction, which he asserts as between material cause and effect and moral cause and effect. He seeks, in many pages of by no means lucid writing, to establish this distinction, but can only show, what few would dispute, that a moral law is not a material law. "I affirm," he says, "that the moral conduct of man (whatever it may be in the eye of God) is not, like the movements of the heavenly bodies, bound up in any conception of a constant undeviating law." Let the reader observe that, a few pages back, we had Professor Sedgwick admitting that "the mind and morals of man are under the regulation of fixed laws." In the choice of his affirmations, I of course adopt the latter, finding in it enough to overthrow the whole effect of the long dissertation on the distinction between moral and material laws. It is enough for me that my vivacious opponent agrees with me in saying, that mind as well as matter is under law. As he has elsewhere deduced from the fact of the organic world being under law, that it must have also originated under law, he cannot save himself from another and similar logical conclusion, though he forces me to draw it for him, that the moral nature of man, being under law, also originated in the manner of law. He will be a little surprised, and so will some of his readers; but such is actually the self-contradictory position into which he has brought himself. As to the denial of a personal and intelligent God, or a belief "that dead inanimate matter may, without external aid, and by its own inherent powers, work itself into what is vital, sensitive, and intellectual," they are hallucinations of his brain as to me, whatever they may be as to others. I believe in a personal and intelligent God, and cannot conceive of dead matter receiving life otherwise than from Him, though of course in the manner of order or law. To attempt to fasten any doctrines upon me different from those I have myself avowed, is a mere trick of controversy, doomed, I trust, to bring its own punishment. 
After all, I ought perhaps to have simply taken up the professor's argument on material cause and effect as an unusually clear and bright example of his manner of controverting a proposition. I lay it down that the Divine Creator acts in the manner of law in the organic, as in every other department of nature. And to this Professor Sedgwick replies, "He who excludes the idea of an intelligent God of nature must believe that matter works itself into life." It is as if I were to remonstrate with a friend on his habit of sitting too late at dinner, and he were to answer, "If you believe that, you must conclude that I never contribute to a single charitable subscription." Or any other non sequitur. Professor Sedgwick, perhaps, does not consider me as one who denies an intelligent God; indeed, he elsewhere is so handsome as to defend me from this vulgar charge. But such is merely his way of answering a philosophical heresy, to which he has elsewhere given his own adhesion. At the same time Professor Sedgwick indulges in a large amount of scolding regarding material causes, as leading to cold, infidel doctrine-things with which the question has nothing to do. Holding him, however, to have admitted that the organic world originated in the manner of law, and that he is justly chargeable as much as myself with all the moral consequences of this belief, the real distinction between him and me is, that, feeling myself at that point, I have a hypothesis to offer as to a mode how-a mode which has much in actual science harmonising with it-while he, though equally constrained to pronounce on the subject, has no mode to suggest, starts back, indeed, from the very idea of such a thing, and in very confusion of mind contradicts his own proposition on the general question. He does, indeed, try to get out of the false position in which his reasoning lands him-a necessity for miracle-by speaking of different characters of laws, mysteries not to be meddled with, and so forth. But the childishness of his dialectics on these points is so palpable, that I decline taking the trouble of any particular effort to expose it. The youngest commoner he addresses must see its worthlessness.

Mr. Sedgwick has spoken of the author of the present work as, in his view, "not only unacquainted with the severe lessons of inductive knowledge," but possessing a mind "apparently incapable of comprehending them." As an illustration of the remark, the Professor 
adds:- "speaking of specific transmutations, he [the author of the Vestiges] has told us that, though there never may have been an instance of it since the beginning of the human race, "yet the doctrine may be shown on grounds altogether apart, to have strong probability on its side.' The author seems never to have learnt that there are not, and never can be, any probabilities in nature that are not suggested by experience."

I suspect that when a person who feels a real loyalty to the inductive philosophy comes into contact with one who does not, he will be very apt to appear to that person in the opposite predicament. He would apparently have no chance of justice from the Woodwardian professor. What was referred to in the above passage quoted from the Sequel to the Vestiges, was that, our experience showing that the world was conducted by its Divine Author under law, the origin of the organic world must have been of the same character alsoa most perfect instance of the inductive method, to my humble apprehension. So much being established, the process of development, the only natural mode ever suggested, or which apparently could be suggested for the origin of the said organic world, had of course strong probability on its side. How, on the other hand, does Mr. Sedgwick observe the Baconian maxims? Admitting with one breath that the origin of the organic world was in the manner of law, he with another patronises special efforts of Creative Power, an activity which has not one iota of observed fact, one sentence of the record of experience, in its favour. Telling us on one page that "there are not, and never can be, any probabilities in nature, that are not suggested by experience," he says in another (p. clxxviii.), "the succession of material phenomena and the acts of his own volition, would never lead a man to the highest form of truth, were there not a principle within himself, a part of his very being, whereby he is led to something far above what he knows and learns by his own experience!" Could it be expected that such a man was to apprehend rightly the author of the Vestiges, or know a true argument on the basis of the inductive philosophy when he saw it?

To come to the fundamental difference between the Author of the Vestiges and Professor Sedgwick. The former lays down the proposition :-it being admitted that the system of the Universe is one 
under the dominion of natural law (natural law being guardedly defined as a mere term for that order which the Deity observes in his operations), it follows that the introduction of species into the world must have been brought about in the manner of natural law also. The proposition is simply a syllogism : what is granted of the whole must be granted of a part. It may, the author admits, be difficult to understand by what process the introduction of species was accomplished; nevertheless, he has suggested one analogous to the fotal history of an individual animal, by which the work might have been done; and it has been shown that the actual history of creation, as far as we can gather it from geology, is in harmony with the requirements of such a process. Here, it is seen, the general argument is the strong one, while the suggestions as to a process form a mere hypothesis. What, on the other hand, has been the course of Professor Sedgwick? Starting from a different point, he says,-Species being now persistent, there being no divergence seen from the law that like produces like, it is unphilosophical to suppose that anything of the character of progressive development has ever taken place on earth. Thus fastening upon the hypothesis which has been started merely as a plausible explanation of certain unseen phenomena, as if it were the fundamental proposition of the book, and totally disregarding that fundamental proposition.

Mr. Sedgwick speaks of the present work as having been ill received by men of science, and he is studious to inculcate his own opinion of the author as a superficial writer, and one who can only bring forward "pretended reasonings."

It is, the author believes, a fact, that many men of science have, like Professor Sedgwick, received this work unfavourably, or at least expressed unfavourable opinions regarding it, and spoken disparagingly of its author. On the other hand, there are some who have allowed the author to understand that they take a different view of himself and his work. Let us assume, however, that many men of science have professed to accord with Professor Sedgwick on this subject-it may still be fair to ask if the decree passed by them is entitled to have the value of law.

It is, I suppose, scarcely allowable that we should point to the obvious temptation there is, in the state of public opinion, for men 
of science to profess the views which many of them have professed on this subject;-for it is of course possible that they may, to a man, be possessed of that magnanimity, and that love of truth for its own sake, which would place them above all flattery of, and submission to, vulgar prejudice. Let us therefore assume that they are all scrupulous to judge of this subject on what they believe to be perfectly pure grounds. It nevertheless strikes me as very remarkable, that a book held by them as so worthless should have provoked from them so many pamphlets, books, papers, prefaces, and ap pendices in opposition-nearly four hundred pages from Mr. Sedgwick aloneshould have also been deemed by several of them worthy of having books written in imitation of everything in it but its faithful logic. For these reasons, I humbly think there may be an unconscious insincerity in their professed opinions.

What is, however, still more remarkable, scarcely one of these gentlemen, in any public demonstration that has come from him on the subject, has shown himself to have a right conception of the fundamental proposition of the work. To be a superficial book, it has been remarkably hard to understand. It has also appeared that they were only able to make up a show of objection to the scientific data on which the work is founded, by misrepresenting these data, by ignoring all the highest authorities, and by clutching at immature announcements which turned out to be fictions. It has been shown that the propositions of the work, which they misunderstood or misrepresented, are in reality admitted or maintained by themselves. From their own writings it has been possible to collect those proofs of progressive organization, the existence of which they denied. It has been shown that they do not know the tendency of the facts of their own sciences, and blunder whenever they attempt to reason upon them :- Professor Sedgwick, for examble, corroborating at one place all the great truths which he has contradicted at another, and only truly contradicting and condemning himself. Now I respect and am grateful to these men for the industry and ingenuity they have exercised in furnishing us with isolated scientific facts; but when I consider what has been stated above, I cannot admit that any general opinion of theirs regarding this work is entitled to be considered as decisive. The weight of that opinion it will be full time to consider, when any one 
of them shall have taken up the actual propositions of the work, and judged of these in connexion with the actual facts, as presented by the highest authorities, in a spirit of unreserved submission to logical rule. Mr. Sedgwick may be assured that I am in the meantime perfectly at ease regarding the vituperations of which he is pleased to be the mouth-piece.

Even with him I can part in perfect good humour. I would, however, suggest that it might be advantageous to himself to change his tone regarding this work and its author. When the Prussian dragoons fled in discomfiture from Jena, they indulged in the most hyperbolic descriptions of the prowess of the French. Let it be a hint to Mr. Sedgwick; otherwise he may find his friends by and bye reasoning in this manner. If the author of the Vestiges be a superficial writer, as Mr. Sedgwick asserts, why, it is so much the worse for Mr. Sedgwick: for, seeing that the author of so weak and shallow a work has been able in comparatively a few pages to expose the incapacity of his adversary to comprehend the arguments he undertakes to meet, his self-contradictions and incoherences, his passionate blindness to the rules of logic, and in short the utter futility of all his outpourings on this subject, how weak, consequently, and super-shallow, must be Mr. Sedgwick himself, out of the mechanical department of the one science in which his name has a place!

\section{Dr. Hitchcock.}

Dr. Hitchcock, an American geologist of reputation, who occupies the respectable position of President of Amherst College, has published a series of popular lectures, under the title of The Religion of Geology and its Connected Sciences; and the ninth lecture is devoted to a consideration of what Dr. Hitchcock calls the Hypothesis of Creation by Law. As this lecture, if not the whole book, has been evidently written in reference to the Vestiges, it might have been expected that a correct account should be given of the views of that work. But no: it seems to be something quite beyond the intellectual scope of the opponents of the Vestiges to give a just description of its leading propositions. Even in the title "Hypothesis of Creation by Law," there 
is an injurious, though probably unintentional misrepresentation, the actual proposition of the Vestiges being "Creation in the manner of law, "- that is, the Creator working in a natural course or by natural means. When the learned lecturer proceeds to state the development hypothesis, he is equally unfair, presenting not that hypothesis at all, but an account of the imperfect approach to it which was made by Lamarck. The "wants" of the primitive simple animals, aided by "another principle, the force of external circumstances," are described as leading to the production of new organs; and "thus have animals been growing more and more complicated and perfect from the earliest periods of geological history." He entirely overlooks the fundamental hypothesis of the Vestiges, that "the several series of animated beings are, under the providence of God, the results of an inherent impulse in the forms of life to advance, in definite times, by generation, through grades of organization terminating in the highest dicotyledons and vertebrata,"-the real hypothesis of development, always presented in a more or less distinct form in the various editions of this work. As Dr. Hitchcock's volume is dated "May I, I 85I," he might have referred to one of the later editions of the Vestiges; in which case, he would have found the above form of the proposition. But even in the second edition, to which we see him elsewhere referring, he might have seen that the idea of the author was " that the simplest and most primitive type, under a law to which that of like production is subordinate, gave birth to the type next above it, that this again produced the next higher, and so on to the highest," the production of new forms being nothing more than "a new stage of progress in gestation, an event as simply natural, and attended as little by any circumstances of a wonderful or startling kind as the silent advance of an ordinary mother from one week to another of her pregnancy." Dr. Hitchcock is the less excusable for confounding this doctrine with the imperfect one of Lamarck, inasmuch as the distinction between them is explicitly stated in the Vestiges, with the following remarks, surely sufficiently plain: "It is possible that wants and the exercise of faculties have entered in some manner into the production of the phenomena. . . . . but certainly not in the way suggested by Lamarck, whose whole notion is obviously inadequate to account for the rise of the organic kingdoms. 
Had the laws of organic development been known in his time, his theory might have been of a more imposing kind." It is in such ways that a well-meaning public is deceived (quite unintentionally) into the idea that "such and such a doctrine has been answeredrefuted-left not a shadow of basis to stand upon. Only see Dr. Hitchcock's unanswerable lectures!" etc. Writers of his class have, I fear, a fatally easy task set before them-not the task of refuting an unpopular doctrine, but that of making an ignorant populace believe that it is refuted.

In proceeding to controversy on special points, the learned President first remarks that "the occurrence of events according to law does not remove the necessity of a divine contriving, superintending, and sustaining Power." Like Mr. Sedgwick, he professes his belief "that every event in the universe takes place according to fixed laws. For what," says he, "is a natural law? Nothing more nor less than the uniform mode in which divine power works." His readers will of course think that here is the orthodox account of natural law, as against the idea of the author of the Vestiges, that law is something which supersedes deity, or leaves him inactive. If they would only look into the Vestiges, and take its author upon his own showing, they would find that his idea of natural law is precisely that stated by Dr. Hitchcock. It has been so through all his editions, and in some of the later he has even argued for natural law necessarily inferring an Intelligence and Will external to itself-" "a Being beyond Nature, its author," law being thus " but another phrase for the action of the ever-present and sustaining God." The president goes on to say, "if the advocates of this hypothesis mean simply that every event is regulated by law, in other words, that with like antecedents, like consequents will be connected, I have no controversy with them." Well, I have never meant anything, never expressed anything, beyond this; consequently, Dr. Hitchcock ought not to have anything to say against me or my views. $\mathrm{He}$ even admits that such is precisely my professed doctrine. Why, then, should he make a controversy on the subject?

Because "this is by no means all that is meant by the hypothesis." It infers, it seems, a denial of "all special and extraordinary laws." It admits of no "miraculous interference in the creation or preserva- 
tion of the universe." Dr. Hitchcock even quotes me as saying, that "it does not appear necessary that God should exercise an immediate superintending power over the mundane economy;" not observing that I only advanced these words as what might be used by others, and immediately proceeded to argue against them, that God was revealed to us through our own nature as "our spiritual father, ever present in all that we do and think." Putting this piece of (I hope, unintentional) misrepresentation aside, the question is, does our hypothesis not admit of any miraculous interference by the Deity, or any special and extraordinary laws?

It should, in the first place, be ascertained what Dr. Hitchcock means by miracle and extraordinary laws. We find his belief to be that miracles are "regulated and controlled by law, like common events;" but the laws by which miracles are produced, are "special and extraordinary." Now, we undertake to say, without risk of challenge, that the idea of extraordinary natural laws is as little admitted in philosophy, as the idea of miracle by natural law is admitted in religion. Both are mere unproved opinions of Dr. Hitchcock, and we at once pronounce them to be things with which we have nothing to do. If it be asked if the miracles of religion, in their ordinary acceptation, as interruptions of a natural order, are to be held as incompatible with the proposition of a creation in the manner of law, we answer, No more surely than with any other part of the universal system of things admitted to be natural. Or, at least, the duty of showing that an admission of the natural here necessarily condemns the belief in miracle, is incumbent on those who take that view. And I have as yet found, in the writings of Sedgwick, Miller, Hiichcock, and others of that party, not the slightest trace of a ground for such a conclusion.

Dr. Hitchcock afterwards proceeds to say, "Admitting every event, miraculous as well as common, is under law, it by no means renders a present directing and energising Deity unnecessary." Who gave matter its laws? Who contrived the wonderful mutual adaptation of organs? Who can point to any inherent power in a law? "Take away God from the universe, and let him cease to act mentally on it, and every movement would as instantly and certainly cease, as would every movement of the human frame, were the mind 
to be withdrawn, or cease to will." "I see not, then, why this law hypothesis does not require an infinite Deity, just as much as the ordinary belief, which supposes that God created the universe by his fiat, and sustains it constantly by his power, and from time to time interferes with the regular sequence of cause and effect by miracles. The only difference seems to be this: While the comnion view represents God as watching over his works, and ready, whenever necessary, to make special interpositions, the law hypothesis introduces him only at the dawn of the universe, exerting his infinite wisdom and power to devise and endow matter with exquisite laws, capable by their inherent, self-executing power, of originating all organic natures, and producing the infinite variety of nature, and keeping in play her countless and unceasing agencies. It was only necessary that he should impress attenuated matter with these laws, and then put the machine in motion, and it would go on for ever, without any need of God's presence or agency; so that he might henceforward give himself up to undisturbed repose."

Strange to say, Dr. Hitchcock, in the earlier part of these remarks, only repeats my own arguments. Law, I have over and over again said, is merely a term of human convenience to express the orderly manner in which the will of God is worked out in external nature; and $\mathrm{He}$ must be ever present in the arrangements of the universe, as the only means by which they could be even for a moment sustained. Amherst College, however, does not seem to be fortunate in the logical lucidity of its president, for, forgetting the representation he has given of a hypothesis of natural creation, he immediately goes on to speak of an "only difference" between the ordinary and the novel views of the creator, - a difference very great indeed, if it existed, no less than that the latter imply a God withdrawn into repose. Still the introduction of this "difference" seems only to be some ill-considered interpolation, for, no sooner is it past, with some remarks on the atheistic system of Laplace, than he quietly resumes: "From these views and reasonings, it is clear, I think, that the hypothesis of creation by law does not necessarily destroy the theory of religion."

Having thus come to precisely the same general doctrine on the subject of creation as the Author of the Vestiges, why does Dr. 
Hitchcock, it may be asked, present himself as an opponent of that work? Reading onward, we find him saying, "The influence of the hypothesis upon practical religion is disastrous." "It is obviously the intention and desire of the advocates of this hypothesis to remove God away from his works and from their thoughts; else why should they so strenuously reject the doctrine of miracles?" "True, when we look at the subject philosophically, we must acknowledge that an event is just as really the work of God when brought about by laws which he ordains and energises, as by miraculous interposition. Still the practical influence of these two views of Providence is quite different." Now, what is all this but confusion and contradiction in Dr. Hitchcock's own mind? Admitted, says he, the hypothesis of creation by law does not necessarily make God less a creator or banish his energising will from the course of mundane affairs. It must be condemned, however, because its influence on practical religion is disastrous. How can these two things be both true? Its advocates reject miracles, says he. Very true, in creation, because creation cannot have been both in the manner of law and by miraculous interposition. The advocates of the doctrine feel that of which Dr. Hitchcock appears utterly unconscious, a wish to be consistent. When Dr. Hitchcock looks at the subject "philosophically," he sees no objection to the hypothesis. Then I am, after all, right in philosophy, by the confession of this learned antagonist; and to be right philosophically is, of course, all I require with one who professes to be a man of science, and desires to reconcile science and religion. Yes, but the "practical influence" malses the matter different. That is to say, a thing may be philosophically true; but if $I$, Dr. Hitchcock, can trace a bad moral effect from it, it must be condemned. So simple or so blinded is this writer, that, even in a work designed to reconcile science and religion, he betrays that it will be necessary to reject a philosophical truth-a thing unmistakeably a revelation of God-if it does not square with some already received dogma. It is much to be feared that those votaries who do not think of science at all, will be apt to cry, Non tali auxilio, non defensoribus istis.

The learned President at length leaves the general question, and asserts that the hypothesis of creation in the manner of law "is not 
sustained by facts." If this were the case, it were a great pity for Dr. Hitchcock to have exposed himself to logical shipwreck on the general question. But is it so? If the reader of the present volume and its Proofs and Illustrations will carefully peruse Dr. Hitchcock's exposition of adverse facts, he will see its weakness at once. We have a few feeble remarks against the nebular hypothesis, which this learned person considers as only resting on unresolved nebular matter in the heavens, - altogether forgetting Laplace's mathematical demonstrations, -ignorant even of the recent addition made to its support by his own countryman Kirkwood. Then equivocal generation is treated. There is no satisfactory proof of an organic being ever springing from inorganic elements. Thus the "strongest argument" of the advocates of the law hypothesis is put an end to. Now, it is not the strongest argument at all, but on the contrary, one always regarded in the Vestiges as of inferior consequence. Dr. Hitchcock argues that no blind impulse, nothing but an intelligent cause, could impart life and intellect-as if anything but an intelligent cause were imagined in the proposition that natural processes were concerned in the origin of life! He then proceeds to contend against the inferences from embryology. It is enough for him, on this point, to be assured that a human embryo will not stop short at an insect, a fish, or a reptile, but is as certain to become a man as the sun is to rise and set. Truly he is easily satisfied on the subject! Dr. Hitchcock does not see that the question is not at all, Will the embryo of any high animal stop at an inferior point? but, Have the embryos of low animals in past times gone on, under a higher gestative law, to superior forms? While analogy does nothing for the first question, beyond the rare and abnormal stoppings of particular organs at lower points of development, and the recession of sex in insects, it manifestly stands in the highest consistency to the second question, for advance is the rule of embryotic development. The geologic arguings of the learned President are only a weak dilution of those of Messrs. Sedgwick and Miller, as, that the highest cephalopoda and fishes came first, that there has been a degradation of forms, and so forth, - all of them dogmas which have already been fully refuted, not on any reasonings of ours, but on the authority of the highest naturalists that can be brought into court. 
Dr. Hitchcock comes finally to a different class of arguments against the hypothesis of natural creation. "It cannot," he says, "explain the wonderful adaptation of animals and plants to their condition and to each other." That demands "infinite wisdom and power." Yes; but infinite wisdom and power, acting in an established divine order, may do just as much as acting in an arbitrary way. These adaptations are, in reality, best explainable on the development hypothesis, for then we see the conditions acting as part causes, so that the effect becomes simple; always, nevertheless, to be held as brought about by divine means.

By this hypothesis we should expect, says Dr. Hitchcock, at least a few examples of the formation of new organs in animals, in the efforts of nature to advance towards a more perfect state. We have specimens of animals from the Egyptian sepulchres, three thousand years old; but in no organ are they different from the present. All this has been elsewhere fully replied to.

Then, "Geology contradicts this hypothesis." No evidence of the development of new organs is seen in fossils. "New species appear, but they differ as decidedly from the previous ones as species now do." How can this hypothesis explain the sudden changes of species from one formation to another, "when its essential principle is, that the progress of development is uniform?" "Nothing can explain them surely but special creative interposition." All this is miserably weak, if not disingenuous. The reader of our Proofs and Illustrations, No. 8, will see very good authority for a progress, and that a gradual one, of species, in all the chief lines of animal being. The gaps are known by the merest tyros in geology to be explained by pauses of local formation. And we must respectfully hint that Dr. Hitchcock's vague "surely" in the last of the above sentences quoted from him, can only be accepted as the impression or whim of his own mind, till he can bring some proofs for its support.

Dr. Hitchcock thinks that the great reproductive power of the lowest animals affords a presumption that they cannot also be producible without parentage, for "this latter mode would supersede the necessity of the former." Dr. Hitchcock forgets that the principal question is as to the way the animated forms first acquired life. He, like every geologist, must admit that life had a beginning. The mode 
of reproduction by parents did not effect that beginning. All arguments about its constancy are therefore of no account in the case.

$\mathrm{He}$ considers as a strong argument against the doctrine of a creation by law, that it infers materialistic views of mind, and puts an end to moral responsibility. "If this system of materialism is true, we ought," he admits, "to embrace it, without any fear of ultimate bad effects." But "a true philosopher will demand very strong evidence before he admits any hypothesis that leads a logical mind to such conclusions." We believe it would have been best for the learned lecturer to admit at once, that while he continues to draw such inferences from the idea of the Creator producing mind in the manner of all the rest of creation, namely, by law, there is no amount of evidence whatever which would induce him to go beyond the mere barren profession, that if proved, it should be embraced.

In conclusion, let us devote a few remarks to the one grand fallacy under favour of which the leading próposition of this work has been, in pamphlets, reviews, and opposing works almost innumerable, assumed to be overturned.

"Spontaneous generation," say these writers, "proves to be a mistake: omne virnm ex ovo is the rule. Ages elapse, and no example of transmutation takes place: therefore species is permanent. For these two reasons, we conclude against the development hypothesis." This is called bringing the question to the bar of science, and it is consequently affirmed that of course the development hypothesis is overthrown and refuted.

It never occurs to these gentlemen, that the disproof of spontaneous generation and transmutation of species, granting it were accomplished, which it is not, would only be sufficient to establish that life does not commence from inorganic elements and species do not change in the present day; which is not the question at issue. The question is, How did this series of phenomena originate? They do not see that their two rules as to present phenomena cannot be applied to the past, without leading to the conclusion that the present series of phenomena has never had a beginning at all-that both Moses's account of the creation of animals and the doctrines of palæontology must be rejected. 
Now, they admit that there was a beginning of species. Many, such as Professor Sedgwick, admit that it was a natural phenomenon. They at the same time allege that individuals alrvays come by parentage and species never change. How are the two beliefs to be reconciled? It is evident that my opponerts must either give up the idea of a beginning of life on earth, which both Genesis and Geology forbid them to do, or admit that invariable parental reproduction and invariability of species can only at the utmost have held good since the beginning. The latter of course is their election, and consequently all this parade of evidence against spontaneous generation and changes of species only shows how superficial and irrelevant are all their ideas upon the subject. The phenomena of the beginning remain to be ascertained from whatever sources may be available. Say the opponents, we do not inquire into them at all; they are an inscrutable mystery. Then, in the name of reason, do not bring up your disproofs of present spontaneous generation, as if they were somehow to settle the question, which it is evident they no how can do.

On the other hand, it has never been assumed here that there are proofs for the Development Hypothesis in spontaneous generation, or in anything else. It is only said, all the operations of God in nature being in an order, or figuratively speaking, by law, it is probable that the origin of species was so likewise, for that is fully seen to be connected in time and fact with the range of natural operations now proceeding on the face of the earth. What was the law? Answer : the physiologist sees a scale in animated nature, and the embryotic progress of a high animal is represented in characters pertaining to the series below it in the scale. The geologist tells us that, to all appearance, the animals were introduced in an order similar to this scale. Over all, it is not conclusively settled that life does not, in certain circumstances, spring from inorganic elements, and that changes of species do not take place, in the present day. We thus see, not perhaps the facts of creation and developmentthat may be left in doubt-but as it were the shadows of those facts, impressing at least their great probability.

It may be believed that so much perverse misjudgment on these points is simply owing to intellectual obtuseness. It may be believed 
that men of undoubted learning and talents are unconscious of the transparent fallacy, that the disproof of nonparental generation, which only reflects on the continuance of animated nature on earth, is conclusive against a particular view of the mode of its beginning - the legitimate tendency of the said disproof being to establish an admitted absurdity, namely, that animated nature has had no beginning at all. It may be believed, even of such men, that they are simply under a mistake when they so grossly misrepresent the proposition brought forward and illustrated in this work, and draw from it vile consequences which may with equal justice be drawn from every fact or hypothesis which tends to establish a law of nature. But assuredly it requires an exaltation of charity beyond all common bounds to make these admissions in their favour. 


\section{INDEX.}

Affinities of organisms ..........

Agassiz, his classification of Devonian

fishes..............60, 64, 197

Animal Kingdom, divisions of ..239-326

Animals, mental constitution of . .369-393

Animated Tribes, general considerations respecting origin of, I44I 58 ; particular considerations re. specting ditto ............ I59-178

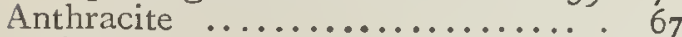

Articulata .............240, 247-256

Astral systems......................

Astronomy, ancient ideas of, erroneous .........................

Azoic rocks ................40-4 4 I

Bees, determination of sex in ....209-210

Belemnites ................... Io8

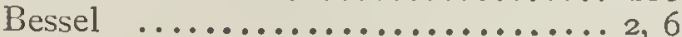

Boulders .................... 1 39

Buckland, Dr. ....................... I 5 I

Calculating machine, results derived from ...............204 -207

Carboniferous formation, $66-84$; plants of, $69-75$; animals of, $77-$ $78,82-83$; arrangement of rocks in, 78 ; rock-washings, $79-8 \mathrm{I}$; reptiles of .............. $8 \mathrm{I}-82$

Centaur....................... 2

Cephalopoda...........5I-52, 85, I08

Chalk, formation of, IIg-I20; shells found in, I20; flint nodules, I20 ; ditto, how formed ........... I2I

Civilisation of mankind $\ldots \ldots .35 \mathrm{~s}-356$

Coal, 67, 69, 7x; plants of the coal era, 69-76; coal strata ..83-84, Io2

Comets .................... I

Corals .............57, 68, 85, 103

Crag and tail ................ I 37

Creation (Animated), purpose and general condition of $\ldots \ldots \ldots 394-418$

Cretaceous system, II7-I24; animals of $\ldots \ldots$............. I22-123

Crinoidea ......46-47,58, 89-90, I03

Crosse, Mr. ............. 62 , I74, I75

Cryptogamia ............... 70

Cuvier, 127 ; his division of the animal kingdom 239

Cycadex ...................... Io2, I23
Cygni. .

Darwin, Charles, description of the Galapagos islands, II 7 ; on chalk formation $\ldots \ldots \ldots \ldots \ldots \ldots \ldots$. I 19

Daubeny, Dr. ................. r6o

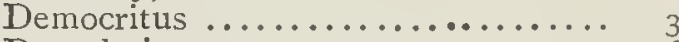

Denudation .................. I36

Development of the vegetable and animal kingdoms, Hypothesis of the ............. I79-237, 393

Devonian Era, 55-56 ; fossils of ..56-66

Diluvium ................. I37

Distribution (Geographical) of organisms ...............238-334

Draper, Prof. ................ r6

Earth, its diameter, I ; its constituent materials, 23-29; its formation, $25-26$; original volume, 30 ; internal heat, 33-34; external crust, 35-39; stratification of rocks, 39 ; first forms of life on the earth, 4I ; adaptation of the earth to its predominating tenants, II 7 ; origin of its animated tribes........ I 44-I78

Ehrenberg, Prof., on the formation of chalk, тा9-т2o; on flint nodules in ditto, r2I; on microscopic animals in ditto ........... $2 \mathrm{I}-\mathrm{I} 22$

Elements, in chemistry..........23-24

Encrinites.................. . 89-90

Eocene age, I26; shells and animals of ..................... 127

Equisetacex................ 7I

Fishes, fossil ...........60-66, 108 Fucoids .................. 42

Gasteropoda ..............50, 108 Geographical distribution of organisms ............... 238-334

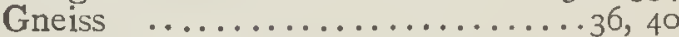

God, as the Author of Nature, I2-I4, 22,

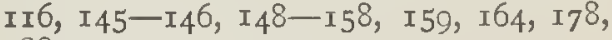
I88, 20I, 20n, $-30-23 \mathrm{I}, 255,330-33 \mathrm{I}$, $385,392,395,398,4$ I6-4I 8

Granite rocks ....................................

Graptolites ................43, 46

Gravitation ...............8, 9, 393 


\section{INDEX.}

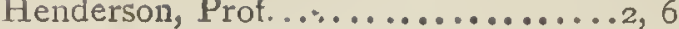

Hercules, constellation............ 4

Herschel, Sir John.............. I I

Herschel, Sir Wm.............

Jupiter, planet................ 8

Kepler, solar law............. 6 , 187

Lamarck's theory of aninial gradation ...............232-234

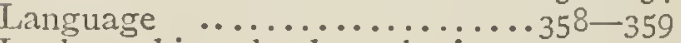

Laplace, his solar hypothesis, I5, I7, 29, $33-34,35$

Law of Nature defined ............. I2

Limestone. . . . . . . . . . . . . . . .66-68

Lyell, Sir Charles, his division of the Tertiary period into four subperiods ................. I26

Mammalia, first appearance of, IIo; abundant in Tertiary period, I27; modern mammals ........307-326

Mankind, early history of .....335-368

Matter ....................... 24

Megalosaurus of the Oolite........ I I4

Mental constitution of animals . .369-393

Milky way ....................

Miocene Age, I26; shells and animals of ..................... I 29

Mollusca ...............240, 256-267

Moon, external characteristics of the ......................... 32

Muschelkalk ................95, IoI

Natural Law .................13-14

Nebular Cosmogony ............. I4-I5

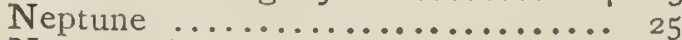

Newton, Gravitation.............8-9

Nichol, Prof. ................ I7

Oolite System, 89, IOo-II7; animals and vegetables peculiar to ...IO4-II5

Organisms, their affnities and geographical distribution ........238-334

Ossiferous Caverns ........... 38 - I39

Owen, Prof................... gI

Palæozoic Period .............39, 86, 89 Permian Formation, $84-89$; reptiles

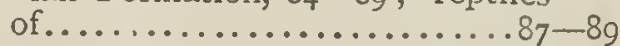

Pictet..................... I 54

Planets ................ 8 , 9- 12

Plateau's experiments ........ I9-2I
Pliocene (Older and Newer) Ages, r26;

PAGE shells and animals of ....... I30- 135 Polypiaria.................45-46 Protozoic Period.................39-53 Pteropoda .................50, ros

Races of Men, 335 et seq.

Radiata................240-247

Reptiles of Carboniferous Era, 8I-82; of Permian Era, $87-89$; of Triassic Era, $92-98$; of Oolite Era, rogI 6 ; of Cretaceous Era......... I23

Rocks, aqueous or sedimentary, 36 39 ; formations or systems; 38 39 ; Azoic ................40-41 Rosse, Earl of................ 5

Sandstone, Lower New Red, 84, 89; Upper New Red..........89 et seq.

Schist, micaceous ............. 37

Secondary Period ............. 39

Sedgwick, Prof., his theory of the Silurian formation ............

Silurian formation, Lower, 39-53, fossils peculiar to, $4 \mathrm{I}-53$; Upper, $54-55$

Sirius ...................... 5

Solar system ................ I-2I Species, the intransibility of, questioned ...............2 $1_{3}-229$

Stars, considered as suns, $\mathrm{I}-3$; number visible............... 3

Sun $\ldots \ldots \ldots \ldots \ldots \ldots \ldots \ldots \ldots \ldots$

Superficial formations, era of, $\mathrm{r}_{3} 6-\mathrm{x} 43$; animals of.............. I4 ${ }^{\mathrm{I}}$ - $\mathrm{I} 43$

Terraces ................... I40

Tertiary Period, 39, 124-136; division into four sub-periods, I 26 ; shells and animals of ditto, I26-I35; volcanic action during T'ertiary period .............. I35-I3t.

Triassic system, 89-I00; animals of................ 92-100

Trilobites $\ldots \ldots \ldots \ldots \ldots \ldots . \cdots 49-50,85$

Uranus .......................... 25

Vertebrata.. .............269-307 Volcanic action prevalent in Tertiary

Period ..................... 356

Weekes, Mr. ......174-175, I77-I78

Zodiacal light ............... 18 

$>$

,

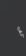

$\checkmark$
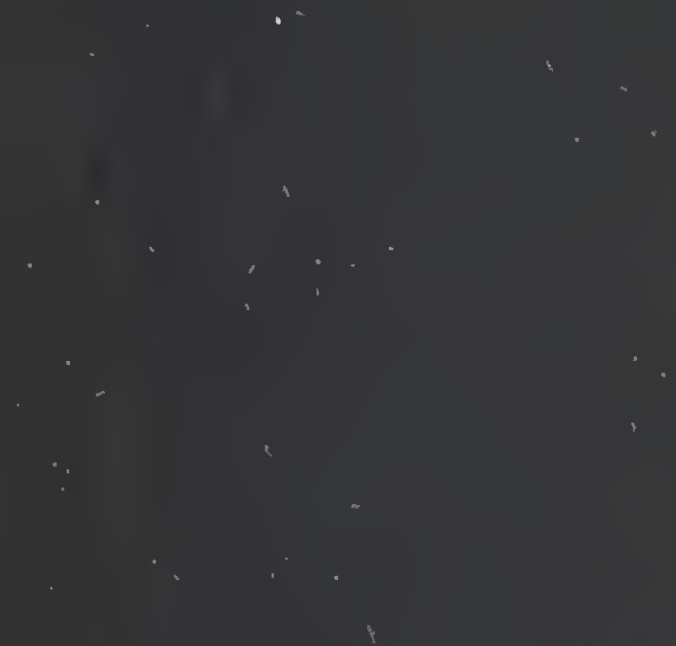


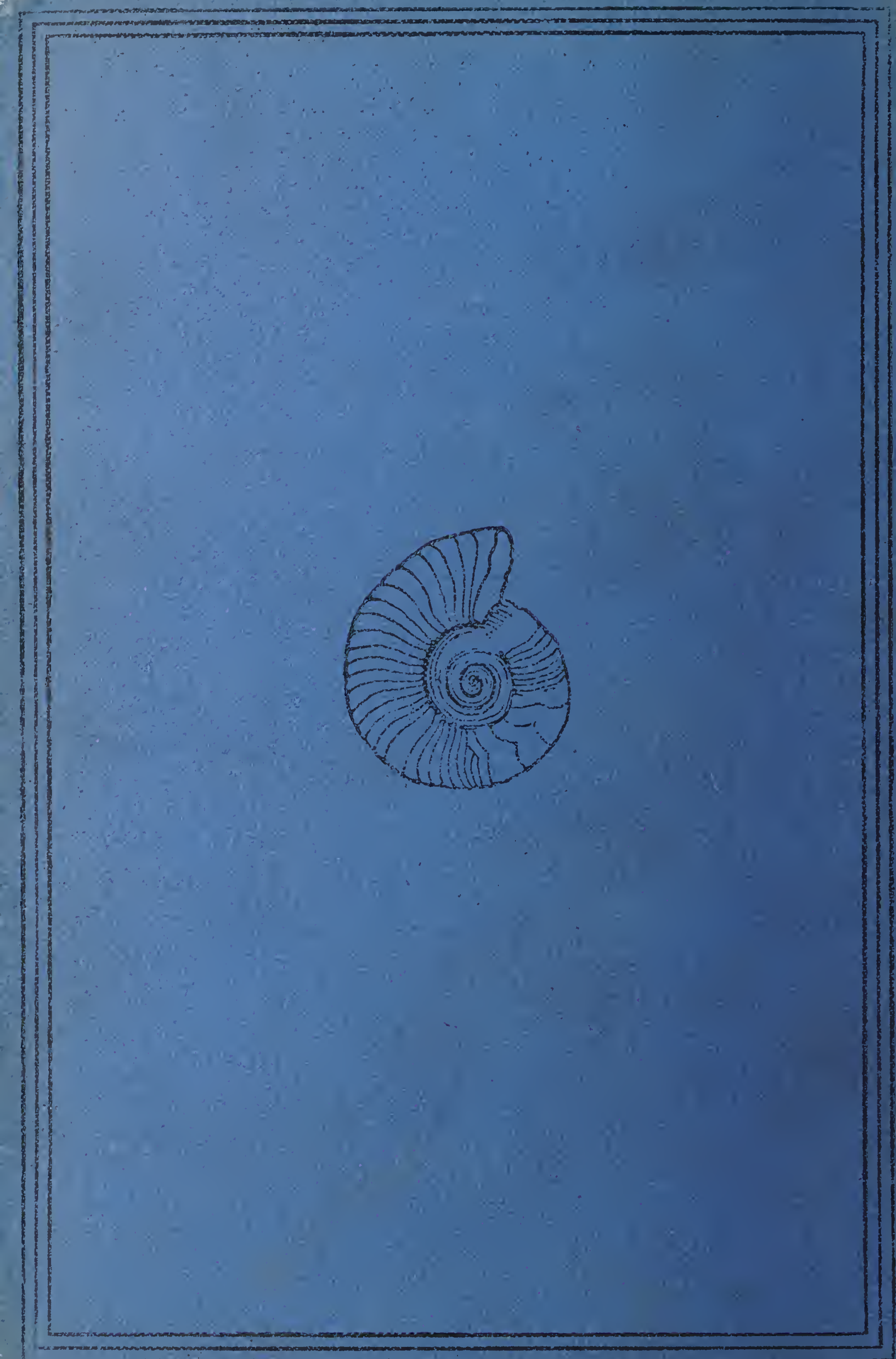

